\title{
CARACTERIZACIÓN PALEOAMBIENTAL Y \\ PALEODIVERSIDAD MALACOLÓGICA EN LOS \\ DEPÓSITOS MARINOS CUATERNARIOS DEL \\ NORTE PATAGÓNICO (SUR DE BUENOS AIRES Y \\ NORTE DE RÍO NEGRO)
}

Lic. Melisa Paola Charó

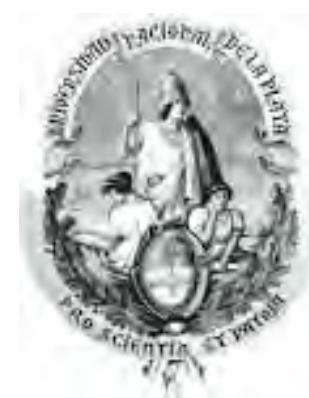

Facultad de Ciencias Naturales y Museo, UNLP

Directores:

Dr. Enrique E. Fucks

Dra. Sandra Gordillo 
A Dios, a mis padres, hermanas y mi compañero del alma 


\section{AGRADECIMIENTOS}

A mis directores de tesis y beca doctoral el Dr. Enrique Fucks y la Dra Sandra Gordillo, por la oportunidad de formarme como doctora en esta institución.

A mi tercer "director" de tesis el Prof. Luis Mario Giaconi por enseñarme a nunca rendirme y a creer en mi sobre todas las cosas. Es mi ejemplo a seguir como profesional y persona, por compartir charlas y sobre su honestidad a la hora de escuchar una opinión o consejo para crecer y ser mejor profesional. Su actitud y su buena predisposición tanto en el desarrollo de la tesis como las pequeñas cosas cotidianas de todos los dias, me hacen considerarlo como unas de las personas que valen la pena encontrárse en la vida.

Al Dr. Kruse por darme la oportunidad de continuar mi tesis y por su generosidad y humildad como persona.

Al Dr. Osvaldo Gentile, al Dr. Enrique Fucks como la Cátedra de Geología del Cuaternario (UNLP) por haberme dado un espacio para desarrollar mis actividades de doctorado.

Al Dr. Riccardi y a la Sra. Susana Tomba por haber colaborado en la ingresión de los ejemplares ilustrados de esta tesis en la colección de paleoinvertebrados de la Facultad de Ciencias Naturales y Museo (UNLP).

A la Lic. Florencia Pisano (FCNYM-CONICET), Lic. Gabriela Boretto (CONICET) y la Lic. Sol Bayer (CONICET) por la colaboración en las tareas de campo durante las campañas realizadas en el transcurso del doctorado.

A mis amigos: Matias, Valeria, Amalia, Federico, Alberto, El Pela, Noe, Fatima, Aron, Cecilia, Romina, Richard, Carlos, Jessica, Natalia, Alejandra, Claudio, Miriam, Jessica, Natalia, Yessi, Fabricio y Facundo por comprender mis ausencias en nuestras reuniones y darme fuerzas para seguir adelante. 
A mis papas, Hugo y Ana por la ayuda incondicional y el amor que me dieron durante todo este tiempo.A mis papas del corazón Hector y Norma, por todos los momentos que me hicieron sentir como una hija más. A mis hermanas queridas por la compañía de ellas y su comprensión: Nancy, Gisela, Johanna y Alina.

Especialmente a mi compañero del alma, Agustín por la paciencia y la compresión en estos últimos meses. Por creer en mí, darme fuerza y seguir adelante junto conmigo. Gracias a la vida por encontrarme a un ser tan especial, compresivo y lleno de amor. 


\section{INDICE}

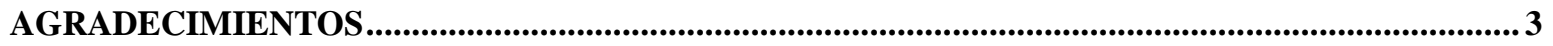

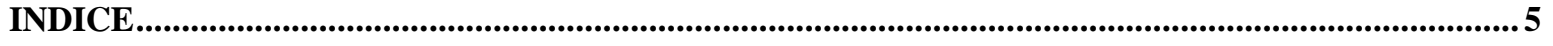

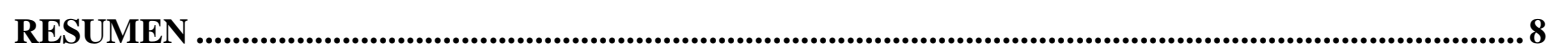

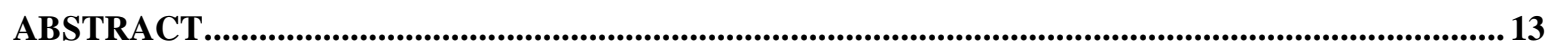

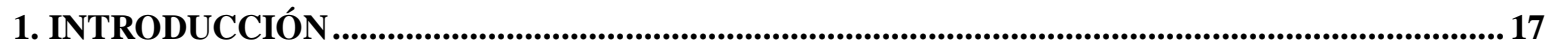

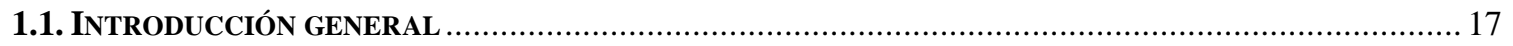

1.2. CiClOS GLACIALES E INTERGLACIALES Y ESTADÍOS ISOTóPICOS MARINOS (MIS) .......................... 19

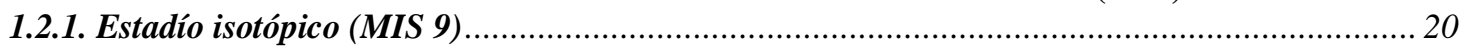

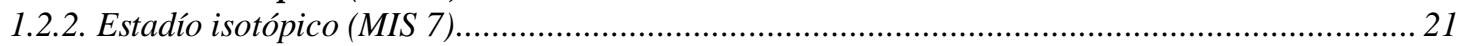

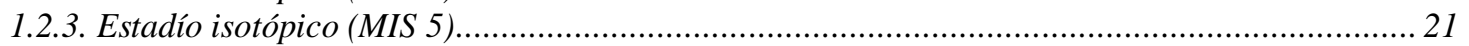

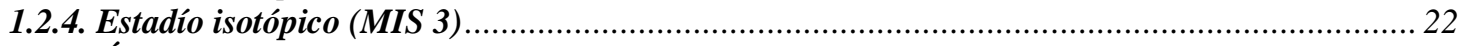

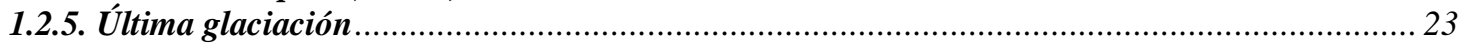

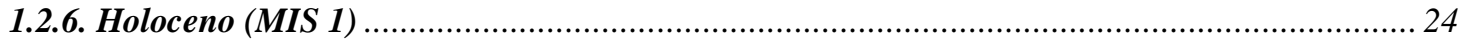

1.3.6.1. Cambios en el nivel del mar durante el Holoceno en Sudamérica .................................................... 25

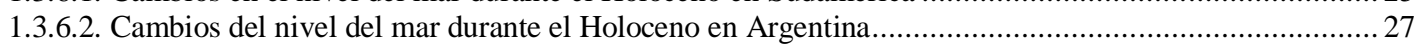

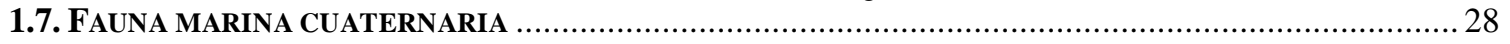

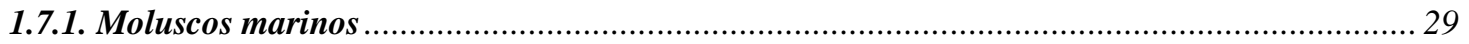

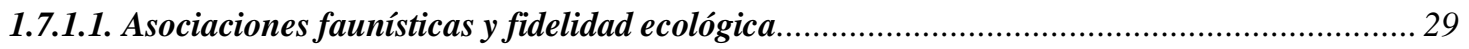

1.7.2. Gasterópodos y bivalvos marinos como "proxies” paleoclimáticos ............................................. 30

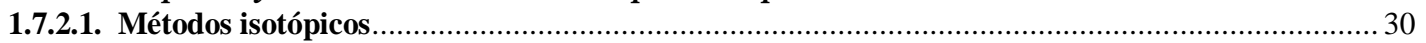

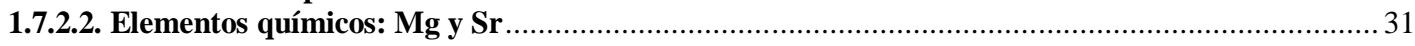

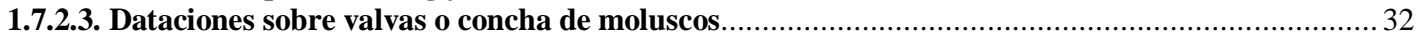

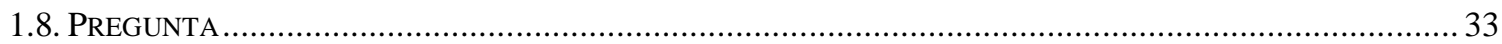

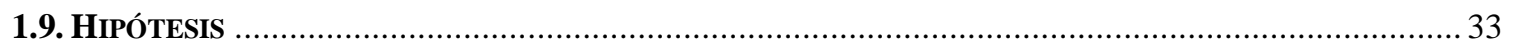

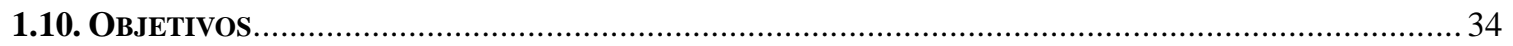

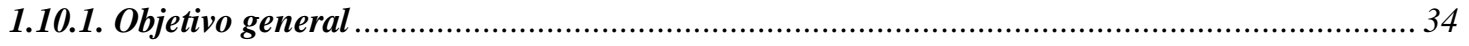

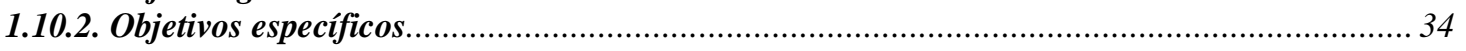

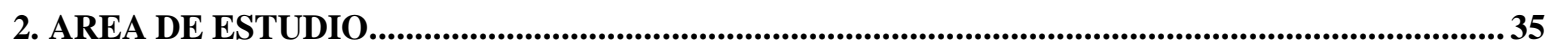

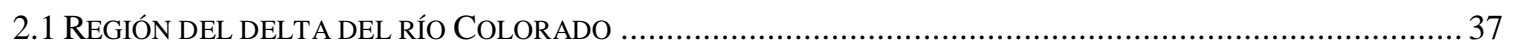

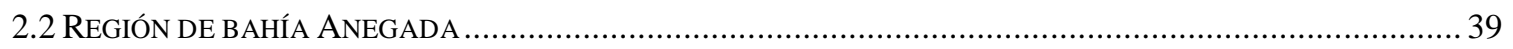

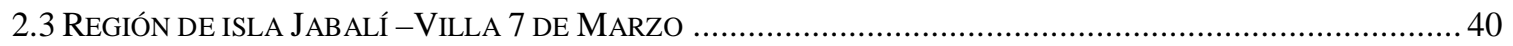

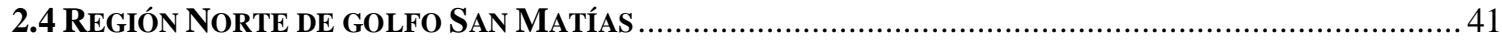

3. ANTECEDENTES GEOLÓGICOS Y PALEONTOLÓGICOS .......................................................... 44

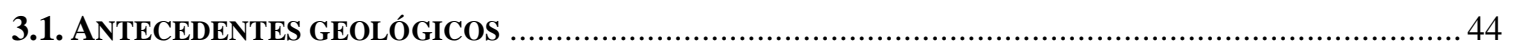

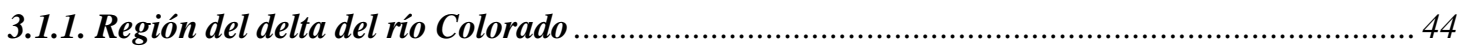

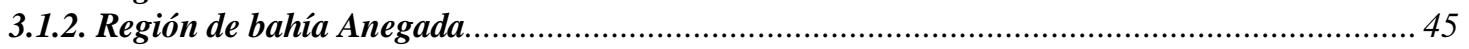

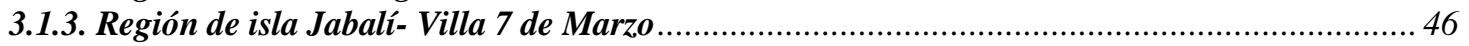

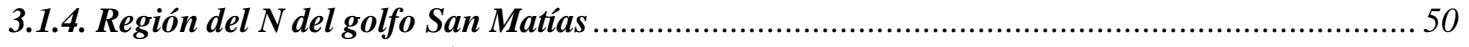

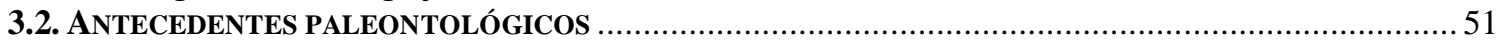

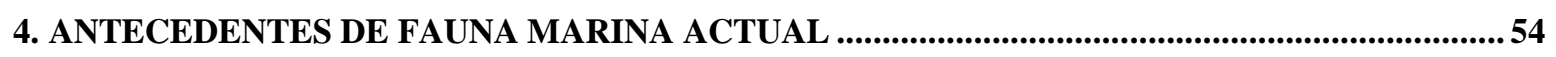

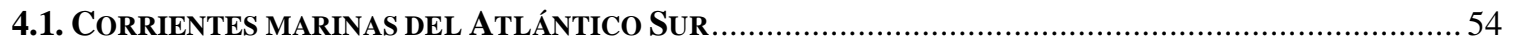

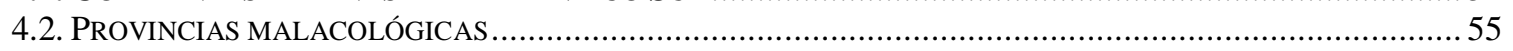

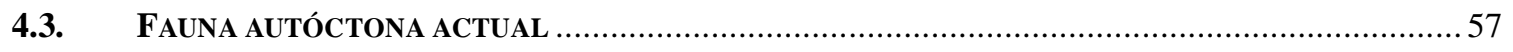

4.3.1. Moluscos del sur de Provincia de Buenos Aires y norte del golfo San Matías ..................... 58

4.3.1.1. Especies de gasterópodos y bivalvos exclusivos de Provincia de Buenos Aires ............................. 58

4.3.1.2. Especies de gasterópodos y bivalvos de la Provincia de Río Negro ……………………….........58

5. METODOLOGÍA DE ESTUDIO ….................................................................................................. 63

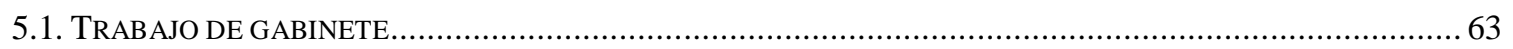




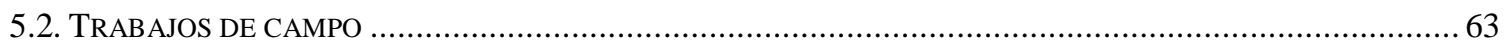

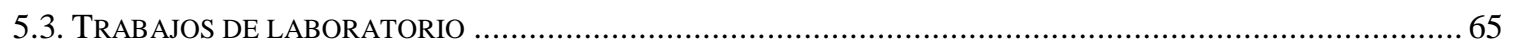

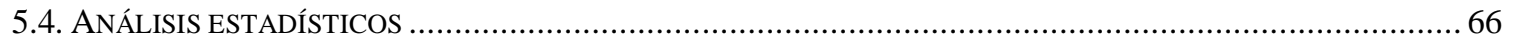

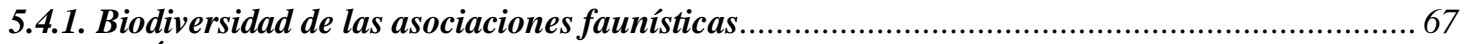

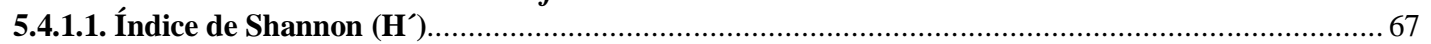

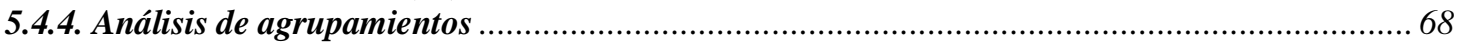

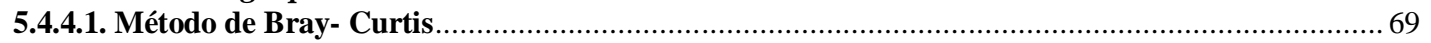

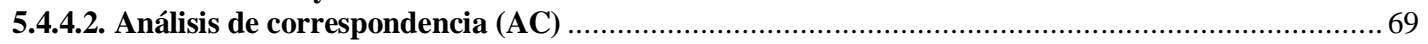

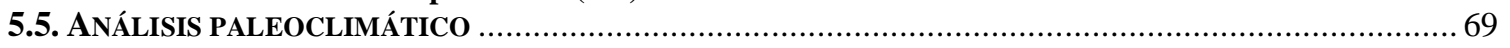

6. REGIÓN DEL DELTA DEL RÍO COLORADO ............................................................................. 71

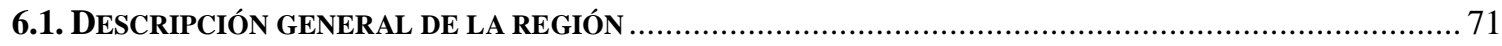

6.2. DESCRIPCIONES DE LOS DEPÓSITOS PLEISTOCENOS DE LA REGIÓN DEL DELTA DEL RÍO COLORADO

6.3. DESCRIPCIONES DE LOS DEPÓSITOS MARINOS HOLOCENOS DE LA REGIÓN DEL DELTA DEL Río

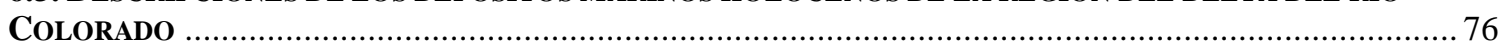

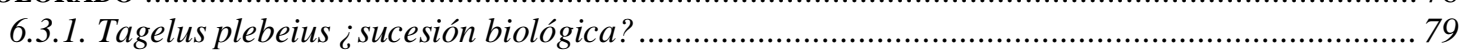

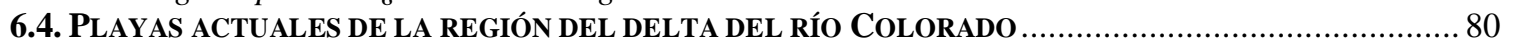

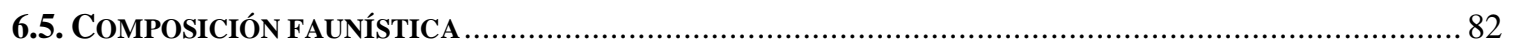

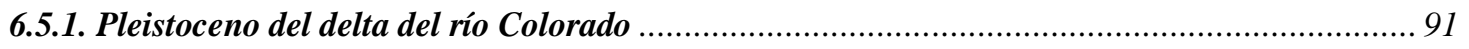

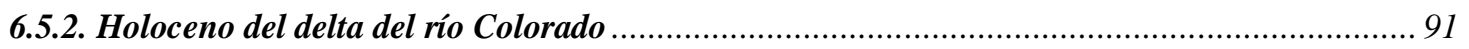

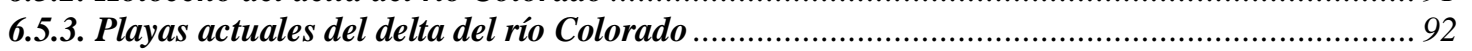

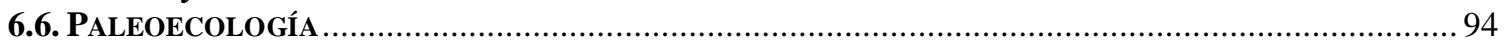

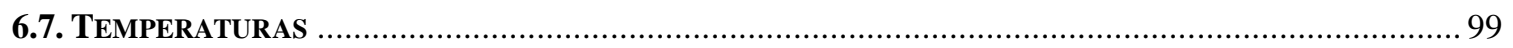

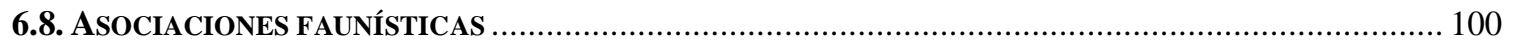

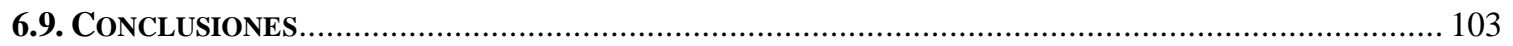

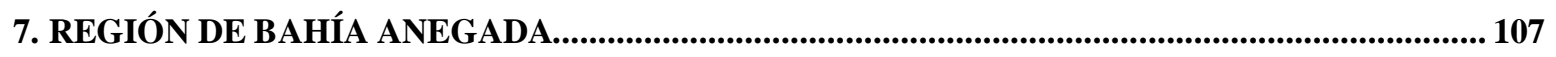

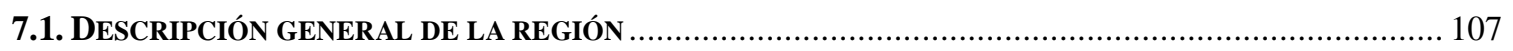

7.2. DESCRIPCIÓN DE LOS DEPÓSITOS PLEISTOCENOS DE LA REGIÓN DE BAHÍA ANEGADA …….............. 112

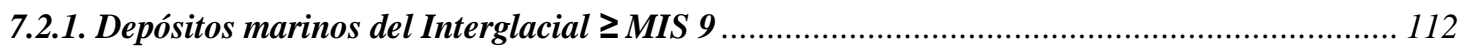

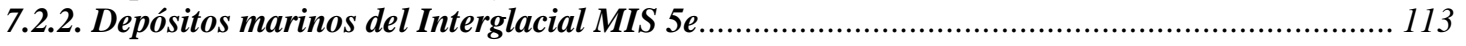

7.3. DESCRIPCIÓN DE LOS DEPÓSITOS HOLOCENOS DE LA REGIÓN DE BAHÍA ANEGADA ………............ 118

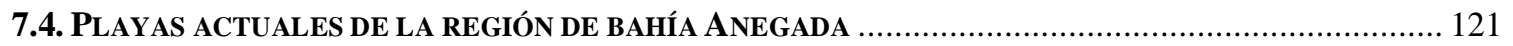

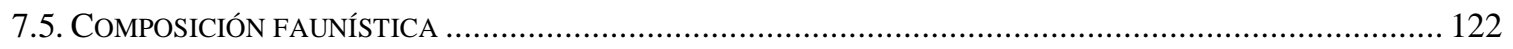

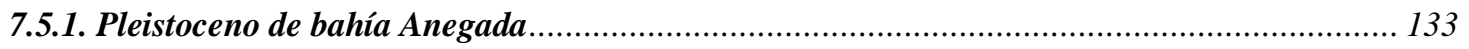

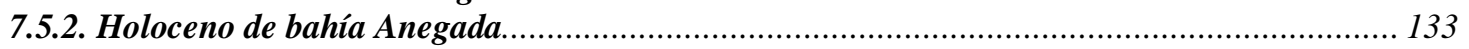

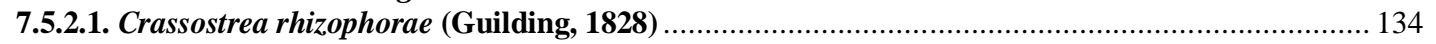

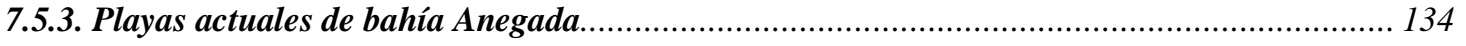

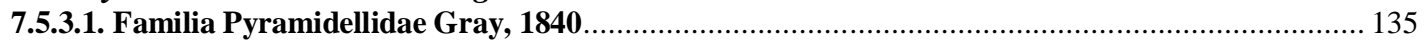

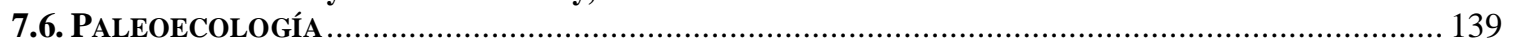

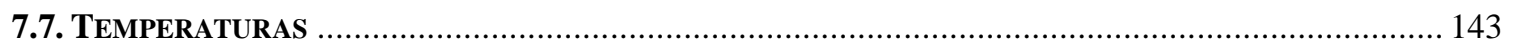

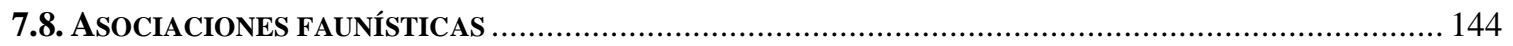

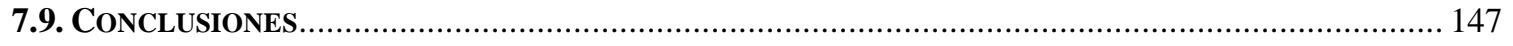

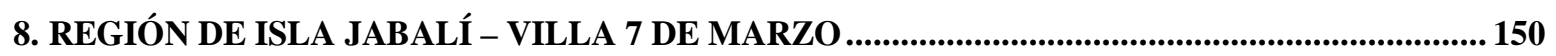

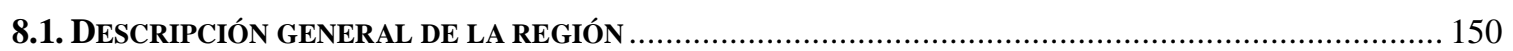

8.2. DEPósITOS PLEISTOCENOS DE LA REGIÓN DE ISLA JABALÍ - VILLA 7 DE MARZO ........................... 155

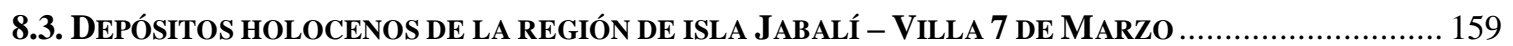

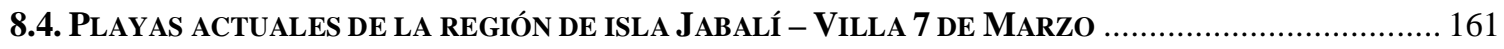

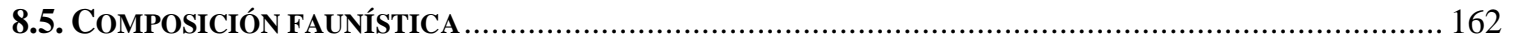

8.5.1. Pleistoceno de la región de isla Jabalí - Villa 7 de Marzo …….......................................... 174

8.5.2. Holoceno de la región de isla Jabalí - Villa 7 de Marzo ................................................... 175

8.5.3. Playas actuales de la región de isla Jabali - Villa 7 de Marzo .................................................. 175

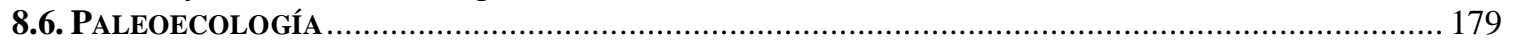

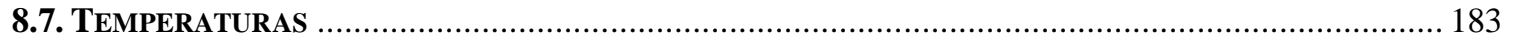




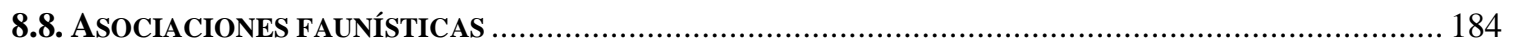

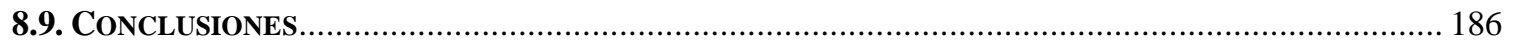

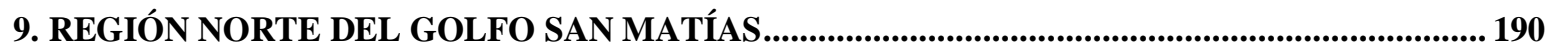

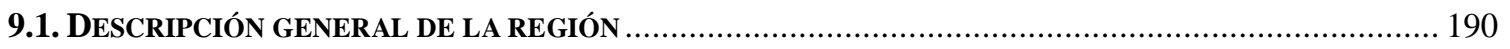

9.2. DESCRIPCIÓN DE DEPÓSITOS PLEISTOCENOS DE LA REGIÓN NORTE DEL GOLFO SAN MATÍAS ....... 197

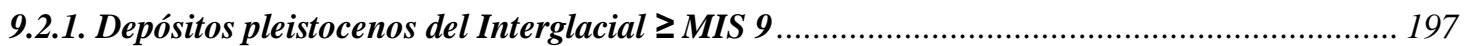

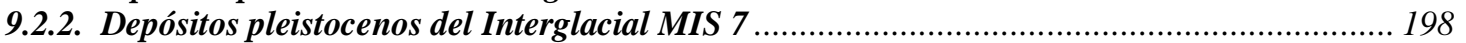

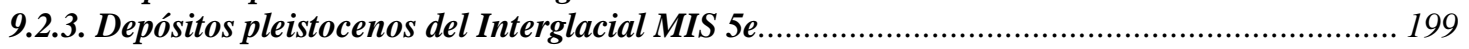

9.3. DESCRIPCIÓN DE LOS DEPÓSITOS HOLOCENOS DE LA REGIÓN NORTE DEL GOLFO SAN MATÍAS (MIS1)201

9.4. Playas aCtUALES de La Región NORTE del golfo SAN MATÍAS ........................................... 204

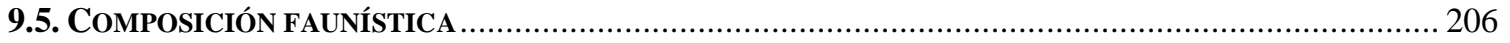

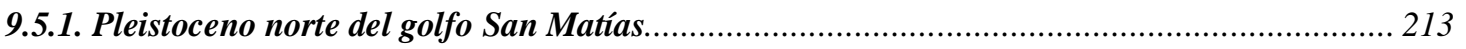

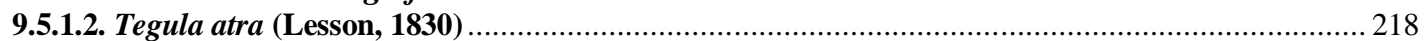

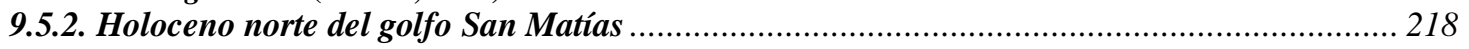

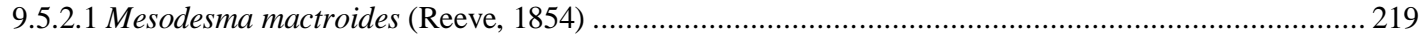

9.5.3. Playas actuales del norte del golfo San Matías....................................................................... 222

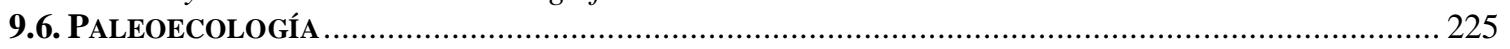

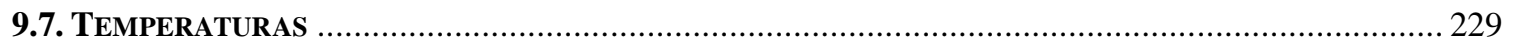

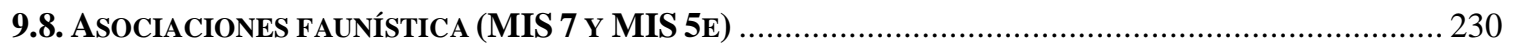

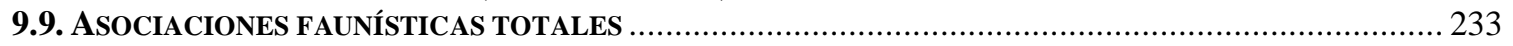

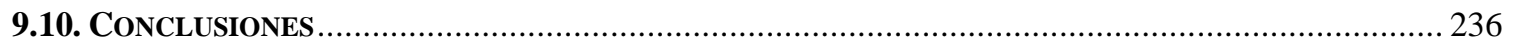

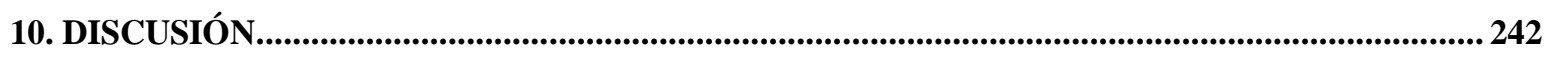

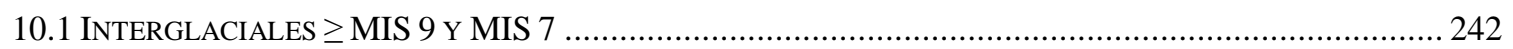

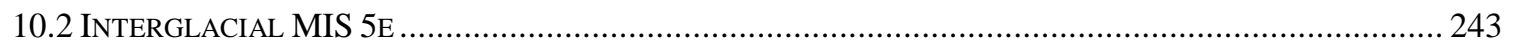

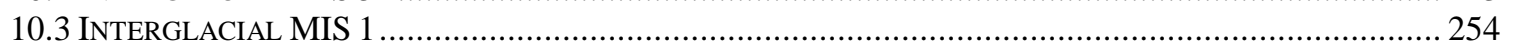

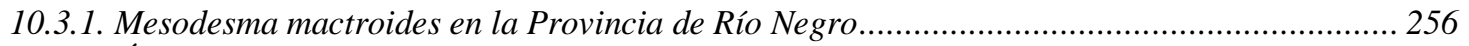

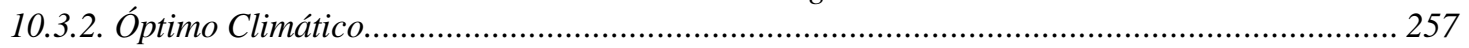

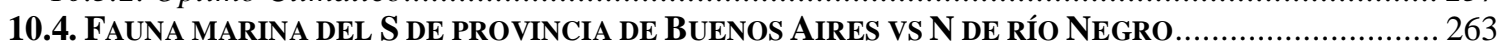

10.5. PRINCIPALES CARACTERÍSTICAS GEOMORFOLÓGICAS Y CAMBIOS FAUNÍSTICOS EN EL PERÍODO COMPRENDIDO ENTRE EL MIS 9 Y LA ACTUALIDAD PARA EL ÁREA ESTUDIADA....................................... 264

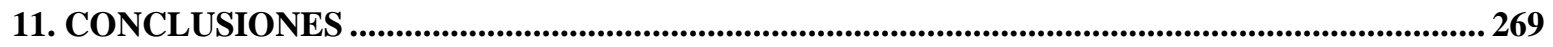

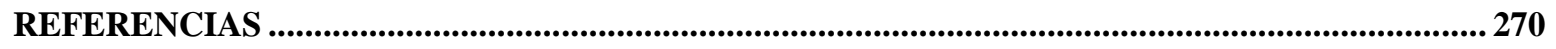




\section{RESUMEN}

El sector litoral del norte patagónico, sur de la Provincia de Buenos Aires y norte de la Provincia de Río Negro, presenta depósitos litorales vinculados a diferentes transgresiones marinas producidas durante el Cuaternario. Estos depósitos marinos han sido objeto de numerosos estudios geomorfológicos, estratigráficos y geocronológicos, pero son escasas las investigaciones realizadas a nivel paleontológico.

El objetivo principal es estudiar la paleodiversidad de moluscos y la caracterización paleoambiental en los diferentes episodios transgresivos a partir de bivalvos y gasterópodos utilizándolos como "proxies” paleoambientales y paleoclimáticos.

El área de estudio se dividió en cuatro regiones según sus características geomorfológicas, tres pertenecientes al sur de la Provincia de Buenos Aires (región del delta del río Colorado, bahía Anegada e isla Jabalí - Villa 7 de Marzo) y una cuarta región perteneciente al norte de la Provincia de Río Negro (norte del golfo San Matías).

Se analizaron en total 84 sitios (31 pleistocenos, 29 holocenos y 24 actuales) que incluye una colección de 7.385 fósiles entre valvas y conchas, determinándose la presencia total de 78 especies (42 bivalvos y 36 gasterópodos), habiendo entre ellas 11 especies de micromoluscos. Esta paleodiversidad malacológica descripta en los depósitos marinos del norte patagónico fue analizada mediante análisis estadísticos descriptivos. Así se determinaron asociaciones faunísticas marinas en función de dos métodos: Bray - Curtis y Análisis de Correspondencia.

Los sitios analizados dispuestos en orden cronológico decrecientes pertenecen a depósitos marinos de los interglaciales $\geq$ MIS 9, MIS 7, MIS 5e, MIS 1 y playas actuales.

Los depósitos más antiguos han sido asignados precisamente al Interglacial $\geq$ MIS 9 constituyendo paleoplayas y cordones litorales. Cabe consignar que todos los depósitos superiores a la cota $16 \mathrm{~m}$ fueron asignados a este Interglacial, sin diferenciar eventos más antiguos. A este Interglacial $\geq$ MIS 9 se asignan los depósitos de los sitios (B1- B2) de cota actual 33 m como así también los sitios (C1 - C4) de cota actual 16 - 18 m. En los primeros (B1- B2) se registró un total de 6 especies (2 bivalvos y 4 gasterópodos) siendo la especie dominante el bivalvo Pitar rostratus. En los segundos $(\mathrm{C} 1-\mathrm{C} 4)$, la fauna de moluscos registró un total de 7 especies (4 bivalvos y 3 gasterópodos), entre los cuales se destaca el 
gasterópodo Buccinanops globulosus. Todas las especies del Interglacial $\geq$ MIS 9 se encuentran representadas en las costas actuales.

Al Interglacial MIS 7 (D1 - D2) corresponden las paleoplayas que se encuentran representadas actualmente por plataformas costeras ubicadas en el área intermareal, a cotas actuales de 1 a $2 \mathrm{~m}$. En éstas se registraron un total de 11 especies (6 bivalvos y 5 gasterópodos) siendo las más abundantes: Glycymeris longior y Amiantis purpurata (bivalvos) y Tegula atra (gasterópodo). La mayoría de las asociaciones faunísticas determinadas para este interglacial se encuentran representadas en las costas actuales, a excepción del gasterópodo Tegula atra. Ésta es una especie de sustrato rocoso, que actualmente vive en el Océano Pacífico, pero se encuentra extinguida en la costa patagónica Argentina a partir del Holoceno (Interglacial MIS 1).

El Interglacial MIS 5e (E1 - E23), en su mayoría, se encuentra representado por cordones litorales (sur de la Provincia de Buenos Aires y principalmente bahía de San Antonio y el balneario Las Grutas, Provincia de Río Negro). Este interglacial se dispone topográficamente entre cotas 5 a $10 \mathrm{~m}$, registrándose en él un total de 44 especies (25 bivalvos y 19 gasterópodos). Entre la fauna marina se destaca la presencia de dos bivalvos: Crassostrea rhizophorae y Anomalocardia brasiliana, y el gasterópodo Tegula atra. Crassostrea rhizophorae se registró en el sur de Provincia de Buenos Aires más específicamente en la región de isla Jabalí - Villa 7 de Marzo. En la actualidad se distribuye desde el Mar Caribe hasta las costas del sur de Brasil y Uruguay. Anomalocardia brasiliana, se encontró en la región norte del golfo San Matías, distribuyéndose actualmente desde las Antillas Francesas hasta las costas de Brasil. Ambas especies de bivalvos son de aguas cálidas viviendo actualmente en latitudes más bajas, no encontrándose representadas en la actualidad en las costas argentinas.

El Interglacial MIS 1 (F1 - F29), se encuentra representado por dos tipos de depósitos: planicies de marea y cordones litorales, disponiéndose ambos a cotas 1 a $6 \mathrm{~m}$. En él se registraron un total de 58 especies (31 bivalvos y 27 gasterópodos). En los depósitos de planicies de marea, la fauna marina se destaca por la abundancia de los bivalvos Tagelus plebeius y Corbula patagonica y del gasterópodo Heleobia australis. El bivalvo infaunal Tagelus plebeius se encuentra en la mayoría de los sitios en forma articulada y en posición de vida. En los cordones litorales, entre la fauna marina presente abundan los bivalvos 
Glycymeris longior, Amiantis purpurata, Pitar rostratus, Ostreola equestris y Ostrea puelchana, y los gasterópodos Tegula patagonica, Bostrycapulus odites, Zidona dufresnei, Olivancillaria carcellesi, Buccinanops cochlidium y Buccinanops globulosus como especies típicas.

Una especie particular, absolutamente minoritaria, en el Interglacial MIS 1, es la aparición de Crassostrea rhizophorae, bivalvo de agua cálida, descripta también como ya se ha explicitado en el Interglacial MIS 5e de la región de isla Jabalí - Villa 7 de Marzo. A pesar de la aparición de este bivalvo en las asociaciones de moluscos de la región norte patagónico durante el MIS 1 no se ve reflejado un aumento de la diversidad de las especies relacionadas con el Óptimo Climático o Hypsitermal del Holoceno Medio.

Otro registro minoritario en el Interglacial MIS 1 es la aparición de Mesodesma mactroides en la región norte del golfo San Matías. Este bivalvo de agua templada se distribuye actualmente desde Río de Janeiro hasta la isla Jabalí, sur de Provincia de Buenos Aires. Su hallazgo se debe probablemente a la existencia de playas de arena fina - mediana con influencia de oleaje y temperaturas templadas durante este interglacial.

Las costas actuales del norte patagónico (G1 - G24) en su mayoría son arenosas, existiendo variaciones como las detectadas en el área norte de la región de bahía Anegada (sur de la Provincia de Buenos Aires) donde adquieren un carácter areno-fangoso y en el norte del golfo San Matías (Provincia de Río Negro), donde se diferenciaron dos tipos de playas distintas: sector intermareal bajo de arena fina - mediana con sectores distales altos, gravosos, de composición organógena y playas de sector intermareal bajo y distal alto, de arena fina - mediana.

De las asociaciones faunísticas, determinadas en el sur de Provincia de Buenos Aires, se destaca la presencia de los bivalvos: Mesodesma mactroides, Solen tehuelchus, Barnea lamellosa y Crassostrea gigas. Esta última es una especie introducida voluntariamente por el hombre en las costas de bahía Anegada y se distribuye en la actualidad hasta al balneario El Cóndor (Provincia de Río Negro), a lo largo de 90 km de costa.

Las playas arenosas finas adyacentes a la desembocadura del río Negro, Villa 7 de Marzo y balneario El Cóndor, difieren respecto a las demás playas del norte patagónico en presencia y abundancia de especies. Entre las mismas se destacan: Plicatula gibbosa (bivalvo) y Crepidula (gasterópodo). Se infiere que la dinámica costera en el sector bajo la influencia 
del río Negro posibilita la aparición de estas dos especies típicas de parches de sustrato rocoso.

Las playas del norte del golfo San Matías, Provincia de Río Negro se encuentran constituidas por asociaciones faunísticas distintas en composición respecto a las asociaciones del sur de Provincia de Buenos Aires. La fauna actual del norte de Río Negro se destaca por la presencia de Aulacomya atra, Retrotapes exalbidus, Ameghinomya antiqua (bivalvos), y Fisurella radiosa radiosa y Crepidula dilatata (gasterópodos), especies de aguas frías pertenecientes a la Provincia malacológica magallánica (sur argentino).

Tanto los bivalvos como los gasterópodos constituyen herramientas paleoclimáticas ("proxies" paleoclimáticos), pero son los primeros los mejores indicadores a los fines de estimar indirectamente paleotemperaturas del agua de mar en virtud que los representantes de este grupo viven en rangos relativamente más acotados de temperatura. En consonancia con ello es posible concluir que en el Interglacial $\geq$ MIS 9 existe una mayor cantidad de especies de aguas cálidasrespecto a los demás interglaciales detectados en el área sur de la Provincia de Buenos Aires.

Respecto a la salinidad se concluye que en el norte patagónico, las faunas marinas asociadas en todos los interglaciales detectados no presentan una variación manifiesta ya que las especies son mayoritariamente eurihalinas, a excepción de lo que acontece en el Interglacial MIS 1 en el sur de la Provincia de Buenos Aires donde se registran asociaciones que contienen componentes de una menor salinidad (oligo-meso y polihalinos), cuestión que también se verifica en las playas actuales con la presencia del bivalvo Tagelus plebeius y el gasterópodo Heleobia australis.

La presencia del bivalvo Crassostrea rhizophorae en el sur de la Provincia de Buenos Aires como así también del bivalvo Anomalocardia brasiliana y muy posiblemente el gasterópodo Tegula atra en el norte de Río Negro, podría ser evidencia que los interglaciales MIS 7, MIS 5e y MIS 1 fueron períodos más cálidos que el actual. Sin embargo, las asociaciones faunísticas determinadas para los interglaciales analizados no sufrieron cambios sustanciales en cuanto a la composición faunística, y salvo los corrimientos latitudinales de las 3 especies mencionadas anteriormente y la presencia de asociaciones faunísticas de aguas frías a templadas a partir del Interglacial MIS 1 a la 
actualidad en el norte de Río Negro (ecotono), solo se registraron cambios en la abundancia numérica de las especies.

Se concluye que los cambios ocurridos en el área norte patagónico durante el Cuaternario obedecen, en parte, a cambios climáticos globales que habrían afectado a la distribución de determinadas especies $y$, en parte, a la existencia de la heterogeneidad de hábitat, donde se desarrollan distintos subambientes, que posibilitan la coexistencia de distintas especies que componen las asociaciones faunísticas locales. 


\section{ABSTRACT}

The coastal area of northern Patagonia, south of the Buenos Aires Province and north of the Río Negro Province, has littoral deposits related to different marine transgressions that occurred during the Quaternary. These marine deposits have been intensively studied from geomorphologic, stratigraphic and geochronologic standpoints, but paleontological investigations have been scarce.

The main subject of this thesis is to study the paleodiversity of molluks and to characterize the paleoenvironment of the different transgressive episodes on the basis of the bivalves and gastropods using them as paleoenvironmental and paleoclimatic "proxies."

The study area was divided into four regions according to their geomorphologic features, three of them pertain to the south of the Buenos Aires Province (the Colorado River Delta, Anegada Bay, and Jabalí Island- Villa 7 de Marzo) and a fourth region to the north of the Río Negro Province (north of San Matías Gulf).

A total of 84 localities were analyzed (31 Pleistocene, 29 Holocene and 24 modern) which include a collection of 7385 fossils, valves and shells, of 78 species (42 bivalves and 36 gastropods), among them, 11 species of micromollusks. This malacological paleodiversity was analyzed through descriptive statistical analyses. Two methods were used to determine marine faunal associations, Bray - Curtis and Correspondence analysis.

The studied localities are marine deposits of the interglacials, from oldest to youngest, $\geq$ MIS 9, MIS 7, MIS 5e, MIS 1 and modern beaches. The oldest deposits were assigned to the Interglacial $\geq$ MIS 9 forming paleobeaches and beach ridges. All the deposits above 16 $\mathrm{m}$ msl were assigned to this Interglacial, discarding older events. To this Interglacial $\geq$ MIS 9 were assigned the deposits from localities (B1- B2) currently $33 \mathrm{~m} \mathrm{msl}$, as well as localities (C1 - C4) currently 16 - 18 m msl. In (B1- B2) six species were recorded (two bivalves and four gastropods) being the bivalve Pitar rostratus the dominant species. In (C1 - C4) seven species (four bivalves and three gastropods) were recorded, among which the gastropod Buccinanops globulosus stands out. All the species from the Interglacial $\geq$ MIS 9 are represented in the modern coasts.

The Interglacial MIS 7 (D1 - D2) is represented by the paleobeaches currently located in the intertidal area, as coastal platforms, at 1-2 m msl. Eleven species were recorded (six 
bivalves and five gastropods), being most abundant the bivalves Glycymeris longior and Amiantis purpurata, and the gastropod Tegula atra. Most associations of this interglacial are represented in the modern coasts, except for Tegula atra. This latter is a rocky substrate species that currently lives in the Pacific Ocean, but became extinct in the Argentine Patagonian coasts since the Holocene (Interglacial MIS 1).

The Interglacial MIS 5e (E1 - E23), is mostly represented by beach ridges mainly in San Antonio Bay (south of the Buenos Aires Province) and Las Grutas Beach (Río Negro Province). This interglacial is topographically between 5 and $10 \mathrm{~m} \mathrm{msl}$, and 44 species were recorded, 25 bivalves and 19 gastropods). Two bivalves, Crassostrea rhizophorae and Anomalocardia brasiliana, and the gastropod Tegula atra are conspicuous. Crassostrea rhizophorae was recorded in the south of the Buenos Aires Province, at the area of Jabalí Island - Villa 7 de Marzo. It is currently distributed from the Caribbean Sea to the coasts of southern Brazil and Uruguay. The other bivalve, Anomalocardia brasiliana, was found in the area of San Matías Gulf, and is currently distributed from the French Antilles to the Brazilian coasts. Both species belong to warm water lineages that live currently in lower latitudes, and not in the Argentine coast.

The Interglacial MIS 1 (F1 - F29) is represented in two different deposits, tidal plains and beach ridges, both at 1 to $6 \mathrm{~m}$ msl, with 58 species (31 bivalves and 27 gastropods). In the tidal plains, the bivalves Tagelus plebeius and Corbula patagonica and the gastropod Heleobia australis are abundant. The infaunal Tagelus plebeius is found in most localities articulated and in life position. In the beach ridges the bivalves Glycymeris longior, Amiantis purpurata, Pitar rostratus, Ostreola equestris and Ostrea puelchana, and the gastropods Tegula patagonica, Bostrycapulus odites, Zidona dufresnei, Olivancillaria carcellesi, Buccinanops cochlidium and Buccinanops globulosus are abundant, are recorded as typical species.

The bivalve Crassostrea rhizophorae is minority in the Interglacial MIS 1. It belongs to a warm water lineage which was described also for the Interglacial MIS 5e of the area of Jabalí Island - Villa 7 de Marzo. However, it was not detected an increase of the diversity of the species related to the Climatic Optimum or Hypsithermal of the middle Holocene. Another minority record in the Interglacial MIS 1 is that of Mesodesma mactroides in the northern area of the San Matías Gulf. This bivalve of temperate water lineage is currently 
distributed from Rio de Janeiro (Brazil) up to the Jabalí Island. Its record is probably related to the existence of fine-medium sand beaches under wave influence, and temperate temperature during this interglacial.

The modern coasts of northern Patagonia (G1 - G24) are mostly sandy. There are variations such as those mud-sandy beaches of the northern area of Anegada Bay, and those of the north of San Matías Gulf where two different types of beaches were recognized, a low intertidal area of fine-medium sand with high distal areas, gravel, organogenic in composition, and beaches of low intertidal and high distal areas of fine-medium sand.

In the faunistic associations of the south of the Buenos Aires Province, the bivalves Mesodesma mactroides, Solen tehuelchus, Barnea lamellosa and Crassostrea gigas stand out. The latter was introduced into the coasts of Anegada Bay and currently inhabits up to the El Cóndor Beach (Río Negro Province) along 90 km coast.

The fine sandy beaches adjacent to the outlet of the Negro River, Villa 7 de Marzo and El Cóndor Beach, differ from the other beaches of northern Patagonia in the presence and abundance of species. Plicatula gibbosa (bivalvo) and Crepidula (gastropod) are here recorded. The presence of these two species typical of rocky substrate would be facilitated by the coastal dynamic of the sector under the influence of the Negro River.

The composition of the molluscan associations of the beaches of the north of San Matías Gulf is different from those of the south of Buenos Aires Province. The modern fauna of northern Río Negro is composed of the bivalves Aulacomya atra, Retrotapes exalbidus, Ameghinomya antiqua, and the gastropods Fisurella radiosa radiosa and Crepidula dilatata, species of cold water of Magellanean malacological province (south of Argentina). Both bivalves and gastropods are useful as paleoclimatic tools (paleoclimatic "proxies"), but the first ones are better indicators to estimate indirectly sea water paleotemperatures because they live in more restricted temperature ranges. Hence, it can be concluded that during the Interglacial $\geq$ MIS 9 there were more warm water species than in the other interglacials recorded in the area of southern Buenos Aires Province.

Concerning the salinity, in northern Patagonia the mollusks recorded in all interglacials show no strong variation since the species are mostly euhaline, except for those of the Interglacial MIS 1 in the south of the Buenos Aires Province where the species were oligo- 
meso and polyhaline. This fact is also recorded in modern beaches with the bivalve Tagelus plebeius and the gastropod Heleobia australis.

The record of the bivalve Crassostrea rhizophorae in the south of the Buenos Aires Province as well as the bivalve Anomalocardia brasiliana and probably the gastropod Tegula atra in the north of the Río Negro Province suggest that the interglacials MIS 7, MIS 5e and MIS 1 were warmer than the present one. However, the composition of the associations recorded in the studied interglacials did not change significantly. Except for the latitudinal changes of the three species mentioned above, and the record of associations of cold to temperate waters since the Interglacial MIS 1 in the north of the Río Negro Province (ecotone), there were only changes in the abundance of each species.

The changes occurred in the area of northern Patagonia during the Quaternary are partly due to global climatic change that would have affected the distribution of certain species, and partly to the existence of heterogeneity of habitats; the development of different subenvironments would enable the coexistence of different species that form the local faunistic associations. 


\section{INTRODUCCIÓN}

\subsection{Introducción general}

El período Cuaternario se ha caracterizado mundialmente por la ocurrencia de importantes oscilaciones climáticas, con extremos representados por períodos glaciales e interglaciales, que dieron lugar a cambios marcados del nivel del mar (Rohling et al., 2008). En las zonas costeras, los eventos transgresivos han quedado registrados por una sucesión de formas de erosión (terrazas costeras y paleoacantilados) y depósitos litorales que, por diferentes causas, se han preservado, constituyendo testigos importantes de los cambios climáticos del pasado más reciente (Shackleton, 1987).

Los yacimientos fosilíferos litorales originados durante el Pleistoceno se conocen a nivel mundial. Hay ejemplos para la costa de Norteamérica (ej. Roy et al., 1998; Parham et al., 2007) pero que también se extienden a México (ej. Ortlieb, 1991; Mush et al., 1992, 2002, 2012; De Diego - Forbis et al., 2004), Bermudas (Hearty, 2002), Japón (ej. Kim et al., 1999; Kitamura et al., 2000), China (Pedoja et al., 2008); Australia (ej. Murray - Wallace and Belperio, 1991;Murray-Wallace et al., 2000) y Europa (ej. Lario et al., 1993; Zazo, 1999; Zazo et al., 2003a; Dumas et al., 2005; Zazo et al., 2010).

A lo largo de la costa de Sudamérica existen depósitos que corresponden a distintos niveles del mar relacionado con los últimos eventos transgresivos en Brasil (ej. Caruso et al., 2000; Barreto et al., 2002; Martín et al., 2003; Suguio et al., 2003), Uruguay (ej. Martínez y del Río, 2005; Goso Aguilar, 2006), Chile (ej. Ortlieb et al., 1997; Quezada et al., 2007) y Argentina (ej. Feruglio, 1950; Angulo et al., 1978; Cionchi, 1987; Codignotto et al., 1988; Rutter et al., 1989; Rutter et al., 1990; Codignotto y Aguirre, 1993; Isla, 1998; Schelmann, 1998; Isla et al., 2000; Rostami et al., 2000; Schellmann y Radtke, 2000, 2003; Weiler, 2000; Schnack et al., 2005; Bujaleski y Isla, 2006; Isla y Bujalesky, 2008; Pedoja et al., 2011; Fucks et al., 2009, 2010, 2012 a,b). 
A lo largo de la costa Argentina, durante las transgresiones del Cuaternario grandes extensiones del litoral bonaerense y norte patagónico se vieron afectados por procesos de acumulación y erosión generados por las distintas oscilaciones del nivel del mar (ej. Isla et al., 2000; Fucks et al. 2010, 2012ab). Autores contemporáneos, estudiaron su geología, geomorfología y su cronología, en la provincia de Buenos Aires (ej. Fidalgo et al., 1973ab; Weiler 1984, 1988; González et al., 1986; Violante y Parker, 1992; Codignotto y Aguirre, 1993; Isla et al., 2000; Weiler, 2000; Schnack et al., 2005; Fucks et al., 2010, 2012a) y en la costa patagónica (ej. Angulo et al., 1978, 1981; Cionchi, 1987; Rostami et al., 2000; Schellmann y Radtke, 2000; Pedoja et al., 2011; Fucks et al., 2012b, entre otros).

Los depósitos marinos costeros perteneciente al Pleistoceno tardío del noreste de la Provincia de Buenos Aires, se encuentran restringidos y discontinuos a lo largo del litoral bonaerense e intercalados o apoyados a los Sedimentos Pampeanos y representados por diferentes facies (Schnack et al., 2005). En sus niveles más elevados los depósitos de esta ingresión tienen cotas de $6-8 \mathrm{~m}$, y se los encuentran distribuidos en forma aislada (Isla Martín Garcia, Pilar, San Fernando, Barrancas de Belgrano, Parque Pereyra Iraola, Tolosa, Cañada de Arregui, Magdalena, Punta Piedras, Pipinas, Puente de Pascua, Laguna Sotelo, Mar del Plata, Centinela del Mar, Quenquén Grande, Claromecó, Bahía Blanca y San Blas (ej. Isla et al., 2000; Schnack et al., 2005) y se los asigna a la Formación Puente de Pascua (ej. Fidalgo et al., 1973; Fucks et al., 2006; Fucks et al., 2010). En algunos lugares, en esta ingresión se los encuentra representados en forma de coquina, con una fuerte grado de cementación (Schnack et al., 2005).

Los depósitos marinos holocenos bonaerenses, fueron los más estudiados y están extensamente distribuidos a lo largo de toda la costa de la Provincia de Buenos Aires, con cotas iguales o inferiores de los $5 \mathrm{~m}$. Estos depósitos recibieron distintas denominaciones como: Formación Querandinense (Ameghino, 1889); Querandinense y Platense (Frenguelli, 1957) y Formación Destacamento Río Salado y Formación Las Escobas (Fidalgo et al., 1973a), y Formación Canal de Las Escobas (Fucks et al., 2010). Esta última unidad fue agrupada recientemente en cuatro miembros: Destacamento Río Salado, Canal 18, Cerro La Gloria y Canal 15 (Fucks et al. 2008, 2010). 
En el norte patagónico, los depósitos marinos del Pleistoceno tardío, están representados a lo largo de la costa norte del golfo San Matías a cotas de aproximadamente de $15 \mathrm{~m}$ máximo ( Fucks et al., 2012b). Estos depósitos fueron separados por Angulo et al. (1978) en Bahía San Antonio, en dos unidades estratigráficas: Formación Baliza San Matías (Pleistoceno Tardío) y la Formación San Antonio (Holoceno). La distinción entre las formaciones se basó en la morfología, grado de litificación y posición estratigráfica. Según Fidalgo et al. (1980), la Formación San Antonio junto con la Formación Baliza San Matías, se correlacionaría con la Formación Pascua y La Formación Las Escobas del noreste bonaerense respectivamente. Estudios recientes (Rutter et al. 1989, 1990; Fucks y Schnack, 2011; Fucks et al., 2012b), distinguen en el norte de Río Negro al menos cuatro ingresiones marinas, tres correspondientes al Pleistoceno y un nivel Holoceno de escaso desarrollo.

\subsection{Ciclos glaciales e interglaciales y estadíos isotópicos marinos (MIS)}

En 1941, Milankovitch elaboró una teoría planetaria que explica que los ciclos glaciales e interglaciales del Cuaternario se deben a modificaciones de parámetros orbitales tales como: excentricidad (100 ka), oblicuidad (41 ka), y precesión de los equinoccios (19ka).

Las oscilaciones climáticas, desde el principio del Pleistoceno, aparentemente habrían seguido seguían ciclos periódicos de unos $40 \mathrm{ka}$, que parecerían obedecer al ciclo de variación de la inclinación del eje terrestre. Hace 1,5 ma (millones de años) la amplitud de los ciclos tendió a aumentar, y a partir de los 600 ka los ciclos glaciales se han sucedido en intervalos de una duración entre 80 y 120 ka (ej. Rutherford and D`Hondt, 2000; Raymo et al., 2006). Esta duración de los ciclos recientes resulta parecida al período de variación de la excentricidad de la órbita terrestre, de unos $100 \mathrm{ka}$.

Los distintos eventos glaciales e interglaciales que ocurrieron durante el Cuaternario se diferenciaron a través de los estadíos isotópicos marinos (marine isotopic stages, MIS). 
Los estadíos isotópicos marinos representan períodos alternativos de momentos fríos y cálidos durante el Cuaternario a partir del $\delta^{18} \mathrm{O}$ de foraminíferos bentónicos, obtenidos de testigos de fondo marinos. Emiliani (1955) permitió dividir el último millón de años en sucesivos estadíos isotópicos (MIS) a partir de la relación $\delta^{18} \mathrm{O} /{ }^{16} \mathrm{O}$. Cada estadío isotópico representa un período glacial o interglacial y revelan el avance y retroceso de los hielos durante las últimas glaciaciones (Fig. 1.1). Es un medio de establecer un marco global estratigráfico para sedimentos marinos (Shackleton et al., 2003).

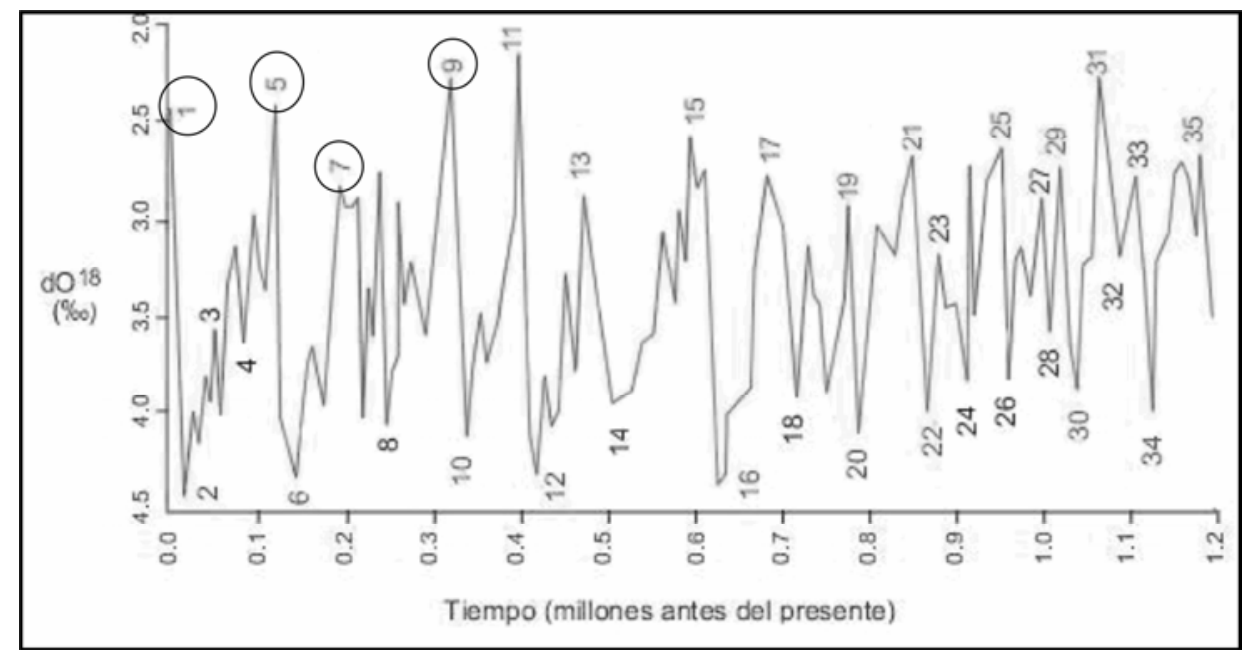

Fig. 1.1: Curva de $\delta^{18} \mathrm{O}$ vs tiempo de los estadíos isotópicos en el último 1.2 ma (Cantolla, 2003)

\subsubsection{Estadío isotópico (MIS 9)}

El estadío isotópico MIS 9 abarcó desde ca. 330 hasta los 310 ka y los niveles del mar eran $3 \pm 3 \mathrm{~m}$ por debajo al nivel del mar actual (Pedoja et al., 2011). En el HN, en la isla Henderson $\left(24^{\circ} 22^{\prime} \mathrm{S} / 128^{\circ} 20^{\prime} \mathrm{O}\right)$, los niveles del mar más altos registrados en el Interglacial MIS 9 son entre los $334 \pm 4$ y $324 \pm 3$ ka coincidentes con el pico máximo de insolación solar de 333 ka (Stirling et al., 2001). En el HN, oeste Mediterráneo (España) la temperatura superficial del mar y la salinidad registrados en este Interglacial son similares a los estadíos MIS 7 y MIS 5e (Zazo et al., 2003a). En la zona frontal polar del HS, se compararon registros de $\delta^{18} \mathrm{O}$ y $\delta^{13} \mathrm{C}$ en testigos de hielo, a través del foraminifero 
planctónico Neogloboquadrina pachyderma, con distintos estadíos isotópicos (MIS 11, 9, 7, 5 y 1), resultando el Interglacial MIS 9 el menos cálido (Hodell et al., 2000).

\subsubsection{Estadío isotópico (MIS 7)}

El Interglacial MIS 7, abarcó desde ca. 237 hasta 190 ka (Robinson et al., 2002). En base a datos isotópicos de algunos testigos oceánicos profundos, se infiere que los valores del nivel oceánico no ha llegado a la altura del cero actual (Shackleton, 1987; Ortlieb, 1987), aunque otros autores estiman valores que lo sitúan en torno a los -20 m (Dutton, 2009).

Las temperaturas de la superficie del mar de este Interglacial fueron más altas que las actuales (Shackleton et al., 1990; Desprat et al., 2006; Isla y Bujalescky, 2006). En las costas europeas, los depósitos marinos del Interglacial MIS 7 describen la aparición de fauna "Senegalesa", fauna marina de las costas de Africa, confirmando a este estadío como cálido en el HN (ej. Hillaire-Marcel et al., 1986, Zazo and Goy 1989; Zazo et al., 2010). Condiciones similares suceden el HS, la presencia actual de fauna de estirpe cálida o extinta en el área en el sur patagónico argentino consideran que las temperaturas superficiales del mar (SST) llegaron ser similares o ligeramente más cálidas al litoral actual (ej. Aguirre et al., 2005, 2007).

\subsubsection{Estadío isotópico (MIS 5)}

El Interglacial MIS 5, particularmente ha sido dividido en subestadios, el a, c y e cálidos y b y d fríos. El estadío isotópico identificado como el MIS 5e, unos de los más estudiados y representados a nivel mundial, abarcó desde los ca. $130 \pm 2$ a $119 \pm 2$ ka (Hearty et al., 2007). Algunos autores recientemente aluden a que hubo por lo menos dos "highsland" durante ese período (ej. Neumann and Hearty,1996; Hearty, 2002; Zazo et al., 2003a; Tuccimei et al., 2006). En este intervalo las temperaturas superficiales del mar (SST) fueron aproximadamente $2{ }^{\circ} \mathrm{C}$ más que la actualidad (Murray-Wallace y Belperio, 1991; Mc Culloch and Esat, 2000; Murray-Wallace et al., 2000; Rohling et al, 2008) a cotas de 5 
y 6 m sobre el nivel del mar actual (Shackleton, 1987; Neumann and Hearty, 1996; Hearty et al. 2007) (Fig. 1.2).

Hay evidencia de fauna cálida en moluscos marinos bentónicos, y cambios en su distribución geográfica en el MIS 5e (ej. Chaar y Farinati, 1988; Cuerda et al. 1991; Lario et al., 1993; Ortlieb et al., 1994; Zazo et al., 2003b; Martínez et al., 2001; Zazo et al., 2003b; Aguirre et al., 2005, 2011; Zazo et al., 2010; Rojas y Urteaga, 2011).

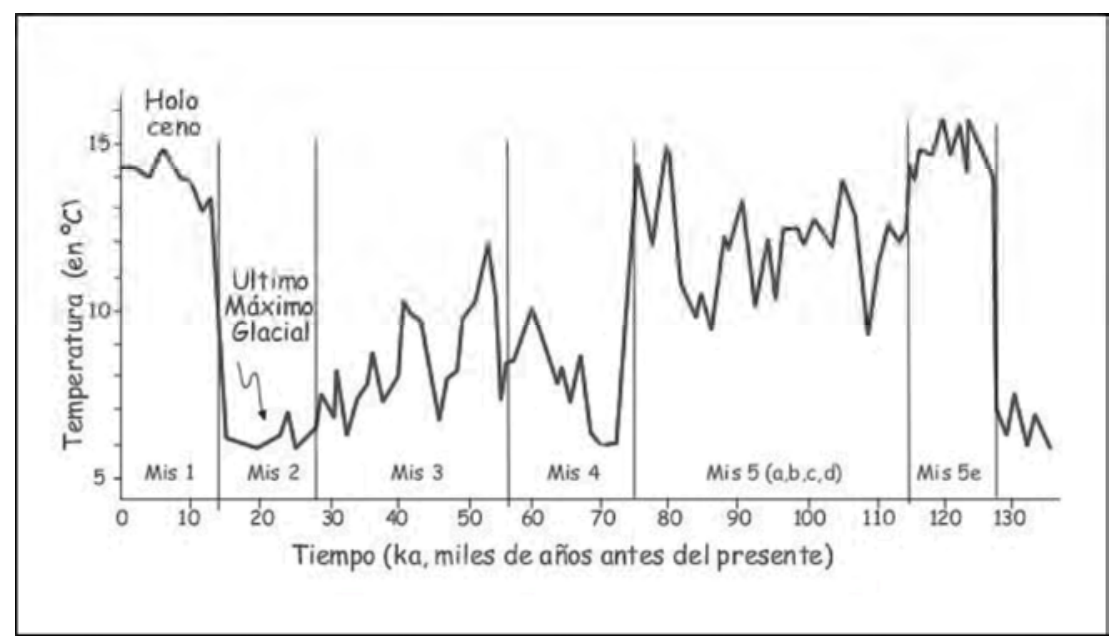

Fig. 1.2: Curva de temperatura $\left({ }^{\circ} \mathrm{C}\right)$ vs tiempo de los últimos interglaciales (Gutiérrez Elorza, 2001).

\subsubsection{Estadío isotópico (MIS 3)}

El Interglacial MIS 3, se define como el período entre los 59 y 29 ka, el intervalo entre la transición desde el evento Heinrich (H) 6 hacia el interestadial Dansgaard-Oeschger (IDO) 17 y la transición desde H 3 hasta IDO 4 (Voelker, 2002). Los distintos eventos Heinrich, fueron reconocidos en los testigos de hielo del noreste del Atlántico Norte, por cambios en el porcentaje del material lítico $(>80 \mu \mathrm{m})$ y coincidentes con la liberación de enormes volúmenes de hielo marino e icebergs (ej. Bond y Lotti, 1995; Broecker, 2002). En el HN se reconocieron 6 eventos distintos en númerosos testigos de hielo durante el Último glacial., coincidiendo con el aumento en la concentración de $N$. pachyderma, foraminífero planctónico, característicos de aguas frías (Bradley, 1999). 
Los eventos Heinrich son precedidos por períodos de calentamiento rápido conocidos como ciclos Dansgaard-Oeschger, también característicos de la Última glaciación, existiendo evidencias en los testigos de hielo de Groenlandia. Algunos autores, indican que los eventos Dansgaard-Oeschger responden a cuasi - períodos de 1.470 años posiblemente atribuidos a la superposición de dos ciclos cortos, incluyendo a oscilaciones internas en el sistema climático y un forzante externo posiblemente el sol (Braun et al., 2005).

Durante el Interglacial MIS 3, las condiciones climáticas en ambos hemisferios, se registraron como templados y húmedos. En el HS se caracteriza por la ausencia de los depósitos de este Interglacial, especialmente en los Océanos Índico y Pacífico y poco representados en superficie en el Atlántico Sur (Voelker, 2002). Los niveles del mar durante este Interglacial en el área del Pacífico, se registró en - $70 \pm 20$ m por debajo del nivel del mar actual a los 60.5 - 35 ka (ej. Chappell, 2002; Sidall et al., 2008, 2010).

\subsection{5. Última glaciación}

El último glacial empezó a los 110 ka, y se caracteriza en las altas latitudes del Atlántico norte por la rápida sucesión de oscilaciones climáticas, eventos Heinrich y ciclos Dansgaard - Oeschger, afectando extensas zonas a nivel mundial provocando un descenso del nivel mar entre 120 y 150 m, culminando hace aproximadamente unos 18 ka ( Hidalgo et al., 2005).

Entre los $12.7 \mathrm{ka}$ y los $11.5 \mathrm{ka}$, existió un período de enfriamiento brusco en el HN denominado "Younger Dryas", probablemente la causa se debió al debilitamiento del sistema de corrientes del Atlántico en la transición del Bølling/Allerød (evento cálido) al Younger Dryas lo que provocó un comportamiento parecido durante la glaciación (Alley, 2000). En el HS, en cambio hubo un desfasaje, en especial en Antártida, aumentando la temperatura desde los $18 \mathrm{ka} \mathrm{y} \mathrm{a} \mathrm{los} 14 \mathrm{ka}$ interrumpiéndose por un enfriamiento producido por el denominado "Antarctic Cold Reserval", culminando hacia los $12.8 \mathrm{ka}$ antes que el "Younger Dryas" (Blunier et al., 1997) (Fig. 1.3). 


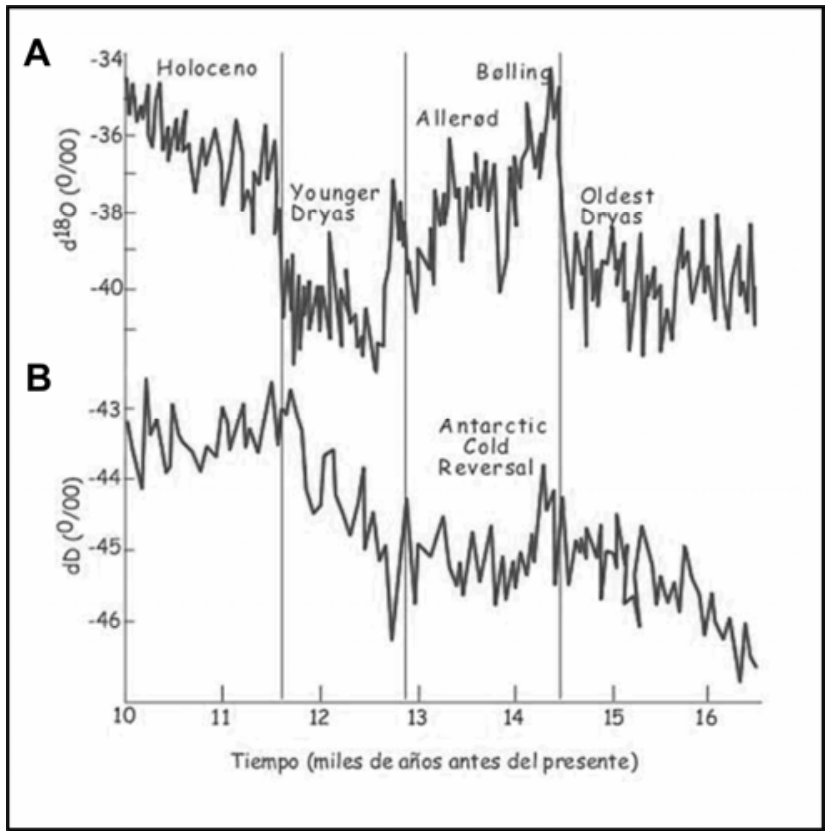

Fig.1.3: Curva de d deuterio y d $\mathrm{O}^{18}$ en función del tiempo. A, Hemisferio Norte y B, Hemisferio Sur (Cantolla, 2003)

\subsubsection{Holoceno (MIS 1)}

El Holoceno es la época interglacial más reciente del período Cuaternario, y se ha definido para los últimos $11.7 \mathrm{ka}$, considerándose que a partir de esa edad se produjo la finalización de la última glaciación (Walker et al., 2009). La temperatura media de la superficie de la Tierra durante el Holoceno osciló entre los $14^{\circ} \mathrm{C}-15^{\circ} \mathrm{C}$, a excepción de algunos períodos cortos de brusco enfriamiento (deMenocal et al., 2000).

El Holoceno se caracteriza a nivel mundial por un evento denominado Óptimo climático o Hypsitermal que se registró principalmente en el HN durante el Holoceno Medio(8.7 - 7.8 ka). Hay evidencias de un aumento de la temperatura superficial del mar y mayor humedad en distintas partes del mundo (ej. Funder y Weidick, 1991; Salvigsen et al., 1991; Hjort et al., 1995; Rohling y Rijk, 1999; Yuan et al., 2011) con algunos registros en el HS (ej. Cohen et al., 1992; Lutaenko, 1993; Aguirre, 1990,1993b, 2002). A nivel mundial este fenómeno es reflejado en las comunidades bióticas, con cambios en la composición, abundancia, diversidad y distribución ( ej. Lutaenko, 1993; Parmesan 2006) y tuvo su punto 
de inflexión hacia el $6 \mathrm{ka}$. A partir de los $4 \mathrm{ka}$, posterior al Hypsitermal, la temperatura oceánica superficial disminuyó hasta la temperatura media actual.

Entre los 1.25 - 0.85 ka se produjo un evento denominado Período Cálido Medieval u Óptimo Climático Medieval, período cálido del Atlántico Norte que coincidió con una gran actividad solar conocida como el Máximo Medieval (Fig. 1.4). En la culminación de este evento cálido le siguió un período frío denominado Pequeña Edad de Hielo, abarcando el siglo XIV hasta comienzos del siglo XIX. Durante el período 1645 - 1715, la actividad solar reflejada en las manchas solares fue sumamente baja, conocido este período como el Mínimo de Maunder, donde las temperaturas de invierno europeas se redujeron entre 1 - 1.5 ${ }^{\circ} \mathrm{C}$ (Shindell et al., 2001). Seguido a este evento se produjó un período de baja intensidad solar que duró desde 1790 a 1830, denominado Mínimo de Dalton, coincidiendo con un período de baja temperatura global, igual que el Mínimo de Mounder y el Mínimo de Spörer, este último acontenció entre los 1450 - 1540.

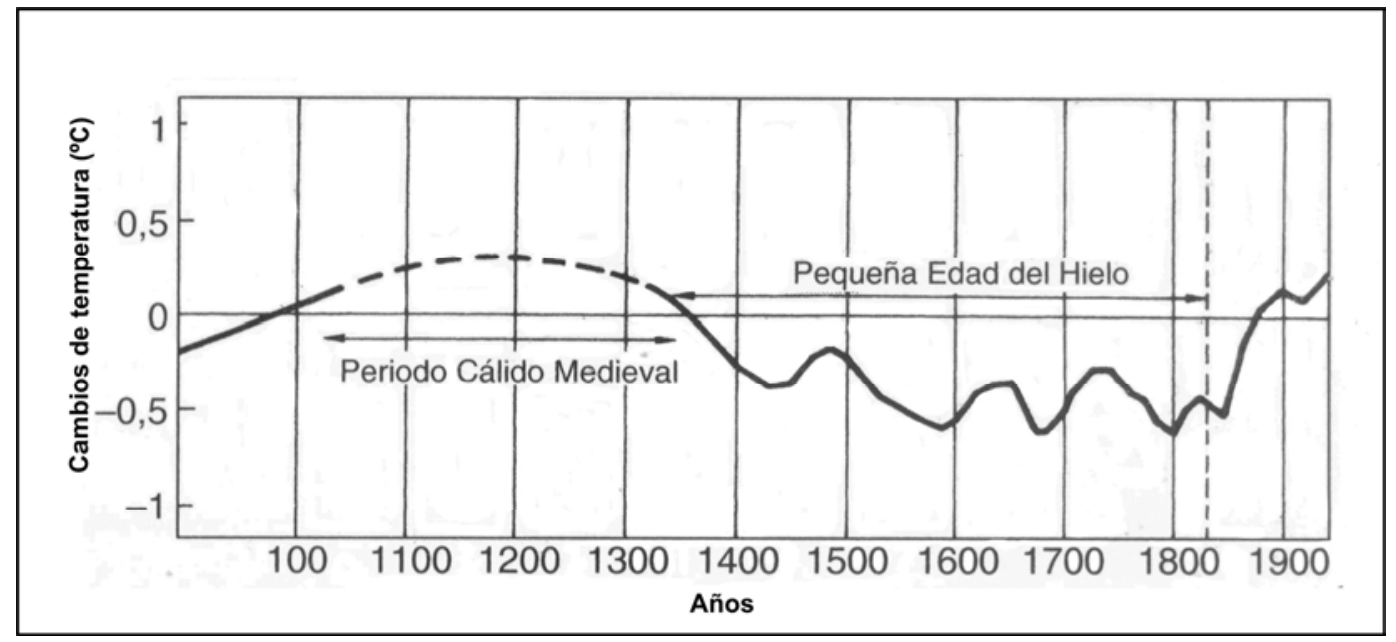

Fig. 1.4 : Curva de cambios de temperatura vs los últimos 2000 años (Gutiérrez Elorza, 2001).

\subsubsection{Cambios en el nivel del mar durante el Holoceno en Sudamérica}

Las curvas del nivel del mar en los últimos 7 ka han variado en el Hemisferio Sur desde los 1 a 5 m ( ej. Isla, 1989; Angulo y Lessa, 1997) (Fig. 1.5). 
En la región de Australia, los niveles más alto del mar alcanzó los 0.5 - 3 m sobre el nivel del mar actual a los 6 - $5 \mathrm{ka}$, a lo largo de la costa noreste del golfo del Carpentaria hasta el centro de Queensland (costa oeste de Australia). En el golfo de Spencer, a lo largo del margen sur del continente, a cotas desde 2.5 - $3.8 \mathrm{~m}$ sobre el nivel del mar ( Nakada y Lambeck, 1989).

En Sudamérica, en la costa E de Brasil, existen numerosos estudios acerca de las distintas cotas alcanzadas del nivel del mar durante el Holoceno Medio (ej. Martin y Suguio, 1978; Martín et al. 1979 ; Dominguez et al., 1990; Angulo et al., 1999; Bezerra et al., 2003). El mínimo valor sugerido es de $2.1 \pm 1 \mathrm{~m}$ en Laguna (Angulo et al., 1999) hasta $5 \mathrm{~m}$ en Pernambuco (Dominguez et al., 1990). Entre ellos, Cananéia y Paranagúa, el nivel del mar alcanzó los 3.5 - 4 m (Angulo y Lessa, 1997), y en Salvador y Angra do Reis entre los 4 5 m ( Martin y Suguio, 1989).

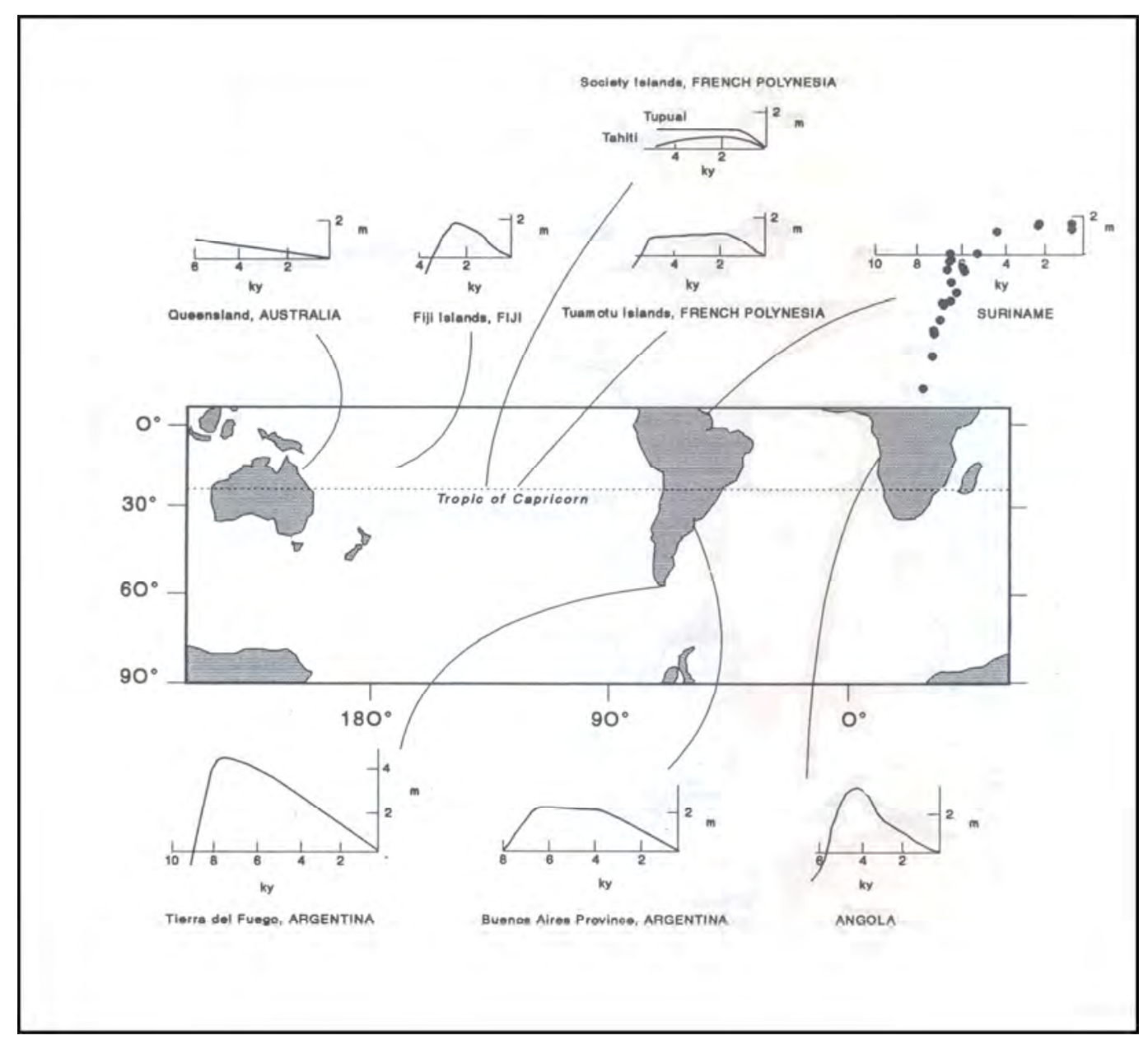


Fig. 1.5: Curva de niveles del Holoceno durante los últimos 6 ka registrados en el Hemisferio Sur (Angulo y Lessa, 1997).

\subsubsection{Cambios del nivel del mar durante el Holoceno en Argentina}

Desde el Neógeno el mar ocupó grandes superficies del sector continental especialmente en el Mioceno tardío hace 10 ma A. P. (Ingresión Paranense) y con diferentes amplitudes durante el Cuaternario (Camacho, 1967).

Hacia fines de la Última glaciación (18 ka) el nivel del mar global descendió entre los 120 m y 150 m quedando expuestas las plataformas continentales. Las edades más antiguas relacionadas con este evento registrado en los sedimentos de la plataforma argentina son aproximadamente 19 ka aunque en áreas cercanas a la zona exterior del Río de la Plata existen datos de hasta $15 \mathrm{ka}$ (Guilderson, 2000). El noreste bonaerense y las regiones marinas vecinas fueron intensamente afectados por la transgresión marina ocurrida como consecuencia de la deglaciación posterior a la última época glacial (Violante y Parker, 2000). Durante el período de los 18 a 7 ka se produjo la mayor fusión de los hielos. El nivel del mar a los 7 ka alcanzó una posición semejante a la actual antes de alcanzar su máximo, el cual se lo documentó a $+6.5 \mathrm{~m}$ a los 6 ka y coincide en edad con el registrado por otros autores en diferentes áreas costeras de Argentina, comprendidas entre los $33^{\circ}$ y $54^{\circ} \mathrm{S}$ (Cavalotto, 2002). En Bahía Samborombón, Aguirre y Whatley (1995) proponen que llegó a un máximo a los $6 \mathrm{ka}$ a cotas de 6m, variando hasta el valor actual (Fig. 1.6).

En la zona costera atlántica de la provincia de Buenos Aires, Isla y Espinosa (1998) proponen el máximo ascenso entre los 3.5 y $4 \mathrm{~m}$ a los 5.5 y $6 \mathrm{ka}$ con un descenso lento a partir de los $3 \mathrm{ka}$. En la región patagónica, las alturas oscilan desde los 3- $7 \mathrm{~m}$ (Rostami et al., 2000; Zanchetta et al., 2012), y a lo largo del Estrecho de Magallanes y el Canal de Beagle a los 5 ka alcanzó un máximo a los 3.35 m (Porter et al., 1984). 
Violante y Parker (2000) explican que la tendencia transgresiva continuó hasta el Holoceno Medio y luego tuvo lugar una fase regresiva con una fuerte progradación costera a los 6 ka, hasta alcanzar su posición actual.

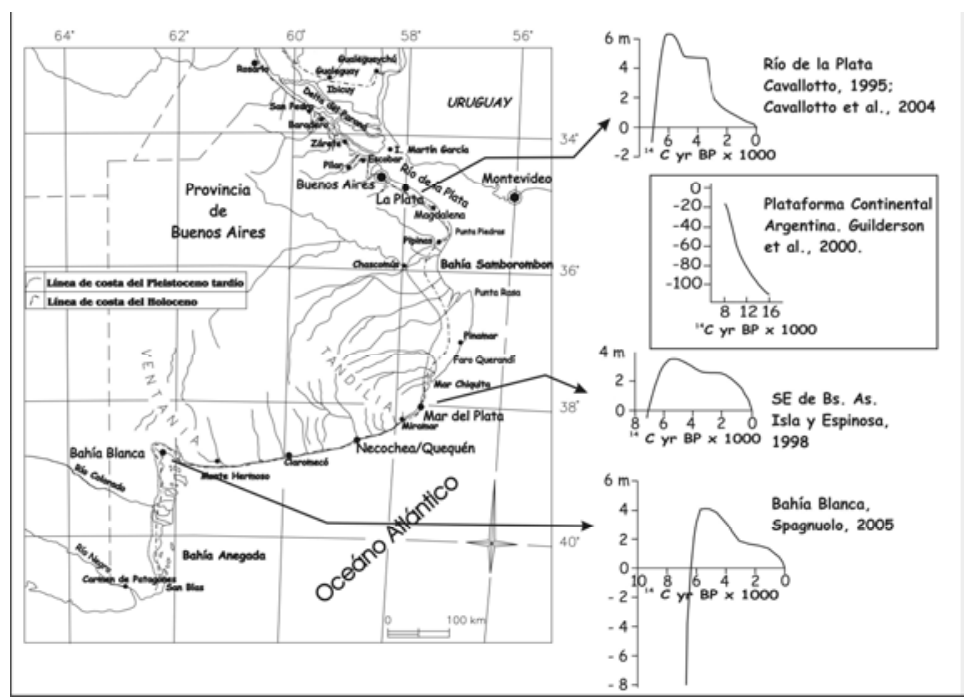

Fig.1.6: Curvas de niveles del Holoceno en la Provincia de Buenos Aires (Schnack et al., 2005).

\subsection{Fauna marina cuaternaria}

La fauna más representativa de estos depósitos marinos cuaternarios son los moluscos, particularmente gasterópodos y bivalvos, y su preservación los hace muy útiles como archivos "proxies” paleoclimáticos y paleoambientales. El análisis de estas especies permite obtener información de los distintos parámetros ambientales como temperatura, salinidad, sustrato, entre otros, logrando una interpretación del paleoambiente y de las paleocomunidades que existieron en las distintas regiones a través del tiempo. Existen además estudios recientes utilizándolos a los moluscos en estudios paleoclimáticos (cambios atmosféricos y oceanográficos) (ej. Díaz y Ortlieb, 1993; Ortlieb et al., 1994; Martínez et al., 1997, 2001, 2006; Guzmán et al., 2001; Maasch et al., 2001; Raigaini et al., 2002; Jones et al., 2010; Rojas y Urteaga, 2011).

A lo largo de la costa Argentina, distintos autores realizaron estudios sobre asociaciones de moluscos fósiles cuaternarios desde el punto de vista paleoclimático, paleobiogeográfico, 
paleoecológico, y taxonómico (ej. Farinati, 1978, 1985, 1994; Gordillo, 1992, 1998; Aguirre y Whatley, 1995; Aguirre, 2003; Aguirre et al., 2005, 2006, 2007; Gordillo et al., 2008; Gordillo, 2009; Cardenas y Gordillo, 2009; Rabassa et al., 2009, entre otros). La mayor parte de los estudios paleontológicos sobre moluscos marinos en la costa de la Provincia de Buenos Aires, se han concentrado en el Holoceno marino. Particularmente en los depósitos marinos del Pleistoceno en la misma área, el contenido fósil (valvas y conchas de moluscos) generalmente se encuentran muy cementados (Aguirre y Fucks, 2004), dificultando el estudio paleoclimático durante el Interglacial MIS 5e.

\subsubsection{Moluscos marinos}

Los moluscos viven en un amplio rango de temperaturas de agua y salinidades, aunque en su mayoría son muchos más diversos en salinidades normales de agua marina. Los

principales factores que controlan la distribución de las especies se relacionan con la orografía de costas, la temperatura y las corrientes marinas.

La diversidad y amplia abundancia de los moluscos en los distintos ambientes los hace referente para estudios paleogeográficos, paleoclimáticos y paleoecológicos durante el Cuaternario de Argentina.

\subsubsection{Asociaciones faunísticas y fidelidad ecológica}

Las valvas y conchas de moluscos encontradas en los depósitos marinos son considerados asociaciones que representan una acumulación de individuos no contemporáneos en un solo conjunto y se producen porque los tiempos de generación de dichos individuos son más rápidos que las tasas de enterramiento. En ese contexto es necesario tener en cuenta los cambios producidos durante la transición de los restos animales de la biósfera a la litósfera, lo que es tratado a través de una disciplina llamada tafonomía (etimológicamente deriva del griego: taphos, tumba; nom, ley), y definida por Efremov (1940) como la ciencia que estudia las leyes del enterramiento. Efremov (1940) admitía que los procesos tafonómicos llevan a la pérdida de información y son la causa de vacíos en el registro fósil, actualmente 
ese concepto se ha revertido ya que numerosas investigaciones (ej. Kidwell, 2001, 2002, 2013, Kidwell y Tomasovich, 2013; entre otros) apoyan la idea que las asociaciones faunísticas tanto de valvas actuales como fósiles aportan información relevante sobre las comunidades vivientes, o paleocomunidades, pudiendo en ambos casos reconstruir los ambientes o paleoambientes a partir del análisis de las asociaciones faunísticas y así interpretar los cambios ambientales y climáticos.

Respecto a las asociaciones de moluscos, Kidwell (2002) señala que estas asociaciones, al representar un promedio dentro de un período de tiempo considerado (time-averaging), capturan una señal fuerte de la abundancia relativa de las especies que normalmente habitan un ambiente, ofreciendo incluso una ventaja respecto a las comunidades vivientes (o paleocomunidades in situ) y que pueden variar de año en año debido a variaciones en el reclutamiento y mortalidad; y por consiguiente sirven para estimar la fiabilidad de la información biológica en el registro fósil.

\subsubsection{Gasterópodos y bivalvos marinos como “proxies” paleoclimáticos}

Gasterópodos como bivalvos poseen un exoesqueleto fundamentalmente formado por calcita $(\mathrm{CO} 3 \mathrm{Ca})$ o aragonita. Durante la construcción las valvas incorporan distintos elementos químicos, los más frecuentes son el Mg y Sr por tener la misma carga divalente que el Ca. La relación isotópica del $\mathrm{C}$ y $\mathrm{O}_{2}$ como los demás elementos trazas sufren modificaciones cuando hay variación en la temperatura o salinidad del agua. Durante la recristalización de las valvas los isótopos están en relación estable con los isótopos del agua y cualquier variación de algún factor ambiental, la relación isotópica de las valvas se modifica, siendo reemplazado por estos elementos trazas o sus isótopos.

\subsubsection{Métodos isotópicos}

Entre los métodos isotópicos más conocidos para interpretaciones paleoclimáticas es calcular la relación $\delta^{18} \mathrm{O} /{ }^{16} \mathrm{O}$ en las valvas de moluscos. Esta relación determina indirectamente paleotemperaturas, volumen de hielo y paleosalinidades. 
La composición isotópica ${ }^{18} \mathrm{O}$ depende de la temperatura del agua y la temperatura de calcificación de las valvas. La utilización de $\mathrm{O}_{2}$ disuelto en el mar para la construcción de las valvas, está disponible de dos formas isotópicas el ${ }^{16} \mathrm{O}$ y ${ }^{18} \mathrm{O}$. En períodos glaciales, el isótopo más liviano $\left({ }^{16} \mathrm{O}\right)$ se libera por evaporación y queda retenido sobre el continente en forma de nieve quedando las aguas del océano enriquecida con el isótopo más pesado ( ${ }^{18}$ O). En los períodos interglaciales, el $\delta^{18} \mathrm{O}$ es menos abundante en relación con el $\delta^{16} \mathrm{O}$. Por tanto, el descenso en la concentración de ${ }^{18} \mathrm{O}$ en las valvas indica un aumento global de las temperaturas y una menor acumulación de hielo en los continentes. Esta relación es afectada por la variabilidad isotópica entre los océanos y la temperatura del agua (Sidall et al., 2006).

El análisis de los isótopos de carbono en sedimentos marinos nos permite estudiar los cambios oceanográficos durante el Cuaternario. Como el oxígeno, el carbono tiene dos isótopos estables naturales $\left({ }^{13} \mathrm{C} \mathrm{y}{ }^{12} \mathrm{C}\right.$ ). El análisis de los isótopos de carbono incluye entre otros, los cambios en la circulación, cambios en la productividad en las capas superiores de los océanos, el flujo de ${ }^{12} \mathrm{C}$ en la superficie oceánica y la variación atmosférica de $\mathrm{CO}_{2}$ (Shackleton et al., 1992). La relación isotópica ${ }^{13} \mathrm{C}^{12} \mathrm{C}$ se utiliza junto con la relación $\delta^{18}$ $\mathrm{O} /{ }^{16} \mathrm{O}$ para la estimación de paleosalinidades.

\subsubsection{Elementos químicos: $\mathrm{Mg}$ y $\mathrm{Sr}$}

La concentración del Mg y el Sr en las valvas de los moluscos depende de varios factores, entre ellos, la proporción original de la relación $\mathrm{Mg} / \mathrm{Ca}$ en el agua, los efectos diagenéticos y la temperatura de las aguas circundantes. Cuando la temperatura superficial del mar (SST) es más alta, el $\mathrm{Mg}^{+2}$ reemplaza con mayor facilidad al $\mathrm{Ca}^{+2}$ en las valvas, el aumento de esta relación nos indica directamente el aumento de la temperatura del agua del océano.

Los organismos marinos que viven cerca de plataformas carbonatadas, es utilizado el $\mathrm{Sr}$ como calculo indirecto de las paleotemperaturas. En épocas glaciares, las plataformas carbonatas quedan expuestas y se meteorizan dejando Sr en el agua oceánica, en pequeñas 
cantidades. Este elemento traza tiene una relación indirecta con el aumento de la temperatura del agua. La cantidad de $\mathrm{Sr}$ no solo se relaciona con la existencia de plataformas carbonatadas sino también se ve afectada por estar cerca de un curso fluvial, alterando la relación $\mathrm{Sr} / \mathrm{Ca}$ (Cléroux et al., 2008).

\subsubsection{Dataciones sobre valvas o concha de moluscos}

La edad de la muestra del fósil es determinada usando diferentes métodos de dataciones según la edad de las mismas y la naturaleza de las muestras. Una de las dataciones más comunes utilizadas para el Cuaternario es el método ${ }^{14} \mathrm{C}$, un isótopo radioactivo de ${ }^{12} \mathrm{C}$. Las dataciones radiocarbónaticas $\left({ }^{14} \mathrm{C}\right)$ son utilizadas para datar edades mínimas de $30 \mathrm{ka}$, utilizadas con frecuencia en valvas marinas de edad Holocena. Para un tiempo de escalas mayores, en los últimos interglaciales se aplican otros métodos de datación como: la serie U/Tr, ESR y racemerización de aminoácidos, entre otros métodos (Stuiver et al., 1998).

El método de las series de uranio $\left({ }^{230} \mathrm{Th} /{ }^{234} \mathrm{U}\right)$, está basado en la incorporación de trazas de los isótopos de ${ }^{238} \mathrm{U}$ y ${ }^{234} \mathrm{U}$ presentes en el agua a la red cristalina de los carbonatos. El tiempo de escala que diagnostican es alrededor de los $350 \mathrm{ka}$ y son utilizados principalmente para muestras de tipo volcánico, carbonáticas y valvas fósiles (Grün et al., 2005).

El método de la resonancia del espín electrónico (ESR) es un método geocronológico absoluto y mide la cantidad de electrones desapareados en la red cristalina a causa de la irradación de material original por radicación a, b ó g, procedentes de ciertos elementos radioactivos presentes en la muestra y su entorno. Calcula un rango temporal de aproximadamente un millón de años (Rutter et al., 1990; Schwarcz y Grün, 1992; Grün et al., 2005).

La racemización de aminoácidos, se basa en el estudio de aminoácidos de proteínas fósiles preservados en materiales carbonatados por el tiempo que no han sido afectados durante la diagénesis. Cuando se forman aminoácidos en los organismos vivientes se presentan 
geométricamente en una sola forma, generalmente izquierda o forma L (levógira) y raramente en derecha o D (dextrógira). Algunos autores utilizan la relación $\mathrm{D} / \mathrm{L}$ de ácido aspártico y leucina (Rutter et al., 1990) entre otros aminoáciodos como valina, alanina, prolina y ácido glutamínico. Al morir el organismo esta relación tiende a equilibrarse, este cambio al ser constante se utiliza para determinar la edad. El rango de aplicación depende de las regiones del planeta; en regiones cálidas ese rango de aplicación es de hasta 2 ma. aproximadamente, con un error de 20 - 30 ka y en las regiones árticas hasta 5 - 6 ma con un error de $100 \mathrm{ka}$.

\subsection{Pregunta}

Para el área el estudio, que abarca el sur de la provincia de Buenos Aires y norte de Río Negro ¿Hubo cambios en la biodiversidad faunística marina durante el Cuaternario?

\subsection{Hipótesis}

- Existen variaciones entre las paleocomunidades de moluscos del sur de Buenos Aires y norte de Río Negro.

- La biodiversidad de gasterópodos y bivalvos de los Interglaciales ( $\geq$ MIS 9, MIS 7 y MIS 5e) correspondientes al período Pleistoceno varían entre sí y con respecto a la fauna de moluscos encontrada en el Interglacial MIS 1.

- La biodiversidad de gasterópodos y bivalvos del Interglacial MIS 1 varían con respecto a la fauna de moluscos encontrados en la actualidad en el área de estudio.

- Existen desplazamientos geográficos de algunas especies relacionados a cambios climáticos ocurridos durante el Cuaternario. 
- Durante el Óptimo Climático, el aumento de las temperaturas superficiales oceánicas se refleja en las paleocomunidades de moluscos del Interglacial MIS 1 en el área de estudio.

\subsection{Objetivos}

\subsubsection{Objetivo general}

Caracterización paleoambiental y paleodiversidad de gasterópodos y bivalvos, durante los diferentes episodios transgresivos del Cuaternario.

\subsubsection{Objetivos específicos}

- Caracterizar asociaciones faunísticas de gasterópodos y bivalvos presentes en los diferentes depósitos del área estudiada.

- Analizar y comparar la composición y la abundancia de moluscos en las distintas asociaciones para evaluar cambios en los patrones de riqueza de especies y abundancia.

- Establecer una relación entre los distintos depósitos litorales marinos (cordones y planicies de marea) con la malacofauna existente.

- Mencionar las especies que cambiaron su distribución geográfica en correlación con las diferentes transgresiones marinas.

- Comparar los depósitos marinos analizados en los distintos interglaciales situados al norte y sur del área de estudio. 


\section{AREA DE ESTUDIO}

El área de estudio abarca el sector costero $\mathrm{S}$ de la Provincia de Buenos Aires desde Península Verde $\left(39^{\circ} 15^{\prime} \mathrm{S} / 62^{\circ} 23^{\prime} \mathrm{O}\right)$ hasta el sur del balneario Las Grutas (norte del golfo San Matías, Río Negro) (4051'S/ 65 $\left.07^{\circ} 0\right)$. Comprendiendo de norte a sur: isla Verde, caleta Brightman, bahía Anegada, bahía San Blas, Faro Segunda Barranca, balneario El Cóndor, Bahía Creek, San Antonio Este, Punta Villarino, Punta Perdices, bahía San Antonio, San Antonio Oeste y Las Grutas.

Los principales rasgos geomorfológicos corresponden a cordones litorales generados en condiciones de alta energía, aunque también, y principalmente para el evento transgresivo del Holoceno, han sido descriptos depósitos correspondientes a ambientes intermareales, lagunas costeras, espigas y formas acantiladas (ej. Angulo, 1981; Weiler, 1984, 2000; Fucks et al., 2012ab).

El área de estudio se ha dividido en 4 regiones según las características geomorfológicas: A: Región del delta del río Colorado, abarca desde Península Verde hasta la isla Otero; B: Región de bahía Anegada, se extiende desde el isla Otero hasta las inmediaciones de la isla Jabalí; C: Región de isla Jabalí - Villa 7 de Marzo, incluye el área litoral y continental de bahía San Blas, desde las inmediaciones de isla Jabalí hasta Villa 7 de Marzo y D: Región norte del golfo San Matías, desde balneario El Cóndor hasta el sur del balneario Las Grutas (Fig. 2.1). 


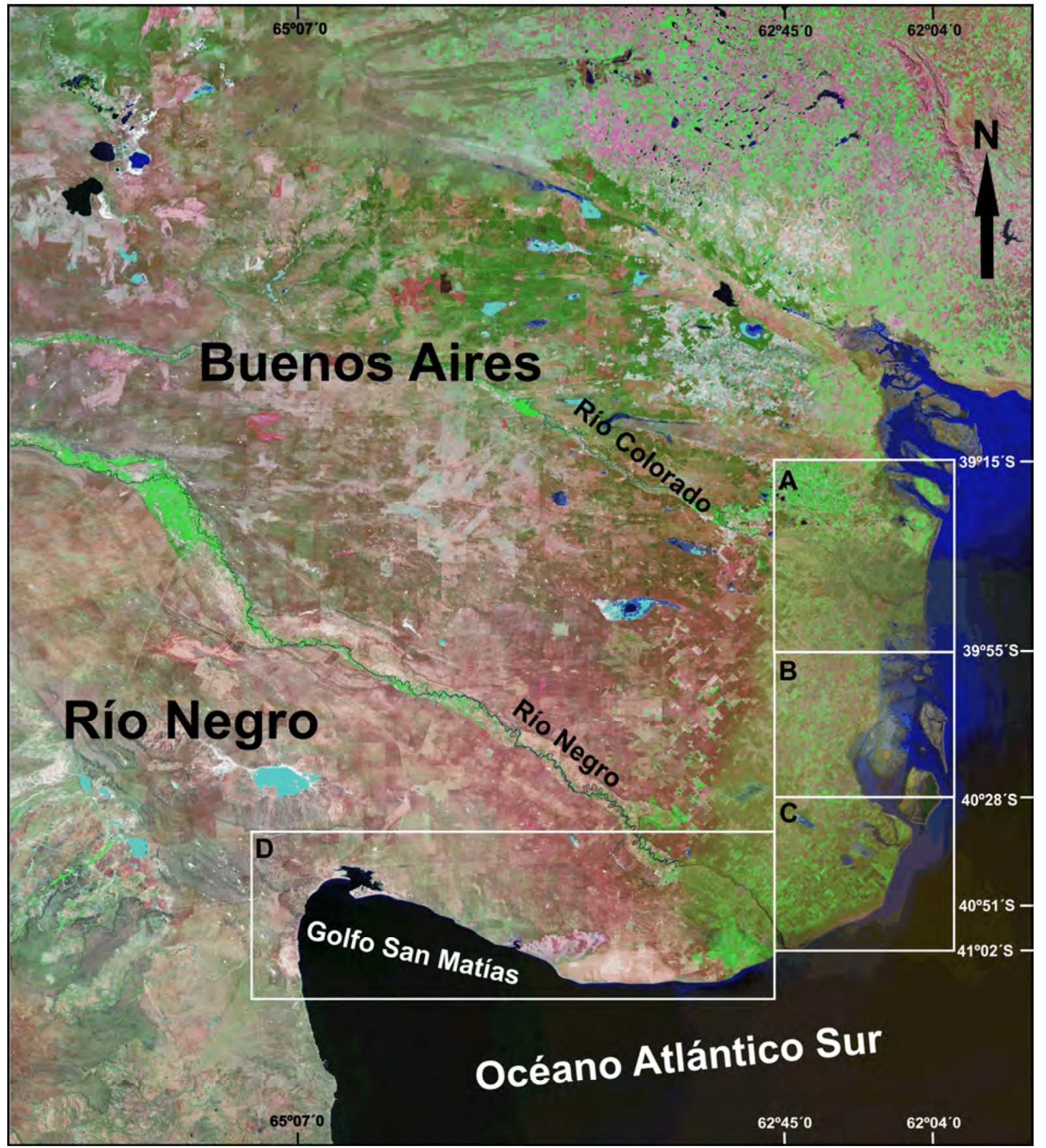

Fig.2.1: Localización del área del estudio. A, Región delta del río Colorado; B, Región de bahía Anegada; C, Región isla Jabalí - Villa 7 de Marzo; D, Región norte del golfo San Matías. 


\subsection{Región del delta del río Colorado}

La región del delta del río Colorado se extiende desde Península Verde (39²0'S/62 $\left.04^{\circ} \mathrm{O}\right)$ hasta la isla Otero $\left(39^{\circ} 55^{\prime} \mathrm{S} / 62^{\circ} 08^{\prime} \mathrm{O}\right)$, cuyo principal curso de agua funcional es el río Colorado.

El delta del río Colorado constituye un cuerpo progradante, compuesto por gran cantidad de cauces activos, como abandonados dentro de los que se destacan, de $\mathrm{N}$ a S: el Colorado Nuevo, el Colorado y el Colorado Viejo. Las planicies deltaícas del río Colorado comprende tanto la zona de canales de desembocadura recientes (Colorado Viejo y Colorado Nuevo), como los "deltas antiguos" que hoy se conocen como Caleta Brighman, Península Verde, bahía Verde y bahía Falsa (Isla y Bértola, 2003).

La bahía Verde es una zona de acreción donde se considera que el factor principal de movilización del material es la corriente de mareas. Dentro de la bahía se distribuyen islas (Puerto, Conejos, Word y Ariadna) y bancos arenosos, entre ellas se destaca Península Verde, la que se convierte en una verdadera isla durante las pleamares de sicigias o durante fuertes tormentas (Weiler, 1984).

La planicie de inundación del río Colorado inferior está limitada al norte por el río Colorado Chico o Nuevo, y al sur por el río Colorado Viejo. De los tres ríos solo el primero, que constituye el cauce principal que corre por el centro del valle, es funcional; los otros dos han sido abandonados en tiempos históricos, pero se reactivan durante las crecientes. Todo este complejo está modificado por acción antrópica, debido fundamentalmente a la gran cantidad de canales realizados.

En la desembocadura del río Colorado, se desarrolla un pequeño delta de unos $3 \mathrm{~km}$ de largo y $5 \mathrm{~km}$ de ancho (Weiler, 1984), con forma cuspidada deformada hacia el norte como consecuencia de la deriva litoral (Codignotto y Weiler, 1980). 
El curso del río Colorado Viejo, en la actualidad se comporta en su parte terminal como un canal de marea que conecta al mar abierto con el área norte de bahía Anegada (Codignotto y Weiler, 1980).

Spalletti e Isla (2003) diferenciaron en el área de influencia de la desembocadura del río Colorado tres lóbulos no operativos y uno actual. El lóbulo 1 comprende desde la bahía Falsa hasta la isla de los Riachos, es el más antiguo y se relaciona con el inicio del período de deglaciación y con posición baja del nivel del mar. La planicie deltaíca de este lóbulo está compuesta por sistemas fluviales multicanales de baja sinuosidad. El lóbulo 2 ubicada en el área de influencia de Bahía Blanca aparece fuertemente degradado y la planicie deltaíca está en estado de destrucción por la acción mareal. El lóbulo 3, ubicada entre la caleta Brightman y el sector norte de la bahía Anegada, está relacionado con un sistema multicanal de alta sinuosidad. Este último lóbulo está sobrepuesto al lóbulo 1 y es el más joven de edad. El estado de máxima transgresión produjo singulares efectos destructivos mareales y de olas sobre la superficie de los lóbulos 1, 2 y 3. Posteriormente, sobre la superficie del lóbulo 3, se acumularon cordones litorales alineados en sentido N - S que corresponden a posiciones más elevadas del nivel del mar en relación con la situación actual (transgresión holocena entre 4 y 3.7 ka). La desembocadura del Colorado Nuevo constituye un pequeño delta de plataforma progradacional (lóbulo 4), su geometría lobulada se debe al retrabajo de corrientes asociadas al oleaje.

En los últimos 6 ka el delta del río Colorado progradó, fue retrabajado y en la actualidad tienen un único lóbulo activo (Spalletti e Isla, 2003).

En el sector continental, se desarrollan depósitos marinos transgresivos holocenos, que actúan como sustrato del sector terminal del complejo deltaíco, aflorando en el subsuelo depósitos finos de ambientes intermareales y cordones litorales del Pleistoceno (ej. Weiler, 1984; Fucks et al., 2012a). 


\subsection{Región de bahía Anegada}

La región de bahía Anegada, se extiende desde isla Otero $\left(39^{\circ} 55^{\prime} \mathrm{S} / 62^{\circ} 08^{\prime} \mathrm{O}\right)$ hasta las inmediaciones de isla Jabalí $\left(40^{\circ} 28^{\prime} \mathrm{S} / 62^{\circ} 11^{\prime} \mathrm{O}\right)$, área S de la Provincia de Buenos Aires.

En el ambiente de bahía Anegada, se forma una barrera arenosa que se encuentra disectada por estrechos de marea (Weiler, 1984). Desde la línea de costa hacia el mar, se desarrollan un conjunto de islas que con formas alargadas y orientaciones $\mathrm{N}$ - S trazan una línea más o menos recta uniendo el delta del Colorado con la isla Jabalí. Rodeando las islas y fundamentalmente en sus sectores occidentales se desarrollan extensas planicies de mareas, que quedan expuestas durante la marea baja. Estas planicies presentan rasgos de erosión, ya que el mar penetra por numerosos canales de marea antiguos y cursos fluviales afuncionales, dando como resultado la formación de islas (Weiler, 1984).

Las islas Otero, Margarita, Gaviota, de Los Riachos, Creek, de los Césares, del sur, Flamenco y Gama presentan en sus sectores expuestos al mar una morfología rectilínea, con el desarrollo de extensas playas de arena de textura mediana a fina, de suaves pendientes y el desarrollo de médanos. Entre ellas, la isla Olga esta compuesta por sedimentos limo- arcillosos a los que se superponen depósitos de rodados formando crestas de playas que no superan el metro de espesor (ej. Nicolas et al., 1986; Weiler, 2000). En todas las islas y sus sectores circundantes, se produce una mezcla permanente de diferentes ambientes, ya sea consolidados por el mar o por el viento (playas y médanos) y llanuras con canales de marea (Fucks et al., 2012a).

En el sector continental se desarrollan los depósitos marinos transgresivos pleistocenos y holocenos, representados por islas barreras, albúferas y reconociendo también para el Holoceno planicies de marea (ej. González y Weiler, 1983, Weiler 1984). Según Fucks et al. (2012a) las geoformas características del Pleistoceno y Holoceno en su mayoría pertenecen a cordones litorales dispuestos a lo largo de la línea de costa hacia el continente con alturas variables. 


\subsection{Región de isla Jabalí -Villa 7 de Marzo}

El área de estudio abarca desde isla Jabalí (40³6' S/62 $\left.11^{\circ} \mathrm{O}\right)$ hasta Villa 7 de Marzo (41 ${ }^{\circ}$ 1 'S/ $\left.62^{\circ} 45^{\prime} \mathrm{O}\right)$ y desde la línea de costa hasta la ruta 3 .

Se distinguen dos entidades geológicas, una de edad terciaria correspondiente a la Formación Belén (Kaaschieter, 1965), en la barranca norte del salitral el Barrancoso, de origen continental producto de las acumulaciones fluviales asociados a deltas y estuarios. La segunda entidad corresponde a una cubierta sedimentaria cuaternaria constituida por distintos tipos de depósitos marinos y continentales (Trebino, 1987). Los rasgos geomorfológicos más característicos están representados por formas cordoniformes de génesis litoral, llanuras de gravas y bajos.

En el sector continental, los cordones litorales pleistocenos y las playas constituyen las morfologías más destacadas. Los cordones litorales del Pleistoceno se encuentran paralelos entre sí y a cotas del orden de los 8 a $10 \mathrm{~m}$, presentando rumbo $\mathrm{N}$ - S, truncados al $\mathrm{N}$ por el arroyo Jabalí y al S por el arroyo Walker (Fucks et al., 2012a).

La isla Jabalí está separada del continente por dos canales de marea someros, denominados arroyo Jabalí y arroyo del Guanaco. El primero es un canal que recibe los efectos de marea, bordeado por planicies de marea formadas por sedimentos finos y vegetados mayormente por Spartina alterniflora. El arroyo del Guanaco está obstruido actualmente en su desembocadura en el Océano Atlántico por cordones de arena (Cuadrado y Gómez, 2010).

La isla Jabalí se caracteriza por cordones litorales holocenos dispuestos en varias direcciones, constituyendo el cuerpo principal de la isla. Sus espesores oscilan entre 8 y 10 m y constituyen en el paisaje una forma ondulada (Trebino, 1987).

Al O de la isla Jabalí, el desarrollo de gran cantidad de cuencas de deflación ocupadas por "salitrales" (Salitrales del Barrancoso, Grande, La Salinita y la Salina del Inglés), entre 
otros, constituyen uno de los rasgos más comunes del área continental. Las cuencas más alejadas de la línea de costa, se encuentran $40 \mathrm{~m}$ por debajo del paisaje que las rodea, disminuyendo progresivamente a medida que nos acercamos a la costa. Presentan en general una morfología alargada en dirección NO - SE (Fucks et al., 2012a). Estas depresiones denominadas playas son características de zonas áridas y semiáridas, cuyo fondo plano está sujeto a inundaciones periódicas o esporádica y a la precipitación de sales por evaporación (Gutiérrez Elorza et al., 2005). En los sectores más bajos suele localizarse la mayor concentración de sales, entre las que predomina el cloruro de sodio, en menor grado yeso y sulfatos alcalinos (Trebino, 1987, Del Blanco et al., 2005). Durante las diferentes transgresiones estas depresiones se vieron ocupadas alternativamente por el mar, razón por la cual es común encontrar sedimentos y fósiles marinos, con edades tanto holocenas como pleistocenas, por ejemplo en Salina del Ingles 72.7 - $94.5 \mathrm{ka}$, (Rutter et al., 1990) y en el Salitral del Barrancoso $5.37 \pm 0.11$ ka (Trebino,1987).

\subsection{Región Norte de golfo San Matías}

El área de estudio se extiende desde las inmediaciones del balneario El Cóndor $\left(41^{\circ} 02^{\prime} \mathrm{S} / 62^{\circ} 49^{\prime} \mathrm{O}\right)$ hasta el $\mathrm{S}$ del balneario Las Grutas $\left(40^{\circ} 51^{\prime} \mathrm{S} / 65^{\circ} 7^{\prime} \mathrm{O}\right)$ abarcando el sector costero N del golfo San Matías.

El golfo San Matías, uno de los golfos patagónicos más importantes de la plataforma Argentina, conforma una cuenca semicerrada de $17.000 \mathrm{~km}^{2}$ con una profundidad del orden de los $200 \mathrm{~m}$, desarrollándose en su sector norte la bahía San Antonio. La bahía anteriormente mencionada, es profunda y corresponde al principal accidente costero del litoral rionegrino (Gelos et al., 1988). Se caracteriza por extensas llanuras de marea fangosas, las que se extienden hasta las inmediaciones de la ruta 3. Se encuentran surcadas por dos importantes canales de marea, a espaldas de las espigas, generándose una compleja red de drenaje dendrítico. Estas llanuras depositacionales se encuentran cubiertas en algunos lugares por vegetación halófila (Spartina sp. y Salicornia sp.) o por colonias densas de mejillín (Brachidontes rodriguezii). Prácticamente todo el sector intermareal E, N y O de la bahía presenta este tipo de morfología, observándose a la salida de ella, bancos 
de arena dominando importantes extensiones como Banco Reparo, Lobos y las Garzas (Fucks et al., 2012b).

El golfo San Matías, durante gran parte del año, se caracteriza por la presencia de un frente termohalino separando las aguas cálidas y salinas del sector norte, de las aguas más frías y menos salinas, que ingresan del sector sur (Piola y Scasso, 1988). La amplitud térmica anual del golfo es mayor que el mar abierto por la limitada renovación de sus aguas, observándose en su interior valores de >33 UPS de salinidad (Guerrero y Piola, 1997; Piola y Rivas, 1997). Una característica dominante de la circulación del golfo San Matías es la presencia de un giro ciclónico que ocupa casi toda su superficie y dos giros anticiclónicos hacia el sur controlados por la acción del viento (Tonini et al., 2007).

La caleta de los Loros ( $\left.41^{\circ} 2^{\prime} \mathrm{S} / 6^{\circ} 4^{\prime} \mathrm{O}\right)$, entre bahía Creek y Punta Mejillón, es una de las dos bocas de marea junto a la bahía San Antonio presentes en el golfo San Matías, con una superficie de $72 \mathrm{~km}^{2}$ (Del Río y Colado, 1999). El sector de mayor desarrollo de planicies de mareas se encuentra en esta caleta, de unos $15 \mathrm{~km}^{2}$ de superficie y escasa pendiente, favoreciendo la depositación de sedimentos finos limo-arcillosos (Gelos et al., 1988).

Estudios geomorfológicos recientes (ej. Fucks y Schnack, 2011; Fucks et al., 2012b), analizan rasgos geomorfológicos a lo largo de la costa norte del gofo San Matías y describen depósitos litorales asignados por los menos a cuatro ciclos transgresivos. Entre estos depósitos marinos, tres de los asignados al Pleistoceno representan a los interglaciales (MIS 9?, MIS 7, MIS 5e) y los depósitos de edad holocena al Interglacial MIS 1. Entre los rasgos geomorfológicos más importantes que caracterizan a los interglaciales del norte del golfo están representados por paleoacantilados, plataformas costeras y cordones litorales (Fucks et al., 2012b).

Sobre el continente, actualmente dominan los sedimentos eólicos que constituyen cordones de médanos o campos de dunas. Los médanos se distribuyen paralelamente a la línea de costa cuyas alturas oscilan entre los $0.50 \mathrm{~m}$ y $5 \mathrm{~m}$ en el sector entre el balneario El Cóndor y punta Villarino, y se caracterizan por ser medanos fijos o semifijos (Gelos et al., 1988). 
Hay dos sectores de desarrollo de campos de dunas, uno al este de Baliza San Matías de aproximadamente $10 \mathrm{~km}$ de extensión y $5 \mathrm{~km}$ de ancho y otro entre caleta de Los Loros y bahía Creek, que alcanza a penetrar hasta $45 \mathrm{~km}$ hacia el continente (ej. González Díaz y Malagnino, 1984; Gelos et al., 1988).

Las playas del norte de Río Negro, se caracterizan por ser playas extensas por acumulaciones de rodados y arenas compuestas por valvas. En punta Mejillón, la playa tiene un ancho que oscila entre $550 \mathrm{~m}$ y 120 m en bahía Rosas, variando la pendiente media en $1.4 \%$ y $12.9 \%$ respectivamente (Gelos et al., 1988). El área de bahía Creek es un sector más abierto del golfo y se presenta como un ambiente heterogéneo caracterizado por playas de rodados (Kokot et al. 2004; Favier Dubois et al. 2006). En las proximidades del Puerto San Antonio Este, las playas tienen unos $400 \mathrm{~m}$ de ancho y una pendiente de sólo $1.3 \%$ en los sectores intermareales más bajos (Isla et al., 2001). 


\section{ANTECEDENTES GEOLÓGICOS Y PALEONTOLÓGICOS}

\subsection{Antecedentes geológicos}

A lo largo del área costera argentina se han identificado diferentes niveles marinos producidos por distintas oscilaciones del nivel del mar durante el Cuaternario quedando reflejados por diferentes morfologías como: paleoplayas, paleoacantilados, cordones litorales, planicies de marea y playas actuales, a los que se asocian a diferentes asociaciones faunísticas.

\subsubsection{Región del delta del río Colorado}

Groeber (1947, 1949) describió depósitos marinos cuaternarios de la Provincia de Buenos Aires, principalmente los depósitos marinos de Península Verde. Asignando a los distintos pisos Samborombonense inferior -superior y Querandinense y reconociendo en el área del río Colorado, 8 cordones medanosos y los consideró vinculados a antiguas líneas de costa.

Los depósitos medanosos del delta del río Colorado, Vilela y Riggi (1956) los relacionaron con salitrales ubicados más al norte (Salitral de la Vidriera y la Gotera, sector bonaerense) asignándoles una edad holocena.

Auer (1959, 1970) señalo entre la zona de bahía Verde e isla Gaviota, la presencia de terrazas marinas a cotas de 6 y 2 - 3 m, asignándole edad posglaciaria.

Cappannini y Lores (1966) interpretan geomorfológicamente y determinan tipos de suelo del valle inferior del río Colorado. Asignándo los depósitos costeros de edad Lujanense Querandinense, basados en el esquema de Frenguelli (1950).

Desde Punta Laberinto hasta el río Colorado Viejo, Codignotto y Weiler (1980) definieron tres niveles de terrazas para esta región. El nivel alto corresponde a la cota de $10-7.50 \mathrm{~m}$, 
el intermedio de cota $7.50 \mathrm{~m}$ y el más bajo a la cota $2.50 \mathrm{~m}$. Estos autores obtuvieron mediante ${ }^{14} \mathrm{C}$ una secuencia cronológica tentativa con edades de $6.63 \pm 0.12 ; 6 \pm 0.15 ; 5.02$ $\pm 0.10 ; 2.75 \pm 0.11 ; 2.59 \pm 0.11 ; 2.15 \pm 0.11 ; 1.3 \pm 0.19$ y $0.409 \pm 0.10 \mathrm{ka}$, en el área de la desembocadura del río Colorado. Las espigas de rodados ubicados al sur del río Colorado Viejo, con edades de $9.46 \pm 0.12 ; 6.75 \pm 0.10 ; 5.9 \pm 0.10$ y $4.85 \pm 0.90 \mathrm{ka}$. Las edades obtenidas entre las distintas crestas de playas muestran un decrecimiento gradual hacia el E entre los $6.93 \pm 0.13$ y $0.407 \pm 0.10$ ka indicando una migración en la línea de costa hacia el E durante el Holoceno.

Alberó et al. (1980) dataron valvas de moluscos en esta regióm a partir del método ${ }^{14} \mathrm{C}$ para el área entre Punta Laberinto y la desembocadura del río Colorado Chico.

En el frente deltaíco del río Colorado, González y Weiler, (1983) muestrearon una secuencia de cordones litorales arenosos con valvas de moluscos, en los cordones más próximos al continente, las edades de ${ }^{14} \mathrm{C}$ oscilan entre los $6 \mathrm{ka}$ y pueden considerarse representativos del máximo alcance de la transgresión marina.

Weiler (1984) reconoció para el sector costero comprendido entre bahía Verde e Isla Gaviota, un evento marino ingresivo-regresivo en el Holoceno. Este evento está representado por una sucesión de crestas de playas arenosas, entre bahía Verde y la desembocadura del río Colorado Viejo, con barreras arenosas asociados a fauna marina similares a las encontradas en las crestas de playas y planicies de mareas antiguas y actuales entre el sector comprendido entre bahía Verde y Punta Laberinto.

\subsubsection{Región de bahía Anegada}

Franchi (1977) reconoció depósitos de planicie de marea en el área de bahía Anegada y los correlacionó a la "ingresión Querandinense” (8 - 6 ka) (Holoceno). 
Weiler (1988) describió los depósitos marinos pleistocenos y holocenos de la parte central de la región morfoestructural denominada "Cuenca del Colorado" o bahía Anegada correlacionándolos con distintos episodios transgresivos. Weiler $(1988,1993)$ describe para la zona tres episodios transgresivos del Pleistoceno Tardío y Holoceno, asociándolos con ambientes de islas barreras y albúferas, correlacionádolos con la transgresión interglacial (Sangamon, edad mínima 43 ka), la transgresión interestadial (Wisconsin medio, 38.5 y 25 ka) y la transgresión posglacial (Holoceno medio) con edades de 5 y 5.2 ka (MIS1).

Las edades obtenidas para el área del canal Villalonga varían entre los $3.69 \pm 0.10$ hasta $5.98 \pm 0.10$ ka y $4.4 \pm 0.08$ y $4.5 \pm 0.09$ ka en el área de Los Pocitos. Para los depósitos pleistocenos los valores oscilan entre 43 y $31 \mathrm{ka}$ y $38.8 \pm 2.80 \mathrm{ka}$ respectivamente, calculados mediante ${ }^{14} \mathrm{C}$ (Weiler, 2000; González y Weiler, 1983; Fucks et al., 2012a).

Estos depósitos transgresivos son correlacionados con los depósitos encontrados a $33^{\circ}$ y $40^{\circ}$ S (González et al., 1986; González y Guida, 1990). Más recientemente, Schnack et al. (2005) proponen que las transgresiones más antiguas descriptas por Weiler corresponderían al Interglacial MIS 5e debiéndose considerar las edades radiocarbónicas como mínimas.

Según Fucks et al. (2012a) los cordones situados hacia el interior del continente, podrían corresponder a dos episodios transgresivos distintos, uno más antiguo que el Interglacial MIS 9? representado por cordones a cotas de 25 - 40m y al Integlacial MIS 5e, los depósitos marinos cuyas cotas son de 7 - 10 m. Las morfologías cordoniformes ubicadas más cerca de la costa, corresponden a los depósitos transgresivos holocenos (MIS1), con cotas de hasta $5 \mathrm{~m}$.

\subsubsection{Región de isla Jabalí- Villa 7 de Marzo}

Witte (1916) fue el primer autor en estudiar la zona y describir la geología de los depósitos costeros de San Blas. Definió cinco estadíos de evolución (I - V) para la región, representados en diferentes sectores de la costa, los sedimentos que lo forman se componen 
únicamente de los estadíos III (Pleistoceno), IV y V (Holoceno). Los depósitos del estadío III, en el área de bahía San Blas, formaban varias islas y sus confines son demarcados por antiguas líneas de costas. El final de este estadío se señala como un período de retroceso repentino del mar. Los depósitos del estadío IV son de origen marino y se encuentran muy alejados de la costa lo que se supone que el nivel del mar durante el Holoceno era más alto que en la actualidad. Los estratos del estadío IV en la parte NE de San Blas se encuentran en su parte extrema representados por dos cordones de "pedregullo", detrás de los cuales se depositaron los extensos salitrales. Los estratos depositados en este estadío no fueron depositados lentamente por el cambio de flujo y reflujo que tienen los rodados en movimiento, sino que fueron depositados sucesivamente sedimentos contra la antigua costa de la isla. Así que, durante el último retroceso del nivel del mar, San Blas quedó unido con la tierra firme formando una península. El estadío $\mathrm{V}$ o aluviones modernos se dividen en depósitos eólicos y marinos. Estos últimos se los puede encontrar en la parte extrema $\mathrm{O}$ de San Blas pero en la costa $\mathrm{S}$ de la península y está compuesto por rodados, arenas y fango limosos.

Autores contemporáneos como Ambrosini (1984) y Trebino (1987) analizaron la geomorfología del área de bahía San Blas, describiendo geoformas pleistocenas, holocenas y actuales. Trebino (1987) reconoció tres niveles de terrazas marinas; la número III de edad holocena y la II y I de edad pleistocena. Los más antiguos localizados en el Rincón de Walker y los más modernos ubicados en la isla Jabalí como resultado de las sucesivas acumulaciones de las crestas y espigas de playa (Echeverría et al., 2006). Para los depósitos del Holoceno, situados a una cota de $3 \mathrm{~m}$ se obtuvieron edades de $2.17 \pm 0.11 ; 3.45 \pm 0.11$; $3.65 \pm 0.80(\mathrm{LP}=2434) ; 4.1 \pm 0.95 ; 5.37 \pm 0.11 ; 2.32 \pm 0.80$ y $3.45 \pm 0.80 \mathrm{ka}^{14} \mathrm{C}$ (Trebino, 1987).

Al O del arroyo Jabalí se ubican los cordones litorales pleistocenos que arrojaron edades de $28.4 \pm 0.80$ y $29.12 \pm 0.97 \mathrm{ka}^{14} \mathrm{C}$, (Trebino, 1987) y $30.78 \pm 1.65$ ka Weiler (2000), considerándose edades mínimas, y que podrían correlacionarse con el Interglacial MIS 5e. 
Schnack et al. (2005) consideraron que los estadios I al III de Witte (1916) son equivalentes a los niveles de terrazas I y II de Trebino (1987), de edad pleistocena, mientras que los depósitos holocenos correspondientes al estadio IV de Witte (1916) serían equivalentes al nivel de terraza III de Trebino (1987).

Las investigaciones geocronológicas más recientes efectuadas en la zona de Faro Segunda Barranca utilizaron las técnicas de ESR y racemización de aminoácidos. Sobre la base del acantilado se han obtenido cronologías de 102 y 108 ka. En el nivel superior del acantilado las edades oscilan entre 94.5, 79 y $72.7 \mathrm{ka}$, todas dataciones a partir del método ESR, aunque la relación $\mathrm{D} / \mathrm{L}$ de ácido aspártico y leucina permitiría atribuirlos a un evento transgresivo más antiguo (Rutter et al., 1989, 1990). Estas últimas secuencias pertenecerían a la unidad estratigráfica perteneciente al Interglacial MIS 5e equivalente a la Terraza V de Feruglio (1950) y al Belgranense (Ameghino, 1889) o a la Formación Puente de Pascua (Fucks et al., 2005).

Fucks et al. (2012 a) reinterpretaron las secuencias estratigráficas del área asignando un mínimo de cuatro ciclos transgresivos para la región. Desde la costa hacia el continente se presentan cordones litorales, planicies con crestas de playa y llanuras de mareas a cotas menores a $5 \mathrm{~m}$ con morfologías muy bien representadas, las que se asociarían al MIS 1 . Por encima y a cotas de 8 - $10 \mathrm{~m}$ se presentan en forma de cordones bien representados asociados al Interglacial MIS 5e. En menor medida que los anteriores, elevándose paulatinamente hasta cotas por encima de los $30 \mathrm{~m}$, los que podrían corresponder genéticamente a dos episodios transgresivos $\geq$ MIS 9 (T. 3.1). 


\begin{tabular}{|c|c|c|c|c|c|}
\hline & $\begin{array}{l}\text { Depósitos } \\
\text { marinos }\end{array}$ & Witte (1916) & Trebino (1987) & & $\begin{array}{l}\text { Fucks et al. } \\
(2012 \mathrm{a})\end{array}$ \\
\hline $\begin{array}{c}\text { Bahía } \\
\text { San } \\
\text { Blas }\end{array}$ & \begin{tabular}{|l|} 
Holoceno \\
Pleistoceno
\end{tabular} & $\begin{array}{l}\text { Estadio V: depósito } \\
\text { actual de playa } \\
\text { Estadio IV: } \\
\text { Depósitos marinos } \\
\text { correspondientes a un } \\
\text { nivel del mar } 1.50 \mathrm{~m} \\
\text { más alto que el actual. } \\
\text { Formación de } \\
\text { salitrales y salinas } \\
\text { cerca del mar. } \\
\text { Islas enfrente de la } \\
\text { costa. } \\
\text { Estadio III: } \\
\text { Bancos marinos de la } \\
\text { costa a nivel del mar } \\
\text { aprox. de 10m más } \\
\text { alto que el actual. } \\
\text { Fósiles marinos } \\
\text { abundantes. } \\
\text { Antiguas crestas de } \\
\text { playas visibles. }\end{array}$ & $\begin{array}{l}\text { Rasgos erosivos } \\
\text { Nivel III: poco } \\
\text { representado en el } \\
\text { área, se lo } \\
\text { reconocen en forma } \\
\text { discontinua a lo } \\
\text { largo del arroyo } \\
\text { Walker, responden } \\
\text { a terrazas más } \\
\text { actuales. } \\
\\
\text { Nivel II: Se } \\
\text { reconocen } \\
\text { alineamientos de } \\
\text { crestas de playas } \\
\text { que responden a } \\
\text { antiguas líneas de } \\
\text { costas. Se localizan } \\
\text { entre los } 10 \text { y } 11 \mathrm{~m} \\
\text { sobre el nivel del } \\
\text { mar. }\end{array}$ & $\begin{array}{l}\text { Rasgos de } \\
\text { acumulación } \\
\text { Sección B: Se } \\
\text { incluyen todas las } \\
\text { acumulaciones } \\
\text { marinas de isla } \\
\text { Jabalí y las ubicadas } \\
\text { al sur. Estas } \\
\text { geoformas suelen } \\
\text { estar truncadas por } \\
\text { la erosión marina e } \\
\text { interdigitado. } \\
\text { Section A: Ubicado } \\
\text { al oeste del arroyo } \\
\text { del Jabalí y limitado } \\
\text { al sur por los arroyos } \\
\text { Walker y el } \\
\text { Guanaco. Se trata de } \\
\text { cordones litorales } \\
\text { ubicados entre los } 9 \\
\text { y } 10 \text { snm. }\end{array}$ & $\begin{array}{l}\text { Cordones } \\
\text { litorales de cotas } \\
\text { entre } 8-10 \mathrm{~m} \\
\text { aprox., } \\
\text { asociados al } \\
\text { Interglacial MIS } \\
\text { 5e. } \\
\text { Cordones } \\
\text { litorales a cotas } \\
\geq 30 \mathrm{~m}, \\
\text { asociados al } \\
\text { Interglacial } \geq \\
\text { MIS 9. }\end{array}$ \\
\hline
\end{tabular}

T. 3.1: Rasgos geomorfológicos de la región de bahía San Blas Witte (1916), Trebino (1987) y

Fucks et al. (2012a). 


\subsubsection{Región del N del golfo San Matías}

Wichmann (1918) fue quien por primera vez describe estos depósitos asignándolos a la formación Cuaternaria, reconociéndola en los alrededores de la costa de bahía San Antonio.

Posteriormente, Feruglio $(1933,1950)$ hace referencia a estos depósitos costeros y fauna asociada. Este autor diferenció para la costa patagónica 5 terrazas marinas en función de las diferentes alturas, siendo los depósitos aquí estudiados equivalentes a la terraza VI (Comodoro Rivadavia) (Martínez et al., 2001).

En bahía San Antonio, Angulo et al. (1978, 1981) diferenciaron dos unidades estratigráficas relacionadas con las unidades marinas: la Formación Baliza San Matías (Pleistoceno tardío) y la Formación San Antonio (Holoceno). La distinción entre las mismas se basó en la morfología, grado de litificación y posición estratigráfica. De la Formación San Antonio se obtuvieron edades ${ }^{14} \mathrm{C}$ en valvas de moluscos con valores de 28 a $40 \mathrm{ka}$ interpretándose como retransportadas de sedimentos más antiguos. Angulo et al. (1981) describen los cordones litorales pertenecientes a la Formación San Antonio, distribuidos en toda el área de la bahía San Antonio, principalmente al norte y al este de la bahía, estando constituidos por grava arenosa con valvas de moluscos. Además describen en el área planicies de marea y antiguos depósitos de playa.

Según Fidalgo et al. (1980), la Formación San Antonio y la Formación Baliza San Matías, se correlacionarían con la Formación Pascua y La Formación Las Escobas, respectivamente, del noreste bonaerense. 
Posteriormente, Rutter et al. (1989, 1990) analizaron distintos depósitos cuaternarios, incluyendo entre ellos San Antonio Oeste, y utilizando aminoácidos y análisis de ESR (electron spin resonance) obtuvieron edades de 97 - 80 y 70 - 66 ka para los depósitos pleistocenos más jóvenes y de $\geq 230$ y $\geq 169$ ka para el depósito Pleistoceno más antiguo. Debido a que el subestadío e del MIS 5 corresponde al evento más cálido se considera que los depósitos mas jóvenes analizados en el área corresponden a este Interglacial y los más antiguos al Interglacial MIS 7 (Fucks et al., 2012b).

Gelos et al. (1993) enfatizó la evolución morfológica de las costa norte del golfo San Matías como consecuencia de eventos sucedidos en el Holoceno. Describiendo los rasgos geomorfológicos entre Punta Villarino y la desembocadura del Río Negro.

Recientemente Fucks et al. (2012b), reconocen en el norte del golfo San Matías al menos cuatro ingresiones marinas, tres de ellas asignadas al Pleistoceno (MIS 5e, MIS 7 y $\geq$ MIS 9?) y la cuarta al Holoceno (MIS 1). Las asignaciones de Formación Baliza San Matías y Formación San Antonio (Angulo et al. 1978), corresponderían a los últimos dos eventos transgresivos del Pleistoceno.

\subsection{Antecedentes paleontológicos}

Las obras clásicas de d’Orbigny (1834-1847, 1842-1844), Darwin (1846), Ameghino (1898, 1908), Ihering (1907) y Wahnish (1939) se basan en colecciones de material tanto fósil como actual procedentes del Atlántico Sudoccidental.

Los primeros trabajos referidos a moluscos marinos en la Provincia de Buenos Aires, son en gran medida geológicos. Autores como Frenguelli $(1928,1945,1950,1957)$ y Richard and Craig (1963) contribuyeron considerablemente al conocimiento de la fauna marina del Cuaternario. En trabajos más contemporáneos, se desarrollaron las primeras menciones de moluscos a través de estudios sistemáticos (Carcelles 1944, 1950; Feruglio, 1950; Carcelles y Williamsom, 1951; Camacho, 1966; Castellanos, 1967, 1990, 1992; Aguirre, 1993c, 1994; entre otros). También se incorporan catalógos (ej. Scarabino, 1977; Ríos, 1994; Aguirre y Farinati, 2000; Forcelli, 2000; Clavijo et al., 2005), estudios paleobiogeográficos (ej. Aguirre, 1993b; Aguirre y Farinati, 1999; 
Aguirre et al., 2005, 2011; Gordillo, 1998; Gordillo et al., 2005, 2008; Bayer et al., 2013), geocronológicos (ej. Farinati, 1985; Gordillo et al., 2005) y geoquímicos (ej. Aguirre et al., 1998, Obelic et al., 1998) ampliando así el conocimiento de los distintos moluscos de la costa Atlántica argentina.

Los trabajos de investigación más recientes, fueron objeto de estudio las asociaciones malacológicas cuaternarias preservadas en los distintos depósitos marinos pleistocenos y holocenos a lo largo de la costa de la Provincia de Buenos Aires. Entre los trabajos más destacados principalmente en el sector noroeste bonaerense y la localidad de Bahía Blanca, contribuyen las investigaciones de Farinati y Camacho (1980); Farinati (1978, 1985, 1993,1994); Chaar et al. (1992); Codignotto y Aguirre (1993); Aguirre (1990, 1993ab, 2002); Aguirre y Whatley (1995); Aguirre y Fucks (2004) y Fucks et al. (2005), entre otros. En Bahía Blanca, estudios sobre valvas y conchas de carácter tafonómico y paleoecológico (ej. Farinati, 1994; Farinati y Aliotta, 1995; Farinati y Zabala, 1995; Farinati et al., 1992, 2006, entre otros) enriquecieron los conocimientos sobre las comunidades marinas asociadas en la Provincia de Buenos Aires.

En la región del norte de Río Negro, Feruglio (1933) realiza el primer catálogo de moluscos patagónicos cuaternarios, quien describe los depósitos marinos desde San Antonio Oeste hasta Tierra del Fuego. Los trabajos actuales que contribuyeron al estudio de las asociaciones malacofaunísticas fósiles en el norte patagónico son las contribuciones de Pastorino $(1991,1994,2000)$ y a lo largo de la patagonia Argentina (ej. Gordillo, 1993, 1998, 1999, 2009; Gordillo e Isla, 2011; Gordillo et al., 1992, 2005 , 2008, 2010; Aguirre, 2003; Aguirre et al., 2005, 2006; Cardenas y Gordillo, 2010; Boretto et al., 2013).

En la última década, se sumaron además trabajos específicos sobre tafonomía, paleoecología, esclerocronología y bioerosión, entre otros, de algunas géneros y especies fósiles como: Genéro Littoridina (De Frascesco y Zárate, 1999), Heleobia australis (Aguirre y Urritia, 2002), Glycymeris longior (Pastorino y Ivanov,1996), Tagelus plebeius (De Francesco y Zárate, 2001), Brachidontes rodriguezii (Aguirre et al., 2006), Ameghinomya antiqua (Boretto et al., 2009) y Amiantis purpurata (Bayer et 
al., 2010), entre otras especies, en los depósitos cuaternarios del norte de la Provincia de Buenos Aires como sur de la costa patagónica Argentina.

Los trabajos desarrollados en el área de tesis, principalmente en el sur de Provincia de Buenos Aires, fueron enfocados principalmente desde el punto de vista sistemático disponibles en catálogos sobre moluscos actuales (Ríos, 1994; Castellanos, 1992; Aguirre y Farinati, 2000) o en el contexto de estudios geomorfológicos y/o geocronológicos que utilizaron valvas y conchas de moluscos como fuente de dataciones (ej. Fidalgo et al, 1980; Trebino, 1987; Rutter et al., 1989, 1990; Weiler, 1993, 2000). En el área costera de la Provincia de Río Negro, hay estudios previos referidos al aréa de tesis, sobre sistemática de moluscos cuaternarios (Pastorino, 2000) en especial de gasterópodos, siendo una gran contribución de información en esta tesis. 


\section{ANTECEDENTES DE FAUNA MARINA ACTUAL}

La fauna bentónica actual de la costa argentina se estudió en su mayoría en ambientes costeros. En la actualidad, las investigaciones realizadas completarían los aspectos descriptivos de la costa y plataforma continental Argentina (Bastida et al., 2007).

\subsection{Corrientes marinas del Atlántico Sur}

En el Oligoceno tardío, hace 29 ma (millones de años), se separó la extremidad sudamericana y la Península Antártica, formándose el Pasaje Drake y el Arco del Scotia (Shackleton y Kennet, 1975ab). Este evento junto con la separación de AustraliaTasmania con respecto de Antártida, originando la Corriente Circumpolar Antártica y el aislamiento térmico de la Antártida. Las aguas frías son transportadas por la Corriente Circumpolar Antártica de temperaturas y salinidades bajas $\left(3.5-11^{\circ} \mathrm{C} ; 34-34.5 \%\right)$ que al entrar al Atlántico por el Pasaje de Drake se bifurca y se forma la Corriente de Malvinas llevando las aguas frías paralelamente a la costa sudamericana. Esta corriente se separa en dos brazos a la altura de las islas Malvinas. La rama oeste, de aguas frías y baja salinidad, debido al aporte de aguas continentales se desplaza hacia el norte sobre la plataforma. La rama este, rodea las islas Malvinas y también se desplaza hacia el norte, pero lo hace contorneando el borde de la plataforma continental, recorriendo de sur a norte el Atlántico sur, desde una latitud aproximada de $55^{\circ} \mathrm{S}$ y hasta la zona comprendida entre los $39^{\circ}$ y $36^{\circ} \mathrm{S}$ (ej. Balech y Ehrlich, 2008, Barré et al., 2006).

Otra corriente de igual importancia circula en sentido contrario sobre el talud continental, la corriente cálida del Brasil. Esta corriente de aguas subtropicales cuyo rango oscilan entre los $18-24^{\circ} \mathrm{C}$ con salinidades de $34.5-36 \%$, y hacia el norte tiene una temperatura y salinidad entre $\operatorname{los} 24-30^{\circ} \mathrm{C}$ y $>36 \%$. A la altura del Río de la Plata $\left(38^{\circ} \mathrm{S}\right.$, Provincia de Buenos Aires) esta corriente comienza a separarse de la costa hasta entrar en contacto con la Corriente de Malvinas y generar una amplia región de características dinámicas tanto espacial como temporal y mezclas de aguas subtropicales con subantárticas. Esta zona de confluencia es llamada Zona de transición, está ubicada entre los $30^{\circ}$ y $46^{\circ}$ a partir de la cual las corrientes viran en dirección opuesta (Piola y 
Matano, 2001). La corriente fría de Malvinas como la corriente cálida de Brasil regulan las temperaturas de las aguas del Atlántico Sur (Fig.4.1).

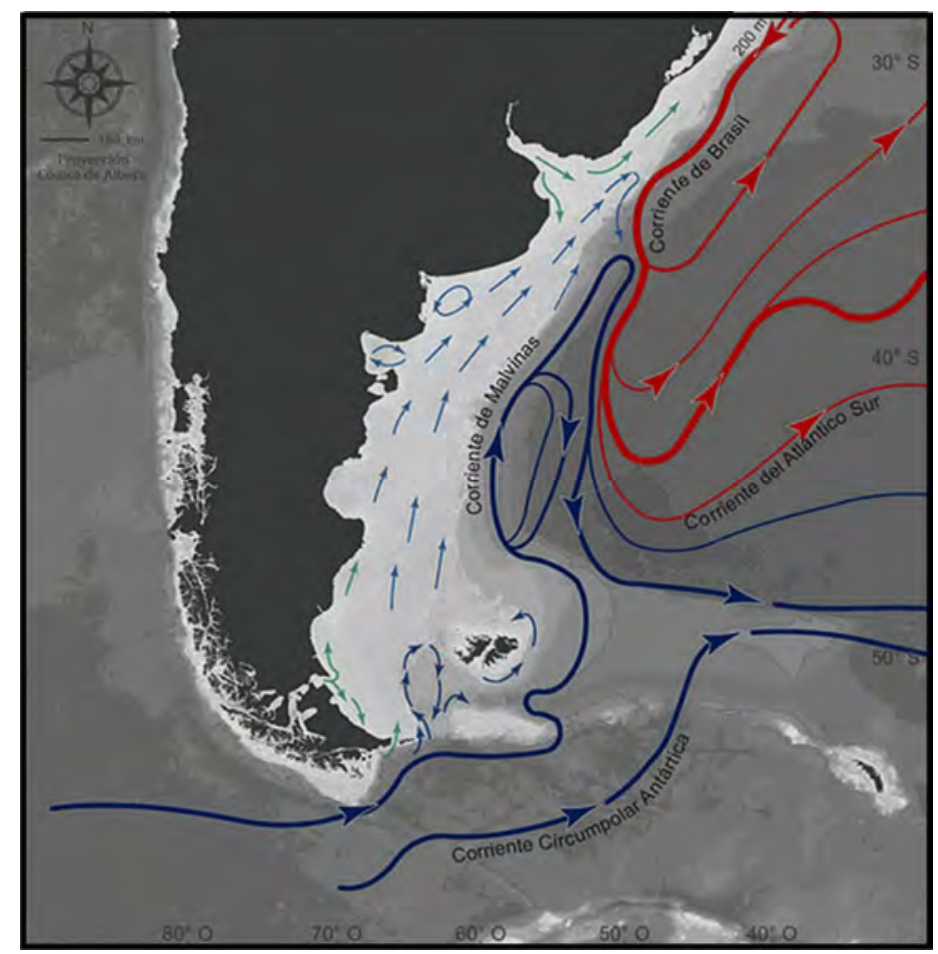

Fig.4.1: Corrientes marinas de la costa Atlántica Sur (Piola y Falabella, 2009).

\subsection{Provincias malacológicas}

La deriva continental, el aislamiento de los continentes y la intensificación de las corrientes oceánicas incrementaron el provincialismo de los invertebrados marinos (Okolodkov, 2010).

Durante el Mioceno tardío, Martínez y del Río (2002a) señalan la existencia de dos provincias malacológicas: Valdesiana y Paraniana integrada fundamentalmente por elementos caribeños a lo largo del litoral Atlántico Sudoccidental. La Provincia Valdesiana se extendió desde península Valdez $\left(42^{\circ} \mathrm{S}\right)$ hacia el sur hasta la costa litoral de la Provincia de Buenos Aires incluyendo a la Formación Puerto Madryn. La Provincia Paraniana ocupó desde el norte a lo largo de la costa de Uruguay hasta el sur de Brasil, incluyendo la Formación Paraná (Argentina) y la Formación Camacho 
(Uruguay). Ambas provincias malacológicas descriptas para el Mioceno dejaron de existir a causa del enfriamiento de las aguas provocado por la formación de la Corrientes de Malvinas, los elementos tropicales retrajeron su distribución hacia el norte (Martínez y del Río, 2002b).

Para el Cuaternario, se identificaron tres provincias malacológicas: la Brasileña, Argentina y Magallánica, que persisten hasta la actualidad. La Provincia Brasileña que se extiende desde el Trópico de Capricornio hasta Río Grande do Sul (28 28'S), y se relaciona con la corriente cálida del Brasil. Hacia el sur continua la Provincia Argentina desde los $28^{\circ} 28^{\prime} \mathrm{S}$ hasta $\operatorname{los} 42-43^{\circ} \mathrm{S}$, considerada como Provinciatono entre la Magallánica y la Brasileña (Martínez y del Río, 2002b). Esta provincia resulta del área de confluencia de la Corriente de Brasil y la Corriente de Malvinas. La Provincia Magallánica se extiende por el Océano Atlántico desde los $42-43^{\circ} \mathrm{S}$ abarcando el archipiélago fueguino, las Islas Malvinas y el Banco Burdwood, penetrando en el Océano Pacífico hasta la zona sur de Chile ( $44^{\circ} \mathrm{S}$ ) (Bastida et al., 2007) (Fig. 4.2).

Aguirre y Farinati (1997) mencionan que las provincias malacológicas cuaternarias ya estaban establecidas desde el Mioceno Medio pero sus límites australes estaban desplazados al sur de su distribución actual. Sin embargo, según Martínez y del Río (2002b), las provincias malacológicas miocenas no son la prefiguración de las actuales Provincia Argentina y Provincia Magallánica; y la existencia de la Provincia Argentina está ligada al desarrollo de la Provincia Magallánica en tiempos post-miocenos, como consecuencia de los cambios neógenos en los patrones de paleocirculación oceánica. 


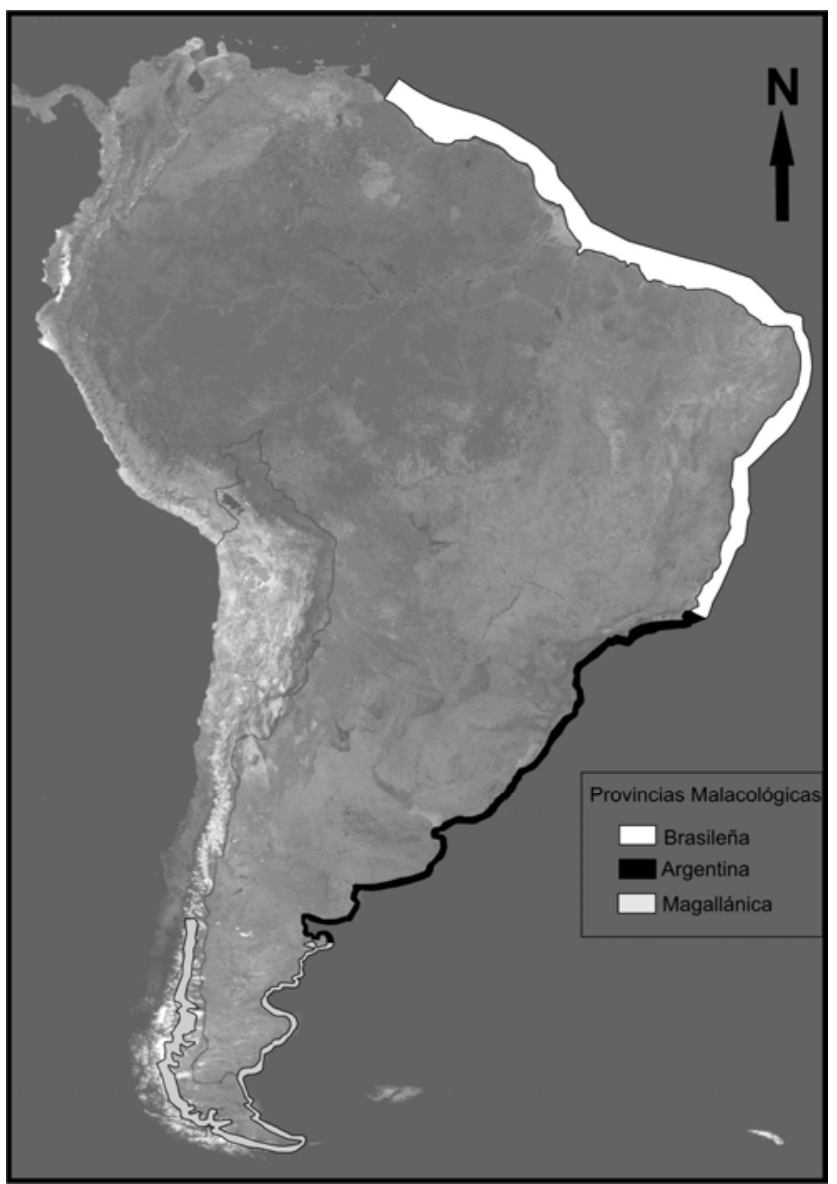

Fig.4.2: Ubicación geográfica de las provincias malacológicas actuales.

\subsection{Fauna autóctona actual}

Muchos autores argentinos han contribuido a la descripción sistemática y ecológica de los distintas invertebrados bentónicos marinos que viven actualmente en la Argentina. En los últimos años, hay una contribución al esclarecimiento a nivel taxonómico tanto de los bivalvos como los gasterópodos ( ej. Pastorino 1993,1999, 2002, 2005, 2009; Simone et al., 2000; Collin, 2005; Pimenta et al., 2011; Penchaszadeh et al., 2002; Signorelli, 2010, Pérez et al., 2013; entre otros), como estudios exhaustivos sobre la ecología y la reproducción de cada uno de ellos (ej. Penchaszadeh,1973; Escofet et al., 1978; Bremec,1986ab, 1988, 2000; Ciocco, 1998; Bala, 1989; Bastida et al., 1991, 1992, 2007; Lasta and Bremec, 1998; Elías et al., 2001; Bigatti, 2005; FernándezAlfaya, 2007, Averbuj, 2009; Cumplido, 2009, entre otros) y sobre biodiversidad en la 
plataforma marina argentina (ej. Roux et al., 1993; Bastida et al., 2007; Boltovskoy, 2007; Balech y Ehrich, 2008) haciendo estudios exhaustivos de las especies autóctonas.

\subsubsection{Moluscos del sur de Provincia de Buenos Aires y norte del golfo San Matías}

Las especies de bivalvos y gasterópodos estudiados en el sur de la Provincia de Buenos Aires como en el norte del golfo San Matías, no pertenecen solo a la Provincia Malacológica Argentina, algunas especies continúan su distribución tanto en el norte (Provincia Malacológica Brasileña) como en la costa patagónica Argentina perteneciendo también a la Provincia Malacológica Magallánica (ej. Aguirre y Farinati, 2000; Balech y Ehrlich, 2008) (T. 4.1 y T. 4.2).

\subsubsection{Especies de gasterópodos y bivalvos exclusivos de Provincia de Buenos} Aires

Las especies de distribución estrecha de la provincia de Buenos Aires son el mejillón Brachidontes rodriguezii, Mactra patagonica, Mesodesma mactroides (almeja amarilla), Tagelus plebeius, Macoma uruguayensis (bivalvos) y Notocochlis isabelleana, Adelomelon brasiliana y Muricopsis necocheanus (gasterópodos) (Balech y Ehrlich, 2008).

\subsubsection{Especies de gasterópodos y bivalvos de la Provincia de Río Negro}

En el norte del golfo San Matías es común encontrar en las playas actuales bivalvos como: Ostrea puelchana, Ensis macha (navaja grande), común en playas arenosas y el bivalvo mactroide Mulinia edulis (Balech y Ehrlich, 2008), Aulacomya atra y Retrotapes exalbidus y gasterópodos como Tegula patagonica, Buccinanops globulosus, entre otros. Así también se encuentran dos bivalvos abundantes: Glycymeris longior y Amiantis purpurata, como fauna existente en las costas de la Provincia de Buenos Aires (Aguirre y Farinati, 2000). 


\begin{tabular}{|c|c|c|c|c|c|}
\hline BIVALVOS & $\begin{array}{c}\text { Provincia } \\
\text { Malacológica } \\
\text { Brasileña }\end{array}$ & $\begin{array}{c}\text { Provincia } \\
\text { Malacológica } \\
\text { Argentina }\end{array}$ & $\begin{array}{c}\text { Provincia } \\
\text { Malacológica } \\
\text { Magallánica }\end{array}$ & $\begin{array}{l}\text { Especies de } \\
\text { aguas cálidas }\end{array}$ & $\begin{array}{c}\text { Area de distribución } \\
\text { actual }\end{array}$ \\
\hline $\begin{array}{l}\text { Familia Nuculidae Gray,1824 } \\
\text { Nucula (N.) nucleus ( Linné, 1758) (Nn) } \\
\text { Ennucula grayi (d'Orbigny,1846) (Eg) } \\
\text { Familia Nuculanidae H. y A. Adams, } 1858 \\
\text { Adrana electa (A. Adams, 1856) (Ael) } \\
\text { Familia Glycymerididae Newton, 1922 } \\
\text { Glycymeris (G.) longior ( Sowerby,1832) (Gl) } \\
\text { Familia Mytilidae Rafinesque,1815 } \\
\text { Mytilus edulis platensis d'Orbigny, 1846 (Me) } \\
\text { Brachidontes (B.) rodriguezii (d'Orbigny, 1846) (Br) } \\
\text { Aulacomya atra (Molina,1782) (Aat) } \\
\text { Familia Pinnidae Leach, 1819 } \\
\text { Atrina seminuda (Lamarck, 1819) (Ast) } \\
\text { Familia Plicatulidae Watson, 1930 } \\
\text { Plicatula gibbosa Lamarck, 1801 (Pg) } \\
\text { Familia Ostreidae Rafinesque,1815 } \\
\text { Crassostrea gigas (Thunberg, 1793) (Cgi) } \\
\text { Ostreola equestris (Say, 1834) (Oe) } \\
\text { Ostrea puelchana d'Orbigny 1841 (Op) } \\
\text { Familia Pectinidae Rafinesque,1815 } \\
\text { Aequipecten tehuelchus (d'Orbigny 1842) (At) } \\
\text { Familia Diplodontidae Dall, 1895 } \\
\text { Diplodonta (D.) patagonica ( d'Orbigny, 1842) (Dp) } \\
\text { Diplodonta (F.) vilardeboana (d'Orbigny, 1846 (Dv) } \\
\text { Familia Carditidae Fleming, 1828 } \\
\text { Carditamera plata (lhering, 1907) (Cpl) } \\
\text { Familia Cardiidae Lamarck, 1809 } \\
\text { Trachycardium muricatum (Linné, 1758) (Tm) } \\
\text { Familia Mactridae Lamarck,1809 } \\
\text { Mactra isabelleana d'Orbigny, 1846 (Mi) } \\
\text { Mactra guidoi Signorelli \& Scarabino, 2010 (Mg) } \\
\text { Raeta (R.) plicatella (Lamarck,1818) (Rp) } \\
\text { Mulinia edulis (King \& Broderip, 1831) (Mud) } \\
\text { Familia Mesodesmatidae Gray, 1839 }\end{array}$ & $\begin{array}{l}\mathbf{X} \\
\mathbf{X} \\
\mathbf{X} \\
\mathbf{X} \\
\mathbf{x} \\
\mathbf{X}\end{array}$ & $\begin{array}{c}\mathbf{X} \\
\mathbf{X} \\
\mathbf{X} \\
\mathbf{X} \\
\mathbf{X} \\
\mathbf{X} \\
\mathbf{X} \\
\mathbf{X} \\
\mathbf{X} \\
--- \\
\mathbf{X} \\
\mathbf{X} \\
\mathbf{X} \\
\mathbf{X} \\
\mathbf{X} \\
\mathbf{X}\end{array}$ & ----- & $\begin{array}{l}x \\
x \\
x \\
x\end{array}$ & $\begin{array}{c}23^{\circ} \mathrm{S}-53.5^{\circ} \mathrm{S} \\
22.93^{\circ} \mathrm{S}-55.5^{\circ} \mathrm{S} \\
22.93^{\circ} \mathrm{S}-39^{\circ} \mathrm{S} \\
10^{\circ} \mathrm{S}-42^{\circ} \mathrm{S} \\
68^{\circ} \mathrm{N}-55.5^{\circ} \mathrm{S} \\
34^{\circ} \mathrm{S}-42^{\circ} \mathrm{S} \\
34^{\circ} \mathrm{S}-55.5^{\circ} \mathrm{S} \\
35^{\circ} \mathrm{N}-35^{\circ} \mathrm{S}^{*} \\
35.3^{\circ} \mathrm{N}-34^{\circ} \mathrm{S}^{*} \\
\mathrm{Cosmopolitan} 37^{\circ} \mathrm{N}-42^{\circ} \mathrm{S} \\
22^{\circ} \mathrm{S}-42^{\circ} \mathrm{S} \\
21^{\circ} \mathrm{S}-53^{\circ} \mathrm{S} \\
21^{\circ} \mathrm{S}-42.58^{\circ} \mathrm{S} \\
21^{\circ} \mathrm{S}-42^{\circ} \mathrm{S} \\
23^{\circ} \mathrm{S}-39^{\circ} \mathrm{S}^{*} \\
35^{\circ} \mathrm{N}-42^{\circ} \mathrm{S} \\
23^{\circ} \mathrm{S}-42^{\circ} \mathrm{S} \\
34^{\circ} \mathrm{S}-42^{\circ} \mathrm{S} \\
39^{\circ} \mathrm{N}-41^{\circ} \mathrm{S} \\
52.7^{\circ} \mathrm{S} *-55.5^{\circ} \mathrm{S}\end{array}$ \\
\hline
\end{tabular}




\section{BIVALVOS}

Mesodesma mactroides (Reeve, 1854) (Mn) Familia Solenidae Lamarck, 1809

Solen tehuelchus (Hanley, 1842) (St)

Familia Telinidae De Blainville,1814

Macoma (P.) uruguayensis (Smith, 1885) (Mu)

Angulus gibber lhering, 1907 (Ang)

Familia Semelidae Stoliczka, 1870

Abra (A.) aequalis (Say, 1822) (Aa)

Familia Solecurtidae d'Orbigny, 1846

Tagelus (T.) plebeius (Ligthfood,1786) (Tp)

Familia Veneridae Rafinesque, 1815

Tivela isabelleana ( d'Orbigny, 1846) (Ti)

Pitar (P.) rostratus (Philippi, 1844) (Pr)

Amiantis purpurata ( Lamarck, 1856) (Ap)

Retrotapes exalbidus (Dillwyn,1817) (Re)

Ameghinomya antiqua (King,1832) (Aa)

Familia Hiatellidae Gray, 1824

Panopea abbreviata Valenciennes, 1839 (Pabb)

Familia Corbulidae Gray, 1823

Corbula (C.) patagonica d'Orbigny, $1846(\mathrm{Cp})$

Corbula (C.) lyoni Pilsbry, 1897 (Cl)

Familia Pholadidae Lamarck, 1809

Cyrtopleura (S.) lanceolata (d'Orbigny, 1846) (Cyl)

Barnea lamellosa (d'Orbigny, 1846) (BI)

Familia Lyonsiidae Rafinesque, 1815

Lyonsia (L.)alvarezii d'Orbigny, $1846(\mathrm{La})$

Familia Periplomatidae Dall, 1895

Periploma ovatum d'Orbigny, $1846(\mathrm{Po})$

Familia Traciidae Stoooliczka, 1870

Thracia similis Couthouy, 1839 (Ts)

T.4.1: Especies de bivalvos encontrados en la zona de tesis con sus siglas. Especi

\begin{tabular}{|c|c|c|c|c|}
\hline $\begin{array}{l}\text { Provincia } \\
\text { Malacológica } \\
\text { Brasileña }\end{array}$ & 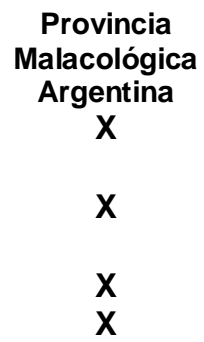 & $\begin{array}{c}\text { Provincia } \\
\text { Malacológica } \\
\text { Magallánica }\end{array}$ & $\begin{array}{l}\text { Especies de } \\
\text { aguas cálidas }\end{array}$ & $\begin{array}{c}\begin{array}{c}\text { Area de distribución } \\
\text { actual }\end{array} \\
23^{\circ} \mathrm{S}-41^{\circ} \mathrm{S} \\
23^{\circ} \mathrm{S}-39^{\circ} \mathrm{S}^{*} \\
29^{\circ} \mathrm{S}-39^{\circ} \mathrm{S}^{*} \\
23^{\circ} \mathrm{S}-43^{\circ} \mathrm{S}\end{array}$ \\
\hline $\mathbf{X}$ & $x$ & & $x$ & $35^{\circ} \mathrm{N}-23^{\circ} \mathrm{S}^{*}$ \\
\hline $\mathbf{x}$ & $\begin{array}{l}\mathbf{X} \\
\mathbf{X} \\
\mathbf{X} \\
\mathbf{X} \\
\mathbf{X} \\
\mathbf{X}\end{array}$ & $\begin{array}{l}\mathbf{X} \\
\mathbf{X}\end{array}$ & $x$ & $\begin{array}{c}42^{\circ} \mathrm{N}-54^{\circ} \mathrm{S}^{*} \\
21^{\circ} \mathrm{S}-42^{\circ} \mathrm{S} \\
22^{\circ} \mathrm{S}-38.7^{\circ} \mathrm{S}^{*} \\
19^{\circ} \mathrm{S}-43^{\circ} \mathrm{S} \\
34^{\circ} \mathrm{S}-55.5^{\circ} \mathrm{S} \\
34^{\circ} \mathrm{S}-54^{\circ} \mathrm{S}\end{array}$ \\
\hline $\mathbf{x}$ & $\begin{array}{l}\mathbf{X} \\
\mathbf{x} \\
\mathbf{x}\end{array}$ & $\mathbf{x}$ & $\begin{array}{l}x \\
x\end{array}$ & $\begin{array}{l}23^{\circ} \mathrm{S}-48^{\circ} \mathrm{S} \\
23^{\circ} \mathrm{S}-43^{\circ} \mathrm{S} \\
19^{\circ} \mathrm{S}-43^{\circ} \mathrm{S}\end{array}$ \\
\hline $\mathbf{X}$ & $\begin{array}{l}x \\
X\end{array}$ & & $x$ & $\begin{array}{c}6^{\circ} S-42^{\circ} S \\
34^{\circ} S-43^{\circ} S\end{array}$ \\
\hline $\mathbf{x}$ & $\begin{array}{l}x \\
x \\
x\end{array}$ & & $x$ & $\begin{array}{l}38.3^{\circ} \mathrm{S}-41^{\circ} \mathrm{S} \\
35^{\circ} \mathrm{S}-40.5^{\circ} \mathrm{S} \\
22^{\circ} \mathrm{S}-42.58^{\circ} \mathrm{S}\end{array}$ \\
\hline
\end{tabular}

$22^{\circ} \mathrm{S}-42.58^{\circ} \mathrm{S}$ Anomalocardia brasiliana (Anom) y Crassostrea rhizophorae (Cri)* especies con diferencias en el área de distribución. 


\begin{tabular}{|c|c|c|c|c|c|}
\hline GASTERÓPODOS & $\begin{array}{c}\text { Provincia } \\
\text { Malacológica } \\
\text { Brasileña } \\
\end{array}$ & $\begin{array}{c}\text { Provincia } \\
\text { Malacológica } \\
\text { Argentina } \\
\end{array}$ & $\begin{array}{c}\text { Provincia } \\
\text { Malacológica } \\
\text { Magallánica } \\
\end{array}$ & $\begin{array}{l}\text { Especies } \\
\text { cálidas }\end{array}$ & $\begin{array}{c}\text { Área de distribución } \\
\text { actual }\end{array}$ \\
\hline $\begin{array}{l}\text { Clado Patellogastropoda } \\
\text { Familia Nacellidae Thiele, 1891 } \\
\text { Nacella (P.) magallanica (Gmelin,1791) (Nm) } \\
\text { Clado Vetigastropoda } \\
\text { Familia Fissurellidae Fleming,1822 } \\
\text { Diodora (D.) patagonica ( d'Orbigny, 1841) (Dp) } \\
\text { Fissurella radiosa radiosa Lesson,1831 (Fr) } \\
\text { Lucapinella henseli (Martens, 1900) (Lh) } \\
\text { Familia Calliostomatidae Thiele, 1924 } \\
\text { Calliostoma carcellesi Clench y Aguacho,1940) (Cc) } \\
\text { Calliostoma coppingeri (E. A. Smith, 1880) (Ca) } \\
\text { Tegula (A.) patagonica (d'Orbigny, 1835) (Tpt) } \\
\text { Clado Littorinimorpha } \\
\text { Familia Calyptraeidae Lamarck,1809 } \\
\text { Bostrycapulus odites (Collin, 2005) (Bo) } \\
\text { Crepidula argentina Simone, Pastorino \& Penchaszadeh, } 2000 \text { (Ca) } \\
\text { Crepidula dilatata Lamarck, 1822 (Cd) } \\
\text { Familia Naticidae Forbes, 1828 } \\
\text { Notocochlis isabelleana (d'Orbigny, 1840) (Ni) } \\
\text { Familia Hydrobiidae } \\
\text { Heleobia australis ( d'Orbigny, 1835) (Ha) } \\
\text { "“Grupo” Ptenoglossa } \\
\text { Familia Epitoniidae S. S.Berry,1910 } \\
\text { Epitonium (E.) georgettinum (d'Orbigny,1840) (Ege) } \\
\text { Epitenium striatellum (Nyst, 1871) ( Est) } \\
\text { Clado Neogastropoda } \\
\text { Familia Muricidae Rafinesque,1815 } \\
\text { Trophon patagonicus (d'Orbigny, 1839) (Tpg) } \\
\text { Trophon geversianus (Pallas,1774) (Tg) } \\
\text { Urosalpinx cala (Pilsbry, 1897) (Uc) } \\
\text { Zidona dufresnei ( Donovan, 1823) (Zd) } \\
\text { Adelomelon (P.) brasiliana (Lamarck, 1811) (Ab) } \\
\text { Adelomelon beckii (Broderip,1838) (Abei) }\end{array}$ & $\begin{array}{l}\mathrm{X} \\
?\end{array}$ & $\begin{array}{l}\mathbf{X} \\
\mathbf{X} \\
\mathbf{X} \\
\mathbf{X} \\
\mathbf{X} \\
\mathbf{X} \\
\mathbf{X}\end{array}$ & $\begin{array}{l}X \\
X \\
X\end{array}$ & $\begin{array}{l}x \\
x\end{array}$ & $\begin{array}{c}23.37^{\circ} \mathrm{S}-44.27^{\circ} \mathrm{S} \\
23^{\circ} \mathrm{S}-41^{\circ} \mathrm{S} \\
\\
32^{\circ} \mathrm{S}-40^{\circ} \mathrm{S} \\
36.42^{\circ} \mathrm{S}-54.98^{\circ} \mathrm{S} \\
32^{\circ} \mathrm{S}-41^{\circ} \mathrm{S} \\
23^{\circ} \mathrm{S}-42^{\circ} \mathrm{S} \\
23^{\circ} \mathrm{S}-52^{\circ} \mathrm{S} \\
20^{\circ} \mathrm{S}-52^{\circ} \mathrm{S}\end{array}$ \\
\hline
\end{tabular}




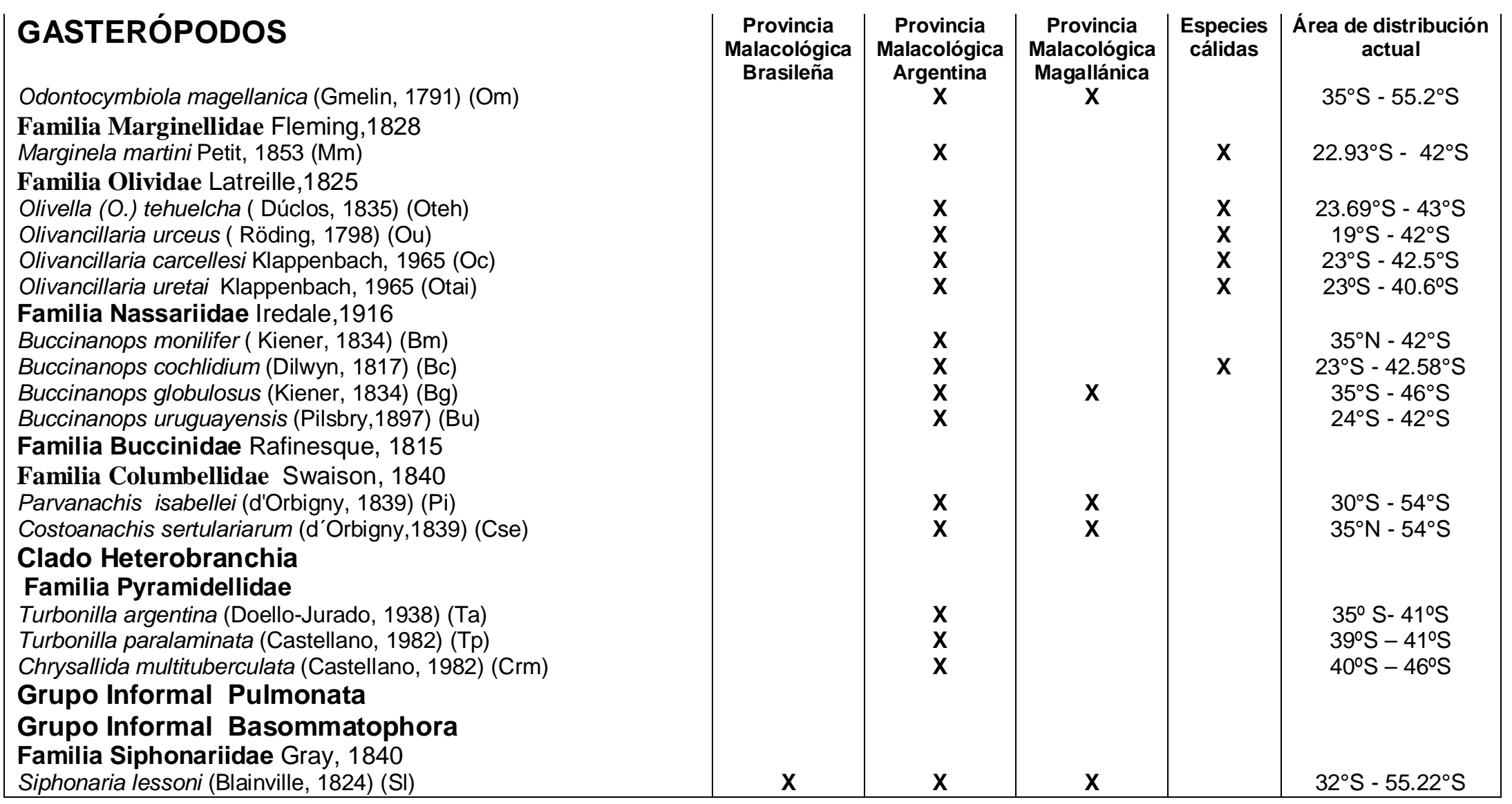

T.4.2: Especies de gasterópodos encontrados en la zona de tesis con sus siglas. Especies no encontradas en costas argentinas actuales presentes en la tesis Tegula atra (Tatra)* especies con diferencias en el área de distribución. 


\section{METODOLOGÍA DE ESTUDIO}

\subsection{Trabajo de gabinete}

A partir de la información recapitulada a través de bibliografía clásica, cartas topográficas, y acceso a fotos e imágenes satelitales se procedió a identificar los lugares propicios para realizar muestreos paleontológicos reconociéndose fundamentalmente cordones pleistocenos y holocenos. A lo fines comparativos se incluye también observaciones a lo largo del litoral actual.

\subsection{Trabajos de campo}

Se realizaron 4 campañas paleontológicas. En marzo de 2010 se realizó una campaña de reconocimiento del área de isla Jabalí y los alrededores. En noviembre de 2010, en diciembre de 2011 y en marzo de 2012 se realizaron campañas al sur de Provincia de Buenos Aires y norte del golfo San Matías, Provincia de Río Negro (Fig. 5.1).

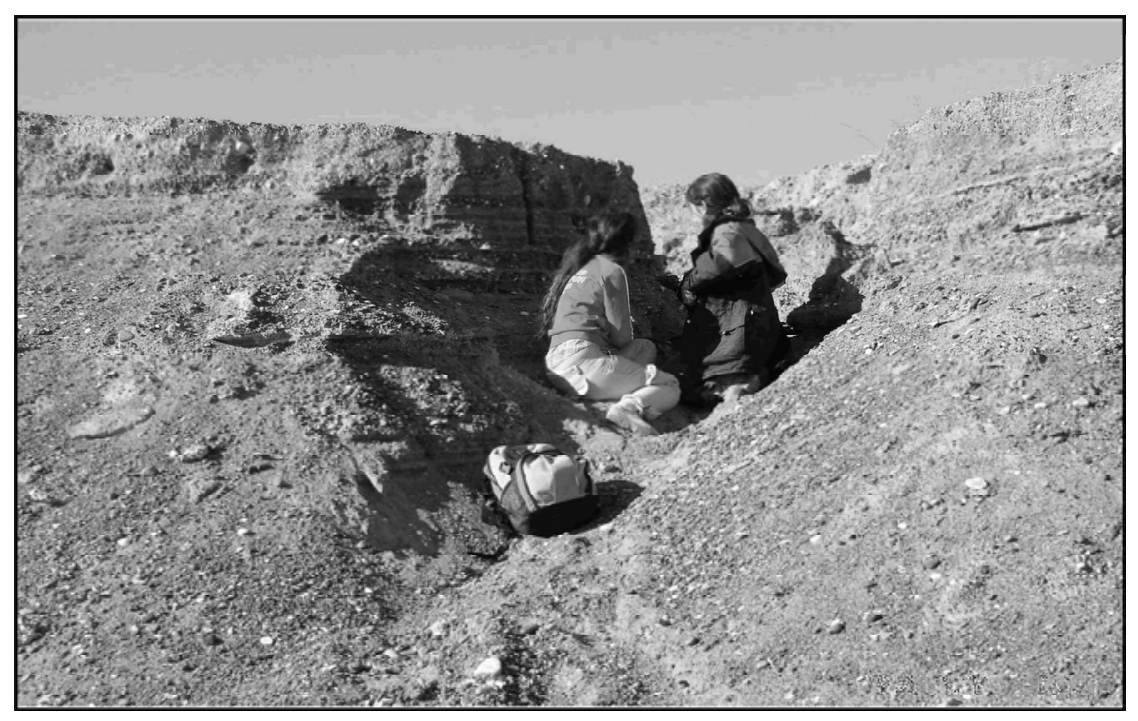

Fig.5.1: Campaña diciembre de 2011 analizando depósitos marinos pleistocenos. 
En el área de estudio se analizaron 84 sitios (7.385 valvas y conchas de moluscos): 31 sitios pleistocenos, 29 sitios holocenos y 24 sitios actuales. El análisis de cada uno de los sitios pertenecientes a depósitos pleistocenos y holocenos se realizó a partir de muestras volumétricas de $1 \mathrm{dm}^{3}$ y en un cuadrante de $1 \mathrm{~m}$ x $1 \mathrm{~m}$ sobre transectas perpendiculares a la línea de costa en playas actuales.

Para facilitar la lectura, a cada sitio se le asignó una letra dependiendo de la edad del depósito $(\mathrm{A}-\mathrm{G})$ y un número dependiendo de la cantidad de sitios analizados en ese período (T. 5.1).

\begin{tabular}{|c|c|c|}
\hline Sitios & Depósitos marinos -Cotas $(\mathbf{m})$ & Interglacial (MIS) \\
\hline A & 60 & Interglacial más antiguo \\
\hline B & $30-40$ & $\geq$ MIS 9 \\
\hline C & $20-15$ & $\geq$ MIS 9 \\
\hline D & 0 (sobre el nivel del mar) & MIS 7 \\
\hline E & $10-5$ & MIS 5e \\
\hline F & $5-1$ & MIS 1 \\
\hline G & 0 & Playas actuales \\
\hline
\end{tabular}

T. 5.1: Nomenclatura utilizada para identificar los sitios por edades.

A cada especie se le asignó una abreviatura, la cual consta, generalmente, de dos letras que corresponden a la primera letra del género, la cual escribiremos en mayúscula y la primera letra de la especie que la escribiremos en minúscula. Algunas especies se le asignaron más de dos letras en el nombre de la especie debido a la repetición de las iniciales en la abreviatura, por ejemplo: Tagelus plebeius (Tp) (bivalvo) y Tegula patagonica (Tpt) (gasterópodo). Aquellos organismos mencionados hasta nivel de género, consta de dos letras, la primera letra en mayúscula correspondiente al género y a continución la letra s, por ejemplo: Crepidula (Cs) (gasterópodo). El uso de esta terminología facilitó no sólo la confección de los gráficos sino también una mejor lectura y visualización de los mismos. 


\subsection{Trabajos de laboratorio}

Las muestras volúmétricas recolectadas fueron expuestas a agua corriente, utilizando 3 tamices de diferente tamaño de talla 2.80, 1.40 y 0.080 mm (Fig. 5.2). A continuación se estableció una secuencia de lavado y secado sobre papel.

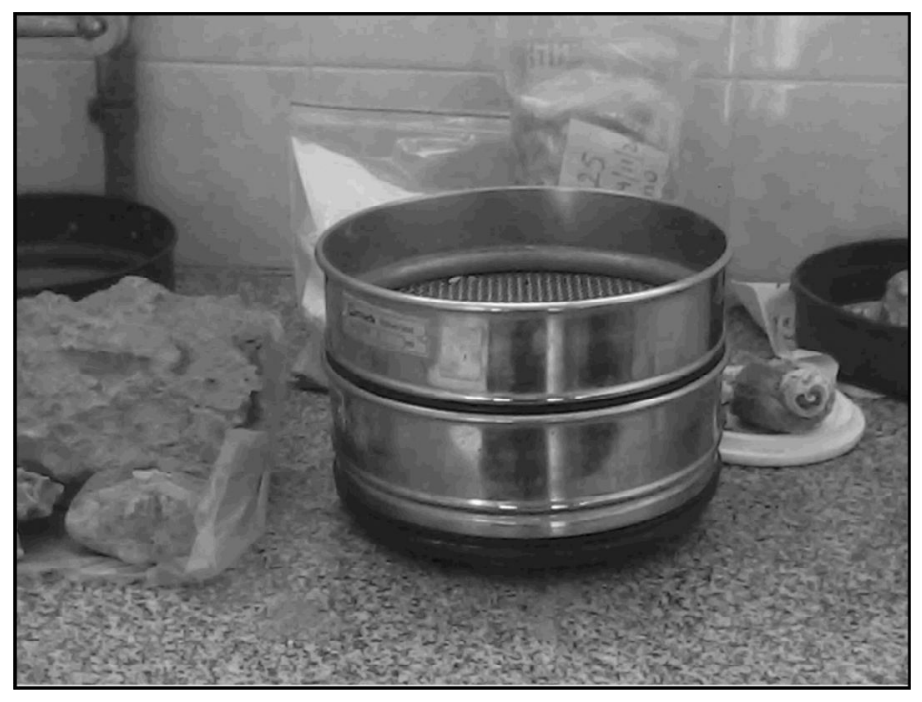

Fig. 5.2: Material de trabajo de laboratorio.

Cada fracción de contenido biogénico recuperado sobre los tamices fue identificada, medida (con calibre digital) y rotulada. Para la identificación de las especies se consultaron catálogos y trabajos específicos. Entre los primeros figuran: Scarabino, 1977; Castellanos, 1992; Ríos, 1994; Aguirre y Farinati, 2000; Forcelli, 2000, entre otros, y trabajos específicos (ej. Pastorino, 1993, 2002, 2005; Simone et al., 2000; Penchaszadeh et al., 2002; Collin, 2005; Teso y Pastorino, 2011, entre otros).En gasterópodos, se consideran los trabajos de Bouchet y Rocroi (2005) y Poppe y Tagaro (2006).

Para ilustrar los bivalvos y gasterópodos de cada región, se seleccionaron los mejores ejemplares de cada especie. Cada especie ilustrada correspondiente a la Provincia de Buenos Aires, está actualmente depositada en la colección de paleoinvertebrados en el Museo de La Plata, (UNLP), inventario con la sigla MLP. Las especies ilustradas que pertenecen a la Provincia de Río Negro, fueron ubicadas en el repositorio de la Facultad 
de Ciencias Exactas, Físicas y Naturales (FCEFyN) de la Universidad de Córdoba (UNC) cuya sigla de repositorio es CEGH-UNC. Todos los ejemplares seleccionados fueron fotografiados con cámara digital y para su procesamiento digital se utilizaron los programas Adobe Photoshop y el Corel versión 13. Las fotografías de los microgasterópodos se obtuvieron a través del MEB (Microscopio Electrónico de Barrido) del Museo de Ciencias Naturales Bernardino Rivadavia, CABA.

\subsection{Análisis estadísticos}

Los moluscos analizados en esta tesis conforman asociaciones faunísticas transportadas que, según lo expresan distintos estudios (ej. Kidwell, 2001, 2002, 2013; Kidwell y Tomasovich, 2013), preservan fidelidad composicional en cuanto a la composición taxonómica y la abundancia relativa de las comunidades que habitaban cada ambiente dentro de un período considerado, y representan la acumulación de individuos no contemporáneos en conjunto.

El uso del término asociación faunística y no de comunidad se debe a que el organismo no preserva sus partes blandas, por lo cual se define el término de asociación faunística como al conjunto recurrente de fósiles derivados de una comunidad (Kauffman y Scout, 1976).

Para realizar los análisis estadísticos descriptivos se utilizó el programa $\mathrm{R}$, que es un sofware libre (http://www.r-proyect.org/) el cual consta de un sistema base y paquetes (packages) o módulos adicionales que extienden su funcionalidad. Un paquete es un conjunto relacionado de funciones, archivos de ayuda y de datos. Este programa se utiliza como lenguaje de programación que, de manera sencilla, permite realizar análisis estadísticos a través de los distintos paquetes. En este trabajo de tesis se usaron dos paquetes: "vegan" y "biodiversityR", ambos para los análisis de comunidades ecológicas en distintas áreas de la biología, aplicados en este trabajo como novedad en las asociaciones faunísticas cuaternarias. 
A partir de análisis multivariados (cluster) del programa $\mathrm{R}$ versión 2.15 .0 (paquete vegan) (Oksanen, 2011) se analizó para cada región el grado de disimilitud de los sitios, por medio del índice de Bray - Curtis, por el método UPGMA agrupando a las asociaciones faunísticas. En este caso se utilizó una matriz de especie por sitio con las abundancias relativas. Como segundo análisis descriptivo multivariado se realizó un Análisis de Correspondencia (AC) para cada región utilizando la misma matriz de especie del método anterior, con el objetivo de observar el grado de relación que tienen todos los sitios entre sí.

Finalmente con los dos análisis descriptivos estadísticos, se separaron los sitios de muestreo en distintos grupos. Para corroborar las agrupaciones del análisis de correspondencia se realizó un tercer gráfico con la totalidad de las especies involucradas en cada grupo.

\subsubsection{Biodiversidad de las asociaciones faunísticas}

Para estudiar la biodiversidad de las asociaciones faunísticas se aplican dos índices: el Índice de Shannon $\left(H^{\prime}\right)$ y la riqueza en cada muestra (número total de especies presentes) (Pla, 2006). Ambos índices se calcularon por medio del uso del programa $\mathrm{R}$, con el paquete "Biodiversity R" (Kindt y Coe, 2005).

\subsubsection{1. Índice de Shannon $\left(\mathrm{H}^{\prime}\right)$}

El índice más frecuente utilizado para la diversidad en comunidades ecológicas actuales, como asociaciones faunísticas fósiles, es el Índice de Shannon $H^{\prime}(1)$, también denominado Índice de Shannon-Weaver (Shannon y Weaver, 1949).

Este índice refleja la heterogeneidad de una comunidad o asociación sobre la base de dos factores: el número de especies presentes y su abundancia relativa (Hammer y Harper, 2006).

El índice de Shannon (Shannon y Weaver, 1949) se define como: 


$$
H^{\prime}=-\sum_{i=1}^{S} p_{i} \ln \left(p_{i}\right)
$$

Donde $p_{i}=\frac{n_{i}}{N}, \quad n_{i}$ es el número de los individuos de cada especie, $N$ es el número total de los ejemplares muestreados y $S$ el número total de especies. Dado que las probabilidades $p_{i} \in[0,1], H^{\prime}$ tomará valores no negativos.

La diversidad máxima se alcanza cuando todas las especies están igualmente presentes, es decir cuando las especies que componen la comunidad o asociación son equiprobables, por lo tanto la probabilidad de la especie $i$ será $p_{i}=\frac{1}{S}$. Llamaremos $H^{\prime}{ }_{\max }$ al valor que toma el índice de Shannon cuando la diversidad es máxima, en este caso, tendremos que $H_{\text {max }}^{\prime}=\ln (S)$.

Un índice de homogeneidad asociado a esta medida de diversidad puede calcularse como el cociente $\frac{H^{\prime}}{H_{\max }^{\prime}}$, que tomará el valor de 1 si todas las especies tienen igual probabilidad de existir en esa comunidad. En las aplicaciones a comunidades, este índice toma frecuentemente valores entre 1 y 4.5 , y si toma un valor por encima de 3 se considera a la comunidad como tipicamente "diversa" (Pla, 2006).

\subsubsection{Análisis de agrupamientos}

Los agrupamientos pueden representar asociaciones faunísticas indirectamente relacionados con variables ambientales, distintos tipos de ambientes como también el conjunto en especies en común, entre otros factores.

En este trabajo se utilizaron dos tipos de análisis de agrupamientos, el método BrayCurtis y el Análisis de Correspondencia (AC) con datos cuantitativos (abundancias relativas) en 84 sitios y 78 especies en total. 


\subsubsection{Método de Bray- Curtis}

El método de Bray - Curtis es un índice de disimilitud $D$ (3). Este método se utilizó para estimar la similitud entre la composición de especies de cada sitio. Se basa en el en el cambio de abundancia de las especies de una muestra con respecto a la otra (Klein, 2004).

$$
D=1-S(3)
$$

Si D toma valores altos, entonces S será más bajo y por lo tanto habrá menor similitud, es decir mayor diferencia. Mientras que si D toma valores más bajos, entonces habrá una mayor similitud, por lo tanto menor diferencia.

Los grupos de los sitios se visualizan a través de un dendograma. En esta representación gráfica, los sitios se van uniendo entre sí en forma jerárquica, comenzando con las más similares y finalizando por las más disímiles. El eje vertical muestra los valores de disimilaridad y el eje horizontal ubica a los sitios. Mientras más bajo se encuentre el punto de unión entre dos sitios, más similares son los sitios entre sí (Legendre y Legendre, 2012).

\subsubsection{Análisis de correspondencia (AC)}

El análisis de correspondencia, es una técnica de la estadística descriptiva que se aplica al análisis de tablas de contingencia y construye un gráfico sobre los ejes cartesianos basado en el grado de relación que tiene cada sitio. Cuando el grado de relación entre ellos es alto, estos aparecerán en el gráfico relativamente juntos (Salvador Figueras, 2003).

\subsection{Análisis paleoclimático}

Para poder arribar a conclusiones paleoambientales con énfasis en la paleoecolgía de las distintas especies encontradas, se confeccionaron tablas según rango de salinidad, modo de vida, profundidad, sustrato,tipo trófico y área de distribución. Estas tablas se llevaron 
a cabo obteniendo datos ecológicos de las distintas especies basados en representantes actuales y en base a diferentes fuentes bibliográficas generales (ej. Lasta et al., 1998; Bastida et al., 2007; Balech y Ehrlich, 2008; Penchaszadeh et al., 2007b, 2008; Morris y Rosenberg, 2005; entre otros) o trabajos específicos (ej. Iribarne et al., 1997; Morsan, 1997; Ciocco, 2000; Collin, 2005; Cumplido, 2009, entre otros). A continuación se compararon los parámetros ecológicos de gasterópodos y bivalvos de cada una de las regiones analizadas mediante diagramas de tortas.

La presencia de especies de aguas cálidas y especies que actualmente se desplazaron a latitudes más bajas se utilizaron también como fuente de información paleoambiental, en este caso, como indicadores de condiciones más cálidas (ej. Valentine, 1955, 1958; Beu, 1974; Aguirre 1993b; Aguirre y Farinati, 1999, 2000). 


\section{REGIÓN DEL DELTA DEL RÍO COLORADO}

\subsection{Descripción general de la región}

La región del delta del río Colorado, se extiende desde Península Verde (39²0'S $62^{\circ}$ $\left.4^{\prime} \mathrm{O}\right)$ hasta la isla Otero $\left(39^{\circ} 55^{\prime} \mathrm{S} / 62^{\circ} 08^{\prime} \mathrm{O}\right)$ ocupando el $\mathrm{N}$ y S del río Colorado Nuevo.

El río Colorado se extiende desde la Cordillera de los Andes hasta el Océano Atlántico, constituyendo el límite entre la Patagonia al sur y la Pampa arenosa al norte (Spalletti e Isla, 2003). Presenta una extensión de 1.200 km, de los cuales $920 \mathrm{~km}$ corresponden al Colorado propiamente dicho (Alcalde, 2011). Este río es el de mayor importancia mientras que los demás presentan muy poco caudal o se activan en períodos de inundación. El sector terminal del delta esta compuesto por depósitos marinos de la ingresión holocena (MIS 1) que actúan como sustrato, aflorando o en subsuelo depósitos finos de ambientes intermareales y cordones litorales, y también de manera aislada, depósitos litorales del Interglacial MIS 5e (Weiler, 1984; Fucks et al., 2012a) (Fig. 6.1). 


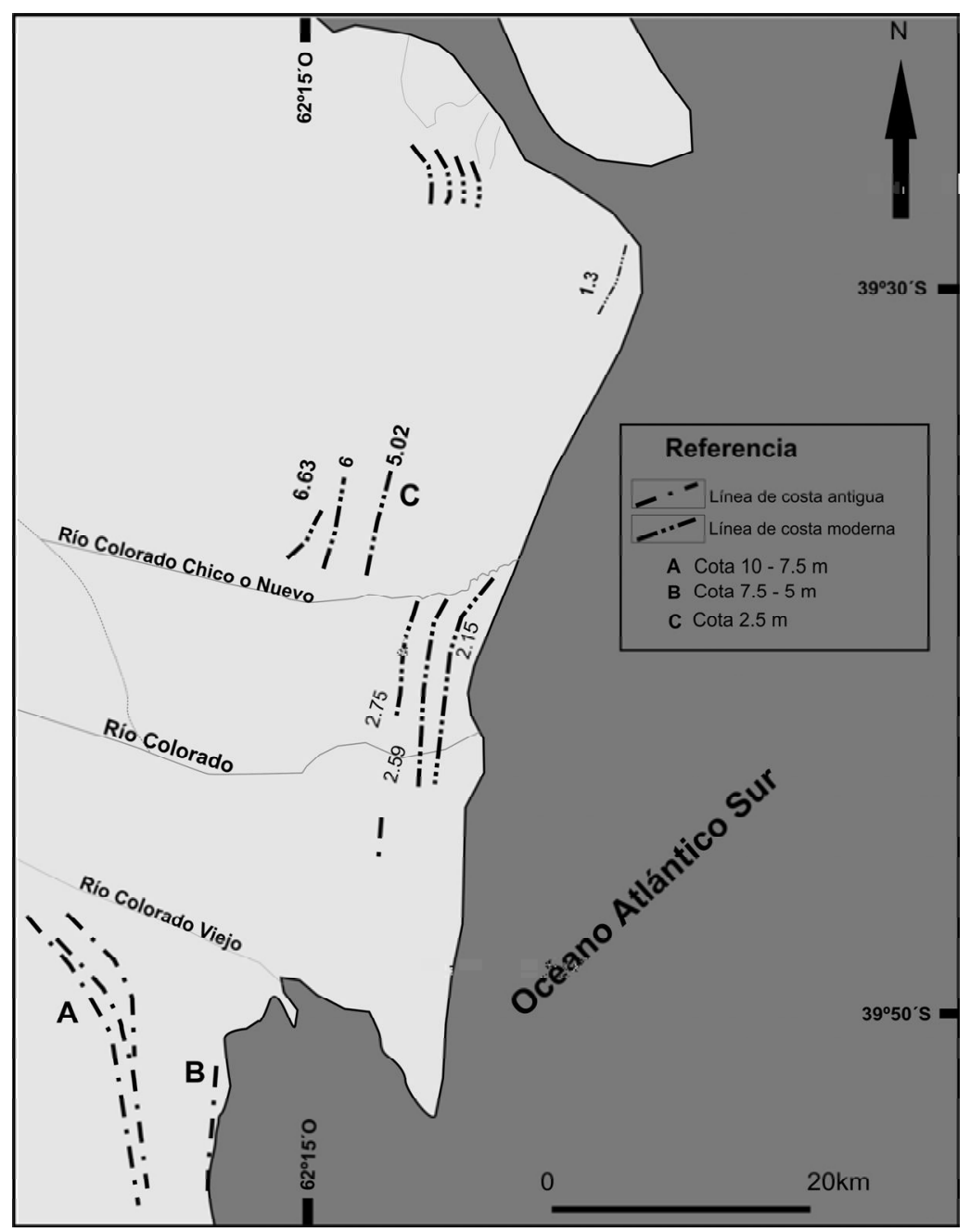

Fig.6.1: Ubicación de cordones pleistocenos y holocenos en el área del delta del río Colorado (Weiler, 1984).

En la región del delta del río Colorado, se analizaron 17 sitios ( 5 pleistocenos, 7 holocenos y 5 actuales) representando los Interglaciales $\geq$ MIS 9, MIS 5e y MIS 1(Fig 6.2 у T.6.1). 


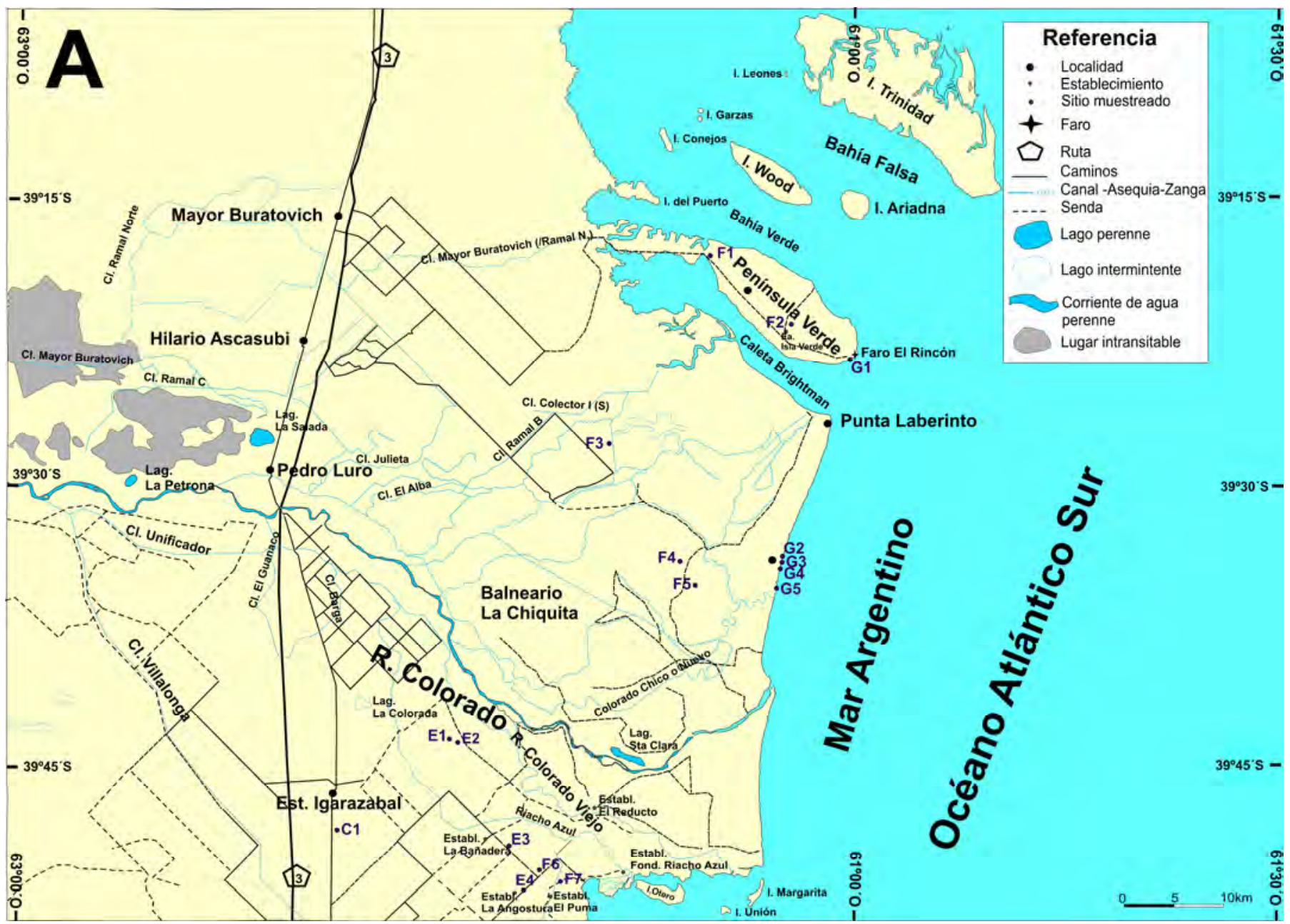

Fig.6.2: Mapa de ubicación de la región del delta del río Colorado, sur de la Provincia de Buenos Aires. 


\begin{tabular}{|c|c|c|c|c|}
\hline № de Sitio & Edad & $\begin{array}{c}\text { Coordenadas } \\
\text { (Lat-Long) }\end{array}$ & $\begin{array}{c}\text { Rasgos } \\
\text { geomorfológicos }\end{array}$ & Cotas (m) \\
\hline C1 & Pleistoceno & $\begin{array}{l}39^{\circ} 48^{\prime} 13.60^{\prime \prime} \mathrm{S} / \\
62^{\circ} 39^{\prime} 56.19^{\prime \prime} \mathrm{O}\end{array}$ & Playa de grava & 16 \\
\hline $\mathrm{E} 1$ & Pleistoceno & $\begin{array}{l}39^{\circ} 47^{\prime} 10.55^{\prime \prime} \mathrm{S} / \\
62^{\circ} 29^{\prime} 22.04^{\prime \prime O}\end{array}$ & Cordón litoral & 6 \\
\hline E2 & Pleistoceno & $\begin{array}{c}39^{\circ} 47^{\prime} 16.66^{\prime \prime} \mathrm{S} / \\
62^{\circ} 28^{\prime} 4.39^{\prime \prime O}\end{array}$ & Cordón litoral & 6 \\
\hline E3 & Pleistoceno & $\begin{array}{l}39^{\circ} 47^{\prime} 10.55^{\prime \prime S} / \\
62^{\circ} 29^{\prime} 22.04^{\prime \prime O}\end{array}$ & Paleocanal & 10 \\
\hline E4 & Pleistoceno & $\begin{array}{l}39^{\circ} 52^{\prime} 0.65^{\prime \prime S} / \\
62^{\circ} 22^{\prime} 52.95^{\prime \prime O}\end{array}$ & Cordón litoral & 6 \\
\hline $\mathrm{F} 1$ & Holoceno & $\begin{array}{l}39^{\circ} 17^{\prime} 39.94 " \mathrm{~S} / \\
62^{\circ} 11^{\prime} 12.81^{\prime \prime O}\end{array}$ & Planicie de marea & 4 \\
\hline F2 & $\begin{array}{l}\text { Holoceno } \\
(2170 \pm 86)\end{array}$ & $\begin{array}{c}39^{\circ} 21^{\prime} 37.47 " \mathrm{~S} / \\
62^{\circ} 5^{\prime} 9.44^{\prime \prime} \mathrm{O}\end{array}$ & Cordón litoral & 4 \\
\hline F3 & Holoceno & $\begin{array}{l}39^{\circ} 28^{\prime} 11 " \mathrm{~S} / \\
62^{\circ} 19^{\prime} 04^{\prime \prime} \mathrm{O}\end{array}$ & Camino y canal & 5 \\
\hline F4 & Holoceno & $\begin{array}{l}39^{\circ} 34^{\prime 2} 23.04 " \mathrm{~S} / \\
62^{\circ} 12^{\prime} 19.55^{\prime \prime O}\end{array}$ & Planicie de marea & 2 \\
\hline F5 & Holoceno & $\begin{array}{l}39^{\circ} 35^{\prime} 45.89^{\prime \prime} \mathrm{S} / \\
62^{\circ} 10^{\prime} 27.18^{\prime \prime} \mathrm{O}\end{array}$ & Planicie de marea o cordon & 3 \\
\hline F6 & Holoceno & $\begin{array}{l}39^{\circ} 51 ' 29.78 " \mathrm{~S} / \\
62^{\circ} 22^{\prime} 35.76 " \mathrm{O}\end{array}$ & Planicie de marea & 3 \\
\hline F7 & Holoceno & $\begin{array}{l}39^{\circ} 52^{\prime} 19.09 " \mathrm{~S} / \\
62^{\circ} 20^{\prime} 54.94 " \mathrm{O}\end{array}$ & Planicie de marea & 4 \\
\hline G1 & actual & $\begin{array}{l}39^{\circ} 23^{\prime} 5.10^{\prime \prime S} / \\
62^{\circ} 0 ' 48.70^{\prime \prime O}\end{array}$ & Playa arenosa & 0 \\
\hline G2 & actual & $\begin{array}{l}39^{\circ} 35^{\prime} 17.69^{\prime \prime} \mathrm{S} / \\
62^{\circ} 5^{\prime} 59.84^{\prime \prime} \mathrm{O}\end{array}$ & Berma de playa arenosa & 0 \\
\hline G3 & actual & $\begin{array}{l}39^{\circ} 35^{\prime} 18.05^{\prime \prime S} / \\
62^{\circ} 5^{\prime} 57.93^{\prime \prime O}\end{array}$ & Berma de playa arenosa & 0 \\
\hline G4 & actual & $\begin{array}{c}39^{\circ} 35^{\prime} 18.46 " \mathrm{~S} / \\
62^{\circ} 55^{\prime} 54.47 " \mathrm{O}\end{array}$ & Playa arenosa & 0 \\
\hline G5 & actual & $\begin{array}{c}39^{\circ} 36^{\prime} 08.6 " \mathrm{~S} / \\
62^{\circ} 06^{\prime} 12^{\prime \prime}\end{array}$ & $\begin{array}{c}\text { Playa de arenosa - } \\
\text { limoarcillosa }\end{array}$ & 0 \\
\hline
\end{tabular}


T. 6.1: Características geomorfológicas de los sitios analizados de la región del delta del río Colorado.

\subsection{Descripciones de los depósitos pleistocenos de la región del delta del río Colorado}

Dentro del ambiente deltaico $\left(39^{\circ} 28^{\prime} \mathrm{S} / 62^{\circ} 19^{\prime} \mathrm{O}\right)$ se observa una loma parcialmente cubierta por médanos, constituida por una grava matriz sostén altamente entoscada, con clastos medianos y grandes bien redondeados y aplanados, situados a cota de $8 \mathrm{~m}$ aproximadamente, cercano al Sitio F3. En este caso este sitio no se analizó por falta de dataciones y restos de valvas no identificados por su alta grado de cementación.

A $12 \mathrm{~km}$ de la localidad Villalonga (Sitio C1) se encuentra un depósito marino perteneciente al Interglacial $\geq$ MIS 9 a cota de $16 \mathrm{~m}$. Presenta escaso contenido fosilífero entre los que figuran: Pitar rostratus y Corbula patagonica (bivalvos) y Buccinanops y Crepidula (gasterópodos).

En el sitio (E1) (39 $\left.47^{\circ} \mathrm{S} / 62^{\circ} 29^{\prime} \mathrm{O}\right)$, representa un cordón litoral a cotas del orden de los $6 \mathrm{~m}$, compuestos por $2 \mathrm{~m}$ de arenas limosas castañas, cubiertas por limos arcillosos, castaños grisáceos con clastos dispersos, esféricos y aplanados tapizados de tosca con restos de moluscos. Entre la fauna marina, presente figuran: Glycymeris longior, Tagelus plebeius (bivalvos) y Heleobia australis, Tegula patagonica y Buccinanps globulosus (gasterópodo).

Los sitios (E2 y E4) conforman cordones litorales a cotas del orden de los $6 \mathrm{~m}$. Entre la fauna marina más abundantes figuran: Glycymeris longior (bivalvos) y Buccinanops globulosus (gasterópodo).

El Sitio E3, representa un paleocanal situado a cota de $10 \mathrm{~m}$. Entre la fauna encontrada se destaca la presencia de Tagelus plebeius, Corbula patagonica y Pitar rostratus (bivalvos), y Heleobia australis (gasterópodos). 


\subsection{Descripciones de los depósitos marinos holocenos de la región del delta del río Colorado}

La Península Verde, constituye un rasgo geomorfológico generado a partir de la transgresión marina holocena, donde pueden identificarse planicies de mareas relictuales y actuales, medanos activos y estabilizados, barrera costera y playas. Se analizaron dos sitios holocenos (F1 y F2), el Sitio F2 con una edad de $2.17 \pm 0.86 \mathrm{ka}$

${ }^{14} \mathrm{C}$ (Weiler, 1984). Entre la fauna marina más abundante figuran: Heleobia australis (gasterópodo) (Sitio F1) y Amiantis purpurata (bivalvo) (Sitio F2) (Charó et al., 2012).

El sector S se caracteriza por la reciente formación de una barrera $\mathrm{N}$ - S separada unos $3.5 \mathrm{~km}$ de la línea de médanos, generándose una extensa llanura de marea arenosa, afectada mayormente por procesos litorales durante las tormentas y por el viento (Fucks et al., 2012a).

En las inmediaciones de la desembocadura del río Colorado Nuevo, hay sedimentos marinos en forma continua a lo largo de $26 \mathrm{~km}$. Los afloramientos F3, F4 y F7 muestran barrancas del orden de los $2 \mathrm{~m}$ de altura, compuestos por sedimentos arcillo limosos, castaño grisáceos, homogéneos, cubiertos en algunos sectores por sedimentos eólicos. Por encima y de manera transicional le continúan sedimentos arenosos castaños grisáceos, laminados, con un espesor mínimo de $0.50 \mathrm{~m}$. Presentan una gran cantidad de fauna de moluscos marinos entre los que se destacan: Tagelus plebeius, Corbula patagonica, Pitar rostratus (bivalvos) y Heleobia australis y Buccinanops globulosus (gasterópodos), presentándose en muchas oportunidades articulados y en posición de vida (Fig. 6.3). 


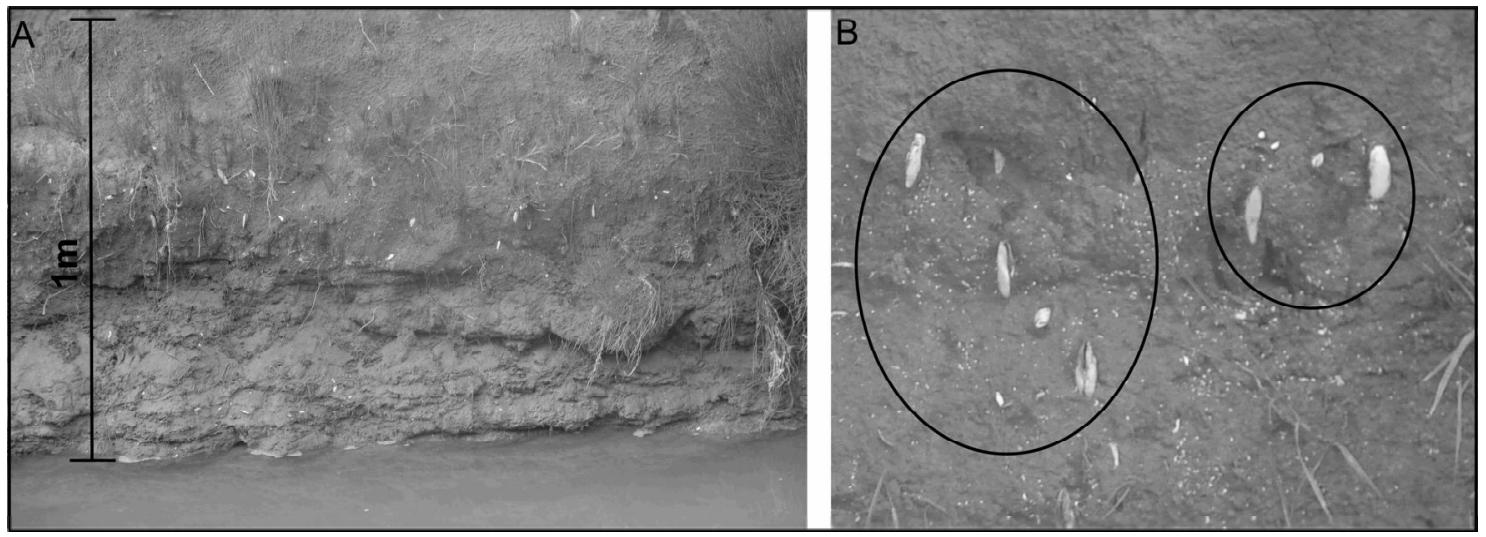

Fig. 6.3: A, Depósitos marinos holocenos cerca de la desembocadura del río Colorado (Sitio F3); B, Tagelus plebeius en forma articulada en el mismo sitio (F3).

A unos $23 \mathrm{~km}$ de la actual línea de costa $\left(39^{\circ} 33^{\prime} \mathrm{S} / 62^{\circ} 13^{\prime} \mathrm{O}\right)$ (Sitio F5) se observa el afloramiento a cota $4-5 \mathrm{~m}$ representado por $2.5 \mathrm{~m}$ de arena arcillosa, castaña, homogénea, con clastos pequeños y fauna de bivalvos y gasterópodos. Entre las más abundantes se destacan: Amiantis purpurata y Mesodesma mactroides (bivalvos) (Fig. $6.4)$.

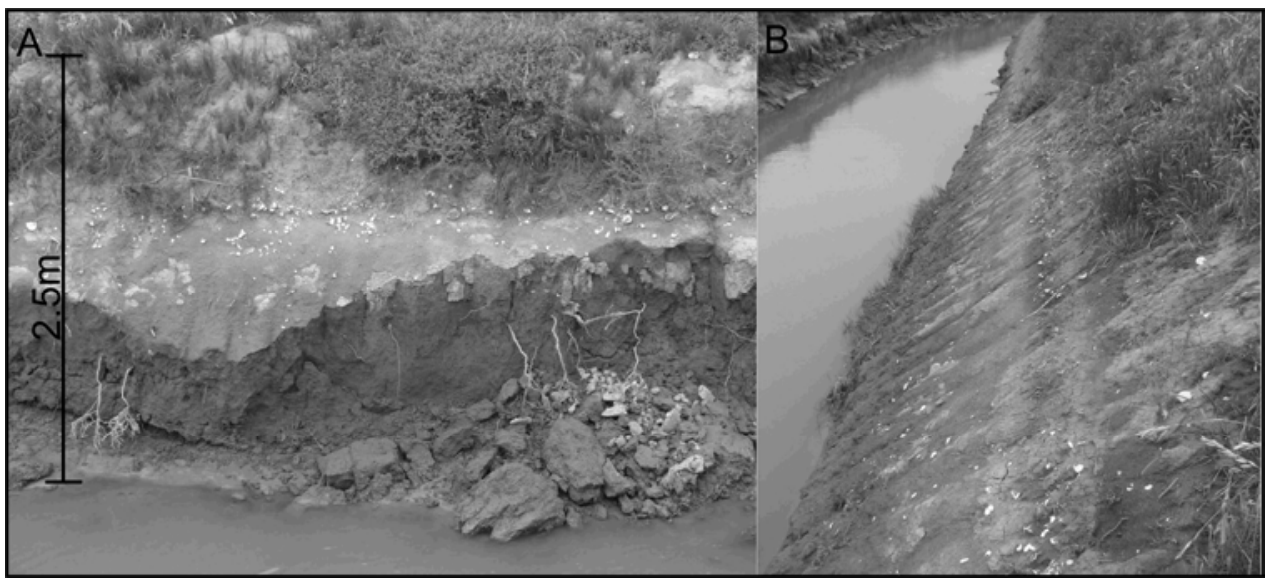

Fig. 6.4: A, B Depósito marino holocenos del delta del río Colorado (Sitio F5).

El Sitio F6 (39 $\left.51^{\prime} \mathrm{S} / 62^{\circ} 22^{\prime} \mathrm{O}\right)$, en un canal reciente se encontró un depósito de $1.40 \mathrm{~m}$ de espesor con alta densidad de Tagelus plebeius (bivalvo) y Heleobia australis (gasterópodo). Se reconocieron tres niveles (A, B y C) que forman parte de un ambiente somero. En el nivel A, compuesto por $0.10 \mathrm{~m}$ de grava fina matriz sostén, el nivel B compuesto por $0.60 \mathrm{~m}$ de una arena fina arcillosa, homogénea, de color castaño oscuro 
con valvas dispersas con Tagelus plebeius en posición de vida y articulado, cubierto por un sedimento arcilloso de color verde castaño de $0.50 \mathrm{~m}$. El nivel C compuesto por 0.20 $\mathrm{m}$ de arena gris pedogenizada. En el nivel B, se realizó una datación ${ }^{14} \mathrm{C}$ que arrojó una edad de $3.69 \pm 0.10 \mathrm{ka}$ (LP 2480) (Fig 6.5 y 6.6).

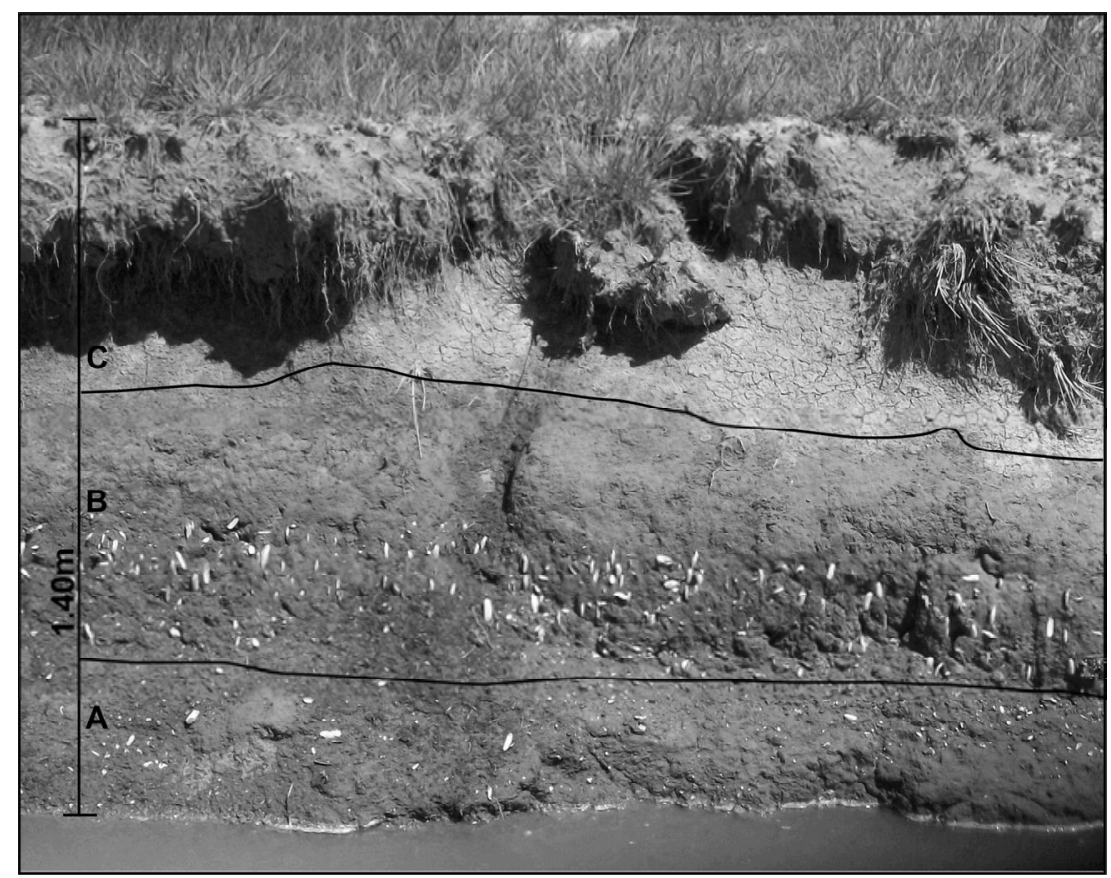

Fig.6.5: Vista frontal de un depósito marino holoceno con valvas articuladas de Tagelus plebeius (Sitio F6).

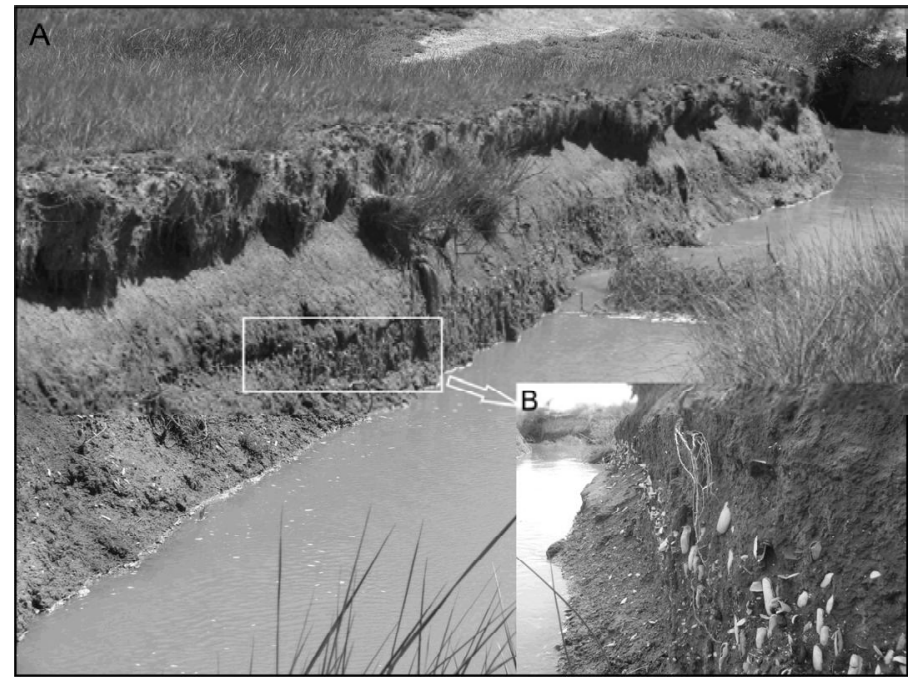

Fig. 6.6: Depósito marino holoceno con Tagelus plebeius en posición de vida (Sitio F6). 


\subsubsection{Tagelus plebeius ¿sucesión biológica?}

Tagelus plebeius (Lightfood, 1786) es un organismo infaunal eurihialino profundo distribuido desde Carolina del Norte ( $34^{\circ} \mathrm{N}$, Estados Unidos) hasta el golfo San Matías ( $41^{\circ} \mathrm{S}$, Argentina) (Morris y Rosenberg, 2005). Esta es una especie gregaria filtradora que construye cuevas permanentes de hasta $50 \mathrm{~cm}$ y carece de movilidad lateral (Gutiérrez y Valero, 2001). Tiene valvas alargadas con ligeras estrías de crecimiento. Vive en ambientes someros en zonas sublitorales y se alimentan en base al sedimento depositado (“deposit-feeding”), y su respiración es aeróbica facultativa (ej. Iribarne et al. 1997; Golfieri et al., 1998) (Fig. 6.7).

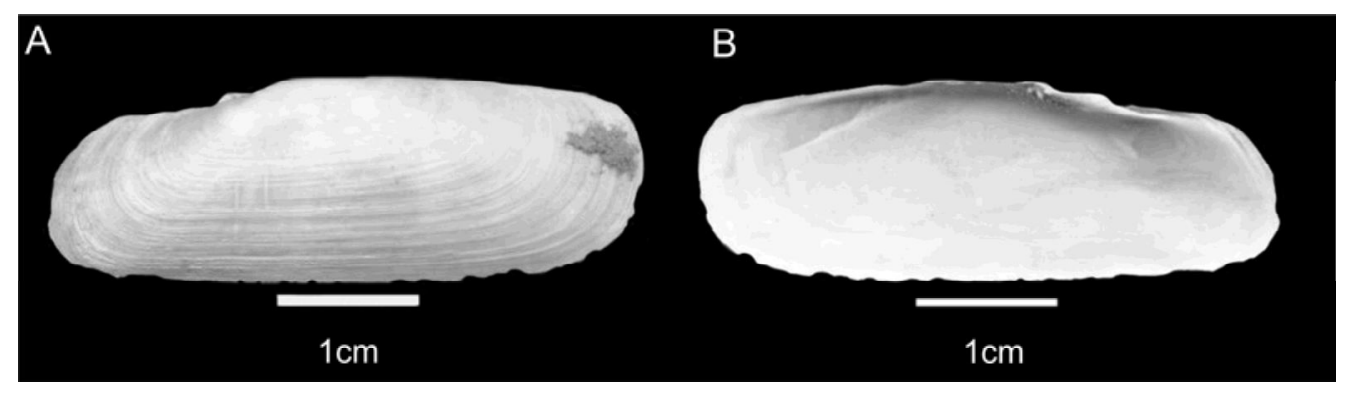

Fig. 6.7: Vista dorsal (A) y ventral (B) de la valva derecha de Tagelus plebeius.

La alta densidad de Tagelus plebeius en depósitos holocenos en la Provincia de Buenos Aires son comunes, en los cuales se encuentran articulados y en posición de vida. Hay antecedentes en la Provincia de Buenos Aires de depósitos extraordinarios de Tagelus plebeius que lo relacionan a una mortandad masiva (ej. Schnack et al., 1982; Farinati et al., 1992) interpretando este suceso como consecuencia de distintos eventos, entre los cuales sugieren rápidos cambios en el nivel del mar, la obstrucción de la boca de lagos estúaricos o episodios de depositación de sedimento por aporte fluvial (Iribarne et al., 1998). En cambio, otros autores como Golfieri et al. (1998) concluyen que la alta densidad de Tagelus plebeius en los depósitos holocenos de río Quenquén Grande $\left(38^{\circ} \mathrm{S}\right.$, sur de Provincia de Buenos Aires) son producto de la superposición de las 
distintas poblaciones y el resultado de cambios graduales en la evolución del ambiente deltaíco como otros factores biológicos (predación o bioturbación).

El Sitio F6, se caracteriza por ser un depósito marino holoceno (planicie de marea) con una alta densidad de Tagelus plebeius articulado y en posición de vida. Podríamos atribuirlo a un comportamiento local del sistema y al comportamiento propio de la especie. Estudios más avanzados, con análisis tafonómicos y paleoecológicos nos acercarán a posibles causas de la alta densidad de la especie en el depósito (Fig. 6.8).

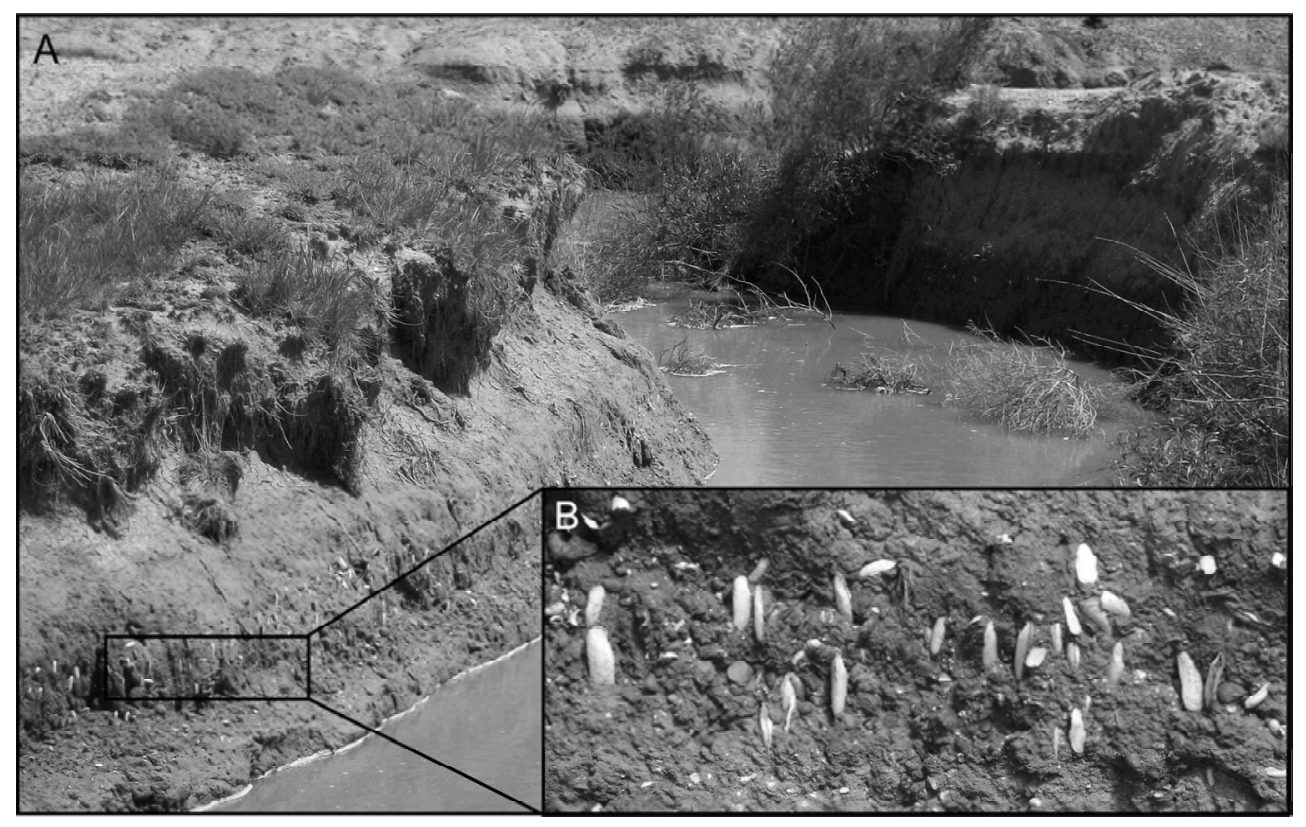

Fig. 6.8: A, Depósito marino holoceno (Sitio) B, Nivel de alta densidad de Tagelus plebeius articulados y en posición de vida.

\subsection{Playas actuales de la región del delta del río Colorado}

El sector comprendido entre Punta Laberinto y proximidades de río Colorado Viejo, presentan una amplia playa arenosa en parte limo-arcilloso, que se angosta hasta el sur, en un tramo de $45 \mathrm{~km}$ y cuyo ancho oscila entre $2 \mathrm{~km}$ en Punta Laberinto y $500 \mathrm{~m}$ en proximidades del río Colorado Viejo (Weiler, 1984). 
La playa de Península Verde $\left(39^{\circ} 23^{\prime} \mathrm{S} / 62^{\circ} 0^{\prime} \mathrm{O}\right)$ (Sitio G1), es una playa arenosa con gran cantidad de fauna marina, la mayoría de las valvas y conchas se encuentran en forma fragmentada. Entre los moluscos, se destaca la abundancia de Adelomelon brasiliana y Zidona dufresnei (gasterópodos) entre otros especies con menor representación (Fig. 6.9).

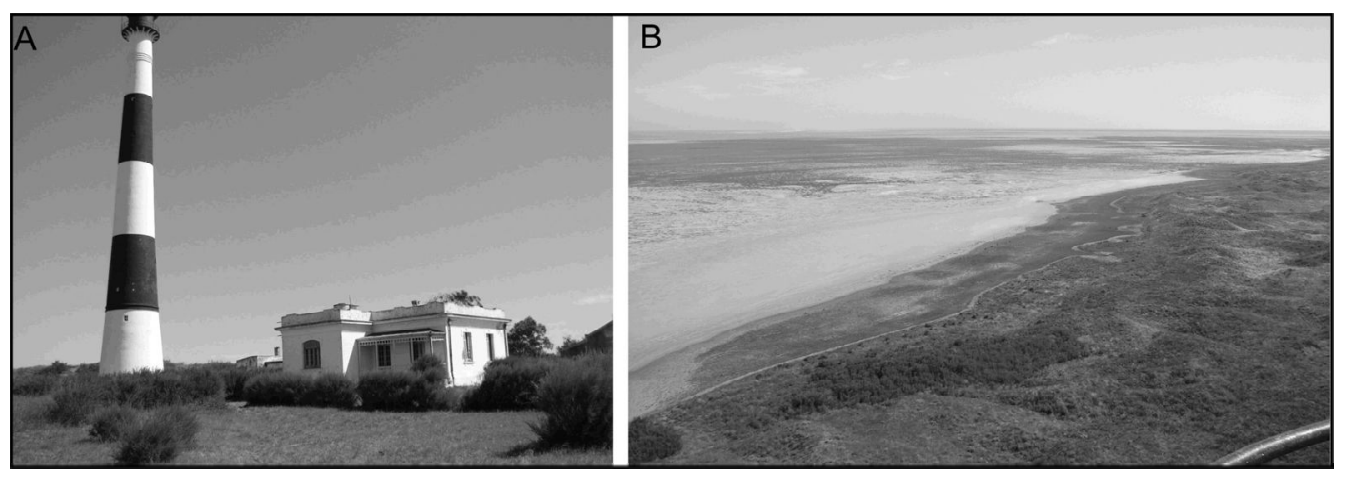

Fig. 6.9: A, Faro San Antonio (Península Verde); B, Vista panorámica de la playa de Península Verde (Sitio G1).

La playa más destacada de la región, es el balneario La Chiquita $\left(39^{\circ} 35^{\prime} \mathrm{S} / 62^{\circ} 05^{\prime} \mathrm{O}\right)$ (Sitio G2 - G4), que se ubica en la bahía Verde, frente a la isla Wood. Es una playa extensa de arena y se caracteriza por un médano frontal de unos $4 \mathrm{~m}$ de altura. En la berma cercana a la línea de costa se destacan las acumulaciones de valvas como Amiantis purpurata y Cyrtopleura lanceolata (bivalvos) (Fig. 6.10).

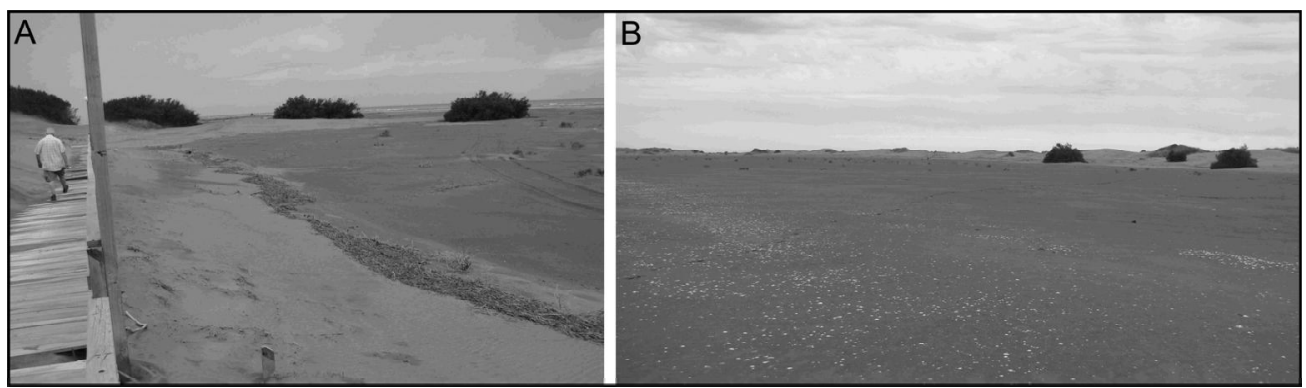

Fig. 6.10: Playas arenosas de Balneario La Chiquita (Sitio G2-G4).

La costa del sector este del delta del río Colorado (Sitio G5) (39³6’S) está representada por una amplia playa arenosa a limo arcillosa, limitada hacia el continente por un cuerpo medanoso parcialmente vegetado. Entre la fauna marina más abundante figuran: 
Ostrea puelchana, Pitar rostratus y Amiantis purpurata (bivalvos). En algunos sectores, como en las cercanías de la desembocadura del río Colorado Chico o Nuevo, se observan fenómenos parciales de erosión (Codignotto y Weiler, 1980) (Fig. 6.11).

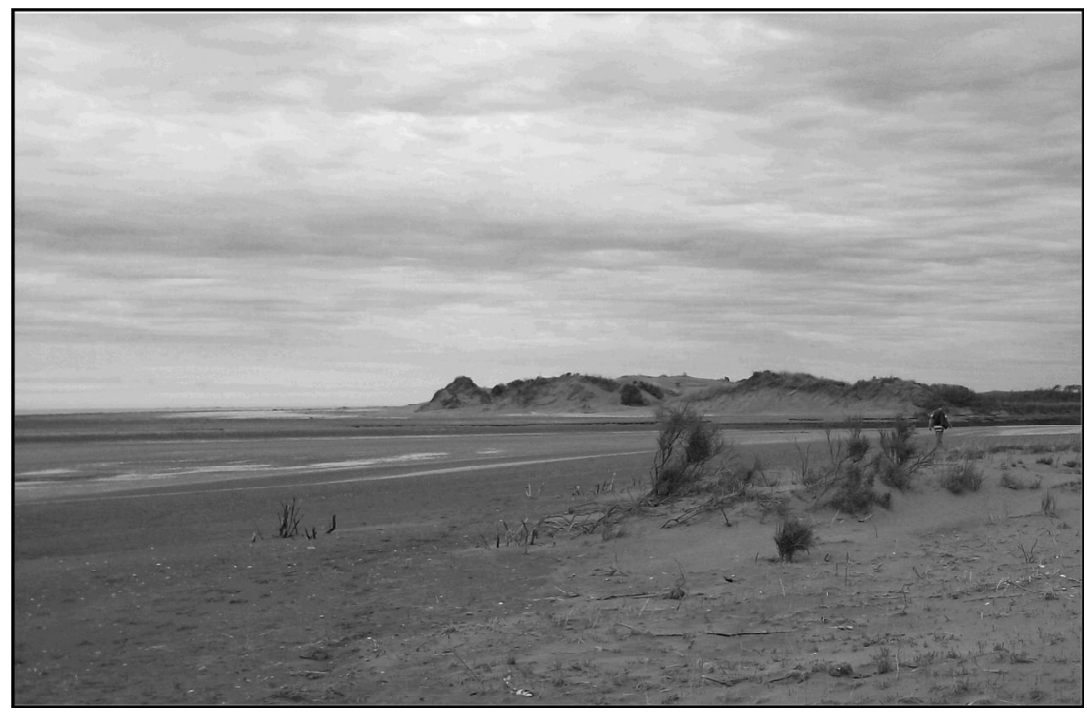

Fig.6.11: Playa próxima a la desembocadura del río Colorado (Sitio G5)

\subsection{Composición faunística}

En el área del norte del delta del río Colorado, se analizaron 17 sitios (5 pleistocenos, 7 holocenos y 5 actuales) y se registró un total de 51 especies (29 bivalvos y 22 gasterópodos) (Fig. 6.12 y 6.13). Entre ellos, se destacan la presencia de 9 micromoluscos: Heleobia australis, Parvanachis isabellei, Olivella tehuelcha, y Turbonilla argentina (gasterópodos) y Nucula nucleus, Ennucula grayi, Carditamera plata, Corbula patagonica y Corbula lyoni (bivalvos) (Fig. 6.14) (T. 6.2 y T.6.3). 


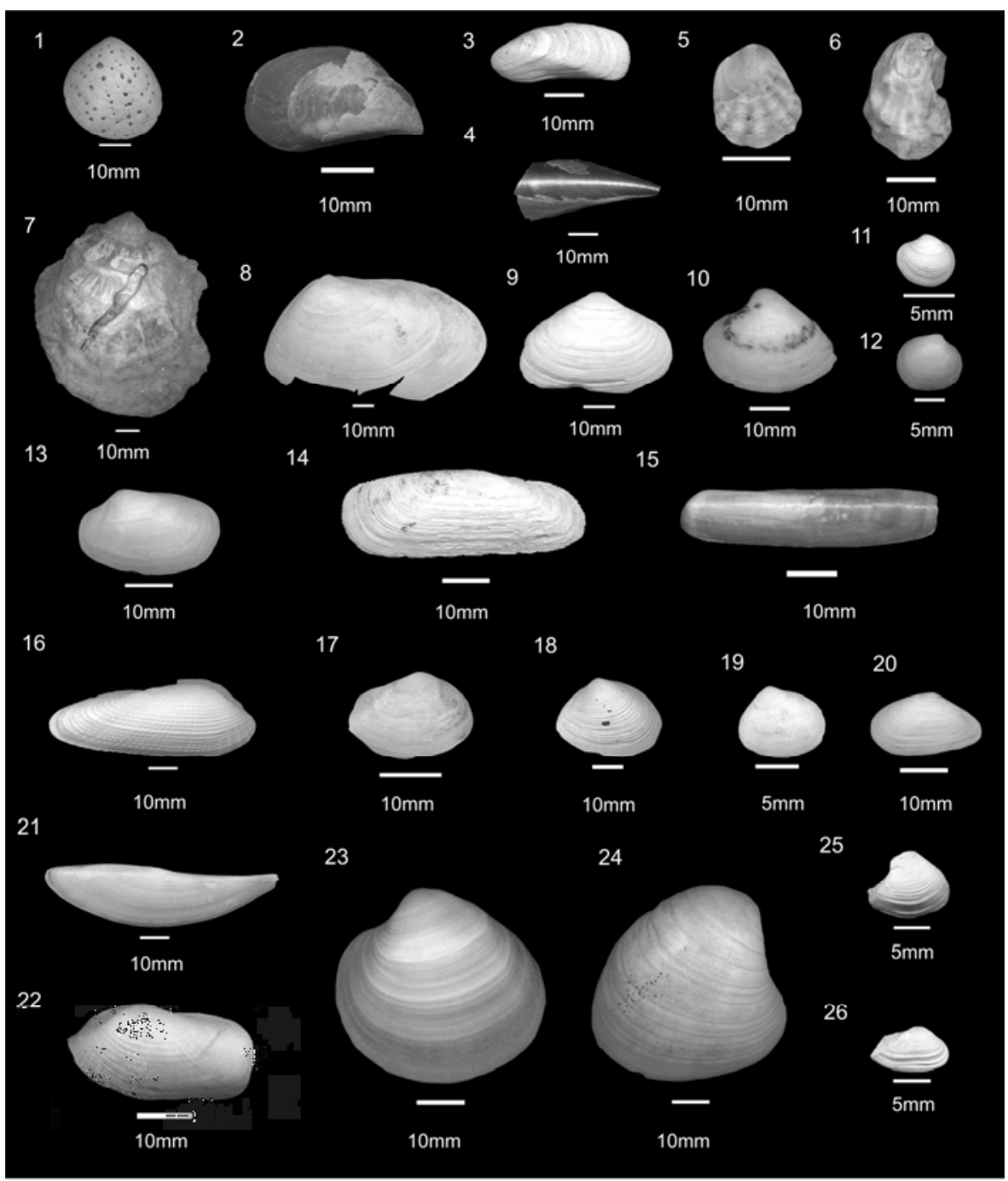

Fig.612: Especies de bivalvos característicos de depósitos marinos del Cuaternarios de la región del delta del río Colorado. Dimensiones en $\mathrm{mm}$.

1, Glycymeris (G.) longior (Sowerby) (MLP: 34.409, actual);2, Mytilus edulis platensis d'Orbigny (MLP: 34.415, actual) ; 3, Brachidontes (B.) Rodriguezii (d'Orbigny) (MLP:34.401, Holoceno); 4, Atrina seminuda (Lamarck) (MLP: 34.399, actual); 5, Plicatula gibbosa Lamarck (MLP: 34.422, actual); 6, Ostreola equestris (Say) (MLP:34448); 7, Ostrea puelchana d'Orbigny (MLP: 34.419, actual);8, Mesodesma mactroides (Reeve) (MLP: 34.414, actual); 9, Mactra guidoi Signorelli \& Scarabino (MLP: 34.412, Holoceno); 10, Mactra isabelleana d'Orbigny (MLP: 34.413, Holoceno); 11, Diplodonta (D.) patagonica ( d'Orbigny) (MLP: 34.406, actual); 12, Diplodonta (F.) vilardeboana ( d'Orbigny) (MLP: 34.408, actual); 13, Periploma ovatum d'Orbigny (MLP: 34.420, actual); 14, Tagelus (T.) plebeius (Ligthfood) (MLP: 34.425, Pleistoceno); 15, Solen tehuelchus (Hanley) (MLP: 34.424, actual); 16, Cyrtopleura (S.) lanceolata (d'Orbigny) (MLP: 34.404, actual); 17, Lyonsia (L.) alvarezii d'Orbigny (MLP: 34.410, Pleistoceno); 18, Raeta (R.) plicatella (Lamarck) (MLP: 34.423, actual); 19, Abra (A.) aequalis (Say) (MLP: 34.395, Pleistoceno); 20, Macoma (P.) uruguayensis (Smith) (MLP: 34.411, actual); 21, Adrana electa (A. Adams) (MLP: 34.398, actual); 22, Barnea lamellosa ( d'Orbigny) (MLP: 34.400 , actual); 23, Amiantis purpurata (Lamarck) (MLP: 34.397, actual); 24, Pitar (P.) rostratus (Philippi) (MLP: 34.421, actual); 25, Corbula (C.) patagonica d'Orbigny (MLP: 34.405, Holoceno); 26, Corbula (C.) Iyoni Pilsbry (MLP: 34.403, actual). 


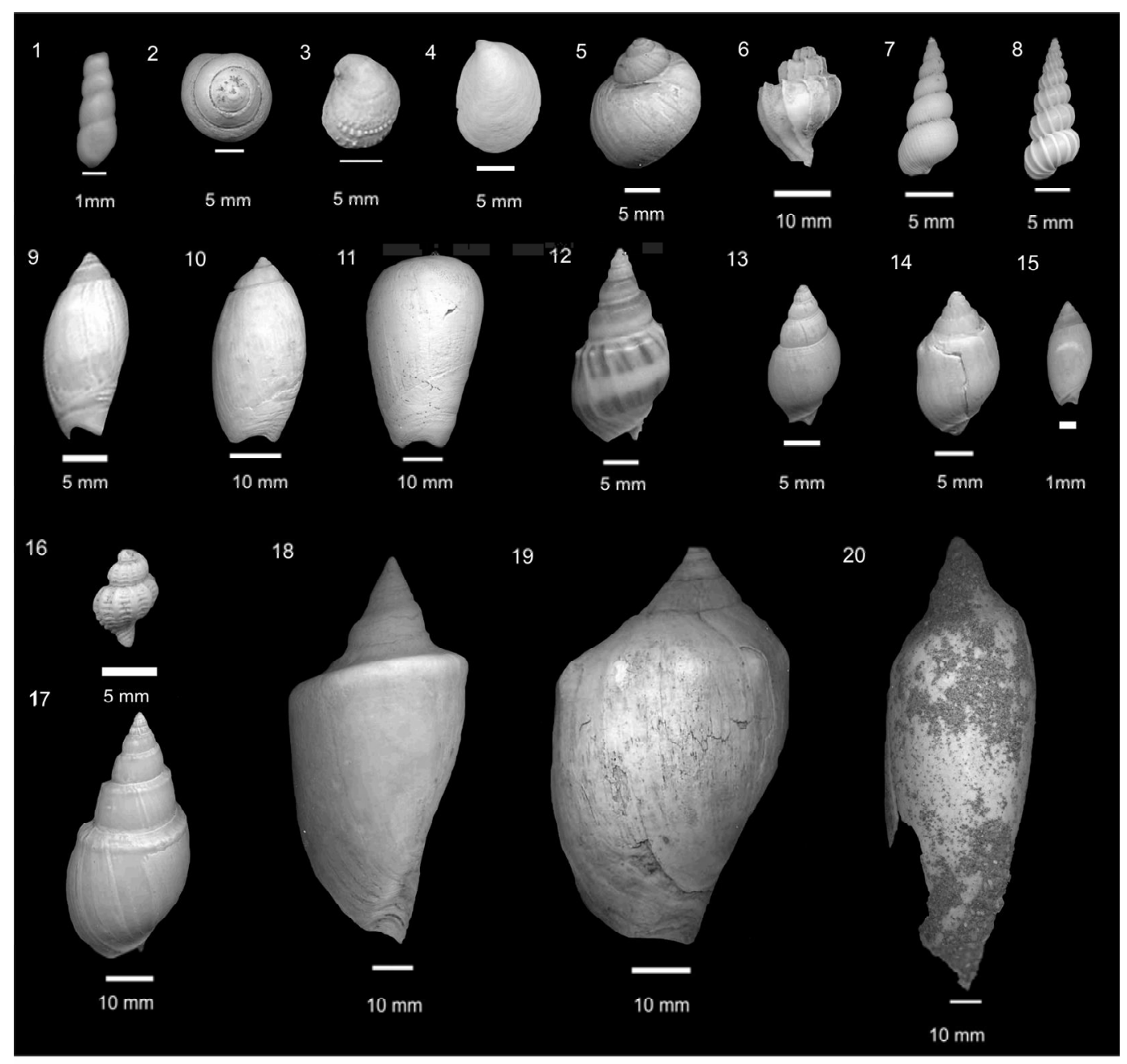

Fig.6.13: Gasterópodos característicos depósitos marinos cuaternario de la región delta del río Colorado. Dimensiones en mrin.

1, Turbonilla argentina (Doello Jurado) (MLP: 33.781, Holoceno); 2, Tegula (A.) patagonica (d'Orbigny) (MLP: 34.392, Holoceno); 3, Bostrycapulus odites (Collin) (MLP:34.392, Pleistoceno); 4, Crepidula argentina Simone, Pastorino \& Penchaszadeh (MLP: 34.384, actual); 5, Notocochlis isabelleana (d'Orbigny) (MLP: 34.388, Holoceno); 6, Trophon patagonicus (d'Orbigny, 1839) (MLP: 34.393, Holoceno); 7, Epitenium striatellum (Nyst) (MLP:34.393, actual); 8, Epitonium (E.) georgettinum (d'Orbigny) (MLP: 34.386, actual); 9 , Olivancillaria uretai Klappenbach (MLP: 34.390, Holoceno); 10, Olivancillaria carcellesi Klappenbach (MLP: 34.389, Holoceno); 11, Olivancillaria urceus (Röding) ( MLP: 34.418, Holoceno); 12, Buccinanops monilifer (Kiener) (MLP: 34.382, Holoceno); 13, Buccinanops uruguayensis (Pilsbry) (MLP: 34.428, actual); 14, Buccinanops globulosus (Kiener) (MLP:34.381, Holoceno); 15, Olivella (O.) tehuelcha (Dúclos) (MLP: 34.391, Holoceno); 16, Urosalpinx cala (Pilsbry) (MLP: 34.447, Holoceno); 17, Buccinanops cochlidium (Dilwyn) (MLP: 34.380, actual); 18, Zidona dufresnei (Donovan) (MLP: 34.394, Holoceno); 19, Adelomelon (P.) brasiliana (Lamarck) (MLP: 34.378, Holoceno); 20, Odontocymbiola magellanica (Gmelin) (MLP: 34.417, Holoceno). 


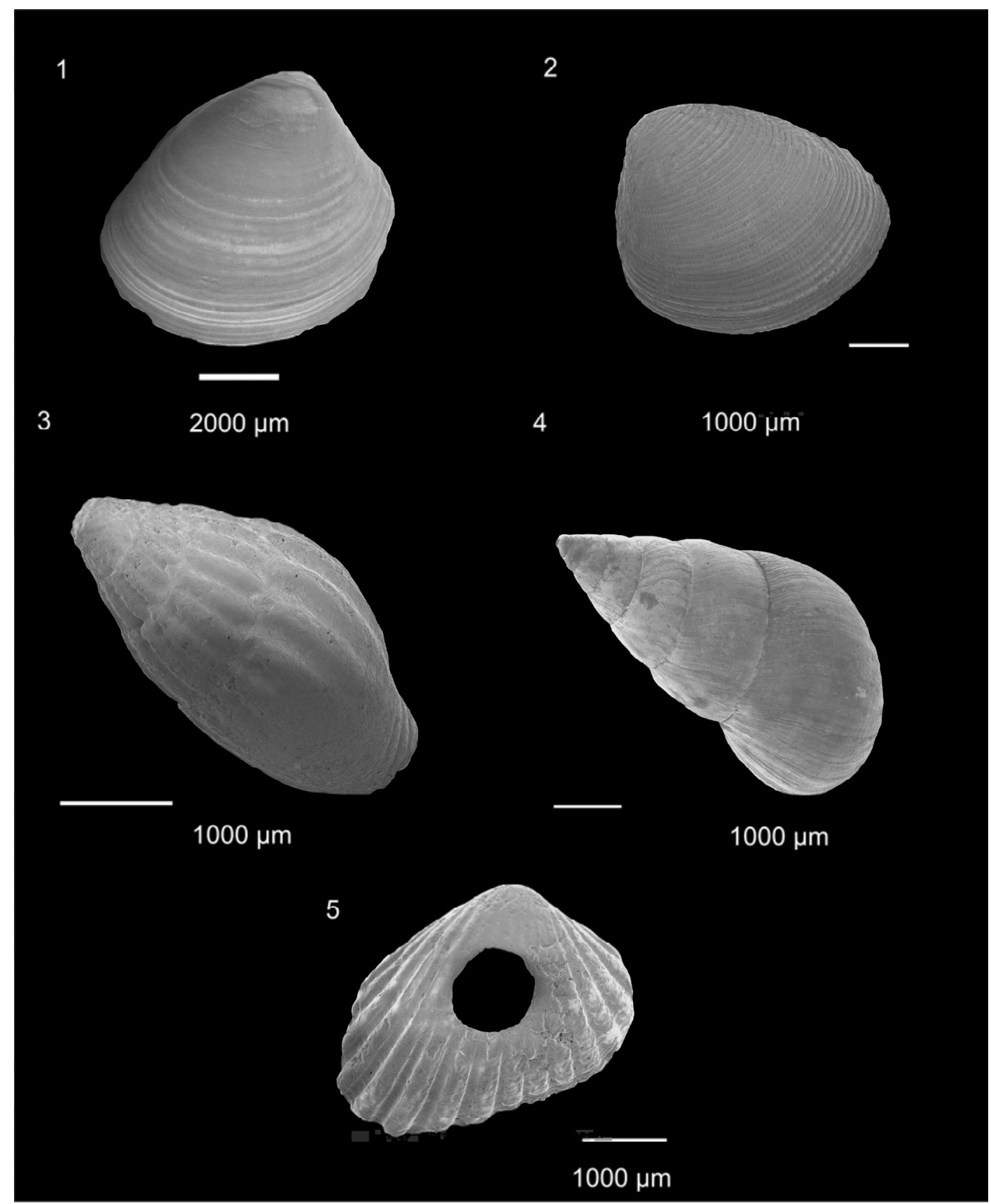

Fig. 6.14: Micromoluscos característicos de depósitos marinos del Cuaternario de la región delta del río Colorado. Dimensiones en $\mu \mathrm{m}$.

1, Nucula (N.) nucleus (Linné, 1758) (MLP: 34.416, actual); 2, Ennucula grayi (d'Orbigny, 1846) (MLP: 34.407, Holoceno); 3, Parvanachis isabellei (d'Orbigny, 1839) (MLP: 34.429 , Holoceno); 4, Heleobia australis (d'Orbigny) (MLP: 34.387, actual); 5, Carditamera plata (Ihering, 1907) (MLP: 34.402, actual). 


\begin{tabular}{|c|c|c|c|c|c|c|c|c|c|c|c|c|c|c|c|c|c|}
\hline Bivalvos & C1 & E1 & E2 & E3 & E4 & F1 & F2 & F3 & F4 & F5 & F6 & F7 & G1 & G2 & G3 & G4 & G5 \\
\hline \multicolumn{18}{|l|}{ Familia Nuculidae Gray,1824 } \\
\hline Nucula (N.) nucleus ( Linné, 1758) & & & & $\mathbf{X}$ & & & & & $\mathbf{X}$ & & $\mathbf{X}$ & $\mathbf{X}$ & $\mathbf{X}$ & & & & \\
\hline Ennucula grayi (d'Orbigny, 1846) & & & & & & & & & $\mathbf{X}$ & & & & & & & & \\
\hline \multicolumn{18}{|l|}{$\begin{array}{l}\text { Familia Nuculanidae H. y A. Adams, } \\
1858\end{array}$} \\
\hline Adrana electa (A. Adams, 1856) & & & & & & & & & & & & & & & & $\mathbf{X}$ & \\
\hline \multicolumn{18}{|l|}{ Familia Glycymerididae Newton, 1922} \\
\hline Glycymeris (G.) longior ( Sowerby, 1832) & & $\mathbf{X}$ & $\mathbf{X}$ & $\mathbf{X}$ & $\mathbf{X}$ & & & & & & & $\mathbf{X}$ & & $\mathbf{X}$ & $\mathbf{X}$ & $\mathbf{X}$ & $\mathbf{X}$ \\
\hline \multicolumn{18}{|l|}{ Familia Mytilidae Rafinesque,1815 } \\
\hline Mytilus edulis platensis d'Orbigny, 1846 & & & & & & & & & & $\mathbf{X}$ & & & $\mathbf{X}$ & & $\mathbf{X}$ & & $\mathbf{X}$ \\
\hline Brachidontes (B.) rodriguezii ( d'Orbigny, 1846) & & & & $\mathbf{X}$ & & & & $\mathbf{X}$ & $\mathbf{X}$ & & $\mathbf{X}$ & $\mathbf{X}$ & $\mathbf{X}$ & & & $\mathbf{X}$ & \\
\hline \multicolumn{18}{|l|}{ Familia Pinnidae Leach, 1819} \\
\hline Atrina seminuda (Lamarck, 1819) & & & & & & & & & & & & & & & $\mathbf{X}$ & & \\
\hline \multicolumn{18}{|l|}{ Familia Plicatulidae Watson, 1930} \\
\hline Plicatula gibbosa Lamarck, 1801 & & & & & & & & & & & & & & & & $\mathbf{X}$ & \\
\hline \multicolumn{18}{|l|}{ Familia Ostreidae Rafinesque,1815 } \\
\hline Ostrea & & & & & & & & & $\mathbf{X}$ & & & & $\mathbf{X}$ & & & & \\
\hline Ostreola equestris (Say, 1834) & & & & & & & & & $\mathbf{X}$ & & & $\mathbf{X}$ & $\mathbf{X}$ & & $\mathbf{X}$ & $\mathbf{X}$ & \\
\hline Ostrea puelchana d'Orbigny 1841 & & & & $\mathbf{X}$ & & & & & $\mathbf{X}$ & & & & $\mathbf{X}$ & $\mathbf{X}$ & $\mathbf{X}$ & $\mathbf{X}$ & $\mathbf{X}$ \\
\hline \multicolumn{18}{|l|}{ Familia Diplodontidae Dall, 1895} \\
\hline Diplodonta (D.) patagonica ( d'Orbigny, 1842) & & & & $\mathbf{X}$ & & & & & & $\mathbf{X}$ & & & & & & & \\
\hline $\begin{array}{l}\text { Diplodonta (F.) vilardeboana ( d'Orbigny, } \\
1846 \text { ) }\end{array}$ & & & & & & & & & & & & & $\mathbf{X}$ & & & & \\
\hline \multicolumn{18}{|l|}{ Familia Carditidae Fleming, 1828} \\
\hline Carditamera plata (Inhering, 1907) & & & & & & $\mathbf{X}$ & & & & & $\mathbf{X}$ & $\mathbf{X}$ & $\mathbf{X}$ & & $\mathbf{X}$ & & \\
\hline \multicolumn{18}{|l|}{ Familia Mactridae Lamarck,1809 } \\
\hline Mactra & & & & & & & & & & & & & & & $\mathbf{X}$ & & \\
\hline Mactra isabelleana d'Orbigny, 1846 & & & & & & & & & & & & & $\mathbf{X}$ & & & & \\
\hline Mactra guidoi Signorelli \& Scarabino, 2010 & & & & & & & & & $\mathbf{X}$ & & & & $\mathbf{X}$ & & & $\mathbf{X}$ & \\
\hline Raeta (R.) plicatella (Lamarck,1818) & & & & $\mathbf{X}$ & & & & & & $\mathbf{X}$ & & & $\mathbf{X}$ & & $\mathbf{X}$ & $\mathbf{X}$ & $\mathbf{X}$ \\
\hline
\end{tabular}




\begin{tabular}{|c|c|c|c|c|c|c|c|c|c|c|c|c|c|c|c|c|c|}
\hline Bivalvos & C1 & E1 & E2 & E3 & E4 & F1 & F2 & F3 & F4 & F5 & F6 & F7 & G1 & G2 & G3 & G4 & G5 \\
\hline \multicolumn{18}{|l|}{ Familia Mesodesmatidae Gray,1839 } \\
\hline Mesodesma mactroides (Reeve, 1854) & & & & & & & & & & $\mathbf{X}$ & & & $\mathbf{X}$ & & $\mathbf{X}$ & $\mathbf{X}$ & \\
\hline \multicolumn{18}{|l|}{ Familia Solenidae Lamarck, 1809} \\
\hline Solen tehuelchus (Hanley, 1842) & & & & & & & & & & & & & $\mathbf{X}$ & & $\mathbf{X}$ & $\mathbf{X}$ & \\
\hline \multicolumn{18}{|l|}{ Familia Telinidae De Blainville,1814 } \\
\hline Macoma (P.) uruguayensis (Smith, 1885) & & & & & & & & $\mathbf{X}$ & & & & & & & & $\mathbf{X}$ & \\
\hline \multicolumn{18}{|l|}{ Familia Semelidae Stoliczka,1870 } \\
\hline Abra (A.) aequalis (Say, 1822) & & & & $\mathbf{X}$ & & & & $\mathbf{X}$ & & & & & & & $\mathbf{X}$ & & \\
\hline \multicolumn{18}{|l|}{ Familia Solecurtidae d'Orbigny, 1846} \\
\hline Tagelus (T.) plebeius (Ligthfood,1786) & & $\mathbf{X}$ & & $\mathbf{X}$ & & & & $\mathbf{X}$ & & & $\mathbf{X}$ & $\mathbf{X}$ & $\mathbf{X}$ & & & $\mathbf{X}$ & \\
\hline \multicolumn{18}{|l|}{ Familia Veneridae Rafinesque, 1815} \\
\hline Pitar (P.) rostratus (Philippi, 1844) & $\mathbf{X}$ & & & $\mathbf{X}$ & $\mathbf{X}$ & $\mathbf{X}$ & $\mathbf{X}$ & $\mathbf{X}$ & $\mathbf{X}$ & $\mathbf{X}$ & $\mathbf{X}$ & $\mathbf{X}$ & & $\mathbf{X}$ & $\mathbf{X}$ & $\mathbf{X}$ & $\mathbf{X}$ \\
\hline Amiantis purpurata ( Lamarck, 1856) & & & & & & & $\mathbf{X}$ & & $\mathbf{X}$ & $\mathbf{X}$ & & $\mathbf{X}$ & $\mathbf{X}$ & $\mathbf{X}$ & $\mathbf{X}$ & $\mathbf{X}$ & $\mathbf{X}$ \\
\hline \multicolumn{18}{|l|}{ Familia Corbulidae Gray, 1823} \\
\hline Corbula (C.) patagonica d'Orbigny, 1846 & $\mathbf{X}$ & & & $\mathbf{X}$ & & & & $\mathbf{X}$ & $\mathbf{X}$ & $\mathbf{X}$ & $\mathbf{X}$ & $\mathbf{X}$ & & & $\mathbf{X}$ & & \\
\hline Corbula (C.) Iyoni Pilsbry, 1897 & & & & & & & & & & & & & & & & $\mathbf{X}$ & \\
\hline \multicolumn{18}{|l|}{ Familia Pholadidae Lamarck,1809 } \\
\hline Cyrtopleura (S.) lanceolata (d'Orbigny, 1846) & & & & & & & & & & & & & $\mathbf{X}$ & & $\mathbf{X}$ & $\mathbf{X}$ & $\mathbf{X}$ \\
\hline Barnea lamellosa ( d'Orbigny, 1846) & & & & & & & & & & & & & & & $\mathbf{X}$ & $\mathbf{X}$ & \\
\hline \multicolumn{18}{|l|}{ Familia Lyonsiidae Rafinesque, 1815} \\
\hline Lyonsia (L.)alvarezii d'Orbigny, 1846 & & & & $\mathbf{X}$ & & & & & & & & & & & & & \\
\hline \multicolumn{18}{|l|}{ Familia Periplomatidae Dall, 1895} \\
\hline Periploma ovatum d'Orbigny, 1846 & & & & & & & & & & & & & & & & $\mathbf{X}$ & \\
\hline
\end{tabular}

T.6.2: Lista sistemática de especies de bivalvos de cada sitio muestreado de la región del delta del río Colorado. 


\begin{tabular}{|c|c|c|c|c|c|c|c|c|c|c|c|c|c|c|c|c|c|}
\hline Gasterópodos & C1 & E1 & E2 & E3 & E4 & F1 & F2 & F3 & F4 & F5 & F6 & F7 & G1 & G2 & G3 & G4 & G5 \\
\hline \multicolumn{18}{|l|}{ Familia Calliostomatidae Thiele, 1924} \\
\hline Tegula (A.) patagonica (d'Orbigny, 1835) & & $\mathbf{X}$ & & $\mathbf{X}$ & $\mathbf{X}$ & & & & $\mathbf{X}$ & & $\mathbf{X}$ & & $\mathbf{X}$ & & & & \\
\hline \multicolumn{18}{|l|}{ Familia Calyptraeidae Lamarck, 1809} \\
\hline Bostrycapulus odites (Collin, 2005) & & & $\mathbf{X}$ & $\mathbf{X}$ & $\mathbf{X}$ & & & $\mathbf{X}$ & $\mathbf{X}$ & & $\mathbf{X}$ & $\mathbf{X}$ & $\mathbf{X}$ & & $\mathbf{X}$ & & $\mathbf{X}$ \\
\hline Crepidula & $\mathbf{X}$ & & & & & & $\mathbf{X}$ & & & & & & $\mathbf{X}$ & & $\mathbf{X}$ & $\mathbf{X}$ & \\
\hline $\begin{array}{l}\text { Crepidula argentina Simone, Pastorino \& } \\
\text { Penchaszadeh, } 2000\end{array}$ & & & & & & & & & & & & $\mathbf{X}$ & & & & & $\mathbf{X}$ \\
\hline \multicolumn{18}{|l|}{ Familia Naticidae Forbes, 1828} \\
\hline Notocochlis isabelleana (d'Orbigny, 1840 ) & & & & & & & & & & $\mathbf{X}$ & & $\mathbf{X}$ & & & $\mathbf{X}$ & $\mathbf{X}$ & \\
\hline \multicolumn{18}{|l|}{ Familia Hydrobiidae Troschel, 1857} \\
\hline Heleobia australis ( d'Orbigny, 1835) & & $\mathbf{X}$ & & $\mathbf{X}$ & & $\mathbf{X}$ & $\mathbf{X}$ & $\mathbf{X}$ & $\mathbf{X}$ & & $\mathbf{X}$ & $\mathbf{X}$ & $\mathbf{X}$ & & $\mathbf{X}$ & & \\
\hline \multicolumn{18}{|l|}{ Familia Epitoniidae S. S.Berry, 1910} \\
\hline $\begin{array}{l}\text { Epitonium (E.) georgettinum } \\
\text { (d'Orbigny, } 1840)\end{array}$ & & & & & & & & & & & & $\mathbf{X}$ & $\mathbf{X}$ & & $\mathbf{X}$ & & \\
\hline Epitonium striatellum (Nyst, 1871) & & & & & & & & & & & & & & & $\mathbf{X}$ & & \\
\hline \multicolumn{18}{|l|}{ Familia Muricidae Rafinesque, 1815} \\
\hline Trophon patagonicus (d'Orbigny, 1839) & & & & & & & & & $\mathbf{X}$ & & & & $\mathbf{X}$ & & & & \\
\hline Urosalpinx cala (Pilsbry, 1897) & & & & & & & & & & & & $\mathbf{X}$ & & & & & \\
\hline \multicolumn{18}{|l|}{ Familia Volutidae Rafinesque, 1815} \\
\hline Zidona dufresnei ( Donovan, 1823) & & & & & & & $\mathbf{X}$ & & $\mathbf{X}$ & & & & $\mathbf{X}$ & & & & \\
\hline Adelomelon (P.) brasiliana (Lamarck, 1811) & & & & & & & & & & $\mathbf{X}$ & & & $\mathbf{X}$ & & $\mathbf{X}$ & $\mathbf{X}$ & $\mathbf{X}$ \\
\hline Odontocymbiola magellanica (Gmelin, 1791) & & & $\mathbf{X}$ & & & & & & $\mathbf{X}$ & & & & & & & & \\
\hline \multicolumn{18}{|l|}{ Familia Olividae Latreille,1825 } \\
\hline Olivella (O.) tehuelcha ( Dúclos, 1835) & & & & & & & & & $\mathbf{X}$ & $\mathbf{X}$ & & & $\mathbf{X}$ & & $\mathbf{X}$ & & \\
\hline Olivancillaria urceus ( Röding, 1798) & & & & & & & $\mathbf{X}$ & & & & & & & & & & \\
\hline Olivancillaria carcellesi Klappenbach, 1965 & & & & & & & & & $\mathbf{X}$ & & & $\mathbf{X}$ & & & $\mathbf{X}$ & & \\
\hline Olivancillaria uretai Klappenbach, 1965 & & & & & & & & & & $\mathbf{X}$ & & & $\mathbf{X}$ & & & & \\
\hline \multicolumn{18}{|l|}{ Familia Nassariidae Iredale, 1916} \\
\hline Buccinanops & $\mathbf{X}$ & & & & & & & & & & & & & & $\mathbf{X}$ & & \\
\hline
\end{tabular}




\begin{tabular}{|l|c|c|c|c|c|c|c|c|c|c|c|c|c|c|c|c|c|}
\hline Gasterópodos & C1 & E1 & E2 & E3 & E4 & F1 & F2 & F3 & F4 & F5 & F6 & F7 & G1 & G2 & G3 & G4 & G5 \\
\hline Buccinanops monilifer (Kiener, 1834) & & & & & & & & & & $\mathbf{X}$ & & & $\mathbf{X}$ & & & X & \\
\hline Buccinanops cochlidium (Dilwyn, 1817) & & & & $\mathbf{X}$ & & & & & $\mathbf{X}$ & $\mathbf{X}$ & & $\mathbf{X}$ & $\mathbf{X}$ & & $\mathbf{X}$ & & \\
\hline Buccinanops globulosus (Kiener, 1834) & & $\mathbf{X}$ & $\mathbf{X}$ & $\mathbf{X}$ & $\mathbf{X}$ & $\mathbf{X}$ & & $\mathbf{X}$ & $\mathbf{X}$ & & & $\mathbf{X}$ & $\mathbf{X}$ & & & & \\
\hline Buccinanops uruguayensis (Pilsbry,1897) & & & & & & & & & $\mathbf{X}$ & & $\mathbf{X}$ & & & & & \\
\hline Familia Columbellidae Swaison, 1840 & & & & & & & & & & & & & & & & \\
\hline Parvanachis isabellei (d'Orbigny, 1839) & & & & & & & & & & $\mathbf{X}$ & & & & & & \\
\hline Familia Pyramidellidae Gray, 1840 & & & & & & & & & & & & & & & & & \\
\hline Turbonilla argentina (Doello-Jurado, 1938) & & & & & & & & & & & $\mathbf{X}$ & & & & & & \\
\hline
\end{tabular}

T.6.3: Lista sistemática de especies de gasterópodos de cada sitio muestreado de la región del delta del río Colorado. 
Según el Índice de Shannon $\left(\mathrm{H}^{\prime}\right)$, los índices más bajos corresponden a los sitios pertenecientes al Interglacial MIS 1 (F1, F3 y F6) y los índices más altos corresponden en su mayoría a los sitios actuales (1.94 - 2.72) (Fig. 6.15 у T. 6.4).

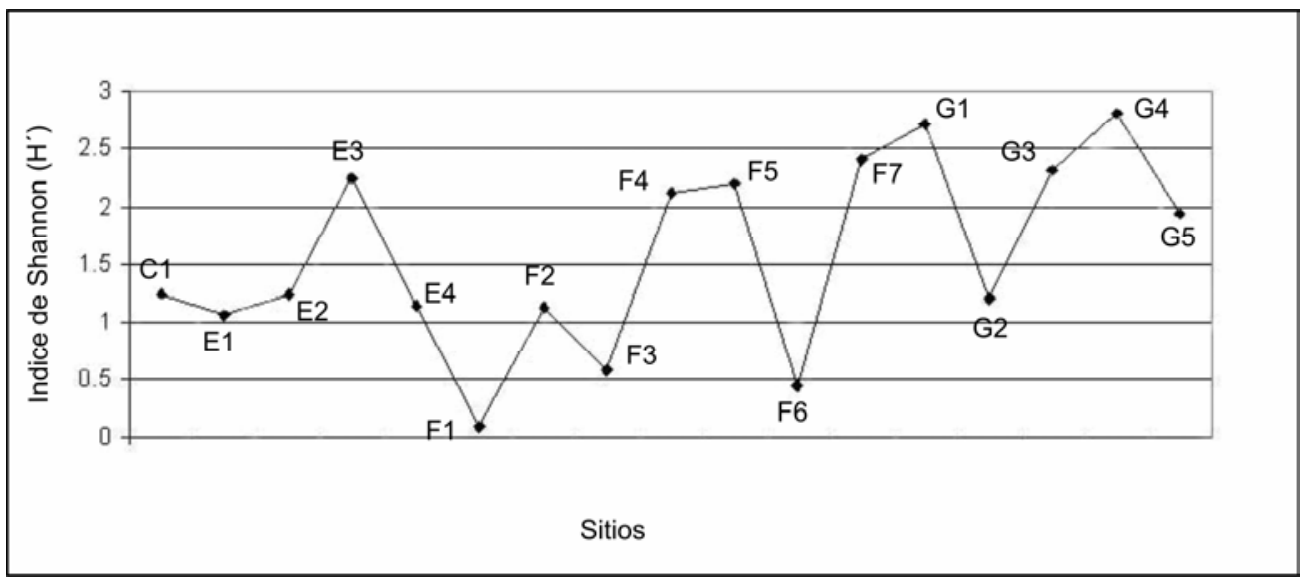

Fig. 6.15: Índice de Shannon ( $\mathrm{H}^{\prime}$ ) de cada sitio de la región del delta del río Colorado.

\begin{tabular}{|c|c|c|}
\hline $\begin{array}{c}\text { № de sitio } \\
\text { C1 }\end{array}$ & $\begin{array}{c}\text { Índice de Shannon } \\
\left(\mathbf{H}^{\prime} \mathbf{)}\right.\end{array}$ & № de especies \\
\hline E1 & 1.24 & 4 \\
\hline E2 & 1.06 & 4 \\
\hline E3 & 2.25 & 17 \\
\hline E4 & 1.14 & 5 \\
\hline F1 & 0.10 & 6 \\
\hline F2 & 1.12 & 9 \\
\hline F3 & 0.58 & 20 \\
\hline F4 & 2.12 & 14 \\
\hline F5 & 2.20 & 11 \\
\hline F6 & 0.44 & 19 \\
\hline F7 & 2.40 & 4 \\
\hline
\end{tabular}




\begin{tabular}{|c|c|c|}
\hline G1 & 2.72 & 30 \\
\hline G2 & 1.21 & 4 \\
\hline G3 & 2.32 & 27 \\
\hline G4 & 2.81 & 23 \\
\hline G5 & 1.94 & 10 \\
\hline
\end{tabular}

T.6.4: Tabla de índices de diversidad $\left(\mathrm{H}^{\prime}\right)$ y número de especies en cada sitio analizado en la región del delta del río Colorado.

\subsubsection{Pleistoceno del delta del río Colorado}

En los depósitos del Pleistoceno del delta del río Colorado se analizaron 5 sitios en total, pertenecientes al Interglacial $\geq$ MIS 9 (C1) y al Interglacial MIS 5e (E1 - E4).

En el pleistoceno perteneciente al Interglacial $\geq$ MIS 9 (C1) se encuentra representado por un cordón litoral y se caracteriza por la presencia de Pitar rostratus y Corbula patagonica (bivalvos) y dos géneros de gasterópodos Crepidula y Buccinanops.

Los depósitos pleistocenos correspondientes al Interglacial MIS 5e (E1 - E4), representan en su mayoría cordones litorales de ambientes de alta energía, a excepción del sitio E3. Se registró un total de 18 especies (12 bivalvos y 6 gasterópodos). Entre la fauna marina se destaca la abundancia de Glycymeris longior, Pitar rostratus (bivalvos) y Tegula patagonica, Bostrycapulus odites y Buccinanops globulosus (gasterópodos) con presencia de Tagelus plebeius (bivalvo) y Heleobia australis (gasterópodo).

\subsubsection{Holoceno del delta del río Colorado}

Los depósitos marinos que representan al MIS 1, registraron un total de 37 especies (17 bivalvos y 20 gasterópodos) en 7 sitios analizados (F1 - F7), en su mayoría representados por planicies de mareas a excepción de los sitios F2 y F5. Entre la fauna marina se destacan en abundancia: Corbula patagonica (bivalvo) y Heleobia australis (gasterópodo) como también la abundancia de Pitar rostratus (bivalvo) y Buccinanops 
globulosus (gasterópodo). Entre las especies la presencia de Tagelus plebeius es abundante en los sitios F6 y F7.

El sitio F6, se destaca particularmente la presencia del microgasterópodo Turbonilla argentina (moluscos de <10mm). Farinati (1978) encontró esta misma especie utilizando la sinonimia Eulimella argentina en depósitos marinos perteneciente a Ingeniero White en bahía Blanca (38 46’S, sur de la Provincia del Sur). Este hallazgo es el primer registro holoceno de la especie en la latitud $39^{\circ} 51^{\prime} \mathrm{S}$ (sur de la Provincia de Buenos Aires), no descripta en la lista sistemática de los trabajos de Weiler (1984, 2000) en el área.

Los sitios F2 y F5, representan a cordones litorales y entre la fauna marina se registran especies como: Amiantis purpurata (bivalvo) y solo en el sitio F5 se destaca la abundancia de Mesodesma mactroides (bivalvo). En ambos depósitos la presencia de Tagelus plebeius (bivalvo) y Heleobia australis (gasterópodo) es característica.

\subsubsection{Playas actuales del delta del río Colorado}

En las playas actuales se registró un total de 42 especies (26 bivalvos y 16 gasterópodos) de 5 sitios analizados (G1 - G5), correspondientes a playas arenosas. Entre la fauna marina se destaca en abundancia Ostreola equestris, Ostrea puelchana, Raeta plicatella, Mesodesma mactroides, Solen tehuelchus, Cyrtopleura lanceolata y Barnea lamellosa (bivalvos) como la asociación Pitar rostratus y Amiantis purpurata y Heleobia australis, Crepidula y Notocochlis isabelleana (gasterópodos) (Fig. 6.16 y Fig. 6.17) 
Bivalvos pleistocenos (E)

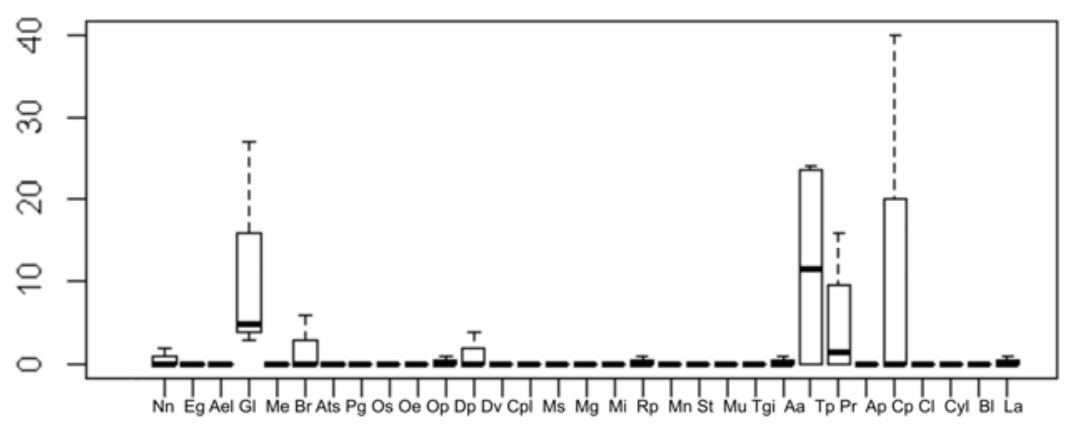

Bivalvos holocenos (F)

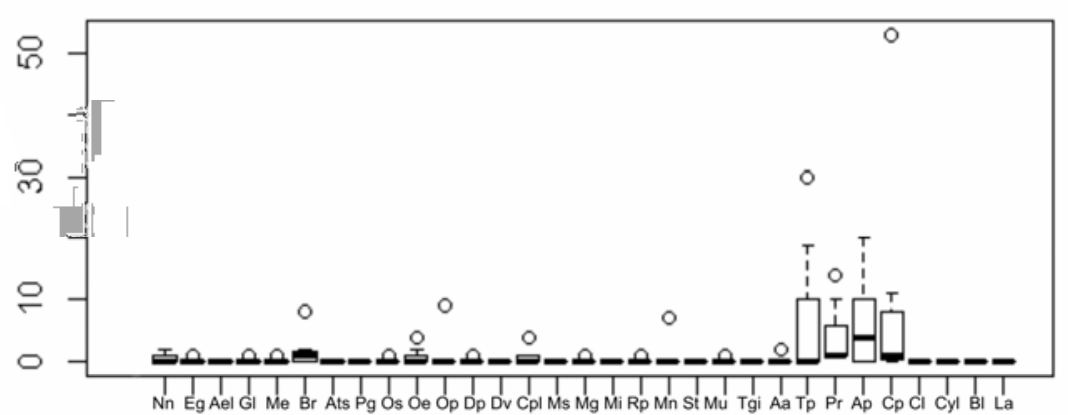

Bivalvos actuales (G)

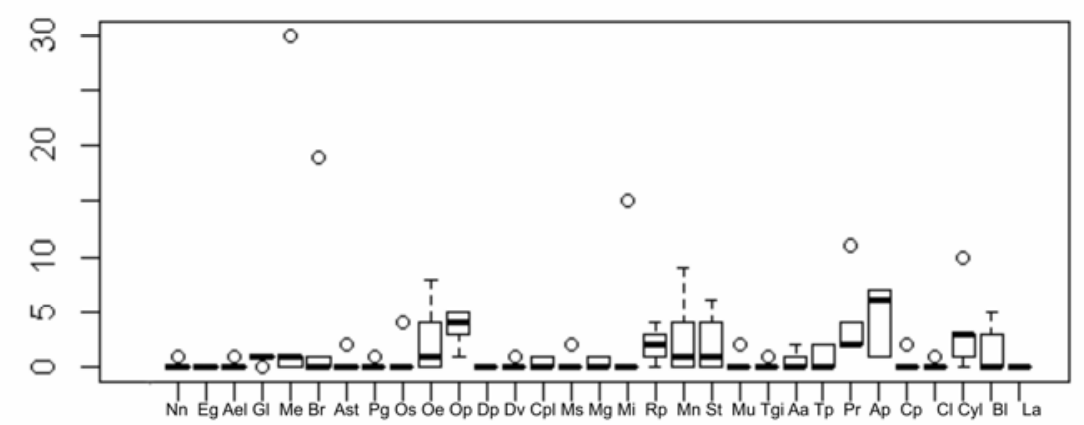

Fig.6.16: Abundancias de bivalvos cuaternarios de la región del río Colorado. 


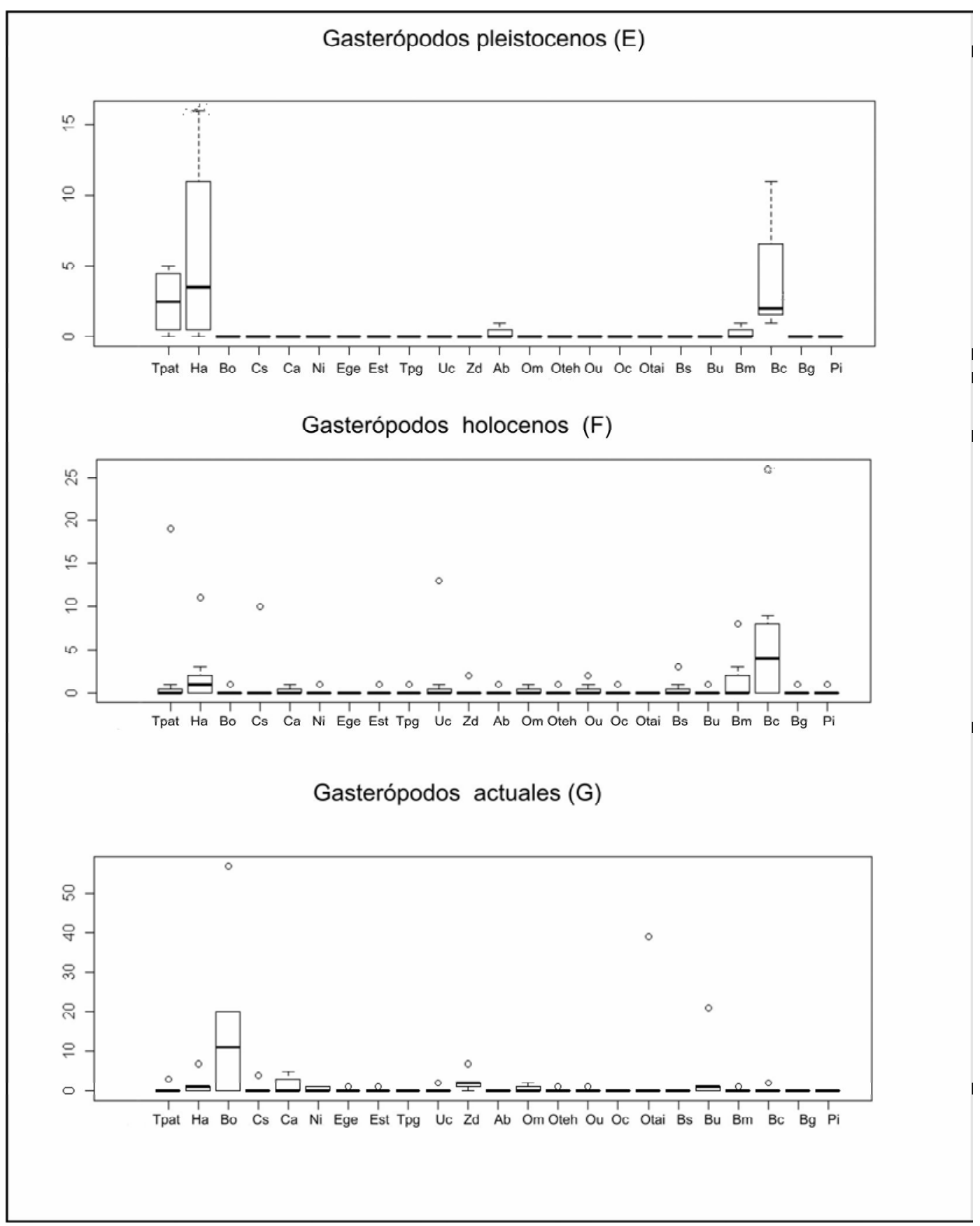

Fig. 6.17: Abundancias de gasterópodos cuaternarios de la región del río Colorado.

\subsection{Paleoecología}

Según la composición faunísticas, entre bivalvos y gasterópodos, predominan las especies marinas sobre las estuariales (ej. Heleobia australis) (T. 6.5 y T. 6.6). 
En el pleistoceno más antiguo(C), perteneciente al Interglacial $\geq$ MIS 9, todas las especies de bivalvos representados son eurihalinas, infaunales de sedimentos arenosos y filtradoras. Entre los gasterópodos, todas las especies son eurihalinas y epifaunales, de sustratos arenosos como rocosos y filtradoras como carnívoras.

En los depósitos pleistocenos (E), perteneciente al Interglacial MIS 5e, la mayoría de los bivalvos son eurihalinos y polihalinos-eurihalinos, infaunales con presencia de especies epifaunales y cementadas. Habitan en sustratos arenosos, con la presencia de especies de sustrato rocoso, son filtradoras, apareciendo especies detritívoras como carnívoras. En el Holoceno aumentan las especies eurihalinas y hay un leve aumento de las especies cementadas y detritívoras con respecto al Interglacial MIS 5e. En la actualidad, hay un aumento de especies de sustrato rocoso (Fig. 6.18).

Durante el Pleistoceno (E), la mayoría de las especies de gasterópodos son eurihalinos aumentando la proporción de especies oligohalinas - polihalinas- mesohalinas. Todas las especies son epifaunales, de sustratos arenosos como rocosos, apareciendo además especies de sustratos mixtos. La mayoría de las especies son carnívoras, con presencia de especies herbívoras y filtradoras. Durante el Holoceno aparecen especies ectoparásitas e infaunales, aumentando las especies de sustratos arenosos y carnívoros. En la actualidad, no hay registros de especies ectoparásitas, y hay un aumento de las especies que viven en sedimentos mixtos y especies herbívoras (Fig. 6.19). 


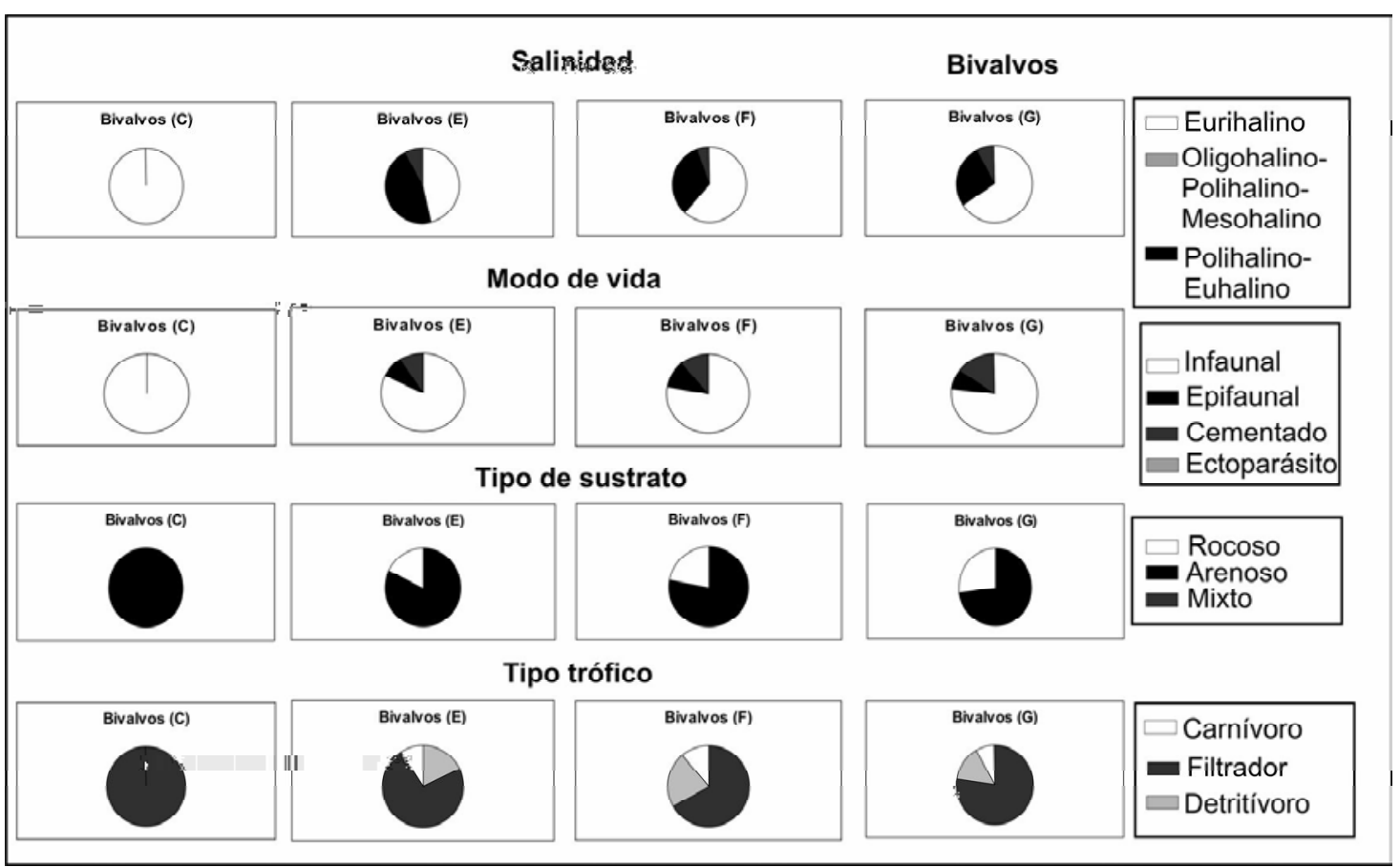

Fig.6.18: Proporción de bivalvos según la salinidad, modo de vida, tipo de sustrato y tipo trófico.

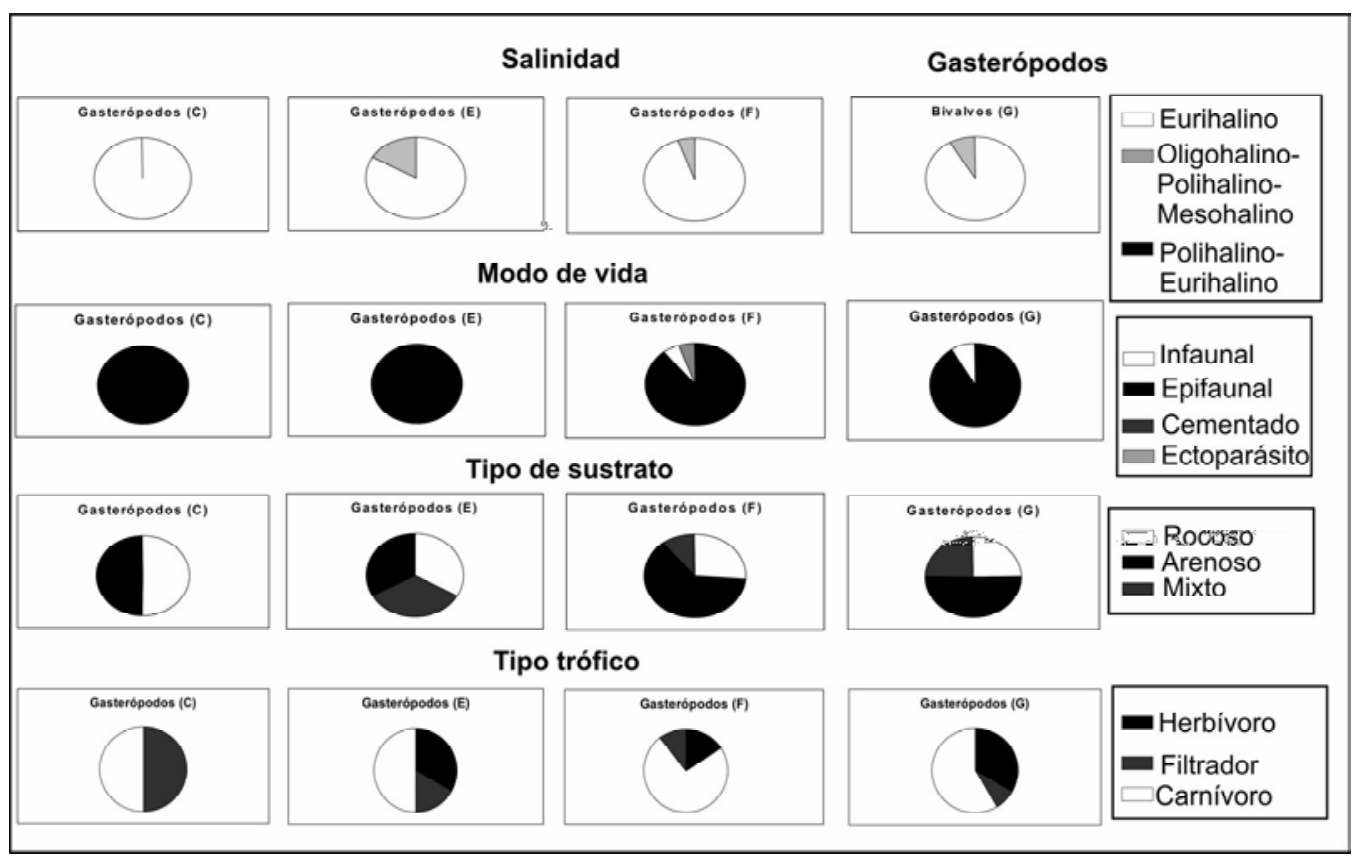

Fig. 6.19: Proporción de gasterópodos según la salinidad, modo de vida, tipo de sustrato y tipo trófico. 


\begin{tabular}{|c|c|c|c|c|c|c|}
\hline BIVALVOS & Salinidad & $\begin{array}{c}\text { Tipo } \\
\text { de } \\
\text { vida }\end{array}$ & $\begin{array}{l}\text { Profundidad } \\
(\mathrm{m})\end{array}$ & Sustrato & $\begin{array}{l}\text { Tipo } \\
\text { trófico }\end{array}$ & Área de distribución \\
\hline Nucula (N.) nucleus ( Linné, 1758) & $E$ & 1 & $0-200$ & $\mathrm{~S}$ & $\mathrm{D}$ & $23^{\circ} \mathrm{S}-53.5^{\circ} \mathrm{S}$ \\
\hline Ennucula grayi (d'Orbigny, 1846) & $E$ & 1 & $5-1850$ & $\mathrm{~S}$ & $\mathrm{D}$ & $22.93^{\circ} \mathrm{S}-55.5^{\circ} \mathrm{S}$ \\
\hline Adrana electa (A. Adams, 1856) & $\mathrm{E}$ & $\mathrm{I}$ & $20-75$ & $\mathrm{~S}$ & $\mathrm{D}$ & $22.93^{\circ} \mathrm{S}-39^{\circ} \mathrm{S}^{*}$ \\
\hline Glycymeris (G.) longior ( Sowerby, 1832) & $\mathrm{E}$ & $\mathrm{I}$ & $10-75$ & $\mathrm{~S}$ & $\mathrm{~F}$ & $10^{\circ} \mathrm{S}-42^{\circ} \mathrm{S}$ \\
\hline Mytilus edulis platensis d'Orbigny, 1846 & $\mathrm{P}-\mathrm{E}$ & Ep & $0-50$ & $\mathrm{R}$ & $\mathrm{F}$ & $68^{\circ} \mathrm{N}-55.5^{\circ} \mathrm{S}$ \\
\hline Brachidontes (B.) rodriguezii ( d'Orbigny, 1846) & $\mathrm{P}-\mathrm{E}$ & Ep & $0-25$ & $\mathrm{R}$ & $\mathrm{F}$ & $34^{\circ} \mathrm{S}-42^{\circ} \mathrm{S}$ \\
\hline Atrina seminuda (Lamarck, 1819) & P-E & $\mathrm{Ce}$ & $0-3$ & $\mathrm{R}$ & $\mathrm{F}$ & $35^{\circ} \mathrm{N}-35^{\circ} \mathrm{S}^{*}$ \\
\hline Plicatula gibbosa Lamarck, 1801 & $E$ & $\mathrm{Ce}$ & $0-120$ & $\mathrm{R}$ & $\mathrm{F}$ & $35.3^{\circ} \mathrm{N}-34^{\circ} \mathrm{S}^{*}$ \\
\hline Ostreola equestris (Say, 1834) & $\mathrm{P}-\mathrm{E}$ & $\mathrm{Ce}$ & $0-80$ & $\mathrm{R}$ & $\mathrm{C}$ & $37^{\circ} \mathrm{N}-42^{\circ} \mathrm{S}$ \\
\hline Ostrea puelchana d'Orbigny 1841 & P-E & $\mathrm{Ce}$ & $0-70$ & $\mathrm{R}$ & C & $22^{\circ} \mathrm{S}-42^{\circ} \mathrm{S}$ \\
\hline Diplodonta (D.) patagonica ( d'Orbigny, 1842) & $\mathrm{E}$ & $\mathrm{I}$ & $36-102$ & $\mathrm{~S}$ & $\mathrm{~F}$ & $21^{\circ} \mathrm{S}-42.58^{\circ} \mathrm{S}$ \\
\hline Diplodonta (F.) vilardeboana ( d'Orbigny, 1846) & $E$ & $\mathrm{I}$ & $25-77$ & $\mathrm{~S}$ & $\mathrm{~F}$ & $21^{\circ} \mathrm{S}-42^{\circ} \mathrm{S}$ \\
\hline Carditamera plata (Ihering, 1907) & $\mathrm{E}$ & $\mathrm{I}$ & $17-70$ & $\mathrm{~S}$ & $\mathrm{~F}$ & $23^{\circ} \mathrm{S}-39^{\circ} \mathrm{S}^{*}$ \\
\hline Mactra guidoi Signorelli \&Scarabino, 2010 & $\mathrm{P}-\mathrm{E}$ & $\mathrm{I}$ & $0-25$ & $\mathrm{~S}$ & $\mathrm{~F}$ & $34^{\circ} \mathrm{S}-42^{\circ} \mathrm{S}$ \\
\hline Mactra isabelleana d'Orbigny, 1846 & P-E & 1 & $0-25$ & $\mathrm{~S}$ & $\mathrm{~F}$ & $23^{\circ} \mathrm{S}-42^{\circ} \mathrm{S}$ \\
\hline Raeta (R.) plicatella (Lamarck,1818) & $\mathrm{P}-\mathrm{E}$ & $\mathrm{I}$ & $0-11$ & $\mathrm{~S}$ & $\mathrm{~F}$ & $39^{\circ} \mathrm{N}-41^{\circ} \mathrm{S}$ \\
\hline Mesodesma mactroides (Reeve, 1854) & $\mathrm{E}$ & $\mathrm{I}$ & $0-20$ & $\mathrm{~S}$ & $\mathrm{~F}$ & $23^{\circ} \mathrm{S}-41^{\circ} \mathrm{S}$ \\
\hline Solen tehuelchus (Hanley, 1842) & $\mathrm{E}$ & $\mathrm{I}$ & $10-18$ & $\mathrm{~S}$ & $\mathrm{~F}$ & $23^{\circ} \mathrm{S}-39^{\circ} \mathrm{S}^{*}$ \\
\hline Macoma (P.) uruguayensis (Smith, 1885) & $E$ & $\mathrm{I}$ & $18-70$ & $\mathrm{~S}$ & $\mathrm{D}$ & $29^{\circ} \mathrm{S}-39^{\circ} \mathrm{S}^{*}$ \\
\hline Abra (A.) aequalis (Say, 1822) & $E$ & I & $0-50$ & $\mathrm{~S}$ & $\mathrm{D}$ & $35^{\circ} \mathrm{N}-23^{\circ} \mathrm{S}^{*}$ \\
\hline Tagelus (T.) plebeius (Ligthfood,1786) & $\mathrm{P}$ & $\mathrm{I}$ & $0-10$ & $\mathrm{~S}$ & $\mathrm{~F}$ & $42^{\circ} \mathrm{N}-54^{\circ} \mathrm{S}$ \\
\hline Pitar (P.) rostratus (Philippi, 1844) & $\mathrm{E}$ & $\mathrm{I}$ & $10-100$ & $\mathrm{~S}$ & $\mathrm{~F}$ & $22^{\circ} \mathrm{S}-38.7^{\circ} \mathrm{S}^{*}$ \\
\hline Amiantis purpurata ( Lamarck, 1856) & $\mathrm{E}$ & $\mathrm{I}$ & $0-20$ & $\mathrm{~S}$ & $\mathrm{~F}$ & $19^{\circ} \mathrm{S}-43^{\circ} \mathrm{S}$ \\
\hline Corbula (C.) patagonica d'Orbigny, 1846 & $E$ & $\mathrm{I}$ & $15-90$ & $\mathrm{~S}$ & $\mathrm{~F}$ & $23^{\circ} \mathrm{S}-43^{\circ} \mathrm{S}$ \\
\hline Corbula (C.) Iyoni Pilsbry, 1897 & $E$ & $\mathrm{I}$ & $11-67$ & $\mathrm{~S}$ & $\mathrm{~F}$ & $19^{\circ} \mathrm{S}-43^{\circ} \mathrm{S}$ \\
\hline Cyrtopleura (S.) lanceolata (d'Orbigny, 1846) & $E$ & $\mathrm{I}$ & $10-27$ & $\mathrm{~S}$ & $\mathrm{~F}$ & $6 \div S-42^{\circ} S$ \\
\hline Barnea lamellosa ( d'Orbigny, 1846) & $\mathrm{E}$ & I & $15-150$ & $\mathrm{R}$ & $\mathrm{F}$ & $34^{\circ} \mathrm{S}-43^{\circ} \mathrm{S}$ \\
\hline Lyonsia (L.)alvarezii d'Orbigny, 1846 & $E$ & $\mathrm{I}$ & $50-86$ & $\mathrm{~S}$ & $\mathrm{~F}$ & $38.3^{\circ} \mathrm{S}-41^{\circ} \mathrm{S}$ \\
\hline Periploma ovatum d'Orbigny, 1846 & $E$ & $\mathrm{I}$ & $?$ & $\mathrm{~S}$ & $\mathrm{~F}$ & $35^{\circ} S-40.5^{\circ} S$ \\
\hline
\end{tabular}

T. 6.5: Requerimientos ecológicos y distribución de bivalvos: $\mathrm{Ep}=$ epifaunal, $\mathrm{I}=$ infaunal, Ec=ectoparásito, $\mathrm{Ce}=$ cementado; $\mathrm{R}=$ rocoso, $\mathrm{S}=$ arenoso; $\mathrm{C}=$ carnívoro,

$\mathrm{D}=$ detritívoro, $\mathrm{He}=$ herbívoro, $\mathrm{F}=$ filtrador; $\mathrm{O}=$ oligohalino $(3-8 \%$ \%), $\mathrm{M}=$ mesohalino $(8-18 \%$ ); $\mathrm{P}=$ polihalino (18-30\%o); E= eurihalino (> 30-35\%o).* Límite sur de la especie diferente a lo encontrado. 


\begin{tabular}{|c|c|c|c|c|c|c|}
\hline GASTERÓPODOS & Salinidad & $\begin{array}{c}\text { Modo } \\
\text { de } \\
\text { vida }\end{array}$ & Profundidad & Sustrato & $\begin{array}{l}\text { Tipo } \\
\text { trófico }\end{array}$ & $\begin{array}{c}\text { Area de } \\
\text { distribución }\end{array}$ \\
\hline Tegula (A.) patagonica (d'Orbigny, 1835) & $\mathrm{E}$ & Ep & $0-57$ & $\mathrm{R}$ & $\mathrm{He}$ & $23^{\circ} \mathrm{S}-54^{\circ} \mathrm{S}$ \\
\hline Bostrycapulus odites (Collin, 2005) & $\mathrm{E}$ & Ep & $0-46$ & $\mathrm{R}$ & $\mathrm{F}$ & $25^{\circ} \mathrm{S}-45.8^{\circ} \mathrm{S}$ \\
\hline $\begin{array}{l}\text { Crepidula argentina Simone, Pastorino \& } \\
\text { Penchaszadeh, } 2000\end{array}$ & $\mathrm{E}$ & Ep & $30-50$ & $\mathrm{R}$ & $\mathrm{F}$ & $38^{\circ} \mathrm{S}-41.03^{\circ} \mathrm{S}$ \\
\hline Notocochlis isabelleana (d'Orbigny, 1840) & $\mathrm{E}$ & 1 & $0-113$ & $\mathrm{~S}$ & $\mathrm{C}$ & $22.4^{\circ} \mathrm{S}-42.58^{\circ} \mathrm{S}$ \\
\hline Heleobia australis ( d'Orbigny, 1835) & $\mathrm{O}, \mathrm{P}, \mathrm{M}$ & Ep & $0-60$ & $\mathrm{M}$ & $\mathrm{He}$ & $24^{\circ} \mathrm{S}-41^{\circ} \mathrm{S}$ \\
\hline Epitonium (E.) georgettinum (Kiener, 1838) & $E$ & Ep & $0-101$ & M & $\mathrm{C}$ & $23.37^{\circ} \mathrm{S}-44.27^{\circ} \mathrm{S}$ \\
\hline Epitonium striatellum (Nyst, 1871) & $\mathrm{E}$ & Ep & 30 & M & C & $23^{\circ} S-41^{\circ} \mathrm{S}$ \\
\hline Trophon patagonicus (d'Orbigny, 1839) & $E$ & $\mathrm{Ep}$ & $0-50$ & $\mathrm{R}$ & $\mathrm{C}$ & $32^{\circ} \mathrm{S}-40^{\circ} \mathrm{S}$ \\
\hline Urosalpinx cala (Pilsbry, 1897) & $\mathrm{E}$ & Ep & $28-28$ & $\mathrm{R}$ & C & $32^{\circ} \mathrm{S}-41^{\circ} \mathrm{S}$ \\
\hline Zidona dufresnei ( Donovan, 1823) & $\mathrm{E}$ & Ep & $10-90$ & $\mathrm{~S}$ & C & $23^{\circ} \mathrm{S}-42^{\circ} \mathrm{S}$ \\
\hline Adelomelon (P.) brasiliana (Lamarck, 1811) & $\mathrm{E}$ & Ep & $0-250$ & $\mathrm{~S}$ & $\mathrm{C}$ & $23^{\circ} \mathrm{S}-52^{\circ} \mathrm{S}$ \\
\hline Odontocymbiola magellanica (Gmelin, 1791) & $E$ & Ep & $10-200$ & M & $\mathrm{C}$ & $35^{\circ} \mathrm{S}-55.2^{\circ} \mathrm{S}$ \\
\hline Olivella (O.) tehuelcha ( Dúclos, 1835) & $E$ & Ep & $15-57$ & $\mathrm{~S}$ & $\mathrm{C}$ & $23.69^{\circ} \mathrm{S}-43^{\circ} \mathrm{S}$ \\
\hline Olivancillaria urceus ( Röding, 1798) & $E$ & Ep & $5-50$ & $\mathrm{~S}$ & $\mathrm{C}$ & $19^{\circ} \mathrm{S}-42^{\circ} \mathrm{S}$ \\
\hline Olivancillaria carcellesi Klappenbach, 1965 & $E$ & Ep & $0-22$ & $\mathrm{~S}$ & $\mathrm{C}$ & $23^{\circ} \mathrm{S}-42.5^{\circ} \mathrm{S}$ \\
\hline Olivancillaria uretai Klappenbach, 1965 & $E$ & Ep & $0-30$ & $\mathrm{~S}$ & $\mathrm{C}$ & $23^{\circ} \mathrm{S}-40.6^{\circ} \mathrm{S}$ \\
\hline Buccinanops monilifer ( Kiener, 1834) & $\mathrm{E}$ & Ep & $0-50$ & $\mathrm{~S}$ & C & $35^{\circ} \mathrm{N}-42^{\circ} \mathrm{S}$ \\
\hline Buccinanops cochlidium (Dilwyn, 1817) & $\mathrm{E}$ & Ep & $5-66$ & $\mathrm{~S}$ & $\mathrm{C}$ & $23^{\circ} \mathrm{S}-42.58^{\circ} \mathrm{S}$ \\
\hline Buccinanops globulosus (Kiener, 1834) & $E$ & Ep & $0-6$ & $\mathrm{~S}$ & $\mathrm{C}$ & $35^{\circ} \mathrm{S}-46^{\circ} \mathrm{S}$ \\
\hline Buccinanops uruguayensis (Pilsbry,1897) & $E$ & Ep & $15-45$ & $\mathrm{~S}$ & $\mathrm{C}$ & $24^{\circ} \mathrm{S}-42^{\circ} \mathrm{S}$ \\
\hline Parvanachis isabellei (d'Orbigny, 1839) & $E$ & Ep & $10-65$ & $\mathrm{~S}$ & $\mathrm{C}$ & $30^{\circ} \mathrm{S}-54^{\circ} \mathrm{S}$ \\
\hline Turbonilla argentina (Doello-Jurado, 1938) & $\mathrm{E}$ & Ec & $18-57$ & $\mathrm{~S}$ & C & $35^{\circ} \mathrm{S}-41^{\circ} \mathrm{S}$ \\
\hline
\end{tabular}

T. 6.6:Requerimientos ecológicos y distribución de gasterópodos: Ep= epifaunal, I=infaunal, Ec=ectoparásito, Ce=cementado; $\mathrm{R}=$ rocoso, $\mathrm{S}=$ arenoso, $\mathrm{M}=$ mixto,;

$\mathrm{C}=$ carnívoro, $\mathrm{D}=$ detritívoro, $\mathrm{He}=$ herbívoro, $\mathrm{F}=$ filtrador; $\mathrm{O}=$ oligohalino (3-8 \%o), $\mathrm{M}=$ mesohalino (8-18 \%o); $\mathrm{P}=$ polihalino (18-30 \%o); E= eurihalino (> 30-35 \%o). 


\subsection{Temperaturas}

Respecto a los bivalvos y según la cantidad de especies de aguas cálidas y aguas no cálidas representadas en cada uno de los interglaciales, desde el Interglacial $\geq$ MIS 9 (C) hay un $50 \%$ de especies que son cálidas manteniéndose constante hasta el Interglacial MIS 1 (F) disminuyendo un $4 \%$ en la actualidad (G) (Fig.6.20). Con respecto a los gasterópodos, las especies de aguas cálidasdurante el Interglacial $\geq$ MIS 9 representan un 50\%. A partir del Interglacial MIS 5e (E) hay un $67 \%$ de especies de aguas cálidasde gasterópodos aumentando un $7 \%$ en el Interglacial MIS 1 (F) y un $9 \%$ más en la actualidad (G) (Fig. 6.21).

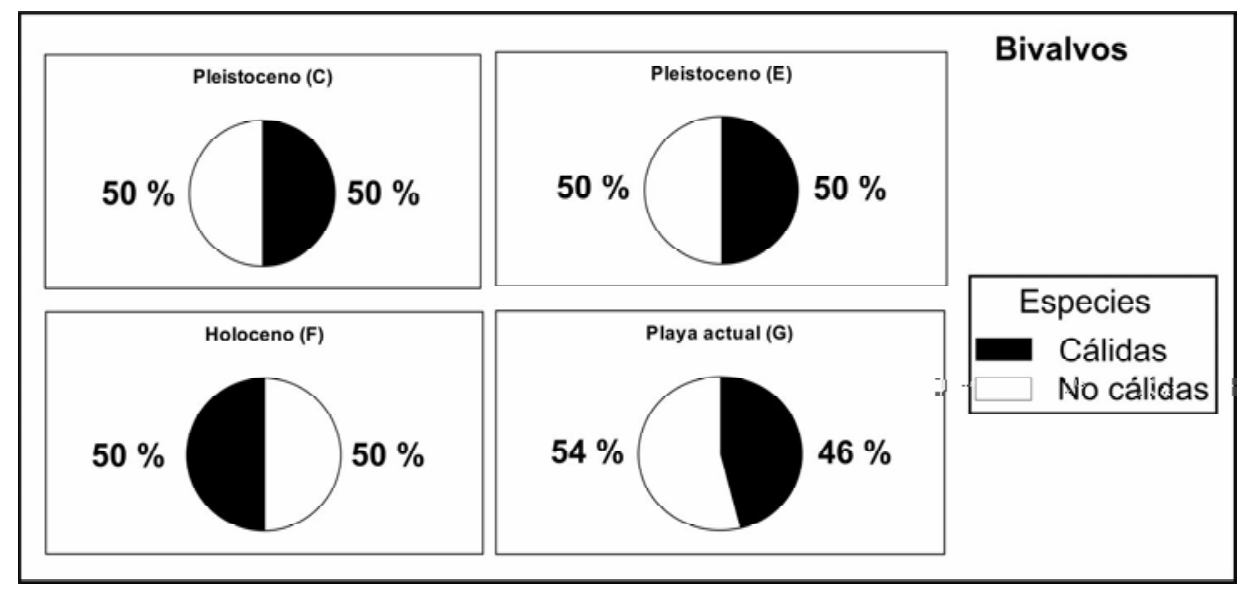

Fig. 6.20: Proporción de especies de bivalvos de aguas cálidas y no cálidas durante el

Cuaternario.

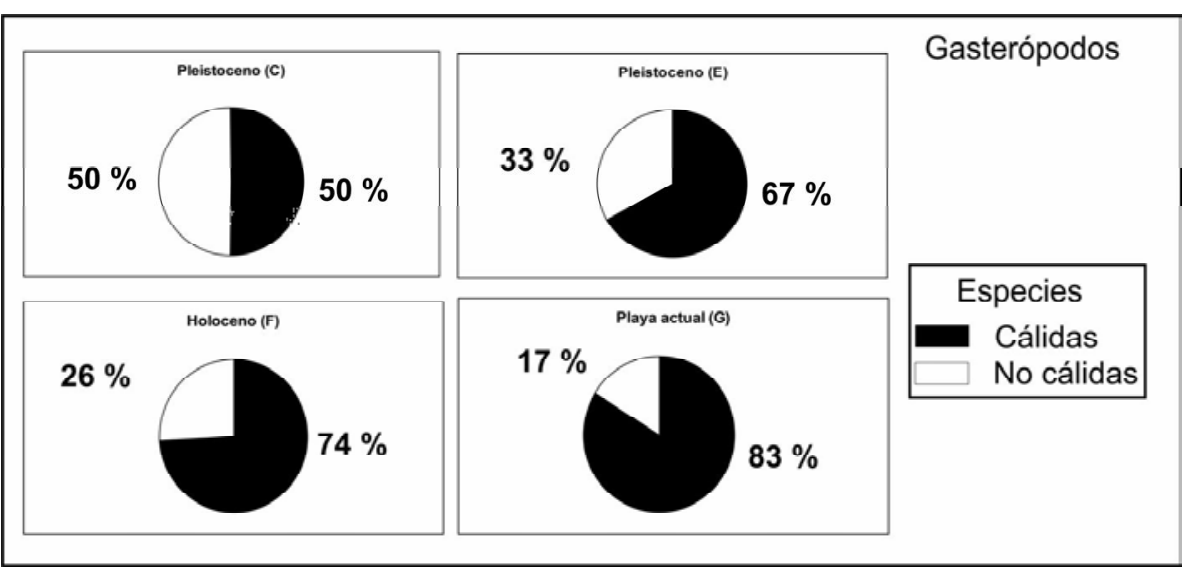


Fig. 6.21: Proporción de especies de gasteropodos de aguas cálidas y no cálidas durante el Cuaternario.

\subsection{Asociaciones faunísticas}

Según el método descriptivo estadístico de Bray - Curtis la fauna marina de la región del delta del río Colorado, se divide en dos grandes grupos: el grupo A corresponde a la asociación faunística perteneciente en su mayoría a sitios actuales y el grupo B a la asociación faunística pertenecientes a sitios pleistocenos y holocenos. El grupo A se divide en dos subgrupos: A1) asociación faunística que corresponden a sitios de playas actuales y A2) asociación faunística que en su mayoría corresponden a sitios de playas actuales a excepción de tres sitios (C1, F2 y F5). El sitio C1 perteneciente al Interglacial $\geq$ MIS 9 y dos sitios F2 y F5 pertenecientes al Interglacial MIS 1. Los sitios (C1, F2 y F5) corresponden a cordones de playas con abundante fauna fósil semejante a los que se encuentran en las playas actuales. Los sitios F2 y F5 se asemejan entre sí por la abundancia de Amiantis purpurata (bivalvo). El grupo B se subdivide a su vez en tres subgrupos: B1) asociación faunística que corresponde al Interglacial MIS 5e que representan cordones litorales B2) asociación faunística correspondiente al Interglacial MIS 1 y representan a planicies de mareas con abundancia de Heleobia australis (gasterópodos).B3) asociación faunística compuesta por dos sitios del Interglacial MIS 5e (E1 y E3) y dos sitios del Interglacial MIS 1 (F4 y F7), siendo el Sitio E3 y el Sitio F7 muy similares entre sí y coincidiendo en la presencia y abundancia de Tagelus plebeius, Pitar rostratus, Corbula patagonica (bivalvos) y Heleobia australis (gasterópodo) (Fig. 6.22). 


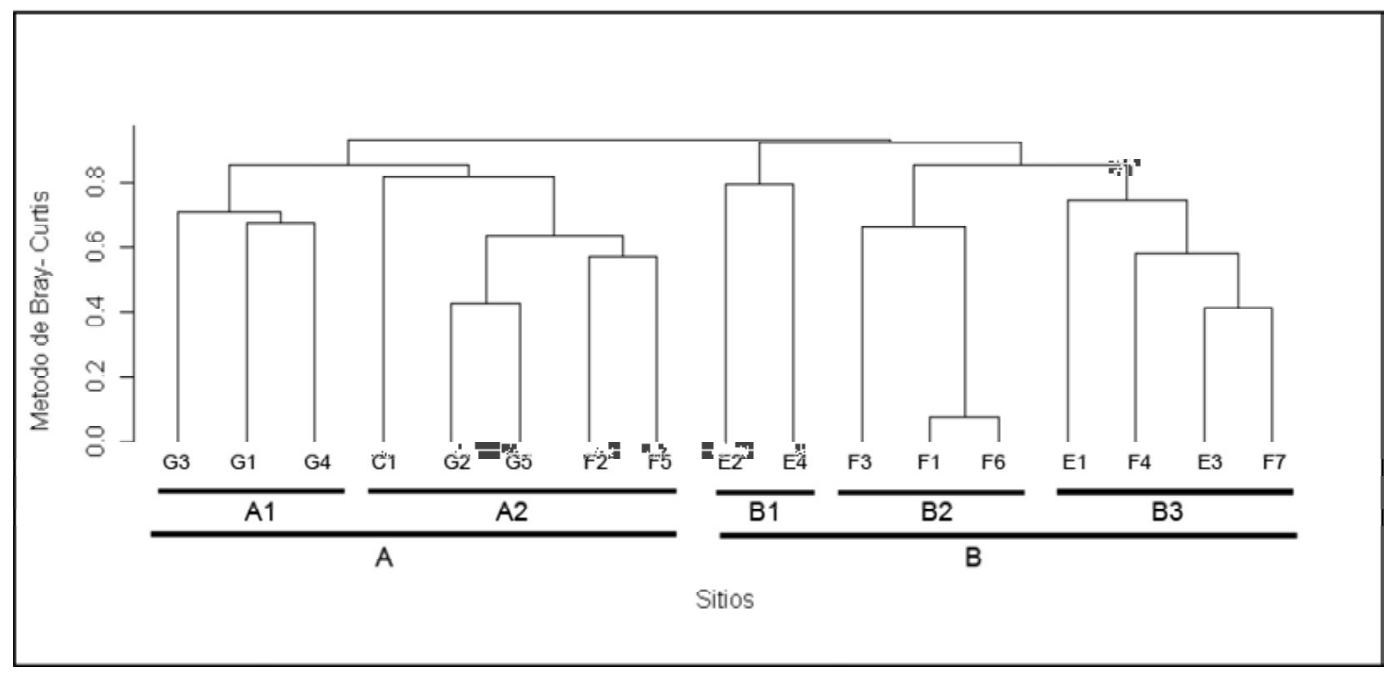

Fig. 6.22: Dendrograma de los sitios analizados, basados en el índice de Bray- Curtis.

Según el método descriptivo de Análisis de Correspondencia (AC), se distinguen 5 asociaciones faunísticas. A) asociación faunística del Interglacial MIS 5e (E2 y E4) que corresponden a cordones litorales con la presencia de Glycymeris longior (bivalvo). B) asociación faunística de dos bivalvos Pitar rostratus y Amiantis purpurata con la presencia de Corbula patagonica, Lyonsia alvarezii y Diplodonta vilardeboana (bivalvos), y Crepidula argentina, Urosalpinx cala, Tegula patagonica, Bostrycapulus odites, Buccinanops globulosus, Buccinanops cochlidium (gasterópodos).C) asociación faunística correspondientes a cordones litorales de arenas y clastos con presencia de Ostrea, Ostreola equestris, Brachidontes rodriguezii y Mactra guidoi (bivalvos) y Buccinanops uruguayensis (gasterópodos). D) asociación faunística del Interglacial MIS 1 (F1, F3, y F6) correspondientes a planicies de mareas, con abundancia de Heleobia australis (gasterópodo). El sitio F3 se caracteriza particularmente por la presencia de dos micromoluscos: Parvanachis isabellei y Turbonilla argentina. E) asociación faunística que corresponde a bermas de playas arenosas actuales (G3 y G4) cercanos entre sí cuya asociación faunística está compuesta por Mesodesma mactroides, Cyrtopleura lanceolata, Barnea lamellosa y Raeta plicatella (bivalvos). En el Sitio G3, se destaca la presencia de Atrina seminuda (bivalvia) y Epitonium striatum (gasterópodo) (Fig. 6.23 y Fig. 6.24). 


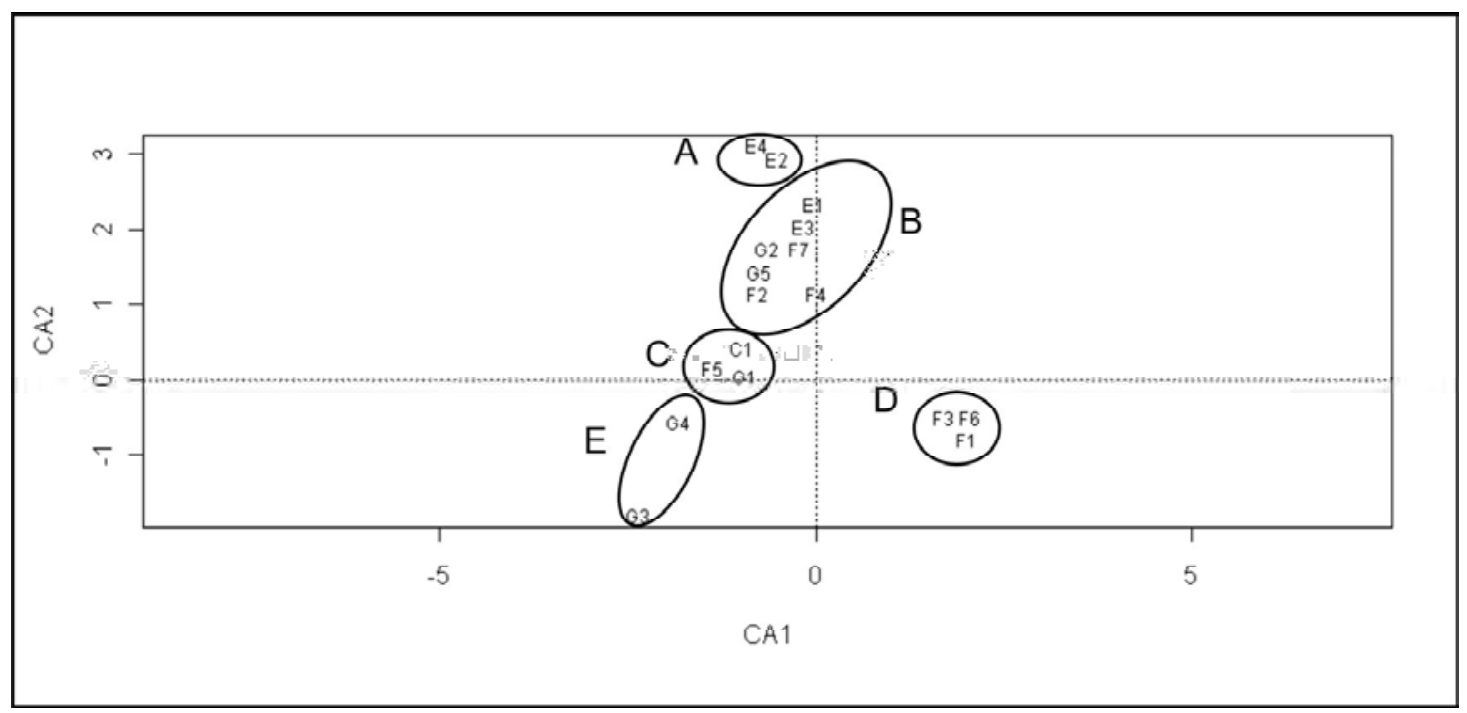

Fig. 6.23: Análisis de Correspondencia (AC) basados en las abundancias de las especies. Todos los sitios conforman cinco grupos A - E.

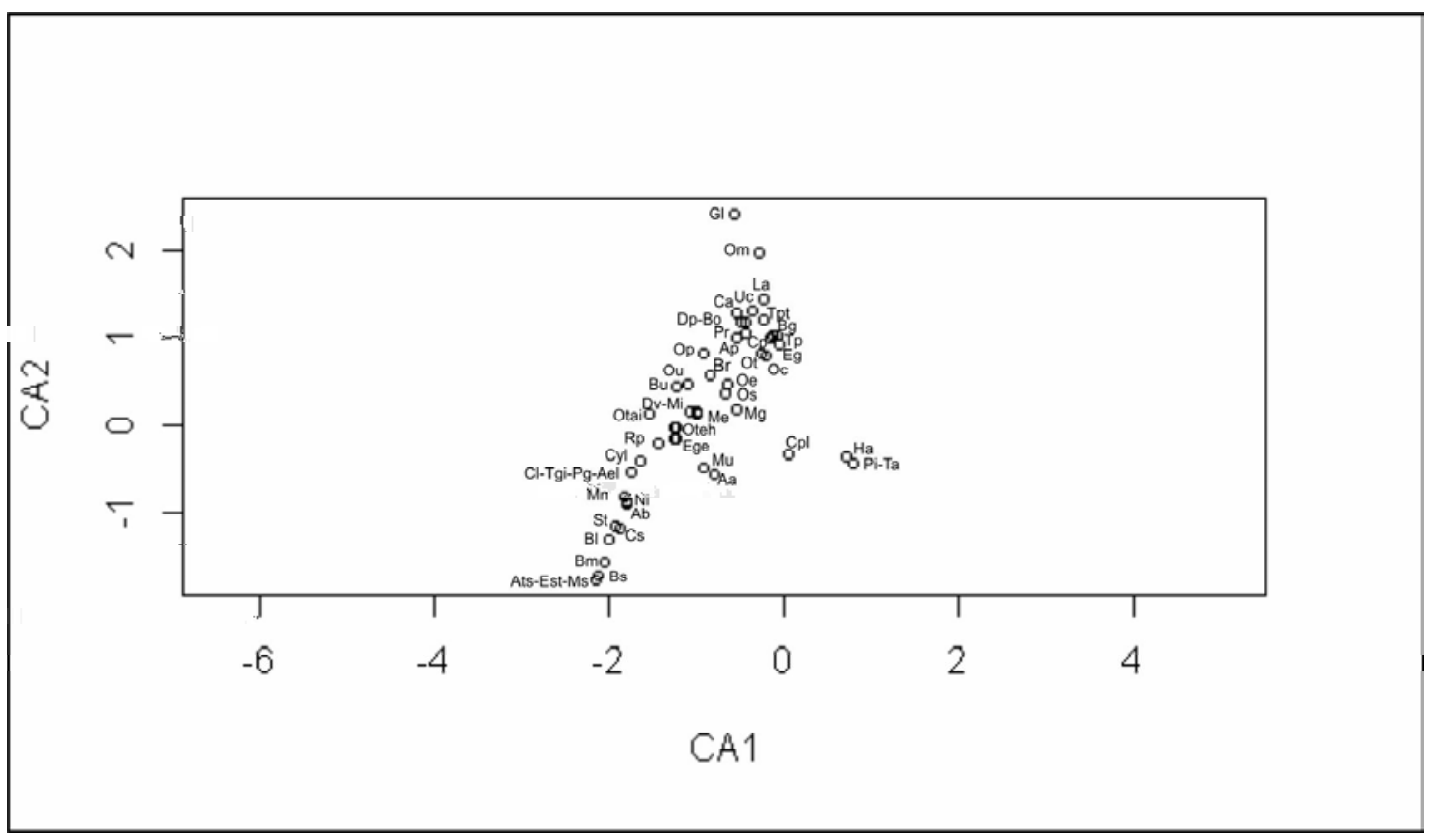

Fig. 6.24: Especies de bivalvos y gasterópodos asociados a los distintos sitios muestreados. 


\subsection{Conclusiones}

En la región del delta del río Colorado, se analizaron 17 sitios (5 pleistocenos, 7 holocenos y 5 actuales) y se registraron un total de 51 especies (29 bivalvos y 22 gasterópodos).

Los índices de diversidad más altos en su mayoría pertenecen a los sitios actuales y los más bajos se encuentran en tres sitios pertenecientes al Interglacial MIS 1. En cuanto a la riqueza en especies, los sitios actuales G1 y G3 son los sitios con mayor cantidad de especies.

El Interglacial $\geq$ MIS 9 se encuentra representado por un cordón litoral. En el mismo se detectaron 2 especies de bivalvos (Pitar rostratus y Corbula patagónica) y 2 géneros de gasterópodos (Buccinanops y Crepidula).

Los depósitos marinos del Interglacial MIS 5e en su mayoría son cordones litorales que representan ambientes de mayor energía. Se registró un total de 18 especies entre gasterópodos y bivalvos. Entre la fauna marina se destaca por la presencia de Glycymeris longior, Pitar rostratus (bivalvos), y Tegula patagonica, Bostrycapulus odites y Buccinanops globulosus (gasterópodos), características de depósitos de alta energía a lo que debe agregarse la presencia sintomática de Tagelus plebeius (bivalvo) y Heleobia australis (gasterópodo), organismos que se desarrollan en ambientes de planicie de marea.

En el Interglacial MIS 1, los depósitos en su mayoría pertenecen a planicies de mareas, ambientes de baja energía, compuestos por 37 especies entre gasterópodos y bivalvos. En la fauna marina se destaca la abundancia de Corbula patagonica (bivalvo) y Heleobia australis (gasterópodo), típicas especies de ambientes de baja energía, como como así también la abundancia de Pitar rostratus (bivalvo) y Buccinanops globulosus (gasterópodo). 
El Interglacial MIS 5e como en el Interglacial MIS 1 tienen en común la presencia y abundancia de Heleobia australis (gasterópodo) y Tagelus plebeius (bivalvo), como fauna típica de ambientes de baja energía, y Glycymeris longior (bivalvo) y Bostrycapulus odites y Buccinanops globulosus (gasterópodos) como especies comunes entre ambos depósitos.

En el Interglacial MIS 1, se destacan dos acontecimientos no descriptos hasta el presente: La presencia de Tagelus plebeius (bivalvo) articulado mostrando la particularidad de encontrarse en posición de vida (Sitios F6 y F7) y la existencia del microgasterópodo Turbonilla argentina, primer registro en el área del delta del río Colorado, sur de la Provincia de Buenos Aires.

Las playas actuales en el área de la región del delta del río Colorado, corresponden en su mayoría a playas arenosas poseyendo un total de 42 especies, entre las cuales se destacan: Ostreola equestris, Ostrea puelchana, Raeta plicatella, Mesodesma mactroides, Solen tehuelchus, Cyrtopleura lanceolata y Barnea lamellosa (bivalvos) y Heleobia australis, Crepidula y Notocochlis isabelleana (gasterópodos) y la asociación de los bivalvos Pitar rostratus - Amiantis purpurata. Por tal razón, las condiciones ecológicas entre la fauna marina holocena con respecto a la actual existe un leve aumento de bivalvos de sustratos arenosos y un aumento en la proporción de gasterópodos de sustratos mixtos y herbívoros.

Los bivalvos y gasterópodos del Interglacial $\geq$ MIS 9, son eurihalinos, en su mayoría de sustratos arenosos, con presencia de gasterópodos asociados a sustratos rocosos, siendo los primeros: infaunales y filtradores, y los segundos: epifaunales, tanto filtradores como carnívoros.

En el Interglacial MIS 5e, la mayoría de los bivalvos son eurihalinos, infaunales y habitan en sustratos arenosos ligados a ambientes rocosos, siendo en su mayoría filtradores, apareciendo especies tanto detritívoras como carnívoras. Los gasterópodos se caracterizan por ser todos epifaunales, de sustratos arenosos, tanto rocosos como mixtos, y en su mayoría son especies eurihalinas y carnívoras. 
Los bivalvos presentes en el Interglacial MIS 1 en comparación con la fauna existente del Interglacial MIS 5e, presenta la siguiente característica: existe un aumento de los bivalvos eurihalinos, cementados y detritívoros mientras que en gasterópodos, aparecen especies ectoparásitas e infaunales, aumentando las especies de sustratos arenosos y carnívoros. Ello implica mayor diversidad de especies producto de la heterogeneidad de ambientes.

Según el análisis paleoecológico entre la fauna marina del Interglacial MIS 1 con respecto al Interglacial MIS 5e existe un leve aumento de bivalvos de sustrato arenosos y un aumento en la proporción de gasterópodos de sustratos mixtos y herbívoros.

Con respecto a la temperatura, desde el Interglacial $\geq$ MIS 9 hasta la actualidad, las especies de gasterópodos presentan un mayor porcentaje de especies de aguas cálidas que los bivalvos. Entre estos últimos en cambio, hay un $50 \%$ de especies de aguas cálidas presentes en el Interglacial $\geq$ MIS 9 que prevalecen hasta el Interglacial MIS 1, disminuyendo en un $4 \%$ en la actualidad.

Según el método descriptivo estadístico de Bray - Curtis, los sitios interglaciales analizados de la región del delta del río Colorado se componen temporalmente de dos asociaciones faunísticas: A) asociación faunística que corresponden a playas actuales y B) asociación faunística que corresponde a sitios pertenecientes a los Interglaciales $\geq$ MIS 9, MIS 5e y MIS 1.

Según el método descriptivo de Análisis de Correspondencia (AC), en la región del delta del río Colorado se distinguen 5 asociaciones faunísticas diferentes: A) asociación faunística del Interglacial MIS 5e que corresponde a cordones litorales con presencia abundante del bivalvo Glycymeris longior. B) asociación faunística de bivalvos Pitar rostratus - Amiantis purpurata. C) asociación faunística de depósitos de cordón litoral de arenas y clastos con presencia de los bivalvos Ostrea., Ostreola equestris, Brachidontes rodriguezii y Mactra guidoi y la especie gasterópoda Buccinanops uruguayensis. D) asociación faunística que corresponde a planicies de marea con 
abundancia en todos los sitios del gasterópodo Heleobia australis. E) asociación faunística que corresponde a sitios actuales de bermas de playa con fauna marina compuesta por los bivalvos Mesodesma mactroides, Cyrtopleura lanceolata, Barnea lamellosa y Raeta plicatella. 


\section{REGIÓN DE BAHÍA ANEGADA}

\subsection{Descripción general de la región}

La región de bahía Anegada, comprende desde isla Otero $\left(39^{\circ} 55^{\prime} \mathrm{S} / 62^{\circ} 08^{\prime} \mathrm{O}\right)$ hasta las inmediaciones de isla Jabalí $\left(40^{\circ} 28^{\prime} \mathrm{S} / 62^{\circ} 11^{\prime} \mathrm{O}\right)$, sur de la provincia de Buenos Aires, compuestos por un conjunto de islas como la islas Otero, Margarita, Gaviota, de Los Riachos, Creek, de los Césares, del sur, Flamenco y Gama.

En el sector continental contiguo a la línea de costa se desarrollan los depósitos transgresivos, representados por una serie de cordones litorales como rasgos geomorfológico más destacable. Los depósitos pleistocenos más antiguos se encuentran representados por depósitos fuertemente entoscados y muy estratificados (Fucks et al., 2012a) con cotas de 15 - 20 m que corresponderían al Interglacial $\geq$ MIS 9. Los depósitos marinos que corresponden al Interglacial MIS 5e, están representados por islas barreras y albuferas, con cotas aproximadas de 5 y $10 \mathrm{~m}$, conformados por gravas clastos sostén y gravas matriz sostén, parcialmente cementados por carbonatos de calcio (ej. Weiler, 1993; Fucks et al., 2012a). Las islas de barreras están formadas por un única cresta y llegan a extenderse a 2 o $3 \mathrm{~km}$ (Weiler, 1993). Contiguo a la línea de costa los cordones litorales más cercanos pertenecientes al MIS 1, se sitúan a cotas del orden de los 4 - $5 \mathrm{~m}$, formando principalmente planicies de mareas y cordones de playa. Estos depósitos se caracterizan por estar compuestos de arenas y gravas con fauna marina fósil y con estatificación entrecruzada de bajo ángulo. Son alargados y se presentan bien individualizados como también adosados unos a otros e inclusive, formando morfologías más amplias con crestas de playa en su superficie. Constituyeron barreras libres creciendo hacia ambos extremos, en el sentido y contrario a la deriva, influenciados probablemente por los fuertes vientos del NNE (Cuadrado y Gómez, 2010) (Fig. 7.1). 


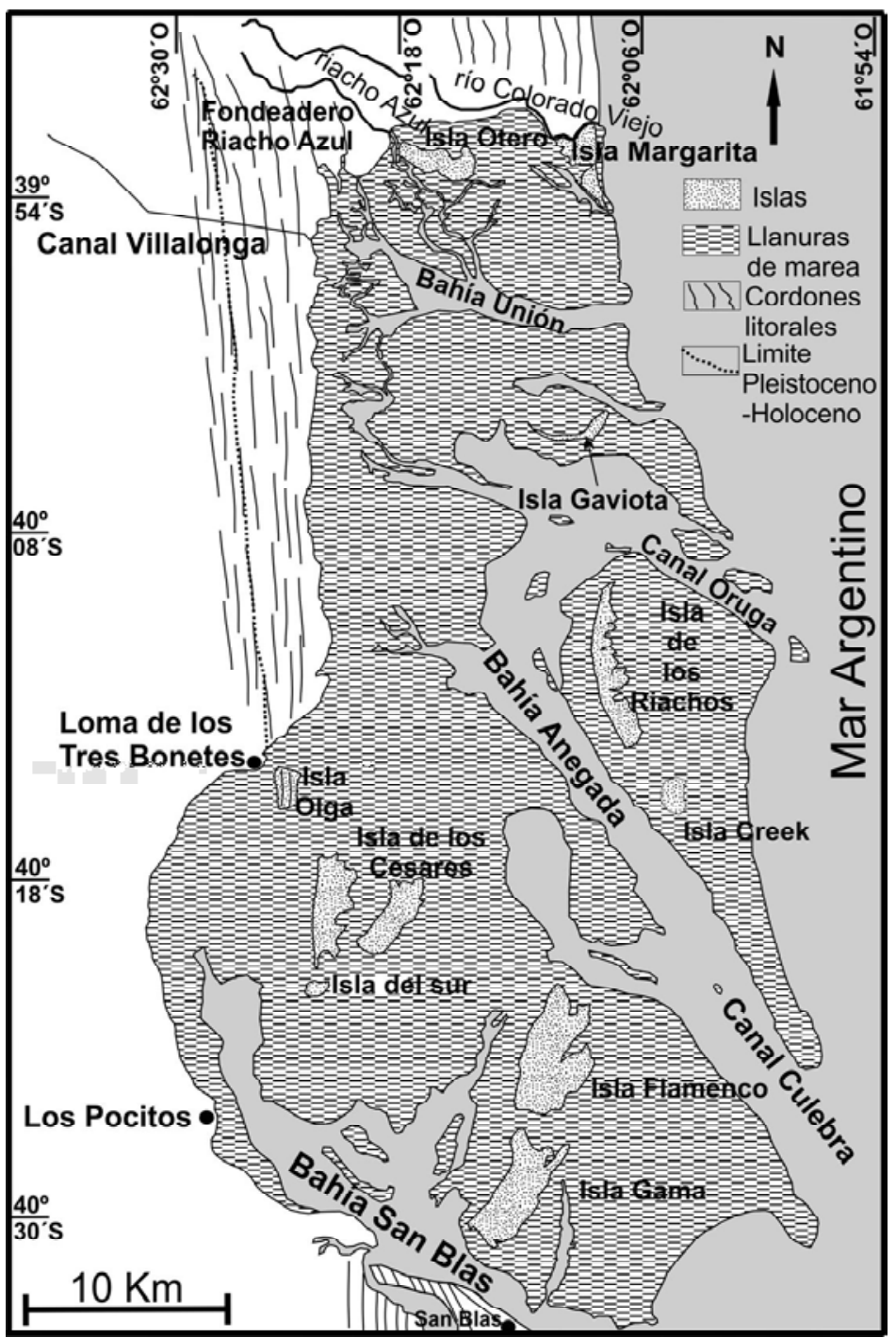

Fig.7.1: Región de bahía Anegada con cordones litorales pleistocenos y holocenos (Charó et al., 2013b).

Existen en la región, cantera abiertas para la explotación de materiales como arena y rodado, como la Cantera Villalonga y la Cantera La Atlántida (Weiler, 1984; Fucks et al., 2012a).

En la región de bahía Anegada se analizó un total de 20 sitios, 3 sitios que pertenecen al Interglacial $\geq$ MIS 9 (C2 - C4), 6 sitios del Interglacial MIS 5e (E5 - E10), 8 sitios del Interglacial MIS 1 y 3 sitios pertecientes a playas actuales (Fig 7.2 y T.7.1). 


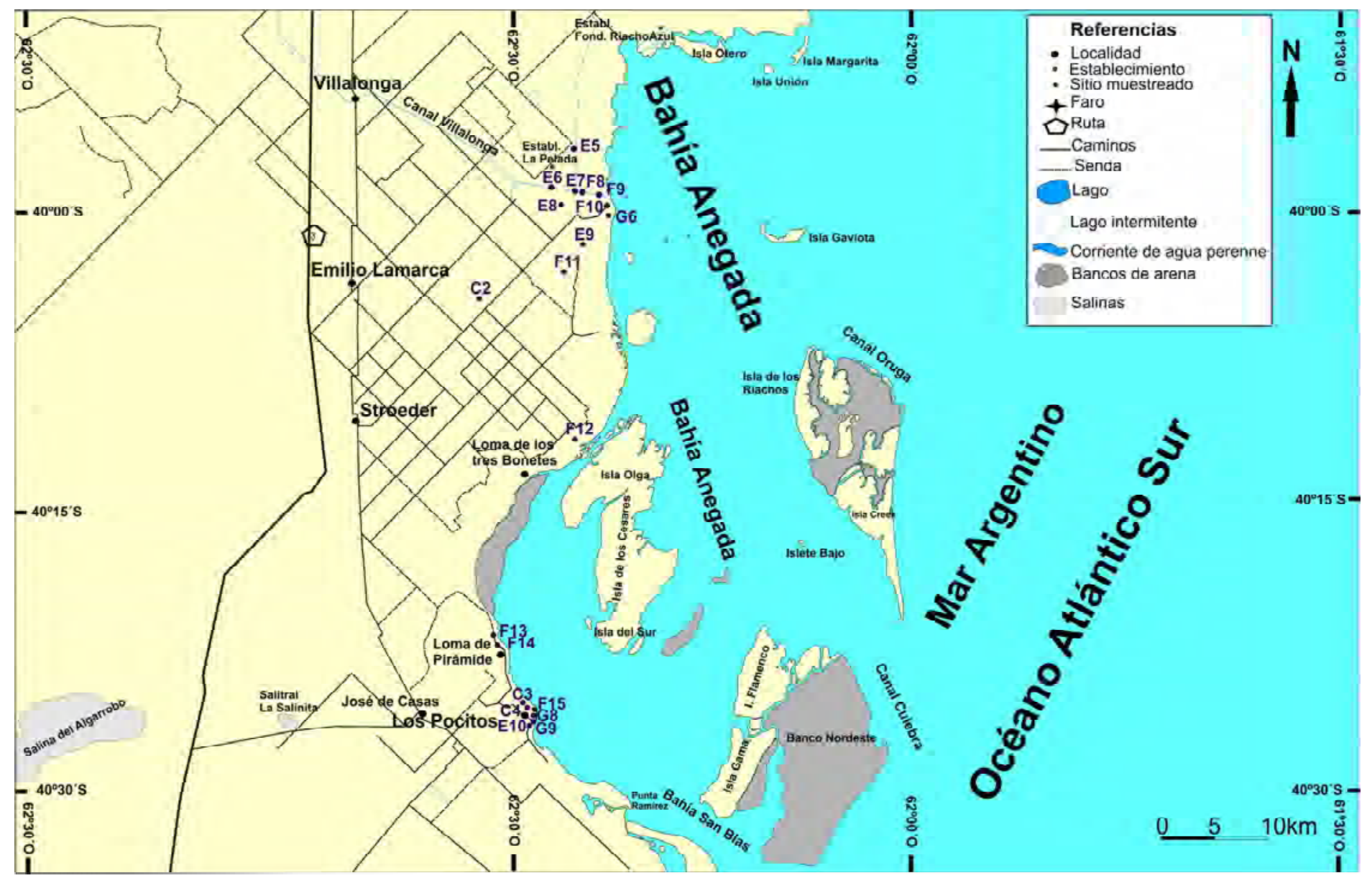

Fig.7.2: Mapa de ubicación de la región de bahía Anegada, sur de la Provincia de Buenos Aires. 


\begin{tabular}{|c|c|c|c|c|}
\hline $\begin{array}{l}\text { № } \\
\text { de } \\
\text { Sitio }\end{array}$ & Edad & $\begin{array}{l}\text { Coordenadas } \\
\text { (Lat-Long) }\end{array}$ & $\begin{array}{c}\text { Rasgos } \\
\text { geomorfológicos }\end{array}$ & $\begin{array}{c}\text { Cotas } \\
\text { topograficos }\end{array}$ \\
\hline $\mathrm{C} 2$ & Pleistoceno & $\begin{array}{l}40^{\circ} 5^{\prime} 27.14 " \mathrm{~S} / \\
62^{\circ} 28^{\prime} 12.97 " \mathrm{O}\end{array}$ & $\begin{array}{l}\text { Cordón litoral con } \\
\text { clastos esféricos y } \\
\text { aplanados }\end{array}$ & 18 \\
\hline C3 & Pleistoceno & $\begin{array}{l}40^{\circ} 25^{\prime} 36.30 " \mathrm{~S} / \\
62^{\circ} 25^{\prime} 39.59 " \mathrm{O}\end{array}$ & $\begin{array}{l}\text { Paleacantilado } \\
\text { afuncional }\end{array}$ & 18 \\
\hline C4 & Pleistoceno & $\begin{array}{l}40^{\circ} 25^{\prime} 44.08 " \mathrm{~S} / \\
62^{\circ} 25^{\prime} 24.66 " \mathrm{O}\end{array}$ & $\begin{array}{l}\text { Depósito litoral con } \\
\text { clasto sostén, } \\
\text { ligeramente } \\
\text { estratificado }\end{array}$ & 18 \\
\hline E5 & Pleistoceno & $\begin{array}{l}39^{\circ} 57^{\prime} 30.87^{\prime \prime S} / \\
62^{\circ} 22^{\prime} 55.37^{\prime \prime O}\end{array}$ & Cordón litoral & 7 \\
\hline E6 & Pleistoceno & $\begin{array}{l}39^{\circ} 59^{\prime 2} 27.18 " \mathrm{~S} / \\
62^{\circ} 23^{\prime} 17.78^{\prime \prime O}\end{array}$ & Cordón litoral & 10 \\
\hline E7 & Pleistoceno & $\begin{array}{l}39^{\circ} 59^{\prime} 38.00 " \mathrm{~S} / \\
62^{\circ} 22^{\prime} 6.02^{\prime \prime} \mathrm{O} 0\end{array}$ & Cordón litoral & 11 \\
\hline E8 & Pleistoceno & $\begin{array}{c}40^{\circ} 0^{\prime} 3.87^{\prime \prime S} / \\
62^{\circ} 22^{\prime} 36.30^{\prime \prime O}\end{array}$ & Cordón litoral & 7 \\
\hline E9 & Pleistoceno & $\begin{array}{l}40^{\circ} 2^{\prime} 17.58^{\prime \prime S} / \\
62^{\circ} 22^{\prime} 4.09^{\prime \prime} \mathrm{O}\end{array}$ & Cordón litoral & 7 \\
\hline E10 & Pleistoceno & $\begin{array}{l}40^{\circ} 26^{\prime} 27.57^{\prime \prime} \mathrm{S} / \\
62^{\circ} 25^{\prime} 22.14^{\prime \prime} \mathrm{O}\end{array}$ & Cordón litoral & 8.6 \\
\hline F8 & Holoceno & $\begin{array}{l}39^{\circ} 59^{\prime} 42.81 " \mathrm{~S} / \\
62^{\circ} 21^{\prime} 14.60^{\prime \prime} \mathrm{O}\end{array}$ & Planicie de marea & 6 \\
\hline F9 & Holoceno & $\begin{array}{l}39^{\circ} 59^{\prime} 46.08^{\prime \prime} \mathrm{S} / \\
62^{\circ} 20^{\prime} 33.15^{\prime \prime} \mathrm{O}\end{array}$ & Cordón litoral & 6 \\
\hline F10 & Holoceno & $\begin{array}{c}40^{\circ} 1 ' 1.50 " \mathrm{~S} / \\
62^{\circ} 19^{\prime} 56.82 " \mathrm{O}\end{array}$ & $\begin{array}{l}\text { Cordón con niveles } \\
\text { arenosos y } \\
\text { conglomerádicos }\end{array}$ & 6 \\
\hline F11 & Holoceno & $\begin{array}{l}40^{\circ} 3 ' 37.23 " \mathrm{~S} / \\
62^{\circ} 23 ' 8.77 " \mathrm{O}\end{array}$ & Planicie de marea & 6 \\
\hline F12 & Holoceno & $\begin{array}{l}40^{\circ} 11 ' 10.42 " \mathrm{~S} / \\
62^{\circ} 21 ' 25.15^{\prime \prime} \mathrm{O}\end{array}$ & $\begin{array}{c}\text { Cordón con niveles } \\
\text { arenosos y }\end{array}$ & 6 \\
\hline
\end{tabular}




\begin{tabular}{|c|c|c|c|c|}
\hline & & & conglomerádicos & \\
\hline F13 & Holoceno & $\begin{array}{l}40^{\circ} 22 ' 2.13^{\prime \prime S} / \\
62^{\circ} 27^{\prime} 49.37^{\prime \prime O}\end{array}$ & Cordón litoral & 4 \\
\hline F14 & Holoceno & $\begin{array}{l}40^{\circ} 22 ' 32.50^{\prime \prime S} / \\
62^{\circ} 27^{\prime} 32.49^{\prime \prime O}\end{array}$ & $\begin{array}{l}\text { Cordón de arena finas } \\
\text { con gravas y valvas }\end{array}$ & 2 \\
\hline F15 & Holoceno & $\begin{array}{l}40^{\circ} 25^{\prime} 49.38 " \mathrm{~S} / \\
62^{\circ} 25^{\prime} 24.19^{\prime \prime} \mathrm{O}\end{array}$ & $\begin{array}{l}\text { Cordón de arena fina } \\
\text { con restos de valvas }\end{array}$ & 1 \\
\hline G6 & actual & $\begin{array}{l}40^{\circ} 0 ' 59.82^{\prime \prime S} / \\
62^{\circ} 19^{\prime} 52.89 " \mathrm{O}\end{array}$ & Playa de arena fina & 0 \\
\hline G7 & actual & $\begin{array}{l}40^{\circ} 26^{\prime} 20.42^{\prime \prime S} / \\
62^{\circ} 25^{\prime} 17.55 " \mathrm{O}\end{array}$ & Playa arenosa & 0 \\
\hline G8 & actual & $\begin{array}{l}40^{\circ} 25^{\prime} 48.34 " \mathrm{~S} / \\
62^{\circ} 25^{\prime} 23.10^{\prime \prime O}\end{array}$ & $\begin{array}{c}\text { Playa arenosa con } \\
\text { valvas }\end{array}$ & 0 \\
\hline
\end{tabular}

T.7.1: Características geomorfológicas de los sitios analizados de la región de bahía Anegada. 


\subsection{Descripción de los depósitos pleistocenos de la región de bahía Anegada}

Se analizaron en total 9 depósitos pleistocenos, tres de ellos pertenecen al Interglacial $\geq$ MIS 9 a cotas del orden de los 18 - 15 m, y los restantes sitios al Interglacial MIS 5e $10-7 \mathrm{~m}$, representando cordones litorales con presencia de fauna fósil.

\subsubsection{Depósitos marinos del Interglacial $\geq$ MIS 9}

El depósito pleistoceno antiguo encontrado en las cercanías de la localidad Los Pocitos $\left(40^{\circ} 26^{\prime} \mathrm{S} / 62^{\circ} 26^{\prime} \mathrm{O}\right)$, es una plataforma marina con clastos redondeados. Entre la fauna marina encontrada figuran dos especies encontradas: Adelomelon brasiliana y Olivancillaria urceus (gasterópodos). A pesar del reconociendo de la fauna a nivel de especie, en este trabajo solo será mencionado ya que hay aún dudas respecto a su edad, y a qué evento Interglacial puede llegar a representar.

Al S de la Loma de los Tres Bonetes $\left(40^{\circ} 13^{\prime} \mathrm{S} / 62^{\circ} 25^{\prime} \mathrm{O}\right)$ las formas cordoniformes pleistocenas como las holocenas prácticamente desaparecen, siendo remplazadas por pequeños depósitos con morfologías poco marcadas, muchas veces imperceptibles o por llanuras salitrosas con fósiles marinos. Se presentan en la costa en forma casi permanente plataformas costeras y acantilados, en algunos sectores no funcionales compuestos parcialmente por la Fm. Río Negro.

En el Sitio C2 a 3 km al N de Loma de los Tres Bonetes, se presenta un cordón litoral a cota de $18 \mathrm{~m}$, compuesto por un núcleo conglomerádico con clastos esféricos y aplanados, altamente cementado por carbonato de calcio, cubierto por médanos. Al pie de la misma se observan rasgos geomorfológicos escalonados que representarían las ingresiones (MIS 5e y 1). Entre la fauna marina figuran: Tagelus plebeius y Pitar rostratus (bivalvos) y Buccinanops globulosus (gasterópodo). 
Hacia el S, en el Sitio C3 en Loma de la Pirámide $\left(40^{\circ} 22^{\prime} \mathrm{S} / 62^{\circ} 27^{\prime} \mathrm{O}\right)$ a cota de $18 \mathrm{~m}$ se observó un acantilado no funcional labrado en areniscas grises de la Fm. Río Negro coronadas por 3 - $4 \mathrm{~m}$ de gravas con rodados esféricos y aplanados, bien estratificados y muy cementados, con restos de Zidona dufresnei (gasterópodos) (Fig. 7.2).

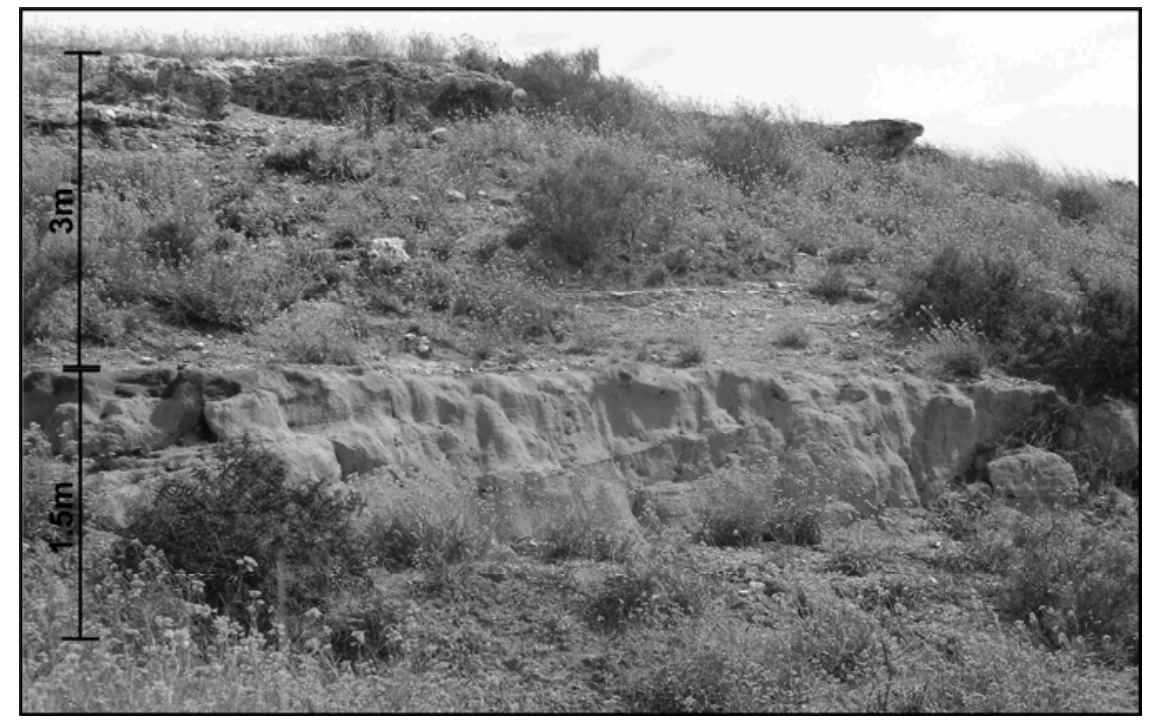

Fig.7.2: Afloramiento pleistoceno en el S de Loma de Pirámide (Sitio C3).

En el límite $\mathrm{N}$ de Los Pocitos, en el Sitio C4 (40 $\left.25^{\prime} \mathrm{S} / 62^{\circ} 25^{\prime} \mathrm{O}\right)$ a una cota de $18 \mathrm{~m}$, se observó un depósito conglomerádico de $2 \mathrm{~m}$ de espesor, clasto sostén, muy cementado por carbonatos de calcio y ligeramente estratificado. Los clastos son pequeños a medianos, con presencia de Glycymeris longior (bivalvo) y Buccinanops cochlidium, y Buccinanops globulosus (gasterópodos).

Todos los depósitos encontrados a cota de 18 m en Los tres Bonetes, Loma de Pirámide y Los Pocitos pertenecen al Interglacial $\geq$ MIS9. La fauna marina es escasa con buena preservación de los caracteres diagnósticos para el reconocimiento hasta nivel de especie.

\subsubsection{Depósitos marinos del Interglacial MIS 5e}

El Sitio E5, es un depósito marino perteneciente al Interglacial MIS 5e, cerca del establecimiento La Pelada $\left(39^{\circ} 57^{\prime} \mathrm{S} / 62^{\circ} 22^{\prime} \mathrm{O}\right)$, se encuentra representado por una 
planicie de marea con sedimentación fina mayoritariamente con valvas y conchas dispersas. Entre la fauna marina se destaca: Pitar rostratus (bivalvo) y Bostrycapulus odites y Tegula patagonica (gasterópodos) (Fig. 7.3).

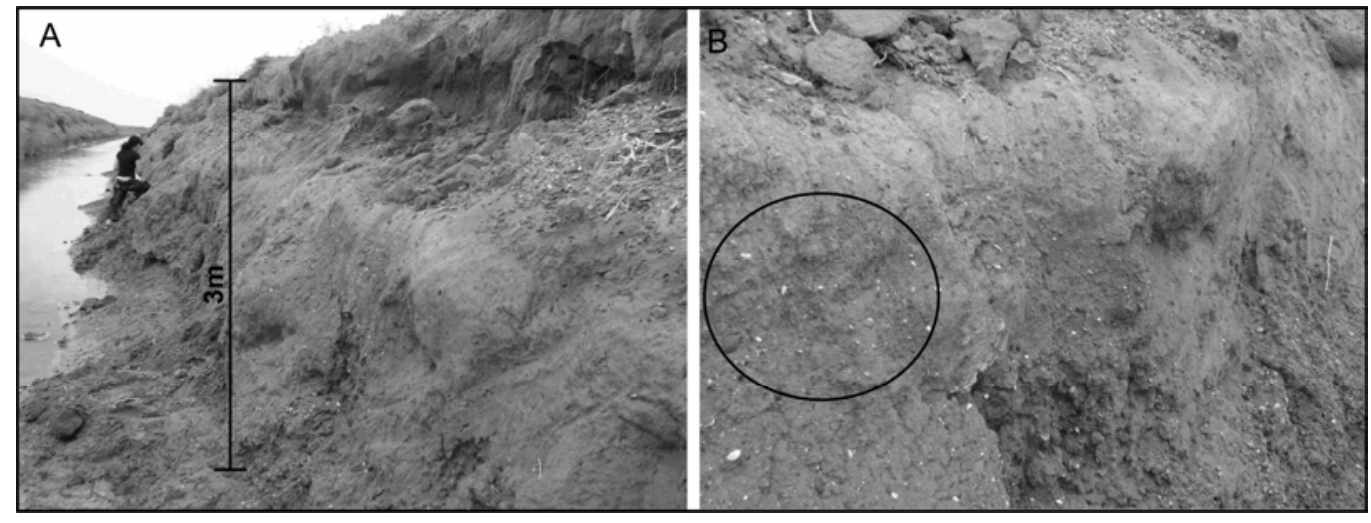

Fig. 7.3: A, Depósito marino pleistoceno (Sitio E5) de sedimento más fino; B, valvas y conchas de moluscos dispersos.

El Sitio E6 (39 $\left.59^{\prime} \mathrm{S} / 6^{\circ} 23^{\prime} \mathrm{O}\right)$, en el canal Villalonga, representa un cordón litoral a cota de $10 \mathrm{~m}$. Se distingue un nivel estratigráfico de limo castaño grisaceo con clastos y valvas dispersas ( $1.70 \mathrm{~m}$ de espesor). Entre la fauna marina abundan Pitar rostratus (bivalvos) y Tegula patagonica, Crepidula argentina, Bostrycapulus odites (gasterópodos) (Fig. 7.4).

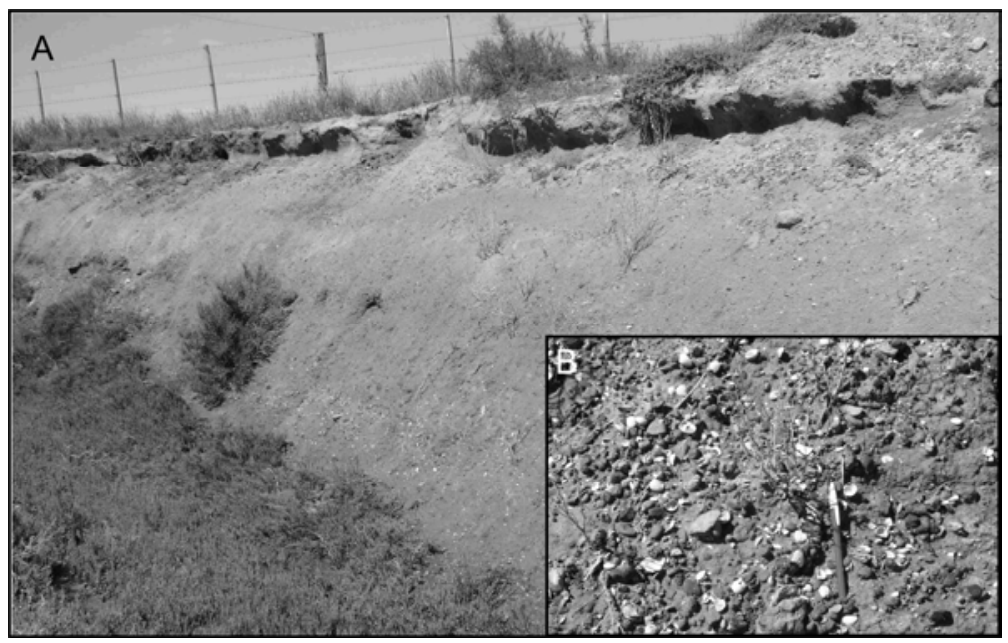

Fig. 7.4: Depósito marino pleistoceno (Sitio E6). 
El cordón litoral más destacado del Interglacial MIS 5e es del Sitio E7, cercano al canal Villalonga. Presenta forma lenticular y un espesor máximo de $8 \mathrm{~m}$ compuesto fundamentalmente por dos unidades. El nivel basal de $1 \mathrm{~m}$ de espesor por encima del nivel del agua, se encuentra compuesto por grava con estratificación cruzada hacia el E, fuertemente cementada por carbonato de calcio, constituyendo una plancha continua en su parte superior de forma ondulada con presencia de Ostreola equestris (Fig. 7.5). Por encima y en discordancia, el nivel superior de $7 \mathrm{~m}$ de espesor máximo, compuesta por gravas clastos sostén esencialmente, aunque también hay estratos de arena y otros de clastos matriz sostén. Presenta coloración grisácea y estratificación cruzada de bajo ángulo hacia el E compuesta por abundante fauna marina en especial de gasterópodos y bivalvos, entre los más abundantes figuran: Glycymeris longior (bivalvo) y Tegula patagonica y Bostrycapulus odites (gasterópodos) (Fig. 7.6).
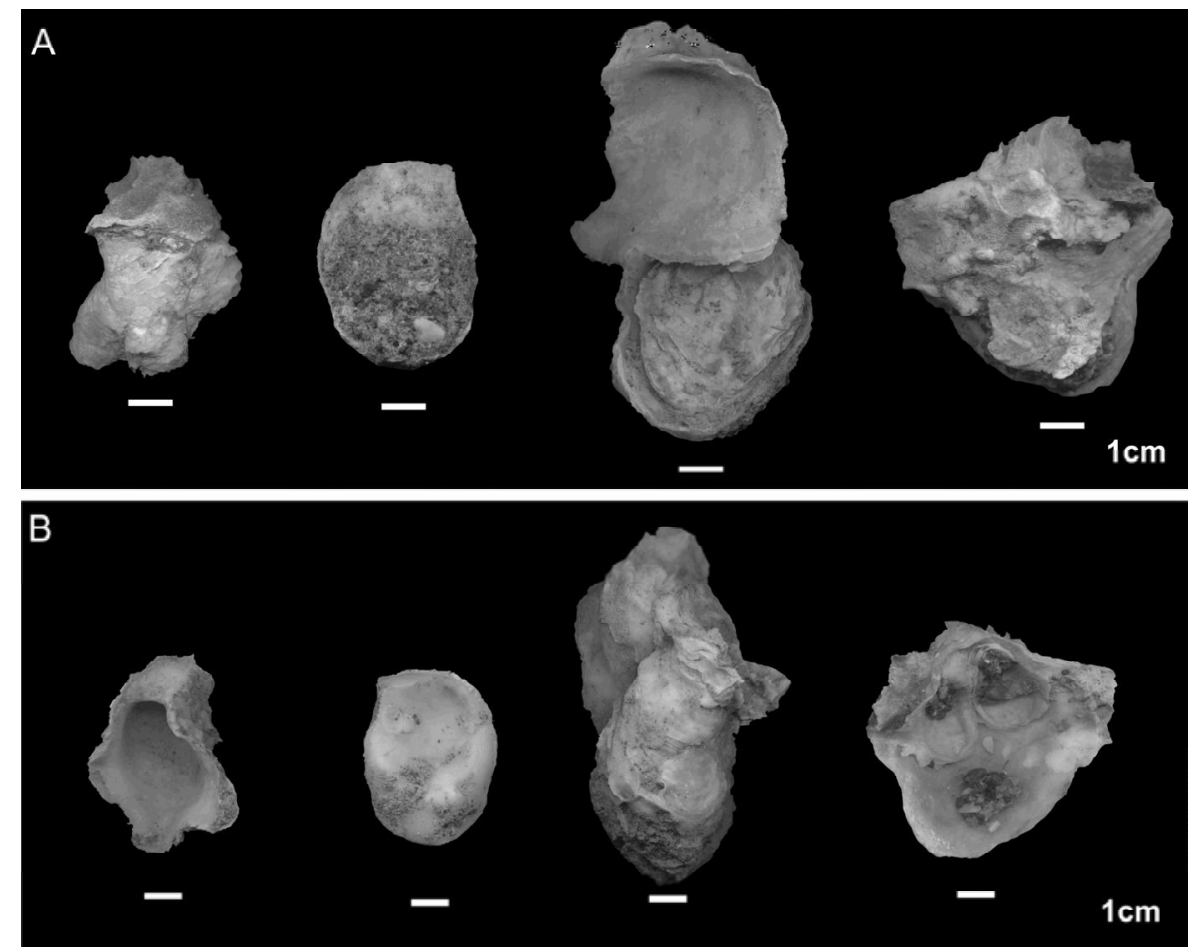

Fig. 7.5: Ostreola equestris (Sitio E7). A, Vista dorsal de Ostreola equestris; B, Vista ventral de Ostreola equestris. 


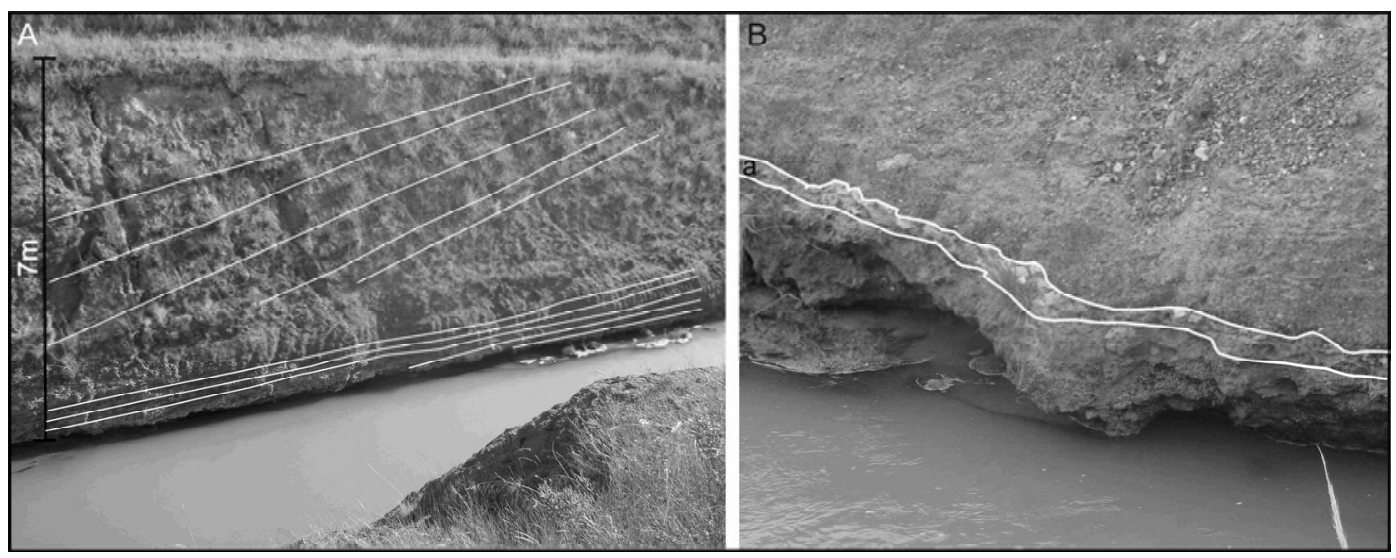

Fig. 7.6: A, Cordón pleistoceno sobre el Canal Villalonga (Sitio E7); B, nivel basal (nivel a) cementado con Ostreola equestris.

Según Fucks et al. (2012a), el nivel basal (Nivel I de Weiler, 1993) con una edad > 43 ka y atribuido al Sangamon por características litológicas y altitud, se asoció a un nivel del mar más antiguo probablemente al Interglacial MIS 7? y lo correlacionando con depósitos similares en la zona de San Antonio Oeste situados en ambientes intermareales. El nivel superior (Nivel II de Weiler, 1993) con edades radiocarbónicas entre 28.7 y $38.5 \mathrm{ka}$, asignados al interestadial, debido a las características litológicas, geomorfológicas y altura, se asoció al Interglacial MIS 5e, correlacionándolo con los depósitos situados en las inmediaciones de San Blas y otras zonas litorales de Patagonia como San Antonio Oeste, península de Valdés, bahía Camarones y bahía Bustamante. Estos depósitos han sido asociados a ambientes de albuferas e islas de barrera (Weiler, 1993), aunque por sus dimensiones, composición y distribución, también podrían corresponder a cordones de tormenta en ambientes intermareales (Fucks et al., 2012a) (Fig. 7.7).

En este trabajo, no se analiza el nivel basal de este último cordón litoral a pesar del reconocimiento de la fauna marina asociada (Ostreola equestris), es probable que pertenezca a un interglacial más antiguo que el Interglacial MIS 5e, posiblemente el Interglacial MIS 7?, pero hay dudas del cuál interglacial pertenezca dicho nivel. 


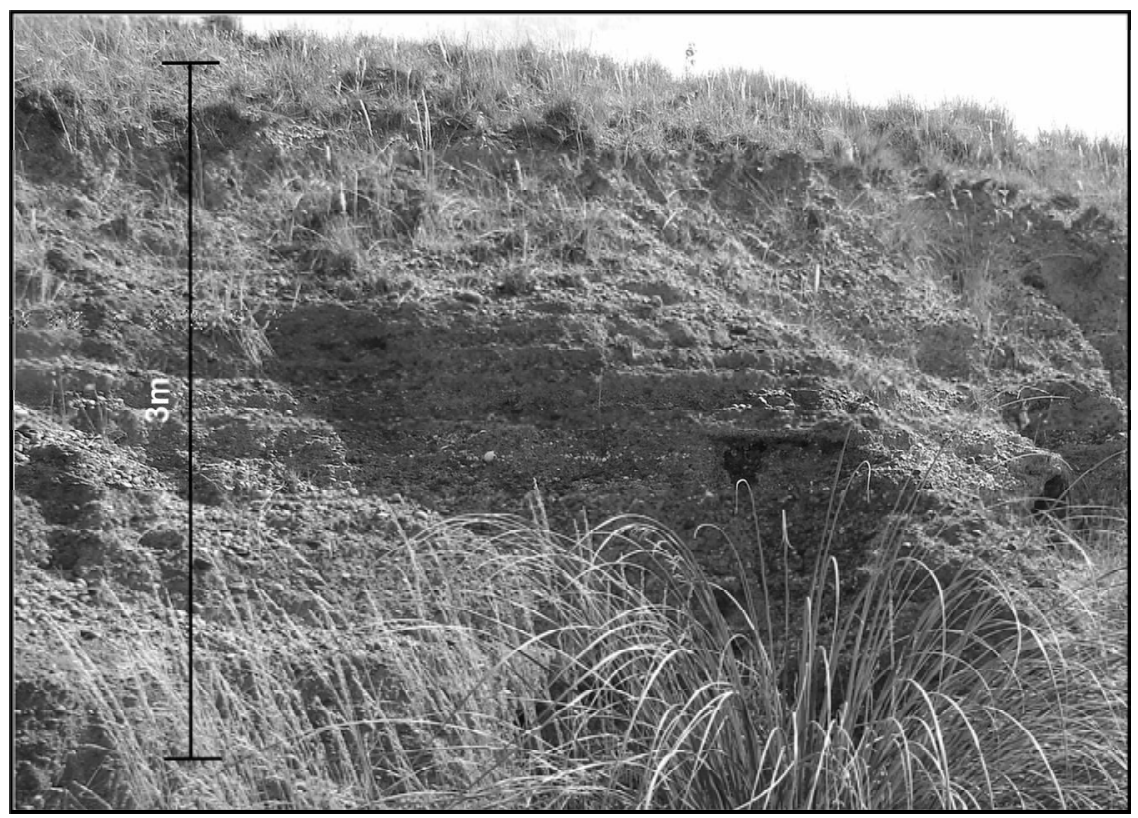

Fig. 7.7: Nivel superior del cordón litoral pleistoceno (Sitio E7).

Los sitios E8 y E9 representan a cordones litorales a cotas de $7 \mathrm{~m}$, ubicados al $\mathrm{S}$ del canal Villalonga. Entre la fauna marina del Sitio E8 abundan: Glycymeris longior (bivalvo) y Bostrycapulus odites y Tegula patagonica (gasterópodos). Mientras que en la fauna marina del Sitio E9, abundan Pitar rostratus y Amiantis purpurata (bivalvos).

Cercano a la localidad de los Pocitos $\left(40^{\circ} 26^{\prime} \mathrm{S} / 62^{\circ} 25^{\prime} \mathrm{O}\right)$ (Sitio E10), hay un afloramiento de $2 \mathrm{~m}$ de espesor compuesto por estratos de arena y rodados (clastos y matriz sostén), con estratificación paralela con presencia de valvas de moluscos. Entre la fauna marina figuran entre las más abundantes: Ostreola equestris, Brachidontes rodriguezii (bivalvos) y Tegula patagonica (gasterópodos) (Fig.7.8). 


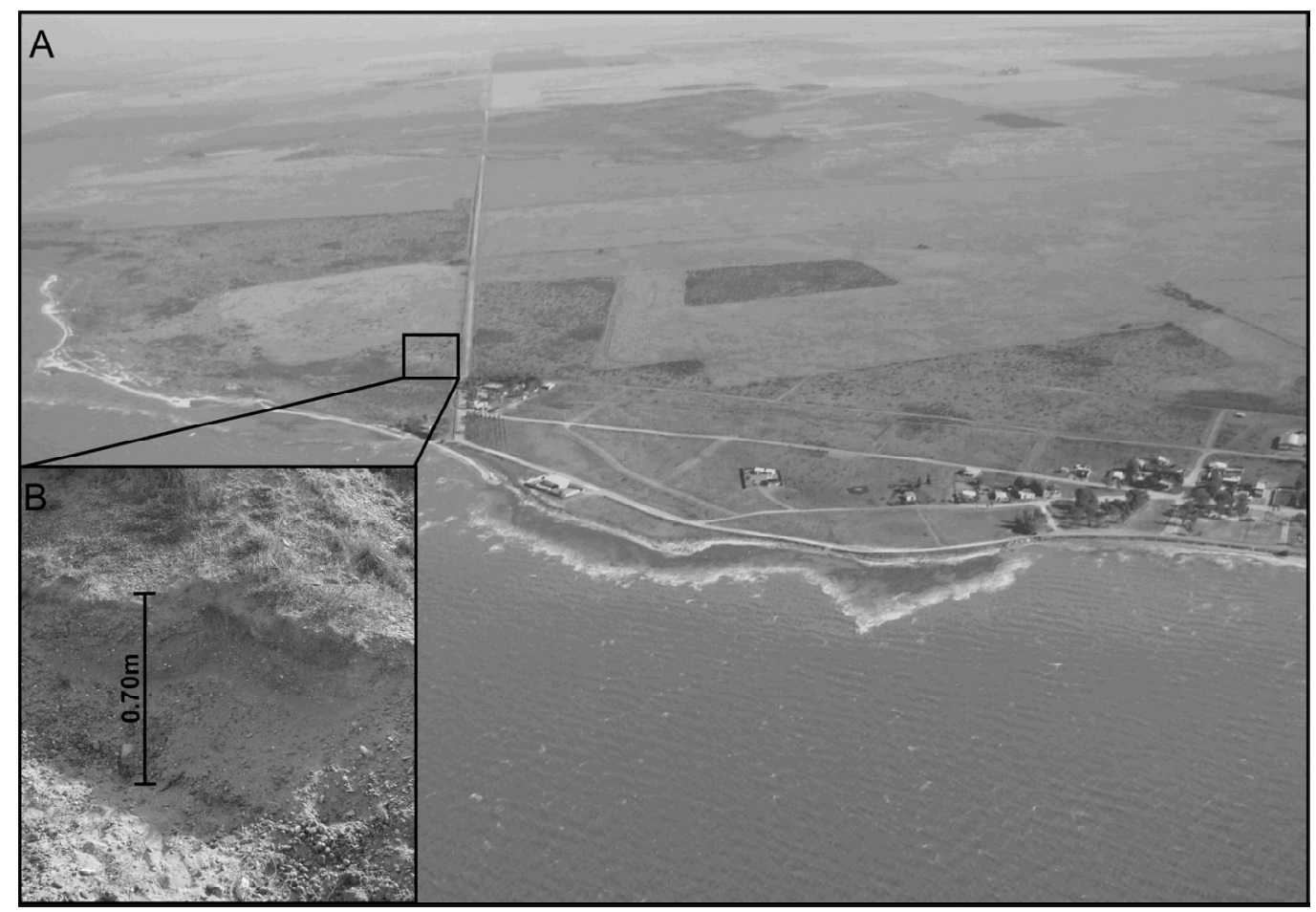

Fig 7.8: A, Fotografía aérea de la localidad Los Pocitos; B, Depósito marino pleistoceno (Sitio E10), con espesor de $0.70 \mathrm{~m}$ expuesto.

\subsection{Descripción de los depósitos holocenos de la región de bahía Anegada}

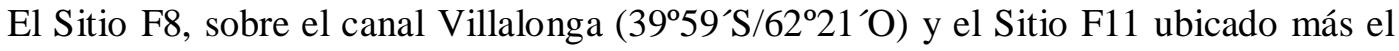
sur $\left(40^{\circ} 3^{\prime} \mathrm{S} / 62^{\circ} 23^{\prime} \mathrm{O}\right)$, representan a planicies de marea, ambientes de menor energía, a cotas de $6 \mathrm{~m}$. Son depósitos homogéneos de arena fina a limosa con restos de moluscos, entre ellos abundan Tagelus plebeius (bivalvo) y Heleobia australis (gasterópodo).

El Sitio F9 (39 59 'S $/ 62^{\circ} 21^{\prime}$ ) $)$, ubicado sobre el canal Villalonga, representa un cordón litoral con estratificación laminar, con niveles de arena y conglomerados con clastos gruesos y restos de valvas. Entre la fauna marina figuran: Pitar rostratus, Amiantis pupurata (bivalvos) y Buccinanops cochlidium y Zidona dufresnei (gasterópodos).

Las canteras ubicadas al sur del canal Villalonga son exposiciones de cordones holocenos (F10, F12 y F13). Presentan entre 3 a 4 m de espesor. Compuestos por 
sedimentos gravosos y arenosos, alternando permanentemente el contendido de ambos, estratificados hacia el E con ángulos bajos (Fig. 7.9 y 7.10).

Entre las canteras más importantes, está la cantera Villalonga (Sitio F10) (40¹'S/ $62^{\circ} 19^{\prime} \mathrm{O}$ ) presentan $3.5 \mathrm{~m}$ de espesor (Fig. 7.9 A y B), compuestos por niveles gravosos con abundante fauna de gasterópodos y bivalvos (Fig. 7-8 C, niveles a, c, e y g) y niveles de arena con poco fauna marina (Fig 7.9 C, niveles b, d, f y h). Posee niveles parcialmente cementados por carbonato de calcio. La cantera La Atlántida (Sitio F12) es una cantera con menor desarrollo que la mencionada anteriormente, de $3 \mathrm{~m}$ de espesor con un similar afloramiento que la Cantera Villalonga (Fig. 7.9).

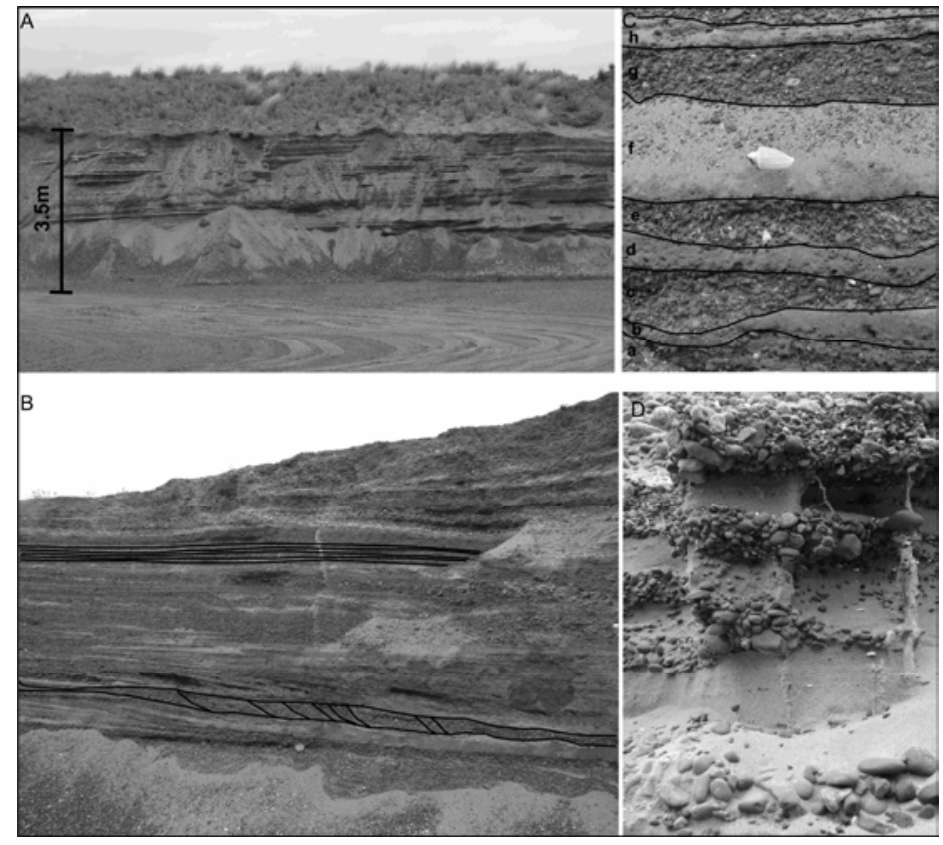

Fig. 7.9: A y B, Vista transversal y paralela al cordón en la cantera Villalonga (Sitio F10); C y D, Perfil de la cantera con intercalación de niveles arenosos y conglomerádicos. 


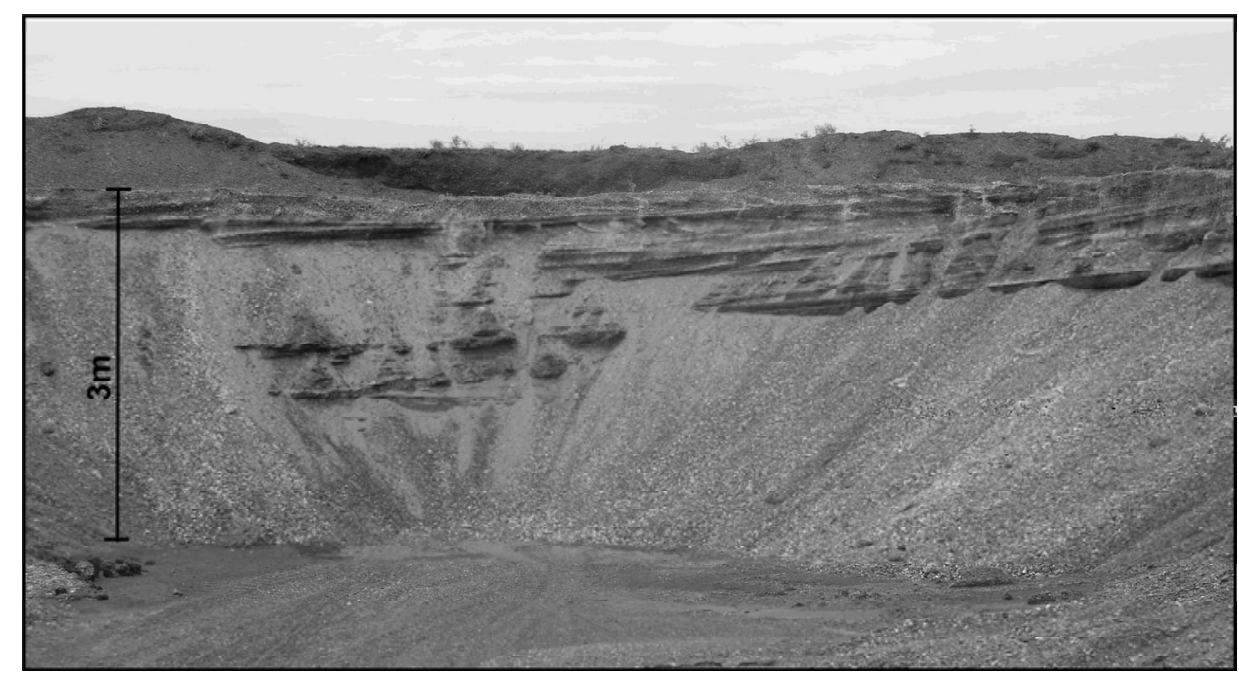

Fig. 7.10: Vista transversal al cordón en la cantera La Atlántida (Sitio F12).

Al sur de Loma de Pirámide, al pie del afloramiento pleistoceno se presentan formas cordoniformes compuestas por arenas y rodados de la ingresión holocena (Sitio F14) con importantes fauna marina fósil. Entre las cuales se destacan: Ostreola equestris, Brachidontes rodriguezii (bivalvos) y Heleobia australis y Buccinanops globulosus (gasterópodos).

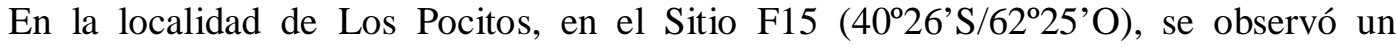
afloramiento de $2 \mathrm{~m}$ de espesor, compuesto por estratos de arena y rodados, con valvas dispuestas en forma caótica, representando microacantilados en la costa actual respecto a los depósitos de playa. El nivel más bajo se presenta en forma de llanura y sobre él se labra un pequeño acantilado de $0.70 \mathrm{~m}$ de altura. Se encuentra en discordancia sobre las areniscas de la Fm. Río Negro, compuesto por rodados, arenas y valvas sin ordenamiento (Fig. 7.11). 


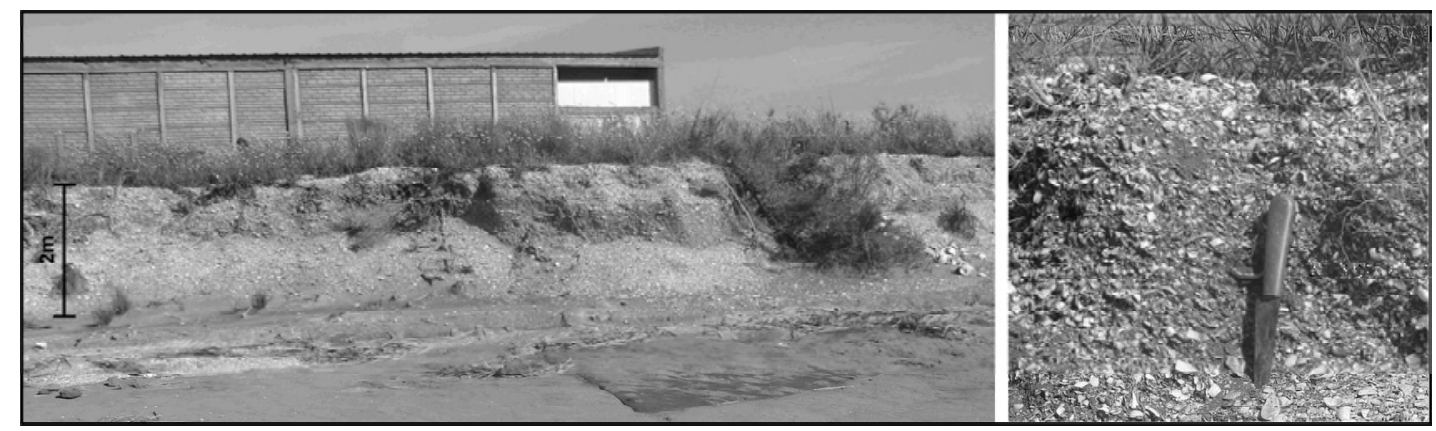

Fig 7.11: Depósito marino holoceno en la localidad Los Pocito (Sitio F15).

En las localidades Loma de los Tres Bonetes, Loma de Pirámide y Los Pocitos se identifican tres depósitos diferentes: los situados a cotas del orden de los 18 -15 m, un segundo grupo a $10-7 \mathrm{~m}$ y aquellos a cotas de 3 - $5 \mathrm{~m}$, asignados a los interglaciales $\geq$ MIS 9, MIS 5e y MIS 1 respectivamente.

\subsection{Playas actuales de la región de bahía Anegada}

Las costas de la región de bahía Anegada se caracterizan por ser muy diferentes, a la altura de la localidad Villalonga $\left(40^{\circ} 0\right.$ 'S $\left./ 62^{\circ} 19^{\prime} \mathrm{S}\right)$ y entre la isla Margarita (39 $\left.55^{\prime} \mathrm{S} / 62^{\circ} 09^{\prime} \mathrm{O}\right)$ y proximidades de isla Olga $\left(40^{\circ} 19^{\prime} \mathrm{S} / 62^{\circ} 18^{\prime} \mathrm{O}\right)$, se caracteriza por estar compuesta por arcilla y limos fangosos, compuesta por llanuras de mareas fangosas y hacia el sur, a la altura de Los Pocitos $\left(40^{\circ} 26^{\prime} \mathrm{S} / 62^{\circ} 25^{\prime} \mathrm{O}\right)$, se encuentra caracterizado por playas de arena con abundancia de valvas de moluscos.

El Sitio G6, cercanías de la localidad Villalonga, ubicada al norte de la región, es una amplia playa de arena fangosa, y entre la fauna marina figuran entre las más abundantes Tagelus plebeius (bivalvo), y Buccinanops globulosus y Zidona dufresnei (gasterópodos).

En el balneario Los Pocitos (Sitio G7) y sus cercanías (Sitio G8), ubicada al sur de la región, se caracteriza por ser playas de ambientes transicionales entre un sector supramareal con acción de olas y acumulaciones de valvas fragmentadas y arenas. Con un sector intermareal que se comporta como una marisma limoarenosa con una sucesión 
vegetal hacia la costa de Sporobolus sp., Salicornia sp. y Spartina sp. Esta vegetación de marisma alterna con parches de acumulaciones de arena (Fig 7.12).

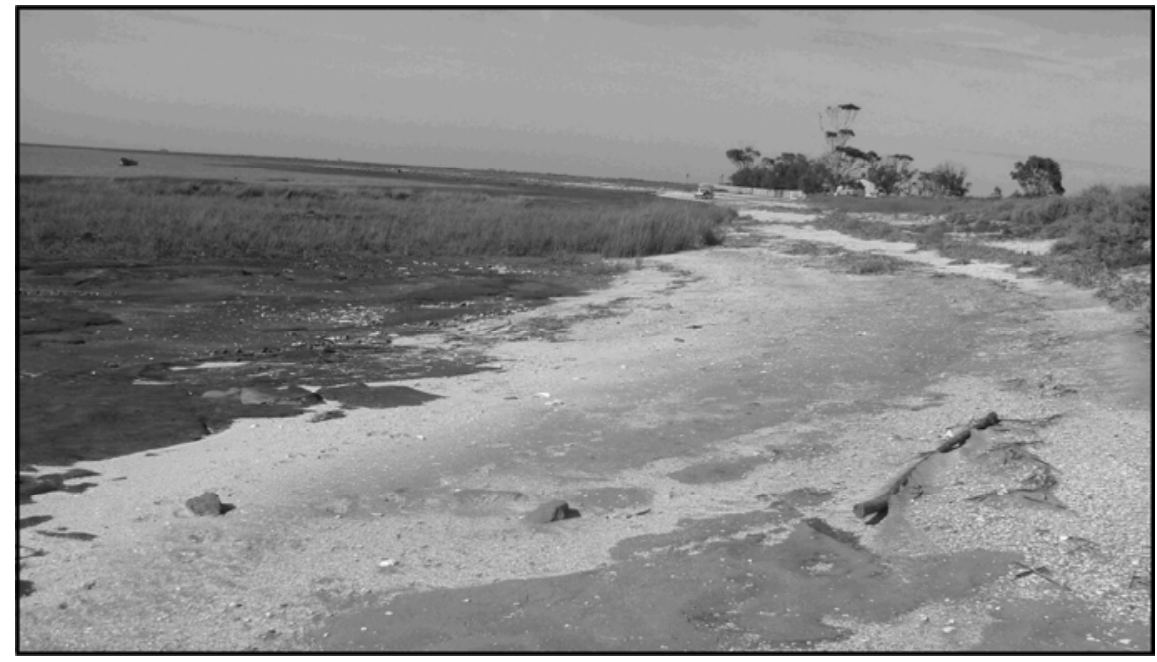

Fig. 7.12: Playa actual de Los Pocitos (Sitio G7).

\subsection{Composición faunística}

En la región de bahía Anegada se analizaron 20 sitios ( 9 pleistocenos, 8 holocenos y 3 playas actuales) y se registró un total de 49 especies ( 25 bivalvos y 24 gasterópodos) (Fig. 7.13 y Fig. 7.14). Entre los cuales 9 especies son micromoluscos: Nucula nucleus, Ennucula grayi, Carditamera plata, Corbula patagonica (bivalvos), y Heleobia australis, Olivella tehuelcha, Parvanachis isabellei, Turbonilla paralaminata y Chrysallida multituberculata (gasterópodos) (T.7.2 - 7.5). 


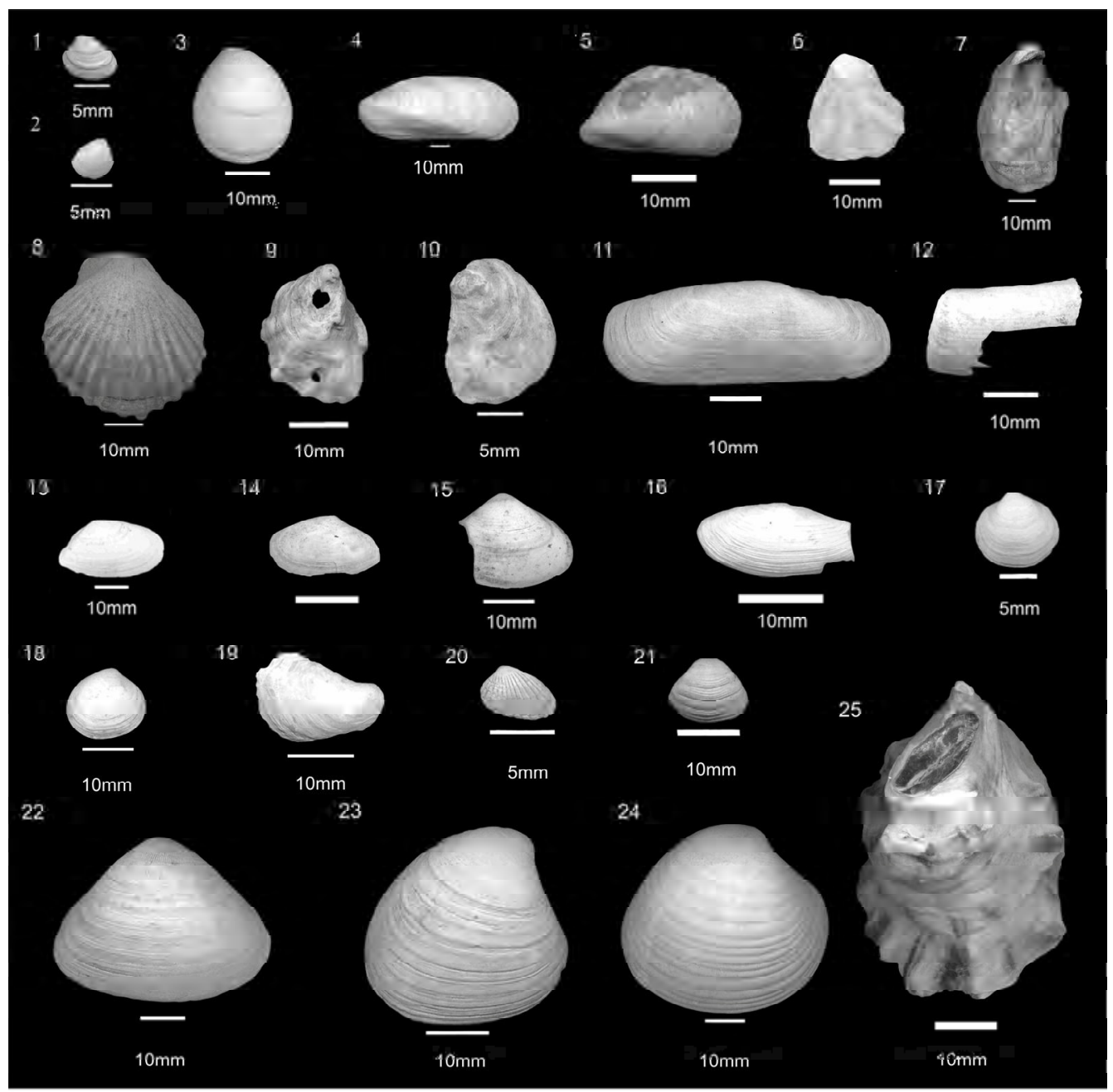

Fig.7.13: Especies de bivalvos característicos de depósitos marinos del Cuaternario de la región de bahía Anegada. Dimensiones en $\mathrm{mm}$.

1, Nucula (N.) nucleus (Linné) (MLP: 33.799, Holoceno); 2, Ennucula grayi ( MLP: 33.810 ,

Holoceno); 3, Glycymeris (G.) longior (Sowerby) (MLP: 33.811, Holoceno); 4, Brachidontes (B.) Rodriguezii (d'Orbigny) (MLP: 33.802, Pleistoceno); 5, Mytilus edulis platensis d'Orbigny (MLP: 34.432, Holoceno); 6, Plicatula gibbosa;Lamarck (MLP: 34.435, Pleistoceno); 7, , Crassostrea rhizophorae (Guilding) (MLP: 33.803, Pleistoceno); 8, Aequipecten tehuelchus (d'Orbigny) (MLP: 33.812, Holoceno); 9, Ostreola equestris (MLP: 33.808, Holoceno);10, Ostrea puelchana d' Orbigny ( MLP:33.813, Holoceno); 11, Tagelus (T.) plebeius (Ligthfoot) (MLP: 33.806, Holoceno); 12, Solen tehuelchus (Hanley) (MLP:34.445, Holoceno); 13,Angulus gibber Ihering (MLP: 34.442 , Holoceno); 14,Macoma (P.) uruguayensis ( Smith) ( MLP: 33.797, Pleistoceno) ; 15, Mactra guidoi (MLP: 33.807, Pleistoceno);16, Adrana electa (A. Adams) (MLP: 34.439, Pleistoceno); 17, Diplodonta (D.)patagonica (d'Orbigny) (MLP: 33.796. Holoceno); 18, Diplodonta (F.) vilardeboana (d'Orbigny)(MLP: 34.443, Holoceno); 19, Lyonsia (L.) Alvarezii (MLP:34.444, Holoceno); 20, Carditamera plata (MLP: 33.809, Holoceno); 21, Corbula (C.) patagonica d'Orbigny (MLP: 33.798, Holoceno); 22, Tivela isabelleana (d'Orbigny) (MLP: 33.804, Pleistoceno); 23, Pitar (P.) rostratus (Philippi)( MLP: 33.805, Holoceno);24, Amiantis purpurata d'Orbigny (MLP: 33.801, Holoceno); 25, Crassostrea gigas (Thunberg) (MLP: 34.437 , actual). 


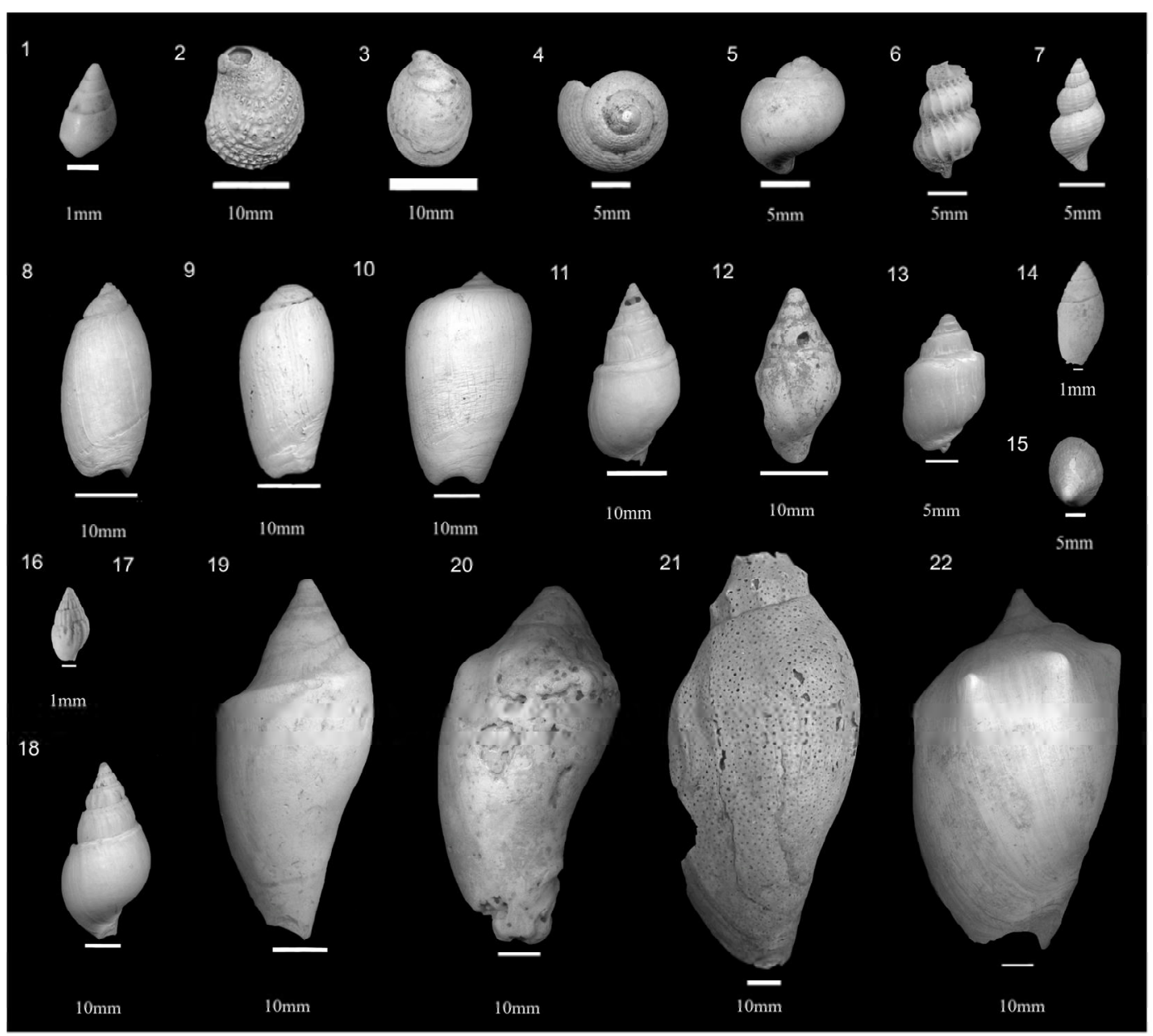

Fig. 7.14: Especies de gasterópodos característicos de depósitos marinos del Cuaternario de la región de Bahía Anegada. Dimensiones en mm

1, Heleobia australis (d'Orbingy) (MLP: 33.786, Pleistoceno); 2, Bostrycapulus odites (Collin) (MLP: 33.784, Holoceno); 3, Crepidula argentina Simone,Past. \& Pen. (MLP:33.780,Pleistoceno);4,Tegula patagonica (d'Orbigny) (MLP:33.785,Pleistoceno); 5, Notocochlis isabelleana d'Orbigny (MLP: 33.787, Pleistoceno); 6, Epitenium (E.) georgettinum (d'Orbigny) (MLP: 24.446, Pleistoceno); 7 , Urosalpinx cala (Pilsbry) (MLP: 34.427, Holoceno); 8, Olivancillaria uretai Klappenbach (MLP: 34.433, Holoceno); 9, Olivancillaria carcellesi (MLP: 33.790, Pleistoceno);10, Olivancillaria urceus (Röding) (MLP: 33.792, Pleistoceno); 11, Buccinanops cochlidium (Dillwyn) (MLP: 33.791, Holoceno); 12 ,

Buccinanops monilifer (Kiener) (MLP: 34.434, Holoceno); 13, Buccinanops globulosus ( MLP: 33.783, Pleistoceno); 14, Olivella (O.) tehuelcha (Duclos) (MLP: 33.782, Pleistoceno); 15, Siphonaria lessiori Blainville (MLP: 33.789 , Pleistoceno); 16, Parvanachis isabellei d'Orbigny (MLP:33.779, Pleistoceno); 17, Costoanachis sertulariarum (d'Orbigny) (MLP: 34.426, actual); 18,Buccinanops uruguayensis (Pilsbry) (MLP; 34.383, Holoceno); 19, Zidona dufresnei (Donovan) (MLP:33.794, Pleistoceno);20, Odontocymbiola magellanica (Gmelin) ( MLP:33.793, Holoceno);21, Adelomelon beckii (Broderip) (MLP: 34.449, Holoceno);22, Adelomelon (P.) brasiliana (Lamarck) ( MLP:33.795, Holoceno). 


\begin{tabular}{|c|c|c|c|c|c|c|c|c|c|c|c|c|}
\hline Bivalvos & $\mathbf{C 2}$ & C3 & C4 & E5 & E6 & E7 & E8 & E9 & E10 & F8 & F9 & F10 \\
\hline \multicolumn{13}{|l|}{ Familia Nuculidae Gray,1824 } \\
\hline \multicolumn{13}{|l|}{ Nucula (N.) nucleus ( Linné, 1758) } \\
\hline Ennucula grayi (d'Orbigny, 1846) & & & & & & & & & $\mathbf{X}$ & & & \\
\hline \multicolumn{13}{|l|}{ Familia Nuculanidae H. y A. Adams, 1858} \\
\hline Adrana electa (A. Adams, 1856) & & & & & & $\mathbf{X}$ & & & & & & \\
\hline \multicolumn{13}{|l|}{ Familia Glycymerididae Newton, 1922} \\
\hline Glycymeris (G.) longior ( Sowerby,1832) & & & $\mathbf{X}$ & $\mathbf{X}$ & $\mathbf{X}$ & $\mathbf{X}$ & $\mathbf{X}$ & & & & $\mathbf{X}$ & $\mathbf{x}$ \\
\hline \multicolumn{13}{|l|}{ Familia Mytilidae Rafinesque,1815 } \\
\hline Mytilus edulis platensis d'Orbigny, 1846 & & & & & & & & & & & & $\mathbf{X}$ \\
\hline Brachidontes $(B)$ rodrigueziii ( d'Orbigny, 1846 ) & & & & & & $\mathbf{X}$ & $\mathbf{X}$ & & $\mathbf{X}$ & & $\mathbf{X}$ & $\mathbf{X}$ \\
\hline \multicolumn{13}{|l|}{ Familia Plicatulidae Watson, 1930} \\
\hline Plicatula gibbosa Lamarck, 1801 & & & & $\mathbf{X}$ & & & & & & & & \\
\hline \multicolumn{13}{|l|}{ Familia Ostreidae Rafinesque,1815 } \\
\hline \multicolumn{13}{|l|}{ Crassostrea rhizophorae (Guilding, 1828) } \\
\hline \multicolumn{13}{|l|}{ Crassostrea gigas (Thunberg, 1793) } \\
\hline Ostrea & & & & & & & & & & & & $\bar{x}$ \\
\hline \multicolumn{13}{|l|}{ Ostreola equestris (Say, 1834) } \\
\hline Ostrea puelchana d'Orbigny 1841 & & & & $\mathbf{X}$ & $\mathbf{X}$ & $\mathbf{X}$ & $\mathbf{X}$ & & & & $\mathbf{X}$ & \\
\hline \multicolumn{13}{|l|}{ Familia Pectinidae Rafinesque, 1815} \\
\hline \multicolumn{13}{|l|}{$\begin{array}{l}\text { Aequipecten tehuelchus (d'Orbigny, 1842) } \\
\text { Familia Diplodontidae Dall, } \mathbf{1 8 9 5}\end{array}$} \\
\hline \multicolumn{13}{|l|}{ Familia Diplodontidae Dall, 1895} \\
\hline Diplodonta (D.) patagonica ( d'Orbigny, 1842) & & & & & & & & & & $\mathbf{X}$ & $\mathbf{X}$ & $\mathbf{x}$ \\
\hline Diplodonta (F.)vilardeboana (d'Orbigny, 1846) & & & & & & & & & & & & \\
\hline \multicolumn{13}{|l|}{ Familia Carditidae Fleming, 1828} \\
\hline Carditamera plata (Inhering, 1907) & & & & & $\mathbf{X}$ & $\mathbf{X}$ & & & $\mathbf{X}$ & & & $\mathbf{x}$ \\
\hline \multicolumn{13}{|l|}{ Familia Mactridae Lamarck,1809 } \\
\hline Mactra sp. & & & & & $\mathbf{X}$ & & & & & & & \\
\hline Mactra guidoi Signorelli \&Scarabino,2010 & & & & & & & & & & & & \\
\hline Familia Solenidae Lamarck, 1809 & & & & & & & & & & & & \\
\hline
\end{tabular}




\begin{tabular}{|c|c|c|c|c|c|c|c|c|c|c|c|c|}
\hline Bivalvos & C2 & C3 & C4 & E5 & E6 & E7 & E8 & E9 & E10 & F8 & F9 & F10 \\
\hline Solen tehuelchus Philippi, 1847 & & & & & & & & & & & & $\mathbf{X}$ \\
\hline \multicolumn{13}{|l|}{ Familia Telinidae De Blainville,1814 } \\
\hline Macoma (P.) uruguayensis (Smith, 1885) & & & & & $\mathbf{X}$ & & & & & & & \\
\hline Angulus gibber Ihering, 1907 & & & & & & & & & & & & $\mathbf{X}$ \\
\hline \multicolumn{13}{|l|}{ Familia Solecurtidae d'Orbigny, 1846} \\
\hline Tagelus (T.) plebeius (Ligthfood,1786) & $\mathbf{X}$ & & & & & & & & & $\mathbf{X}$ & $\mathbf{X}$ & \\
\hline \multicolumn{13}{|l|}{ Familia Veneridae Rafinesque,1815 } \\
\hline Tivela isabelleana (d'Orbigny, 1846 ) & & & & & $\mathbf{X}$ & & & & & & & \\
\hline Pitar (P.) rostratus (Philippi, 1844) & $\mathbf{X}$ & & & $\mathbf{X}$ & $\mathbf{X}$ & $\mathbf{X}$ & $\mathbf{X}$ & $\mathbf{X}$ & $\mathbf{X}$ & & $\mathbf{X}$ & $\mathbf{X}$ \\
\hline Amiantis purpurata ( Lamarck, 1856) & & & & & $\mathbf{X}$ & & $\mathbf{X}$ & $\mathbf{X}$ & $\mathbf{X}$ & & $\mathbf{X}$ & $\mathbf{X}$ \\
\hline \multicolumn{13}{|l|}{ Familia Corbulidae Gray, 1823} \\
\hline Corbula (C.) patagonica d’Orbigny, 1846 & & & & $\mathbf{X}$ & $\mathbf{X}$ & $\mathbf{X}$ & & & $\mathbf{X}$ & $\mathbf{X}$ & $\mathbf{X}$ & $\mathbf{X}$ \\
\hline \multicolumn{13}{|l|}{ Familia Lyonsiidae Rafinesque, 1815} \\
\hline Lyonsia (L.)alvarezii d'Orbigny, 1846 & & & & & & & & & & & & $\mathbf{X}$ \\
\hline
\end{tabular}

T.7.2: Lista sistemática de especies de bivalvos de cada sitio muestreado de la región de bahía Anegada. 


\begin{tabular}{|c|c|c|c|c|c|c|c|c|}
\hline Bivalvos & F11 & F12 & F13 & F14 & F15 & G6 & G7 & G8 \\
\hline Familia Nuculidae Gray,1824 & & & & & $\mathbf{X}$ & & & \\
\hline \multicolumn{9}{|l|}{ Nucula (N.) nucleus ( Linné, 1758) } \\
\hline Ennucula grayi (d'Orbigny, 1846) & & & & & & & & $\mathbf{X}$ \\
\hline \multicolumn{9}{|l|}{ Familia Nuculanidae H. y A. Adams, 1858} \\
\hline \multicolumn{9}{|l|}{ Adrana electa (A. Adams, 1856) } \\
\hline \multicolumn{9}{|l|}{ Familia Glycymerididae Newton, 1922} \\
\hline Glycymeris (G.) longior ( Sowerby,1832) & & & & & & $\mathbf{X}$ & & \\
\hline \multicolumn{9}{|l|}{ Familia Mytilidae Rafinesque,1815 } \\
\hline Mytilus edulis platensis d'Orbigny, 1846 & & & & $\mathbf{X}$ & & & & \\
\hline Brachidontes $(B)$ rodriguezii ( d'Orbigny, 1846 ) & & & & $\mathbf{X}$ & & & $\mathbf{X}$ & $\mathbf{X}$ \\
\hline \multicolumn{9}{|l|}{ Familia Plicatulidae Watson, 1930} \\
\hline \multicolumn{9}{|l|}{ Plicatula gibbosa Lamarck, 1801} \\
\hline \multicolumn{9}{|l|}{ Familia Ostreidae Rafinesque,1815 } \\
\hline Crassostrea rhizophorae (Guilding, 1828) & & & & & $\mathbf{X}$ & & & \\
\hline Crassostrea gigas (Thunberg, 1793) & & & & & & & $\mathbf{X}$ & $\mathbf{X}$ \\
\hline Ostrea & & & & & & & & $\mathbf{X}$ \\
\hline \multicolumn{9}{|l|}{ Ostreola equestris (Say, 1834) } \\
\hline Ostrea puelchana d'Orbigny 1841 & & $\mathbf{X}$ & $\mathbf{X}$ & & & & $\mathbf{X}$ & \\
\hline \multicolumn{9}{|l|}{ Familia Pectinidae Rafinesque, 1815} \\
\hline Aequipecten tehuelchus (d'Orbigny, 1842) & & & $\mathbf{X}$ & & & & & \\
\hline \multicolumn{9}{|l|}{ Familia Diplodontidae Dall, 1895} \\
\hline \multicolumn{9}{|l|}{ Diplodonta (D.) patagonica ( d'Orbigny, 1842) } \\
\hline Diplodonta (F.) vilardeboana (d'Orbigny, 1846) & & & & & & & & $\mathbf{X}$ \\
\hline \multicolumn{9}{|l|}{ Familia Carditidae Fleming, 1828} \\
\hline Carditamera plata (Inhering, 1907) & & $\mathbf{X}$ & & & $\mathbf{X}$ & & & $\mathbf{X}$ \\
\hline \multicolumn{9}{|l|}{ Familia Mactridae Lamarck,1809 } \\
\hline \multicolumn{9}{|l|}{ Mactra sp. } \\
\hline Mactra guidoi Signorelli \&Scarabino,2010 & & & & & $\mathbf{X}$ & & & \\
\hline \multicolumn{9}{|l|}{ Familia Solenidae Lamarck, 1809} \\
\hline Solen tehuelchus Philippi, 1847 & & & & & & & & \\
\hline
\end{tabular}




\begin{tabular}{|l|c|c|c|c|c|c|c|c|}
\hline BivalvoS & F11 & F12 & F13 & F14 & F15 & G6 & G7 & G8 \\
\hline Familia Telinidae De Blainville,1814 & & & & & & & & \\
\hline Macoma (P.) uruguayensis (Smith, 1885) & & & & & & & & \\
\hline Angulus gibber Ihering, 1907 & & & & & & & & \\
\hline Familia Solecurtidae d'Orbigny,1846 & & & & & & & & \\
\hline Tagelus (T.) plebeius (Ligthfood,1786) & $\mathbf{X}$ & & & $\mathbf{X}$ & $\mathbf{X}$ & $\mathbf{X}$ & & $\mathbf{X}$ \\
\hline Tivela isabelleana (d'Orbigny, 1846) & & & & & & & \\
\hline Pitar (P.) rostratus (Philippi, 1844) & & $\mathbf{X}$ & $\mathbf{X}$ & $\mathbf{X}$ & $\mathbf{X}$ & $\mathbf{X}$ & $\mathbf{X}$ & $\mathbf{X}$ \\
\hline Amiantis purpurata (Lamarck, 1856) & & $\mathbf{X}$ & $\mathbf{X}$ & $\mathbf{X}$ & $\mathbf{X}$ & $\mathbf{X}$ & & \\
\hline Familia Corbulidae Gray, 1823 & & & & & & & & \\
\hline Corbula (C.) patagonica d'Orbigny, 1846 & & & & $\mathbf{X}$ & $\mathbf{X}$ & & $\mathbf{X}$ & $\mathbf{X}$ \\
\hline Familia Lyonsiidae Rafinesque, 1815 & & & & & & & & \\
\hline Lyonsia (L.)alvarezii d'Orbigny,1846 & & & & & & & & $\mathbf{X}$ \\
\hline
\end{tabular}

T.7.3: Lista sistemática de especies de bivalvos de cada sitio muestreado de la región de bahía Anegada. 


\begin{tabular}{|l|l|l|l|l|l|l|l|l|l|l|l|l|}
\hline Gasterópodos & C2 & C3 & C4 & E5 & E6 & E7 & E8 & E9 & E10 & F8 & F9 & F10 \\
\hline Familia Calliostomatidae Thiele, 1924 & & & & & & & & & & & & \\
\hline Tegula (A.) patagonica (d'Orbigny, 1835) & & & & $\mathbf{X}$ & $\mathbf{X}$ & $\mathbf{X}$ & $\mathbf{X}$ & $\mathbf{X}$ & $\mathbf{X}$ & & $\mathbf{X}$ & $\mathbf{X}$ \\
\hline Familia Calyptraeidae Lamarck,1809 & & & & & & & & & & & \\
\hline Bostrycapulus odites (Collin, 2005) & & & & $\mathbf{X}$ & $\mathbf{X}$ & $\mathbf{X}$ & & $\mathbf{X}$ & & & & $\mathbf{X}$ \\
\hline Crepidula & & & & & & & & & & \\
\hline Crepidula argentina Simone, Pastorino \& \\
Penchaszadeh, 2000
\end{tabular}




\begin{tabular}{|l|l|l|l|l|l|l|l|l|l|l|l|l|}
\hline Gasterópodos & C2 & C3 & C4 & E5 & E6 & E7 & E8 & E9 & E10 & F8 & F9 & F10 \\
\hline Buccinanops uruguayensis (Pilsbry, 1897) & & & & & X & & X & & & & & \\
\hline Familia Columbellidae Swaison, 1840 & & & & & & & & & & & & \\
\hline Parvanachis isabellei (d'Orbigny, 1839) & & & & & X & & X & & X & & & X \\
\hline Costoanachis sertulariarum (d'Orbigny, 1839) & & & & & & X & & & & & & \\
\hline Familia Pyramidellidae Gray, 1840 & & & & & & & & & & & & \\
\hline Turbonilla paralamilata (Castellano, 1982) & & & & & & & & & & & & \\
\hline $\begin{array}{l}\text { Chrysallida multituberculata (Castellano, } \\
\text { 1982) }\end{array}$ & & & & & & & & & & & \\
\hline Familia Siphonariidae Gray, 1840 & & & & & & & & & & & & \\
\hline Siphonaria lessoni (Blainville, 1824) & & & & & & & & & & & & \\
\hline
\end{tabular}

T.7.4: Lista sistemática de especies de gasterópodos de cada sitio muestreado de la región de bahía Anegada. 


\begin{tabular}{|c|c|c|c|c|c|c|c|c|}
\hline Gasterópodos & F11 & F12 & F13 & F14 & F15 & G6 & G7 & G8 \\
\hline \multicolumn{9}{|l|}{ Familia Calliostomatidae Thiele, 1924} \\
\hline Tegula (A.) patagonica (d'Orbigny, 1835) & & & $\mathbf{X}$ & $\mathbf{X}$ & & $\mathbf{X}$ & & $\mathbf{X}$ \\
\hline \multicolumn{9}{|l|}{$\begin{array}{l}\text { Familia Calyptraeidae } \\
\text { Lamarck, } 1809\end{array}$} \\
\hline Bostrycapulus odites (Collin, 2005) & & $\mathbf{X}$ & $\mathbf{X}$ & $\mathbf{X}$ & $\mathbf{X}$ & & & \\
\hline Crepidula & $\mathbf{X}$ & $\mathbf{X}$ & & & & & & \\
\hline \multicolumn{9}{|l|}{$\begin{array}{l}\text { Crepidula argentina Simone, Pastorino \& } \\
\text { Penchaszadeh, } 2000\end{array}$} \\
\hline \multicolumn{9}{|l|}{ Familia Naticidae Forbes, 1828} \\
\hline Notocochlis isabelleana (d'Orbigny, 1840) & & $\mathbf{X}$ & & & & & & \\
\hline \multicolumn{9}{|l|}{ Familia Hydrobiidae Troschel, 1857} \\
\hline Heleobia australis ( d'Orbigny, 1835) & $\mathbf{X}$ & $\mathbf{X}$ & & $\mathbf{X}$ & $\mathbf{X}$ & $\mathbf{X}$ & $\mathbf{X}$ & $\mathbf{X}$ \\
\hline \multicolumn{9}{|l|}{ Familia Epitoniidae S. S.Berry, 1910} \\
\hline \multicolumn{9}{|l|}{$\begin{array}{l}\text { Epitonium (E.) georgettinum } \\
\text { (d'Orbigny, 1840) }\end{array}$} \\
\hline \multicolumn{9}{|l|}{ Familia Muricidae Rafinesque, 1815} \\
\hline Urosalpinx cala (Pilsbry, 1897) & & & & & & $\mathbf{X}$ & & \\
\hline \multicolumn{9}{|l|}{ Familia Volutidae Rafinesque, 1815} \\
\hline \multicolumn{9}{|l|}{ Odontocymbiola magellanica (Gmelin, 1791) } \\
\hline Zidona dufresnei ( Donovan, 1823) & & $\mathbf{X}$ & $\mathbf{X}$ & & $\mathbf{X}$ & $\mathbf{X}$ & & $\mathbf{X}$ \\
\hline Adelomelon (P.) brasiliana (Lamarck, 1811) & & $\mathbf{X}$ & & & & $\mathbf{X}$ & & \\
\hline \multicolumn{9}{|l|}{ Adelomelon beckii (Broderip,1838) } \\
\hline \multicolumn{9}{|l|}{ Familia Olividae Latreille, 1825} \\
\hline Olivella (O.) tehuelcha ( Dúclos, 1835) & & & & & & $\mathbf{X}$ & & \\
\hline Olivancillaria urceus ( Röding, 1798) & & $\mathbf{X}$ & & & & & & \\
\hline Olivancillaria carcellesi Klappenbach, 1965 & & & & $\mathbf{X}$ & & & & \\
\hline Olivancillaria uretai Klappenbach, 1965 & & & & & $\mathbf{X}$ & & & \\
\hline \multicolumn{9}{|l|}{ Familia Nassariidae Iredale, 1916} \\
\hline Buccinanops & & & & & & & & $\mathbf{X}$ \\
\hline Buccinanops monilifer ( Kiener, 1834) & & $\mathbf{X}$ & & & & & & \\
\hline Buccinanops cochlidium (Dilwyn, 1817) & & $\mathbf{X}$ & & & $\mathbf{X}$ & & & \\
\hline Buccinanops globulosus (Kiener, 1834) & & $\mathbf{X}$ & $\mathbf{X}$ & $\mathbf{X}$ & $\mathbf{X}$ & $\mathbf{X}$ & $\mathbf{X}$ & $\mathbf{X}$ \\
\hline \multicolumn{9}{|l|}{ Buccinanops uruguayensis (Pilsbry, 1897) } \\
\hline \multicolumn{9}{|l|}{$\begin{array}{l}\text { Familia Columbellidae Swaison, } \\
1840\end{array}$} \\
\hline Parvanachis isabellei (d'Orbigny, 1839) & & $\mathbf{X}$ & & & & & & $\mathbf{X}$ \\
\hline \multicolumn{9}{|l|}{ Costoanachis sertulariarum (d'Orbigny, 1839) } \\
\hline \multicolumn{9}{|l|}{ Familia Pyramidellidae Gray, 1840} \\
\hline Turbonilla paralamilata (Castellano, 1982) & & & & & & & & $\mathbf{X}$ \\
\hline $\begin{array}{l}\text { Chrysallida multituberculata (Castellano, } \\
\text { 1982) }\end{array}$ & & & & & & & & $\mathbf{X}$ \\
\hline \multicolumn{9}{|l|}{ Familia Siphonariidae Gray, 1840} \\
\hline Siphonaria lessoni (Blainville, 1824) & & & $\mathbf{X}$ & & & & & \\
\hline
\end{tabular}

T.7.5: Lista sistemática de especies de gasterópodos de cada sitio muestreado de la región de bahía Anegada. 
Según el índice de Shannon $\left(\mathrm{H}^{\prime}\right)$, los depósitos pleistocenos más antiguos (C2 - C4), pertenecientes al Interglacial $\geq$ MIS 9 presentan los índices más bajos registrados. Los depósitos pleistocenos (E5 - E10), pertenecientes al Interglacial MIS 5e, tienen índices desde (1.65 - 2.36). Entre los índices más altos en su mayoría figuran los sitios pertenecientes al Interglacial MIS 1 (2.05-2.90) a excepción de dos sitios (F8 y F11) (Fig. 7.15 y T. 7.4).

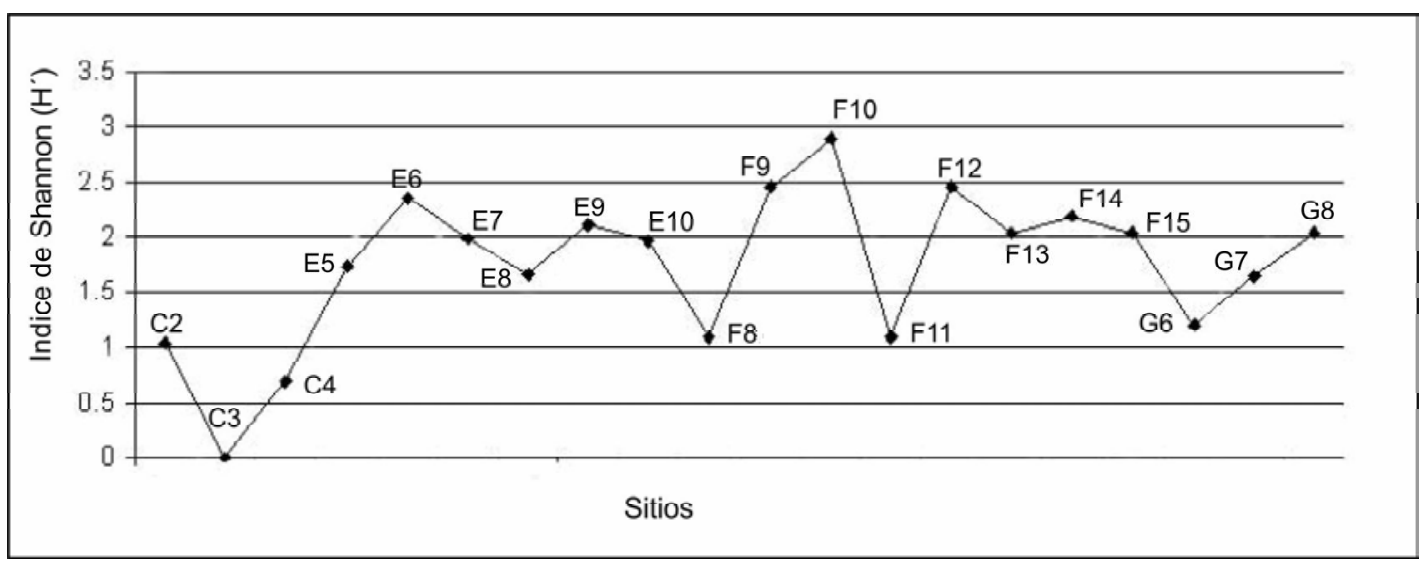

Fig. 7.15: Gráfico del índice de Shannon ( $\mathrm{H}^{\prime}$ ) de cada sitio de la región de bahía Anegada.

\begin{tabular}{|c|c|c|}
\hline $\mathbf{N}$ - de sitio & $\begin{array}{c}\text { Índice de Shannon } \\
\left(\mathbf{H}^{\prime} \mathbf{)}\right.\end{array}$ & № de especies \\
\hline C2 & 1.04 & 3 \\
\hline C3 & 0 & 2 \\
\hline C4 & 0.70 & 13 \\
\hline E5 & 1.74 & 21 \\
\hline E6 & 2.36 & 14 \\
\hline E7 & 1.99 & 12 \\
\hline E8 & 1.65 & 9 \\
\hline E9 & 2.11 & 10 \\
\hline E10 & 1.97 & 5 \\
\hline F8 & 0.82 & 14 \\
\hline F9 & 2.46 & 25 \\
\hline F10 & 2.90 & 14 \\
\hline
\end{tabular}




\begin{tabular}{|c|c|c|}
\hline & & 3 \\
\hline F11 & 1.10 & 15 \\
\hline F12 & 2.46 & 10 \\
\hline F13 & 2.05 & 12 \\
\hline F14 & 2.18 & 17 \\
\hline F15 & 2.05 & 10 \\
\hline G6 & 1.20 & 7 \\
\hline G7 & 1.64 & 19 \\
\hline G8 & 2.05 & \\
\hline
\end{tabular}

T.7.4: Tabla de índices de diversidad ( $\left.\mathrm{H}^{\prime}\right)$, y riqueza en cada sitio analizado en la región de bahía Anegada.

\subsubsection{Pleistoceno de bahía Anegada}

En los depósitos pleistocenos, se registró un total de 28 especies (14 bivalvos y 14 gasterópodos) de 9 sitios analizados. En los depósitos pleistocenos más antiguos (C2 C4) que pertenecerían al Interglacial $\geq$ MIS9, se registraron 6 especies del total (3 bivalvos y 3 gasterópodos) y la especie más abundantes resultó Buccinanops globulosus (gasterópodo). Mientras que en el Interglacial MIS 5e (E5 - E10), todos los sitios representan a cordones litorales de cotas de $10-7 \mathrm{~m}$ y se registró un total de 27 especies (12 bivalvos y 15 gasterópodos). Entre las especies más abundantes figuran: Glycymeris longior, Ostrea puelchana, Pitar rostratus, Amiantis purpurata (bivalvos), y Tegula patagonica, Heleobia australis, Bostrycapulus odites y Crepidula argentina (gasterópodos).

\subsubsection{Holoceno de bahía Anegada}

En los depósitos holocenos, se registró un total de 37 especies (19 bivalvos y 18 gasterópodos) de 8 sitios analizados. Los depósitos marinos pertenecientes al Interglacial MIS 1, representan a planicies de mareas (F8 y F11) y cordones litorales (F9, F10 y F12-15). Entre las especies más abundantes se encuentran: Pitar rostratus, Amiantis purpurata, Corbula patagonica (bivalvos), y Heleobia australis, Buccinanops 
globulosus, Zidona dufresnei y Tegula patagonica (gasterópodos). Entre ellos, se destaca en el Sitio F15, la presencia de Crassostrea rhizophorae (bivalvo). Este bivalvo actualmente no se encuentra en las aguas de las costas argentinas.

\subsubsection{Crassostrea rhizophorae (Guilding, 1828)}

Crassostrea rhizophorae, es un bivalvo típico de aguas más cálidas, que actualmente se distribuye a lo largo del Mar Caribe hasta las costas del sur de Brasil y Uruguay (Ríos, 1994; Varela et al., 2007; Melo et al., 2010). Este bivalvo puede medir hasta $120 \mathrm{~mm}$, es de forma variable, generalmente alargada, gruesa con la valva superior pequeña y aplanada.

\subsubsection{Playas actuales de bahía Anegada}

En las costas actuales, se registró un total de 21 especies (13 bivalvos y 8 gasterópodos) en 3 sitios analizados. En el norte del área, las playas son llanuras de mareas fangosas y al sur se caracterizan por se playas arenosas con abundante restos de valvas y conchas. Entre las especies más abundantes se encuentran Pitar rostratus, Corbula patagonica, Crassostrea gigas, Brachidontes rodriguezii (bivalvos), y Buccinanops globulosus, Zidona dufresnei y Bostrycapulus odites (gasterópodos) (Fig. 7.17 y Fig. 7.18).

Entre la fauna marina no autóctona, se destaca la aparición de Crassostrea gigas, es un bivalvo que vive en aguas del Pacífico (Japón), y fue introducida para su cultivo en Argentina en 1981. Se encuentra con abundancia en el Sitio G7, en la localidad de Los Pocitos. Esta especie, inicia su expansión desde bahía Anegada llegando en la actualidad hasta el balneario El Cóndor $\left(41^{\circ} \mathrm{S}\right.$, provincia de Río Negro) (Castaño et al., 2009).

En las playas cercana a Los Pocitos (Sitio G8), entre la fauna se destaca la aparición de 2 microgasterópodos (< $10 \mathrm{~mm}$ ), Turbonilla paralaminata (Castellano, 1992) y Chrysallida multituberculata (Castellano, 1992). 


\subsubsection{Familia Pyramidellidae Gray, 1840}

La Familia Pyramidellidae, pertenece a la superfamilia Pyramidelloidea del Clado Heterobranchia (Poppe \& Tagaro, 2006), es una familia de microgasterópodos poco estudiado en los depósitos marinos cuaternarios en la Argentina.

Los micromoluscos se caracterizan por poseer una concha pequeña, cuya altura fluctúa aproximadamente desde los $5 \mathrm{~mm}$ (Naranjo García, 2003) hasta los $10 \mathrm{~mm}$ como altura máxima (Farinati et al., 2006).

Los micromoluscos cuaternarios han sido mencionados solo como fauna acompañante en los depósitos del noreste bonaersense (Aguirre 1990,1993a, b), pero no han sido utilizados como objeto de estudio como indicadores paleoecológicos (ej. Brinckman, 1964; De Francesco y Hassan, 2009).

Castellanos (1982) realizó estudios exhaustivos sistemáticos de micromoluscos en la plataforma argentina y hace referencia a la Familia Pyramedilladae entre otras familias de microgasterópodos.

En el Cuaternario de Argentina, autores como Farinati (1993, 1994) y Farinati et al. (2006), han llevado a cabo trabajos de micromoluscos a nivel sistemático y tafonómico de depósitos holocenos de la localidad Bahía Blanca (sur de Provincia de Buenos Aires). Aguirre (1993) por su parte hace una mención preliminar de algunos microgasterópodos encontrados en depósitos holocenos del área noreste de la Provincia de Buenos Aires.

La presencia de los micromoluscos Turbonilla paralaminata y Chrysallida multituberculata, constribuye y corrobora la distribución geográfica actual de ambas especies, enriqueciendo el análisis paleoecológico de las asociaciones faunísticas que vivieron en la actualidad en la región de bahía Anegada (Fig. 7.16). 
A

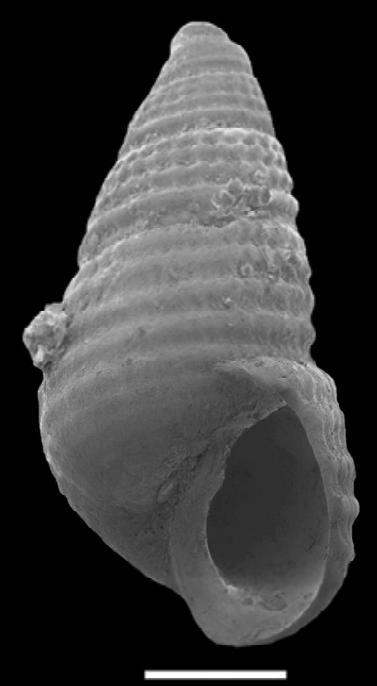

$500 \mu \mathrm{m}$

B

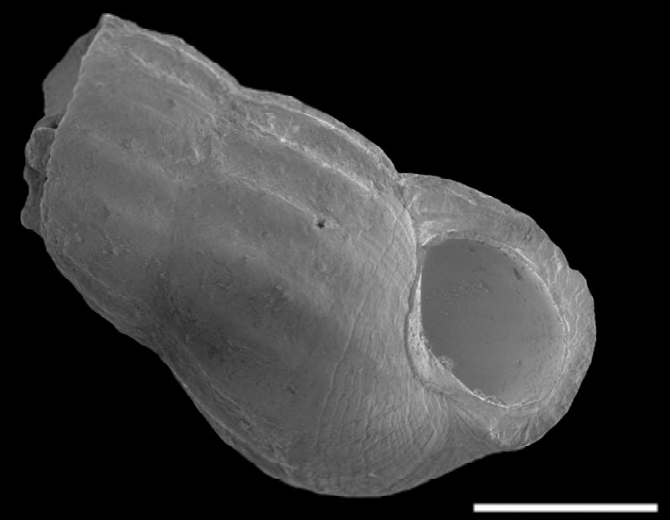

$500 \mu \mathrm{m}$

Fig. 7.16: A, Chrysallida multituberculata (Castellanos) (MLP: 34.430, actual); B, Turbonilla paralaminata (Castellanos).(MLP:34.431, actual). 
Bivalvos pleistocenos ( C )

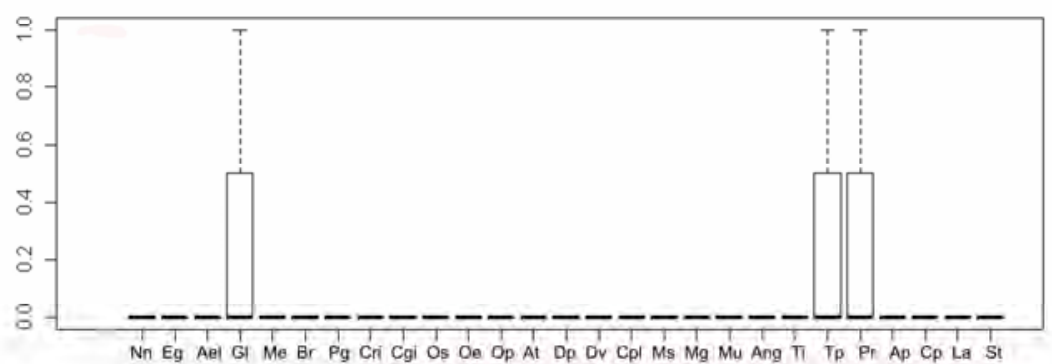

Bivalvos pleistocenos $(\mathrm{E})$

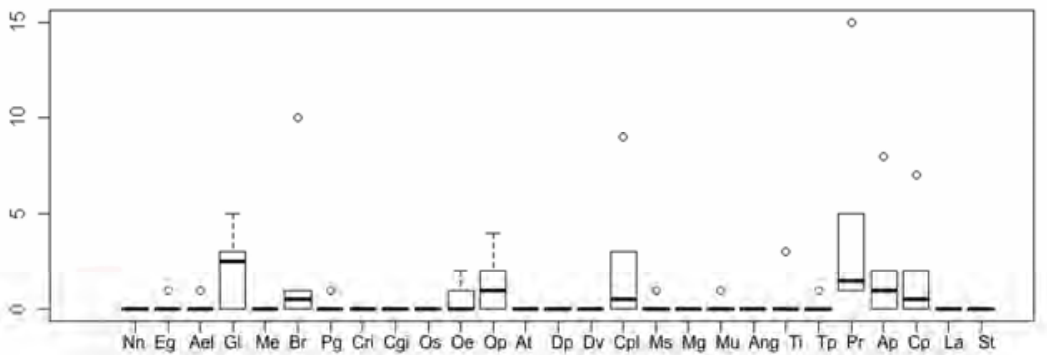

Bivalvos holocenos $(F)$

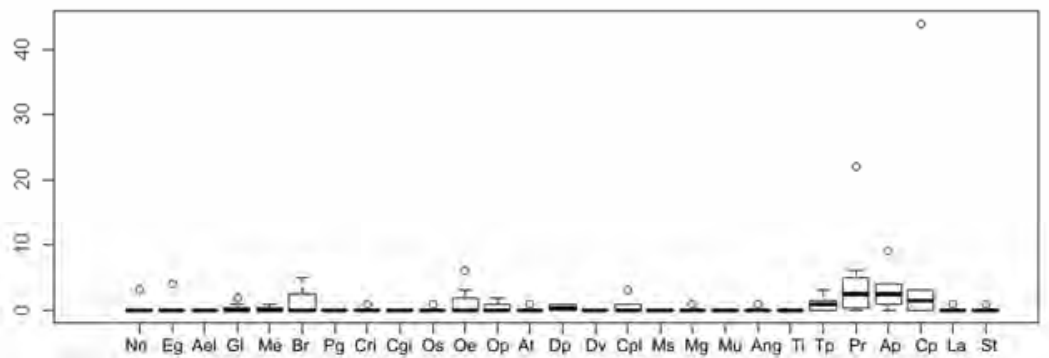

Bivalvos actuales $(G)$

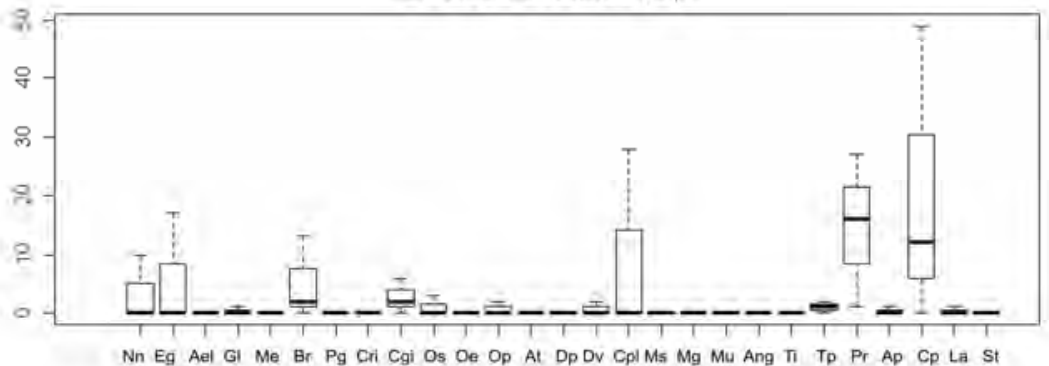

Fig. 7.17: Abundancias de bivalvos cuaternarios de la región de bahía Anegada. 
Gasterópodos pleistocenos ( C )

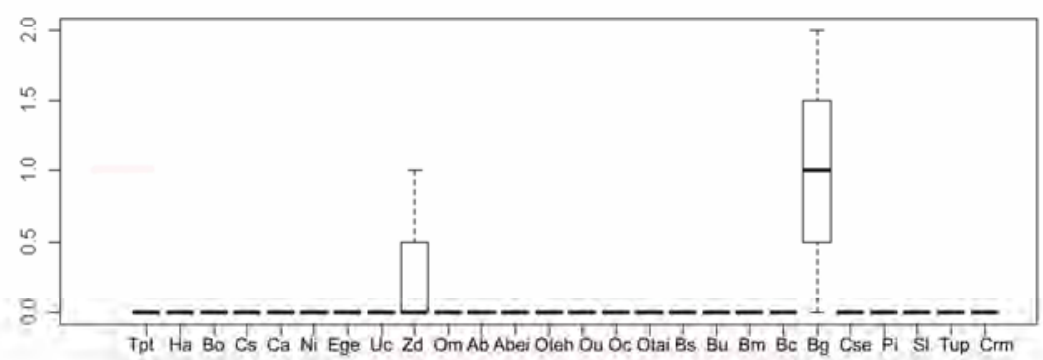

Gasterópodos pleistocenos (E)

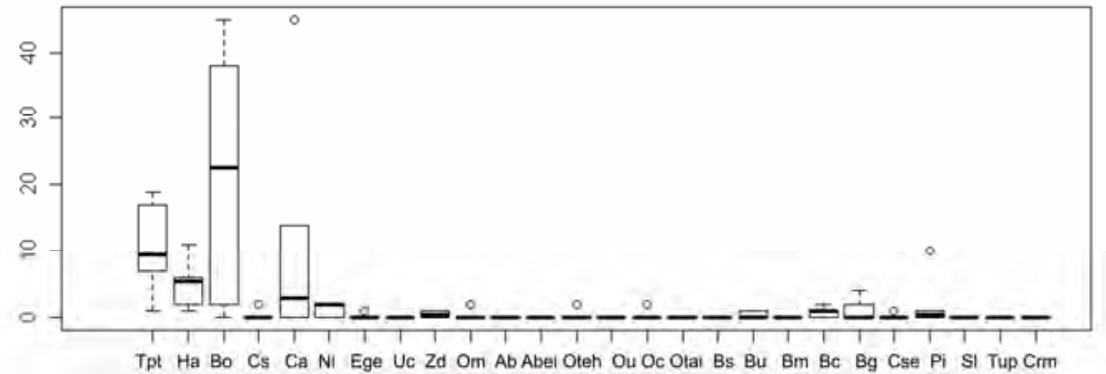

Gasterópodos holocenos (F)

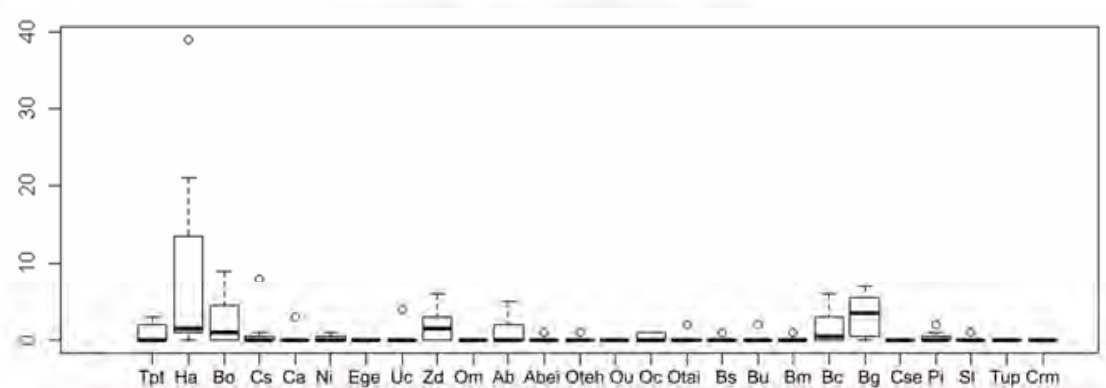

Gasterópodos actuales (G)

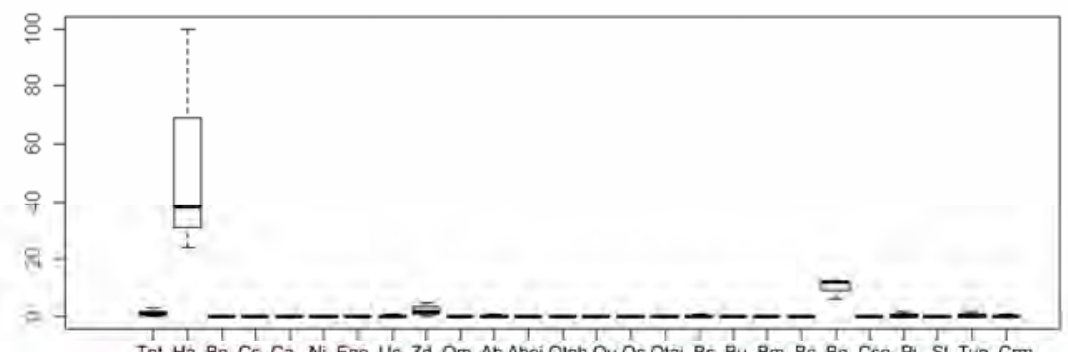

Tpt Ha Bo Cs Ca Ni Ege Uc Zd Om Ab Abei Oleh Ou Oc Otai Bs Bu Bm Bc Bg Cse PI St Túp Cm

Fig. 7.18: Abundancias de gasterópodos cuaternarios de la región de bahía Anegada. 


\subsection{Paleoecología}

En el Pleistoceno más antiguo (C), perteneciente al Interglacial $\geq$ MIS 9, los bivalvos en su mayoría son oligohalino - polihalinos - eurihalinos, todas epifaunales, de sustratos arenosos y herbívoros. A partir del Interglacial MIS 5e (E), en su mayoría son eurihalinos, infaunales con proporción de especies cementadas y epifaunales, de sustratos arenosos con aumento en la proporción de especies de sustrato rocoso, y en su mayoría herbívoros apareciendo especies carnívoras. Durante el Interglacial MIS 1 (F) la mayoría de los bivalvos son eurihalinos, hay un aumento en la proporción de epifaunales, apareciendo especies mixtas y filtradoras. En playas actuales (G), las especies mixtas y las filtradoras no se representan, aumentando las especies infaunales, permaneciendo casi similares los demás factores paleoecológicos (Fig 7.19 y Tabla 7.6).

Entre los gasterópodos, en el Pleistoceno más antiguo $(\mathrm{C})$, perteneciente al Interglacial $\geq$ MIS 9, son todos eurihalinos, epifaunales, de sustratos arenosos y carnívoros. A partir del Interglacial MIS 5e (E), en su mayoría son eurihalinos apareciendo especies oligohalinas - polihalinas- mesohalinas y epifaunales, con un aumento en la proporción de infaunales y especies ectoparásitas. Aparecen especies de sustratos rocosos y mixtos disminuyendo las especies carnívoras, y apareciendo herbívoros y filtradores. Durante el Interglacial MIS 1 (F), no se representan las especies ectoparásitas, aumenta la proporción de especies de sustratos arenosos, y las especies carnívoras. En playas actuales (G), hay un aumento en la proporción de especies ectoparásitas y desapareciendo las especies filtradoras (Fig. 7.20 y Tabla 7.7). 


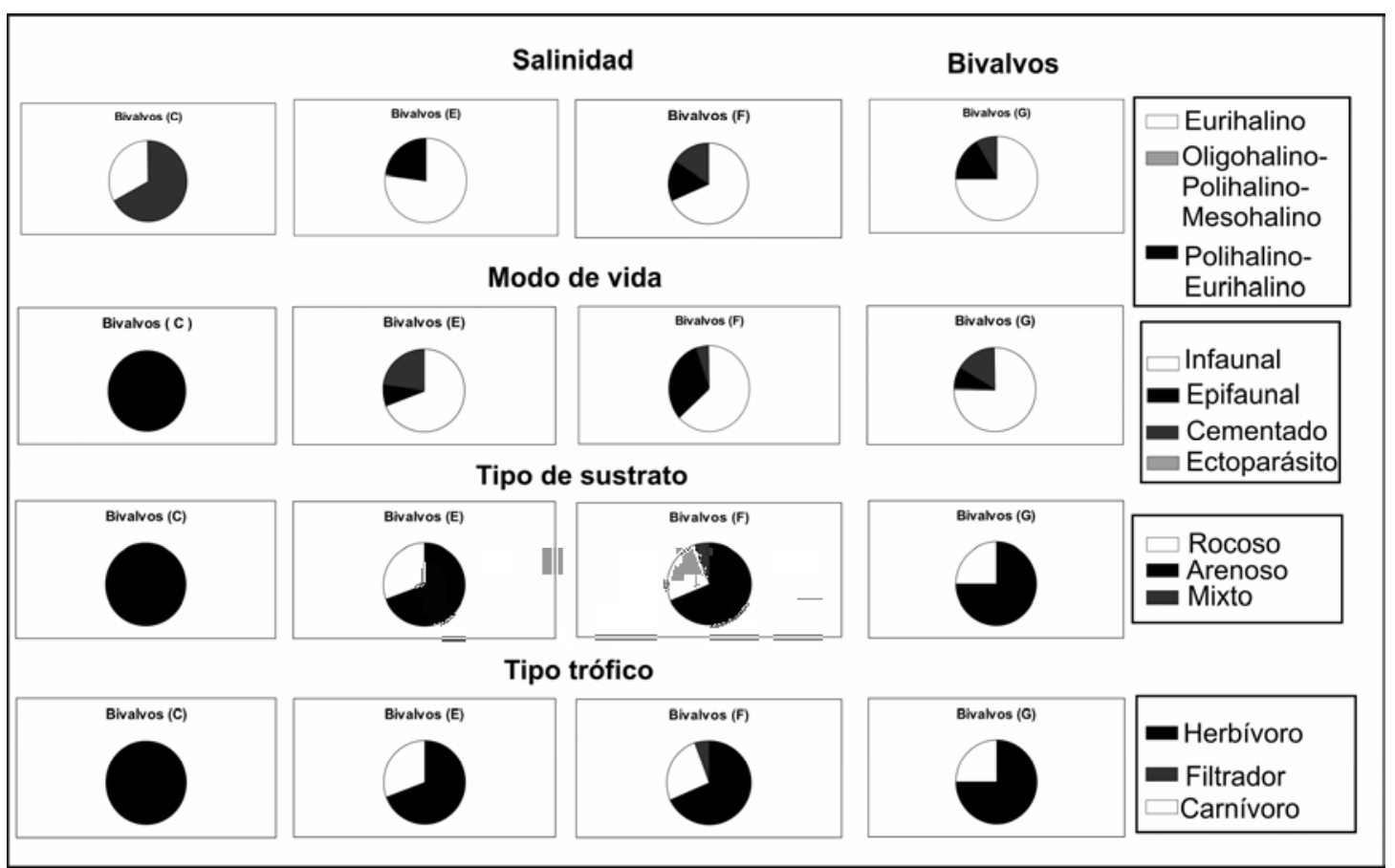

Fig. 7.19: Proporción de bivalvos según la salinidad, modo de vida, tipo de sustrato y tipo trófico.

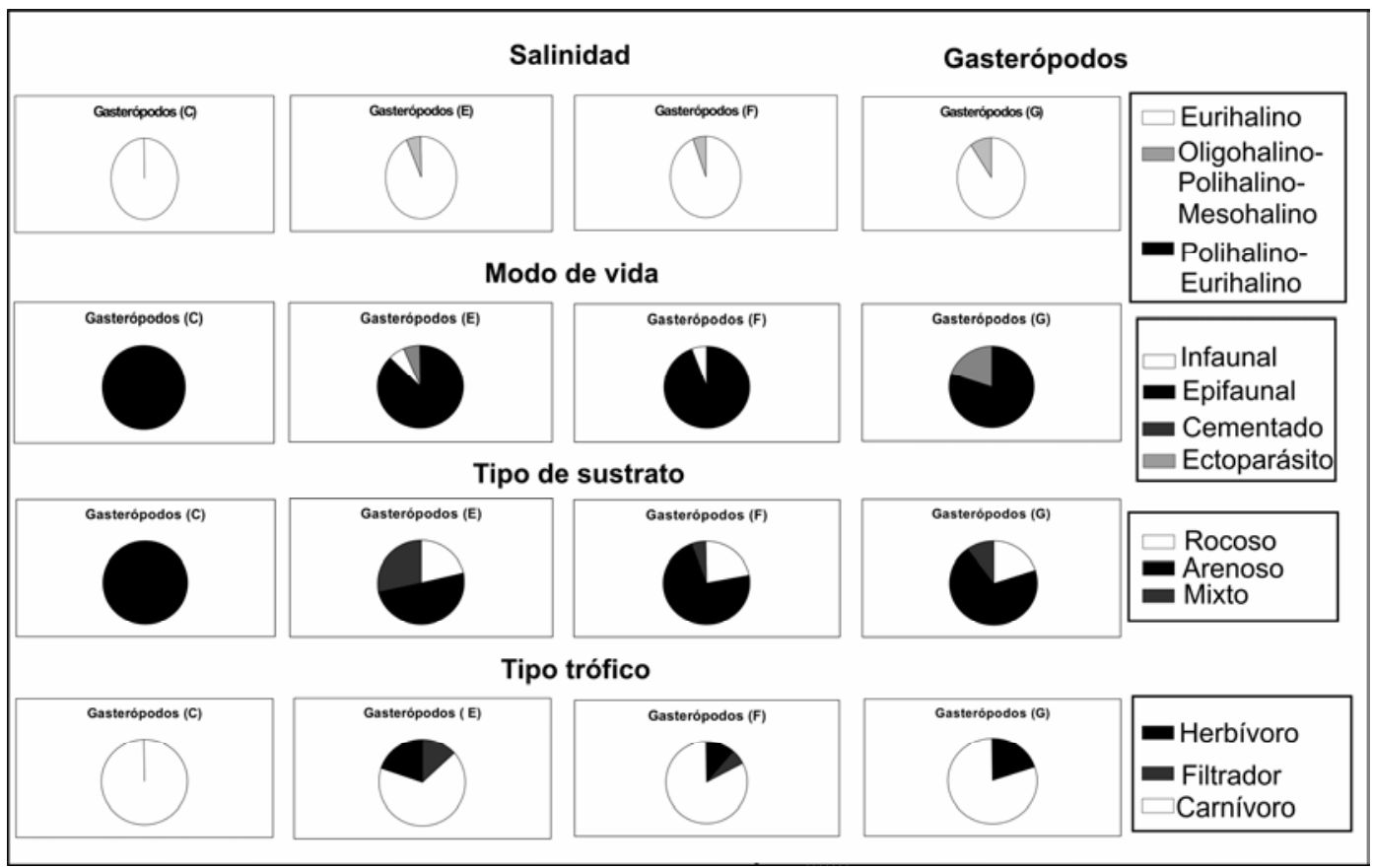

Fig. 7.20: Proporción de gasterópodos según la salinidad, modo de vida, tipo de sustrato y tipo trófico. 


\begin{tabular}{|c|c|c|c|c|c|c|}
\hline BIVALVOS & Salinidad & $\begin{array}{c}\text { Modo } \\
\text { de vida }\end{array}$ & $\begin{array}{c}\text { Profundid } \\
\text { ad }\end{array}$ & Sustrato & $\begin{array}{c}\text { Tipo } \\
\text { trófico }\end{array}$ & Área de distribución \\
\hline Nucula (N.) nucleus ( Linné, 1758) & $E$ & 1 & $0-200$ & $\mathrm{~S}$ & $\mathrm{D}$ & $23^{\circ} \mathrm{S}-53.5^{\circ} \mathrm{S}$ \\
\hline Ennucula grayi (d'Orbigny,1846) & $E$ & $\mathrm{I}$ & $5-1850$ & $\mathrm{~S}$ & $\mathrm{D}$ & $22.93^{\circ} \mathrm{S}-55.5^{\circ} \mathrm{S}$ \\
\hline Adrana electa (A. Adams, 1856) & $\mathrm{E}$ & I & $20-75$ & $\mathrm{~S}$ & $\mathrm{D}$ & $22.93^{\circ} \mathrm{S}-39^{\circ} \mathrm{S}$ \\
\hline Glycymeris (G.) longior ( Sowerby, 1832) & $\mathrm{E}$ & I & $10-75$ & $\mathrm{~S}$ & $\mathrm{~F}$ & $10^{\circ} \mathrm{S}-42^{\circ} \mathrm{S}$ \\
\hline Mytilus edulis platensis d'Orbigny, 1846 & P-E & Ep & $0-50$ & $\mathrm{R}$ & $\mathrm{F}$ & $68^{\circ} \mathrm{N}-55.5^{\circ} \mathrm{S}$ \\
\hline Brachidontes $(B)$ rodriguezii ( d'Orbigny, 1846) & P-E & Ep & $0-25$ & $\mathrm{R}$ & $\mathrm{F}$ & $34^{\circ} \mathrm{S}-42^{\circ} \mathrm{S}$ \\
\hline Plicatula gibbosa Lamarck, 1801 & $E$ & $\mathrm{Ce}$ & $0-120$ & $\mathrm{R}$ & $\mathrm{F}$ & $35.3^{\circ} \mathrm{N}-34^{\circ} \mathrm{S}^{*}$ \\
\hline Crassostrea rhizophorae (Guilding, 1828) & $\bar{P}-\mathrm{E}$ & $\mathrm{Ce}$ & $0-50$ & $\mathrm{R}$ & $\mathrm{C}$ & $21.4^{\circ} \mathrm{N}-35^{\circ} \mathrm{S}$ \\
\hline Crassostrea gigas (Thunberg, 1793) & $\mathrm{E}$ & $\mathrm{Ce}$ & $0-40$ & $\mathrm{R}$ & $\mathrm{F}$ & Cosmopolitan \\
\hline Ostreola equestris (Say, 1834) & $\mathrm{P}-\mathrm{E}$ & $\mathrm{Ce}$ & $0-80$ & $\mathrm{R}$ & C & $37^{\circ} \mathrm{N}-42^{\circ} \mathrm{S}$ \\
\hline Ostrea puelchana d'Orbigny 1841 & P-E & $\mathrm{Ce}$ & $0-70$ & $\mathrm{R}$ & $\mathrm{C}$ & $22^{\circ} \mathrm{S}-42^{\circ} \mathrm{S}$ \\
\hline Aequipecten tehuelchus (d'Orbigny, 1842) & $\mathrm{E}$ & Ep & $10-120$ & $\mathrm{M}$ & $\mathrm{F}$ & $21^{\circ} \mathrm{S}-53^{\circ} \mathrm{S}$ \\
\hline Diplodonta (D.) patagonica ( d'Orbigny, 1842) & $E$ & $\frac{1}{1}$ & $36-102$ & $\mathrm{~S}$ & $\mathrm{~F}$ & $21^{\circ} \mathrm{S}-42.58^{\circ} \mathrm{S}$ \\
\hline Diplodonta (F.) vilardeboana (d'Orbigny, 1846) & $\mathrm{E}$ & $\mathrm{I}$ & $25-77$ & $\mathrm{~S}$ & $\mathrm{~F}$ & $21^{\circ} \mathrm{S}-42^{\circ} \mathrm{S}$ \\
\hline Carditamera plata (Ihering, 1907) & $\bar{E}$ & 1 & $17-70$ & $\mathrm{~S}$ & $\mathrm{~F}$ & $23^{\circ} \mathrm{S}-39^{\circ} \mathrm{S}^{*}$ \\
\hline Mactra guidoi Signorelli \&Scarabino,2010 & P-E & 1 & $0-25$ & $\mathrm{~S}$ & $\mathrm{~F}$ & $34^{\circ} \mathrm{S}-42^{\circ} \mathrm{S}$ \\
\hline Solen tehuelchus (Hanley, 1842) & $\mathrm{E}$ & $\mathrm{I}$ & $10-18$ & $\mathrm{~S}$ & $\mathrm{~F}$ & $23^{\circ} \mathrm{S}-39^{\circ} \mathrm{S}^{*}$ \\
\hline Macoma $(P$.$) uruguayensis (Smith, 1885)$ & $E$ & 1 & $18-70$ & $\mathrm{~S}$ & $\mathrm{D}$ & $29^{\circ} \mathrm{S}-39^{\circ} \mathrm{S}^{*}$ \\
\hline Angulus gibber Ihering, 1907 & $\mathrm{E}$ & $\mathrm{I}$ & $13-55$ & $\mathrm{~S}$ & $\mathrm{D}$ & $23^{\circ} \mathrm{S}-43^{\circ} \mathrm{S}$ \\
\hline Tagelus $(T$.$) plebeius (Ligthfood,1786)$ & $\mathrm{P}$ & 1 & $0-10$ & $\mathrm{~S}$ & $\mathrm{~F}$ & $42^{\circ} \mathrm{N}-54^{\circ} \mathrm{S}$ \\
\hline Tivela isabelleana (d'Orbigny, 1846) & $E$ & I & $0-55$ & $\mathrm{~S}$ & $\mathrm{~F}$ & $21^{\circ} \mathrm{S}-42^{\circ} \mathrm{S}$ \\
\hline Pitar (P.) rostratus (Philippi, 1844) & $\mathrm{E}$ & $\mathrm{I}$ & $10-100$ & $\mathrm{~S}$ & $\mathrm{~F}$ & $22^{\circ} \mathrm{S}-38.7^{\circ} \mathrm{S}^{*}$ \\
\hline Amiantis purpurata ( Lamarck, 1856) & $E$ & $\mathrm{I}$ & $0-20$ & $\mathrm{~S}$ & $\mathrm{~F}$ & $19^{\circ} \mathrm{S}-43^{\circ} \mathrm{S}$ \\
\hline Corbula (C.) patagonica d'Orbigny, 1846 & $\mathrm{E}$ & $\mathrm{I}$ & $15-90$ & $\mathrm{~S}$ & $\mathrm{~F}$ & $23^{\circ} \mathrm{S}-43^{\circ} \mathrm{S}$ \\
\hline Lyonsia (L.)alvarezii d'Orbigny, 1846 & $\bar{E}$ & 1 & $50-86$ & $\mathrm{~s}$ & $\mathrm{~F}$ & $38.3^{\circ} \mathrm{S}-41^{\circ} \mathrm{S}$ \\
\hline
\end{tabular}

T. 7.6: Requerimientos ecológicos y distribución de bivalvos: $\mathrm{Ep}=$ epifaunal, $\mathrm{I}=$ infaunal, $\mathrm{C}=$ cementado; $\mathrm{Ec}=\mathrm{ectoparásito;} \mathrm{R}=$ rocoso, $\mathrm{S}=\mathrm{arenoso}, \mathrm{M}=\mathrm{mixto}$; $\mathrm{C}=$ carnívoro, $\mathrm{D}=$ detritívoro, He=herbívoro, $\mathrm{F}=$ filtrador; $\mathrm{O}=$ oligohalino (3-8 \%), $\mathrm{M}=$ mesohalino (8-18\%); $\mathrm{P}=$ polihalino (18-30\%); $\mathrm{E}=$ eurihalino (> 30-35 $\%$ o). ${ }^{*}$ Límite sur de la especie diferente a lo encontrado. 


\begin{tabular}{|c|c|c|c|c|c|c|}
\hline GASTERÓPODOS & Salinidad & $\begin{array}{l}\text { Modo de } \\
\text { vida }\end{array}$ & Profundidad & Sustrato & $\begin{array}{c}\text { Tipo } \\
\text { trófico }\end{array}$ & $\begin{array}{c}\text { Área de } \\
\text { distribución }\end{array}$ \\
\hline Tegula (A.) patagonica (d'Orbigny, 1835) & $\mathrm{E}$ & Ep & $0-57$ & $\mathrm{R}$ & $\mathrm{He}$ & $23^{\circ} \mathrm{S}-54^{\circ} \mathrm{S}$ \\
\hline Bostrycapulus odites (Collin, 2005) & $\mathrm{E}$ & Ep & $0-46$ & $\mathrm{R}$ & $\mathrm{F}$ & $25^{\circ} \mathrm{S}-45.8^{\circ} \mathrm{S}$ \\
\hline $\begin{array}{l}\text { Crepidula argentina Simone, Pastorino } \\
\text { \&Penchaszadeh, } 2000\end{array}$ & $E$ & Ep & $30-50$ & $\mathrm{R}$ & $\mathrm{F}$ & $38^{\circ} \mathrm{S}-41.03^{\circ} \mathrm{S}$ \\
\hline Notocochlis isabelleana (d'Orbigny, 1840) & $E$ & $\mathrm{I}$ & $0-113$ & $\mathrm{~S}$ & $\mathrm{C}$ & $22.4^{\circ} \mathrm{S}-42.58^{\circ} \mathrm{S}$ \\
\hline Heleobia australis ( d'Orbigny, 1835) & $\mathrm{O}, \mathrm{P}, \mathrm{M}$ & Ep & $0-60$ & $\mathrm{M}$ & $\mathrm{He}$ & $24^{\circ} \mathrm{S}-41^{\circ} \mathrm{S}$ \\
\hline Epitonium (E.) georgettinum (d'Orbigny, 1840) & $\mathrm{E}$ & Ep & $0-101$ & $\mathrm{M}$ & $\mathrm{C}$ & $23.37^{\circ} \mathrm{S}-44.27^{\circ}$ \\
\hline Urosalpinx cala (Pilsbry, 1897) & $\mathrm{E}$ & Ep & $28-28$ & $\mathrm{R}$ & $\mathrm{C}$ & $32^{\circ} \mathrm{S}-41^{\circ} \mathrm{S}$ \\
\hline Zidona dufresnei ( Donovan, 1823) & $\mathrm{E}$ & Ep & $10-90$ & $\mathrm{~S}$ & $\mathrm{C}$ & $23^{\circ} \mathrm{S}-42^{\circ} \mathrm{S}$ \\
\hline Odontocymbiola magellanica (Gmelin, 1791) & $\mathrm{E}$ & Ep & $10-200$ & $\mathrm{M}$ & $\mathrm{C}$ & $35^{\circ} \mathrm{S}-55.2^{\circ} \mathrm{S}$ \\
\hline Adelomelon (P.) brasiliana (Lamarck, 1811) & $E$ & Ep & $8-70$ & S & $\mathrm{C}$ & $23^{\circ} \mathrm{S}-52^{\circ} \mathrm{S}$ \\
\hline Adelomelon beckii (Broderip,1838) & $E$ & Ep & $40-75$ & $\mathrm{~S}$ & $\mathrm{C}$ & $20^{\circ} \mathrm{S}-52^{\circ} \mathrm{S}$ \\
\hline Olivella (O.) tehuelcha ( Dúclos, 1835) & $\mathrm{E}$ & Ep & $15-57$ & S & C & $23.69^{\circ} \mathrm{S}-43^{\circ} \mathrm{S}$ \\
\hline Olivancillaria urceus ( Röding, 1798) & $\mathrm{E}$ & Ep & $5-50$ & $\mathrm{~S}$ & C & $19^{\circ} \mathrm{S}-42^{\circ} \mathrm{S}$ \\
\hline Olivancillaria carcellesi Klappenbach, 1965 & $\mathrm{E}$ & Ep & $0-22$ & $\mathrm{~S}$ & C & $23^{\circ} \mathrm{S}-42.5^{\circ} \mathrm{S}$ \\
\hline Olivancillaria uretai Klappenbach, 1965 & $E$ & Ep & & $\mathrm{S}$ & C & $23^{\circ}=5-40.6^{\circ} S$ \\
\hline Buccinanops monilifer ( Kiener, 1834) & $\mathrm{E}$ & Ep & $0-50$ & S & C & $35^{\circ} \mathrm{N}-42^{\circ} \mathrm{S}$ \\
\hline Buccinanops cochlidium (Dilwyn, 1817) & $\mathrm{E}$ & Ep & $5-66$ & $\mathrm{~S}$ & C & $23^{\circ} \mathrm{S}-42.58^{\circ} \mathrm{S}$ \\
\hline Buccinanops globulosus (Kiener, 1834) & $\mathrm{E}$ & Ep & $0-6$ & $\mathrm{~S}$ & C & $35^{\circ} \mathrm{S}-46^{\circ} \mathrm{S}$ \\
\hline Buccinanops uruguayensis (Pilsbry, 1897) & $\mathrm{E}$ & Ep & $15-45$ & $\mathrm{~S}$ & $\mathrm{C}$ & $24^{\circ} \mathrm{S}-42^{\circ} \mathrm{S}$ \\
\hline Parvanachis isabellei (d'Orbigny, 1839) & $\mathrm{E}$ & Ep & $10-65$ & $\mathrm{~S}$ & $\mathrm{C}$ & $30^{\circ} \mathrm{S}-54^{\circ} \mathrm{S}$ \\
\hline Costoanachis sertulariarum (d'Orbigny, 1839) & $\mathrm{E}$ & Ep & $0-20$ & $\mathrm{M}$ & $\mathrm{C}$ & $35^{\circ} \mathrm{N}-54^{\circ} \mathrm{S}$ \\
\hline Turbonilla paralamilata (Castellano, 1982) & $\mathrm{E}$ & Ec & $30-65$ & $\mathrm{~S}$ & $\mathrm{C}$ & $39 \div 5-41^{\circ} S$ \\
\hline Chrysallida multituberculata (Castellano, 1982) & $\mathrm{E}$ & Ec & $30-65$ & $\mathrm{~S}$ & $\mathrm{C}$ & $40^{\circ} S-46^{\circ}=S$ \\
\hline Siphonaria lessoni (Blainville, 1824) & $\mathrm{E}$ & Ep & 0 & $\mathrm{R}$ & $\mathrm{He}$ & $32^{\circ} \mathrm{S}-55.22^{\circ} \mathrm{S}$ \\
\hline
\end{tabular}

T. 7.7: Requerimientos ecológicos y distribución de gasterópodos: $\mathrm{Ep}=$ epifaunal, $\mathrm{I}=$ infaunal, Ec=ectoparásito, $\mathrm{Ce}=\mathrm{cementado}$; $\mathrm{R}=\mathrm{rocoso}, \mathrm{S}=\mathrm{arenoso}$, $\mathrm{M=mixto}$; $\mathrm{C}=$ carnívoro, $\mathrm{D}=$ detritívoro, He=herbívoro, $\mathrm{F}=$ filtrador; $\mathrm{O}=$ oligohalino (3-8 \%o), $\mathrm{M}=$ mesohalino (8-18 \%o); $\mathrm{P}=$ polihalino (18-30 \%o); $\mathrm{E}=$ eurihalino (> 30-35\%o). 


\subsection{Temperaturas}

Según la cantidad de especies de aguas cálidasy no cálidas representadas en cada uno de los interglaciales, desde el Interglacial $\geq$ MIS 9 (C) un $67 \%$ las especies de bivalvos son cálidas, disminuyendo casi en un $21 \%$ desde el Interglacial MIS 5e (E) hasta el Interglacial MIS 1 (F), aumentando en la actualidad (G) en un $3 \%$ (Fig. 7.21). Con respecto a los gasterópodos desde el Interglacial $\geq$ MIS 9 (C) hay un $67 \%$ de especies cálidas, y se mantiene constante hasta el Interglacial MIS 1 (F), disminuyendo un $7 \%$ en la actualidad (G) (Fig. 7.22).

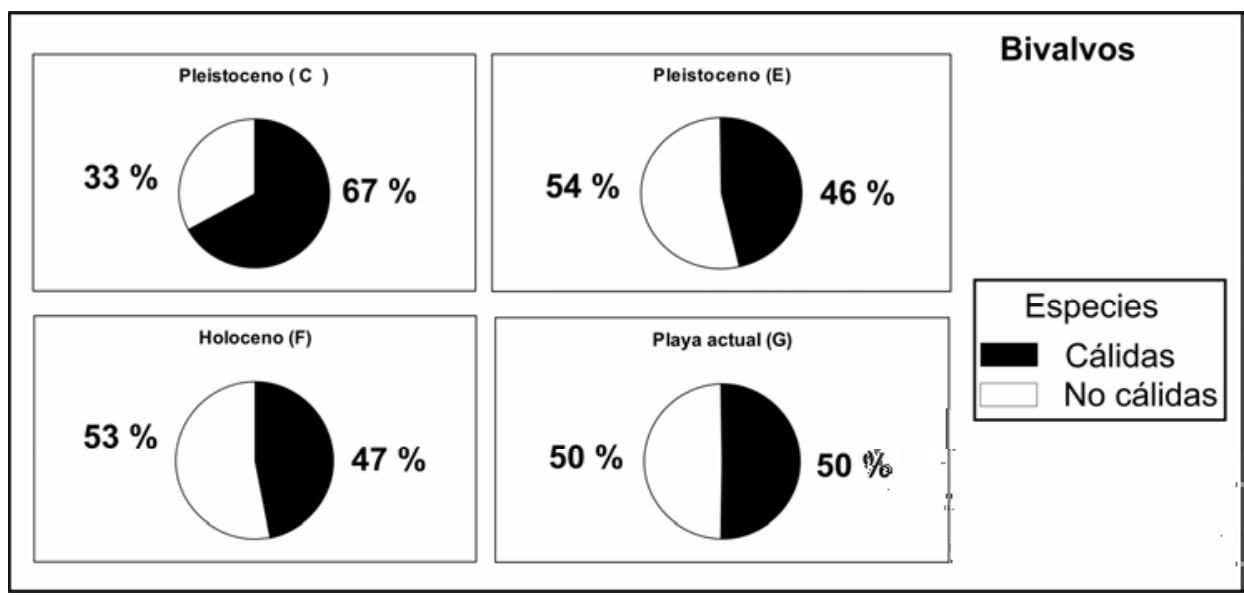

Fig. 7.21: Proporción de especies de bivalvos de aguas cálidas y no cálidas durante el

Cuaternario.

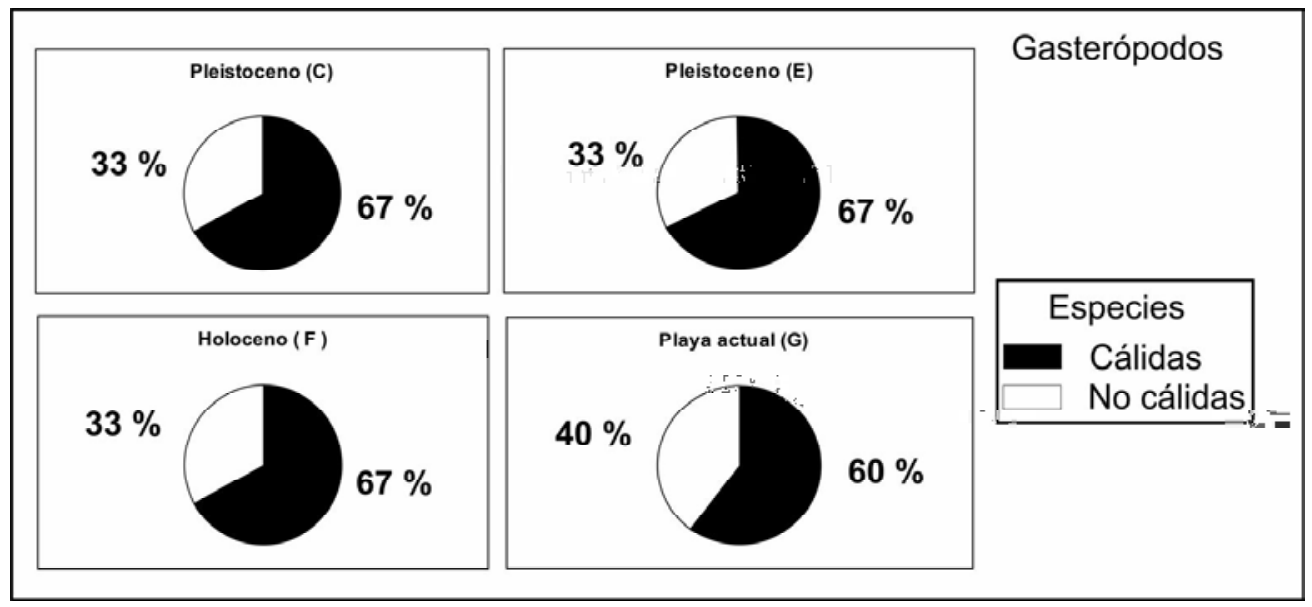


Fig. 7.22: Proporción de especies de gasteropodos de aguas cálidas y no cálidas durante el Cuaternario.

\subsection{Asociaciones faunísticas}

Según el método descriptivo estadístico de Bray - Curtis, los sitios interglaciales analizados de la región de bahía Anegada, se componen de tres asociaciones quedando aislado el Sitio C3. A) asociación faunística en su mayoría incluye todos los sitios actuales y dos sitios pertenecientes al Interglacial MIS 1 (F8 y F15) corresponden todos a playas arenosas exceptuando F8 que proviene de un ambiente de baja energía. Todos los sitios tienen en común la presencia de Heleobia australis y el género de Buccinanops (gasterópodos). B) asociación faunistica divida en dos subgrupos: B1) asociación faunística pertenecientes a cordones litorales del Interglacial MIS 5e, todos los sitios tienen en común la presencia de Glycymeris longior, Ostrea puelchana y Pitar rostratus (bivalvos) y Tegula patagonica y Crepidula argentina (gasterópodos). B2) asociación faunística que en su mayoría pertenecientes al Integlacial MIS 1 con excepción de dos sitios pertenecientes al Interglacial MIS 5e (E9 y E10), todos representados por cordones litorales, con la presencia de la asociación Pitar rostratus Amiantis purpurata. Todos los sitios del Interglacial MIS 1 representados en este subgrupo tienen en común la presencia de Buccinanops globulosus y todos los sitios pertenecientes al Interglacial MIS 5e tienen en común: Ostreola equestris (bivalvo), y Heleobia australis y Tegula patagonica (gasterópodos). C) asociación faunística pertenecientes en su mayoría al Interglacial $\geq$ MIS 9 con excepción de un sitio perteneciente al Interglacial MIS 1(F11), todos tienen en común un bajo índice de diversidad y bajo valor en riqueza de especies. El sitio $\mathrm{C} 3$, no corresponde a ningún grupo, pertenece a un paleoacantilado no funcional correspondiente al Interglacial $\geq$ MIS 9 compuesto por sedimentos finos poco cementado (Fig. 7.23). 


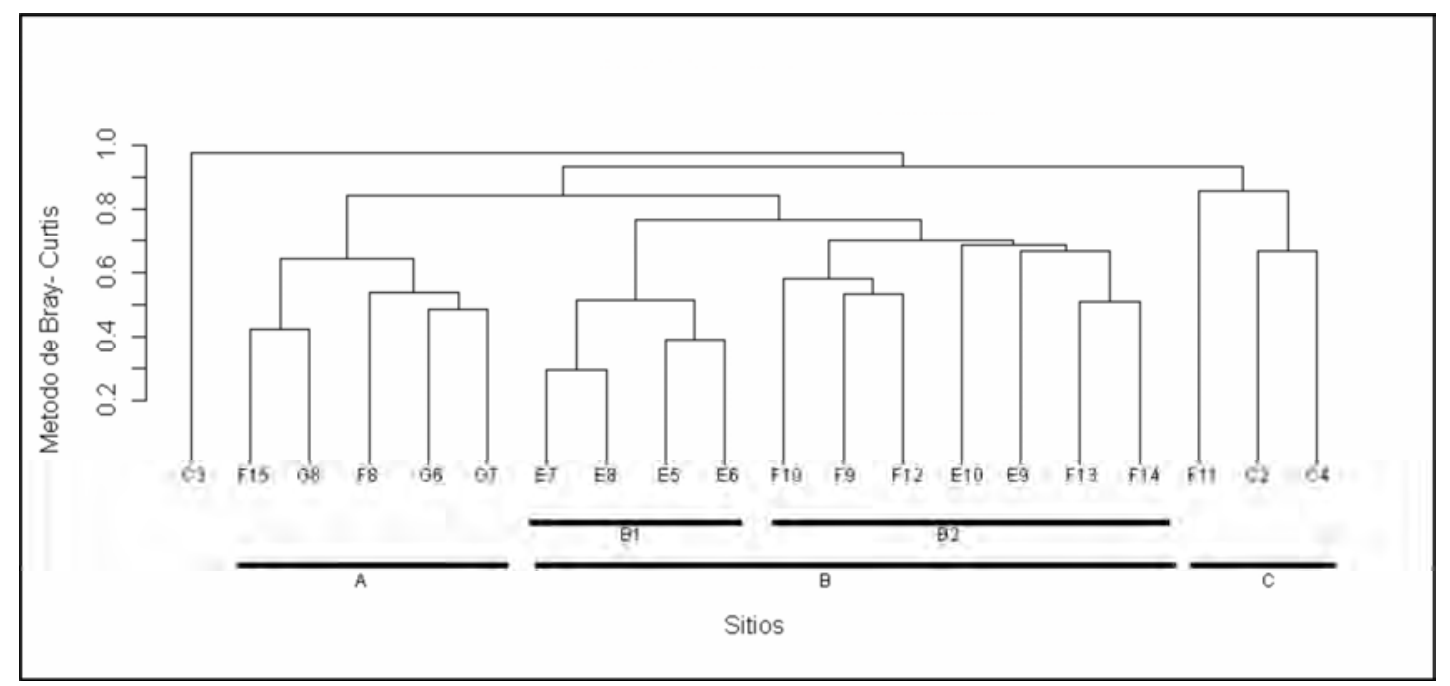

Fig. 7.23: Dendrograma de los sitios analizados basados en el índice de Bray- Curtis.

Según el método descriptivo de Análisis de Correspondencia (AC), en la región de bahía Anegada se distingue 4 asociaciones faunísticas diferentes con excepción de los sitios C3 y E10. A) asociación faunística perteneciente en su mayoría al Interglacial MIS 1, con excepción de 2 sitios pertenecientes al Interglacial $\geq$ MIS 9 y MIS 5e. Todos los sitios analizados corresponden a ambientes de alta energía, con una asociación particular de especies, entre los que se destacan Ostreola equestris (bivalvo), Urosalpinx cala, Adelomelon brasiliana, Olivancillaria carcellesi, Buccinanops monilifer y Buccinanops cochlidium (gasterópodos). B) asociación faunística que en su mayoría corresponde a playas arenosas actuales, con excepción de un sitio perteneciente al Interglacial MIS 1 (F15). Todos los sitios analizados pertenecen a la localidad de Los Pocitos, y tienen en común la presencia de Pitar rostratus (bivalvo) y Heleobia australis y Buccinanops globulosus (gasterópodos). C) asociación faunística compuesta por Tagelus plebeius, Corbula patagonica (bivalvos), Heleobia australis y el género Buccinanops (gasterópodos). D) asociación faunística pertenecientes a los sitios cercanos al Canal Villalonga del Interglacial MIS 5e que corresponden a ambientes de alta energía con alta riqueza en especies, en las cuales se destaca Glycymeris longior, Ostrea puelchana, Pitar rostratus (bivalvos) y Tegula patagonica y Crepidula argentina (gasterópodos). (Fig. 7.24 y Fig. 7.25). 


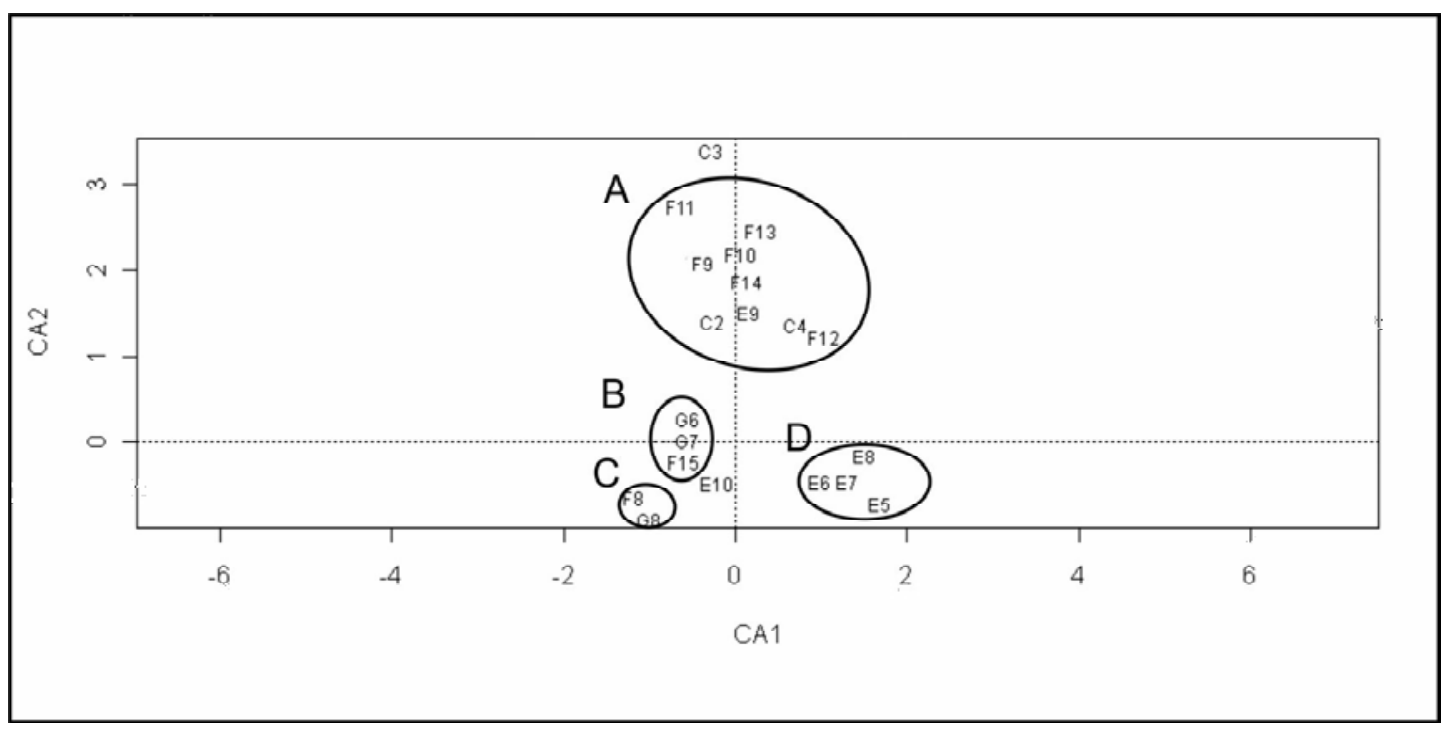

Fig. 7.24: Análisis de Correspondencia (AC) basados en la abundancia de las especies, todos los sitios confirman cuatro grupos A-D.

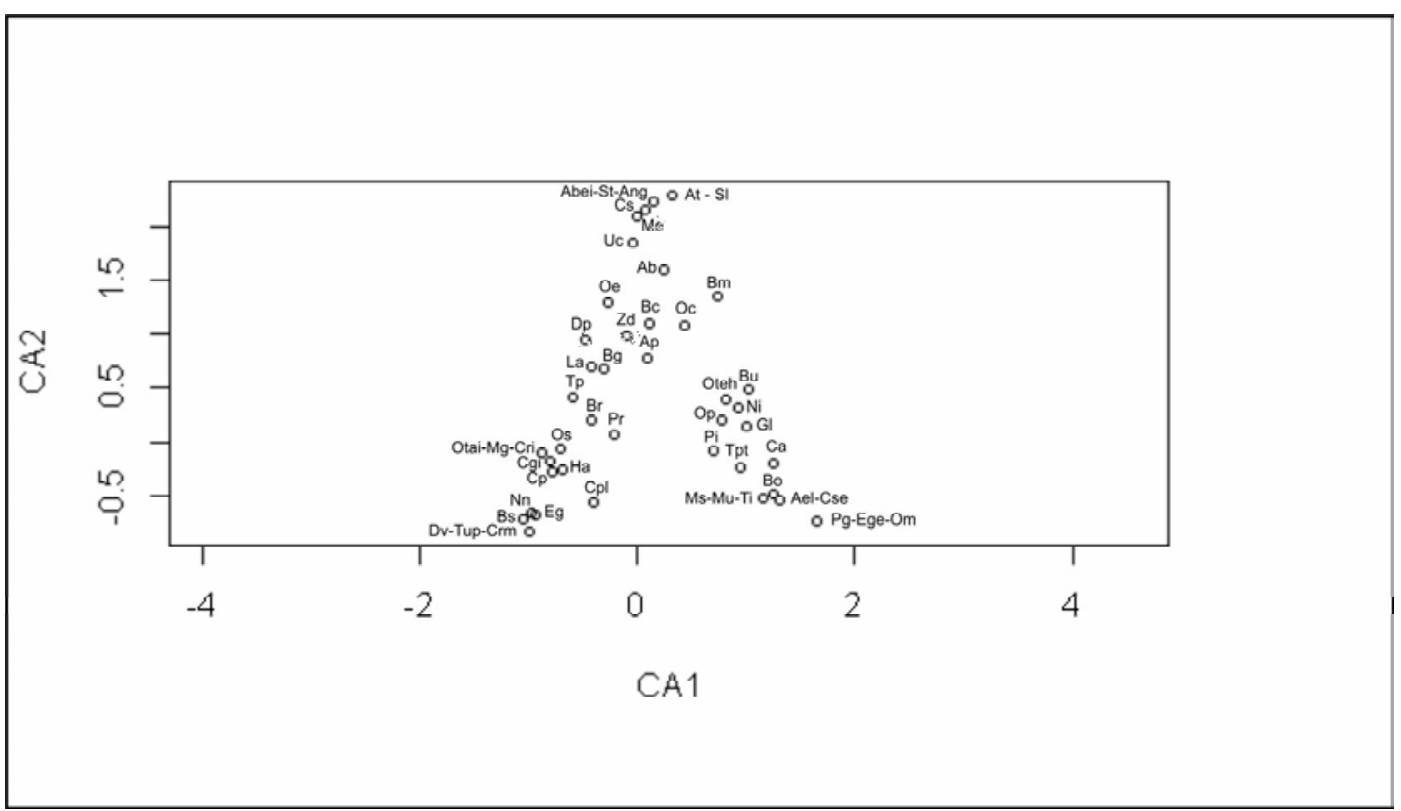

Fig. 7.25: Especies de bivalvos y gasterópodos asociados a los distintos sitios muestreados. 


\subsection{Conclusiones}

La región bahía Anegada se extiende desde isla Otero hasta las inmediaciones de isla Jabalí (Sur de la Provincia de Buenos Aires). En ella se describen los interglaciales $\geq$ MIS 9, MIS 5e y MIS 1 con un total de 20 sitios analizados (9 pleistocenos, 8 holocenos y 3 actuales), registrándose 49 especies ( 25 bivalvos y 24 gasterópodos).

Los índices más altos de diversidad en su mayoría son los sitios pertenecientes al Interglacial MIS 1 con excepción de F11 perteneciendo a un ambiente de menor energía. Los índices más bajos registrados pertenecen a C3 y C4, pertenecientes al Interglacial $\geq$ MIS 9 .

En el Interglacial $\geq$ MIS 9 en su mayoría se encuentra representado por cordones litorales con presencia en todos los depósitos por el gasterópodo Buccinanops globulosus. Los bivalvos son en mayoría oligohalino - polihalinos - eurihalinos, todos

epifaunales, de sustratos arenosos y herbívoros, y los gasterópodos son todos eurihalinos, epifaunales, de sedimentos arenosos y carnívoros.

En el Interglacial MIS 5e, todos los sitios representan a cordones litorales. En los mismos se detectaron un total de 28 especies, entre las más abundantes figuran: Glycymeris longior, Ostrea puelchana, Pitar rostratus, Amiantis purpurata (bivalvos) y Tegula patagonica, Heleobia australis, Bostrycapulus odites y Crepidula argentina (gasterópodos). Tantos los bivalvos como los gasterópodos en su mayoría son eurihalinos, de sustratos arenosos, con aumento de especies rocosas respecto al período anterior aumentado la proporción de gasterópodos de especies oligohalinos polihalinos - mesohalinos y de sustratos mixtos. Los bivalvos en su mayoría son herbívoros y aparecen especies cementadas, epifaunales y carnívoras. En cambio, los gasterópodos en su mayoría son carnívoros, apareciendo especies herbívoras y filtradores, como infaunales y ectoparásitas.

El Interglacial MIS 1, está representado por depósitos de planicies de mareas y cordones litorales, compuesto por 37 especies. En las planicies de marea, se destacan las especies Tagelus plebeius (bivalvo) y Heleobia australis (gasterópodos), mientras que en los 
cordones litorales existen la asociación de dos moluscos, Pitar rostratus - Amiantis purpurata, como también son comunes la presencia de Ostreola equestris (bivalvo) y Buccinanops cochlidium y Heleobia australis (gasterópodos).

De acuerdo al análisis paleoecológico, tanto los bivalvos como los gasterópodos en el Interglacial MIS 1 siguen condiciones similares al Interglacial MIS 5e. En bivalvos aumenta la proporción de epifaunales, apareciendo especies mixtas y filtradoras. En cuanto, a los gasterópodos, no se representan las especies ectoparásitas, aumentando la proporción de especies de sustratos arenosos, y los carnívoros.

En este Interglacial MIS 1, se destaca la presencia del bivalvo Crassostrea rhizophorae, actualmente ausente en las costas argentinas. Esta especie se distribuye a latitudes más bajas, llegando hasta las costas de Uruguay, siendo un posible indicador de condiciones más cálidas para este Interglacial en el área mencionada.

Las playas actuales de la región de bahía Anegada son heterogéneas, en el norte del área, son llanuras de mareas fangosas y hacia el sur a los alrededores de la localidad Los Pocitos, se caracterizan por se playas arenosas con abundante restos de valvas y conchas. Se registró un total de 21 especies, y entre las más abundantes figuran: Pitar rostratus, Corbula patagonica, Crassostrea gigas, Brachidontes rodriguezii (bivalvos), y Buccinanops globulosus, Zidona dufresnei y Bostrycapulus odites (gasterópodos).

En estas playas se destaca el bivalvo invasor Crassostrea gigas, iniciando su expansión desde 1981 en bahía Anegada, llegando en la actualidad hasta el balneario El Cóndor ( $41^{\circ} \mathrm{S}$, provincia de Río Negro).

Según la temperatura, el $67 \%$ de los bivalvos y gasterópodos durante el Interglacial $\geq$ MIS 9 son especies cálidas. En el caso de los bivalvos en el Interglacial MIS 5e como en el Interglacial MIS 1 disminuye casi en un 20\% las especies de aguas cálidascon un aumento del $3 \%$ en la actualidad. En gasterópodos, desde el Interglacial $\geq$ MIS 9 hasta el Interglacial MIS 5e se mantiene constante el porcentaje de las especies de aguas cálidasen un $67 \%$ disminuyendo un $7 \%$ en la actualidad. 
Según el método descriptivo estadístico de Bray - Curtis, los sitios Interglaciales analizados de la región de bahía Anegada se componen por tres asociaciones diferentes: A) asociación faunística pertenecientes en su mayoría a sitios actuales de playas arenosas Todos los sitios tienen en común la presencia de Heleobia australis y el género de Buccinanops (gasterópodos). B) asociación faunística dividida en dos subgrupos, B1) asociación faunística pertenecientes a cordones litorales del Interglacial MIS 5e, todos los sitios tienen en común la presencia de Glycymeris longior, Ostrea puelchana y Pitar rostratus (bivalvos) y Tegula patagonica y Crepidula argentina (gasterópodos) y B2) asociación faunística pertenecientes en su mayoría al Interglacial MIS 1 representados por cordones litorales, con la presencia de dos bivalvos asociación Pitar rostratus - Amiantis purpurata. C) asociación faunística perteneciente en su mayoría al Interglacial $\geq$ MIS 9 poseyendo bajo índice de diversidad y bajo valor en riqueza de especies.

Según el método descriptivo de Análisis de Correspondencia (AC), en la región de bahía Anegada se distingue 4 asociaciones faunísticas diferentes: A) asociación faunística perteneciente en su mayoría al Interglacial MIS 1 que corresponden todos a ambientes de alta energía, con una asociación particular de especies, entre los que se destacan Ostreola equestris (bivalvo), Urosalpinx cala, Adelomelon brasiliana, Olivancillaria carcellesi, Buccinanops monilifer y Buccinanops cochlidium (gasterópodos). B) asociación faunística que en su mayoría corresponde a playas arenosas actuales, perteneciente todas a la localidad de Los Pocitos, y tienen en común la presencia de Pitar rostratus (bivalvo) y Heleobia australis y Buccinanops globulosus (gasterópodos). C) asociación faunística compuesta por Tagelus plebeius, Corbula patagonica (bivalvos), Heleobia australis y el género Buccinanops (gasterópodos). D) asociación faunística perteneciente a los sitios cercanos al Canal Villalonga del Interglacial MIS 5e que corresponden a ambientes de alta energía con alta riqueza en especies, en las cuales se destaca Glycymeris longior, Ostrea puelchana, Pitar rostratus (bivalvos) y Tegula patagonica y Crepidula argentina (gasterópodos). 


\section{REGIÓN DE ISLA JABALÍ - VILLA 7 DE MARZO}

\subsection{Descripción general de la región}

La región de isla Jabalí - Villa 7 de Marzo se ubica al S de la Provincia de Buenos Aires, abarcando el área que se desarrolla desde las inmediaciones de isla Jabalí $\left(40^{\circ} 28^{\prime}\right.$ S/62 ${ }^{\circ} 11^{\prime}$ O), Faro Segunda Barranca, Punta Redonda hasta Villa 7 de Marzo (41 $01^{\prime} \mathrm{S} /$ $62^{\circ} 45^{\prime} \mathrm{O}$ ) y desde la línea de costa actual hasta las inmediaciones de la ruta 3 (Fig. 8.1).

En el sector litoral, el canal San Blas constituye un rasgo importante, separando la isla Jabalí de la isla Gama, presentando una longitud aproximada de $13 \mathrm{~km}$ y un ancho promedio de 2 km (Cuadrado y Gómez, 2010).

En el área continental más occidental, las cotas varían entre los 15 y los 35 m, observándose una suave llanura en la que sobresalen elevaciones circulares y alargadas compuestas de gravas aplanadas muy cementadas con carbonatos de calcio con restos de moluscos, indicativos de su génesis litoral y que corresponderían a los niveles más antiguos observados y que podrían corresponder a dos unidades independientes pertenecientes al Interglacial $\geq$ MIS 9 (Fucks et al., 2012a).

Cerca de la costa actual, se destaca una serie de cordones litorales dispuestos a cotas del orden de los 8 - $10 \mathrm{~m}$, dispuestos en forma paralela u oblicua a la costa, compuestos por gravas friables, con incipientes procesos de entoscamiento, los que corresponderían al evento transgresivo del Interglacial MIS 5e. Presentan rumbo N-S, encontrándoselos en la región de la isla Jabalí truncados al norte por el arroyo homónimo y al sur por el arroyo Walker (Fucks et al., 2012a). Estos cordones se presentan a lo largo de gran parte de la costa hasta el Faro Segunda Barranca (Fig 8.1 A).

La isla Jabalí se caracteriza por presentar depósitos holocenos, pudiéndose dividir geomorfológicamente en dos sectores bien diferenciados. El oriental, de morfología llana, compuesto por arenas limosas, castaño-grisáceas, finamente estratificadas en el sector inferior y homogéneo y más castaño el superior; y el sector occidental, 
representado por una significativa cantidad de cordones adosados unos a otros, paralelos, transversales u oblicuos entre sí (Ambrosini, 1984; Trebino, 1987; Fucks et al. 2011, Fucks et al., 2012a). El Interglacial MIS 1 representan cordones litorales compuestos por gravas y arenas bien estratificadas de tipo entrecruzada de bajo ángulo, de colores grises, con espesores máximos de $4 \mathrm{~m}$, conformando pequeños acantilados activos y resaltos topográficos entre las diferentes agrupaciones que ellos constituyen. En algunos casos, la gran cantidad y disposición, permitirían considerarlos como planicies con crestas de playas (beach strand Plain) (Fucks et al., 2012a) (Fig 8.1 B y C).

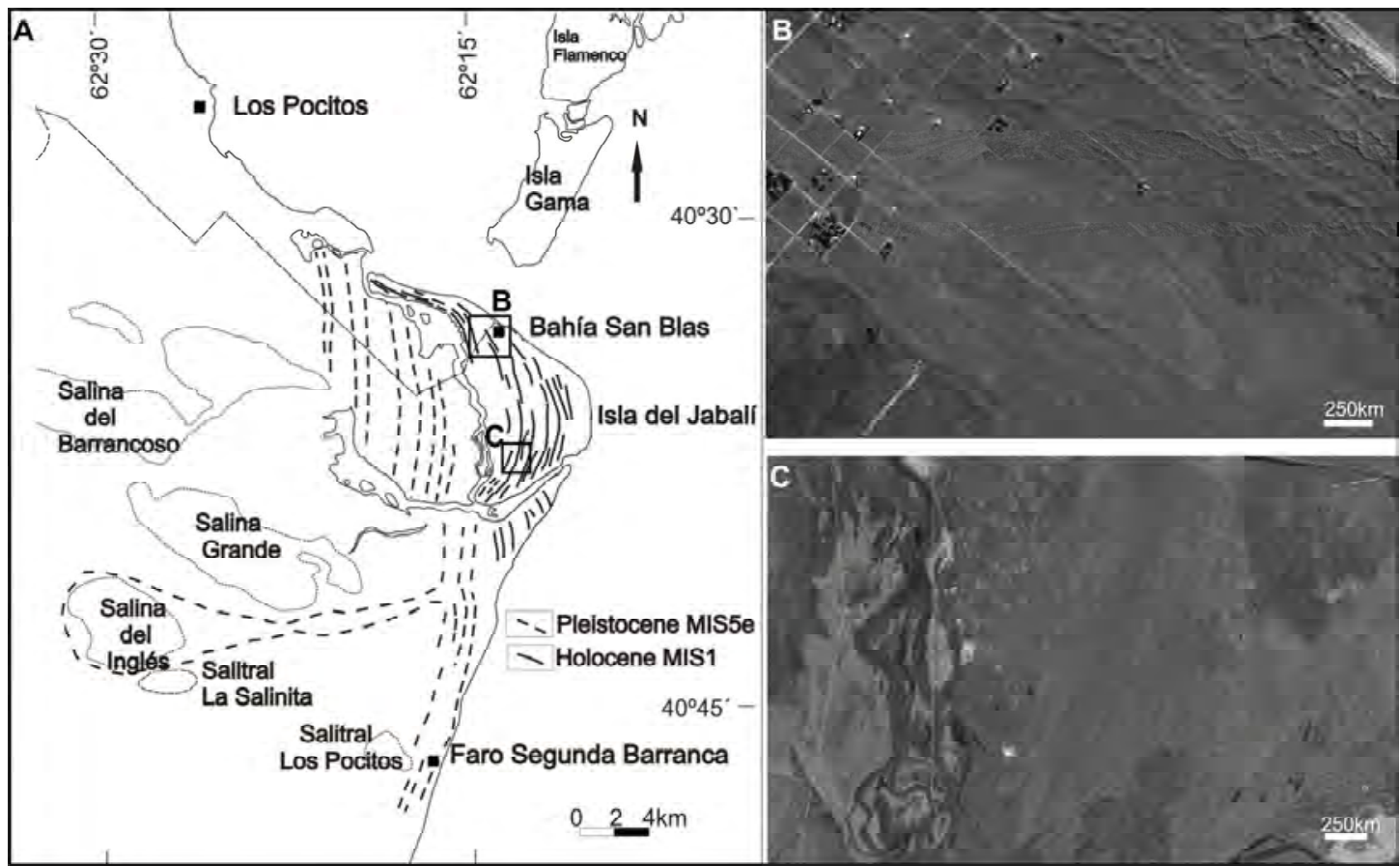

Fig 8.1: A, Depósitos pleistocenos y holocenos del área de isla jabalí - Faro Segunda Barranca; B y C, Fotos satelitales de los cordones holocenos de la isla Jabalí. 


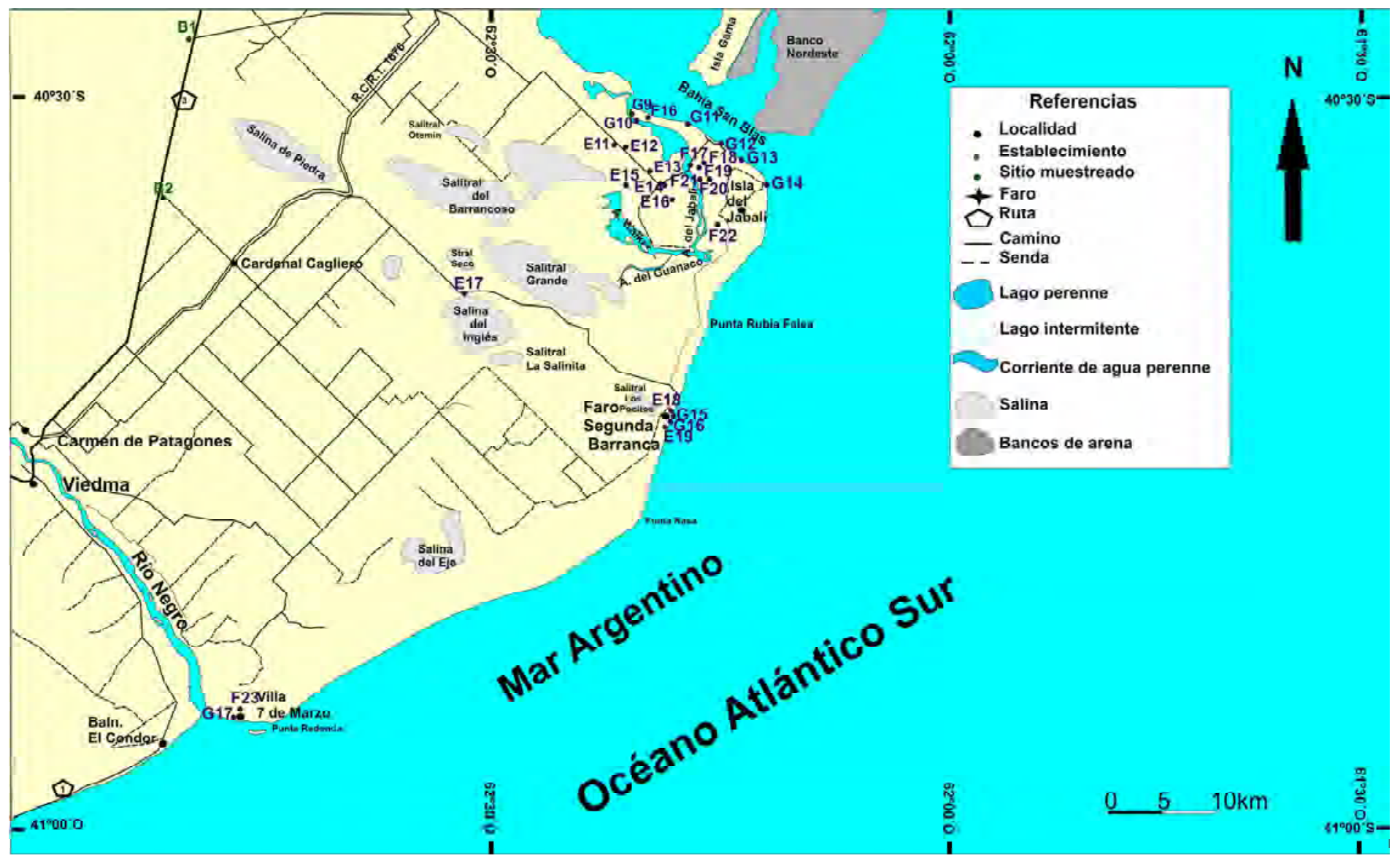

Fig. 8.2: Mapa de ubicación de la región de isla Jabalí - Villa 7 de Marzo, sur de la Provincia de Buenos Aires. 


\begin{tabular}{|c|c|c|c|c|}
\hline $\begin{array}{l}\text { No de } \\
\text { Sitio }\end{array}$ & Edad & $\begin{array}{c}\text { Coordenadas (Lat- } \\
\text { Long) }\end{array}$ & Rasgos geomorfológicos & $\begin{array}{c}\text { Cotas } \\
(\mathrm{m})\end{array}$ \\
\hline B1 & Pleistoceno & $\begin{array}{l}40^{\circ} 27^{\prime} 32.77^{\prime \prime S} / \\
62^{\circ} 47^{\prime} 57.66^{\prime \prime O}\end{array}$ & $\begin{array}{l}\text { Cordón litoral con } \\
\text { sedimentos de arena y } \\
\text { clastos }\end{array}$ & 32 \\
\hline B2 & Pleistoceno & $\begin{array}{l}40^{\circ} 35^{\prime} 30.36 " \mathrm{~S} / \\
62^{\circ} 49^{\prime} 52.91^{\prime \prime O}\end{array}$ & $\begin{array}{l}\text { Cordón con clastos } \\
\text { entoscados }\end{array}$ & 33 \\
\hline E11 & Pleistoceno & $\begin{array}{c}40^{\circ} 33^{\prime} 58.50^{\prime \prime S} / \\
62^{\circ} 19^{\prime} 7.30^{\prime \prime} \mathrm{O}\end{array}$ & Cordón litoral & 9 \\
\hline E12 & Pleistoceno & $\begin{array}{l}40^{\circ} 34^{\prime} 6.70^{\prime \prime S} / \\
62^{\circ} 18^{\prime} 52.12^{\prime \prime O}\end{array}$ & Cordón litoral & 7 \\
\hline E13 & Pleistoceno & $\begin{array}{l}40^{\circ} 35^{\prime} 9.90 " \mathrm{~S} / \\
62^{\circ} 17 ' 28.80^{\prime \prime} \mathrm{O}\end{array}$ & Cordón litoral & 7 \\
\hline E14 & Pleistoceno & $\begin{array}{l}40^{\circ} 35^{\prime} 19.40^{\prime \prime S} / \\
62^{\circ} 17^{\prime} 5.80^{\prime \prime O}\end{array}$ & Cordón litoral & 4 \\
\hline E15 & Pleistoceno & $\begin{array}{l}40^{\circ} 35^{\prime} 47.35^{\prime \prime S} / \\
62^{\circ} 19^{\prime} 11.93^{\prime \prime} \mathrm{O}\end{array}$ & Cordón litoral & 5 \\
\hline E16 & Pleistoceno & $\begin{array}{l}40^{\circ} 36^{\prime} 6.17 " \mathrm{~S} / \\
62^{\circ} 16^{\prime} 10.55^{\prime \prime} \mathrm{O}\end{array}$ & Cordón litoral & 5 \\
\hline E17 & Pleistoceno & $\begin{array}{c}40^{\circ} 40^{\prime} 49.99 " \mathrm{~S} / \\
62^{\circ} 30^{\prime} 6.60^{\prime \prime} \mathrm{O}\end{array}$ & Afloramiento de $50 \mathrm{~cm}$ & 2 \\
\hline E18 & Pleistoceno & $\begin{array}{l}40^{\circ} 46^{\prime} 24.02 " \mathrm{~S} / \\
62^{\circ} 16^{\prime} 17.24 " \mathrm{O}\end{array}$ & $\begin{array}{l}\text { Cordón litoral con } \\
\text { intercalación de arenas } \\
\text { finas y clastos }\end{array}$ & 8 \\
\hline E19 & Pleistoceno & $\begin{array}{l}40^{\circ} 46^{\prime} 34.56 " \mathrm{~S} / \\
62^{\circ} 16^{\prime} 24.50^{\prime \prime} \mathrm{O}\end{array}$ & $\begin{array}{l}\text { Facies de sedimentos } \\
\text { finos }\end{array}$ & 10 \\
\hline F16 & Holoceno & $\begin{array}{l}40^{\circ} 32^{\prime} 9.43^{\prime \prime S} / \\
62^{\circ} 17^{\prime} 22.55^{\prime \prime O}\end{array}$ & Planicie de marea & 1 \\
\hline F17 & Holoceno & $\begin{array}{l}40^{\circ} 34^{\prime} 14.33^{\prime \prime S} / \\
62^{\circ} 15^{\prime} 19.45 " \mathrm{O}\end{array}$ & Planicie de marea & 1 \\
\hline F18 & Holoceno & $\begin{array}{l}40^{\circ} 34^{\prime} 9.30^{\prime \prime S} / \\
62^{\circ} 13^{\prime} 57.80 " \mathrm{O}\end{array}$ & $\begin{array}{l}\text { Cordón litoral con } \\
\text { intercalación de arenas } \\
\text { finas y clastos }\end{array}$ & 4 \\
\hline
\end{tabular}




\begin{tabular}{|c|c|c|c|c|}
\hline F19 & Holoceno & $\begin{array}{l}40^{\circ} 34^{\prime} 23.59 " \mathrm{~S} / \\
62^{\circ} 14^{\prime} 11.71 " \mathrm{O}\end{array}$ & Planicie de marea & 3 \\
\hline F20 & Holoceno & $\begin{array}{l}40^{\circ} 34^{\prime} 56.20^{\prime \prime} \mathrm{S} / \\
62^{\circ} 14^{\prime} 11.43^{\prime \prime} \mathrm{O}\end{array}$ & Planicie de marea & 5 \\
\hline F21 & Holoceno & $\begin{array}{c}40^{\circ} 34^{\prime} 51.91 " \mathrm{~S} / \\
62^{\circ} 13^{\prime} 7.14 " \mathrm{O}\end{array}$ & $\begin{array}{l}\text { Cordón litoral con } \\
\text { intercalación de arenas } \\
\text { finas y clastos }\end{array}$ & 4 \\
\hline F22 & Holoceno & $\begin{array}{l}40^{\circ} 37^{\prime} 9.00^{\prime \prime S} / \\
62^{\circ} 12^{\prime} 49.20^{\prime \prime O}\end{array}$ & Planicie de marea & 5 \\
\hline F23 & Holoceno & $\begin{array}{l}41^{\circ} 01^{\prime} 13.6 " \mathrm{~S} / \\
62^{\circ} 47^{\prime} 08.1 " \mathrm{O}\end{array}$ & Cordon litoral & 2 \\
\hline G9 & actual & $\begin{array}{c}40^{\circ} 31^{\prime} 40.80^{\prime \prime S} / \\
62^{\circ} 19^{\prime} 5.40^{\prime \prime} \mathrm{O}\end{array}$ & $\begin{array}{c}\text { Playa de gravas y } \\
\text { arenas }\end{array}$ & 0 \\
\hline G10 & actual & $\begin{array}{l}40^{\circ} 32^{\prime} 9.32 " \mathrm{~S} / \\
62^{\circ} 18^{\prime} 47.16^{\prime \prime} \mathrm{O}\end{array}$ & $\begin{array}{c}\text { Playa de gravas y } \\
\text { arenas }\end{array}$ & 0 \\
\hline G11 & actual & $\begin{array}{l}40^{\circ} 32 ' 20.12 " \mathrm{~S} / \\
62^{\circ} 15^{\prime} 22.08^{\prime \prime O}\end{array}$ & $\begin{array}{c}\text { Playa de gravas y } \\
\text { arenas }\end{array}$ & 0 \\
\hline G12 & actual & $\begin{array}{l}40^{\circ} 33^{\prime} 15.68 " \mathrm{~S} / \\
62^{\circ} 13^{\prime} 28.38^{\prime \prime O}\end{array}$ & $\begin{array}{c}\text { Playa de gravas y } \\
\text { arenas }\end{array}$ & 0 \\
\hline G13 & actual & $\begin{array}{l}40^{\circ} 34^{\prime} 11.70^{\prime \prime} \mathrm{S} / \\
62^{\circ} 11^{\prime} 49.86^{\prime \prime} \mathrm{O}\end{array}$ & $\begin{array}{c}\text { Playa de gravas y } \\
\text { arenas }\end{array}$ & 0 \\
\hline G14 & actual & $\begin{array}{l}40^{\circ} 35^{\prime} 35.92 " \mathrm{~S} / \\
62^{\circ} 10^{\prime} 15.78^{\prime \prime} \mathrm{O}\end{array}$ & $\begin{array}{c}\text { Playa de gravas y } \\
\text { arenas }\end{array}$ & 0 \\
\hline G15 & actual & $\begin{array}{l}40^{\circ} 46^{\prime} 30.80^{\prime \prime S /} / \\
62^{\circ} 16^{\prime} 18.50 " \mathrm{O}\end{array}$ & $\begin{array}{l}\text { Playa arenosas con } \\
\text { restos de clastos } \\
\text { redondeados }\end{array}$ & 0 \\
\hline G16 & actual & $\begin{array}{l}40^{\circ} 46^{\prime} 32.91 " \mathrm{~S} / \\
62^{\circ} 16^{\prime} 19.95^{\prime \prime O}\end{array}$ & $\begin{array}{l}\text { Playa arenosas con } \\
\text { restos de clastos } \\
\text { redondeados }\end{array}$ & 0 \\
\hline G17 & actual & $\begin{array}{l}41^{\circ} 011^{\prime} 53.3^{\prime \prime} \mathrm{S} / \\
62^{\circ} 45^{\prime} 13.6^{\prime \prime} \mathrm{O}\end{array}$ & Playa arenosa & 0 \\
\hline
\end{tabular}

T.8.1: Cuadro comparativo geomorfológico y descriptivo de los depósitos marinos de la región de isla Jabalí - Villa 7 de Marzo. 


\subsection{Depósitos pleistocenos de la región de isla Jabalí - Villa 7 de Marzo}

Se analizaron 11 sitios pleistocenos, dos sitios pertenecientes al Interglacial $\geq$ MIS 9 (B1 - B2) y 9 sitios (E11- E19) al Interglacial MIS 5e, corresponden en su mayoría a cordones litorales con abundante fauna marina fósil.

El Sitio B1, perteneciente al Interglacial $\geq$ MIS9, se presenta como un afloramiento de 2.5 m compuesto por gravas con matriz areno-limosa, homogénero de color gris (Fig. 82). Entre la fauna encontrada figuran: Pitar rostratus, Glycymeris longior (bivalvos) y Buccinanops cochlidium y Olivancillaria urceus (gasterópodos).

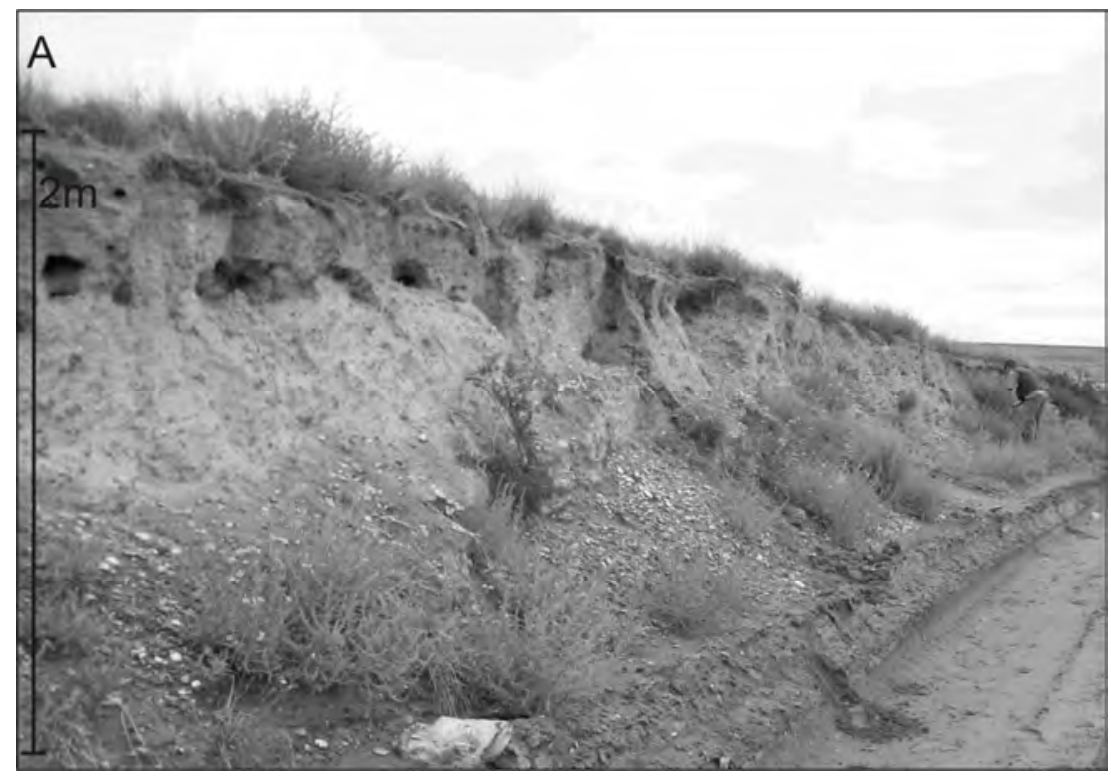

Fig. 8.2: Depósito pleistoceno en la entrada del pueblo de bahía San Blas (Sitio B1).

El Sitio B2 $\left(40^{\circ} 39^{\prime} \mathrm{S} / 62^{\circ} 44^{\prime} \mathrm{O}\right)$, se trata de una cantera de grava, homogénea y entoscada situado a $33 \mathrm{~m}$ de altura con $3 \mathrm{~m}$ de espesor. En función a la altura del depósito y el elevado grado de cementación, correspondería a un depósitos más antiguo que Interglacial MIS 5e (Fucks et al., 2012a) asignándolo posiblemente al Interglacial $\geq$ MIS 9. Entre la fauna hallada figuran: Pitar rostratus (bivalvo) y Zidona dufresnei (gasterópodo) (Fig. 8.3). 


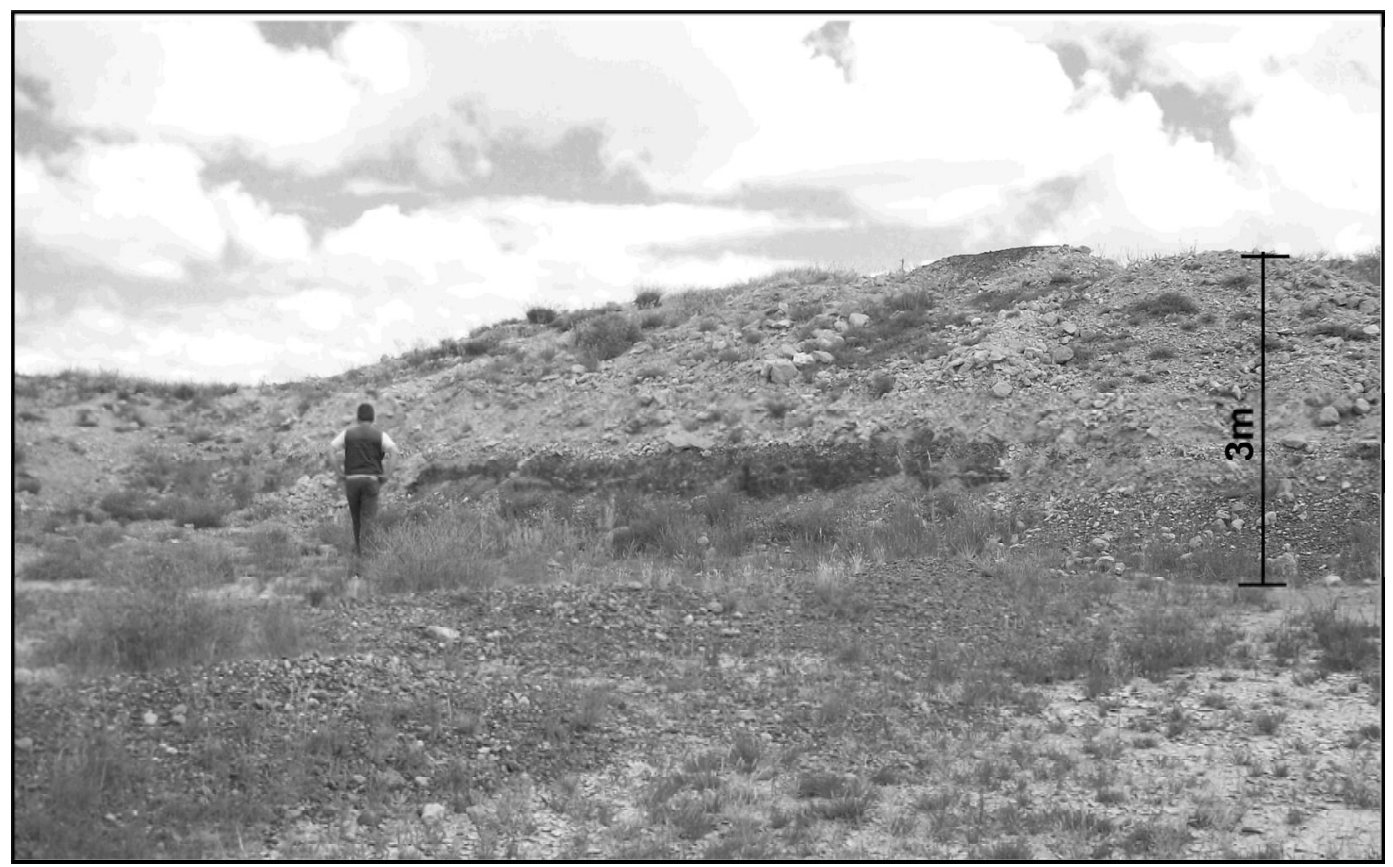

Fig. 8.3: Depósito pleistoceno en la localidad cercana a Cardenal Cagliero (Sitio B2).

Los sitios E11 - E16, representan a cordones litorales, pertenecientes a ambientes de alta energía, compuestos por gravas friables con poca presencia de carbonato de calcio, a cotas de $10-8 \mathrm{~m}$. Entre la fauna marina figuran como los más abundantes: Pitar rostratus y Amiantis purpurata (bivalvos), este último bivalvo no presente en los sitios E11 y E15 y Buccinanops globulosus (gasterópodo).

En Salina del Ingles (Sitio E17), ubicado en las cercanías del Faro Segunda Barranca, se presenta uno de los depósitos evaporíticos más importantes del área de estudio. Presentan forma ovoidal con un eje mayor de longitud de $5.5 \mathrm{~km}$ en dirección $\mathrm{E}$ - O y $4.8 \mathrm{~km}$ de ancho. El tipo de sedimento que los conforman corresponde a limos de colores pardos a verdosos con cristales de yeso y fósiles de moluscos (Etcheverría et al., 2006). En el extremo occidental se desarrolla un nivel de yeso selenítico de unos $50 \mathrm{~cm}$ de potencia cuya matriz es fango arcilloso castaño, algo carbonático (Del Blanco et al., 2005). El depósito pleistoceno analizado de unos $50 \mathrm{~cm}$ de espesor, permitió observar moluscos como Pitar rostratus (bivalvo) articulados y en posición de vida (Fig. 8.4). En total se observaron 19 especies (10 bivalvos y 9 gasterópodos) en buen estado de preservación y con presencia de precipitados de yeso sobre las valvas y conchas. Entre 
los moluscos más abundantes se encuentran: Pitar rostratus (bivalvo) y Olivancillaria urceus, Tegula patagonica y Zidona dufresnei (gasterópodos) y micromoluscos como: Nucula nucleus, Carditamera plata y Corbula patagonica (bivalvos) y Heleobia australis (gasterópodo).

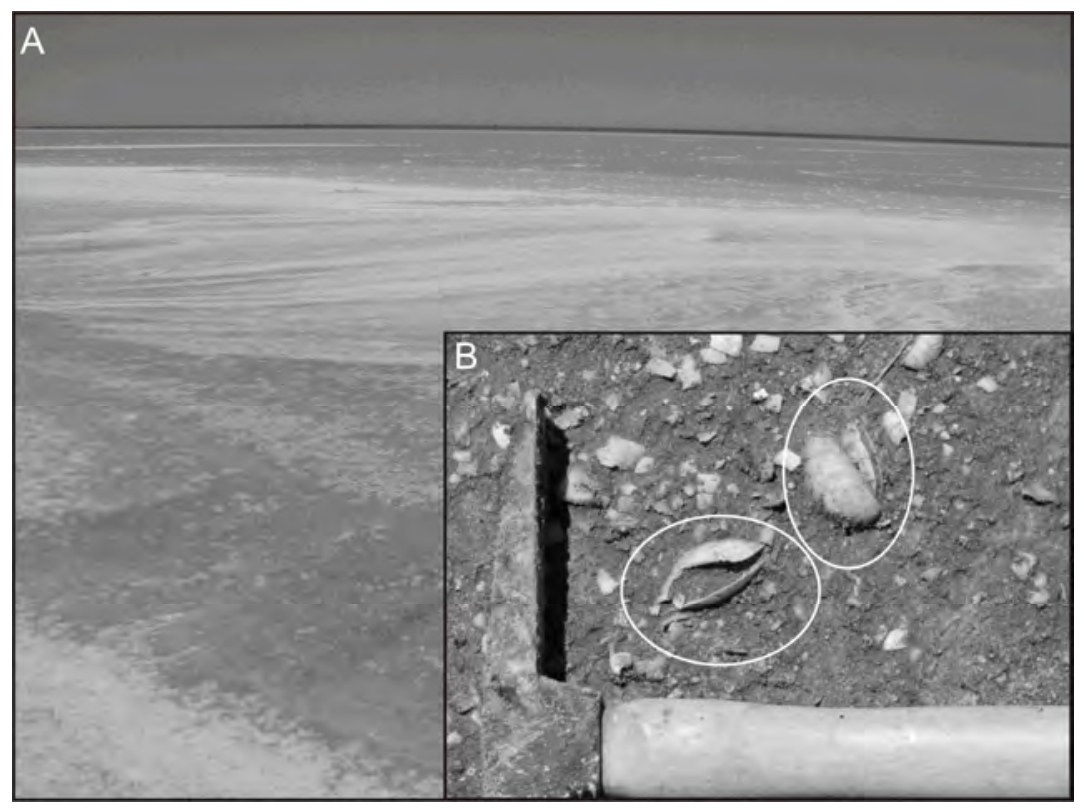

Fig. 8-4: A, Depósito pleistoceno del Interglacial MIS 5e en Salina El Ingles (Sitio E17); B, Pitar rostratus articulado y en posición de vida.

Los Sitios E18 y E19 corresponden al Pleistoceno del Faro Segunda Barranca (Fig. 8.5). Este afloramiento está constituido por dos niveles. El nivel superior (Sitio E18), está compuesto por gravas clastosoportadas, aunque coronando el perfil hay estratos de arena y arenas conglomerádicas. La coloración en conjunto es gris, con una estratificación bien definida de tipo paralela a cruzada de bajo ángulo con una leve inclinación hacia el S, observándose algunos estratos parcialmente entoscados. Entre los restos fósiles se destacan: Tegula patagonica, Bostrycapulus odites, Crepidula, Olivella tehuelcha (gasterópodos) y Pitar rostratus, Mytilus edulis platensis, Brachidontes rodriguezii, Aequipecten tehuelchus, Ostreola equestris, Ostrea puelchana y Pitar rostratus (bivalvos) (Fig. 8.6). 


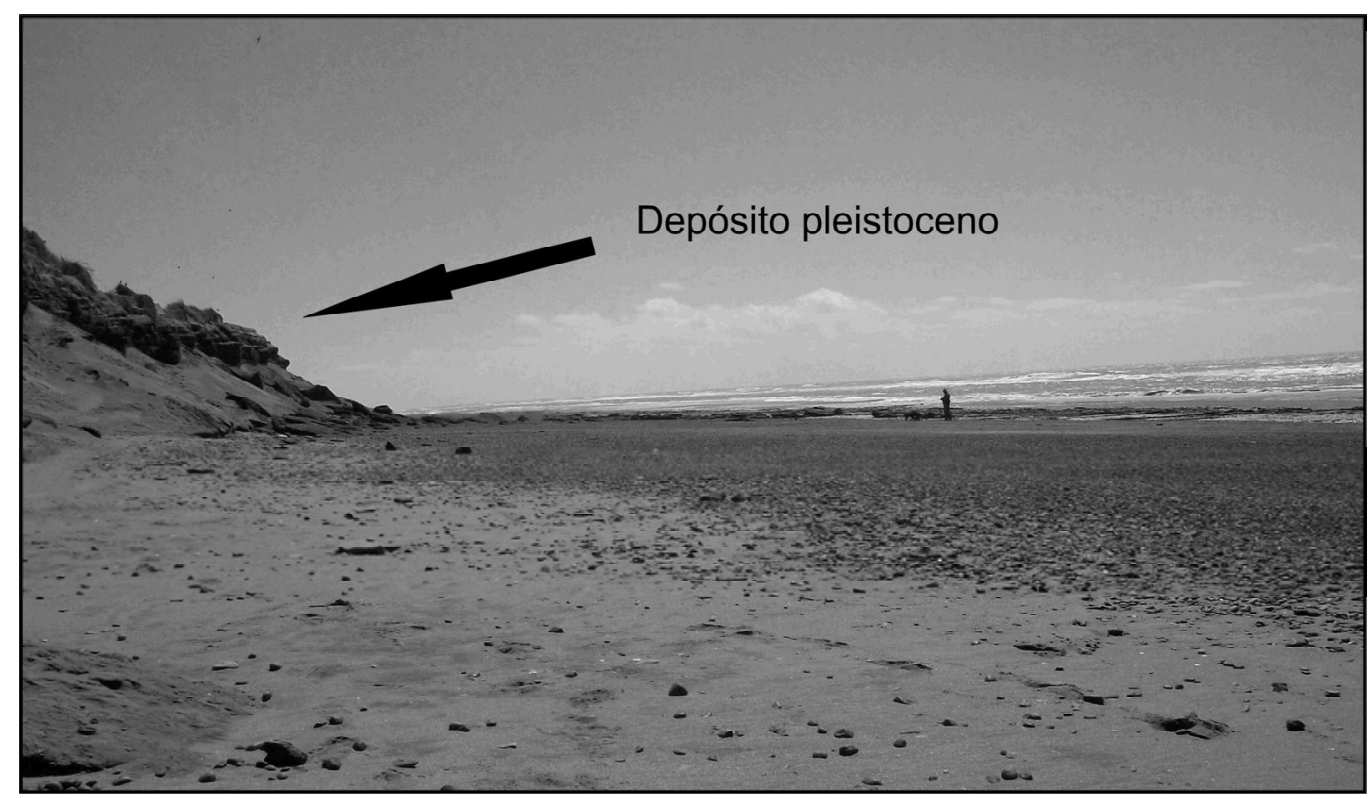

Fig. 8.5: Depósito pleistoceno de Faro Segunda Barranca (Sitios E18 y E19).

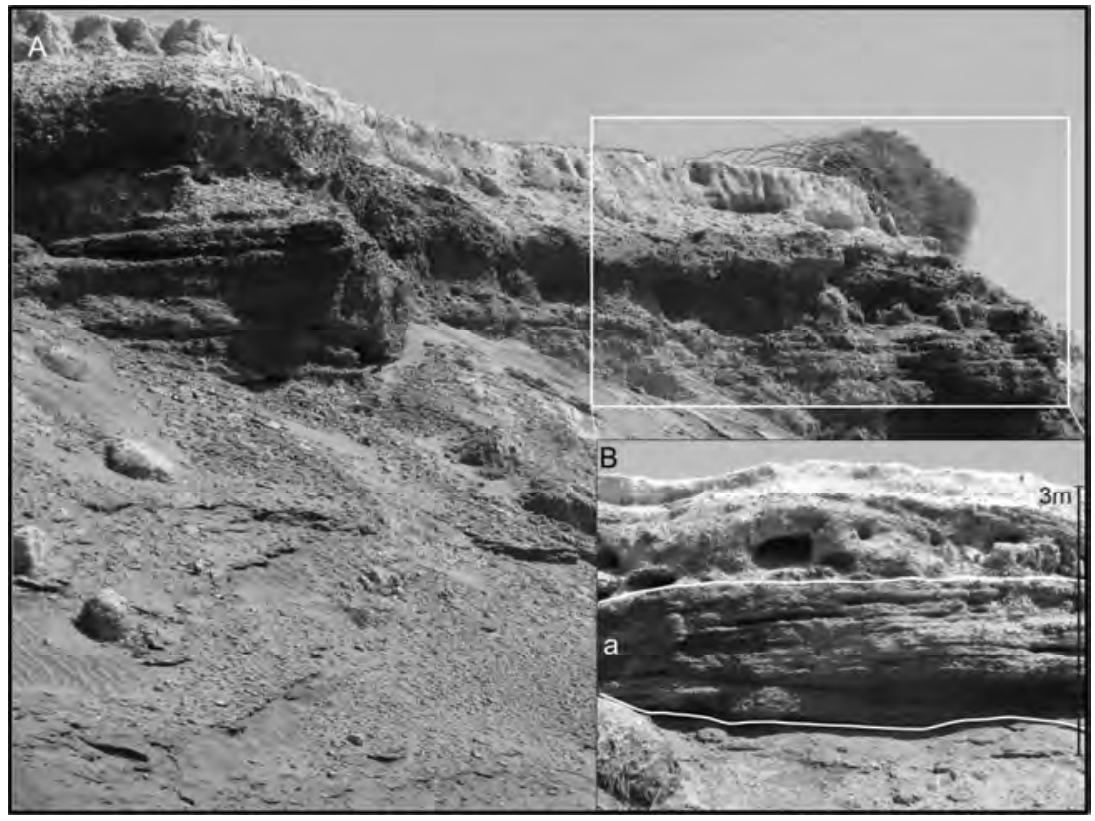

Fig. 8.6: Nivel superior del depósito pleistoceno en Faro Segunda Barranca (Sitio E18).

El nivel inferior (Sitio E19) se compone de $2 \mathrm{~m}$ de sedimentos areno-limosos, castaños amarillentos y con rodados dispersos. Entre la fauna de moluscos figuran: Tegula patagonica, Bostrycapulus odites, Urosalpinx cala, Parvanachis isabellei, Buccinanops 
cochlidium y Buccinanops globulosus (gasterópodos) y Mytilus edulis platensis y Brachidontes rodrigueziii (bivalvos) (Fig. 8.7). En la base del acantilado en esta localidad se han obtenido cronologías de 102 y 108 ka aunque la relación D/L de ácido aspártico y leucina permitiría atribuirlos a un evento transgresivo más antiguo (Rutter et al., 1989, 1990).

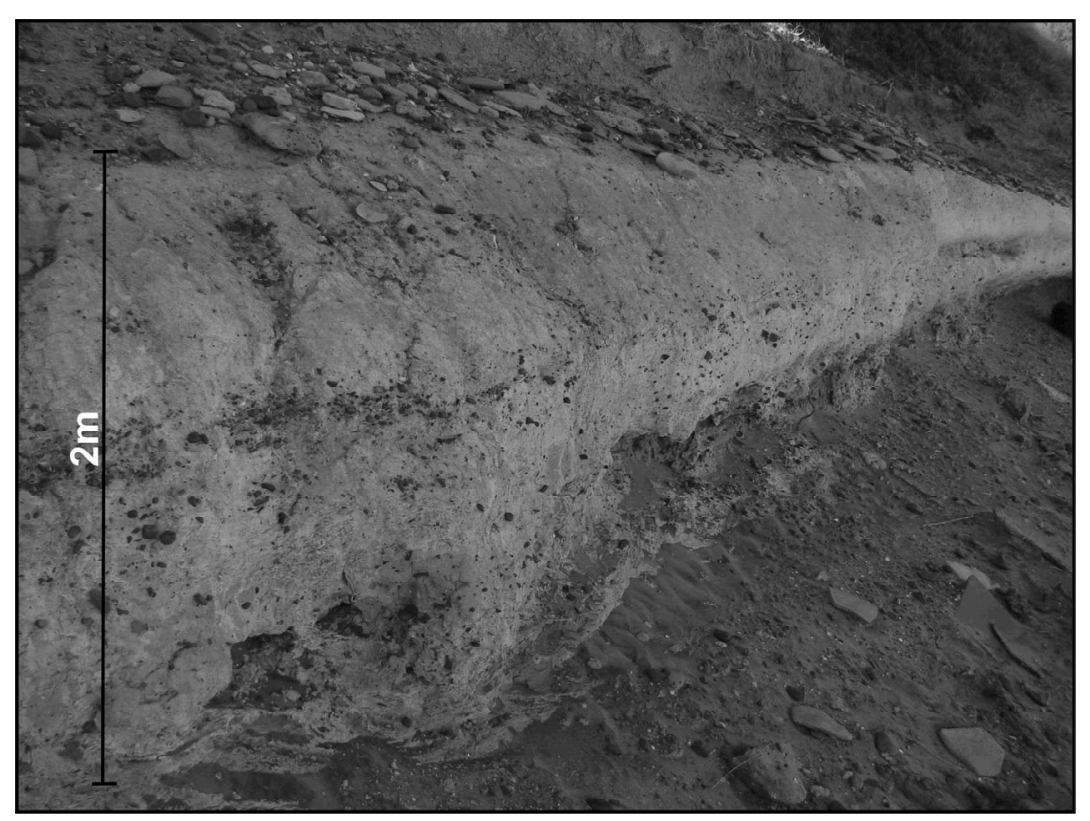

Fig.8.7: Nivel inferior del depósito pleistoceno en Faro Segunda Barranca (Sitio E19).

\subsection{Depósitos holocenos de la región de isla Jabalí - Villa 7 de Marzo}

En Isla Jabalí se encuentran la totalidad de los depósitos del Interglacial MIS 1 reconocidos y están representados en dos tipos de geoformas: el sector oeste se caracteriza por depósitos de planicies de marea (Sitios F16, F17, F19 y F20), generados en ambientes de baja energía, caracterizados por la presencia de Heleobia australis (gasterópodo) y Corbula patagonica y Tagelus plebeius (bivalvos). Estos últimos se presentan en muchas oportunidades articulados y en posición de vida (Fig. 8.8). El sector este de la isla se caracteriza por la gran cantidad de cordones litorales (Sitios F18 y F21) (Fig. 8.9). El cordón litoral que representa al Sitio F21 está compuesto por arenas y gravas bien estratificadas (Fig. $8.9 \mathrm{Ba}, \mathrm{b}$ ) con restos de valvas y conchas. Entre la fauna más común figuran: Pitar rostratus, Amiantis purpurata, Glycymeris longior, 
Ostreola equestris (bivalvos) y Tegula patagonica, Bostrycapulus odites, Buccinanops globulosus (gasterópodos).

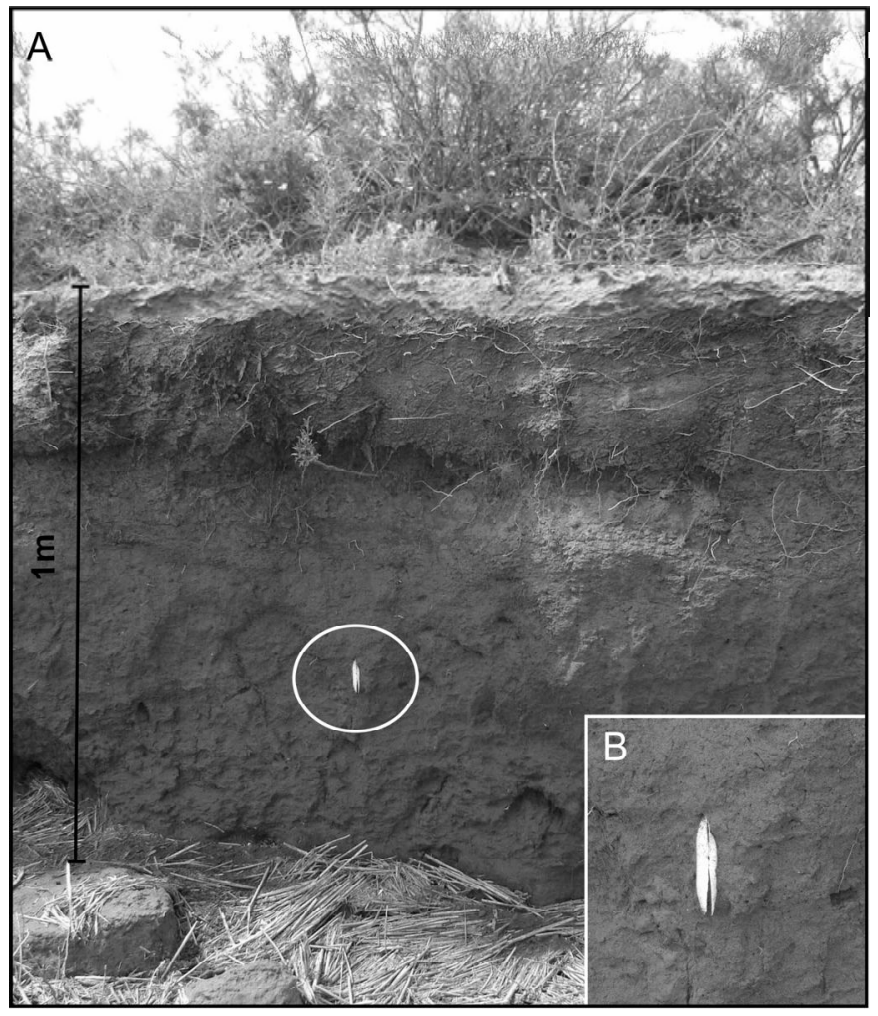

Fig. 8.8: Depósito holoceno con Tagelus plebeius en posición de vida (Sitio F17).

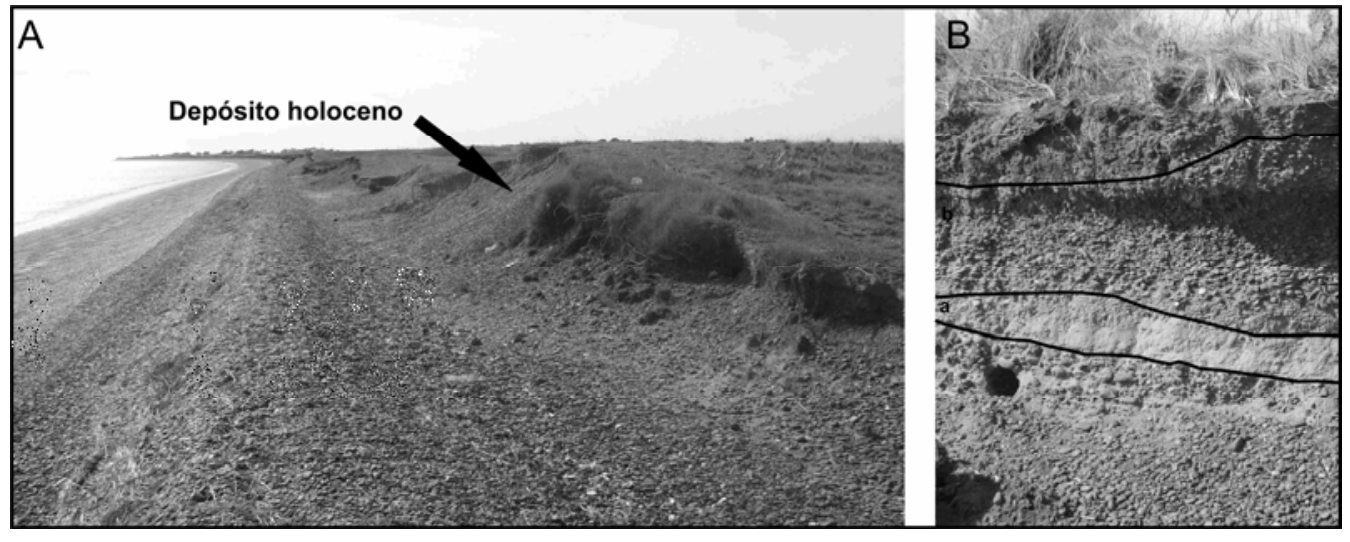

Fig. 8.9: A, Depósito holoceno en isla jabalí (Sitio F18) y B, Depósito holoceno con intercalación de arena fina (nivel a) y clastos -sostén (nivel b) (Sitio F21). 


\subsection{Playas actuales de la región de isla Jabalí - Villa 7 de Marzo}

A lo largo de la costa de isla Jabalí, las playas están compuestas por rodados y arenas (G9 - G14). Del norte de isla Jabalí y hasta las proximidades de la baliza La Ballena se reconocen playas de rodados, son playas de pendientes pronunciadas (valores máximos entre $15-20^{\circ}$ ) (ej. Trebino, 1987; Cuadrado y Gomez, 2010) y muy reducidas arealmente. A medida que se asciende en latitud el sector de playa se amplia y la pendiente disminuye (Trebino, 1987) (Fig. 8.10). Entre la fauna marina se destacan entre los más abundantes: Crassostrea gigas, Pitar rostratus y Amiantis purpurata (bivalvos) y Bostrycapulus odites (gasterópodo). En el Sitio G14, con presencia en abundancia de Mesodesma mactroides y Solen tehuelchus (bivalvos).

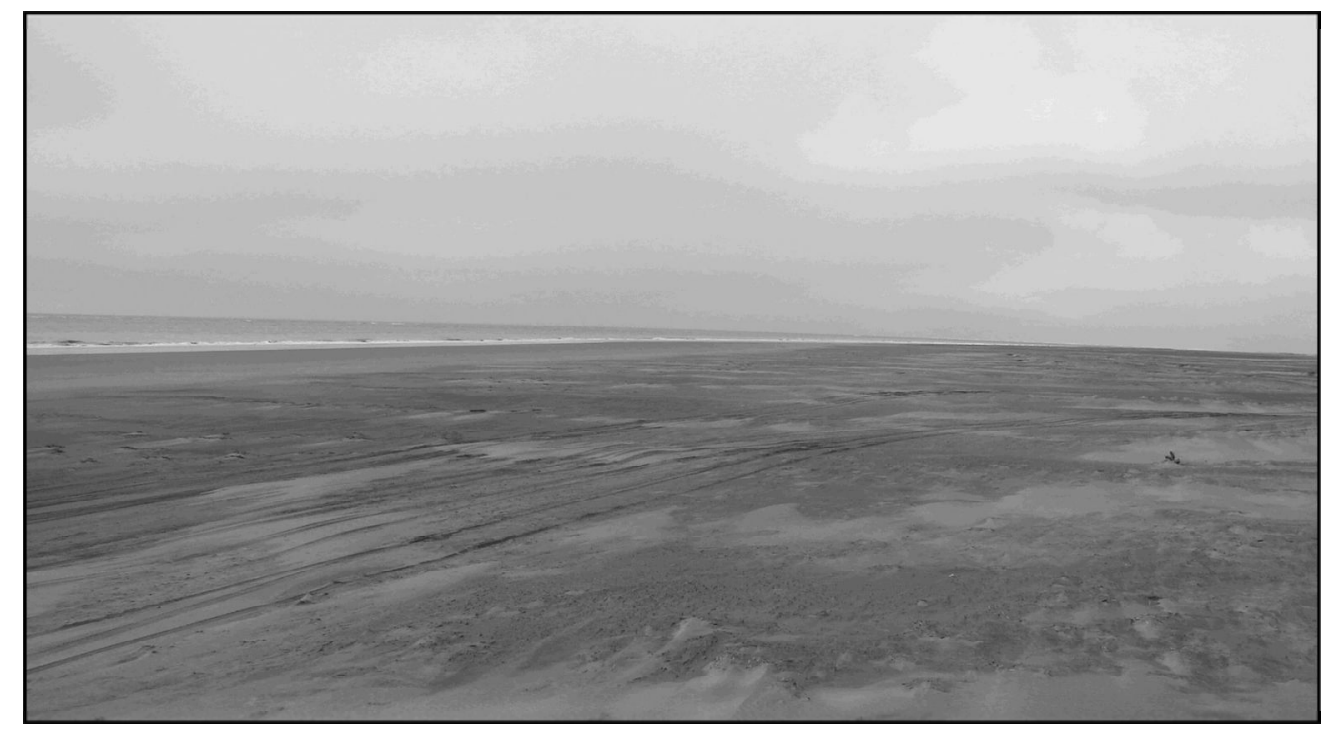

Fig. 8.10: Playa actual isla Jabalí (Sitio G10).

Las playas (G15 y G16), en cercanías del Faro Segunda Barranca (40 46'S/62 $16^{\circ} \mathrm{O}$ ) son playas arenosas con presencia de clastos redondeados con restos de fauna marina, entre las que se destaca con mayor abundancia: Trophon patagonicus (gasterópodo), distinguiendo estas playas de las playas arenosas y gravosas de isla Jabalí.

La playa de Villa de 7 de Marzo (Sitio G17) se localiza sobre la margen izquierda en la desembocadura del río Negro, presentando una extensa playa distal compuesta por arena y algo de grava. Entre la fauna marina se destaca la presencia de Crepidula, 
Bostrycapulus odites (gasterópodos), y Plicatula gibbosa y Ostrea puelchana (bivalvos) (Fig. 8.11).

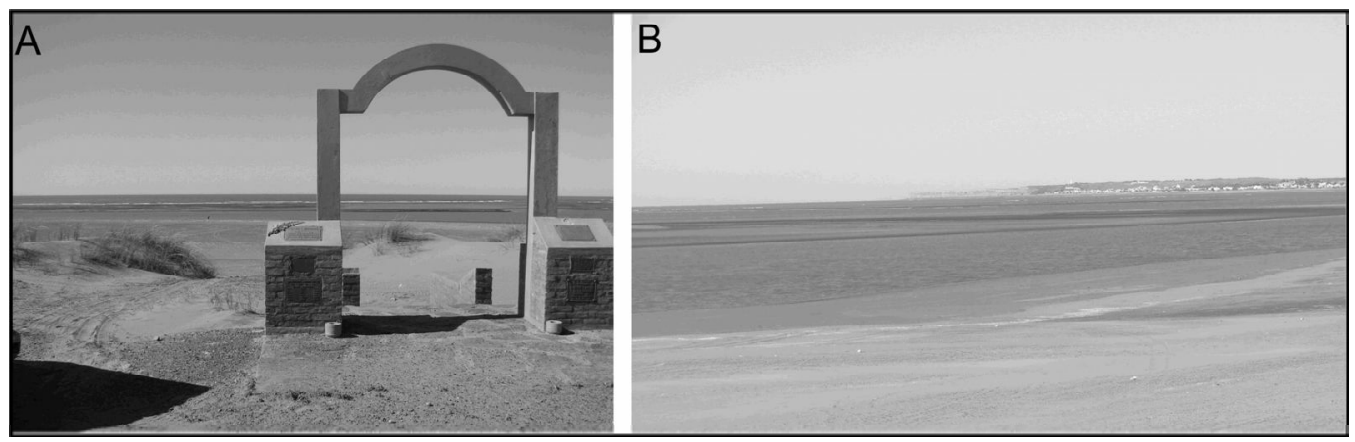

Fig. 8.11: Playa actual en la localidad Villa de 7 Marzo (Sitio G17).

\subsection{Composición faunística}

Entre los depósitos de los interglaciales $\geq$ MIS 9, MIS 5e y MIS 1 y playas actuales estudiados en la región de isla Jabalí - Villa 7 de Marzo, se analizaron 28 sitios y se registró un total de 51 especies ( 27 bivalvos y 24 gasterópodos) entre los que se destacan 8 micromoluscos: Nucula nucleus, Ennucula grayi, Carditamera plata, Corbula patagonica, Corbula lyoni (bivalvos) y Heleobia australis, Olivella tehuelcha, Parvanachis isabellei (gasterópodos) (Fig 8.12 y Fig. 8.13) (T. 8.2 - 8.5). 


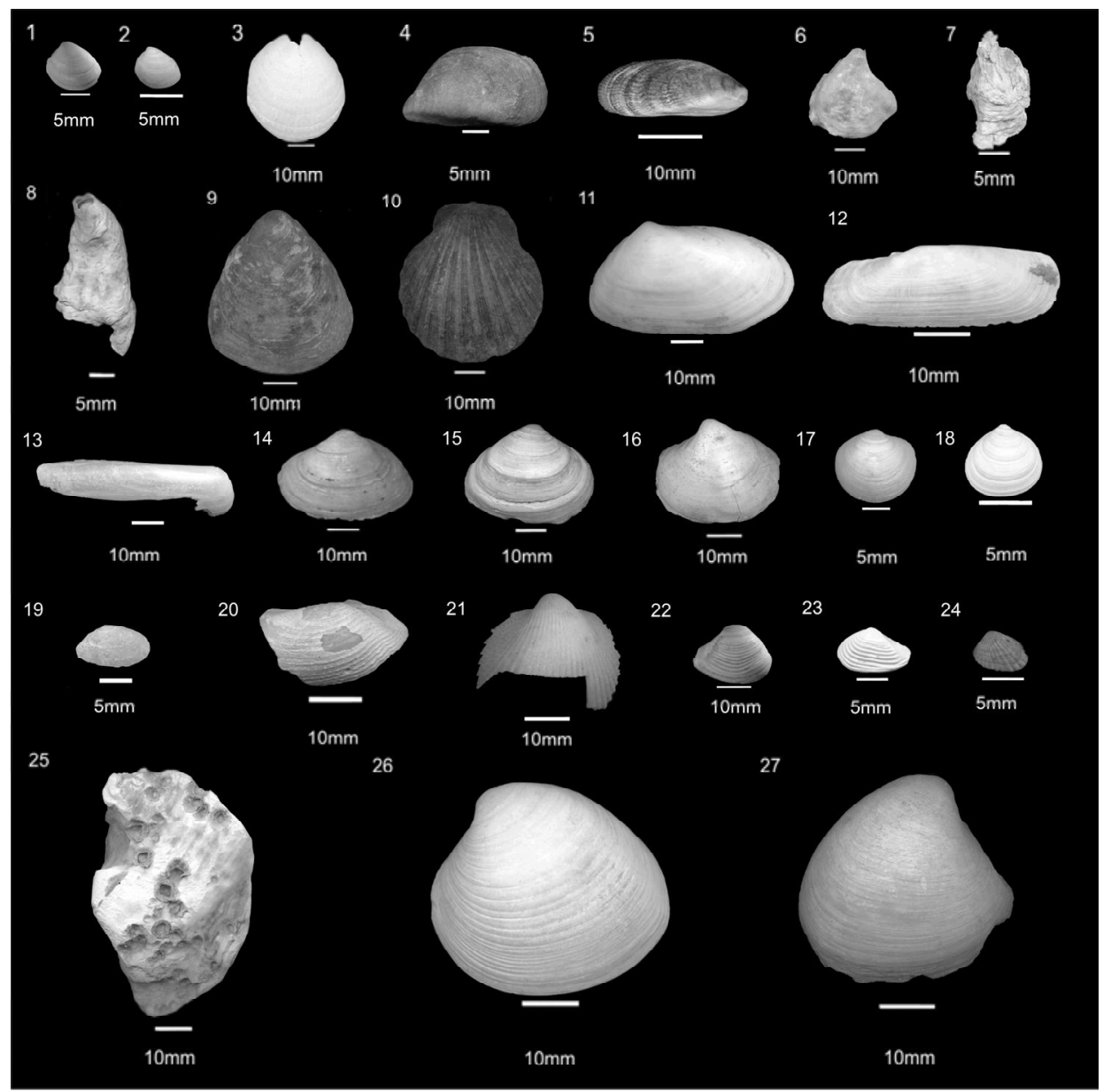

Fig. 8.12: Especies de bivalvos característicos de depósitos marinos del Cuaternarios de la región isla Jabalí - Villa 7 de Marzo. Dimensiones en $\mathrm{mm}$.

1, Nucula (N.) nucleus (Linné) (MLP: 33.410, Holoceno); 2, Ennucula grayi (d'Orbigny) (MLP: 33.411, Holoceno);3, Glycymeris (G.) longior (Sowerby) (MLP: 33.403, Holoceno); 4, Mytilus edulis platensis d'Orbigny (MLP: 33.409, actual); 5, Brachidontes (B.) Rodriguezii ( d'Orbigny) (MLP:33.994, actual); 6. Plicatula gibbosa Lamarck (MLP: 33.415, Pleistoceno); 7, Ostreola equestris (Say) (MLP: 34.448, Holoceno);8, Crassostrea rhizophorae (Guilding) (MLP: 33.998, Pleistoceno); 9, Ostrea puelchana d'Orbigny (MLP:33.412, Pleistoceno); 10, Aequipecten tehuelchus (d'Orbigny) (MLP: 33.996, Pleistoceno); 11, Mesodesma mactroides (Reeve) (MLP:33.407, actual);12, Tagelus (T.) plebeius (Ligthfood) (MLP:33.418,

Holoceno);13, Solen tehuelchus (Hanley) (MLP: 33.416, actual); 14, Mactra guidoi Signorelli \& Scarabino (MLP: 33.406, Pleistoceno); 15, Mactra isabelleana d'Orbigny (MLP:33.405, actual); 16, Mulinia edulis (King \& Broderip) (MLP:33.408, Holoceno); 17, Diplodonta (D.) patagonica ( d'Orbigny) (MLP: 33.402, Holoceno); 18, Diplodonta (E.) vilardésoana \{ d'Orbigny) (MLP: 33.400, Holoceno); 19, Macoma (P.) uruguayensis (Smith)

(MLP:34.441,Pleistoceno); 20, Barnea lamellosa (d'Orbigny) (MLP: 33.993, actual); 21, Trachycardium muricatum (Linné) (MLP: 33.417, Pleistoceno); 22, Corbula (C.) patagonica d'Orbigny (MLP: 33.401, Holoceno); 23, Corbula (C.) lyoni Pilsbry (MLP: 33.999, Holoceno); 24, Carditamera plata (Inhering) (MLP: 33.995, Pleistoceno); 25, Crassostrea gigas (Thunberg) (MLP:33.997, actual); 26, Amiantis purpurata ( Lamarck) (MLP: 33.992, actual); 27, Pitar (P.) rostratus (Philippi) (MLP: 33.414, Pleistoceno). 


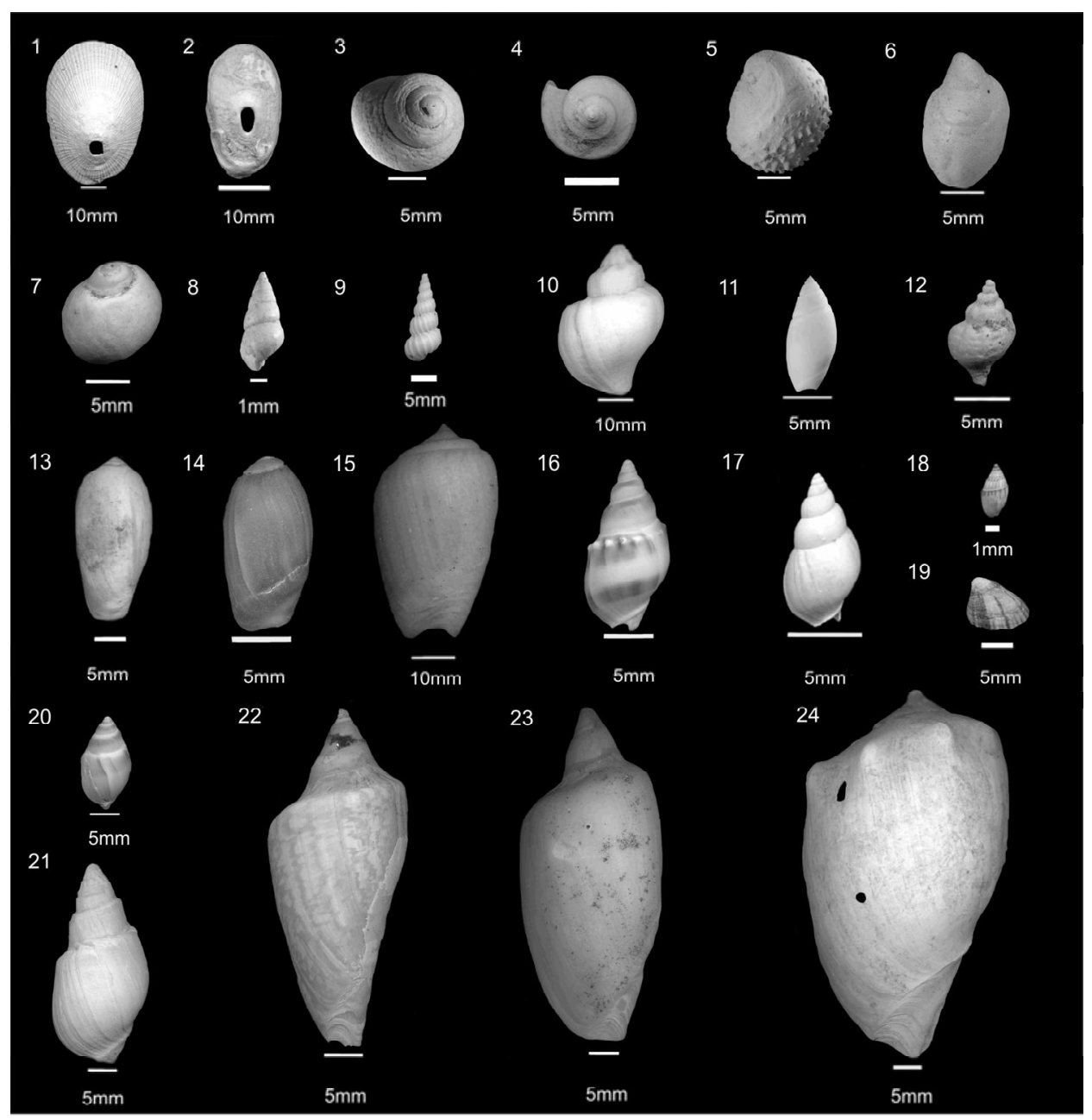

Fig. 8.13: Especies de gasterópodos característicos de depósitos marinos del Cuaternarios de la región isla Jaball - Villa 7 de Marzo. Dimensiones en mm.

1, Diodora (D.) patagonica ( d'Orbigny) (MLP: 34.026, Holoceno); 2, Lucapinella henseli (Martens) (MLP: 34.027, actual);3, Tegula (A.) patagonica (d'Orbigny) (MLP: 34.033, Holoceno); 4, Calliostoma coppingeri ( Smith) (MLP: 34.046, Pleistoceno); 5, Bostrycapulus odites (Collin) (MLP: 34.025, Holoceno); 6 , Crepidula argentina Simone, Pastorino \& Penchaszadeh (MLP: 34.028, Holoceno); 7, Notocochlis isabel'masara (d' Orbigny) (MLP: 34.035, Pleistoceno); 8 , Heleobia australis (d'Orbigny) (MLP: 34.038, Holoceno); 9, Epitonium (E.) georgettinum (MLP: 34.438, actual); 10, Trophon patagonicus (d'Orbigny) (MLP: 34.037, actual); 11, Olivella (O.) tehuelcha (Dúclos) (MLP: 34.036, Holoceno); 12, Urosalpinx cala (Pilsbry) (MLP: 34.041, Pleistoceno); 13, Marginella martini Petit (MLP: 34.044, Pleistoceno); 14, Olivancillaria carcellesi Klappenbach (MLP: 34.039, actual); 15, Olivancillaria urceus ( Röding) (MLP: 34.042, Pleistoceno); 16, Buccinanops monilifer (Kiener) (MLP: 34.040, actual); 17, Buccinanops uruguayensis (Pilsbry) (MLP: 34.034, Holoceno); 18, Parvanachis isabellei (d'Orbigny) (MLP: 34.436, actual);19, Siphonaria lessoni (Blainville) (MLP: 34.440, Pleistoceno); 20, Buccinanops globulosus (Kiener) (MLP: 34.043, Holoceno); 21, Buccinanops cochlidium (Dilwyn) (MLP: 34.032, Holoceno); 22, Zidona dufresni ( Donovan) (MLP: 34.029, Holoceno); 23, Odontocymbiola magellanica (Gmelin) (MLP: 34.030, Holoceno); 24, Adelomelon (P.) brasiliana (Lamarck) (MLP: 34.031, Holoceno). 


\begin{tabular}{|c|c|c|c|c|c|c|c|c|c|c|c|c|c|}
\hline Bivalvos & B1 & B2 & E11 & E12 & E13 & E14 & E15 & E16 & E17 & E18 & E19 & F16 & F17 \\
\hline \multicolumn{14}{|l|}{ Familia Nuculidae Gray, 1824} \\
\hline Nucula (N.) nucleus ( Linné, 1758) & & & & & & & & & $\mathbf{X}$ & & & $\mathbf{X}$ & $\mathbf{X}$ \\
\hline Ennucula grayi (d'Orbigny, 1846) & & & & & & & & & & & & $\mathbf{X}$ & \\
\hline \multicolumn{14}{|l|}{ Familia Glycymerididae Newton, 1922} \\
\hline Glycymeris (G.) longior ( Sowerby,1832) & $\mathbf{X}$ & & & & & & & & & & & & \\
\hline \multicolumn{14}{|l|}{ Familia Mytilidae Rafinesque,1815 } \\
\hline Mytilus edulis platensis d'Orbigny, 1846 & & & & & & & & & & $\mathbf{X}$ & $\mathbf{X}$ & $\mathbf{X}$ & \\
\hline Brachidontes $(B)$ rodriguezii ( d'Orbigny, 1846) & & & & $\mathbf{X}$ & & & & & & $\mathbf{X}$ & $\mathbf{X}$ & $\mathbf{X}$ & \\
\hline \multicolumn{14}{|l|}{ Familia Plicatulidae Watson, 1930} \\
\hline Plicatula gibbosa Lamarck, 1801 & & & & & & & & & $\mathbf{X}$ & & & & \\
\hline \multicolumn{14}{|l|}{ Familia Ostreidae Rafinesque, 1815} \\
\hline Crassostrea rhizophorae (Guilding, 1828) & & & & & & & $\mathbf{X}$ & & & & & & \\
\hline \multicolumn{14}{|l|}{ Crassostrea gigas (Thunberg, 1793) } \\
\hline Ostrea & & & & $\mathbf{X}$ & & & & & & & & & \\
\hline Ostreola equestris (Say, 1834) & & & & & & $\mathbf{X}$ & & & & $\mathbf{X}$ & & $\mathbf{X}$ & $\mathbf{X}$ \\
\hline Ostrea puelchana d'Orbigny 1841 & & & & & & $\mathbf{X}$ & & & & $\mathbf{X}$ & & & \\
\hline \multicolumn{14}{|l|}{ Familia Pectinidae Rafinesque, 1815} \\
\hline Aequipecten tehuelchus (d'Orbigny, 1842) & & & & $\mathbf{X}$ & & & & & $\mathbf{X}$ & $\mathbf{X}$ & & & \\
\hline \multicolumn{14}{|l|}{ Familia Diplodontidae Dall, 1895} \\
\hline Diplodonta (D.) patagonica ( d'Orbigny, 1842) & & & & & & & & & $\mathbf{X}$ & & & $\mathbf{X}$ & \\
\hline Diplodonta (F.) vilardeboana ( d'Orbigny, 1846) & & & & & & & & & & & & $\mathbf{X}$ & \\
\hline \multicolumn{14}{|l|}{ Familia Carditidae Fleming, 1828} \\
\hline Carditamera plata (Inhering, 1907) & & & & & & & & & $\mathbf{X}$ & & & & $\mathbf{X}$ \\
\hline \multicolumn{14}{|l|}{ Familia Cardiidae Lamarck, 1809} \\
\hline Trachycardium muricatum (Linné, 1758) & & & & & & & & & $\mathbf{X}$ & & & & \\
\hline \multicolumn{14}{|l|}{ Familia Mactridae Lamarck,1809 } \\
\hline \multicolumn{14}{|l|}{ Mactra isabelleana d'Orbigny, 1846} \\
\hline Mactra guidoi Signorelli \& Scarabino, 2010 & & & & & & & & & $\mathbf{X}$ & & & & \\
\hline \multicolumn{14}{|l|}{ Mulinia edulis (King \& Broderip, 1831) } \\
\hline \multicolumn{14}{|l|}{ Familia Mesodesmatidae Gray,1839 } \\
\hline \multicolumn{14}{|l|}{ Mesodesma mactroides (Reeve, 1854) } \\
\hline Familia Solenidae Lamarck, 1809 & & & & & & & & & & & & & \\
\hline
\end{tabular}




\begin{tabular}{|l|c|c|c|c|c|c|c|c|c|c|c|c|c|}
\hline Bivalvos & B1 & B2 & E11 & E12 & E13 & E14 & E15 & E16 & E17 & E18 & E19 & F16 & F17 \\
\hline Solen tehuelchus (Hanley, 1842) & & & & & & & & & & & & & \\
\hline Familia Telinidae De Blainville,1814 & & & & & & & & & & & & & \\
\hline Macoma (P.) uruguayensis (Smith, 1885) & & & & & & & & & $\mathbf{X}$ & & & $\mathbf{X}$ & \\
\hline Familia Solecurtidae d'Orbigny,1846 & & & & & & & & & & & & & \\
\hline Tagelus (T.) plebeius (Ligthfood,1786) & & & & & & & & & & & & & $\mathbf{X}$ \\
\hline Familia Veneridae Rafinesque,1815 & & & & & & & & & & & & & \\
\hline Pitar (P.) rostratus (Philippi, 1844) & $\mathbf{X}$ & $\mathbf{X}$ & $\mathbf{X}$ & $\mathbf{X}$ & $\mathbf{X}$ & $\mathbf{X}$ & $\mathbf{X}$ & $\mathbf{X}$ & $\mathbf{X}$ & $\mathbf{X}$ & & $\mathbf{X}$ & $\mathbf{X}$ \\
\hline Amiantis purpurata (Lamarck, 1856) & & & & $\mathbf{X}$ & $\mathbf{X}$ & $\mathbf{X}$ & & & & & & & \\
\hline Familia Corbulidae Gray, 1823 & & & & & & & & & & & & \\
\hline Corbula (C.) patagonica d'Orbigny, 1846 & & & & & & & $\mathbf{X}$ & & $\mathbf{X}$ & & & $\mathbf{X}$ & $\mathbf{X}$ \\
\hline Corbula (C.) Iyoni Pilsbry, 1897 & & & & & & & & & & & & & \\
\hline Familia Pholadidae Lamarck, 1809 & & & & & & & & & & & & & \\
\hline Barnea lamellosa (d'Orbigny, 1846) & & & & & & & & & & & & & \\
\hline
\end{tabular}

T 8.2: Lista sistemática de especies de bivalvos de cada sitio muestreado de la región de isla Jabalí - Villa 7 de Marzo. 


\begin{tabular}{|c|c|c|c|c|c|c|c|c|c|c|c|c|c|c|c|}
\hline Bivalvos & F18 & F19 & F20 & F21 & F22 & F23 & G9 & G10 & G11 & G12 & G13 & G14 & G15 & G16 & G17 \\
\hline \multicolumn{16}{|l|}{ Familia Nuculidae Gray,1824 } \\
\hline \multirow{2}{*}{\multicolumn{16}{|c|}{$\begin{array}{l}\text { Nucula (N.) nucleus ( Linné, 1758) } \\
\text { Ennucula aravi (d'Orbiany 1846) }\end{array}$}} \\
\hline & & & & & & & & & & & & & & & \\
\hline \multicolumn{16}{|l|}{ Familia Glycymerididae Newton, 1922} \\
\hline Glycymeris (G.) longior ( Sowerby,1832) & & & & & & $\mathbf{X}$ & & & & & & & & & $\mathbf{X}$ \\
\hline \multicolumn{16}{|l|}{ Familia Mytilidae Rafinesque, 1815} \\
\hline Mytilus edulis platensis d'Orbigny, 1846 & & & $\mathbf{X}$ & & & & $\mathbf{X}$ & $\mathbf{X}$ & & & & $\mathbf{X}$ & & & $\mathbf{X}$ \\
\hline Brachidontes $(B)$ rodriguezii ( d'Orbigny, 1846 ) & & & & & & & $\mathbf{X}$ & & $\mathbf{X}$ & $\mathbf{X}$ & & & $\mathbf{X}$ & $\mathbf{X}$ & \\
\hline \multicolumn{16}{|l|}{ Familia Plicatulidae Watson, 1930} \\
\hline Plicatula gibbosa Lamarck, 1801 & & & & & & $\mathbf{X}$ & & & & & & & & & $\mathbf{X}$ \\
\hline \multicolumn{16}{|l|}{ Familia Ostreidae Rafinesque, 1815} \\
\hline \multicolumn{16}{|l|}{ Crassostrea rhizophorae (Guilding, 1828) } \\
\hline Crassostrea gigas (Thunberg, 1793) & & & & & & & $\mathbf{X}$ & & $\mathbf{X}$ & $\mathbf{X}$ & & & $\mathbf{X}$ & & \\
\hline Ostrea & & & & & & $\mathbf{X}$ & & & & & $\mathbf{X}$ & & & $\mathbf{X}$ & \\
\hline Ostreola equestris (Say, 1834) & & & & & & & & $\mathbf{X}$ & & & $\mathbf{X}$ & $\mathbf{X}$ & & $\mathbf{X}$ & \\
\hline Ostrea puelchana d'Orbigny 1841 & & & $\mathbf{X}$ & & & $\mathbf{X}$ & & & $\mathbf{X}$ & & & $\mathbf{X}$ & & & $\mathbf{X}$ \\
\hline \multicolumn{16}{|l|}{ Familia Pectinidae Rafinesque, 1815} \\
\hline Aequipecten tehuelchus (d'Orbigny, 1842) & & & $\mathbf{X}$ & & & & $\mathbf{X}$ & & & & & & $\mathbf{X}$ & & $\mathbf{X}$ \\
\hline \multicolumn{16}{|l|}{ Familia Diplodontidae Dall, 1895} \\
\hline \multicolumn{16}{|l|}{ Diplodonta (D.) patagonica ( d'Orbigny, 1842) } \\
\hline \multicolumn{16}{|l|}{$\begin{array}{l}\text { Diplodonta (F.) vilardeboana ( d'Orbigny, } \\
1846 \text { ) }\end{array}$} \\
\hline \multicolumn{16}{|l|}{ Familia Carditidae Fleming, 1828} \\
\hline \multicolumn{16}{|l|}{ Carditamera plata (Inhering, 1907) } \\
\hline \multicolumn{16}{|l|}{ Familia Cardiidae Lamarck, 1809} \\
\hline \multicolumn{16}{|l|}{ Trachycardium muricatum (Linné, 1758) } \\
\hline \multicolumn{16}{|l|}{ Familia Mactridae Lamarck,1809 } \\
\hline Mactra isabelleana d'Orbigny, 1846 & & & $\mathbf{X}$ & & & & & & & & & & & & \\
\hline Mactra guidoi Signorelli \& Scarabino, 2010 & & & & & & & & & & & & $\mathbf{X}$ & & & $\mathbf{X}$ \\
\hline
\end{tabular}




\begin{tabular}{|c|c|c|c|c|c|c|c|c|c|c|c|c|c|c|c|}
\hline Bivalvos & F18 & F19 & F20 & F21 & F22 & F23 & G9 & G10 & G11 & G12 & G13 & G14 & G15 & G16 & G17 \\
\hline Mulinia edulis (King \& Broderip, 1831) & & & $\mathbf{X}$ & & & & & & & & & & & & \\
\hline \multicolumn{16}{|l|}{ Familia Mesodesmatidae Gray,1839 } \\
\hline Mesodesma mactroides (Reeve, 1854) & & & & & & & & $\mathbf{X}$ & & & & $\mathbf{X}$ & & & \\
\hline \multicolumn{16}{|l|}{ Familia Solenidae Lamarck, 1809} \\
\hline Solen tehuelchus (Hanley, 1842) & & & & & & & & $\mathbf{X}$ & & & & $\mathbf{X}$ & & & $\mathbf{X}$ \\
\hline \multicolumn{16}{|l|}{ Familia Telinidae De Blainville,1814 } \\
\hline \multicolumn{16}{|l|}{ Macoma $(P$.$) uruguayensis (Smith, 1885)$} \\
\hline \multirow{2}{*}{\multicolumn{16}{|c|}{ Familia Solecurtidae d'Orbigny, 1846}} \\
\hline & & & & & & & & & & & & & & & \\
\hline \multicolumn{16}{|l|}{ Familia Veneridae Rafinesque,1815 } \\
\hline Pitar (P.) rostratus (Philippi, 1844) & $\mathbf{X}$ & $\mathbf{X}$ & $\mathbf{X}$ & & & $\mathbf{X}$ & $\mathbf{X}$ & $\mathbf{X}$ & $\mathbf{X}$ & $\mathbf{X}$ & $\mathbf{X}$ & $\mathbf{X}$ & $\mathbf{X}$ & & \\
\hline Amiantis purpurata ( Lamarck, 1856) & $\mathbf{X}$ & & $\mathbf{X}$ & & & & $\mathbf{X}$ & $\mathbf{X}$ & & $\mathbf{X}$ & $\mathbf{X}$ & $\mathbf{X}$ & & & \\
\hline \multicolumn{16}{|l|}{ Familia Corbulidae Gray, 1823} \\
\hline Corbula (C.) patagonica d'Orbigny, 1846 & $\mathbf{X}$ & $\mathbf{X}$ & & $\mathbf{X}$ & $\mathbf{X}$ & & & & & $\mathbf{X}$ & & & & & \\
\hline Corbula (C.) Iyoni Pilsbry, 1897 & & & & $\mathbf{X}$ & & & & & & & & & & & \\
\hline \multicolumn{16}{|l|}{ Familia Pholadidae Lamarck,1809 } \\
\hline Barnea lamellosa ( d’Orbigny, 1846) & & & & & & & & $\mathbf{X}$ & & & & $\mathbf{X}$ & & & \\
\hline
\end{tabular}

T 8.3: Lista sistemática de especies de bivalvos de cada sitio muestreado de la región de isla Jabalí - Villa 7 de Marzo. 


\begin{tabular}{|c|c|c|c|c|c|c|c|c|c|c|c|c|c|}
\hline Gasterópodos & B1 & B2 & E11 & E12 & E13 & E14 & E15 & E16 & E17 & E18 & E19 & F16 & F17 \\
\hline \multicolumn{14}{|l|}{ Familia Fissurellidae Fleming,1822 } \\
\hline \multicolumn{14}{|l|}{ Diodora (D.) patagonica (d'Orbigny, 1841) } \\
\hline \multirow{2}{*}{\multicolumn{14}{|c|}{$\begin{array}{l}\text { Lucapinella henseli (Martens, 1900) } \\
\text { Familia Calliostomatidae Thiele. } 1924\end{array}$}} \\
\hline \multicolumn{5}{|l|}{ Familia Calliostomatidae Thiele, 1924} & & & & & & & & & \\
\hline Tegula (A.) patagonica (d’Orbigny, 1835 ) & & & & $\mathbf{X}$ & & $\mathbf{X}$ & $\mathbf{X}$ & & $\mathbf{X}$ & $\mathbf{X}$ & $\mathbf{X}$ & $\mathbf{X}$ & \\
\hline Calliostoma coppingeri ( Smith, 1880) & & & & & & & & & & & $\mathbf{X}$ & & \\
\hline \multicolumn{14}{|l|}{ Familia Calyptraeidae Lamarck,1809 } \\
\hline Bostrycapulus odites (Collin, 2005) & & & & $\mathbf{X}$ & & $\mathbf{X}$ & & & $\mathbf{X}$ & $\mathbf{X}$ & $\mathbf{X}$ & $\mathbf{X}$ & \\
\hline Crepidula & & & & & & & & & $\mathbf{X}$ & $\mathbf{X}$ & & & \\
\hline \multicolumn{14}{|l|}{$\begin{array}{l}\text { Crepidula argentina Simone, Pastorino \& } \\
\text { Penchaszadeh, } 2000\end{array}$} \\
\hline \multicolumn{14}{|l|}{ Familia Naticidae Forbes, 1828} \\
\hline Notocochlis isabelleana (d'Orbigny, 1840) & & & & & & & $\mathbf{X}$ & & & & & & \\
\hline \multicolumn{14}{|l|}{ Familia Hydrobiidae Troschel, 1857} \\
\hline Heleobia australis ( d'Orbigny, 1835) & & & & & & & $\mathbf{X}$ & & $\mathbf{X}$ & & & $\mathbf{X}$ & $\mathbf{X}$ \\
\hline \multicolumn{14}{|l|}{ Familia Epitoniidae S. S.Berry, 1910} \\
\hline \multicolumn{14}{|l|}{ Epitonium (E.) georgettinum (d'Orbigny,1840) } \\
\hline \multicolumn{14}{|l|}{ Familia Muricidae Rafinesque, 1815} \\
\hline Trophon patagonicus (d'Orbigny, 1839) & & & & & & & $\mathbf{X}$ & & & & & & \\
\hline Urosalpinx cala (Pilsbry, 1897) & & & & & & & & & & & $\mathbf{X}$ & & \\
\hline \multicolumn{14}{|l|}{ Familia Volutidae Rafinesque, 1815} \\
\hline Zidona dufresnei ( Donovan, 1823) & & $\mathbf{X}$ & & & & & $\mathbf{X}$ & & $\mathbf{X}$ & & & & $\mathbf{X}$ \\
\hline Adelomelon (P.) brasiliana (Lamarck, 1811) & & & & & & & & & & & & & \\
\hline Odontocymbiola magellanica (Gmelin, 1791) & & & & & & & & & & & & & \\
\hline
\end{tabular}




\begin{tabular}{|c|c|c|c|c|c|c|c|c|c|c|c|c|c|}
\hline Gasterópodos & B1 & B2 & E11 & E12 & E13 & E14 & E15 & E16 & E17 & E18 & E19 & F16 & F17 \\
\hline \multicolumn{14}{|l|}{ Familia Olividae Latreille, 1825} \\
\hline Olivella (O.) tehuelcha ( Dúclos, 1835) & & & & & & & $\mathbf{X}$ & & & & & $\mathbf{X}$ & \\
\hline Olivancillaria urceus ( Röding, 1798) & $\mathbf{X}$ & & & & & & & & $\mathbf{X}$ & & & & \\
\hline Olivancillaria carcellesi Klappenbach, 1965 & & & & & & & & & $\mathbf{X}$ & & & $\mathbf{X}$ & \\
\hline \multicolumn{14}{|l|}{ Familia Marginellidae Fleming, 1828} \\
\hline Marginella martini Petit, 1853 & & & & & & & $\mathbf{X}$ & & & & & & \\
\hline \multicolumn{14}{|l|}{ Familia Nassariidae Iredale, 1916} \\
\hline Buccinanops & & & & & & & & & & & & $\mathbf{X}$ & \\
\hline \multicolumn{14}{|l|}{ Buccinanops monilifer ( Kiener, 1834) } \\
\hline Buccinanops cochlidium (Dilwyn, 1817) & $\mathbf{X}$ & & & & & & & & $\mathbf{X}$ & & $\mathbf{X}$ & & \\
\hline Buccinanops globulosus (Kiener, 1834) & & & $\mathbf{X}$ & & $\mathbf{X}$ & & $\mathbf{X}$ & & & & $\mathbf{X}$ & $\mathbf{X}$ & \\
\hline Buccinanops uruguayensis (Pilsbry,1897) & & & & & & & $\mathrm{X}$ & & & & & $\mathbf{X}$ & \\
\hline \multicolumn{14}{|l|}{ Familia Columbellidae Swaison, 1840} \\
\hline Parvanachis isabellei (d'Orbigny, 1839) & & & & & & & & & & & $\mathbf{X}$ & & \\
\hline \multicolumn{14}{|l|}{ Familia Siphonariidae Gray, 1840} \\
\hline Siphonaria lessoni (Blainville, 1824) & & & & & & & & & $\mathbf{X}$ & & & & \\
\hline
\end{tabular}

T 8.4: Lista sistemática de especies de gasterópodos de cada sitio muestreado de la región de isla Jabalí - Villa 7 de Marzo. 


\begin{tabular}{|c|c|c|c|c|c|c|c|c|c|c|c|c|c|c|c|}
\hline Gasterópodos & F18 & F19 & F20 & F21 & F22 & F23 & G9 & G10 & G11 & G12 & G13 & G14 & G15 & G16 & G17 \\
\hline \multicolumn{16}{|l|}{ Familia Fissurellidae Fleming,1822 } \\
\hline Diodora (D.) patagonica ( d'Orbigny, 1841) & & & & & & & & & & & & & $\mathbf{X}$ & & \\
\hline Lucapinella henseli (Martens, 1900) & & & & & & & & & & $\mathbf{X}$ & & & & & \\
\hline \multicolumn{16}{|l|}{ Familia Calliostomatidae Thiele, 1924} \\
\hline Tegula (A.) patagonica (d'Orbigny, 1835) & $\mathbf{X}$ & & $\mathbf{X}$ & & & & $\mathbf{X}$ & & & $\mathbf{X}$ & $\mathbf{X}$ & & $\mathbf{X}$ & $\mathbf{X}$ & $\mathbf{X}$ \\
\hline \multicolumn{16}{|l|}{ Calliostoma coppingeri ( Smith, 1880) } \\
\hline \multicolumn{16}{|l|}{ Familia Calyptraeidae Lamarck, 1809} \\
\hline Bostrycapulus odites (Collin, 2005) & $\mathbf{X}$ & & $\mathbf{X}$ & & & $\mathbf{X}$ & $\mathbf{X}$ & $\mathbf{X}$ & $\mathbf{X}$ & $\mathbf{X}$ & $\mathbf{X}$ & $\mathbf{X}$ & & $\mathbf{X}$ & $\mathbf{X}$ \\
\hline Crepidula & & & & & & $\mathbf{X}$ & & & & & $\mathbf{X}$ & & & $\mathbf{X}$ & $\mathbf{X}$ \\
\hline $\begin{array}{l}\text { Crepidula argentina Simone, Pastorino \& } \\
\text { Penchaszadeh, } 2000\end{array}$ & $\mathbf{X}$ & & $\mathbf{X}$ & & & & $\mathbf{X}$ & & $\mathbf{X}$ & $\mathbf{X}$ & & & & & \\
\hline \multicolumn{16}{|l|}{ Familia Naticidae Forbes, 1828} \\
\hline \multicolumn{16}{|l|}{ Notocochlis isabelleana (d'Orbigny, 1840) } \\
\hline \multicolumn{16}{|l|}{ Familia Hydrobiidae Troschel, 1857} \\
\hline Heleobia australis ( d'Orbigny, 1835) & $\mathbf{X}$ & $\mathbf{X}$ & & $\mathbf{X}$ & $\mathbf{X}$ & & $\mathbf{X}$ & & & & & & & & \\
\hline \multicolumn{16}{|l|}{ Familia Epitoniidae S. S.Berry, 1910} \\
\hline Epitonium (E.) georgettinum (d'Orbigny,1840) & & & & & & & & & & & & & & & $\mathbf{X}$ \\
\hline \multicolumn{16}{|l|}{ Familia Muricidae Rafinesque, 1815} \\
\hline Trophon patagonicus (d'Orbigny, 1839) & & & $\mathbf{X}$ & & & $\mathbf{X}$ & & & & & & & $\mathbf{X}$ & $\mathbf{X}$ & $\mathbf{X}$ \\
\hline \multicolumn{16}{|l|}{ Urosalpinx cala (Pilsbry, 1897) } \\
\hline \multicolumn{16}{|l|}{ Familia Volutidae Rafinesque, 1815} \\
\hline Zidona dufresnei ( Donovan, 1823) & $\mathbf{X}$ & & $\mathbf{X}$ & & & & $\mathbf{X}$ & & $\mathbf{X}$ & & & & & $\mathbf{X}$ & \\
\hline Adelomelon (P.) brasiliana (Lamarck, 1811) & $\mathbf{X}$ & & & & & & & & & & & $\mathbf{X}$ & & & \\
\hline Odontocymbiola magellanica (Gmelin, 1791) & & & $\mathbf{X}$ & & & & & & & & & & & & \\
\hline \multicolumn{16}{|l|}{ Familia Olividae Latreille,1825 } \\
\hline \multicolumn{16}{|l|}{ Olivella (O.) tehuelcha ( Dúclos, 1835) } \\
\hline \multicolumn{16}{|l|}{ Olivancillaria urceus ( Röding, 1798) } \\
\hline Olivancillaria carcellesi Klappenbach, 1965 & $\mathbf{X}$ & & $\mathbf{X}$ & & & & & & $\mathbf{X}$ & & & & & $\mathbf{X}$ & \\
\hline
\end{tabular}




\begin{tabular}{|c|c|c|c|c|c|c|c|c|c|c|c|c|c|c|c|}
\hline Gasterópodos & F18 & F19 & F20 & F21 & F22 & F23 & G9 & G10 & G11 & G12 & G13 & G14 & G15 & G16 & G17 \\
\hline \multicolumn{16}{|l|}{ Familia Marginellidae Fleming, 1828} \\
\hline Marginella martini Petit, 1853 & & & & & & & & & $\mathbf{X}$ & & & & & & \\
\hline \multicolumn{16}{|l|}{ Familia Nassariidae Iredale,1916 } \\
\hline Buccinanops & & & & & & & & & & & & & & $\mathbf{X}$ & \\
\hline Buccinanops monilifer ( Kiener, 1834) & & & $\mathbf{X}$ & & & & & & & & & $\mathbf{X}$ & $\mathbf{X}$ & $\mathbf{X}$ & $\mathbf{X}$ \\
\hline Buccinanops cochlidium (Dilwyn, 1817) & $\mathbf{X}$ & & $\mathbf{X}$ & & & $\mathbf{X}$ & & & & & & & & & \\
\hline Buccinanops globulosus (Kiener, 1834) & & & & & $\mathbf{X}$ & $\mathbf{X}$ & & $\mathbf{X}$ & $\mathbf{X}$ & $\mathbf{X}$ & & & $\mathbf{X}$ & & $\mathbf{X}$ \\
\hline \multirow{2}{*}{\multicolumn{16}{|c|}{$\begin{array}{l}\text { Buccinanops uruguayensis (Pilsbry,1897) } \\
\text { Familia Columbellidae Swaison, } 1840\end{array}$}} \\
\hline & & & & & & & & & & & & & & & \\
\hline Parvanachis isabellei (d'Orbigny, 1839) & & & & & & & & & & & & & $\mathbf{X}$ & & \\
\hline \multicolumn{16}{|l|}{ Familia Siphonariidae Gray, 1840} \\
\hline Siphonaria lessoni (Blainville, 1824) & & & & & & & & & & & & & & & \\
\hline
\end{tabular}

T 8.5: Lista sistemática de especies de gasterópodos de cada sitio muestreado de la región de isla Jabalí - Villa 7 de Marzo. 
Según el índice de diversidad de Shannon ( $\left.\mathrm{H}^{\prime}\right)$, los sitios actuales tienen mayor diversidad variando entre los valores 2.3 - 1.24 comparados con los sitios pertenecientes al Interglacial MIS 1 que muestran valores bajos entre los $0.22-0.90$, salvo dos sitios $\left(\mathrm{H}_{\mathrm{F} 28}^{\prime}=2.28 ; \mathrm{H}_{\mathrm{F} 21}^{\prime}=2.60\right)$, los cuales corresponden a cordones de tormenta. Mientras que los sitios asociados al Interglacial MIS 5e (E) presentan valores que oscilan entre los $0.64-1.98$ siendo los valores más altos $\left(\mathrm{H}_{\mathrm{E} 15}^{\prime}=2.09\right.$ y $\mathrm{H}_{\mathrm{E} 17}^{\prime}=2.52$ ). Además, entre los sitios pertenecientes al Interglacial $\geq$ MIS 9, el sitio B2 es uno con los índices más bajos encontrados junto al sitio del Interglacial MIS 1 (Sitio F17) (Fig. 8-14) (T. 8.6).

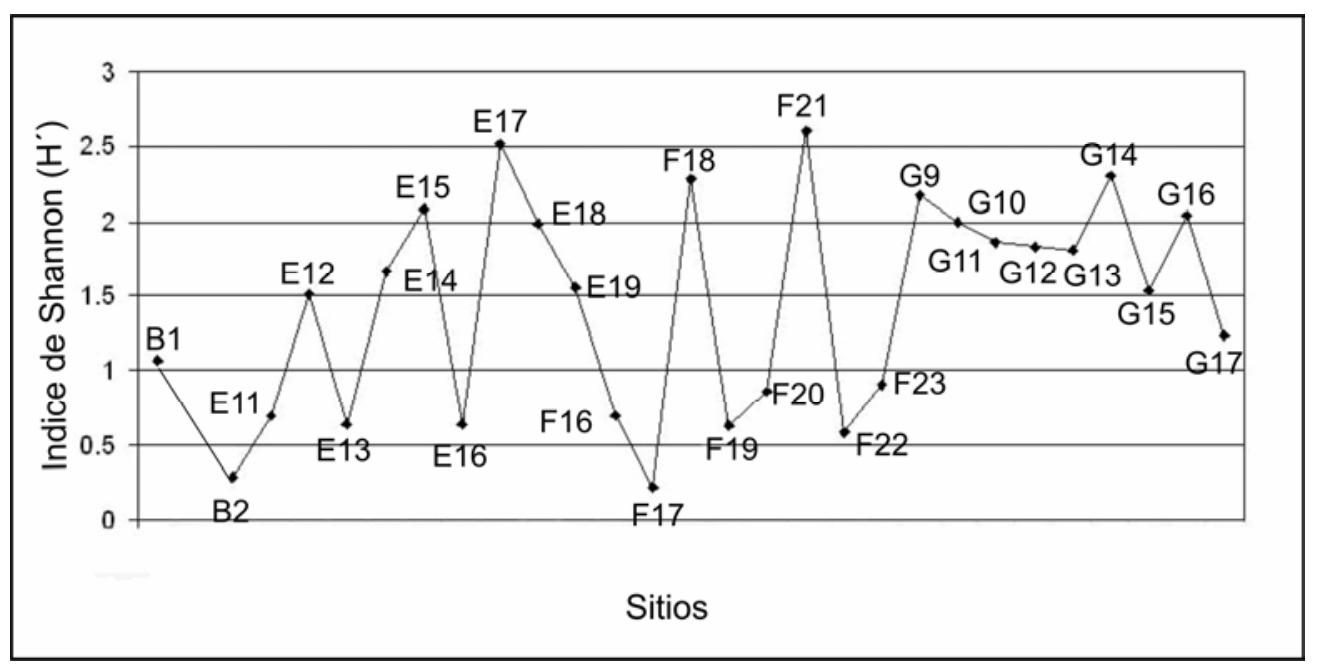

Fig. 8.14: Gráfico del índice de Shannon - Wiever $\left(\mathrm{H}^{\prime}\right)$ de cada sitio de la región de isla Jabalí Villa 7 de Marzo.

\begin{tabular}{|c|c|c|}
\hline № de sitio & $\begin{array}{c}\text { Índice de Shannon } \\
\left(\mathbf{H}^{\prime}\right)\end{array}$ & № de especies \\
\hline B1 & 1.07 & 4 \\
\hline B2 & 0.29 & 2 \\
\hline E11 & 0.69 & 2 \\
\hline E12 & 1.51 & 7 \\
\hline E14 & 0.64 & 3 \\
\hline E15 & 1.67 & 6 \\
\hline E16 & 2.09 & 12 \\
\hline E17 & 0.64 & 3 \\
\hline
\end{tabular}




\begin{tabular}{|c|c|c|}
\hline E18 & 1.98 & 10 \\
\hline E19 & 1.55 & 10 \\
\hline F16 & 0.69 & 18 \\
\hline F17 & 0.22 & 8 \\
\hline F18 & 2.28 & 11 \\
\hline F19 & 0.63 & 4 \\
\hline F20 & 0.86 & 3 \\
\hline F21 & 2.60 & 16 \\
\hline F22 & 0.59 & 4 \\
\hline F23 & 0.90 & 10 \\
\hline G9 & 2.17 & 11 \\
\hline G10 & 2.00 & 9 \\
\hline G11 & 1.86 & 10 \\
\hline G12 & 1.83 & 10 \\
\hline G13 & 1.81 & 7 \\
\hline G14 & 2.31 & 11 \\
\hline G15 & 1.53 & 10 \\
\hline G16 & 2.04 & 11 \\
\hline G17 & 1.24 & 14 \\
\hline
\end{tabular}

T. 8.6: Tabla de índices de diversidad $\left(\mathrm{H}^{\prime}\right)$, y riqueza en cada sitio analizado en la región de isla Jabalí - Villa 7 de Marzo.

\subsubsection{Pleistoceno de la región de isla Jabalí - Villa 7 de Marzo}

En esta región se analizaron un total de 11 sitios y se registraron 34 especies (17 bivalvos y 17 gasterópodos). En los depósitos más antiguos, se reconocen dos depósitos que pertenecen al Interglacial $\geq$ MIS 9 (B1 y B2) con cotas de 33 m aproximadamente registrándose un total de 7 especies (4 bivalvos y 3 gasterópodos). Entre la fauna marina se destaca Glycymeris longior, Pitar rostratus (bivalvos) y Zidona dufresnei, Olivancillaria urceus, Buccinanops cochlidium y Buccinanops globulosus (gasterópodos).

En el Interglacial MIS 5e (E11 - E19), todos representan a cordones litorales, y se registró un total de 31 especies (15 bivalvos y 16 gasterópodos). Entre la fauna marina más abundante figuran: Pitar rostratus (bivalvo) y Bostrycapulus odites, Tegula patagonica y Buccinanops globulosus (gasterópodos).

Se destaca la presencia en el Sitio E15, de un bivalvo de estirpe cálida, Crassostrea rhizophorae perteneciente a la Familia Ostreidae, que en la actualidad no se registra en la costa argentina. 


\subsubsection{Holoceno de la región de isla Jabalí - Villa 7 de Marzo}

En los cordones litorales holocenos se analizaron 8 sitios y se recolectaron un total de 33 especies (20 bivalvos y 13 gasterópodos) con buena preservación y en algunos casos con fauna articulada. Los depósitos marinos pertenecientes al Interglacial MIS 1 del área están representados por dos tipos de depósitos, cordones litorales y planicies de mareas.

Entre los cordones litorales (F18 y F21), correspondientes a ambientes de alta energía entre la fauna marina encontrada figuran: Pitar rostratus, Amiantis purpurata, Glycymeris longior, Ostreola equestris (bivalvos) y Tegula patagonica, Bostrycapulus odites, Buccinanops globulosus (gasterópodos).En las planicies de marea (Sitios F16, F17, F19 y F20), correspondientes a ambientes de menor energía, la fauna asociada se caracteriza por la presencia de Heleobia australis (gasterópodo), y Corbula patagonica y Tagelus plebeius (bivalvos). En la mayoría de estos depósitos se observan entre los ejemplares de Tagelus plebeius articulados y en posición de vida.

\subsubsection{Playas actuales de la región de isla Jabalí - Villa 7 de Marzo}

En las playas de Isla Jabalí se analizaron 9 sitios, constituidas por rodados y arenas y se registraron en total 30 especies (15 gasterópodos y 15 bivalvos), entre los cuales abundan: Brachidontes rodrigueziii, Ostreola equestris, Pitar rostratus, Amiantis purpurata (bivalvos) y Bostrycapulus odites (gasterópodos). Entre la fauna se destaca la presencia: Mesodesma mactroides, Solen tehuelchus, Barnea lamellosa y Crassostrea gigas, bivalvos típicos de playas del área sur de la Provincia de Buenos Aires a excepción de este último bivalvo (Fig. 8.15 y Fig. 8.16).

En las playas de Faro Segunda Barranca, se analizaron 2 sitios y se registró un total de 16 especies (10 gasterópodos y 6 bivalvos), siendo los más abundantes: Ostreola 
equestris (bivalvos) y Trophon patagonicus, Bostrycapulus odites, y Tegula patagonica (gasterópodos).

Las playas de Villa 7 de Marzo, cercano al río Negro, se diferencia de las demás playas por el tipo de playa arenoso-fino y la abundancia de Plicatula gibbosa, Ostrea puelchana (bivalvos) y Crepidula (gasterópodo). 


\section{Bivalvos pleistocenos (B)}

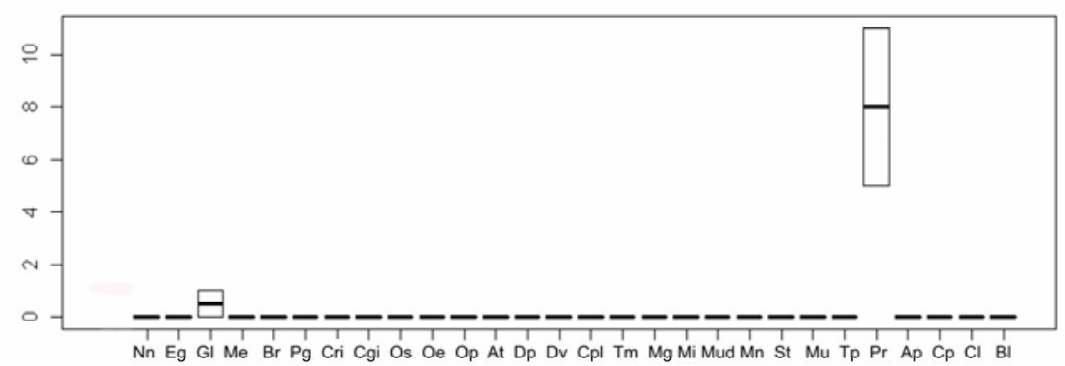

Bivalvos pleistocenos (E)

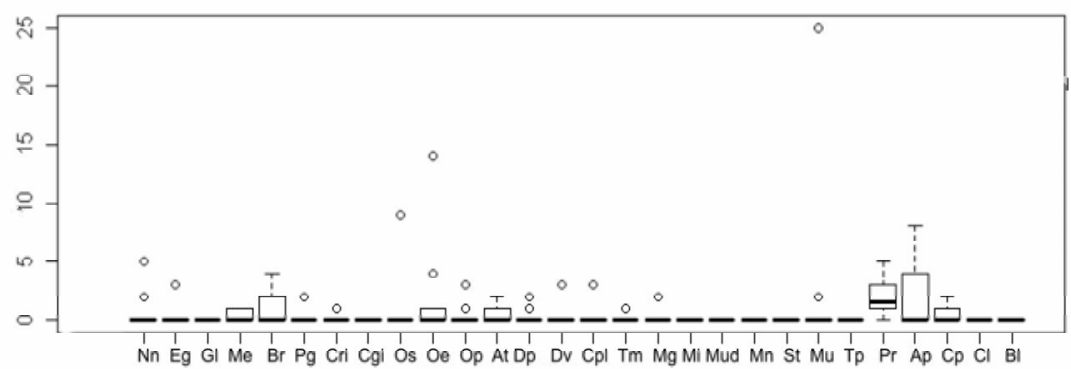

Bivalvos holocenos $(F)$

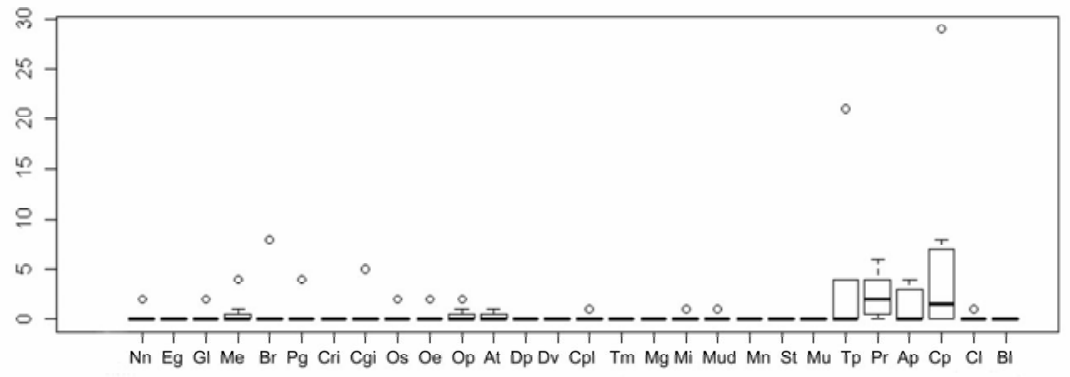

Bivalvos actuales $(G)$

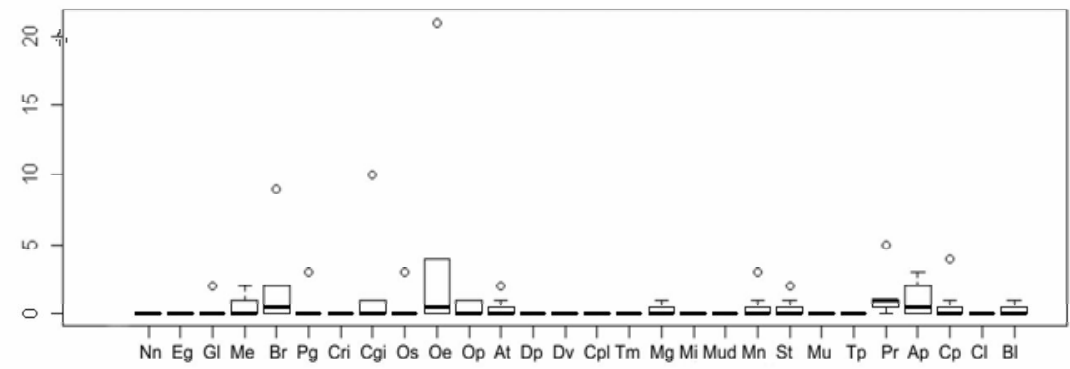

Fig. 8.15: Abundancias de bivalvos cuaternarios de la región de isla Jabalí - Villa 7 de Marzo. 


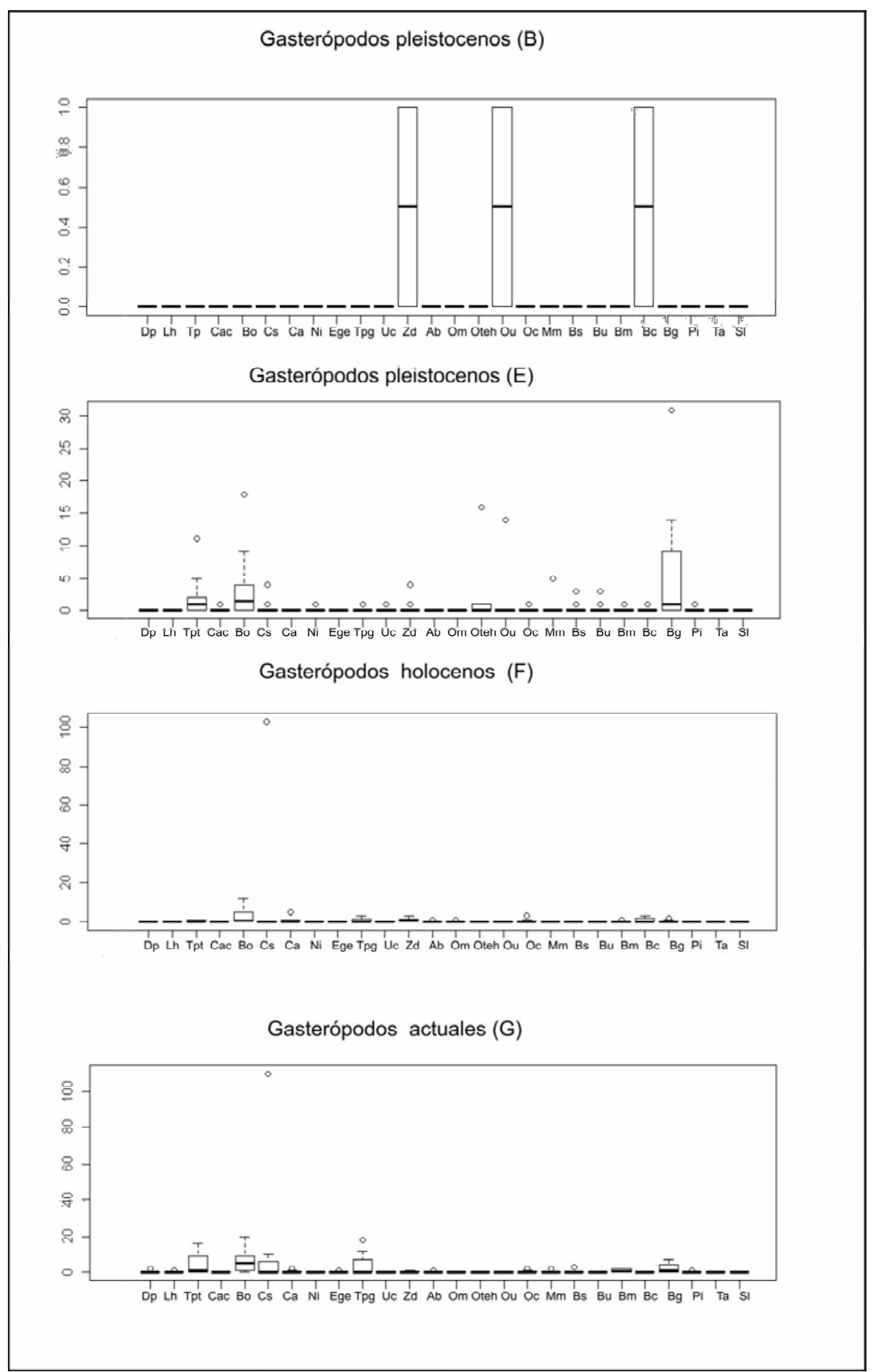

Fig. 8.16: Abundancias de gasterópodos cuaternarios de la región de isla Jabalí - Villa 7 de Marzo. 


\subsection{Paleoecología}

En el Interglacial $\geq$ MIS 9 (B) todos los bivalvos son eurihalinos, infaunales, de sustratos arenosos y filtradores. A partir del Interglacial MIS 5e (E) son en su mayoría polihalinos - eurihalinos, infaunales con presencia de epifaunales y cementados, de sustratos arenosos con presencia de rocosos y mixtos, y filtradores con un aumento respecto al período anterior en la proporción de carnívoros y detritívoros. En el Interglacial MIS 1 (F) aumentan los bivalvos eurihalinos, infaunales, de sustratos arenosos, y filtradores. En la actualidad (G), se observa un cambio, ya que desaparecen las especies polihalinas- eurihalinas, cementadas y detritívoros, aumentando las especies de sustratos rocosos (Fig.8.17) (T. 8.6).

En el Interglacial $\geq$ MIS 9 (B), todos los gasterópodos son eurihalinos, epifaunales, de sustratos arenosos y carnívoros. A partir del Interglacial MIS 5e (E), la mayoría de los gasterópodos son eurihalinas, epifaunales con un aumento en la proporción de infaunales y ectopárasitos. La mayoría de los gasterópodos son de sustratos arenosos, con un aumento en la proporción de rocosos y mixtos, y carnívoros con presencia de herbívoros y filtradores. En el Interglacial MIS 1 (F), son todos epifaunales, aumentando las especies carnívoras y filtradoras. En la actualidad, aparecen especies cementadas aumentando la proporción de los gasterópodos herbívoros (Fig. 8.18) (T. 8.7). 


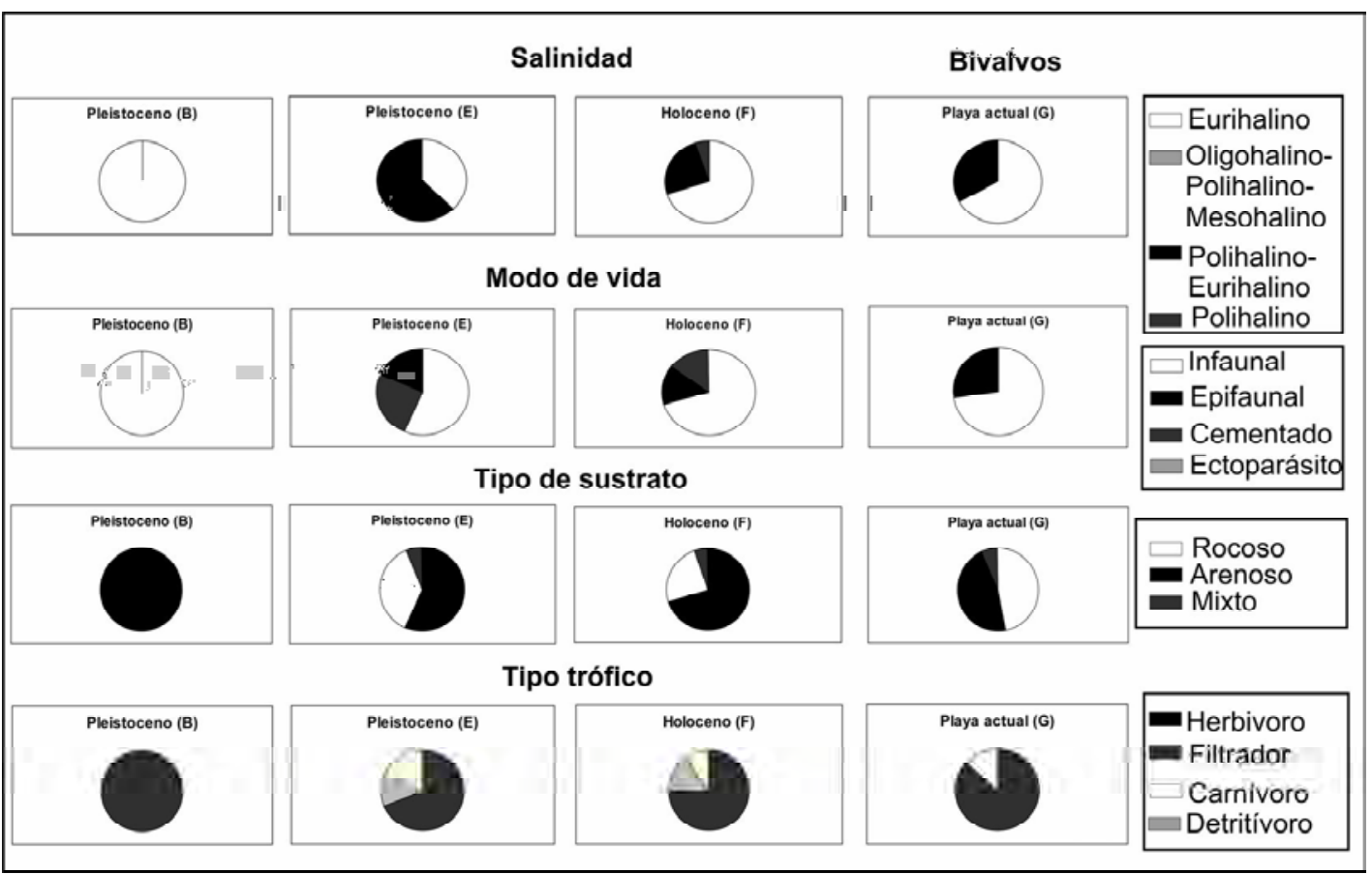

Fig. 8.17: Proporción de bivalvos según la salinidad, modo de vida, tipo de sustrato y tipo trófico.

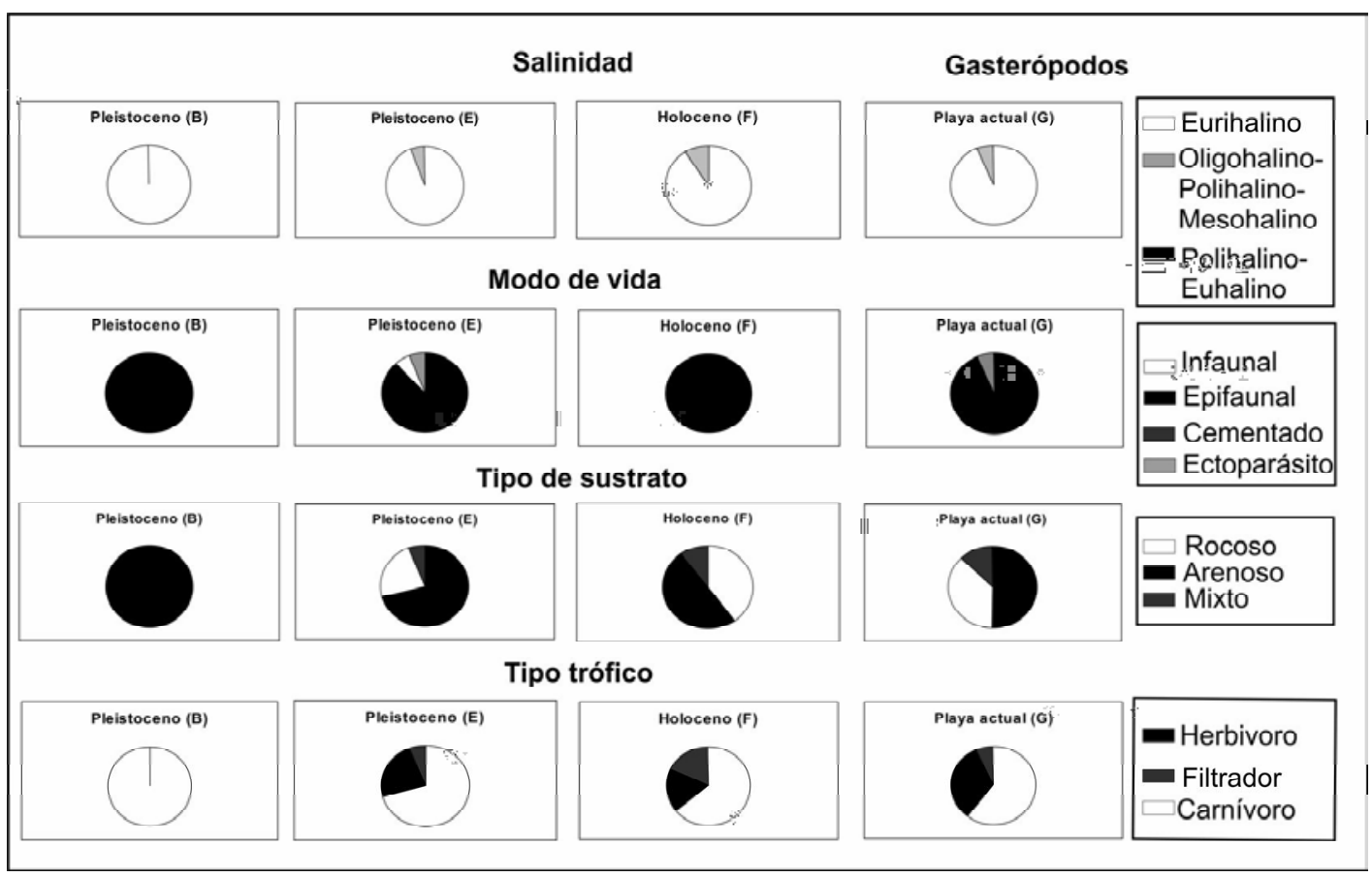

Fig. 8.18: Proporción de gasterópodos según la salinidad, modo de vida, tipo de sustrato y tipo trófico. 


\begin{tabular}{|c|c|c|c|c|c|c|}
\hline BIVALVOS & Salinidad & $\begin{array}{l}\text { Modo } \\
\text { de vida }\end{array}$ & $\begin{array}{c}\text { Profundid } \\
\text { ad }\end{array}$ & Sustrato & $\begin{array}{c}\text { Tipo } \\
\text { trófico }\end{array}$ & Área de distribución \\
\hline Nucula (N.) nucleus ( Linné, 1758) & $\mathrm{E}$ & 1 & $0-200$ & $\mathrm{~S}$ & $\mathrm{D}$ & $23^{\circ} \mathrm{S}-53.5^{\circ} \mathrm{S}$ \\
\hline Ennucula grayi (d’Orbigny, 1846$)$ & $\mathrm{E}$ & $\mathrm{I}$ & $5-1850$ & $\mathrm{~S}$ & $\mathrm{D}$ & $22.93^{\circ} \mathrm{S}-55.5^{\circ} \mathrm{S}$ \\
\hline Glycymeris (G.) longior ( Sowerby, 1832) & $\mathrm{E}$ & $\mathrm{I}$ & $10-75$ & $\mathrm{~S}$ & $\mathrm{~F}$ & $10^{\circ} \mathrm{S}-42^{\circ} \mathrm{S}$ \\
\hline Mytilus edulis platensis d'Orbigny, 1846 & $P-E$ & Ep & $0-50$ & $\mathrm{R}$ & $\mathrm{F}$ & $68^{\circ} \mathrm{N}-55.5^{\circ} \mathrm{S}$ \\
\hline $\begin{array}{l}\text { Brachidontes (B) rodriguezii ( d'Orbigny, } \\
1846 \text { ) }\end{array}$ & $\mathrm{P}-\mathrm{E}$ & Ep & $0-25$ & $\mathrm{R}$ & $\mathrm{F}$ & $34^{\circ} \mathrm{S}-42^{\circ} \mathrm{S}$ \\
\hline Plicatula gibbosa Lamarck, 1801 & $\mathrm{E}$ & $\mathrm{Ce}$ & $0-120$ & $\mathrm{R}$ & $\mathrm{F}$ & $35.3^{\circ} \mathrm{N}-34^{\circ} \mathrm{S}^{*}$ \\
\hline Crassostrea rhizophorae (Guilding, 1828) & $P-E$ & $\mathrm{Ce}$ & $0-50$ & $\mathrm{R}$ & $\mathrm{C}$ & $21.4^{\circ} \mathrm{N}-35^{\circ} \mathrm{S}^{*}$ \\
\hline Crassostrea gigas (Thunberg, 1793) & $\mathrm{E}$ & $\mathrm{Ce}$ & $0-40$ & $\mathrm{R}$ & $\mathrm{F}$ & Cosmopolitan \\
\hline Ostreola equestris (Say, 1834) & $P-E$ & $\mathrm{Ce}$ & $0-80$ & $\mathrm{R}$ & $\mathrm{C}$ & $37^{\circ} \mathrm{N}-42^{\circ} \mathrm{S}$ \\
\hline Ostrea puelchana d'Orbigny 1841 & P-E & $\mathrm{Ce}$ & $0-70$ & $\mathrm{R}$ & C & $22^{\circ} \mathrm{S}-42^{\circ} \mathrm{S}$ \\
\hline Aequipecten tehuelchus (d'Orbigny, 1842) & $E$ & Ep & $10-120$ & $\mathrm{M}$ & $\mathrm{F}$ & $21^{\circ} \mathrm{S}-53^{\circ} \mathrm{S}$ \\
\hline $\begin{array}{l}\text { Diplodonta (D.) patagonica ( d'Orbigny, } \\
1842 \text { ) }\end{array}$ & $\mathrm{E}$ & $\frac{1}{4}$ & $36-102$ & $\mathrm{~S}$ & $\mathrm{~F}$ & $21^{\circ} \mathrm{S}-42.58^{\circ} \mathrm{S}$ \\
\hline $\begin{array}{l}\text { Diplodonta (F.) vilardeboana ( d'Orbigny, } \\
1846 \text { ) }\end{array}$ & $\mathrm{E}$ & $\mathrm{I}$ & $25-77$ & $\mathrm{~S}$ & $\mathrm{~F}$ & $21^{\circ} \mathrm{S}-42^{\circ} \mathrm{S}$ \\
\hline Carditamera plata (Ihering, 1907) & $\mathrm{E}$ & $\mathrm{I}$ & $17-70$ & $\mathrm{~S}$ & $\mathrm{~F}$ & $23^{\circ} \mathrm{S}-39^{\circ} \mathrm{S}^{*}$ \\
\hline Trachycardium muricatum (Linné, 1758) & $\mathrm{E}$ & $\mathrm{I}$ & $0-11$ & $\mathrm{~S}$ & $\mathrm{~F}$ & $35^{\circ} \mathrm{N}-42^{\circ} \mathrm{S}$ \\
\hline Mactra isabelleana d'Orbigny, 1846 & P-E & $\mathrm{I}$ & $0-25$ & $\mathrm{~S}$ & $\mathrm{~F}$ & $23^{\circ} \mathrm{S}-42^{\circ} \mathrm{S}$ \\
\hline Mactra guidoi Signorelli \&Scarabino,2010 & P-E & $\mathrm{I}$ & $0-25$ & $\mathrm{~S}$ & $\mathrm{~F}$ & $34^{\circ} \mathrm{S}-42^{\circ} \mathrm{S}$ \\
\hline Mulinia edulis (King \& Broderip, 1831) & $E$ & $\mathrm{I}$ & $0-30$ & $\mathrm{~S}$ & $\mathrm{~F}$ & $52.7^{\circ} \mathrm{S}-55.5^{\circ} \mathrm{S} *$ \\
\hline Mesodesma mactroides (Reeve, 1854) & $\mathrm{E}$ & $\mathrm{I}$ & $0-20$ & $\mathrm{~S}$ & $\mathrm{~F}$ & $23^{\circ} \mathrm{S}-41^{\circ} \mathrm{S}$ \\
\hline Solen tehuelchus (Hanley, 1842) & $\mathrm{E}$ & $\mathrm{I}$ & $10-18$ & $\mathrm{~S}$ & $\mathrm{~F}$ & $23^{\circ} \mathrm{S}-39^{\circ} \mathrm{S}^{*}$ \\
\hline Macoma (P.) uruguayensis (Smith, 1885) & $E$ & $\mathrm{I}$ & $18-70$ & $\mathrm{~S}$ & $\mathrm{D}$ & $29^{\circ} \mathrm{S}-39^{\circ} \mathrm{S}^{*}$ \\
\hline Tagelus (T.) plebeius (Ligthfood,1786) & $P$ & $\mathrm{I}$ & $0-10$ & $\mathrm{~S}$ & $\mathrm{~F}$ & $42^{\circ} \mathrm{N}-54^{\circ} \mathrm{S}$ \\
\hline Pitar (P.) rostratus (Philippi, 1844) & $\mathrm{E}$ & $\mathrm{I}$ & $10-100$ & $\mathrm{~S}$ & $\mathrm{~F}$ & $22^{\circ} \mathrm{S}-38.7^{\circ} \mathrm{S}^{*}$ \\
\hline Amiantis purpurata ( Lamarck, 1856) & $E$ & $\mathrm{I}$ & $0-20$ & $\mathrm{~S}$ & $\mathrm{~F}$ & $19^{\circ} \mathrm{S}-43^{\circ} \mathrm{S}$ \\
\hline Corbula (C.) patagonica d'Orbigny, 1846 & $E$ & $\mathrm{I}$ & $15-90$ & $\mathrm{~S}$ & $\mathrm{~F}$ & $23^{\circ} \mathrm{S}-43^{\circ} \mathrm{S}$ \\
\hline Corbula (C.) Iyoni Pilsbry, 1897 & $\mathrm{E}$ & $\mathrm{I}$ & $11-67$ & $\mathrm{~S}$ & $\mathrm{~F}$ & $19^{\circ} \mathrm{S}-43^{\circ} \mathrm{S}$ \\
\hline Barnea lamellosa (d'Orbigny, 1846) & $\mathrm{E}$ & $\mathrm{I}$ & $15-150$ & $\mathrm{R}$ & $\mathrm{F}$ & $34^{\circ} \mathrm{S}-43^{\circ} \mathrm{S}$ \\
\hline
\end{tabular}

T. 8.6: Requerimientos ecológicos y distribución de bivalvos: $\mathrm{Ep}=$ epifaunal, I=infaunal, $\mathrm{C}=$ cementado; $\mathrm{E}=$ ectoparásito; $\mathrm{R}=$ rocoso, $\mathrm{S}=$ arenoso, $\mathrm{M}=$ =mixto, $\mathrm{Ce}=$ cementado; $\mathrm{C}=$ carnívoros, $\mathrm{D}=$ detritívoros, $\mathrm{He}=$ herbívoros, $\mathrm{F}=$ filtradores; $\mathrm{O}=$ oligohalinos (3-8 \%o), $\mathrm{M}=$ mesohalinos $(8-18 \%$ \%); $\mathrm{P}=$ polihalinos $(18-30 \%$ \%); $\mathrm{E}=$ eurihalinos (> 30-35\%o).*Límite sur de la especie diferente a lo encontrado. 


\begin{tabular}{|c|c|c|c|c|c|c|}
\hline GASTERÓPODOS & Salinidad & $\begin{array}{c}\text { Modo } \\
\text { de vida }\end{array}$ & Profundidad & Sustrato & $\begin{array}{c}\text { Tipo } \\
\text { trófico }\end{array}$ & $\begin{array}{c}\text { Área de } \\
\text { distribución }\end{array}$ \\
\hline Diodora (D.) patagonica (d'Orbigny, 1841) & $\mathrm{E}$ & Ep & $0-15$ & $\mathrm{R}$ & $\mathrm{He}$ & $11^{\circ} \mathrm{N}-45^{\circ} \mathrm{S}$ \\
\hline Lucapinella henseli (Martens, 1900) & $\mathrm{E}$ & Ep & $0-55$ & $\mathrm{R}$ & $\mathrm{He}$ & $23^{\circ} \mathrm{S}-53^{\circ} \mathrm{S}$ \\
\hline Tegula (A.) patagonica (d'Orbigny, 1835) & $\mathrm{E}$ & Ep & $0-57$ & $\mathrm{R}$ & $\mathrm{He}$ & $23^{\circ} \mathrm{S}-54^{\circ} \mathrm{S}$ \\
\hline Calliostoma coppingeri (E. A. Smith, 1880) & $\mathrm{E}$ & Ep & $13-86$ & $\mathrm{~S}$ & $\mathrm{He}$ & $30^{\circ} \mathrm{S}-44.21^{\circ} \mathrm{S}$ \\
\hline Bostrycapulus odites (Collin, 2005) & $\mathrm{E}$ & Ep & $0-46$ & $\mathrm{R}$ & $\mathrm{F}$ & $25^{\circ} \mathrm{S}-45.8^{\circ} \mathrm{S}$ \\
\hline $\begin{array}{l}\text { Crepidula argentina Simone, Pastorino } \\
\text { \& Penchaszadeh, } 2000\end{array}$ & $E$ & Ep & $30-50$ & $\mathrm{R}$ & $\mathrm{F}$ & $38^{\circ} \mathrm{S}-41.03^{\circ} \mathrm{S}$ \\
\hline Notocochlis isabelleana (d'Orbigny, 1840) & $\mathrm{E}$ & $\mathrm{I}$ & $0-113$ & $\mathrm{~S}$ & C & $22.4^{\circ} \mathrm{S}-42.58^{\circ} \mathrm{S}$ \\
\hline Heleobia australis ( d'Orbigny, 1835) & $\mathrm{O}, \mathrm{P}, \mathrm{M}$ & Ep & $0-60$ & M & $\mathrm{He}$ & $24^{\circ} \mathrm{S}-41^{\circ} \mathrm{S}$ \\
\hline Epitonium (E.) georgettinum (d'Orbigny, 1840) & $\mathrm{E}$ & Ep & $0-101$ & M & C & $23.37^{\circ} \mathrm{S}-44.27^{\circ}$ \\
\hline Trophon patagonicus (d'Orbigny, 1839) & $\mathrm{E}$ & Ep & $0-50$ & $\mathrm{R}$ & C & $32^{\circ} S-40^{\circ} S$ \\
\hline Urosalpinx cala (Pilsbry, 1897) & $\mathrm{E}$ & Ep & $28-28$ & $\mathrm{R}$ & $\mathrm{C}$ & $32^{\circ} \mathrm{S}-41^{\circ} \mathrm{S}$ \\
\hline Zidona dufresnei ( Donovan, 1823) & $\mathrm{E}$ & Ep & $10-90$ & $\mathrm{~S}$ & $\mathrm{C}$ & $23^{\circ} \mathrm{S}-42^{\circ} \mathrm{S}$ \\
\hline Adelomelon (P.) brasiliana (Lamarck, 1811) & $\mathrm{E}$ & Ep & $8-70$ & $\mathrm{~S}$ & C & $23^{\circ} \mathrm{S}-52^{\circ} \mathrm{S}$ \\
\hline Odontocymbiola magellanica (Gmelin, 1791) & $\mathrm{E}$ & Ep & $10-200$ & M & C & $35^{\circ} \mathrm{S}-55.2^{\circ} \mathrm{S}$ \\
\hline Olivella (O.) tehuelcha ( Dúclos, 1835) & $\mathrm{E}$ & Ep & $15-57$ & $\mathrm{~S}$ & C & $23.69^{\circ} \mathrm{S}-43^{\circ} \mathrm{S}$ \\
\hline Olivancillaria urceus ( Röding, 1798) & $\mathrm{E}$ & Ep & $5-50$ & $\mathrm{~S}$ & C & $19^{\circ} \mathrm{S}-42^{\circ} \mathrm{S}$ \\
\hline Olivancillaria carcellesi Klappenbach, 1965 & $\mathrm{E}$ & Ep & $0-22$ & $\mathrm{~S}$ & $\mathrm{C}$ & $23^{\circ} \mathrm{S}-42.5^{\circ} \mathrm{S}$ \\
\hline Marginela martini Petit, 1853 & $\mathrm{E}$ & Ep & $10-80$ & $\mathrm{~S}$ & C & $22.93^{\circ} \mathrm{S}-42^{\circ} \mathrm{S}$ \\
\hline Buccinanops monilifer ( Kiener, 1834) & $\mathrm{E}$ & Ep & $0-50$ & $\mathrm{~S}$ & C & $35^{\circ} \mathrm{N}-42^{\circ} \mathrm{S}$ \\
\hline Buccinanops cochlidium (Dilwyn, 1817) & $\mathrm{E}$ & Ep & $5-66$ & $\mathrm{~S}$ & C & $23^{\circ} \mathrm{S}-42.58^{\circ} \mathrm{S}$ \\
\hline Buccinanops globulosus (Kiener, 1834) & $\mathrm{E}$ & Ep & $0-6$ & $\mathrm{~S}$ & C & $35^{\circ} \mathrm{S}-46^{\circ} \mathrm{S}$ \\
\hline Buccinanops uruguayensis (Pilsbry,1897) & & Ep & $15-45$ & $\mathrm{~S}$ & $\mathrm{C}$ & $24^{\circ} \mathrm{S}-42^{\circ} \mathrm{S}$ \\
\hline Parvanachis isabellei (d'Orbigny, 1839) & $\mathrm{E}$ & Ec & $10-65$ & $\mathrm{~S}$ & C & $30^{\circ} \mathrm{S}-54^{\circ} \mathrm{S}$ \\
\hline Siphonaria lessoni (Blainville, 1824) & $\mathrm{E}$ & Ep & 0 & $\mathrm{R}$ & $\mathrm{He}$ & $32^{\circ} \mathrm{S}-55.22^{\circ} \mathrm{S}$ \\
\hline
\end{tabular}

T. 8.7: Requerimientos ecológicos y distribución de gasterópodos: $\mathrm{Ep}=$ epifaunal, $\mathrm{I}=$ infaunal, Ec=ectoparásito; $\mathrm{R}=$ rocoso, $\mathrm{S}=$ arenoso, $\mathrm{M}=\mathrm{mixto}, \mathrm{Ce}=\mathrm{cementado}$; $\mathrm{C}=$ carnívoros, $\mathrm{D}=$ detritívoros, $\mathrm{He}=$ herbívoros, $\mathrm{F}=$ filtradores; $\mathrm{O}=$ oligohalinos $(3-8 \%$ \%), $\mathrm{M}=$ mesohalinos $(8-18 \%$ \%); $\mathrm{P}=$ polihalinos $(18-30 \%)$; $\mathrm{E}=$ eurihalinos $(>30-35$ 


\subsection{Temperaturas}

De acuerdo a esta variable, la mayor cantidad de bivalvos de especies de aguas cálidasse dan en en el Interglacial MIS 9 (B) con un 50\%, a partir del Interglacial MIS 5e (E) disminuye en un 6\% llegando a la actualidad (G) a un 33\% (Fig. 8.19). Con respecto a los gasterópodos todos son especies de aguas cálidas(100\%), disminuyendo desde el Interglacial MIS 5e (E) hasta la actualidad (G) en un 44\% (Fig.8.20).

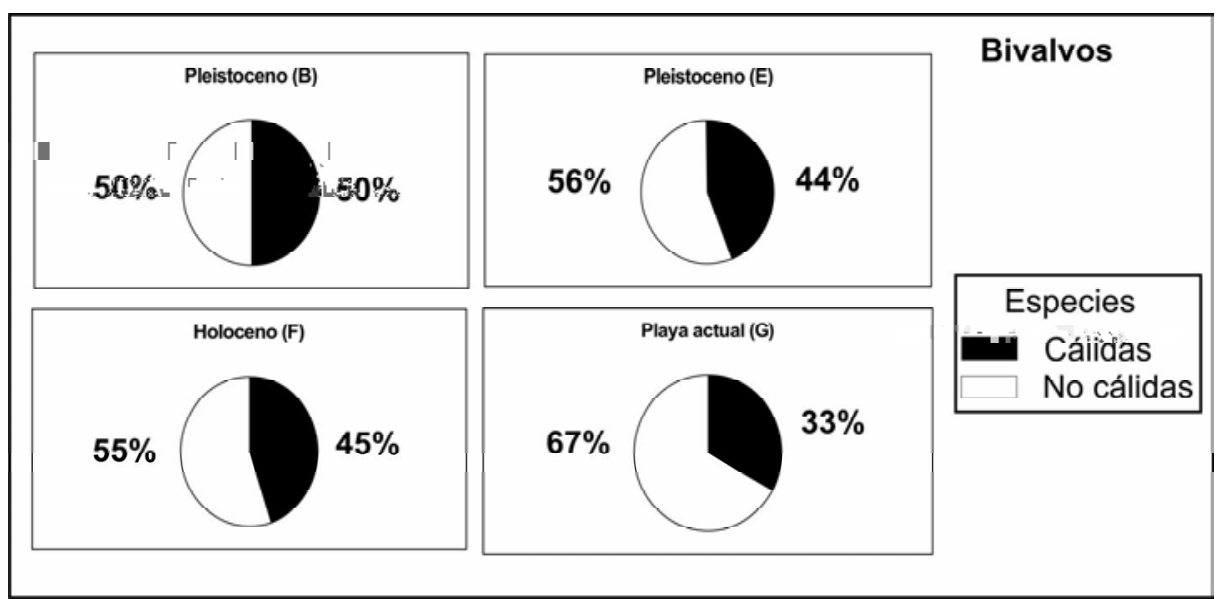

Fig. 8.19: Proporción de especies de bivalvos de aguas cálidas y no cálidas durante el

Cuaternario.

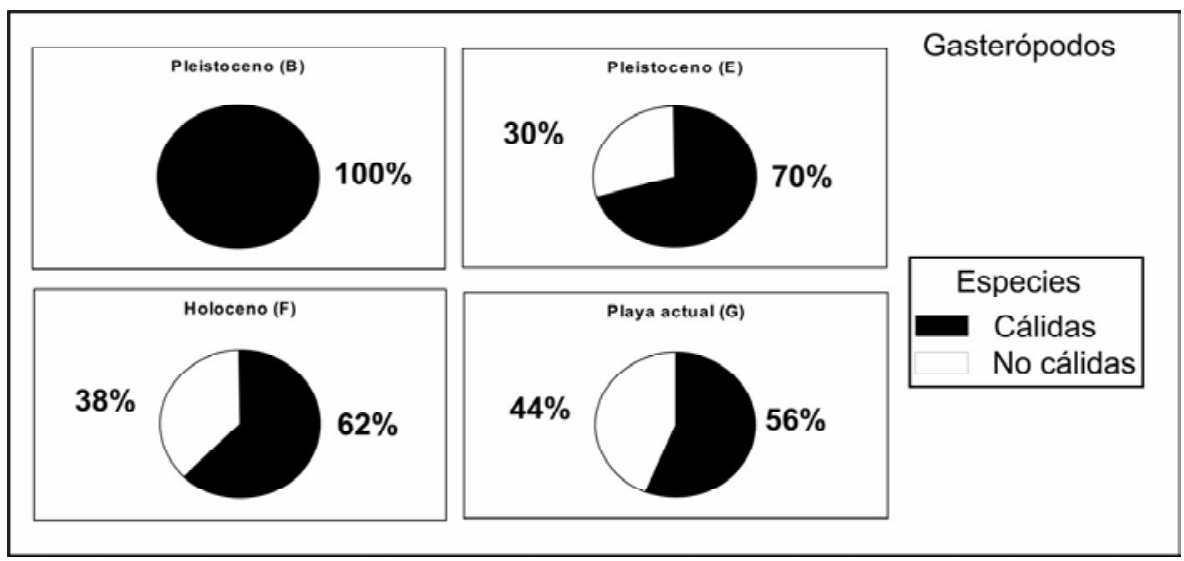

Fig. 8.20: Proporción de especies de gasteropodos de aguas cálidas y no cálidas durante el Cuaternario. 


\subsection{Asociaciones faunísticas}

Según el método descriptivo estadístico de Bray - Curtis los sitios analizados de los distintos Interglaciales de la región de isla Jabalí - Villa 7 de Marzo se componen por dos asociaciones diferentes: A) asociación faunísticas que corresponden en su mayoría a los Interglaciales $\geq$ MIS 9 y MIS 5e y playas actuales a excepción de dos sitios que pertenecen al Interglacial MIS 1 (F18 y F21). Todos los sitios analizados representan a cordones litorales pertenecientes a ambientes de mayor energía. Los sitios más similares son F23 y G17, ambos pertenecientes a la localidad de Villa 7 de Marzo. B) asociación faunística perteneciente al Interglacial MIS 1, todos correspondientes a ambientes de baja energía. Representan planicies de mareas con presencia del bivalvo Tagelus plebeius, como la fauna típica de estos ambientes. (Fig. 8.21).

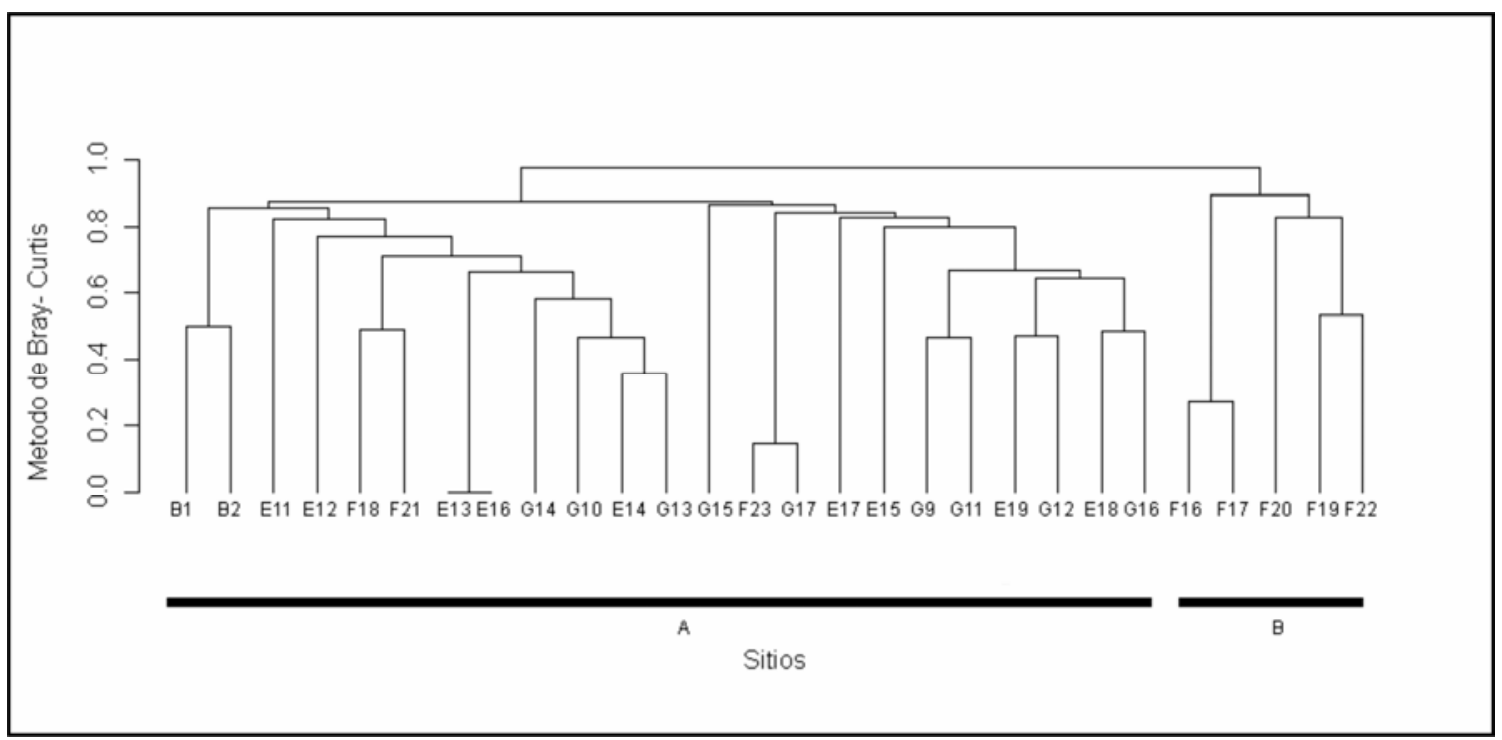

Fig. 8.21: Dendrograma de los sitios analizados basados en el índice de Bray- Curtis.

Según el método descriptivo del Análisis de Correspondencia (AC), se distinguen 3 asociaciones faunísticas a excepción del sitio E14: A) asociación faunísticas pertenecientes a los sitios de la localidad Villa 7 de Marzo (F23 y G17) siendo las especies más abundantes Plicatula gibbosa (bivalvo) y Crepidula argentina 
(gasterópodos) con presencia de Glycymeris longior y Macoma uruguayensis (bivalvos). B) asociación faunística pertenecientes al Interglacial MIS 1 todos corresponden a ambientes de menor energía, con abundancia de Tagelus plebeius (bivalvo). C) asociación faunística pertenecientes a los Interglaciales $\geq$ MIS 9, MIS 5e y playas actuales, todos los sitios correspondientes a ambientes de alta energía. Entre la fauna marina figuran: Amiantis purpurata, Brachidontes rodriguezii y Buccinanops cochlidium, entre otros moluscos presentes (Fig.8.22 y Fig.8.23).

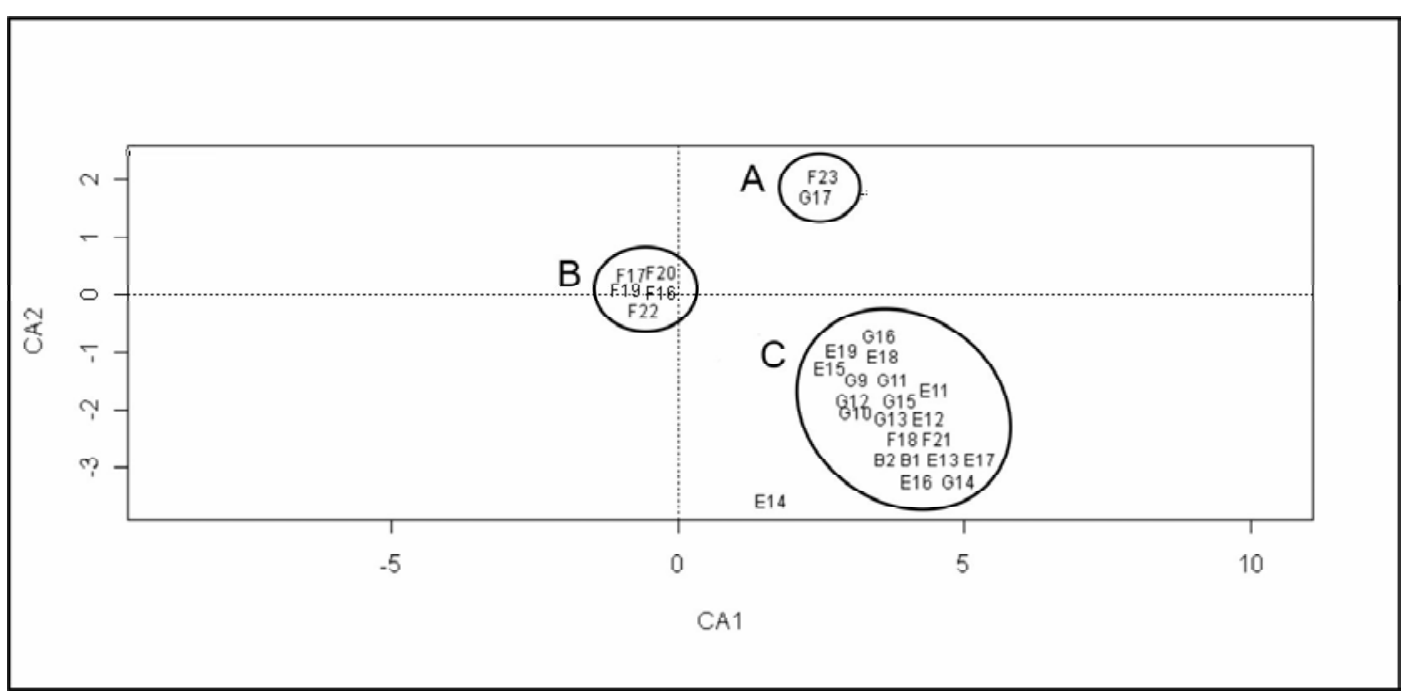

Fig. 8.22: Análisis de Correspondencia (AC) basados en la abundancia de las especies, todos los sitios confirman tres grupos A-C. 


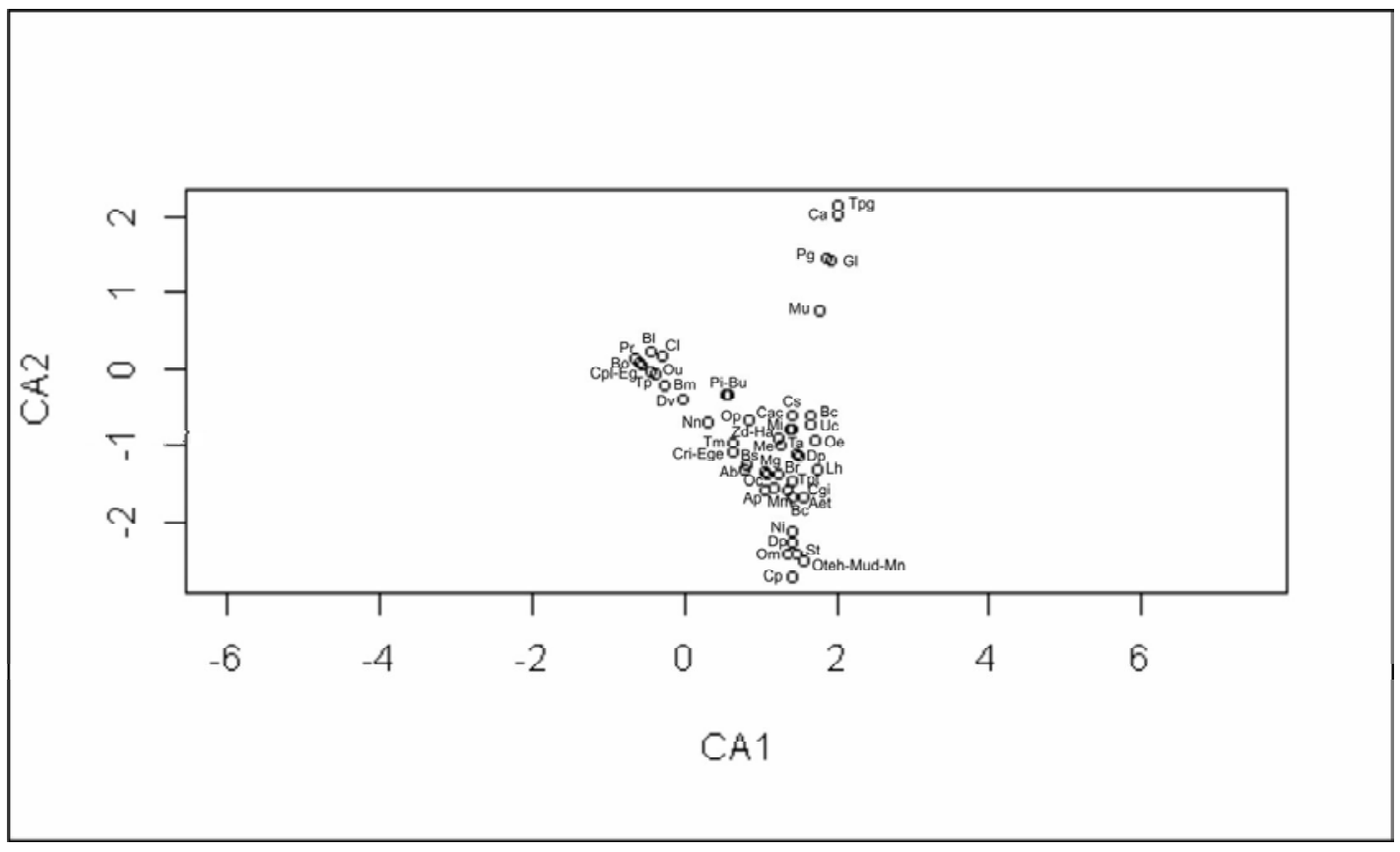

Fig. 8.23: Especies de bivalvos y gasterópodos asociados a los distintos sitios muestreados.

\subsection{Conclusiones}

La región Isla Jabalí - Villa 7 de Marzo se extiende desde los alrededores de la localidad de San Blas, en las inmediaciones de la isla Jabalí, hasta la Villa 7 de Marzo ubicada en la desembocadura del Río Negro, límite sur de la Provincia de Buenos Aires. En ella se describe la presencia de los interglaciales $\geq$ MIS 9, MIS 5e y MIS 1 en función de un total de 27 sitios analizados (11 pleistocenos, 8 holocenos y 8 actuales), registrándose un total de 51 especies (27 bivalvos y 24 gasterópodos), entre ellos se destacan la presencia de 8 de micromoluscos.

Los índices de diversidad más altos pertenecen en su mayoría a los sitios de playas actuales, luego le siguen los sitios pertenecientes al Interglacial MIS 5e siendo los del Interglacial MIS 1 los más bajos con excepción de dos sitios (F18 y F21) que pertenecen cordones litorales. 
Según la temperatura, las especies de aguas cálidasde bivalvos están representados en mayor cantidad en los Interglacial $\geq$ MIS 9 y MIS 1 . Con respecto a los gasterópodos se registraron mayor cantidad de especies de aguas cálidasen los Interglaciales > MIS 9 y MIS 5e.

En el Interglacial $\geq$ MIS 9, todos los sitios analizados pertenecen a cordones litorales registrándose un total de 7 especies. Entre la fauna marina se destacan los bivalvos: Glycymeris longior y Pitar rostratus. Entre los gasterópodos: Zidona dufresnei, Olivancillaria urceus, Buccinanops cochlidium y Buccinanops globulosus. Todos los bivalvos y gasterópodos se caracterizan por ser eurihalinos y de sustratos arenosos. Los bivalvos, además, son infaunales y filtradores mientras que los gasterópodos son epifaunales y carnívoros.

En el Interglacial MIS 5e, todos los sitios analizados corresponden a cordones litorales, producto de ambientes de alta energía. Se registraron un total de 31 especies de las cuales 15 son de bivalvos y 16 son de gasterópodos. Entre la fauna marina se destacan: Pitar rostratus (bivalvo) y Bostrycapulus odites, Tegula patagonica y Buccinanops globulosus (gasterópodos). La mayoría de los bivalvos son polihalinos - eurihalinos siendo los gasterópodos de ambiente eurihalino. Tanto bivalvos como gasterópodos en su mayoría son de sustratos arenosos, con presencia de especies rocosas y mixtas predominando entre los bivalvos organismos filtradores con presencia de carnívoros y detritívoros. En cambio, entre los gasterópodos, predominan los organismos carnívoros con presencia de herbívoros y filtradores.

En este Interglacial MIS 5e, se destaca la presencia del bivalvo Crassostrea rhizophorae que actualmente vive en latitudes mas cálidas. Este sería un indicador ambiental de magnitud debido a que su presencia en esta región en este período interglacial indicaría que hace ca. $120 \mathrm{ka}$ hubo mayores condiciones de temperatura que las actuales.

En el Interglacial MIS 1, todos los sitios analizados corresponden a cordones litorales y planicies de mareas, registrándose un total de 33 especies. El sector oriental de la isla Jabalí se caracteriza por presentar cordones litorales, destacándose entre la fauna 
marina: Pitar rostratus, Amiantis purpurata, Glycymeris longior, Ostreola equestris (bivalvos) y Tegula patagonica, Bostrycapulus odites, Buccinanops globulosus (gasterópodos). El sector occidental presenta depósitos de planicies de marea generados en ambientes de baja energía, y la fauna marina se caracteriza por la presencia de Heleobia australis (gasterópodo), Corbula patagonica y Tagelus plebeius (bivalvos). Este último bivalvo se caracteriza por encontrarse en forma articulada y en posición de vida.

De acuerdo al análisis paleoecológico, la fauna marina bivalva del Interglacial MIS 1 posee las mismas características generales que la del Interglacial MIS 5e. En ambos la mayoría de los bivalvos son polihalinos - eurihalinos, infaunales, de sustratos arenosos, y filtradores denotándose en este último interglacial un mayor número de organismos que en el Interglacial MIS 1. Todas las especies de gasterópodos son epifaunales, y en su mayoría siguen siendo eurihalinos, de sustratos arenosos, y carnívoros, pero aumentando en el Interglacial MIS 1 las especies carnívoras y filtradoras.

Las playas en su mayoría se encuentran compuestas por arenas y clastos redondeados. Se registraron un total 30 especies. Entre las más abundantes figuran: Brachidontes rodriguezii, Ostreola equestris, Pitar rostratus, Amiantis purpurata (bivalvos) y Bostrycapulus odites (gasterópodos). Además, sin ser tan abundantes, se registró la presencia de 4 especies bivalvos características de este tipo de ambiente: Mesodesma mactroides, Solen tehuelchus, Barnea lamellosa y Crassostrea gigas.

Respecto a las playas actuales de esta tercera región, la playa de la localidad de Villa 7 de Marzo presenta un rasgo particular respecto a las demás. El tipo de playa, de sedimento arenoso fino, y la abundancia de dos especies de bivalvos, Plicatula gibbosa y Ostrea puelchana, y el gasterópodo Crepidula podría atribuirse a la influencia que el río Negro produce en el sector debido a la sedimentación de sedimentos finos que arrastra en su curso. Lo mismo ocurre en sector sur del mismo río. Así en la playa del Balneario El Cóndor se verifican los mismos sedimentos y misma fauna recién descripta. 
Con excepción de lo recientemente descripto para las playas adyacentes a la desembocadura del Río Negro, entre el Interglacial MIS 1 y la playa actual existen cambios graduales en los factores ambientales. Así, los bivalvos en su mayoría son eurihalinos e infaunales, de sustratos arenosos y todos son filtradores desapareciendo las especies polihalinasy detritívoras, en tanto los gasterópodos son en su mayoría eurihalinos, epifaunales, de sustratos arenosos, y carnívoros apareciendo especies cementadas y aumentando las especies herbívoras.

Los bivalvos característicos del Interglacial >MIS 9, son todos eurihalinos, infaunales, de sustratos arenosos y filtradores. A partir del Interglacial MIS 5e, la mayoría de los bivalvos son polihalinos - eurihalinos, siguen en su mayoría siendo infaunales, de sustratos arenosos y filtradores pero aparecen especies epifaunales y cementadas, de sustratos rocosos y mixtos, y carnívoros y detritívoros. En el Interglacial MIS 1, se acentuan los infaunales, de sustratos arenosos, y filtradores. En la actualidad, se observa un cambio, desaparecen las especies polihalinas- eurihalinas, cementadas y detritívoros y aumentan las especies de sedimentos rocosos. 


\section{REGIÓN NORTE DEL GOLFO SAN MATÍAS}

\subsection{Descripción general de la región}

El área de estudio abarca el sector costero del golfo San Matías y se extiende desde las inmediaciones del balneario El Cóndor $\left(41^{\circ} 02^{\prime} \mathrm{S} / 62^{\circ} 49^{\prime} \mathrm{O}\right)$ hasta el sur del balneario Las Grutas $\left(40^{\circ} 51^{\prime} \mathrm{S} / 65^{\circ} 7^{\prime} \mathrm{O}\right)$, representado por acantilados, cordones litorales (depósitos de grava y arenas), paleoplayas y plataformas costeras.

En los sectores intermareales al norte del golfo San Matías, se encuentran afloramientos de arenas y gravas sometidas a erosión que corresponden a un nivel del mar pleistoceno (Rutter et al., 1990). Estas plataformas costeras son de suave pendiente hacia el mar, de varios kilómetros de largo y 500 a 1000 m de ancho visibles durante las mareas bajas. Sus mayores representaciones se encuentran en baliza San Matías y al sur de Las Grutas. Este evento transgresivo correspondería al Interglacial MIS 7 cuya altura con respecto al nivel del mar fue inferior al Interglacial MIS 5e (Shackleton, 1987; Ortlieb, 1987), y han sido identificado tanto al $\mathrm{S}$ como al E de la zona estudiada (Gelos et al., 1988, 1993).

Sobre el continente, aledaño a la costa se desarrollan morfologías litorales que representan antiguos niveles del mar, con o sin morfologías cordoniformes. Desde el S de Las Grutas y paralelo a la costa y a una cota de aproximadamente $15 \mathrm{~m}$ como máximo, se observa una franja continua con el desarrollo de lineaciones paralelas $u$ oblicuas a la línea de costa de escasa altura relativa entre los 0,5 - $1 \mathrm{~m}$, separadas por depresiones. Este rasgo se va perdiendo hacia el NE, observándose nuevamente al $\mathrm{N}$ de la bahía de San Antonio, en la margen N de la ruta 3, curvándose hacia el SE siguiendo el contorno de la actual línea de costa. Esta morfología constituye una franja continua alrededor de la bahía, con o sin morfologías cordoniformes en su superficie, pero claramente representada por gravas con cantidades variables de valvas (Fucks et al., 2012b). Entre los rasgos geomorfológicos más destacados en la región, se encuentran a una altura de 8 - 15 m correspondiendo al Interglacial MIS 5e. 
En el área baliza San Matías, se encuentran depósitos asignados al Interglacial MIS 1 a una cota de 2 - $5 \mathrm{~m}$, cubiertos parcialmente por depósitos medanosos. En algunos sectores, es prácticamente irreconocible, estando reemplazado por llanuras de marea (Fig. 9.1).

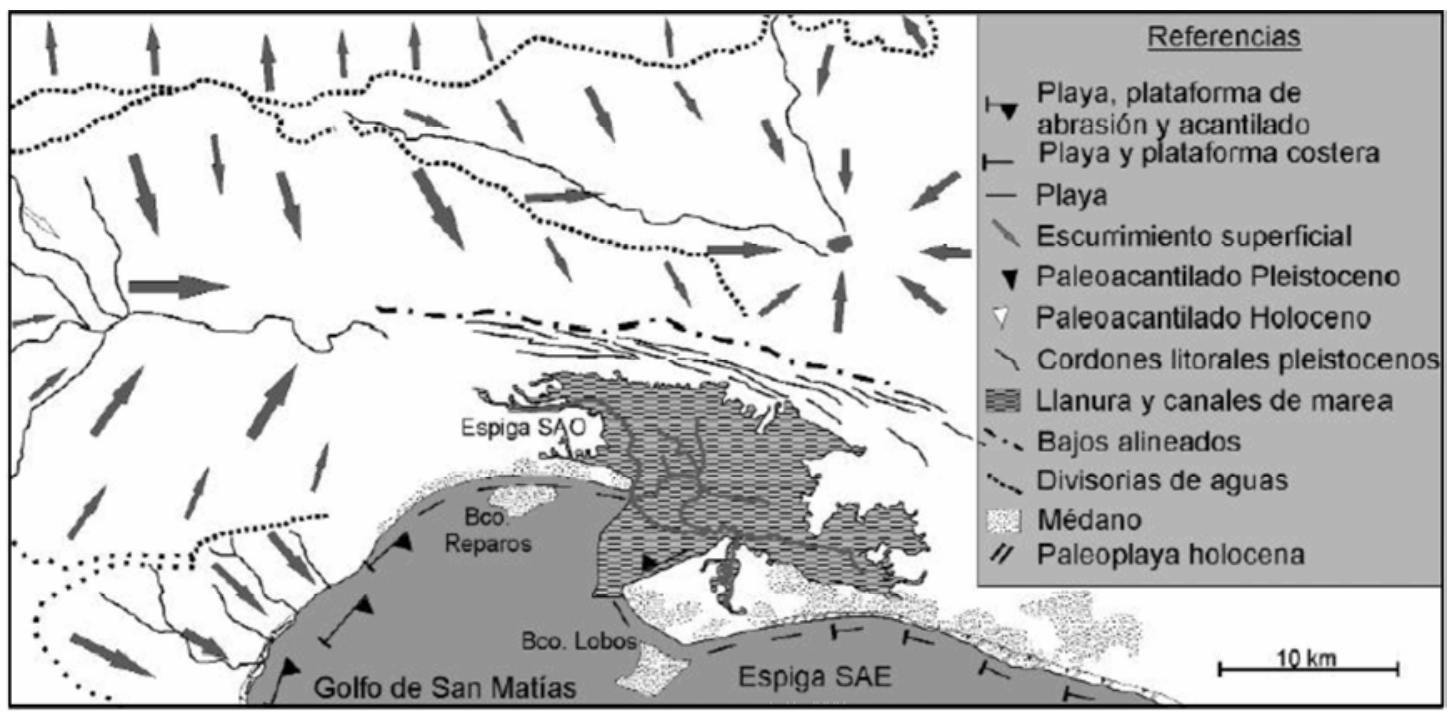

Fig. 9.1: Cordones pleistocenos y holocenos de la Región norte del golfo San Matías (Fucks et

$$
\text { al., 2012b) }
$$

Las playas actuales de esta región, están compuestas por arena mediana a fina en los sectores intermareales bajos, con anchos que superan los centenares de metros y pendientes suaves con valvas de moluscos, y en algunos sectores se observan cordones de tormenta de reciente formación (ej. Morsan 1997; Fucks et al., 2012b).

En el sector continental, cercano a la costa, se han desarrollado importantes cuerpos medanosos, algunos de ellos estabilizados por la vegetación y otros activos, con dirección paralela a la costa y sentido $\mathrm{O}$ a E. Analizando individualmente las morfologías dentro de cada cuerpo de arena puede apreciarse que en general existe una superposición y unión de ellos, tendiendo a morfologías piramidales o reticuladas (Fucks et al., 2012b). 
En el norte del golfo San Matías, se analizaron 19 sitios (6 pleistocenos, 6 holocenos y 7 playas actuales) que representan paleoacantilados, paleoplayas y cordones litorales (Fig. 9.2 y Fig. 9.3) (T. 9.1). 


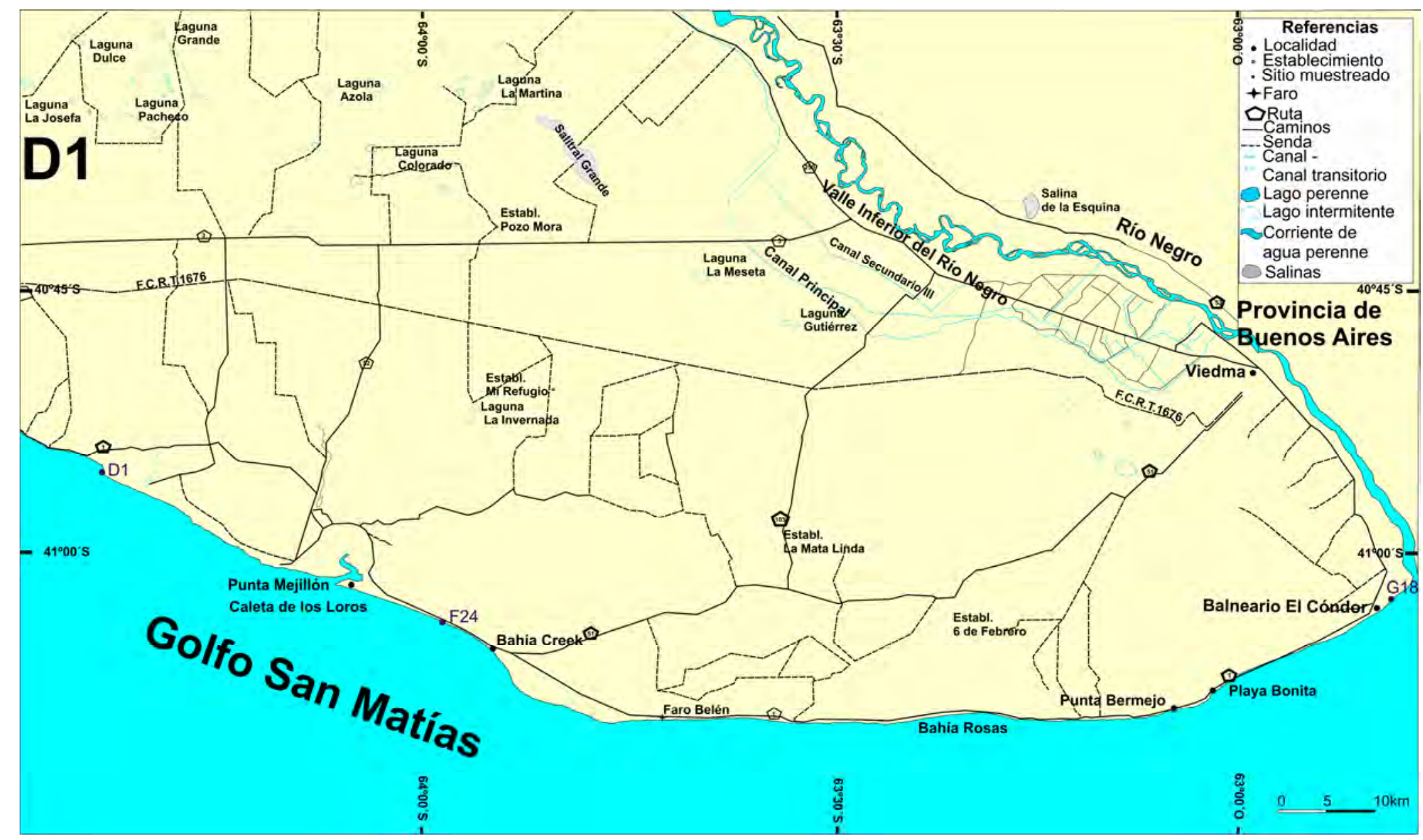

Fig.9.2: Mapa del sector oriental de la región norte del golfo San Matías. 


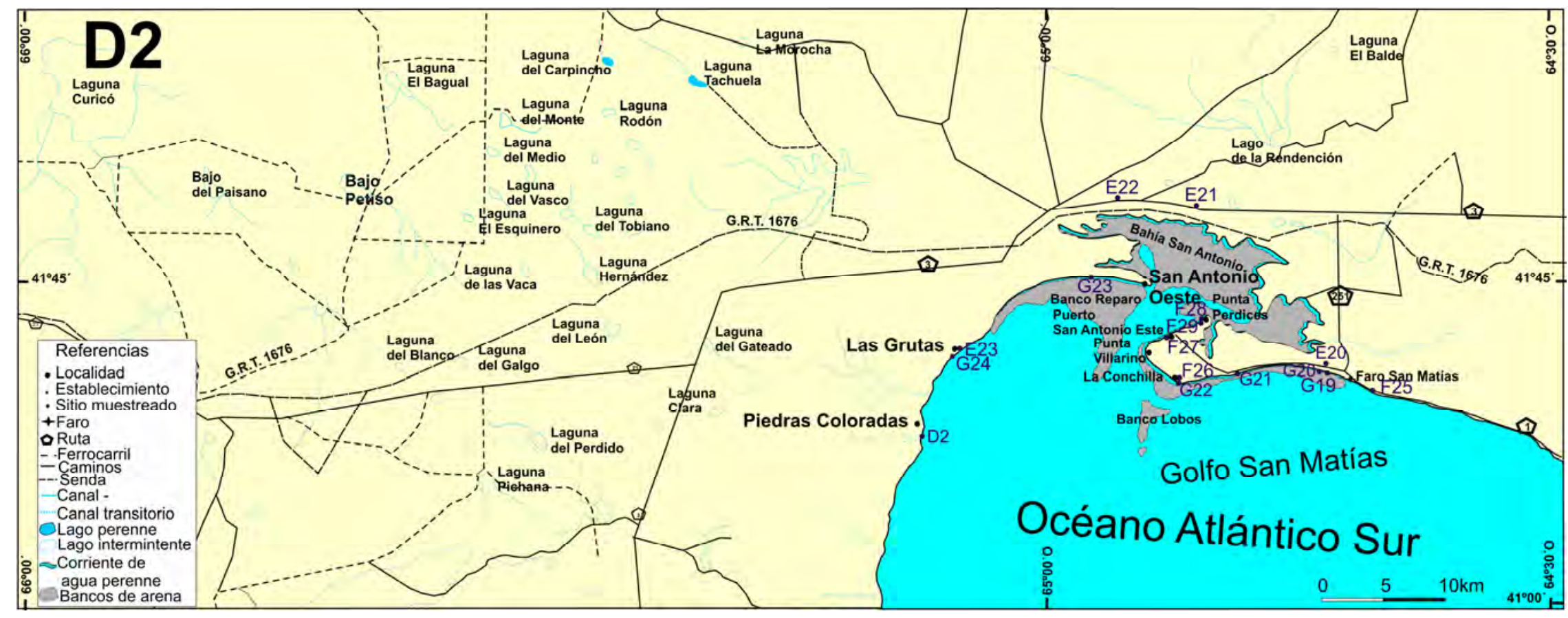

Fig.9.3: Mapa del sector occidental de la región norte del golfo San Matías. 


\begin{tabular}{|c|c|c|c|c|}
\hline $\begin{array}{l}\text { № de } \\
\text { Sitio }\end{array}$ & Edad & $\begin{array}{c}\text { Coordenadas } \\
\text { (Lat-Long) }\end{array}$ & $\begin{array}{c}\text { Rasgos } \\
\text { geomorfológicos }\end{array}$ & $\begin{array}{c}\text { Cotas } \\
\text { (m) }\end{array}$ \\
\hline $\mathrm{D} 1$ & MIS 7 & $\begin{array}{l}40^{\circ} 49^{\prime} 14.62 " \mathrm{~S} / \\
64^{\circ} 44^{\prime} 14.29 " \mathrm{O}\end{array}$ & $\begin{array}{l}\text { Plataforma costera } \\
\text { depósito de gravas } \\
\text { cementadas }\end{array}$ & $2-1$ \\
\hline D2 & MIS7 & $\begin{array}{l}40^{\circ} 51^{\prime} 45.77 " \mathrm{~S} / \\
65^{\circ} 77^{\prime} 32.70^{\prime \prime} \mathrm{O}\end{array}$ & $\begin{array}{l}\text { Plataforma costera } \\
\text { depósito de gravas } \\
\text { cementadas }\end{array}$ & $2-1$ \\
\hline E20 & MIS5e & $\begin{array}{l}40^{\circ} 49^{\prime} 4.45^{\prime \prime S} / \\
64^{\circ} 44^{\prime} 22.58^{\prime \prime O}\end{array}$ & $\begin{array}{l}\text { Cordón de arenas y } \\
\text { gravas con poca } \\
\text { cementación }\end{array}$ & 8 \\
\hline E21 & MIS5e & $\begin{array}{l}40^{\circ} 42^{\prime} 34.38^{\prime \prime S} / \\
64^{\circ} 51^{\prime} 53.09^{\prime \prime} \mathrm{O}\end{array}$ & $\begin{array}{l}\text { Cordón litoral de } \\
\text { depósito de arenas y } \\
\text { clastos dispersos }\end{array}$ & 9 \\
\hline E22 & MIS5e & $\begin{array}{l}40^{\circ} 42^{\prime 2} 28.41^{\prime \prime S} / \\
64^{\circ} 57^{\prime} 51.711^{\prime \prime}\end{array}$ & $\begin{array}{l}\text { Cordón litoral de } \\
\text { arenas y gravas con } \\
\text { poca cementación }\end{array}$ & 9 \\
\hline E23 & MIS 5e & $\begin{array}{c}40^{\circ} 48^{\prime 2} 20.95^{\prime \prime S /} \\
65^{\circ} 4{ }^{\prime} 35.72 " \mathrm{O}\end{array}$ & $\begin{array}{l}\text { Paleoacantilado } \\
\text { depósito de arenas con } \\
\text { clastos dispersos }\end{array}$ & 10 \\
\hline F24 & Holoceno & $\begin{array}{l}41^{\circ} 03^{\prime} 35.6^{\prime \prime} \mathrm{S} / \\
63^{\circ} 59^{\prime} 30.7^{\prime \prime} \mathrm{O}\end{array}$ & Playa & $8-5$ \\
\hline F25 & Holoceno & $\begin{array}{l}40^{\circ} 50^{\prime} 22.22 " \mathrm{~S} / \\
64^{\circ} 39^{\prime} 18.36 " \mathrm{O}\end{array}$ & Playa regresiva & 5 \\
\hline F26 & Holoceno & $\begin{array}{l}40^{\circ} 49^{\prime} 44.58^{\prime \prime S} / \\
64^{\circ} 52^{\prime} 39.12^{\prime \prime}\end{array}$ & Microacantilado & $9-7$ \\
\hline F27 & Holoceno & $\begin{array}{l}40^{\circ} 47^{\prime} 50.38^{\prime \prime S} / \\
64^{\circ} 52^{\prime} 50.73^{\prime \prime} \mathrm{O}\end{array}$ & Acantilado & $9-5$ \\
\hline F28 & Holoceno & $\begin{array}{l}40^{\circ} 47^{\prime} 09.9 " \mathrm{~S} / \\
64^{\circ}-50^{\prime} 52.2^{\prime \prime} \mathrm{O}\end{array}$ & Crestas de playa & $9-5$ \\
\hline F29 & Holoceno & $\begin{array}{l}40^{\circ} 47^{\prime} 6.23 " \mathrm{~S} / \\
64^{\circ} 50^{\prime} 55.26 " \mathrm{O}\end{array}$ & Crestas de playa & $9-5$ \\
\hline G18 & actual & $\begin{array}{l}41^{\circ} 02^{\prime} 52.4^{\prime \prime} \mathrm{S} / \\
62^{\circ} 49^{\prime} 17.5^{\prime \prime} \mathrm{O}\end{array}$ & Playa arenosa & 0 \\
\hline
\end{tabular}




\begin{tabular}{|c|c|c|c|c|}
\hline $\begin{array}{l}\text { № de } \\
\text { Sitio }\end{array}$ & Edad & $\begin{array}{l}\text { Coordenadas } \\
\text { (Lat-Long) }\end{array}$ & $\begin{array}{c}\text { Rasgos } \\
\text { geomorfológicos }\end{array}$ & $\begin{array}{l}\text { Cotas } \\
(\mathrm{m})\end{array}$ \\
\hline G19 & actual & $\begin{array}{l}40^{\circ} 49^{\prime} 13.83^{\prime \prime S} / \\
64^{\circ} 44^{\prime} 20.94^{\prime \prime O}\end{array}$ & $\begin{array}{l}\text { Playa de arena y } \\
\text { plataforma costera }\end{array}$ & 0 \\
\hline G20 & actual & $\begin{array}{c}40^{\circ} 49^{\prime} 16.86^{\prime \prime S} / \\
64^{\circ} 44^{\prime} 9.32 " \mathrm{O}\end{array}$ & $\begin{array}{l}\text { Playa de arena y } \\
\text { plataforma costera }\end{array}$ & 0 \\
\hline G21 & actual & $\begin{array}{l}40^{\circ} 47^{\prime} 44.12^{\prime \prime} \mathrm{S} / \\
64^{\circ} 52^{\prime} 38.57^{\prime \prime} \mathrm{O}\end{array}$ & Playa arenosa & 0 \\
\hline G22 & actual & $\begin{array}{l}40^{\circ} 49^{\prime} 50.58^{\prime \prime S} / \\
64^{\circ} 52^{\prime} 46.47^{\prime \prime O}\end{array}$ & $\begin{array}{l}\text { Playas de arena y } \\
\text { grava (conchilla) }\end{array}$ & 0 \\
\hline G23 & actual & $\begin{array}{c}40^{\circ} 45^{\prime} 17.15^{\prime \prime} \mathrm{S} / \\
64^{\circ} 56^{\prime} 33.7^{\prime \prime} \mathrm{O}\end{array}$ & Playa arenosa & 0 \\
\hline G24 & actual & $\begin{array}{l}40^{\circ} 48^{\prime} 21.82 " \mathrm{~S} / \\
65^{\circ} 4{ }^{\prime} 35.62 " \mathrm{O}\end{array}$ & Playa arenosa & 0 \\
\hline
\end{tabular}

T. 9.1: Características geomorfológicas de los sitios analizados de la región norte del golfo San Matías. 


\subsection{Descripción de depósitos pleistocenos de la región norte del golfo San Matías}

A lo largo del norte del golfo San Matías, se reconocieron tres ciclos transgresivos pleistocenos, que pertenecen al Interglacial $\geq$ MIS 9, MIS 7 y MIS 5e. Según Fucks et al. (2012b) los depósitos transgresivos del interglacial MIS 7 y MIS 5e son los que denominan litoestratigraficamente en la actualidad como Formación Baliza San Matías y Formación San Antonio respectivamente, quedando sin designación los depósitos de edad holocena.

\subsubsection{Depósitos pleistocenos del Interglacial $\geq$ MIS 9}

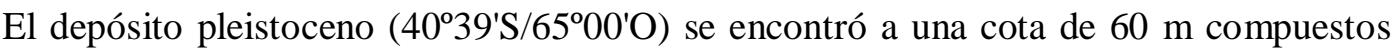
por gravas clastos sostén cementados por carbonato de calcio, correspondiendo al Interglacial $\geq$ MIS 9. La fauna marina es poco preservada definiéndola hasta nivel de género. Los escasos fragmentos de valvas encontrados pertenecen al género Ostrea En este caso no se incluyeron en el análisis de muestreos (Fig.9.4).

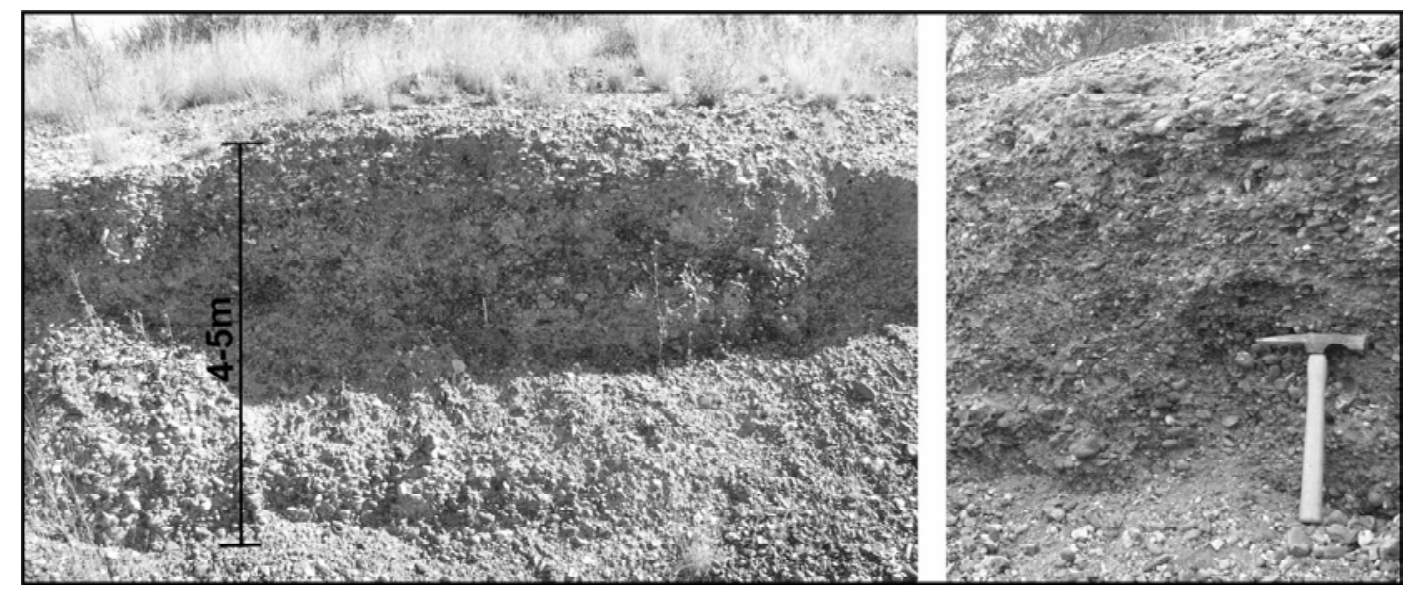

Fig 9.4: Afloramiento pleistoceno a cota de $60 \mathrm{~m}$, con Ostrea 


\subsubsection{Depósitos pleistocenos del Interglacial MIS 7}

Sobre la costa norte del golfo San Matías, dentro de los sitios estudiados, se desarrollan amplias plataformas costeras representadas por amplias planicies de suave pendiente hacia el mar, de varios kilómetros de largo y 500 a 1000 m de ancho visibles durante las mareas bajas (Fucks et al., 2012b). Sobre estas plataformas formadas en rocas marinas del Mioceno, se depositaron sedimentos del Interglacial MIS 7, ubicándose topográficamente en la actualidad en una posición intermareal, compuestos por arenas y/o conglomerados, parcial o totalmente litificados, conformando estratos de $20-50 \mathrm{~cm}$ de potencia, variando entre una inclinación suave hasta 25 - 30 hacia el SE (Martínez et al. 2001; Fucks et al., 2012b). Los depósitos analizados corresponden al sur de Faro San Matías y sur de Piedras Coloradas (Sitios D1 y D2). Rutter et al. (1990) obtienen edades aproximadas de >169 y 218 ka correlacionándolas con los depósitos ubicados en Caleta Falsa (provincia de Río Negro, Argentina) (Fig. 9.5).

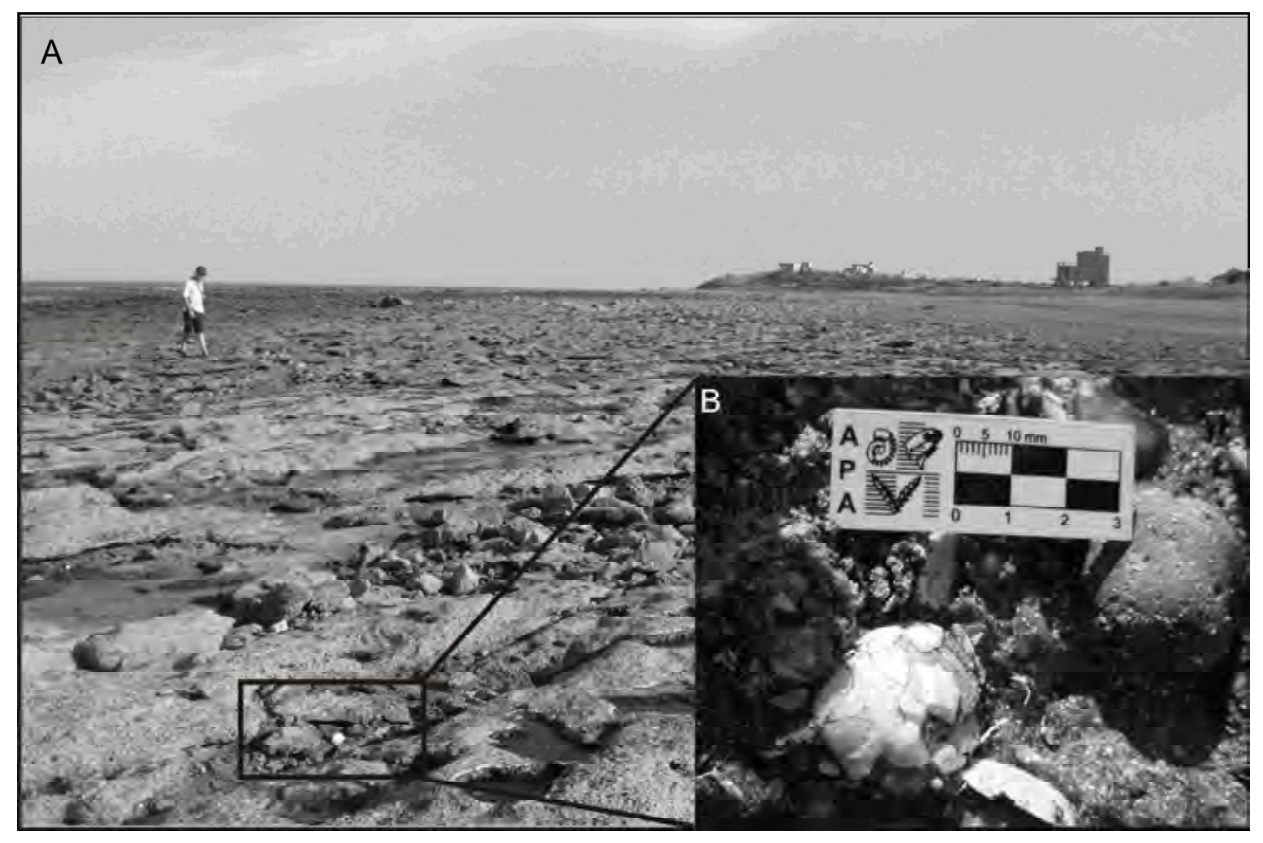

Fig. 9.5: Plataforma costera del Interglacial MIS 7 al sur de Faro San Matías (Sitio D1). 


\subsubsection{Depósitos pleistocenos del Interglacial MIS 5e}

Uno de los rasgos geomorfológicos destacados del área es el desarrollo de paleoacantilados que representan resaltos más o menos continuos del orden aproximado de 1 - 3 m de espesor. Éstos fueron producidos por la ingresión holocena sobre los depósitos del Interglacial MIS 5e.

Debido a que el MIS 5 del subestadio e es la transgresión máxima, los demás MIS 5 de los subestadios a, b y c no están representados en la costa norte del golfo, ya que estarían debajo del nivel del mar actual, consideramos que todos los depósitos analizados en el área son los representados para el Interglacial MIS 5e.

El Sitio E20, al oeste del Faro San Matías, el Interglacial MIS 5e, corresponden a un cordón litoral de $8 \mathrm{~m}$ de cota, constituido por estratos de arena con gravas con poca cementación y restos de valvas enteras. Entre la fauna marina encontrada figuran: Glycymeris longior y Amiantis purpurata (bivalvos) y Adelomelon brasiliana (gasterópodo).

En el interior del golfo San Matías, se analizaron dos sitios (E21 y E22). En Baliza Camino, el Sitio E21 pertenece a la Ingresión MIS 5e y está representada por un depósito de playa de $0.70 \mathrm{~cm}$ de espesor alternando finos estratos de gravas clastosostén y arena, con fósiles articulados y en posición de vida representados principalmente por Brachidontes rodriguezii, un bivalvo típico de sustratos duros intermareales (Fig. 9.6).

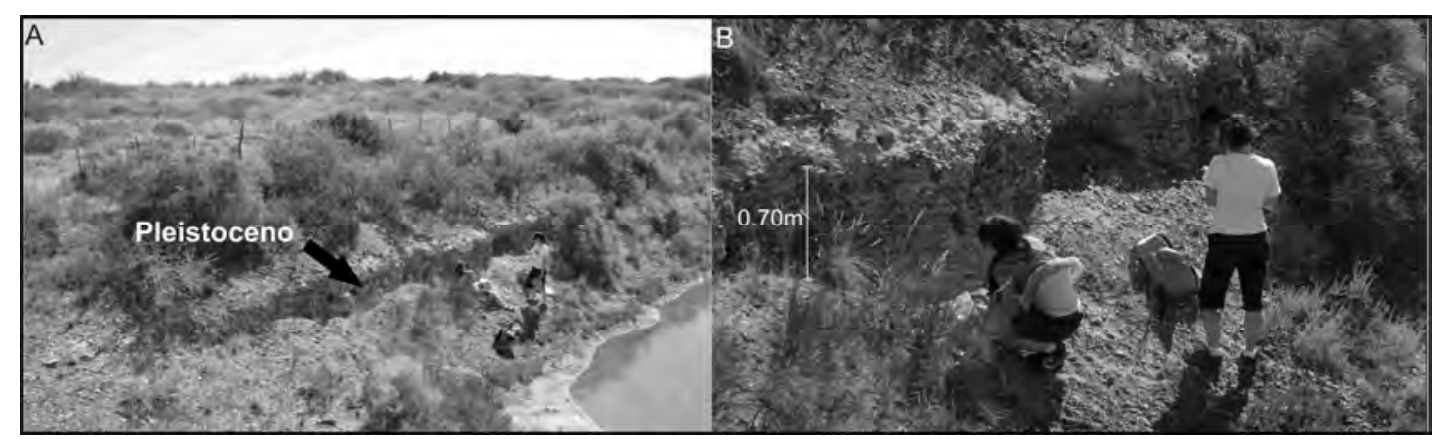


Fig. 9.6: A y B, Afloramiento del Interglacial MIS 5e de Baliza Camino (Sitio E21).

En el Sitio E22 (40 $\left.42^{\prime} \mathrm{S} / 64^{\circ} 57^{\prime} \mathrm{O}\right)$, el Interglacial MIS 5e está representado por un cordón litoral de $1.30 \mathrm{~m}$ de altitud, a cota de $9 \mathrm{~m}$, compuesto por facies arenosas con valvas dispuestas con la concavidad hacia abajo y facies conglomerádicas. Entre la fauna marina más abundante figuran: Aequipecten tehuelchus, Glycymeris longior y Amiantis purpurata (Fig. 9.6).

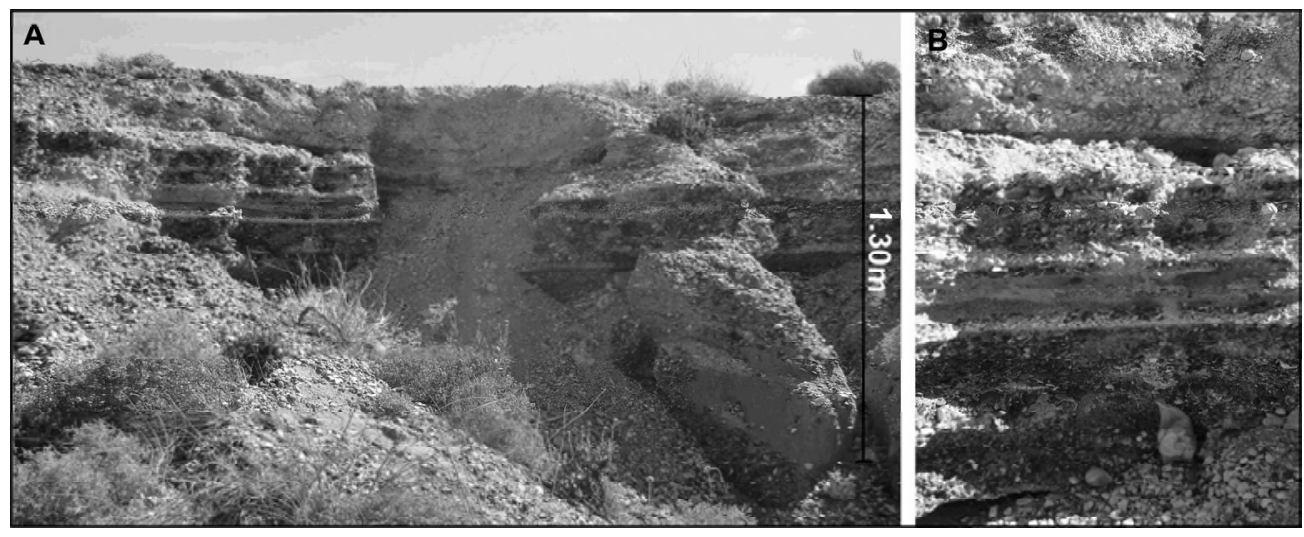

Fig. 9.6: Alfloramiento del Interglacial MIS 5e (Sitio E22).

La localidad más representativa del Interglacial MIS 5e corresponde al balneario La Rinconada (Sitio E23), en Las Grutas (1 - $1.5 \mathrm{~m}$ de espesor) (Fig. 9.8) donde se observan sedimentos arenosos (Fig. 9.8C a, c y e), que alternan con gravas finas (Fig. 9.8C b y d), finamente estratificadas y cubiertos por arenas y limos castaños con fauna de moluscos (Fucks et al. 2012). Según Rutter et al. (1990) las edades de estos depósitos oscilan entre los 107 y 72 ka. A pesar de la edad calculada, Rutter et al. (1989, 1990) y Fuck et al. (2012b) asocian este afloramiento con el subestadio e del Interglacial MIS 5. 


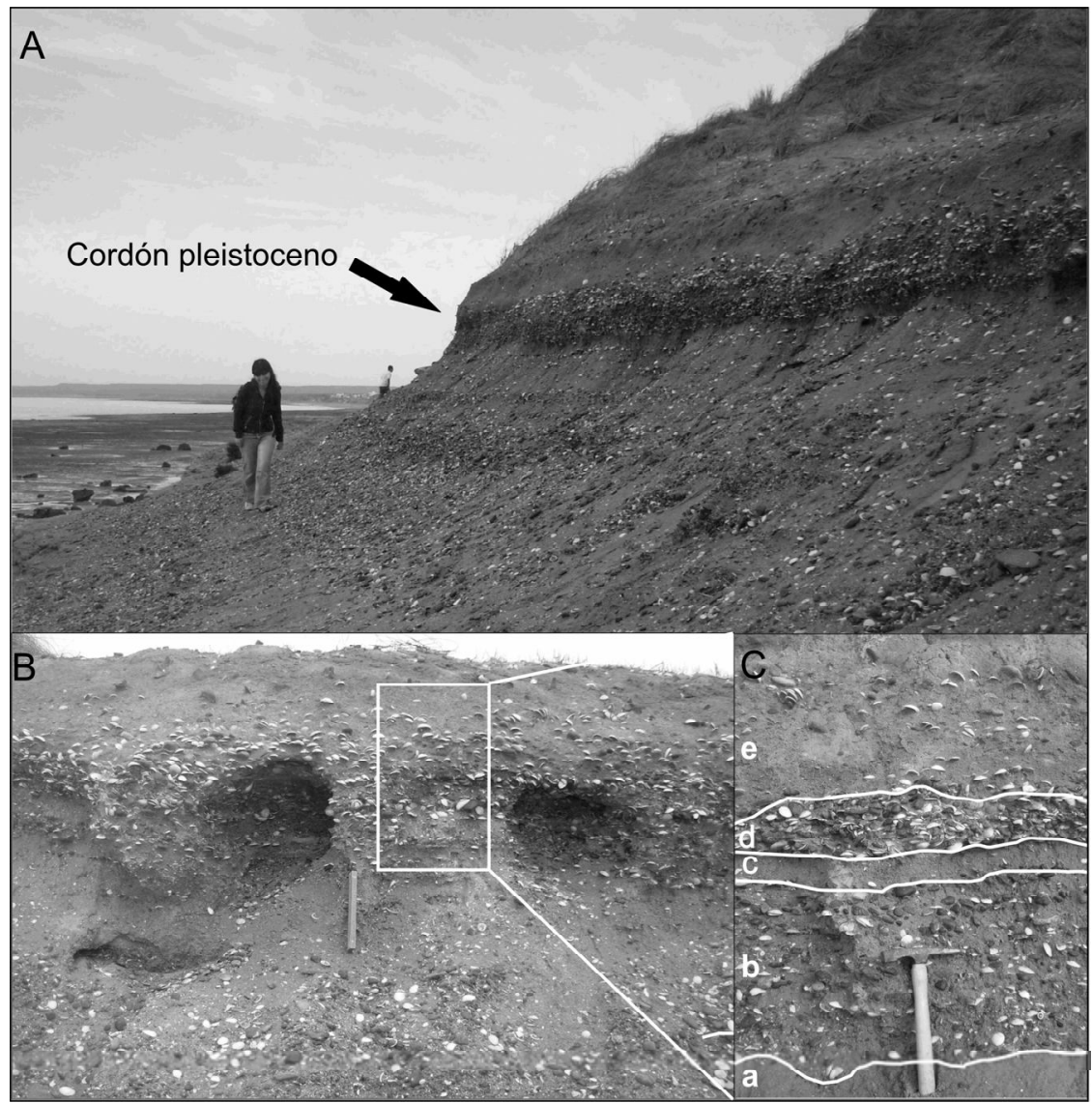

Fig. 9.8: A, B Afloramiento del pleistoceno en La Rinconada (Sitio E23); C, perfil en detalle con alternancia de arenas (a, c y e) y gravas con valvas (b y d).

\subsection{Descripción de los depósitos holocenos de la región norte del golfo San Matías (MIS1)}

La representación de los depósitos marinos pertenecientes al Interglacial MIS 1 a lo largo de la costa del Norte del golfo San Matías es escasa y corresponden al retroceso marino posterior al máximo transgresivo del Holoceno Medio (Favier Dubois et al., 2006). Debido a la altitud alcanzada sobre el nivel actual (3 - $4 \mathrm{~m}$ ) los sectores acantilados no se vieron sobrepasados por esta transgresión, manifestándose más claramente en las costas bajas o sectores fácilmente erosionables. Desde la finalización de los acantilados al $\mathrm{N}$ de Las Grutas pueden observarse, debajo de los médanos, estratos finos de arena y rodados finos, con restos de valvas (Sitio F24 y F25). 
En el Sitio F26, en La Conchilla, corresponde a un microacantilado de $1.50 \mathrm{~m}$ de potencia se diferencian 4 niveles. El primer nivel con $70 \mathrm{~cm}$ de potencia de clastossostén y valvas fragmentadas (Fig. 9.9B a). El segundo nivel con $30 \mathrm{~cm}$ de potencia de arena más fina con valvas aisladas (Fig. 9.9B b). El tercer nivel tiene $10 \mathrm{~cm}$ de potencia compuesto por arenas con gran cantidad de valvas fragmentados (Fig. 9.9B c) y el cuarto nivel de $0.50 \mathrm{~cm}$ compuesto por arenas más fina con valvas enteras (Fig. 9.9B,d). En este depósito se realizó una datación de ${ }^{14} \mathrm{C}$ que arrojó una edad de $2.43 \pm 0.60 \mathrm{ka}$ (LP: 2889).

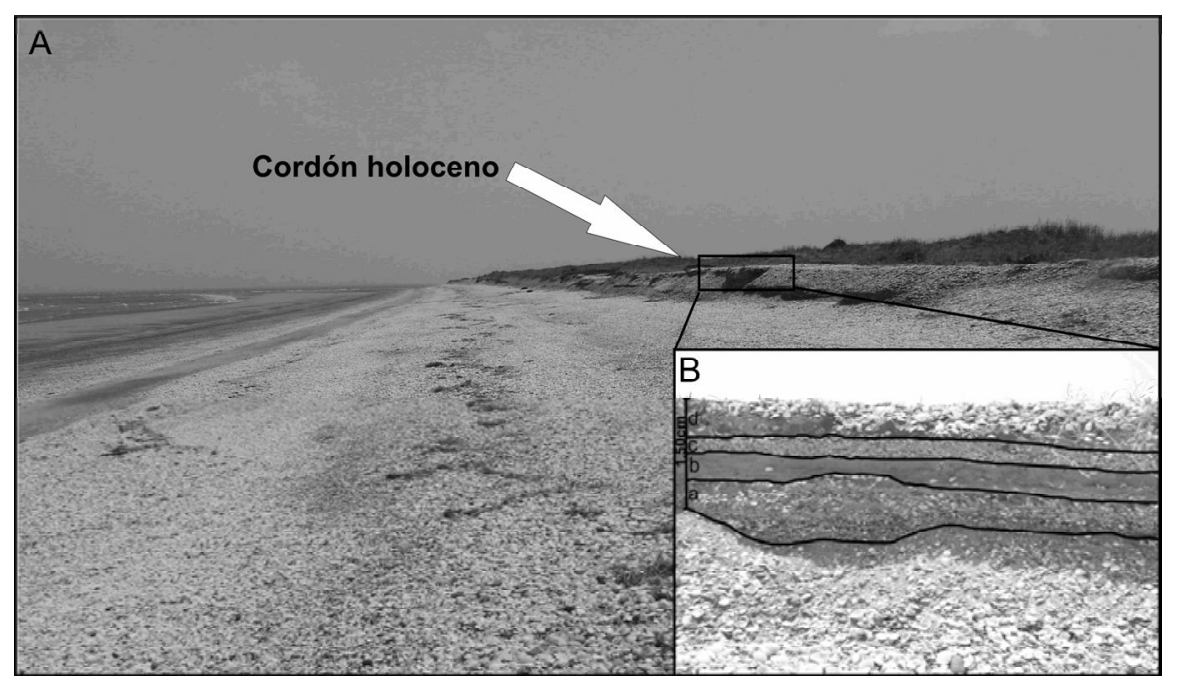

Fig. 9.9: A, Microacantilado holoceno en La Conchilla; B, perfil del microacantilado compuesto por 4 niveles con presencia de valvas (Sitio F26).

En las inmediaciones del puerto de SAE (Sitio F27) se observa a lo largo de unos 200 $\mathrm{m}$ un afloramiento de $2 \mathrm{~m}$ pertenecientes al Interglacial MIS 1, cubiertos por 1 - $4 \mathrm{~m}$ de médanos (Fig. 9.10). Los depósitos ingresivos están compuestos por dos tipos de estratos paralelos de 10 - $15 \mathrm{~cm}$ de espesor con contactos transicionales. Se presentan estratos compuestos por valvas en posición caóticas, con restos enteros y fracturados, en general con la concavidad hacia abajo con proporciones importantes de rodados. Los estratos de sedimento más finos suelen ser variables, aunque siempre el depósito es clastos- sostén. 


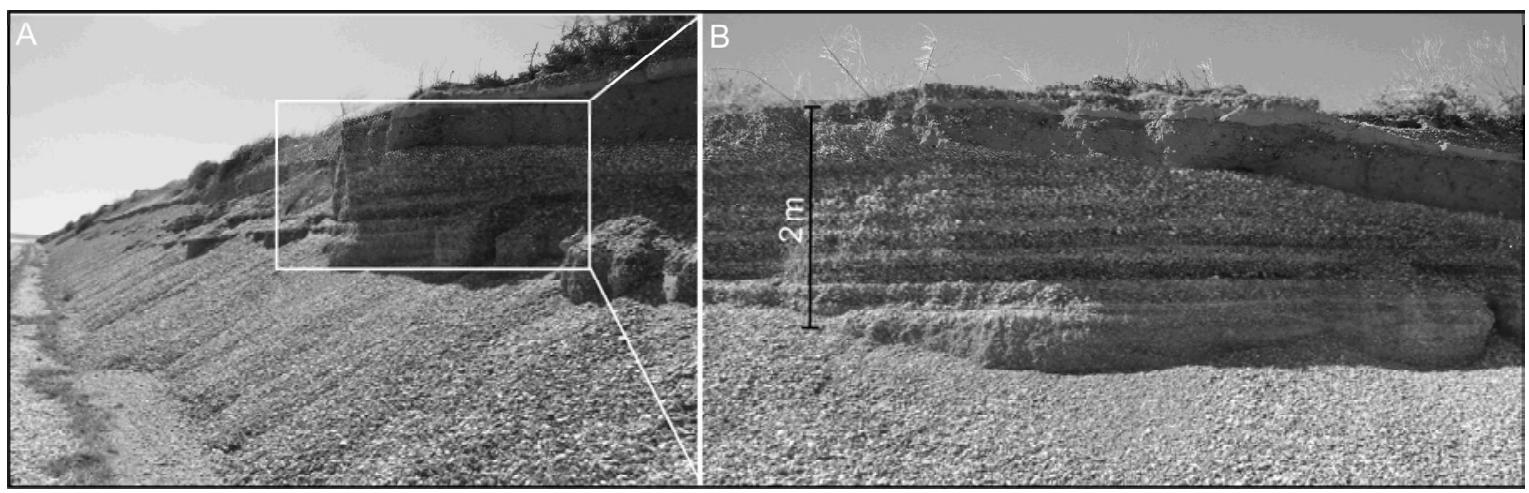

Fig. 9.10: A, B Acantilado holoceno cercano al puerto San Antonio Este (Sitio F27).

En cercanías de Punta Perdices (Sitio F28), se observan una serie de crestas de playa de escasa altura relativa, $100 \mathrm{~m}$ de ancho y longitudes superiores a $1 \mathrm{~km}$ y con restos de valvas. Entre las crestas más altas y la más bajan las cotas varían entre los $9-5 \mathrm{~m}$ (Fig. 9.11). Aledaños a las crestas, hay una cantera perteneciente al Interglacial MIS 1 (Sitio F29) con un espesor entre los 0.60 - $0.50 \mathrm{~m}$ con alternancia de arena medianas con valvas enteras (Fig. 9.12).

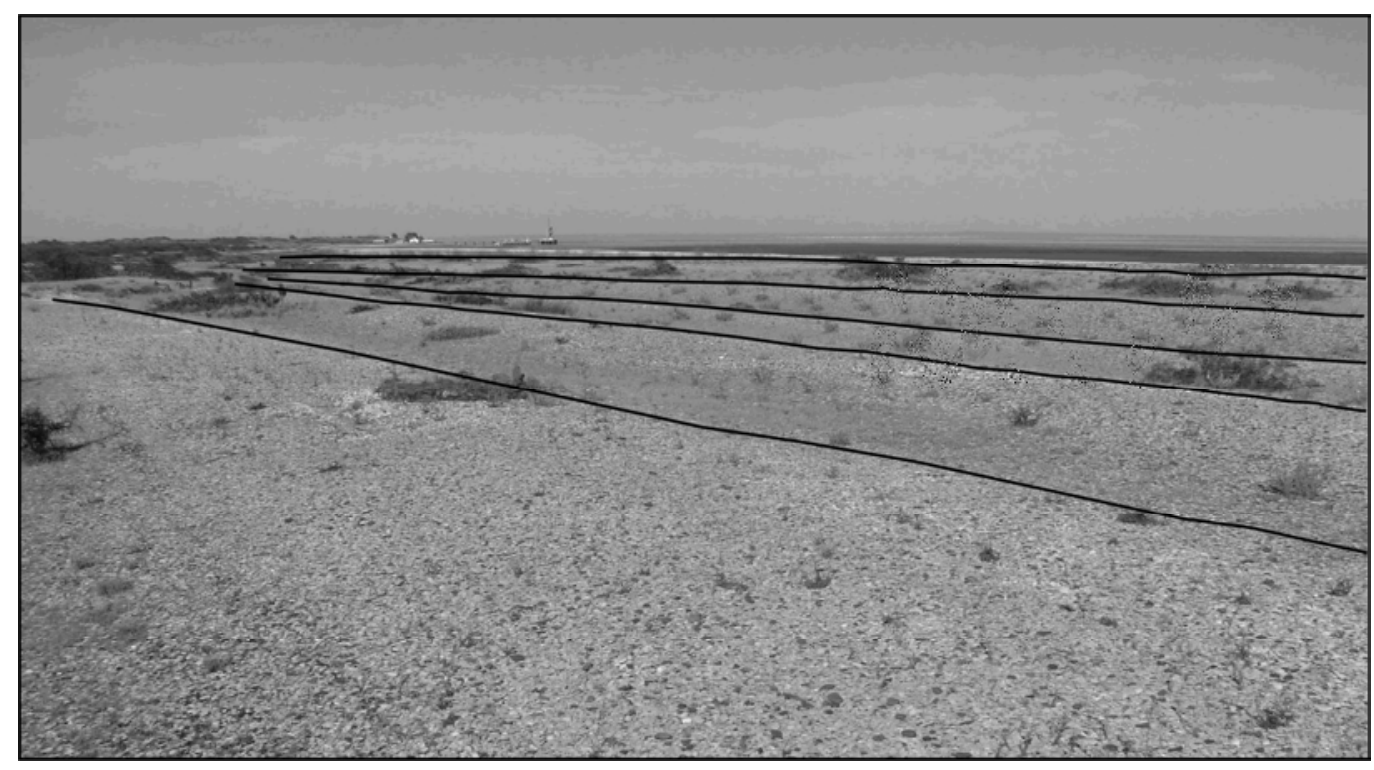

Fig. 9.11: Crestas holocenas de Punta Perdices (Sitio F28). 


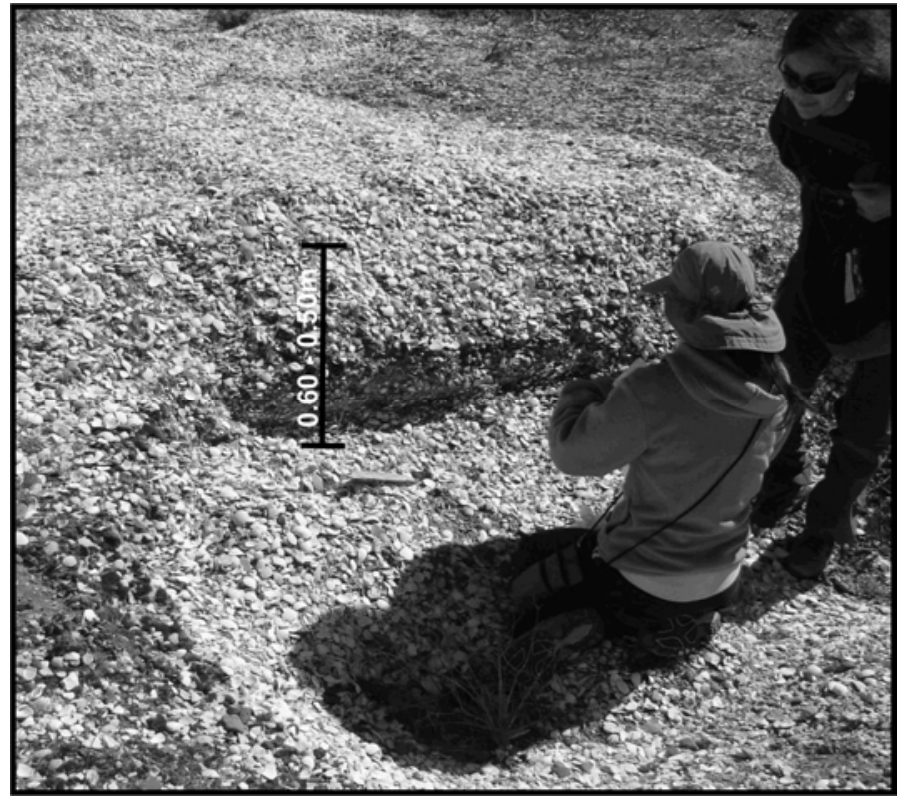

Fig. 9.12: Cantera holocena de Punta Perdices (Sitio F29).

\subsection{Playas actuales de la región norte del golfo San Matías}

Las playas actuales de la región norte de Río Negro están compuestas en muchos sectores casi exclusivamente por moluscos enteros y fracturados en la parte superior y arena mediana a fina en los sectores intermareales bajos, con anchos que superan los centenares de metros.

Al sur de la baliza San Matías, las playas se caracterizan de dos tipos; la mitad norte las playas tiene un ancho de entre 32 y $80 \mathrm{~m}$ que hacia el mar pasan a una plataforma de abrasión y hacia el continente a una berma arenosa que se continua en un cordón medanoso, con pendiente que va entre 7 y $10 \%$. En la mitad sur las playas son arenosas en algunos sitios arena gravosa gruesa, discontinuas y más pequeñas (Gelós et al. 1993).

El sitio mas cercano al límite provincial (Buenos Aires - Río Negro) es el balneario El Cóndor (Sitio G18) $\left(41^{\circ} 02^{\prime} \mathrm{S} / 62^{\circ} 49^{\prime} \mathrm{O}\right)$, se caracteriza por ser una playa de arena fina con un ancho aproximado de $750 \mathrm{~m}$. Entre la fauna marina se destacan entre las más abundantes: Plicatula gibbosa, Ostrea puelchana (bivalvos) y Crepidula (gasterópodos). 
Los sitios G19 y G20, cercano al Faro San Matías, corresponden a playas arenosas de mar abierto constituidas sobre la plataforma costera, que representan al Interglacial MIS 7. Entre la fauna marina figuran: Amiantis purpurata, Retrotapes exalbidus y Aequipecten tehuelchus (bivalvos) y Buccinanops cochlidium (gasterópodo).

El Sitio G21 (4047'S/64 $\left.52^{\prime} \mathrm{O}\right)$, en cercanías del Puerto de San Antonio Este, se caracteriza por ser una playa de arena compuestas por gran cantidad de valvas. Entre la fauna marina se destacan: Brachidontes rodriguezii, Mytilus edulis (bivalvos) y Tegula patagonica y Crepidula (gasterópodos).

La playa actual La Conchilla (Sitio G22) $\left(40^{\circ} 49^{\prime} \mathrm{S} / 64^{\circ} 52^{\prime} \mathrm{O}\right)$, es una playa extensa de arena, en la zona supramareal, la composición es prácticamente organógenas con gran cantidad de valvas de moluscos en su mayoría representadas por Amiantis purpurata (bivalvo) (Fig. 9.13).

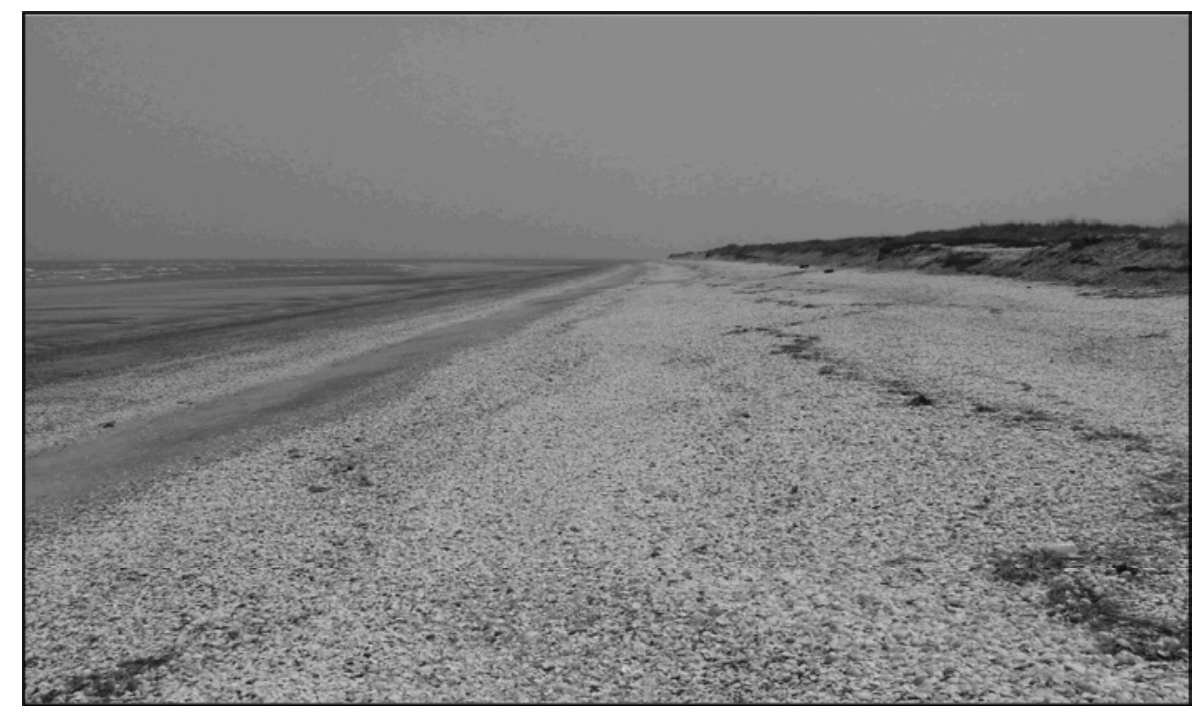

Fig. 9.13: Playa actual La Conchilla (G22).

La costa de Playa Villarino, a $45 \mathrm{~km}$ de San Antonio Oeste, está conformada en su mayoría por el bivalvo Amiantis purpurata. Esta zona está constituida por una playa de arena fina de pendiente muy suave, de unos $11 \mathrm{~km}$ de longitud y hasta $600 \mathrm{~m}$ de ancho. 
Las playas desarrolladas dentro de la bahía de San Antonio poseen pendientes más importantes del orden de $15-20^{\circ}$ y están compuestas casi exclusivamente de gravas finas y medianas, y valvas de moluscos, observándose cordones de tormenta de reciente formación (ej. Morsan 1997; Fucks et al., 2012b).

El Sitio G23 (404ㄴ $\left.\mathrm{S} / 64^{\circ} 56^{\prime} \mathrm{O}\right)$, cercano a San Antonio Oeste, representa una playa de arena fina con un ancho entre los 200 - 300 m constituida por Glycymeris longior y Brachidontes rodriguezii (bivalvos) y Bostrycapulus odites y Buccinanops globulosus (gasterópodos), entre la fauna marina más abundantes.

La playa actual del balneario Las Grutas (Sitio G24) (40 $\left.48^{\prime} \mathrm{S} / 65^{\circ} 4^{\prime} \mathrm{O}\right)$, es una playa arenosa entre el acantilado y la plataforma costera variando en ancho entre los 60 - $20 \mathrm{~m}$ formando una cuña sobre el acantilado. Entre los moluscos más abundantes figuran: Glycymeris longior y Brachidontes rodriguezii (bivalvos) y Buccinanops globulosus y Olivancillaria carcellesi (gasterópodos) (Fig. 9.14).

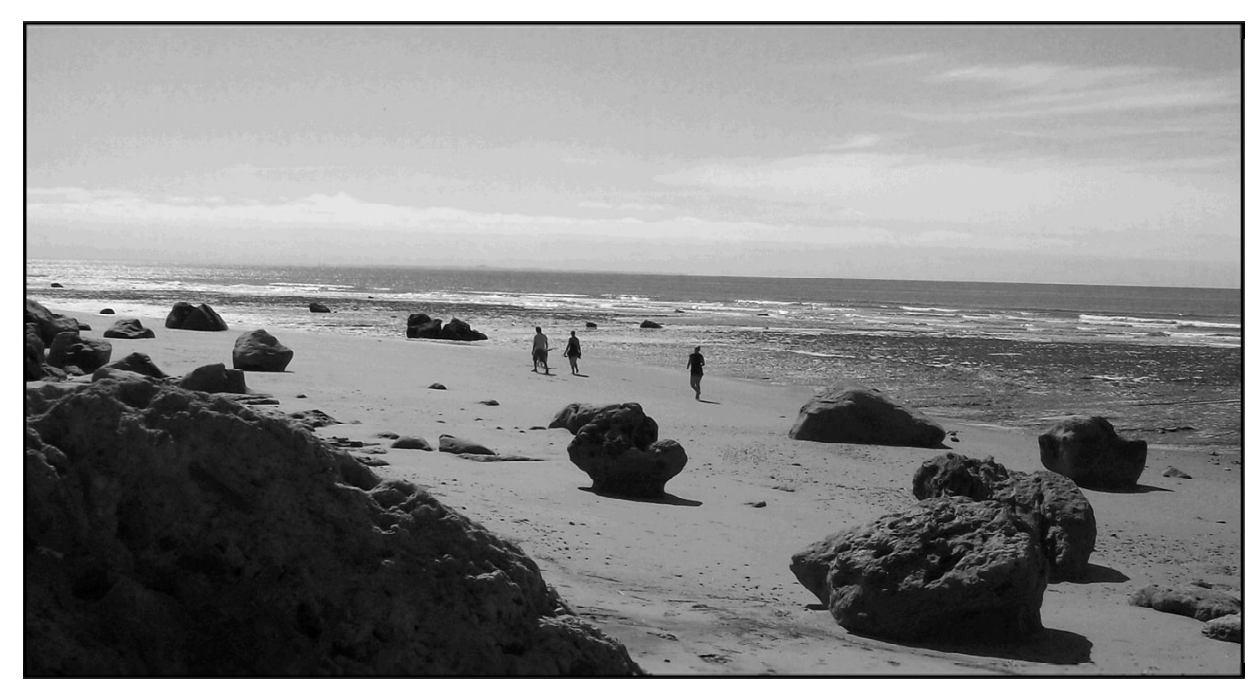

Fig. 9.14: Playas arenosas del balneario Las Grutas (Sitio G24)

\subsection{Composición faunística}

En la región del norte del golfo San Matías se analizaron 19 sitios (6 pleistocenos, 6 holocenos y 7 playas actuales) y se registró un total de 42 especies (20 bivalvos y 22 
gasterópodos) (T. 9.2 y T. 9.3). Entre los cuales se identificaron 5 son micromoluscos: Corbula lyoni (bivalvo) y Heleobia australis, Parvanachis isabellei, Olivella tehuelcha y Costoanachis sertulariarum (gasterópodos). 


\begin{tabular}{|c|c|c|c|c|c|c|c|c|c|c|c|c|c|c|c|c|c|c|c|}
\hline BIVALVOS & D1 & D2 & E20 & E21 & E22 & E23 & F24 & F25 & F26 & F27 & F28 & F29 & G18 & G19 & G20 & G21 & G22 & G23 & G24 \\
\hline \multicolumn{20}{|l|}{$\begin{array}{l}\text { Familia Glycymerididae Newton, } \\
1922\end{array}$} \\
\hline Glycymeris (G.) longior ( Sowerby, 1832) & & $\mathbf{X}$ & $\mathbf{X}$ & $\mathbf{X}$ & $\mathbf{X}$ & $\mathbf{X}$ & & & & & $\mathbf{X}$ & $\mathbf{X}$ & $\mathbf{X}$ & $\mathbf{X}$ & $\mathbf{X}$ & & & $\mathbf{X}$ & $\mathbf{X}$ \\
\hline \multicolumn{20}{|l|}{ Familia Mytilidae Rafinesque,1815 } \\
\hline Mytilus edulis platensis d'Orbigny, 1846 & & & & & & $\mathbf{X}$ & & & & $\mathbf{X}$ & $\mathbf{X}$ & & $\mathbf{X}$ & & $\mathbf{X}$ & $\mathbf{X}$ & & & \\
\hline $\begin{array}{l}\text { Brachidontes (B) rodriguezii ( d'Orbigny, } \\
1846 \text { ) }\end{array}$ & $\mathbf{X}$ & $\mathbf{X}$ & & $\mathbf{X}$ & & $\mathbf{X}$ & & $\mathbf{X}$ & & & & & $\mathbf{X}$ & & $\mathbf{X}$ & $\mathbf{X}$ & & $\mathbf{X}$ & $\mathbf{X}$ \\
\hline Aulacomya atra (Molina,1782) & & & & & & & & & & & $\mathbf{X}$ & & & & & & & & $\mathbf{X}$ \\
\hline \multicolumn{20}{|l|}{ Familia Pectinidae Rafinesque, 1815} \\
\hline Aequipecten tehuelchus (d' Orbigny, 1842) & $\mathbf{X}$ & & & $\mathbf{X}$ & $\mathbf{X}$ & & & $\mathbf{X}$ & & $\mathbf{X}$ & $\mathbf{X}$ & & & $\mathbf{X}$ & $\mathbf{X}$ & & $\mathbf{X}$ & & \\
\hline \multicolumn{20}{|l|}{ Familia Plicatulidae Watson, 1930} \\
\hline Plicatula gibbosa Lamarck, 1801 & & $\mathbf{X}$ & & & & & & & & & & & $\mathbf{X}$ & & & & & & \\
\hline \multicolumn{20}{|l|}{ Familia Ostreidae Rafinesque, 1815} \\
\hline \multicolumn{20}{|l|}{ Ostrea } \\
\hline Ostreola equestris (Say, 1834) & & & & & & & & & & & & & & & & $\mathbf{X}$ & & $\mathbf{X}$ & $\mathbf{X}$ \\
\hline Ostrea puelchana d’Orbigny 1841 & & & & & $\mathbf{X}$ & $\mathbf{X}$ & & $\mathbf{X}$ & & $\mathbf{X}$ & $\mathbf{X}$ & $\mathbf{X}$ & $\mathbf{X}$ & $\mathbf{X}$ & $\mathbf{X}$ & $\mathbf{X}$ & & $\mathbf{X}$ & $\mathbf{X}$ \\
\hline \multicolumn{20}{|l|}{ Familia Cardiidae Lamarck, 1809} \\
\hline Trachycardium muricatum (Linné, 1758) & & & & & & $\mathbf{X}$ & & & & & $\mathbf{X}$ & & & $\mathbf{X}$ & & & & & \\
\hline \multicolumn{20}{|l|}{ Familia Mactridae Lamarck, 1809} \\
\hline $\begin{array}{l}\text { Mactra guidoi Signorelli \& F. Scarabino, } \\
2010\end{array}$ & & $\mathbf{X}$ & & & & & & & & & & & & & & & & $\mathbf{X}$ & \\
\hline \multicolumn{20}{|l|}{ Familia Mesodesmatidae Gray, 1839} \\
\hline Mesodesma mactroides (Reeve, 1854) & & & & & & & & & & $\mathbf{X}$ & & & & & & & & & \\
\hline \multicolumn{20}{|l|}{ Familia Veneridae Rafinesque, 1815} \\
\hline Tivela isabelleana ( d'Orbigny, 1846) & & & $\mathbf{X}$ & & $\mathbf{X}$ & $\mathbf{X}$ & & & & & & & & & & & & & \\
\hline Anomalocardia brasiliana (Gmelin, 1791) & & & & $\mathbf{X}$ & & & & & & & & & & & & & & & \\
\hline Pitar (P.) rostratus (Philippi, 1844) & & & $\mathbf{X}$ & & $\mathbf{X}$ & $\mathbf{X}$ & & & & & & & & & & & & & $\mathbf{X}$ \\
\hline Amiantis purpurata ( Lamarck, 1856) & $\mathbf{X}$ & $\mathbf{X}$ & $\mathbf{X}$ & $\mathbf{X}$ & $\mathbf{X}$ & $\mathbf{X}$ & $\mathbf{X}$ & $\mathbf{X}$ & $\mathbf{X}$ & $\mathbf{X}$ & $\mathbf{X}$ & $\mathbf{X}$ & & $\mathbf{X}$ & $\mathbf{X}$ & $\mathbf{X}$ & $\mathbf{X}$ & $\mathbf{X}$ & $\mathbf{X}$ \\
\hline Retrotapes exalbidus (Dillwyn,1817) & & & & & & & $\mathbf{X}$ & & & & & & & $\mathbf{X}$ & & & & & \\
\hline Ameghinomya antiqua (King,1832) & & & & & & & $\mathbf{X}$ & & & & & & & $\mathbf{X}$ & $\mathbf{X}$ & & & & \\
\hline
\end{tabular}




\section{BIVALVOS}

Familia Hiatellidae Gray, 1824

Panopea abbreviata Valenciennes, 1839

Familia Corbulidae Lamarck, 1818

Corbula (C.) lyoni (Pilsbry, 1897)

Familia Thraciidae Stoliczka, 1870

Thracia similis Couthouy, 1839

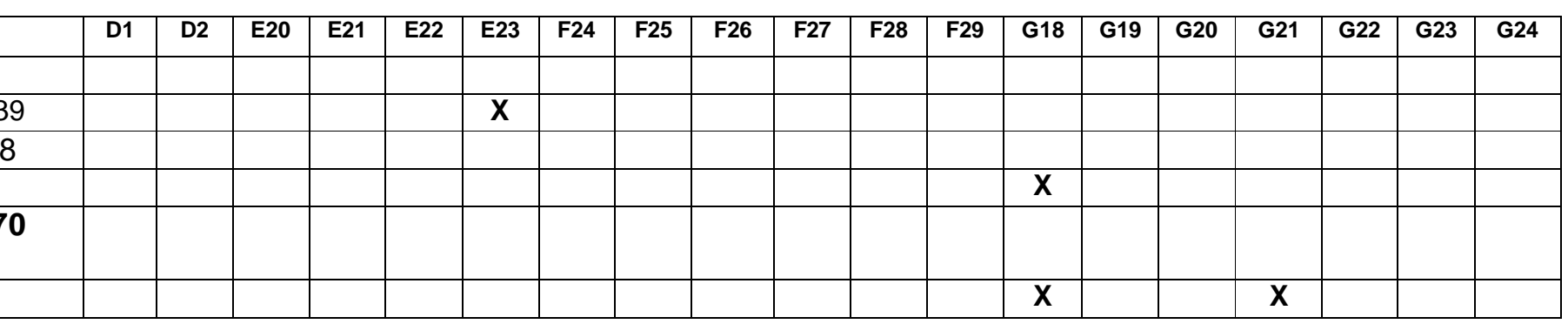

T.9.2: Lista sistemática de especies de bivalvos de cada sitio muestreado de la región del norte del golfo San Matías 


\begin{tabular}{|c|c|c|c|c|c|c|c|c|c|c|c|c|c|c|c|c|c|c|c|}
\hline GASTERÓPODOS & D1 & D2 & E20 & E21 & E22 & E23 & F24 & F25 & F26 & F27 & F28 & F29 & G18 & G19 & G20 & G21 & G22 & G23 & G24 \\
\hline \multicolumn{20}{|l|}{ Familia Nacellidae Thiele, 1891} \\
\hline Nacella (P.) magallanica (Gmelin,1791) & & & & & & & & $\mathbf{X}$ & & & & & & & & & & & \\
\hline \multicolumn{20}{|l|}{ Familia Fissurellidae Fleming, 1822} \\
\hline Fissurella radiosa radiosa Lesson, 1831 & & & & & & & & & & & $\mathbf{X}$ & & & & & & & & \\
\hline Lucapinella henseli (Martens, 1900) & & & & & & & & & & & & & $\mathbf{X}$ & & & & & & $\mathbf{X}$ \\
\hline \multicolumn{20}{|l|}{$\begin{array}{l}\text { Familia Calliostomatidae Thiele, } \\
1924\end{array}$} \\
\hline Tegula (A.) patagonica (d'Orbigny, 1835) & & & & & & $\mathbf{X}$ & & & & & $\mathbf{X}$ & $\mathbf{X}$ & & & $\mathbf{X}$ & $\mathbf{X}$ & & & \\
\hline Tegula atra Lesson 1830 & $\mathbf{X}$ & $\mathbf{X}$ & & & & $\mathbf{X}$ & & & & & & & & & & & & & \\
\hline \multicolumn{20}{|l|}{$\begin{array}{l}\text { Familia Calyptraeidae Blainville, } \\
1824\end{array}$} \\
\hline Bostrycapulus odites (Collin, 2005) & & $\mathbf{X}$ & & $\mathbf{X}$ & & & & $\mathbf{X}$ & & & $\mathbf{X}$ & & $\mathbf{X}$ & $\mathbf{X}$ & $\mathbf{X}$ & $\mathbf{X}$ & $\mathbf{X}$ & $\mathbf{X}$ & $\mathbf{X}$ \\
\hline Crepidula & & $\mathbf{X}$ & & & & & & & $\mathbf{X}$ & $\mathbf{X}$ & $\mathbf{X}$ & & $\mathbf{X}$ & $\mathbf{X}$ & $\mathbf{X}$ & $\mathbf{X}$ & $\mathbf{X}$ & & \\
\hline Crepidula dilatata Lamarck, 1822 & & & & & & & & & & & & $\mathbf{X}$ & & $\mathbf{X}$ & & & & & $\mathbf{X}$ \\
\hline \multicolumn{20}{|l|}{ Familia Naticidae Forbes, 1828} \\
\hline Notocochlis isabelleana (Collin,2005) & & & & & & & & & & & & & & & $\mathbf{X}$ & & & & \\
\hline \multicolumn{20}{|l|}{ Familia Hydrobiidae Troschel, 1857} \\
\hline Heleobia australis ( d'Orbigny, 1835) & & & $\mathbf{X}$ & $\mathbf{X}$ & & & & & & & & & & & $\mathbf{X}$ & & & & \\
\hline \multicolumn{20}{|l|}{ Familia Muricidae da Costa, 1776} \\
\hline Trophon sp & & & & & & & & & & & & & & & $\mathbf{X}$ & $\mathbf{X}$ & $\mathbf{X}$ & & \\
\hline Trophon patagonicus (d'Orbigny, 1839) & $\mathbf{X}$ & & & & & $\mathbf{X}$ & & & & & $\mathbf{X}$ & & & & & & & $\mathbf{X}$ & \\
\hline Trophon geversianus (Pallas, 1774) & & & & & & & & $\mathbf{X}$ & & & & & & & & & & $\mathbf{X}$ & \\
\hline \multicolumn{20}{|l|}{ Familia Volutidae Rafinesque, 1815} \\
\hline $\begin{array}{l}\text { Adelomelon (P.) brasiliana (Lamarck, } \\
\text { 1811) }\end{array}$ & & & $\mathbf{X}$ & & & & & & & & & & & & & & & & \\
\hline $\begin{array}{l}\text { Odontocymbiola magellanica (Gmelin, } \\
\text { 1791) }\end{array}$ & & & & & & & & $\mathbf{X}$ & & & & $\mathbf{X}$ & & $\mathbf{X}$ & & & & & $\mathbf{X}$ \\
\hline \multicolumn{20}{|l|}{ Familia Olividae Latreille, 1825} \\
\hline Olivella (O.) tehuelcha (Dúclos, 1835) & & & & & & & & & & & & & $\mathbf{X}$ & & $\mathbf{X}$ & & & & $\mathbf{X}$ \\
\hline Olivancillaria urceus ( Röding, 1798) & & & $\mathbf{X}$ & & $\mathbf{X}$ & & & & & & & & & & & & & & \\
\hline & & & & & & & & & & & & & & & & & & & \\
\hline
\end{tabular}




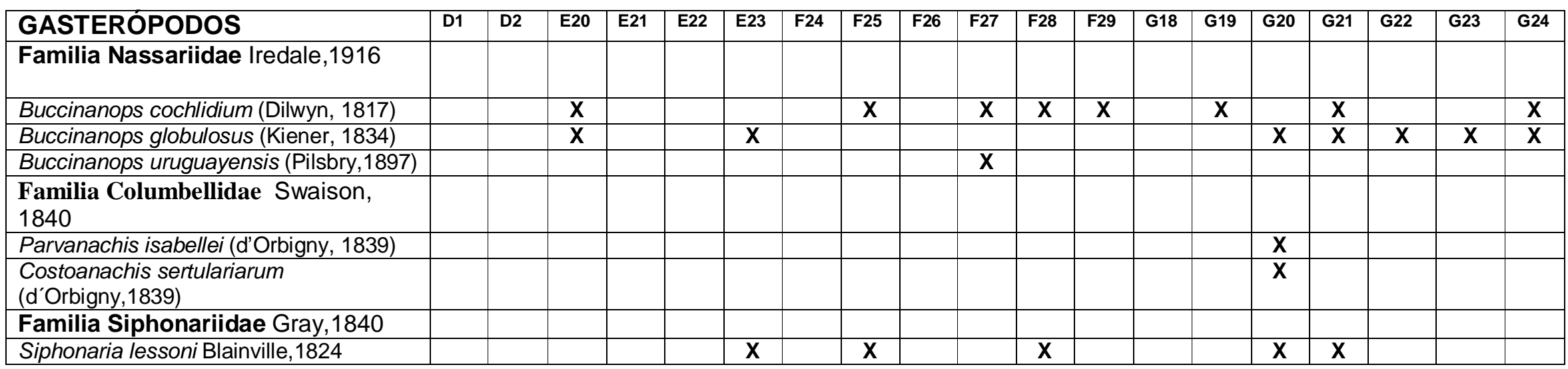

T.9.3: Lista sistemática de especies de gasterópodos de cada sitio muestreado de la región del norte del golfo San Matías. 
Según el índice de Shannon $\left(\mathrm{H}^{\prime}\right)$, los índices más bajos corresponden a dos sitios pertenecientes al Interglacial MIS $1\left(\mathrm{H}_{\mathrm{F} 24}^{\prime}=0.90 \mathrm{y} \mathrm{H}_{\mathrm{F} 26}^{\prime}=0.67\right)$ y los índices más altos corresponden en su mayoría a los sitios de playas actuales que varían entre los 1.50 2.52 y a excepción de dos sitios, perteneciente al Interglacial MIS 5e y MIS 1 respectivamente $\left(\mathrm{H}_{\mathrm{E} 23}^{\prime}=2.38\right.$ y H$\left._{\mathrm{F} 28}^{\prime}=2.36\right)($ Fig. 9.15) (T. 9.4).

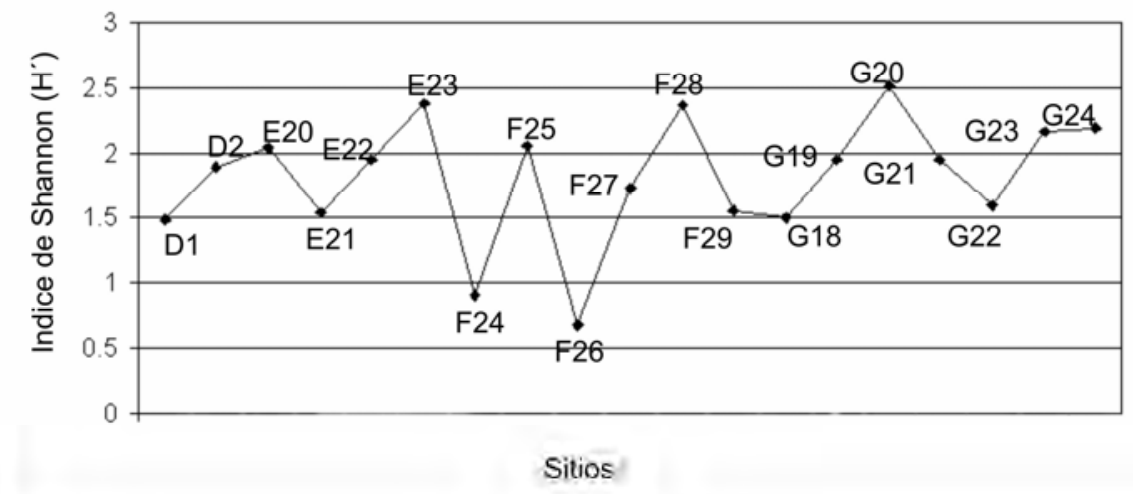

Fig. 9.15: Gráfico del índice de Shannon de cada sitio de la región norte del golfo San Matías.

\begin{tabular}{|c|c|c|}
\hline № de sitio & $\begin{array}{c}\text { Índice de Shannon } \\
\left(\mathbf{H}^{\prime} \mathbf{)}\right.\end{array}$ & № de especies \\
\hline D1 & 1.49 & 5 \\
\hline D2 & 1.89 & 11 \\
\hline E20 & 2.04 & 7 \\
\hline E21 & 1.54 & 7 \\
\hline E22 & 1.94 & 16 \\
\hline E23 & 2.38 & 3 \\
\hline F24 & 0.90 & 11 \\
\hline F25 & 2.05 & 2 \\
\hline F26 & 0.67 & 9 \\
\hline F27 & 1.73 & 15 \\
\hline F28 & 2.36 & 8 \\
\hline F29 & 1.55 & \\
\hline
\end{tabular}




\begin{tabular}{|c|c|c|}
\hline & & 11 \\
\hline G18 & 1.50 & 12 \\
\hline G19 & 1.94 & 19 \\
\hline G20 & 2.52 & 14 \\
\hline G21 & 1.95 & 7 \\
\hline G22 & 1.60 & 11 \\
\hline G23 & 2.16 & 15 \\
\hline G24 & 2.19 & \\
\hline
\end{tabular}

T.9.4: Tabla de índices de diversidad ( $\mathrm{H}^{\prime}$ ) y la riqueza en especies en cada sitio analizado de la región norte del golfo San Matías.

\subsubsection{Pleistoceno norte del golfo San Matías}

Los depósitos pertenecientes a los Interglaciales MIS 7 y MIS 5e del norte del golfo San Matías, se analizaron en total 6 sitios y se registraron 24 especies (11 gasterópodos y 13 bivalvos). Las especies de moluscos que aparecieron con mayor frecuencia fueron los gasterópodos Tegula atra y Buccinanops globulosus, y los bivalvos Glycymeris longior, Brachidontes rodriguezii y Amiantis purpurata.

Los depósitos marinos pertenecientes al Interglacial MIS 7, corresponden a paleoplayas, representando actualmentea a plataformas costeras compuestas por arenas y/o conglomerados, parcial o totalmente litificados, ubicados en el área intermareal. El análisis de los sitios D1 y D2 registró un total de 11 especies (5 gasterópodos y 6 bivalvos) en muy buen estado de preservación, pudiendo identificarse en su mayoría a nivel de especie. Entre la fauna más abundante figuran: Glycymeris longior y Amiantis purpurata (bivalvos) y Tegula atra (gasterópodo) (Fig.9.16). 


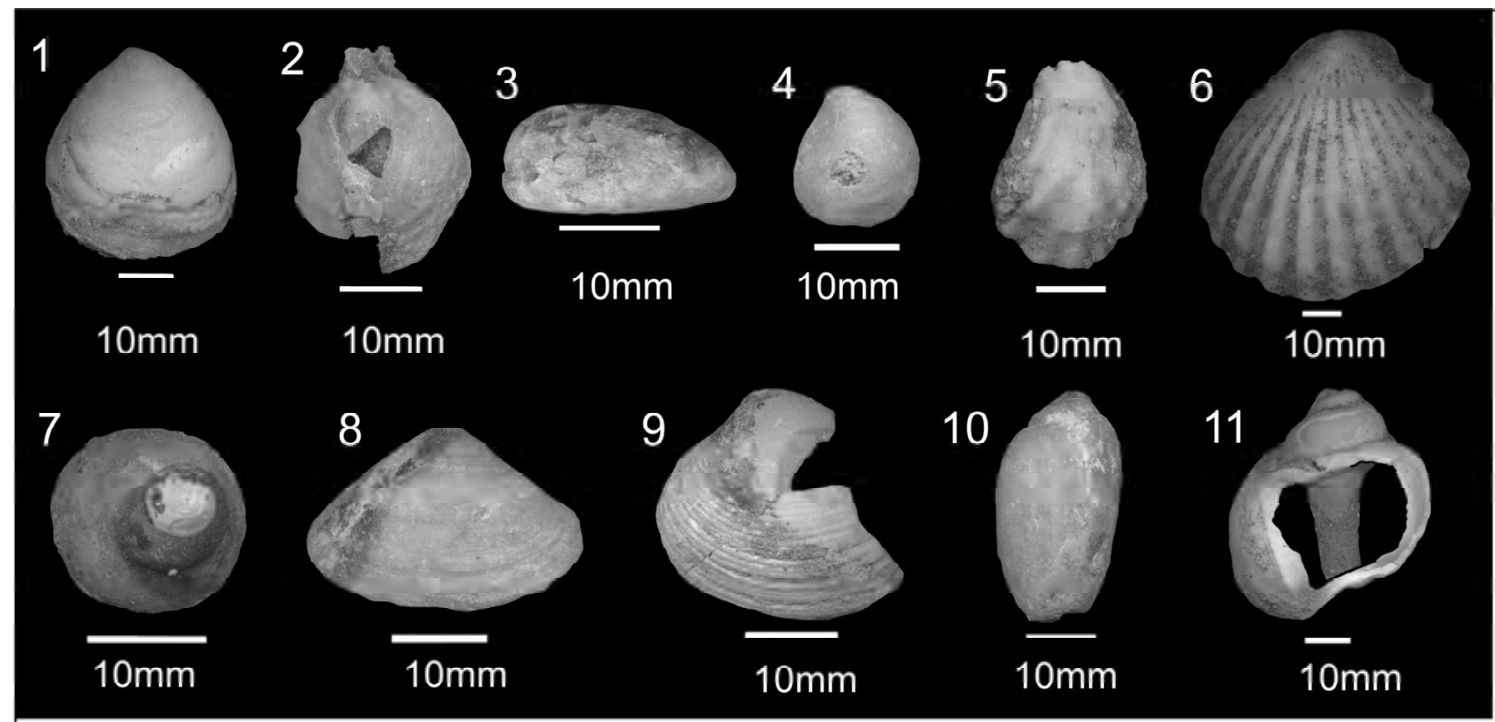

Fig. 9.16: Especies de gasterópodos y bivalvos característicos de depósitos marinos del Interglacial MIS 7 del N del golfo de San Matías.

1, Glycymeris (G.) longior (Sowerby) (CEGH-UNC:25628, sur de Piedras Coloradas);2,Crepidula sp.(CEGH-UNC: 25638, sur de Piedras Coloradas); 3, Brachidontes (B.) rodriguezii (d'Orbigny)(CEGH-UNC:25631, sur de Piedras Coloradas; 4, Bostrycapulus odites (Collin) (CEGHUNC:25637, sur de Piedras Coloradas); 5, Plicatula gibbosa Lamarck (CEGH-UNC:25630, sur de Piedras Coloradas);6, Aequipecten tehuelchus (d'Orbigny)(CEGH-UNC:25627, sur del Faro San Matías);7, Tegula atra (Lesson) (CEGH-UNC: 25636, sur de Piedras Coloradas);8, Mactra guidoi Signorelli \& Scarabino (CEGH-UNC:25632, sur de Piedras Coloradas);9, Amiantis purpurata (Lamarck) ( CEGH-UNC:25.629, sur de Piedras Coloradas); 10, Olivancillaria carcellesi Klappenbach (CEGH-UNC:25633, sur de Piedras Coloradas);11, Trophon patagonicus (d'Orbigny) (CEGH-UNC 25635, sur de Faro San Matías). 
En el Interglacial MIS 5e, representados por cordones litorales (E20 - E23), a cotas de 8 - 10 m hubo mayor diversificación de especies que en el Interglacial MIS 7. En total se registraron 22 especies (11 gasterópodos y 11 bivalvos). Entre las especies de moluscos más abundantes figuran: Amiantis purpurata, Glycymeris longior y Brachidontes rodriguezii (bivalvos) y Heleobia australis, Olivancillaria carcellesi y Olivancillaria urceus (gasterópodos) (Fig. 9.17 y Fig. 9.18). En estos depósitos se destaca la presencia de Anomalocardia brasiliana (Sitio E21), una especie de estirpe cálida que en la actualidad se distribuye a latitudes más bajas, estando ausente en la costa argentina. Es un bivalvo infaunal cálido y se distribuye desde las Antillas Francesas $\left(18^{\circ} \mathrm{N}\right)$ hasta las costas de Brasil (33 S) (Oliveira et al., 2011). 


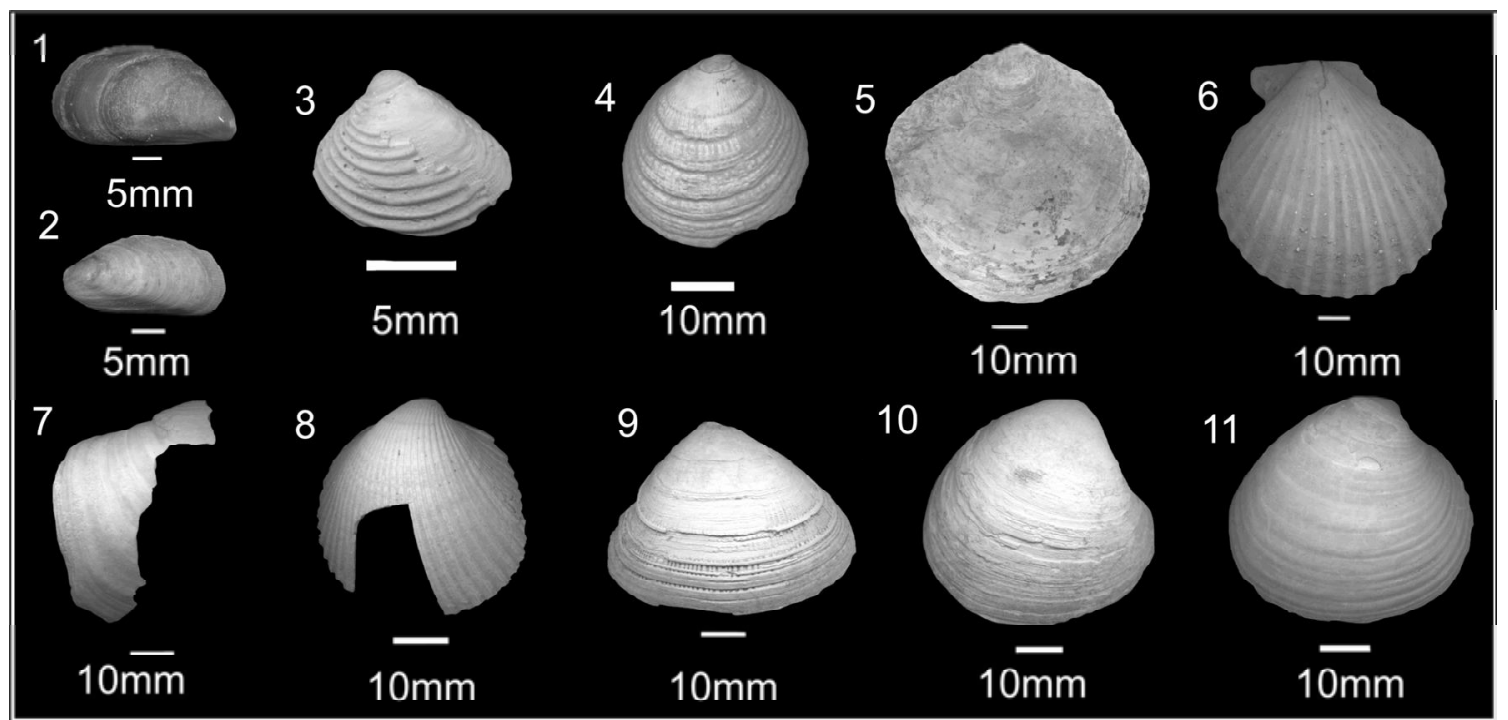

Fig.9.17: Especies de bivalvos característicos de depósitos marinos del Interglacial MIS 5e de la región norte del golfo San Matías.

1, Mytilus edulis platensis d'Orbigny (CEGH-UNC:25604, La Rinconada);2, Brachidontes (B.) Rodriguezii (d'Orbigny) (CEGH-UNC: 25601, La Rinconada);3, Anomalocardia brasiliana (Gmelin) (CEGH-UNC:25609, Baliza Camino);4, Glycymeris (G.) longior (Sowerby) (CEGH-UNC:25600, Baliza Camino); 5, Ostrea puelchana d'Orbigny (CEGH-UNC:25607, Bahía San Antonio);6, Aequipecten tehuelchus (d'Orbigny)(CEGH-UNC:25606, Baliza Camino);7, Panopea abbreviata Valenciennes CEGH-UNC:25605, La Rinconada);8, Trachycardium muricatum (Linné)(CEGH-UNC: 25602, La Rinconada);9, Tivela isabelleana (d'Orbigny) (CEGH-UNC:25603, Bahía San Antonio);10, Pitar (P.) rostratus (Philippi) (CEGh-UNC: 25598, Bahía San Antonio);11, Amiantis purpurata d'Orbigny (CEGHUNC:25599, Baliza Camino). 


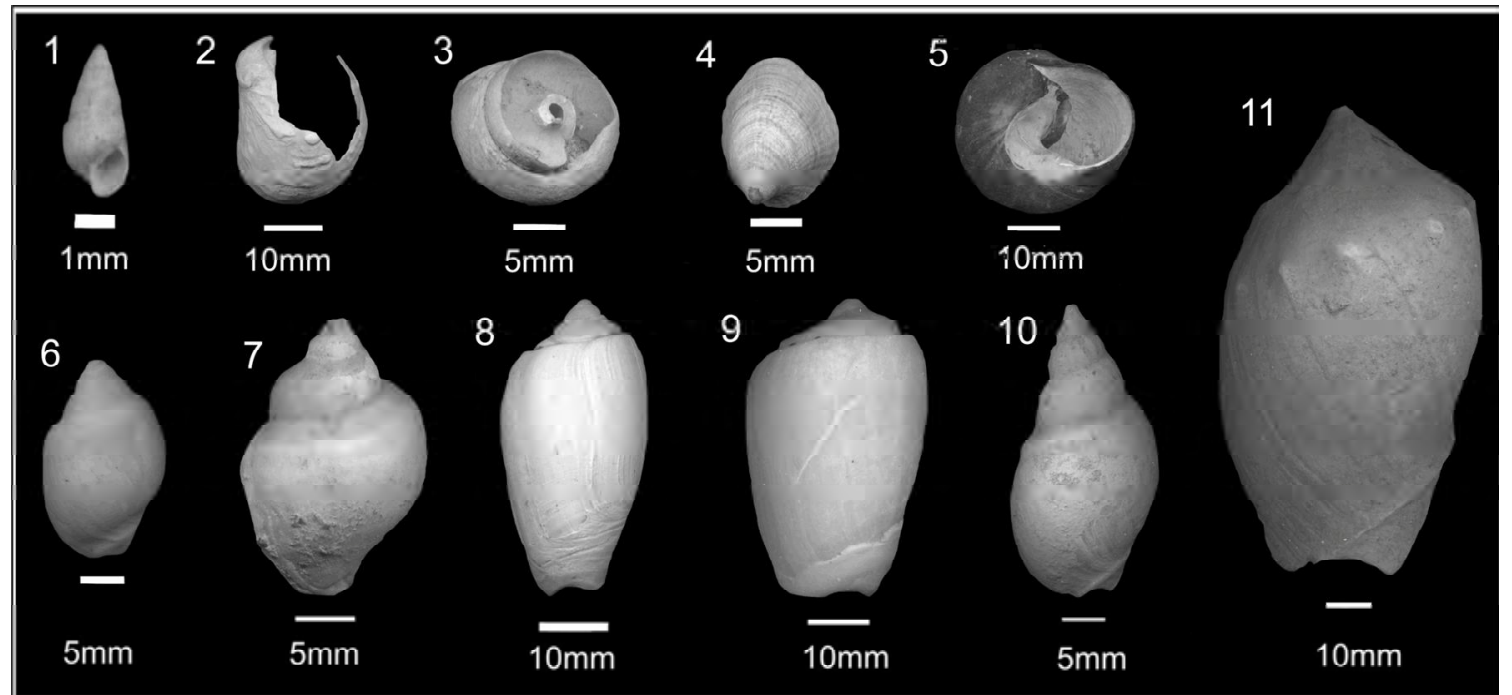

Fig.9.18: Especies de gasterópodos característicos de depósitos marinos del Interglacial MIS $5 \mathrm{e}$ de la región norte del golfo San Matías.

1, Heleobia australis (d'Orbigny)(CEGH-UNC:25619, Baliza Camino);2, Bostrycapulus odites (Collin) (CEGH-UNC: 25621, Baliza Camino);3, Tegula patagonica (d'Orbigny) (CEGH-UNC; 25614, Bålizã Camino); 4, Siphonaria lessoni Blainville (CEGH-UNC:25624, La Rinconada);5, Tegula atra (Lesson) (CEGH-UNC:25615, La Rinconada);6, Buccinanops globulosus (Kiener) (CEGH-UNC:25616, Baliza Camino);7, Trophon patagonicus (d'Orbigny)(CEGH-UNC:25617, La Rinconada);8, Olivancillaria carcellesi Klappenbach (CEGH-UNC:25613, Baliza Camino); 9, Olivancillaria urceus (Röding)(CEGHUNC:25618, Baliza Camino);10, Buccinanops cochlidium (CEGH-UNC:25622, San Antonio Este); 11, Adelomelon (P.) brasiliana (Lamarck) (CEGH-UNC:25625, sur del Faro San Matías). 


\subsubsection{Tegula atra (Lesson, 1830)}

Tegula atra o caracol negro es un gasterópodo de concha gruesa y globosa de color variable desde violeta hasta negro. El exterior es liso, con líneas de crecimientos oblicuas muy débilmente marcadas (Fig. 9.19). Vive en sustrato rocoso y se distribuye actualmente en el Océano Pacífico. Es abundante su registro durante el Pleistoceno en el norte patagónico (Provincia de Río Negro) y los depósitos pleistocenos de la provincia de Chubut (ej. Pastorino, 2000; Aguirre, 2003; Aguirre et al., 2006) y no hay evidencia de su existencia en los cordones holocenos a lo largo de la costa patagónica Argentina ni evidencias que vivan en las playas actuales en el Océano Atlántico.

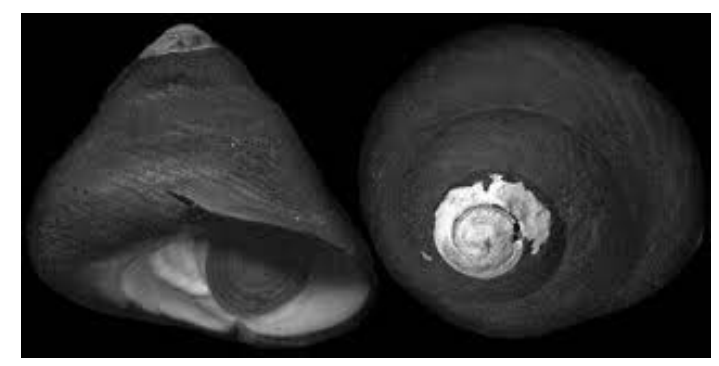

Fig. 9.19: Tegula atra de depósitos marinos pleistocenos del norte del golfo San Matías.

\subsubsection{Holoceno norte del golfo San Matías}

Los depósitos marinos pertenecientes al Interglacial MIS 1 están representados por cordones litorales de facies arenosas y conglomerádicas con restos de valvas. Se analizaron 6 sitios (F24 - F29) y entre la fauna marina se registró un total de 23 especies (11 bivalvos y 12 gasterópodos) (Fig. 9.21 y 9.22). Entre las especies más abundantes se destacan: Amiantis purpurata, Ostrea puelchana y Aequipecten tehuelchus (bivalvos), y Buccinanops cochlidium, Crepidula y Olivancillaria carcellesi (gasterópodos).

Entre la fauna marina holocena se destaca la aparición de Mesodesma mactroides (bivalvo) con un único ejemplar encontrado a lo largo del norte del golfo San Matías, siendo esta especie registrada en la actualidad hasta el sur de la Provincia de Buenos Aires. 


\subsubsection{Mesodesma mactroides (Reeve, 1854)}

El bivalvo Mesodesma mactroides se registró en el sitio F27 que corresponde a un microacantilado holoceno cerca del Puerto de San Antonio Este. Es un bivalvo infaunal de carácter migratorio que vive en zonas sublitorales superior hasta el litoral superior (Thompson y Sanchez de Bock, 2007). El límite sur actual de la especie se registró hasta la isla Jabalí $\left(40^{\circ} \mathrm{S}\right.$, sur de la provincia de Buenos Aires, Argentina) (e.i. Ríos 1994; Cremonte and Figueras, 2004; Fiori y Morsan, 2004; Fiori y Defeo, 2006; Herrmann et al., 2010; Charó et al., 2013) pero algunos autores registran la especie actualmente hasta la desembocadura del Río Negro (Bastida et al., 1991) e incluso hasta Río Negro ( $\left.41^{\circ} \mathrm{S}\right)$ (ej. Thompson y Sánchez de Bock, 2007). De acuerdo a los análisis efectuados esta especie es encontrada por primera vez en la región durante el Interglacial MIS 1. 


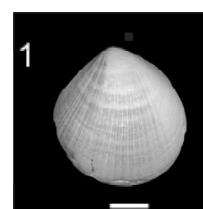

$10 \mathrm{~mm}$

5

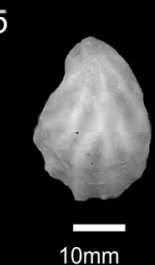

9

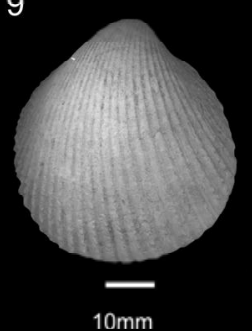

13

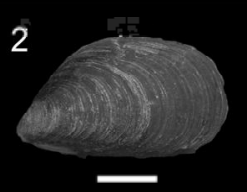

$10 \mathrm{~mm}$

\section{3}

6

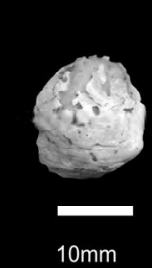

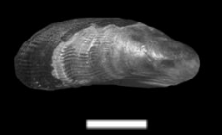

$10 \mathrm{~mm}$

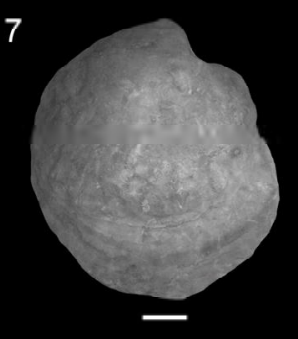

$10 \mathrm{~mm}$

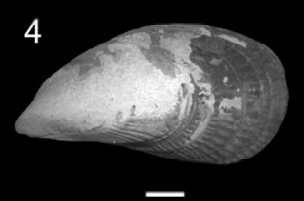

$10 \mathrm{~mm}$

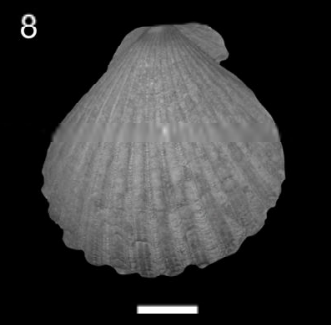

$10 \mathrm{~mm}$
10

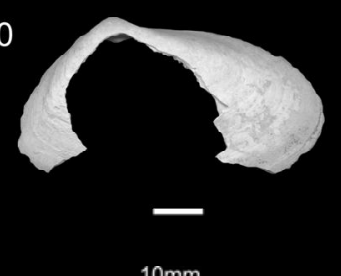

11

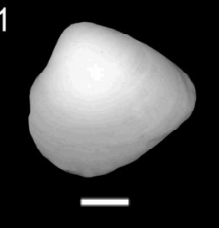

$10 \mathrm{~mm}$

15
12

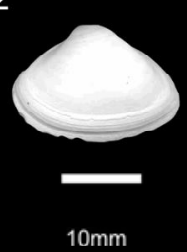

16

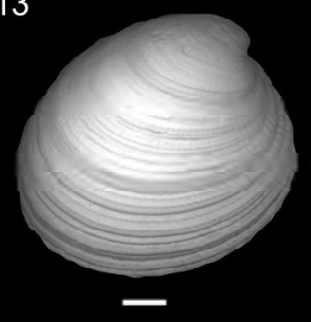

$10 \mathrm{~mm}$
14

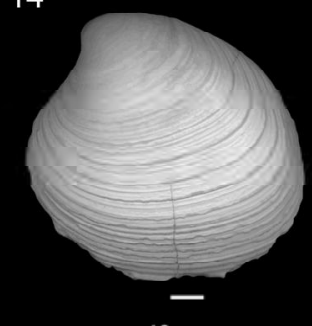

$10 \mathrm{~mm}$

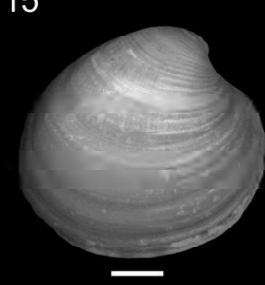

$10 \mathrm{~mm}$

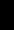

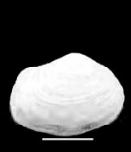

$10 \mathrm{~mm}$

17

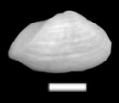

$5 \mathrm{~mm}$

Fig.9.20: Especies de bivalvos holocenos y actuales de la región norte del golfo San Matías. Dimensiones en $\mathrm{mm}$.

1, Glycymeris (G.) longior (Sowerby) (CEGH-UNC: 25705, actual); 2, Mytilus edulis platensis d'Orbigny (CEGH-UNC: 25706, actual); 3, Brachidontes (B.) rodriguezii (d'Orbigny) (CEGH-UNC: 25707, actual); 4, Aulacomya atra (Molina) (CEGH-UNC: 25.708, actual); 5, Plicatula gibbosa Lamarck (CEGH-UNC: 25.710, actual); 6, Ostreola equestris (Say) (CEGH-UNC: 25.711, actual); 7, Ostrea puelchana d'Orbigny (CEGH-UNC: 25.712, Holoceno); 8, Aequipecten tehuelchus (d'Orbigny) (CEGH-UNC: 25.709, Holoceno); 9, Trachycardium muricatum (Linné) (CEGHUNC: 25.713, Holoceno); 10, Mesodesma mactroides (Reeve) (CEGH-UNC: 25.610, Holoceno); 11, Pitar (P.) rostratus (Philippi) (CEGH-UNC: 25.715 , actual);12, Mactra guidoi Signorelli \& Scarabino (CEGH-UNC:25.714, actual); 13, Ameghinomya antiqua (King \& Broderip, 1832) (CEGH-UNC: 25718, Holoceno); 14 , Retrotapes exalbidus (Dillwyn) (CEGH-UNC: 25.717, Holoceno); 15, Amiantis purpurata (Lamarck) (CEGH-UNC:25716, actual); 16, Thracia similis Couthos (CEGH-UNC: 25.720, actual); 17, Corbula (C.) Lyoni Pilsbry (CEGH-UNC: 25.719, actual). 


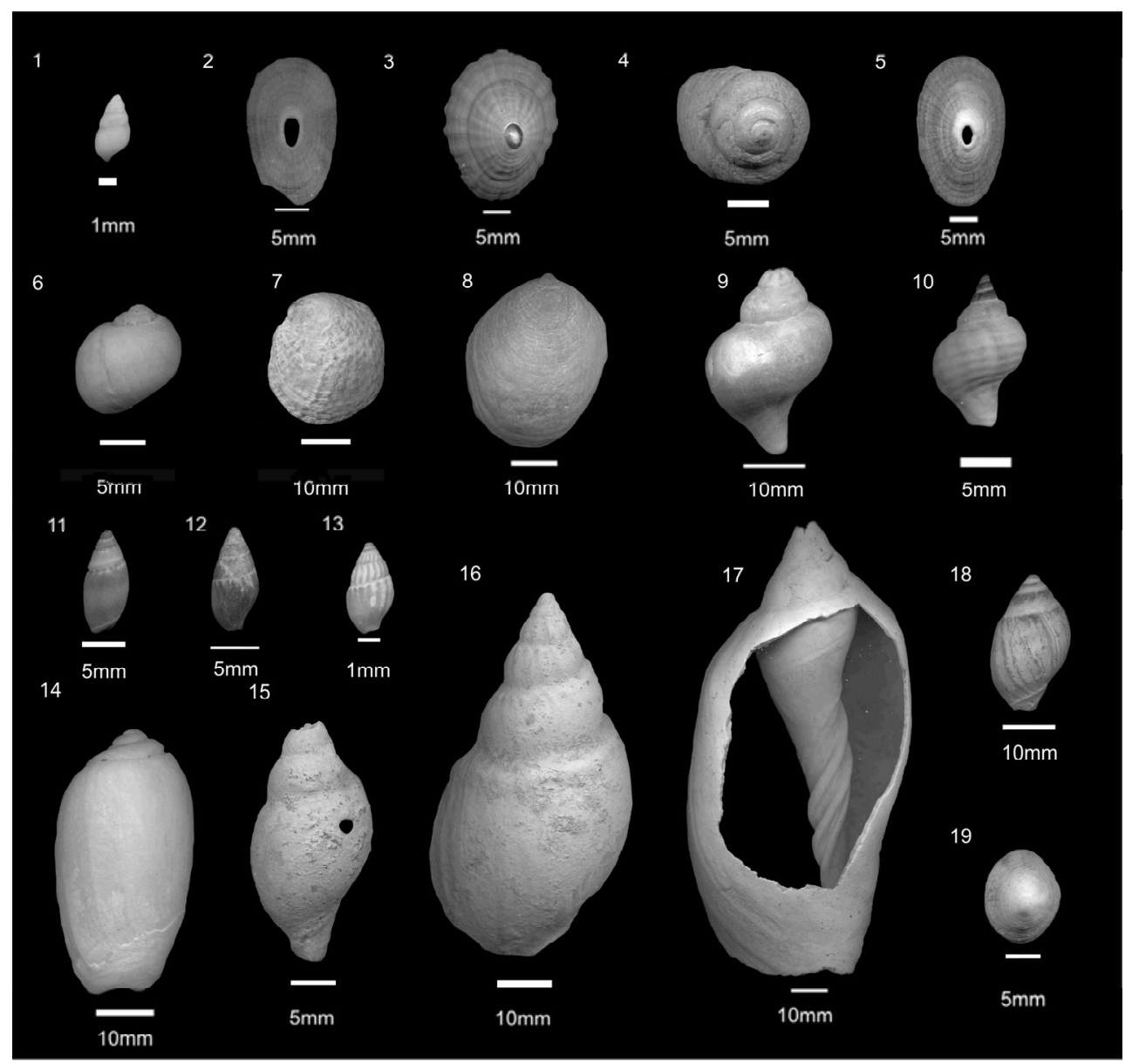

Fig. 9-21: Especies de gasterópodos holocenos y actuales de la región del norte del golfo San Matías

1, Heleobia australis (d'Orbigny) (CEGH-UNC: 25.723, actual); 2, Lucapinella henseli (Martens) (CEGH-UNC: 25689, actual); 3, Nacella ( $P$.) magallanica (Gmelin) (CEGHUNC: 25.688, Holoceno); 4, Tegula (A.) patagonica (d'Orbigny) (CEGH-UNC: 25.690, Holoceno);5, Fissurella radiosa radiosa Lesson (CEGH-UNC: 25.687, Holoceno); 6 , Notocochlis isabelleana (d'Orbigny) (CEGH-UNC: 25.694, actual); 7, Bostrycapulus odites (Collin) (CEGH-UNC:25.691, actual); 8, Crepidula dilatota Lamar'ck (CEGH-UMC: 25.693, actual) ; 9, Trophon patagonicus (d'Orbigny) (CEGH-UNC: 25.695, actual); 10 , Trophon geversianus (Pallas) (CEGH-UNC: 25.696); 11, Olivella (O.) tehuelcha (Dúclos) (CEGH-UNC: 25.698, actual); 12, Costoanachis sertulariarum (d'Orbigny) (CEGH-UNC: 25.702, actual); 13, Parvanachis isabellei (d'Orbigny) (CEGH-UNC: 25.701, actual); 14, Olivancillaria carcellesi Klappenbach (CEGH-UNC: 25.699, Holoceno); 15, Buccinanops uruguayensis (Pilsbry) ( CEGH-UNC: 25.724, actual); 16, Buccinanops cochlidium (Dillwyn) (CEGH-UNC: 25.622, Holoceno); 17, Odontocymbiola magellanica (Gmelin) (CEGH-UNC: 25.697, actual) ; 18, Buccinanops globulosus (Kiener) (CEGH-UNC: 25. 700, actual); 19, Siphonaria lessoni Blainville (CEGH-UNC: 25. 723, Holoceno). 


\subsubsection{Playas actuales del norte del golfo San Matías}

Las playas son muy extensas de anchos que superan los centenares de metros, compuestas de arena mediana a fina en sectores intermareales y en otros sectores casi exclusivamente gravosas compuestas por valvas de moluscos. En total se analizaron 6 sitios y se registró una fauna marina compuesta por 31 especies (16 bivalvos y 15 gasterópodos), entre los cuales se destacan: Brachidontes rodriguezii, Glycymeris longior y Amiantis purpurata (bivalvos) y Crepidula, Buccinanops globulosus, Bostrycapulus odites y Olivancillaria carcellesi (gasterópodos) (Fig. 9.22 y 9.23).

Entre las especies encontradas se destaca la presencia de Aulacomya atra, Retrotapes exalbidus, Ameghinomya antiqua (bivalvos) y Fisurella radiosa radiosa y Crepidula dilatata (gasterópodos) como fauna típica encontrada en las playas de Río Negro. 


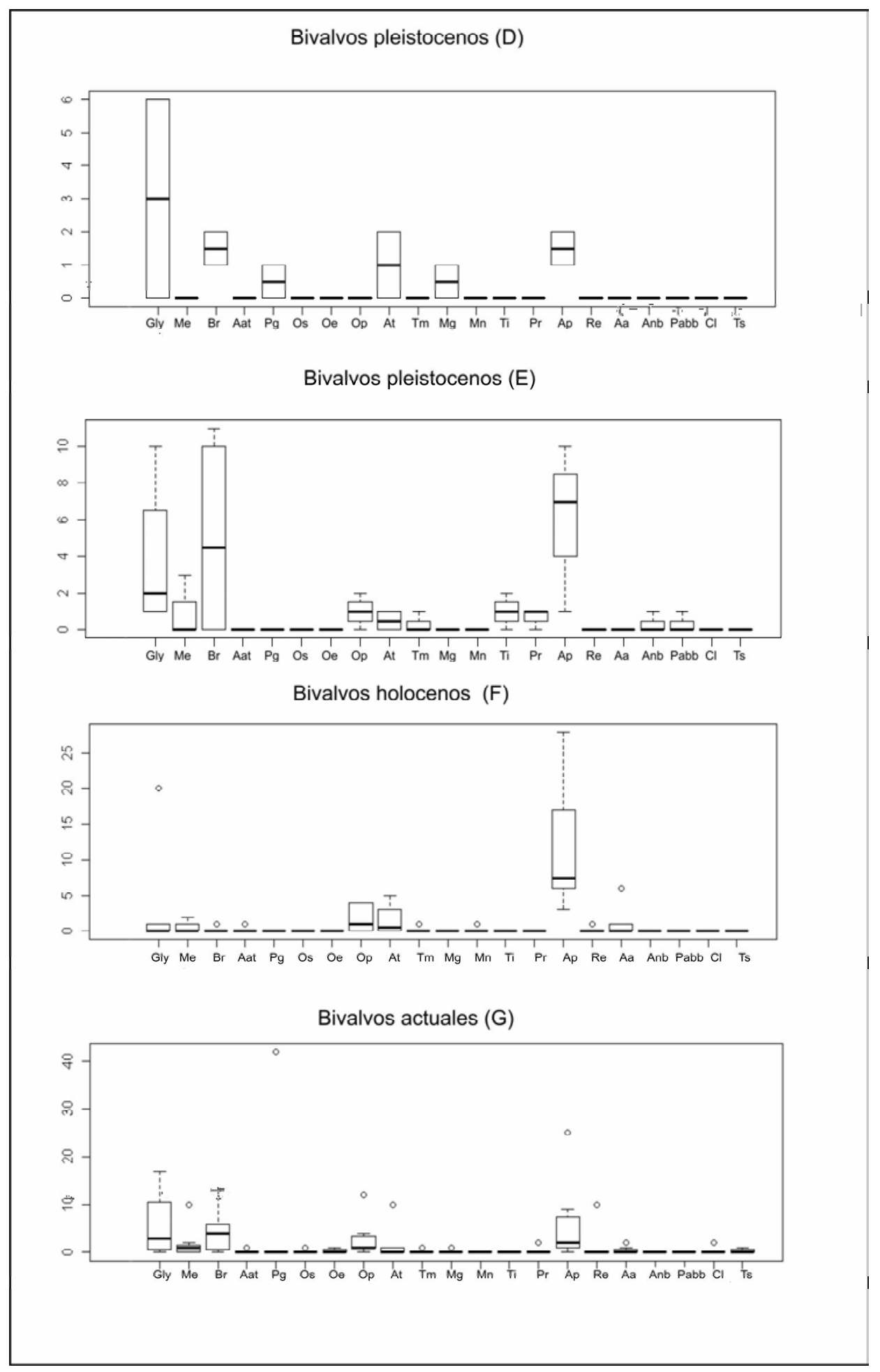

Fig. 9.22: Abundancias de bivalvos durante el Cuaternario en la región del norte del golfo San Matías. 


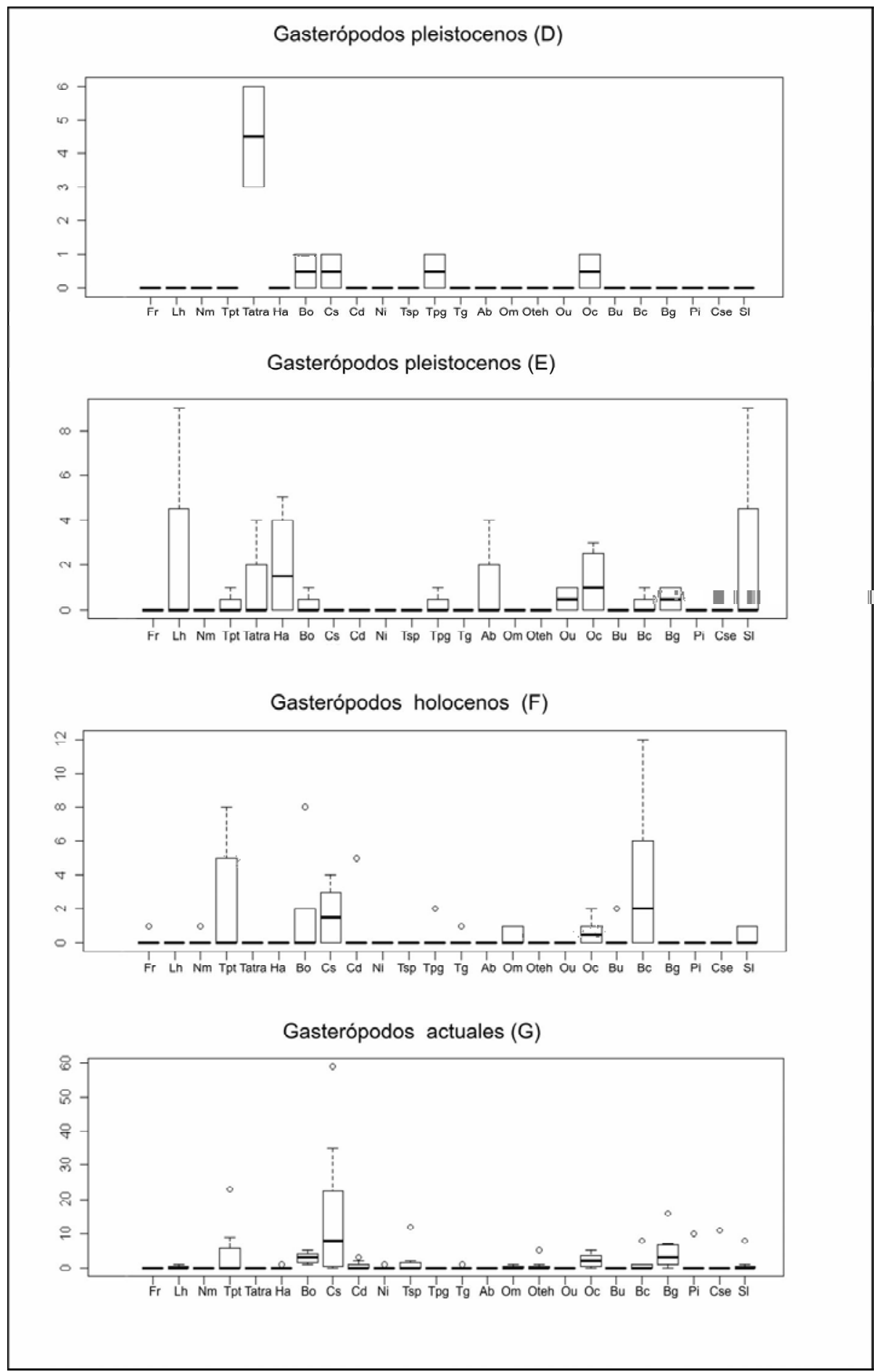

Fig. 9.23: Abundancias de gasterópodos durante el Cuaternario en la región norte del golfo San Matías. La sigla Tsp indica el género Trophon 


\subsection{Paleoecología}

Según el análisis paleoecológicos, la fauna de moluscos en el Integlacial MIS7 (D) se caracteriza por la abundancia de bivalvos eurihalinos en su mayoría infaunales y epifaunales, de sustratos arenosos con proporción de rocosos y mixtos y todos filtradores. En el Interglacial MIS 5e (E), los bivalvos en su mayoría son eurihalinos, aumentando en proporción los eurihalinos - polihalinos. En su mayoría son infaunales, de sustratos arenosos y apareciendo especies carnívoras. A partir del Interglacial MIS 1 (F) hasta la actualidad (G) permanecen casi constantes los factores ecológicos de las especies en cuanto a la salinidad, modo de vida, tipo de sustrato y tipo trófico (Fig. 9.24) (T. 9.5).

En el Interglacial MIS 7 (D) todos los gasterópodos son eurihalinos, epifaunales, en su mayoría de sustratos rocosos y arenosos, y carnívoros con un aumento en la proporción de especies filtradoras y herbívoras. A partir del Interglacial MIS 5e (E), la mayoría de los gasterópodos son eurihalinos con la aparición de especies oligohalinos - polihalinos - mesohalinos. Son todas las especies epifaunales, y aumentan las de sustratos rocosos, y las especies herbívoras. En el Interglacial MIS 1 (F), los gasterópodos son todos eurihalinos, epifaunales, con aumento de rocosos y carnívoros. En la actualidad (G), la mayoría de las especies son eurihalinas, con aumento en la de oligohalino - polihalino mesohalino y aparecen las especies infaunales. Hay un aumento de las especies de sustratos arenosos y carnívoras (Fig. 9.25) (T. 9.6). 


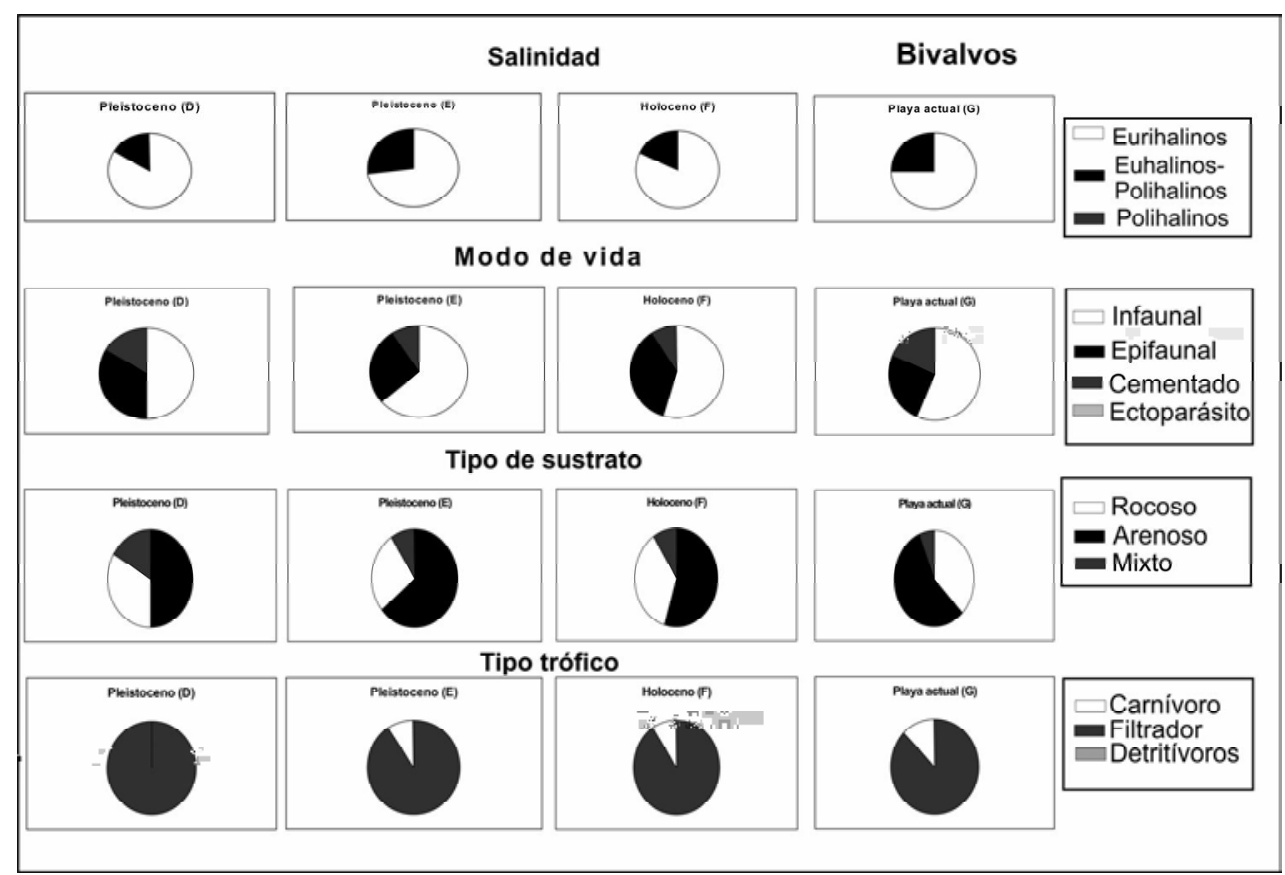

Fig. 9.24: Proporción de bivalvos según la salinidad, modo de vida, tipo de sustrato y tipo trófico.

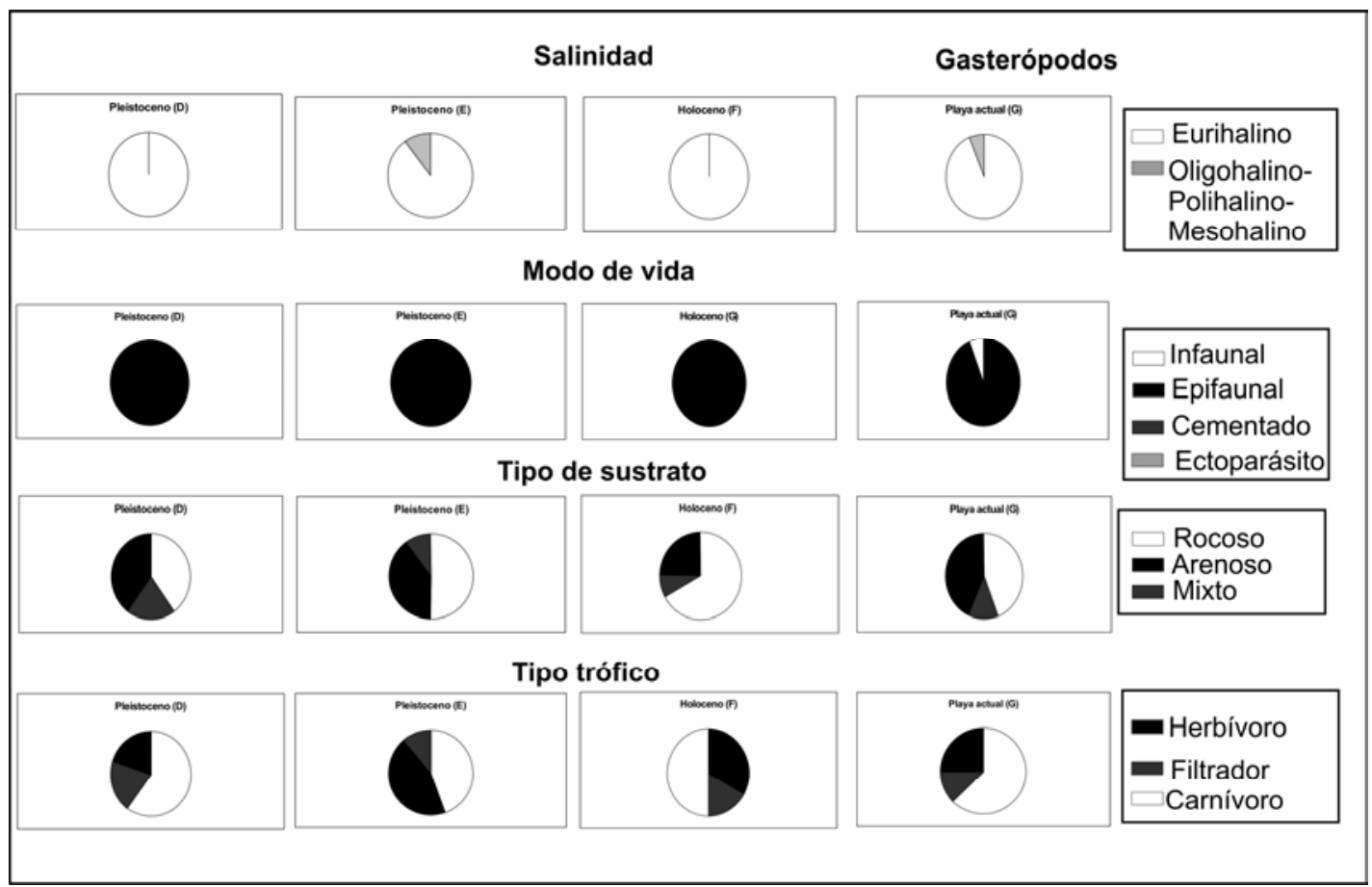

Fig. 9.25: Proporción de gasterópodos según la salinidad, modo de vida, tipo de sustrato y tipo trófico. 


\begin{tabular}{|c|c|c|c|c|c|c|}
\hline BIVALVOS & Salinidad & $\begin{array}{l}\text { Modo } \\
\text { de vida }\end{array}$ & $\begin{array}{c}\text { Profundid } \\
\text { ad }\end{array}$ & Sustrato & $\begin{array}{l}\text { Tipo } \\
\text { trófico }\end{array}$ & Área de distribución \\
\hline Glycymeris (G.) Iongior ( Sowerby,1832) & $\mathrm{E}$ & I & $10-75$ & $\mathrm{~S}$ & $\mathrm{~F}$ & $10^{\circ} \mathrm{S}-42^{\circ} \mathrm{S}$ \\
\hline Mytilus edulis platensis d'Orbigny, 1846 & $P-E$ & Ep & $0-50$ & $\mathrm{R}$ & $\mathrm{F}$ & $68^{\circ} \mathrm{N}-55.5^{\circ} \mathrm{S}$ \\
\hline Brachidontes $(B)$ rodriguezii ( d'Orbigny, 1846) & $E$ & Ep & $0-25$ & $\mathrm{R}$ & $\mathrm{F}$ & $34^{\circ} \mathrm{S}-42^{\circ} \mathrm{S}$ \\
\hline Aulacomya atra (Molina,1782) & $\mathrm{E}$ & Ep & $0-30$ & $\mathrm{R}$ & $\mathrm{F}$ & $34^{\circ} \mathrm{S}-55.5^{\circ} \mathrm{S}$ \\
\hline Aequipecten tehuelchus (d'Orbigny, 1842) & $E$ & Ep & $10-120$ & $\mathrm{M}$ & $\mathrm{F}$ & $21^{\circ} \mathrm{S}-53^{\circ} \mathrm{S}$ \\
\hline Plicatula gibbosa Lamarck, 1801 & $E$ & $\mathrm{Ce}$ & $0-120$ & $\mathrm{R}$ & $\mathrm{F}$ & $35.3^{\circ} \mathrm{N}-34^{\circ} \mathrm{S}^{*}$ \\
\hline Ostreola equestris (Say, 1834) & $P-E$ & $\mathrm{Ce}$ & $0-80$ & $\mathrm{R}$ & C & $37^{\circ} \mathrm{N}-42^{\circ} \mathrm{S}$ \\
\hline Ostrea puelchana d'Orbigny 1841 & $P-E$ & $\mathrm{Ce}$ & $0-70$ & $\mathrm{R}$ & $\mathrm{C}$ & $22^{\circ} \mathrm{S}-42^{\circ} \mathrm{S}$ \\
\hline Trachycardium muricatum (Linné, 1758) & $E$ & I & $0-11$ & $\mathrm{~S}$ & $\mathrm{~F}$ & $35^{\circ} \mathrm{N}-42^{\circ} \mathrm{S}$ \\
\hline Mactra guidoi Signorelli \&Scarabino & $P-E$ & $\mathrm{l}$ & $0-25$ & $\mathrm{~S}$ & $\mathrm{~F}$ & $34^{\circ} \mathrm{S}-42^{\circ} \mathrm{S}$ \\
\hline Mesodesma mactroides (Reeve, 1854) & $E$ & $\mathrm{I}$ & $0-20$ & S & $\mathrm{F}$ & $23^{\circ} \mathrm{S}-41^{\circ} \mathrm{S}$ \\
\hline Tivela isabelleana ( d'Orbigny, 1846) & $E$ & I & $0-55$ & $\mathrm{~S}$ & $\mathrm{~F}$ & $21^{\circ} \mathrm{S}-42^{\circ} \mathrm{S}$ \\
\hline Anomalocardia brasiliana (Gmelin, 1791) & $\mathrm{P}-\mathrm{E}$ & l & $0.3-5$ & $\mathrm{~S}$ & $\mathrm{~F}$ & $18^{\circ} \mathrm{N}-39^{\circ} \mathrm{S}^{*}$ \\
\hline Pitar (P.) rostratus (Philippi, 1844) & $E$ & $\mathrm{I}$ & $10-100$ & $\mathrm{~S}$ & $\mathrm{~F}$ & $22^{\circ} \mathrm{S}-38.7^{\circ} \mathrm{S}^{*}$ \\
\hline Amiantis purpurata ( Lamarck, 1856) & $\mathrm{E}$ & $\mathrm{I}$ & $0-20$ & $\mathrm{~S}$ & $\mathrm{~F}$ & $19^{\circ} \mathrm{S}-43^{\circ} \mathrm{S}$ \\
\hline Retrotapes exalbidus (Dillwyn,1817) & $\bar{E}$ & $\mathrm{l}$ & $50-70$ & $\mathrm{~S}$ & $\mathrm{~F}$ & $34^{\circ} \mathrm{S}-55.5^{\circ} \mathrm{S}$ \\
\hline Ameghinomya antiqua (King,1832) & $E$ & I & $5-50$ & $\mathrm{~S}$ & $\mathrm{~F}$ & $34^{\circ} \mathrm{S}-54^{\circ} \mathrm{S}$ \\
\hline Panopea abbreviata Valenciennes, 1839 & $E$ & I & $25-75$ & S & $\mathrm{F}$ & $23^{\circ} \mathrm{S}-48^{\circ} \mathrm{S}$ \\
\hline Corbula (C.) lyoni Pilsbry, 1897 & $E$ & I & $11-67$ & $\mathrm{~S}$ & $\mathrm{~F}$ & $19^{\circ} \mathrm{S}-43^{\circ} \mathrm{S}$ \\
\hline Thracia similis Couthouy, 1839 & $\mathrm{E}$ & l & $50-86$ & $\mathrm{~S}$ & $\mathrm{~F}$ & $22^{\circ} \mathrm{S}-42.58^{\circ} \mathrm{S}$ \\
\hline
\end{tabular}

T. 9.5:Requerimientos ecológicos y distribución de bivalvos: $\mathrm{Ep}=$ epifaunal, $\mathrm{I}=$ infaunal, $\mathrm{C}=$ =ementado; $\mathrm{E}=\mathrm{ectoparásito;} \mathrm{R}=$ rocoso, $\mathrm{S}=$ arenoso, $\mathrm{M}=$ mixto, $\mathrm{Ce}=$ cementado; $\mathrm{C}=$ carnívoros, $\mathrm{D}=$ detritívoros, He=herbívoros, $\mathrm{F}=$ filtradores; $\mathrm{O}=$ oligohalinos $(3-8 \%$ \% $), \mathrm{M}=$ mesohalinos $(8-18 \%$ \% $)$ P= polihalinos $(18-30 \%$ \% ; $\mathrm{E}=$ eurihalinos (> 30-35\%o). ${ }^{\star}$ Límite sur de la especie diferente a lo encontrado. 


\begin{tabular}{|c|c|c|c|c|c|c|}
\hline GASTERÓPODOS & Salinidad & $\begin{array}{l}\text { Modo } \\
\text { de vida }\end{array}$ & Profundidad & Sustrato & $\begin{array}{l}\text { Tipo } \\
\text { trófico }\end{array}$ & Área de distribución \\
\hline Nacella (P.) magallanica (Gmelin,1791) & $E$ & Ep & $0-200$ & $\mathrm{R}$ & $\mathrm{He}$ & $38.5^{\circ} \mathrm{S}^{*}-55.5^{\circ} \mathrm{S}$ \\
\hline Fissurella radiosa radiosa Lesson, 1831 & $E$ & Ep & 0 & $\mathrm{R}$ & $\mathrm{He}$ & $48^{\circ} \mathrm{S}-55^{\circ} \mathrm{S}$ \\
\hline Lucapinella henseli (Martens, 1900) & $E$ & Ep & $0-55$ & $\mathrm{R}$ & $\mathrm{He}$ & $23^{\circ} \mathrm{S}-53^{\circ} \mathrm{S}$ \\
\hline Tegula (A.) patagonica (d'Orbigny, 1835) & $\mathrm{E}$ & Ep & $0-57$ & $\mathrm{R}$ & $\mathrm{He}$ & $23^{\circ} \mathrm{S}-54^{\circ} \mathrm{S}$ \\
\hline Tegula atra Lesson 1830 & $\mathrm{E}$ & Ep & $0-9$ & $\mathrm{R}$ & $\mathrm{He}$ & $38^{\circ} S-55^{\circ} S^{*}$ \\
\hline Bostrycapulus odites (Collin, 2005) & $E$ & Ep & $0-46$ & $\mathrm{R}$ & $F$ & $25^{\circ} \mathrm{S}-45.8^{\circ} \mathrm{S}$ \\
\hline Crepidula dilatata Lamarck, 1822 & $E$ & Ep & $0-66$ & $\mathrm{R}$ & $\mathrm{F}$ & $35^{\circ} \mathrm{S}-55.8^{\circ} \mathrm{S}$ \\
\hline Notocochlis isabelleana (d'Orbigny, 1840) & $\mathrm{E}$ & 1 & $0-113$ & $\mathrm{~S}$ & $\mathrm{C}$ & $22.4^{\circ} \mathrm{S}-42.58^{\circ} \mathrm{S}$ \\
\hline Heleobia australis ( d'Orbigny, 1835) & $\mathrm{O}, \mathrm{P}, \mathrm{M}$ & Ep & $0-60$ & $\mathrm{M}$ & $\mathrm{He}$ & $24^{\circ} \mathrm{S}-41^{\circ} \mathrm{S}$ \\
\hline Trophon patagonicus (d'Orbigny, 1839) & $\mathrm{E}$ & Ep & $0-55$ & $\mathrm{R}$ & $\mathrm{C}$ & $32 \div S-40 \div S$ \\
\hline Trophon geversianus (Pallas, 1774) & $\mathrm{E}$ & Ep & $0-586$ & $\mathrm{R}$ & $\mathrm{C}$ & $36.42^{\circ} \mathrm{S}-54.98^{\circ} \mathrm{S}$ \\
\hline Adelomelon (P.) brasiliana (Lamarck, 1811) & $E$ & Ep & $8-70$ & $\mathrm{~S}$ & C & $23^{\circ} \mathrm{S}-52^{\circ} \mathrm{S}$ \\
\hline Odontocymbiola magellanica (Gmelin, 1791) & $\mathrm{E}$ & Ep & $10-200$ & $\mathrm{M}$ & $\mathrm{C}$ & $35^{\circ} \mathrm{S}-55.2^{\circ} \mathrm{S}$ \\
\hline Olivella (O.) tehuelcha ( Dúclos, 1835) & $E$ & Ep & $15-57$ & $\mathrm{~S}$ & $\mathrm{C}$ & $23.69^{\circ} \mathrm{S}-43^{\circ} \mathrm{S}$ \\
\hline Olivancillaria urceus ( Röding, 1798) & $\mathrm{E}$ & Ep & $5-50$ & $\mathrm{~S}$ & $\mathrm{C}$ & $19^{\circ} \mathrm{S}-42^{\circ} \mathrm{S}$ \\
\hline Olivancillaria carcellesi Klappenbach, 1965 & $\mathrm{E}$ & Ep & $0-22$ & S & C & $23^{\circ} \mathrm{S}-42.5^{\circ} \mathrm{S}$ \\
\hline Buccinanops uruguayensis (Pilsbry,1897) & $E$ & Ep & $15-45$ & S & $\mathrm{C}$ & $24^{\circ} \mathrm{S}-42^{\circ} \mathrm{S}$ \\
\hline Buccinanops cochlidium (Dilwyn, 1817) & $\mathrm{E}$ & Ep & $5-66$ & $\mathrm{~S}$ & $\mathrm{C}$ & $23^{\circ} \mathrm{S}-42.58^{\circ} \mathrm{S}$ \\
\hline Buccinanops globulosus (Kiener, 1834) & $\mathrm{E}$ & Ep & $0-6$ & $\mathrm{~S}$ & $\mathrm{C}$ & $35^{\circ} \mathrm{S}-46^{\circ} \mathrm{S}$ \\
\hline Parvanachis isabellei (d'Orbigny, 1839) & $\mathrm{E}$ & Ep & $10-65$ & $\mathrm{~S}$ & $\mathrm{C}$ & $30^{\circ} \mathrm{S}-54^{\circ} \mathrm{S}$ \\
\hline Costoanachis sertulariarum (d'Orbigny,1839) & $\mathrm{E}$ & Ec & $0-20$ & S & $\mathrm{C}$ & $35^{\circ} \mathrm{N}-54^{\circ} \mathrm{S}$ \\
\hline Siphonaria lessoni (Blainville, 1824) & $\mathrm{E}$ & Ep & 0 & $\mathrm{R}$ & $\mathrm{He}$ & $32^{\circ} \mathrm{S}-55.22^{\circ} \mathrm{S}$ \\
\hline
\end{tabular}

T. 9.6:Requerimientos ecológicos y distribución de gasterópodos: $\mathrm{Ep}=$ epifaunal, $\mathrm{I}=$ infaunal, $\mathrm{E}=\mathrm{ectoparásito} ; \mathrm{R}=\mathrm{rocoso}, \mathrm{S}=\mathrm{arenoso}, \mathrm{M}=$ mixto, Ce=cementado;

$\mathrm{C}=$ carnívoros, $\mathrm{D}=$ detritívoros, $\mathrm{He}=$ herbívoros, $\mathrm{F}=$ filtradores; $\mathrm{O}=$ oligohalinos $(3-8 \%$ \%), $\mathrm{M}=$ mesohalinos $(8-18 \%$ \%); $\mathrm{P}=$ polihailinos $(18-30 \%$ \%); $\mathrm{E}=$ eurihalinos (> 30-

$35 \%$ ).*Rango de distribución en el océano Pacífico. 


\subsection{Temperaturas}

Según la cantidad de especies de aguas cálidasy no cálidas representadas en cada uno de los Interglaciales, el mayor porcentaje de bivalvos cálidas se encuentran en el Interglacial MIS 5e (E) con un $27 \%$ y en las playas actuales (G) con un 31\%. (Fig. 9.26).Con respecto a los gasterópodos, el mayor porcentaje de especies de aguas cálidasse encuentran en el Interglacial MIS 7 (D) con un $80 \%$ y en el Interglacial MIS 5e (E) con un 60\% disminuyendo las especies de aguas cálidasen un $44 \%$ en la actualidad (G) (Fig. 9.27).

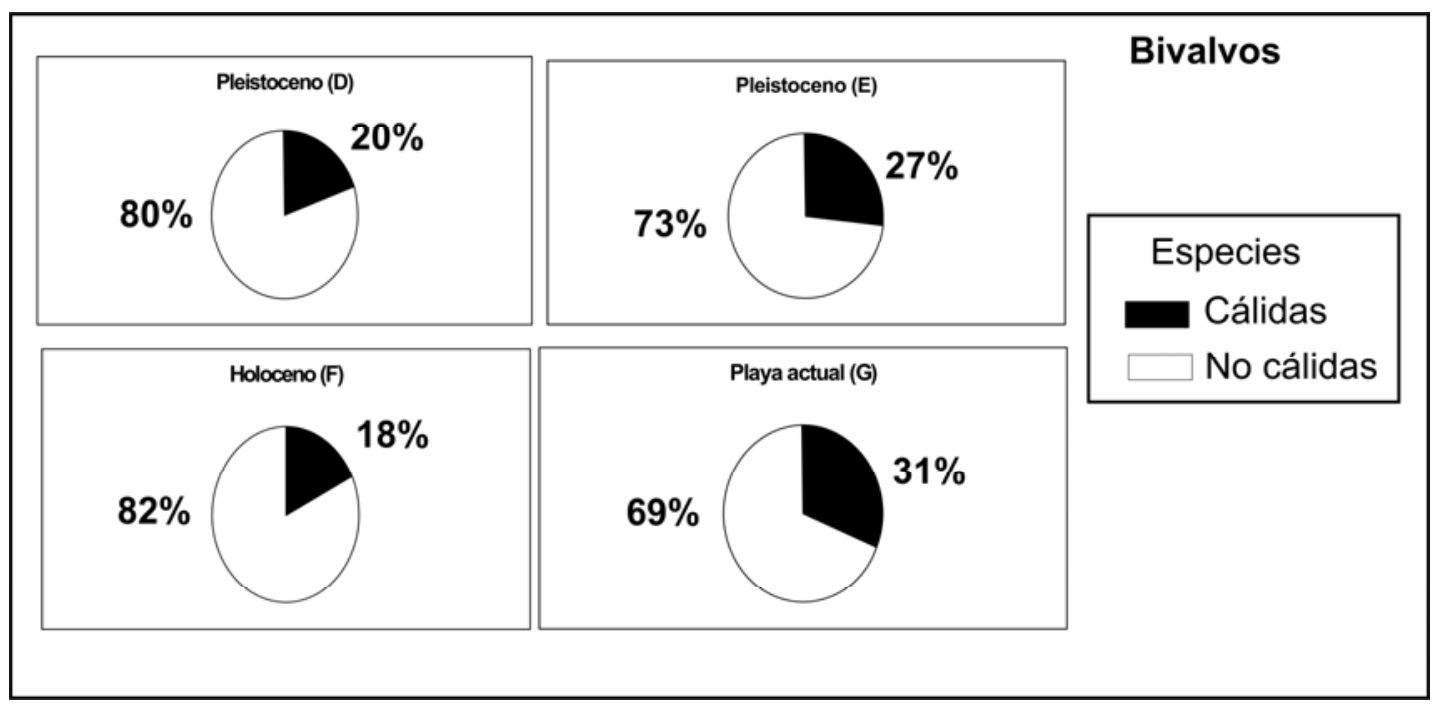

Fig. 9.26: Proporción de especies de bivalvos de aguas cálidas y no cálidas durante el Cuaternario. 


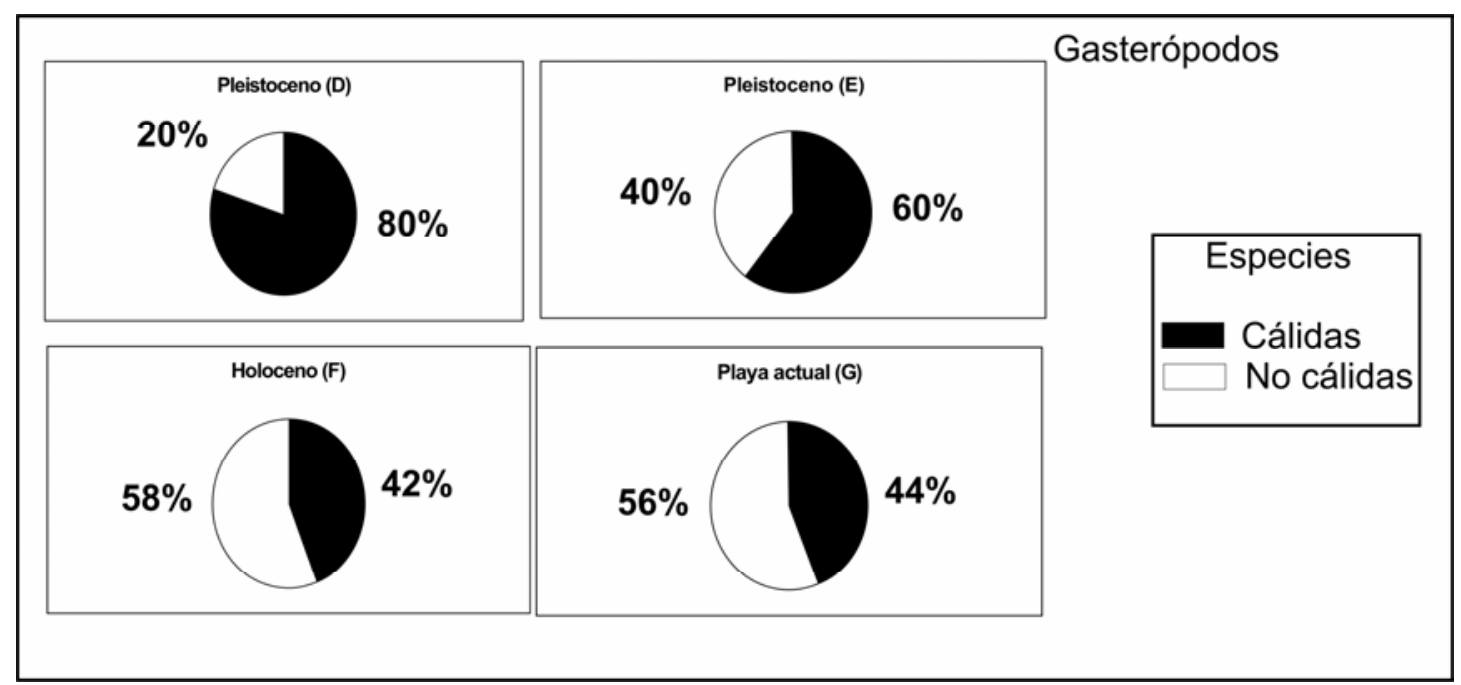

Fig. 9.27: Proporción de especies de gasteropodos de aguas cálidas y no cálidas durante el Cuaternario.

\subsection{Asociaciones faunística (MIS 7 y MIS 5e)}

Aplicando el método descriptivo estadístico de Bray - Curtis, dichos interglaciales se componen por dos asociaciones faunísticas distintas: A) asociación faunística pertenecientes al Interglacial MIS 5e. A su vez el grupo A se subdivide en dos subgrupos: A1) asociación faunística que corresponden a los sitios E20 y E22. A2) asociación faunística que corresponde a los sitios E21 y E23. B) asociación faunística perteneciente al Interglacial MIS 7 (Fig. 9.28). 


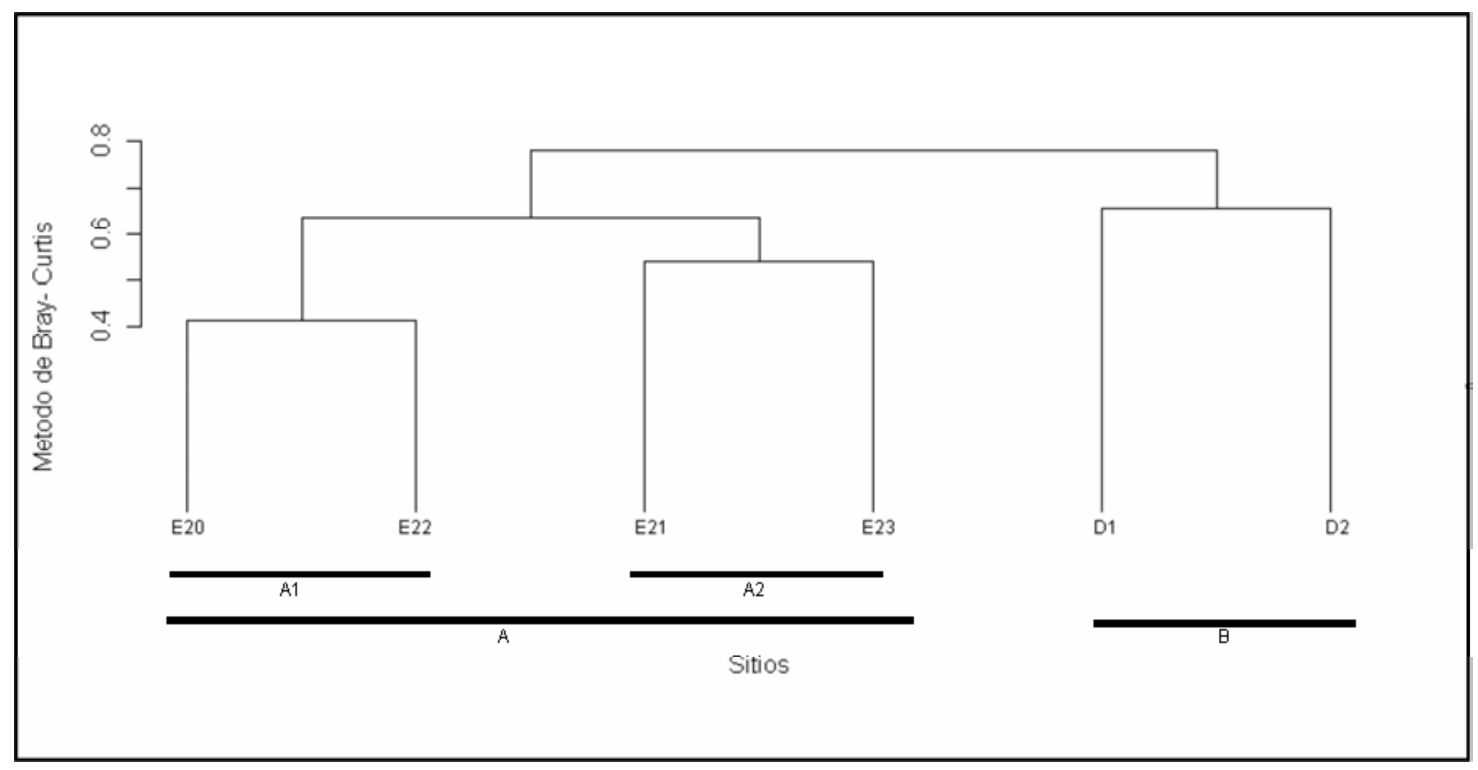

Fig. 9.28: Dendrograma de los sitios analizados basados en el índice de Bray- Curtis.

Consecuentemente, aplicando el método descriptivo de Análisis de Correspondencia (AC) se distinguen 3 asociaciones faunísticas diferentes para esta cuarta región: A) asociación faunística correspondiente a depósitos de paleoplayas del Interglacial MIS 7 (D1 y D2) que se caracteriza por la abundancia de Tegula atra (gasterópodo). B) asociación faunística perteneciente al Interglacial MIS 5e (E21 y E23) correspondiente a cordones litorales de arena y gravas dispersas, caracterizados por la presencia de Panopea abbreviata, Trachicardium muricatum, Mytilus edulis platensis (bivalvos) y Siphonaria lessoni, Lucapinella henseli y Tegula patagonica (gasterópodos). C) asociación faunística correspondiente a depósitos de arena y grava que pertenecen al Interglacial MIS 5e (E20 y E22) que se caracteriza por la presencia de Glycymeris longior (bivalvo) y Bostrycapulus odites (gasterópodos) (Fig. 9.29 y Fig. 9.30). 


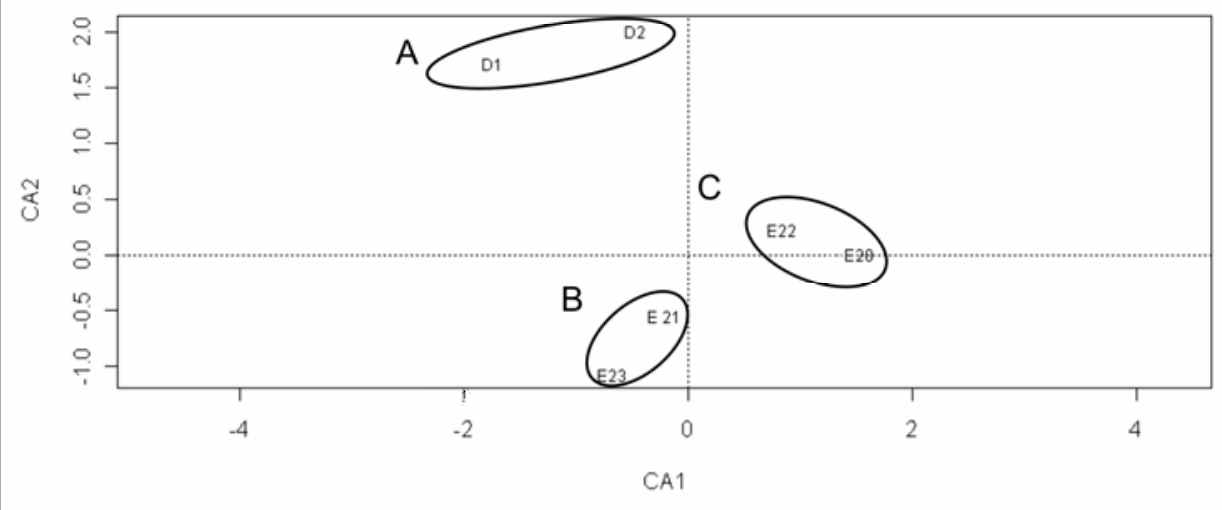

Fig. 9.29: Análisis de correspondencia (AC) basados en la abundancia de las especies, todos los sitios de los Interglaciales MIS 7 y MIS 5e confirman tres grupos A-C.

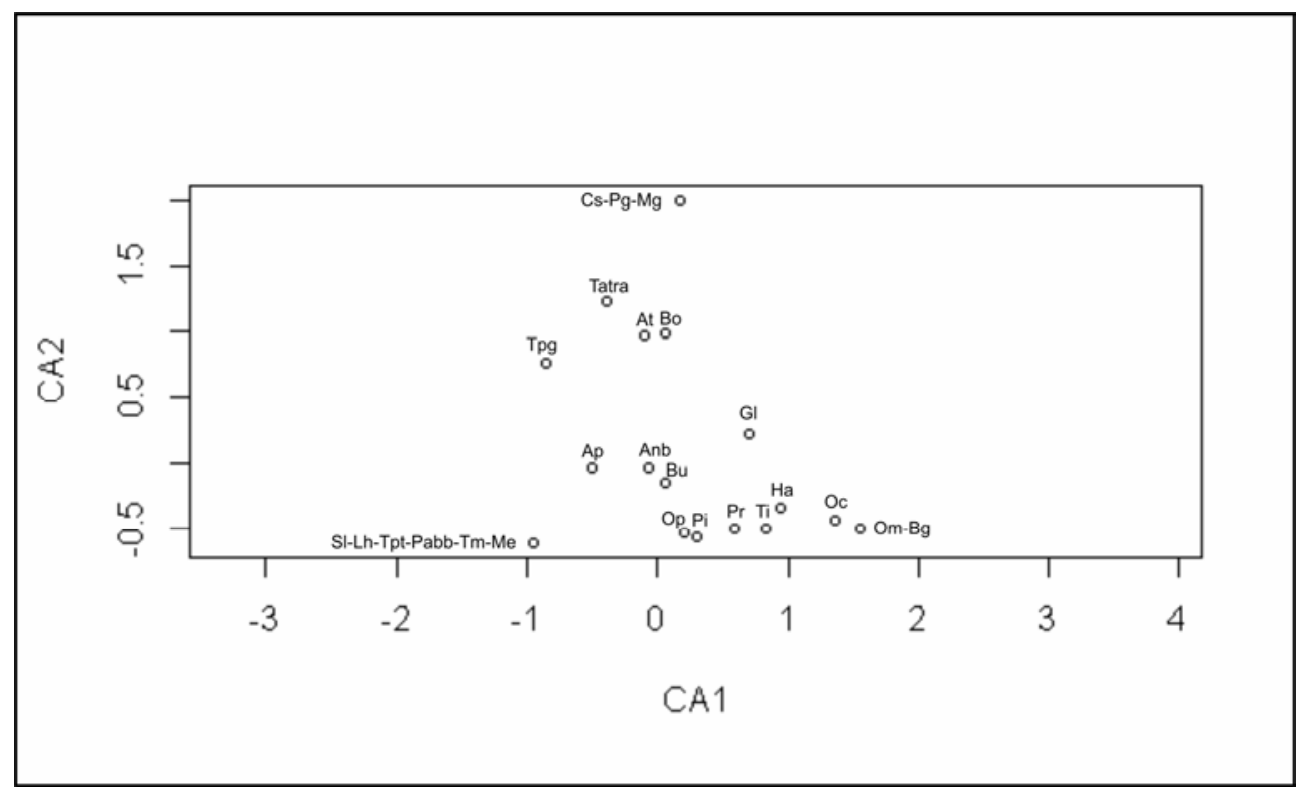

Fig. 9.30: Especies de bivalvos y gasterópodos asociados a los distintos sitios muestreados. 


\subsection{Asociaciones faunísticas totales}

Ampliando el análisis para todos los interglaciales los involucrados anteriormente (MIS 7 y MIS 5e), el Interglacial MIS 1 y las del ambiente de playas actuales, siguiendo el método descriptivo estadístico de Bray - Curtis, todos los interglaciales de la región del norte del golfo San Matías en realidad se componen por 3 asociaciones distintas quedando aislado el sitio F24: A) asociación faunística (D1 y E22) con presencia de dos bivalvos Amiantis purpurata y Aequipecten tehuelchus. B) asociación faunística con presencia abundante del género Crepidula, entre ellos los sitios G20 y G21 son lo más similares entre sí, tienen en común la abundancia de Brachidontes rodriguezii (bivalvo). En esta asociación todos los sitios pertenecen a playas actuales. C) Este grupo se divide a su vez en dos subgrupos. C1) asociación faunística perteneciente en su mayoría al Interglacial MIS 1 con excepción de dos sitios de playas actuales G19 y G22. Los sitios F27 y G19 son lo más similares entre sí (índice de Bray Curtis aproximadamente de 0.40), ambos se ubican en cercanías de San Antonio Oeste, y se destacan por la abundancia de Amiantis purpurata, Aequipecten tehuelchus (bivalvos) y Buccinanops cochlidium (gasterópodo). Los sitios F26 y G22 son similares entre sí (índice de Bray Curtis aproximadamente de 0.40), y que coinciden en que se ubican en La Conchilla, cercanos a punta Villarino y que abundan Amiantis purpurata (bivalvo) y Crepidula (gasterópodo). C2) asociación faunística perteneciente en su mayoría a los interglaciales MIS 7 y MIS 5e que se caracterizan por la abundancia de Glycymeris longior, Brachidontes rodriguezii (bivalvos) y Buccinanops globulosus (gasterópodo). Los sitios actuales G23 y G24 tienen un alto índice de diversidad y mayor número de especies y con abundancias en especies similares a los sitios del interglacial MIS 5e (E20, E21 y E23) y del Interglacial MIS 7 (D2). Entre los más abundantes figuran: Glycymeris longior, Brachidontes rodriguezii (bivalvos) y Buccinanops globulosus (gasterópodo) (Fig. 9.31). 


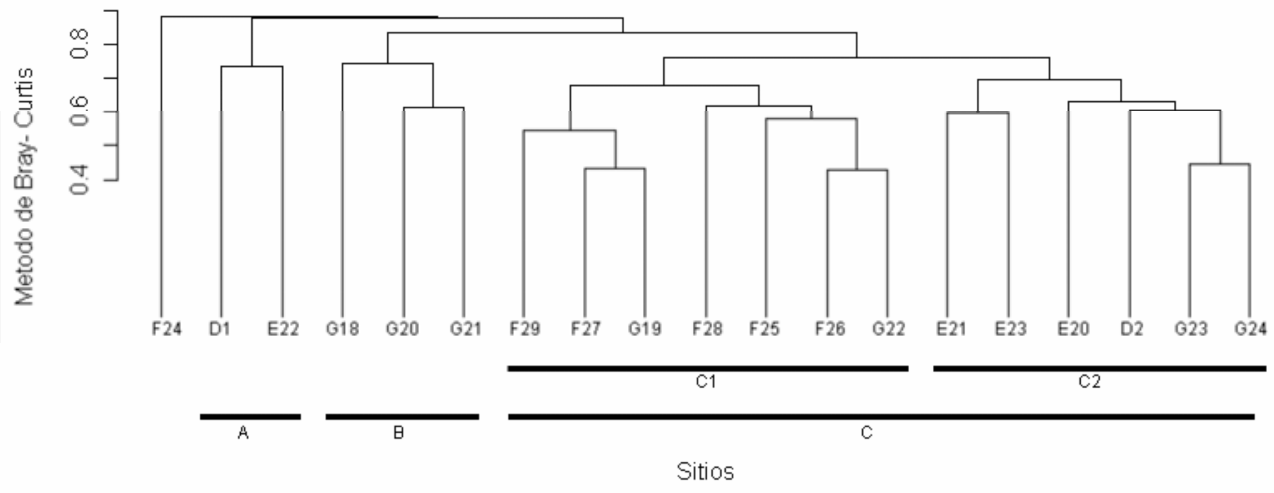

Fig. 9.31: Dendrograma de los sitios analizados basados en el índice de Bray- Curtis.

Consecuentemente, ampliando también el análisis estadístico a todos los interglaciales descriptos para esta cuarta región y aplicando el método descriptivo de Análisis de Correspondencia (AC), se distinguen 2 asociaciones faunísticas diferentes en todos los sitios analizados, con excepción de 4 de ellos (F24, G18, G21 y G22): A) asociación faunística que corresponde en su mayoría al Interglacial Mis 7 (D1 - D2) y al Interglacial MIS 1 (a excepción de F24), teniendo en común al bivalvo Amiantis purpurata como la especie más abundante. B) asociación faunística que corresponde al Interglacial MIS 5e (E21 y E23) y playa actual (G23 y G24), teniendo en común la abundancia de 3 bivalvos: Brachidontes rodriguezii, Glycymeris longior y Amiantis purpurata en menor proporción. Del análisis del gráfico respectivo, tanto el grupo A como el grupo B se encuentran cercanos lo cual significaría que las especies bivalvos y gasterópodas intervinientes en ambos grupos son aproximadamente las mismas, poseyendo además una abundancia relativa similar. Cabe destacarse la presencia abundante de Amiantis purpurata (bivalvo) en todos los sitios, a excepción del sitio G18 (Playa El Cóndor, al sur de la desembocadura del Río Negro).

Los sitios actuales G18, G21 y G22, según el método de Bray - Curtis pertenecen al mismo grupo (B) donde abundan el género Crepidula Sin embargo a diferencias entre ellos. El 
Sitio G18 se caracteriza por la presencia y abundancia de Plicatula gibbosa y Corbula lyoni (bivalvos) y pertenece a la playa del balneario del Cóndor, cercano al río Negro. Tanto el Sitio G20 como G21, indican diferencias entre la fauna marina con la presencia en el Sitio G20 de dos micromoluscos: Costoanachis sertularium y Parvanachis isabellei (gasterópodos) y en el Sitio G21 de Ostreola equestris y Mytilus edulis platensis (bivalvos) y Bostrycapulus odites, Tegula patagonica (gasterópodos) (Fig. 9.32 y Fig. 9.33).

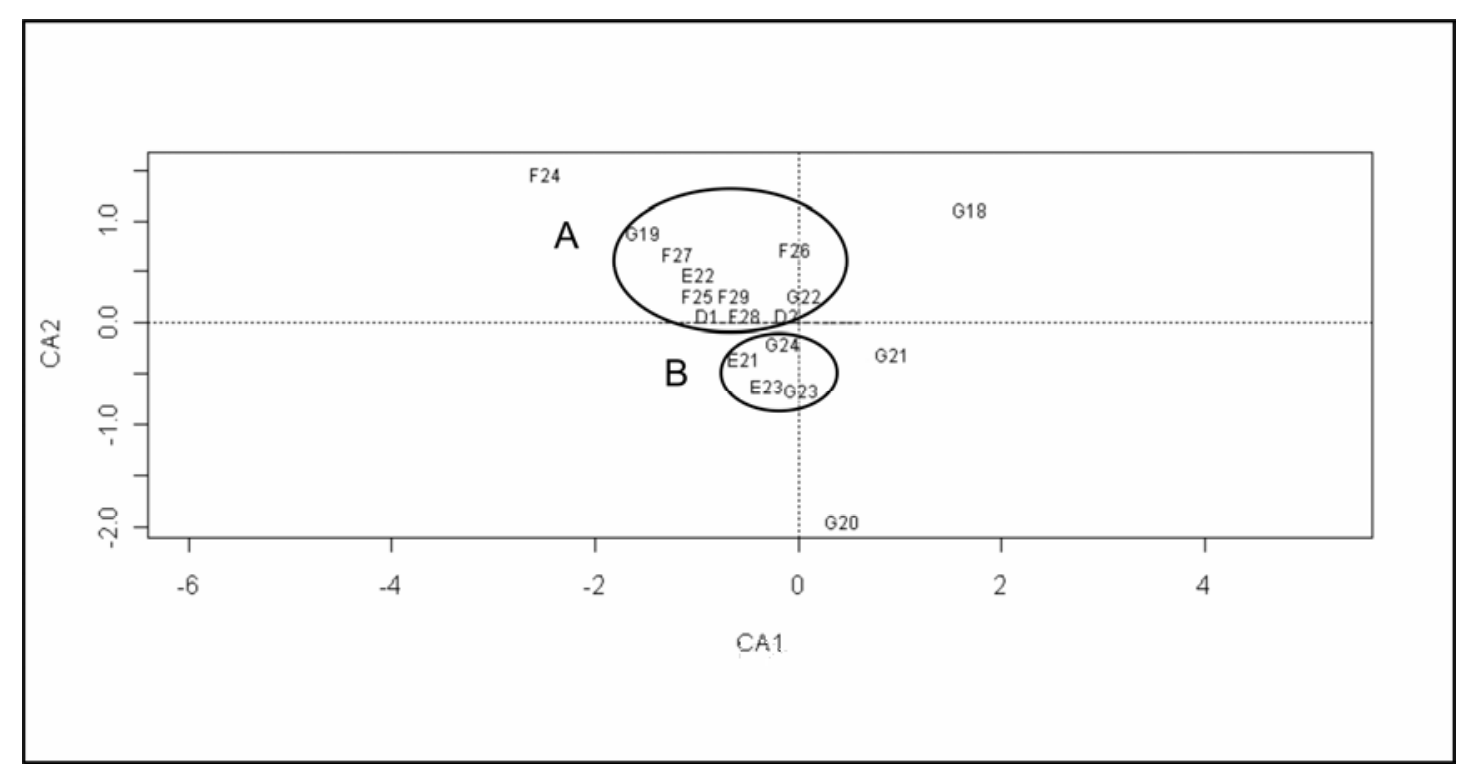

Fig. 9.32: Análisis de correspondencia (AC) basados en la abundancia de las especies, todos los sitios confirman dos grupos A y B a excepción de F24, G18, G20 y G21. 


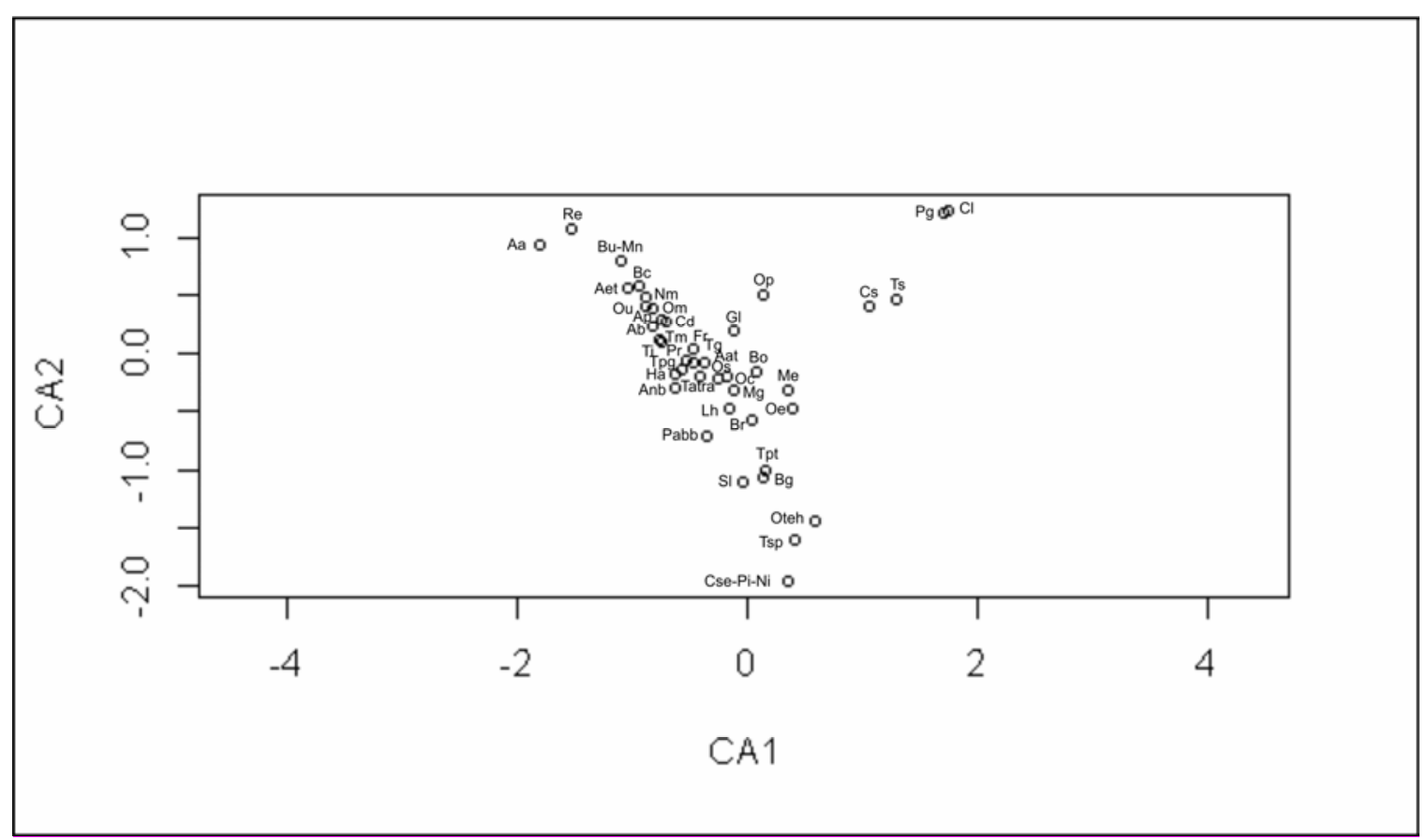

Fig. 9.33: Especies de bivalvos y gasterópodos asociados a los distintos sitios muestreados.

\subsection{Conclusiones}

La región norte del golfo San Matías se extiende desde el balneario El Cóndor (margen sur del río Negro) hasta el sur del Balneario Las Grutas (Norte de Provincia de Río Negro). En ella se describe la presencia de los interglaciales MIS 7, MIS 5e y MIS 1, a través de 19 sitios analizados ( 6 pleistocenos, 6 holocenos y 7 playas actuales) registrándose un total de 42 especies ( 20 bivalvos y 22 gasterópodos).

Los sitios más diversos en su mayoría son los actuales con excepción de dos sitios (F23 y F28) y los índices más bajos corresponden a dos sitios del Interglacial MIS 1 (F24 y F26).

Según la temperatura, las especies de aguas cálidasde bivalvos están representados en mayor cantidad en el Interglacial MIS 5e y en la actualidad. Mientras que las especies de gasteropodos de aguas cálidas se encuentran con mayor frecuencia en el Interglacial MIS 7 y MIS 5e. 
En el Interglacial MIS 7 todos los sitios analizados corresponden a paleoplayas representadas actualmente como plataformas costeras en el sector intermareal registrándose un total de 11 especies. Entre la fauna más abundante figuran: Glycymeris longior y Amiantis purpurata (bivalvos) y Tegula atra (gasterópodo). Los bivalvos en su mayoría son eurihalinos, infaunales e epifaunales, pero todos filtradores. En tanto los gasterópodos son eurihalinos, epifaunales, y en su mayoría carnívoros con menor proporción de especies filtradoras y herbívoras. Tanto bivalvos como gasterópodos en su mayoría pertenecen a ambientes de sustrato arenoso, con menor proporción de especies de sustratos rocosos y mixtos.

En el Interglacial MIS 5e todos los sitios corresponden a cordones litorales como así también a paleoacantilados registrándose un total de 22 especies. Entre las especies más abundantes figuran: Amiantis purpurata, Glycymeris longior y Brachidontes rodriguezii bivalvos) y Heleobia australis, Olivancillaria carcellesi y Olivancillaria urceus (gasterópodos).

De acuerdo al análisis paleoecológico, las especies presentes en el Interglacial MIS 5e son similares en cuanto a su composición faunística a las del Interglacial MIS 7 habiendo diferencias en cuanto a la abundancia de organismos a favor del MIS 5e, tal como se analizó en el capítulo 9. Los bivalvos son, en su mayoría, eurihalinos apareciendo en menor proporción especies eurihalinas-polihialinas, infaunales, de sustrato arenoso, y filtradores apareciendo en menor proporción especies carnívoras. Entre los gasterópodos, la mayoría son eurihalinos con presencia de especies oligohalinos - polihalinos - mesohalinos. Son todas especies epifaunales, en su mayoría carnívoras de sustrato arenoso con aumento de especies de sustrato rocoso apareciendo también, aunque en menor proporción, especies herbívoras.

En el Interglacial MIS 5e, se destaca la presencia del bivalvo Anomalocardia brasiliana, una especie de estirpe cálida que en la actualidad se distribuye a latitudes más bajas, 
llegando hasta las costas de Brasil. Su aparición es una evidencia que el Interglacial MIS 5e fue un período más cálido respecto al actual.

Entre los moluscos marinos dominantes tanto en el Interglacial MIS 7 como en el Interglacial MIS 5e se halla Tegula atra, que en la actualidad se encuentra extinta en las costas patagónicas argentinas. Dada su mayor antigüedad en el Pacífico, la existencia de Tegula atra en la costa atlántica de Patagonia durante el Pleistoceno indica que pudo haber un pasaje en el extremo sur de América entre el Pacífico y el Atlántico y que algunos factores ambientales (temperatura superficial del agua, sedimento, salinidad, etc.) habrían sido aptos para el desarrollo larval de Tegula atra. Estos factores habrían cambiado a partir de la última glaciación (110 k - 18 k).

El Interglacial MIS 1 está caracterizado por la presencia de cordones litorales de facies arenosas y conglomerádicas. Se registraron 23 especies. Entre la fauna marina más abundante se destaca: Amiantis purpurata, Ostrea puelchana y Aequipecten tehuelchus (bivalvos), y Buccinanops cochlidium, Crepidula y Olivancillaria carcellesi (gasterópodos).

En este Interglacial MIS 1 los requerimientos ecológicos de las especies son similares a los del Interglacial MIS 5e. Sin embargo, en cuanto a los gasterópodos, los mismos son todos eurihalinos apareciendo en menor proporción especies de sustrato rocoso.

En el microacantilado del sitio F27 (Interglacial MIS 1), sito en el interior de la actual bahía de San Antonio y datado con una antigüedad de 3 k, se destaca la aparición de Mesodesma mactroides (bivalvo) como único ejemplar encontrado. Su aparición indica la existencia de playas de arena fina-mediana con influencia de oleaje y temperaturas templadas durante el Holoceno, debiendo destacarse que esta especie en la actualidad (Reciente) sólo ha sido descripta hasta el Sur de la Provincia de Buenos Aires. 
Las playas actuales en está región, son extensas y muchas veces superan en dimensión los centenares de metros. Existen desde el punto de vista granulométrico 2 tipos de playas: a) sector intermareal bajo de arena fina-mediana con sectores distales altos, gravosos de composición organógena. b) Sector intermareal bajo y distal alto de arena fina-mediana.

En este ambiente se registraron un total de 31 especies, entre las cuales se destacan: Brachidontes rodriguezii, Glycymeris longior y Amiantis purpurata (bivalvos) y Crepidula, Buccinanops globulosus, Bostrycapulus odites y Olivancillaria carcellesi (gasterópodos).

La presencia, además, de Aulacomya atra, Retrotapes exalbidus, Ameghinomya antiqua (bivalvos) y Fisurella radiosa radiosa y Crepidula dilatata (gasterópodos) son especies de fauna típica encontrada en las playas de la Provincia de Río Negro siendo que las mismas no han sido descriptas en la fauna marina actual del sur de la Provincia de Buenos Aires.

Los bivalvos permanecen casi en condiciones similares desde el Interglacial MIS 5e hasta la actualidad en cuanto a la salinidad, modo de vida, tipo de sustrato y tipo trófico. No ocurre lo mismo con los gasterópodos ya que los mismos presentan un número mas heterogéneo de especies, aumentando las oligohalino - polihalino - mesohalino, las de sustrato arenoso y carnívoras e incluso apareciendo especies infaunales.

La cantidad de especies encontradas en esta cuarta región posibilitó la realización de un análisis exhaustivo comparativo entre los interglaciales MIS 7 y MIS 5e. Aplicando primeramente el método descriptivo estadístico de Bray - Curtis, dichos interglaciales se componen por dos asociaciones diferentes: A) asociación faunística pertenecientes al Interglacial MIS 5e. B) asociación faunística perteneciente al Interglacial MIS 7.

Consecuentemente, aplicando el método descriptivo de Análisis de Correspondencia (AC) se distinguen 3 asociaciones faunísticas diferentes: A) asociación faunística correspondiente a depósitos de paleoplayas del Interglacial MIS 7 que se caracteriza por la abundancia de Tegula atra (gasterópodo). B) asociación faunística perteneciente al 
Interglacial MIS 5e correspondiente a cordones litorales de arena y gravas dispersas, caracterizados por la presencia de Panopea abbreviata, Trachicardium muricatum, Mytilus edulis platensis (bivalvos) y Siphonaria lessoni, Lucapinella henseli y Tegula patagonica (gasterópodos). C) asociación faunística correspondiente a depósitos de arena y grava que pertenecen al Interglacial MIS 5e que se caracteriza por la presencia de Glycymeris longior (bivalvo) y Bostrycapulus odites (gasterópodos).

Sin embargo, ampliando el análisis estadístico con lo cual se involucra, además de lo descripto en párrafos anteriores, la fauna del Interglacial MIS 1 y la del ambiente de playas actuales y siguiendo el método descriptivo estadístico de Bray - Curtis, todos los interglaciales de la región del norte del golfo San Matías en realidad se componen por 3 asociaciones distintas: A) asociación faunística con presencia de dos bivalvos Amiantis purpurata y Aequipecten tehuelchus. B) asociación faunística con presencia abundante del género Crepidula En esta asociación todos los sitios pertenecen a playas actuales. C) Este grupo se divide a su vez en dos subgrupos. C1) asociación faunística perteneciente en su mayoría al Interglacial MIS 1 y C2) asociación faunística perteneciente en su mayoría a los interglaciales MIS 7 y MIS 5e que se caracterizan por la abundancia de Glycymeris longior, Brachidontes rodriguezii (bivalvos) y Buccinanops globulosus (gasterópodo).

Consecuentemente, ampliando también el análisis estadístico a todos los interglaciales descriptos para esta región y aplicando el método descriptivo de Análisis de Correspondencia (AC), se distinguen 2 asociaciones faunísticas diferentes en todos los sitios analizados, con excepción de 4 de ellos (F24, G18, G21 y G22): A) asociación faunística que corresponde en su mayoría al Interglacial Mis 7 y al Interglacial MIS 1, teniendo en común al bivalvo Amiantis purpurata como la especie más abundante. B) asociación faunística que corresponde al Interglacial MIS 5e y playa actual, teniendo en común la abundancia de 3 bivalvos: Brachidontes rodriguezii, Glycymeris longior y Amiantis purpurata en menor proporción. Del análisis del gráfico respectivo, tanto el grupo A como el grupo B se encuentran cercanos lo cual significaría que las especies bivalvos y gasterópodas intervinientes en ambos grupos son aproximadamente las mismas poseyendo 
además una abundancia relativa similar. Cabe destacarse muy especialmente la presencia abundante de Amiantis purpurata (bivalvo) en todos los sitios, a excepción del sitio G18 (Playa El Cóndor, al sur de la desembocadura del Río Negro). 


\section{DISCUSIÓN}

En base a los resultados obtenidos en esta tesis, tanto los bivalvos como los gasterópodos constituyen herramientas paleoclimáticas ("proxies" paleoclimáticos), pero son los primeros los mejores indicadores a los fines de estimar indirectamente paleotemperaturas del agua de mar, ya que viven en rangos acotados de temperaturas (cálidos, cálidostemplados y fríos) siendo buenos referentes de este factor ambiental.

\subsection{Interglaciales $\geq$ MIS 9 y MIS 7}

En el sector norte patagónico se analizaron dos interglaciales, $\geq$ MIS 9 y MIS 7, no detectados en el noreste de la provincia de Buenos Aires. En las tres regiones pertenecientes al sur de Provincia de Buenos Aires, en el Interglacial $\geq$ MIS 9 se registró un total de 9 especies de moluscos y entre ellos existe un $50 \%$ a $67 \%$ de especies de aguas cálidas de bivalvos, siendo este el primer registro de fauna marina de moluscos más antigua para la Provincia de Buenos Aires. En el Interglacial MIS 7, analizado en la región norte del golfo San Matías, se registró un total de 11 especies determinando la presencia de un 20 $\%$ de especies de bivalvos de cálidas. La mayoría de las especies registradas en ambos interglaciales siguen viviendo en las costas actuales argentinas, con excepción del gasterópodo Tegula atra, ausente a partir del Interglacial MIS 1.

Ambos interglaciales ( $\geq$ MIS 9 y MIS 7) analizados en el norte patagónico revelaron la

presencia de moluscos de aguas cálidas en comparación con los depósitos marinos del noreste bonaerenses, no hay investigaciones realizadas en el área por la ausencia de la conservación de estos depósitos (Aguirre y Fucks, 2004). Siendo el área de tesis como novedad en el análisis de gasterópodos y bivalvos en estos interglaciales en la Provincia de Buenos Aires. Mientras que las costas sur patagonico, Aguirre et al $(2005,2007)$ área como bahía Vera- Camarones $\left(44.2^{\circ}\right.$ y $\left.45^{\circ} \mathrm{S}\right)$ y bahía Bustamente - Caleta Olivia $\left(44.9^{\circ}-45.3^{\circ} \mathrm{S}\right.$, Chubut), las condiciones ambientales (sustrato, profundidas y condiciones energéticas) durante el Pleistoceno tardío (MIS 7 y MIS 5e) sugieren SST similares al litoral actual e 
incluso levemente más altas que en la actualidad, registrando fauna de aguas cálidas templadas.

\subsection{Interglacial MIS 5e}

Los depósitos marinos pertenecientes al Interglacial MIS 5e del área norte patagónico registraron un total de 44 especies (25 bivalvos y 19 gasterópodos). Éstos se representan por cordones litorales y planicies de mareas a la largo del sur bonaerense, y por cordones litorales al norte del golfo San Matías, con escaso contenido de carbonato de calcio, logrando un mejor reconocimiento de las especies de bivalvos y gasterópodos. En la región de isla Jabalí - Villa 7 de Marzo la fauna marina de los interglaciales MIS 5 y MIS 1 registraron, respectivamente, un total de 34 y 33 especies. La misma similitud se registró en región norte del golfo San Matías donde se reconocieron 22 especies para el Interglacial MIS 5e en contraposición a 23 especies encontradas en el Interglacial MIS 1; por lo tanto, tampoco se observa para esta última región mencionada mayor cantidad de especies de gasterópodos y bivalvos en el Interglacial MIS 1 en relación al Interglacial MIS 5e (T. 10.1). Además, en el sector noreste de la Provincia de Buenos Aires, a diferencia con el norte patagónico, los moluscos marinos del Interglacial MIS 5e se caracterizan aparentemente por tener una menor abundancia y diversidad en especies en comparación con el Holoceno (MIS 1) (Aguirre y Fucks, 2004). Esto podría deberse a una menor representación del Interglacial MIS 5e, y a que la mayoría de las valvas y conchas encontradas en los depósitos marinos pleistocenos están disueltas y/o cristalizadas, haciendo muy difícil la identificación a nivel de especies. Esta fauna marina pleistocena se estudió principalmente desde Cañada del Arregui hasta Bahía Blanca. En Punta Piedras, Magdalena, y Puente de Pascua, se destacan por su abundancia los géneros Mactra, Crassostrea, Anomalocardia, Urosalpinx, Thais y Noetia (ej. Aguirre 1993, Aguirre y Fucks, 1994; Aguirre y Farinati, 1999, entre otros), siendo la mayoría de estas especies típicas de aguas más cálidas, viviendo actualmente a latitudes más bajas (T. 10.2 y 10.3). 
En el sur patagónico, Aguirre et al. (2005) analizan depósitos marinos correspondientes al Interglacial MIS 5e, en el área de bahía Bustamente - Caleta Malaspina $\left(44.9^{\circ}-45.3^{\circ} \mathrm{S}\right)$ registrando condiciones similares de SST con el litoral actual. En el área de bahia Camarones- Caleta Olivia $\left(44.2^{\circ}-45^{\circ} \mathrm{S}\right)$, Aguirre et al. (2007) registran altos valores de diversidad de especies de moluscos y alta abundancia de especies de aguas cálidas en los depositos marinos analizados en este mismo interglacial. La alta diversidad de especies y la abundancias de especies de aguas templadas-cálidas se debe probablemente a las altas temperaturas registradas en el mar hace $120 \mathrm{ka}$ en similares condiciones ambientales con el Interglacial MIS 1 (Aguirre et al., 2005, 2007 y 2011). 


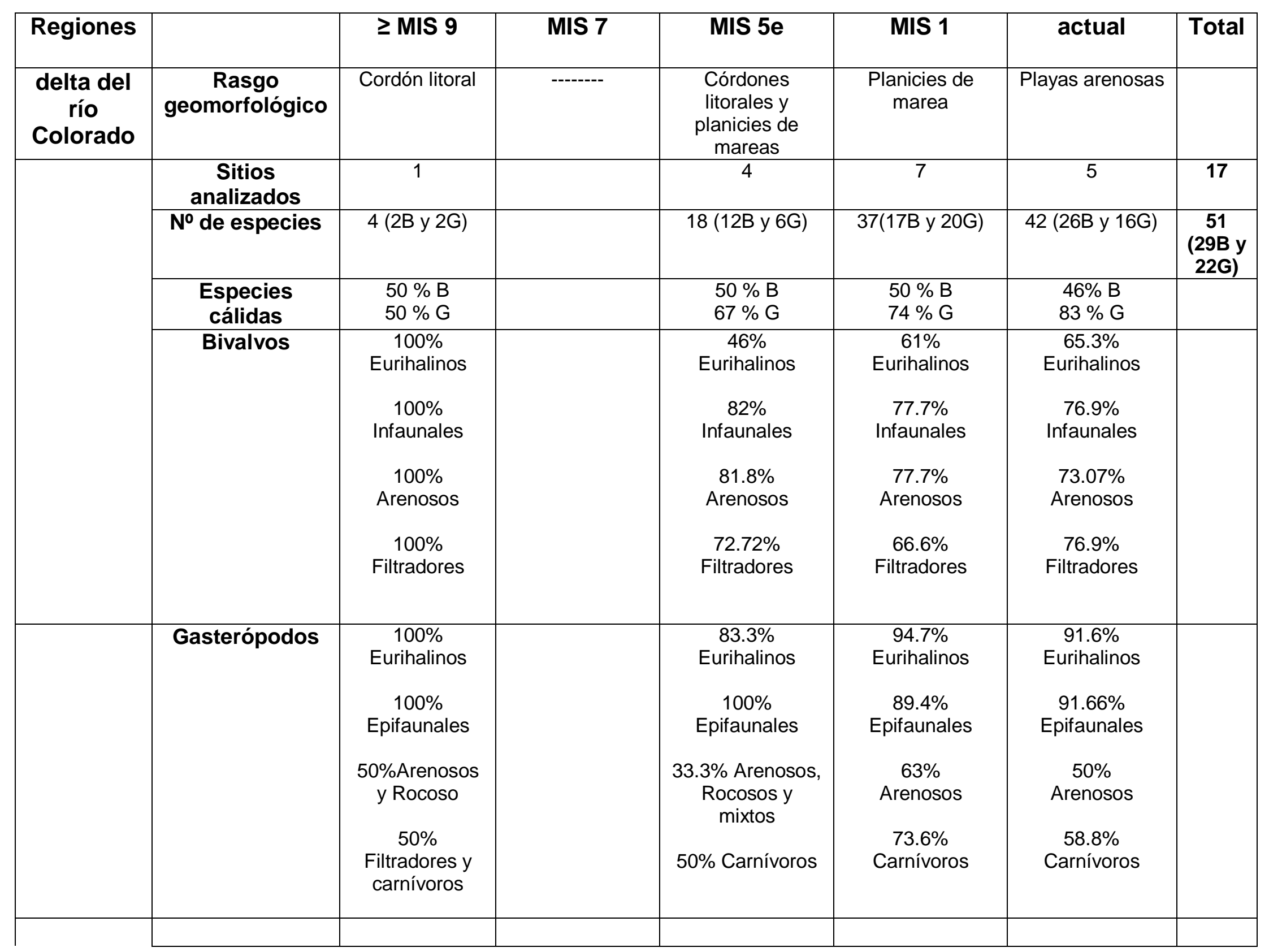




\begin{tabular}{|c|c|c|c|c|c|c|c|}
\hline $\begin{array}{l}\text { bahía } \\
\text { Anegada }\end{array}$ & $\begin{array}{c}\text { Rasgo } \\
\text { geomorfológico }\end{array}$ & $\begin{array}{l}\text { Plataforma } \\
\text { marina y } \\
\text { cordones } \\
\text { litorales }\end{array}$ & ------- & $\begin{array}{c}\text { Cordones } \\
\text { litorales y } \\
\text { planicies de } \\
\text { marea }\end{array}$ & $\begin{array}{c}\text { Cordones } \\
\text { litorales y } \\
\text { planicies de } \\
\text { marea }\end{array}$ & $\begin{array}{l}\text { Playas areno- } \\
\text { fangosas y } \\
\text { playas arenosas }\end{array}$ & \\
\hline & $\begin{array}{c}\text { Sitios } \\
\text { analizados }\end{array}$ & 3 & & 6 & 8 & 3 & 20 \\
\hline & № de especies & 6 (3B y 3G) & & $28(14 \mathrm{~B}$ y $14 \mathrm{G})$ & $37(19 B$ y $18 G)$ & 21 (13B y $8 G)$ & $\begin{array}{c}49 \\
(25 B y \\
24 G)\end{array}$ \\
\hline & $\begin{array}{l}\text { Especies } \\
\text { cálidas }\end{array}$ & $\begin{array}{c}67 \% \mathrm{~B} \\
100 \% \mathrm{G}\end{array}$ & & $\begin{array}{l}46 \% \mathrm{~B} \\
67 \% \mathrm{G}\end{array}$ & $\begin{array}{l}47 \% \mathrm{~B} \\
67 \% \mathrm{G}\end{array}$ & $\begin{array}{l}50 \% \mathrm{~B} \\
60 \% \mathrm{G}\end{array}$ & \\
\hline & Bivalvos & $\begin{array}{c}66.6 \% \\
\text { Eurihalino } \\
100 \% \\
\text { Epifaunal } \\
100 \% \\
\text { Arenosos } \\
100 \% \\
\text { Filtradores }\end{array}$ & & $\begin{array}{c}76.9 \% \\
\text { Eurihalino } \\
69 \% \\
\text { Infaunal } \\
69.2 \% \\
\text { Arenosos } \\
61.5 \% \\
\text { Filtradores }\end{array}$ & $\begin{array}{c}63 \% \\
\text { Eurihalino } \\
68.4 \% \\
\text { Infaunal } \\
68.4 \% \\
\text { Arenosos } \\
78.4 \% \\
\text { Arenosos }\end{array}$ & $\begin{array}{c}75 \% \\
\text { Eurihalino } \\
75 \% \\
\text { Infaunal } \\
75 \% \\
\text { Arenosos } \\
75 \% \text { Filtradores }\end{array}$ & \\
\hline & Gasterópodos & $\begin{array}{c}100 \% \\
\text { Eurihalino } \\
100 \% \\
\text { Epifaunal } \\
100 \% \\
\text { Arenosos } \\
100 \% \\
\text { Carnívoros }\end{array}$ & & $\begin{array}{c}93.3 \% \\
\text { Eurihalino } \\
86.8 \% \\
\text { Epifaunal } \\
50 \% \\
\text { Arenosos } \\
66.6 \% \\
\text { Carnívoros }\end{array}$ & $\begin{array}{c}94.4 \% \\
\text { Eurihalino } \\
94.4 \% \\
\text { Epifaunal } \\
72 \% \\
\text { Arenosos } \\
82 \% \\
\text { Carnívoros }\end{array}$ & $\begin{array}{c}90 \% \\
\text { Eurihalino } \\
80 \% \\
\text { Epifaunal } \\
70 \% \\
\text { Arenosos } \\
80 \% \text { Carnívoros }\end{array}$ & \\
\hline \multirow[t]{4}{*}{$\begin{array}{l}\text { isla Jabalí } \\
\text { - Villa } 7 \\
\text { de Marzo }\end{array}$} & $\begin{array}{c}\text { Rasgo } \\
\text { geomorfológico }\end{array}$ & $\begin{array}{l}\text { Afloramiento } \\
\text { marino y } \\
\text { cordón litoral }\end{array}$ & --------- & $\begin{array}{l}\text { Cordones } \\
\text { litorales }\end{array}$ & $\begin{array}{c}\text { Cordones } \\
\text { litorales y } \\
\text { planicies de } \\
\text { marea } \\
\end{array}$ & Playas arenosas & \\
\hline & $\begin{array}{c}\text { Sitios } \\
\text { analizados }\end{array}$ & 2 & & 9 & 8 & 9 & 28 \\
\hline & № de especies & 5 (2B y 3G) & & 34 (17B y 17G) & 33 (20B y 13G) & 30 (15G y 15B) & $\begin{array}{c}51 \\
(27 B y \\
24 G)\end{array}$ \\
\hline & $\begin{array}{l}\text { Especies } \\
\text { cálidas }\end{array}$ & $\begin{array}{c}50 \% \mathrm{~B} \\
100 \% \mathrm{G}\end{array}$ & & $\begin{array}{l}44 \% \mathrm{~B} \\
70 \% \mathrm{G}\end{array}$ & $\begin{array}{l}45 \% \mathrm{~B} \\
62 \% \mathrm{G}\end{array}$ & $\begin{array}{l}33 \% \mathrm{~B} \\
56 \% \mathrm{G}\end{array}$ & \\
\hline
\end{tabular}




\begin{tabular}{|c|c|c|c|c|c|c|c|}
\hline & Bivalvos & $\begin{array}{c}100 \% \\
\text { Eurihalino } \\
100 \% \\
\text { Infaunal } \\
100 \% \\
\text { Arenosos } \\
100 \% \\
\text { Filtradores }\end{array}$ & & $\begin{array}{c}62.5 \% \text { Eurihalino } \\
56 \% \\
\text { Infaunal } \\
56 \% \\
\text { Arenosos y } \\
37.5 \% \text { Rocosos } \\
68.7 \% \\
\text { Filtradores }\end{array}$ & $\begin{array}{c}70 \% \text { Eurihalino } \\
70 \% \\
\text { Infaunal } \\
70 \% \\
\text { Arenosos } \\
75 \% \\
\text { Filtradores }\end{array}$ & $\begin{array}{c}66.6 \% \text { Eurihalino } \\
72.7 \% \\
\text { Infaunal } \\
46.6 \% \text { Rocosos } \\
\text { y arenosos } \\
86.6 \% \\
\text { Filtradores }\end{array}$ & \\
\hline & Gasterópodos & $\begin{array}{c}100 \% \\
\text { Eurihalino } \\
100 \% \\
\text { Epifaunal } \\
100 \% \\
\text { Arenosos } \\
100 \% \\
\text { Carnívoros }\end{array}$ & & $\begin{array}{c}94 \% \\
\text { Eurihalino } \\
88.3 \% \\
\text { Epifaunal } \\
70.5 \% \\
\text { Arenosos } \\
70.5 \% \\
\text { Carnívoros }\end{array}$ & $\begin{array}{c}90 \% \\
\text { Eurihalino } \\
100 \% \\
\text { Epifaunal } \\
50 \% \\
\text { Arenosos } \\
63.6 \% \\
\text { Carnívoros }\end{array}$ & $\begin{array}{c}93.7 \% \\
\text { Eurihalino } \\
93.7 \% \text { Epifaunal } \\
50 \% \text { Arenosos } \\
60 \% \text { Carnívoros }\end{array}$ & \\
\hline \multirow[t]{5}{*}{$\begin{array}{l}\text { Norte del } \\
\text { golfo San } \\
\text { Matías }\end{array}$} & $\begin{array}{c}\text { Rasgo } \\
\text { geomorfológico }\end{array}$ & --------- & $\begin{array}{l}\text { Plataformas } \\
\text { costeras }\end{array}$ & $\begin{array}{l}\text { Paleoacantilados } \\
\text { y cordones } \\
\text { litorales }\end{array}$ & $\begin{array}{l}\text { Cordones } \\
\text { litorales }\end{array}$ & $\begin{array}{c}2 \text { tipos de } \\
\text { playas: } \\
\text { 1-Sector } \\
\text { intermareal bajo } \\
\text { de arena fina- } \\
\text { mediana y distal } \\
\text { gravoso } \\
\text { 2- Sector } \\
\text { intermareal bajo } \\
\text { y distal de arena } \\
\text { fina.mediana }\end{array}$ & \\
\hline & $\begin{array}{c}\text { Sitios } \\
\text { analizados }\end{array}$ & & 2 & 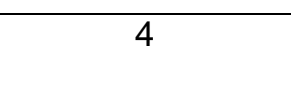 & 6 & 7 & 19 \\
\hline & № de especies & & 11 (6B y $5 G)$ & 22 (11B y $11 \mathrm{G})$ & 23 (11B y $12 \mathrm{G})$ & $31(16 \mathrm{~B}$ y $15 \mathrm{G})$ & $\begin{array}{c}42 \\
(20 y \\
22)\end{array}$ \\
\hline & $\begin{array}{l}\text { Especies } \\
\text { cálidas }\end{array}$ & & $\begin{array}{l}20 \% \mathrm{~B} \\
80 \% \mathrm{G}\end{array}$ & $\begin{array}{l}27 \% \text { B } \\
60 \% \text { G }\end{array}$ & $\begin{array}{l}18 \% \mathrm{~B} \\
42 \% \mathrm{G}\end{array}$ & $\begin{array}{l}31 \% \mathrm{~B} \\
44 \% \mathrm{G}\end{array}$ & \\
\hline & Bivalvos & & $\begin{array}{c}83 \% \text { Eurihalino } \\
50 \% \text { Infaunal } \\
50 \% \text { Arenosos }\end{array}$ & $\begin{array}{c}72.7 \% \text { Eurihalino } \\
70 \% \text { Infaunal } \\
63 \% \text { Arenosos }\end{array}$ & $\begin{array}{c}81.8 \% \text { Eurihalino } \\
54 \% \text { Infaunal } \\
54.5 \% \text { Arenosos }\end{array}$ & $\begin{array}{c}\text { 75\%Eurihalino } \\
56 \% \text { Infaunal } \\
56 \% \text { Arenosos }\end{array}$ & \\
\hline
\end{tabular}




\begin{tabular}{|c|c|c|c|c|}
\hline & $100 \%$ Filtradores & 90.9\%Filtradores & 90.9\%Filtradores & 87.5\%Filtradores \\
\hline Gasterópodos & $\begin{array}{c}100 \% \\
\text { Eurihalino } \\
100 \% \\
\text { Epifaunal } \\
40 \% \\
\text { Arenosos y } \\
\text { Rocosos } \\
60 \% \\
\text { Carnívoros }\end{array}$ & $\begin{array}{c}90 \% \\
\text { Eurihalino } \\
100 \% \\
\text { Epifaunal } \\
50 \% \\
\text { Rocosos } \\
\\
44.4 \% \\
\text { Carnívoros y } \\
\text { Herbívoros }\end{array}$ & $\begin{array}{c}100 \% \\
\text { Eurihalino } \\
100 \% \\
\text { Epifaunal } \\
66.6 \% \\
\text { Rocosos } \\
\\
50 \% \\
\text { Carnívoros }\end{array}$ & $\begin{array}{c}93.7 \% \\
\text { Eurihalino } \\
93.7 \% \\
\text { Epifaunal } \\
43.7 \% \text { Arenosos } \\
\text { y Rocosos } \\
\\
62.5 \% \\
\text { Carnívoros }\end{array}$ \\
\hline
\end{tabular}

T.10.1. Cuadro comparativo del área norte patagónico. 


\begin{tabular}{|c|c|c|c|c|c|c|}
\hline Bivalvos & $\begin{array}{l}\text { Cañada } \\
\text { de } \\
\text { Arregui }\end{array}$ & $\begin{array}{l}\text { Punta } \\
\text { Indio }\end{array}$ & $\begin{array}{c}\text { Bahía } \\
\text { Samborom } \\
\text { bón }\end{array}$ & $\begin{array}{l}\text { Faro } \\
\text { de } \\
\text { Quer } \\
\text { andí }\end{array}$ & $\begin{array}{l}\text { Quenqu } \\
\text { én } \\
\text { Salado }\end{array}$ & $\begin{array}{c}\text { Bahía } \\
\text { Blanca }\end{array}$ \\
\hline \multicolumn{7}{|l|}{ Familia Noetiidae Steward, 1930} \\
\hline Noetia bisulcata (Lamarck, 1819) & $\mathbf{X}$ & $\mathbf{X}$ & $\mathbf{X}$ & & & \\
\hline \multicolumn{7}{|l|}{ Familia Glycymerididae Newton, 1922} \\
\hline Glycymeris (G.) longior ( Sowerby, 1832) & $\mathbf{X}$ & $\mathbf{X}$ & & $\mathbf{X}$ & & \\
\hline \multicolumn{7}{|l|}{ Familia Mytilidae Rafinesque, 1815} \\
\hline Brachidontes $(B)$ rodriguezii ( d'Orbigny, 1846) & & $\mathbf{X}$ & & $\mathbf{X}$ & & $\mathbf{X}$ \\
\hline \multicolumn{7}{|l|}{ Familia Pectinidae Rafinesque, 1815} \\
\hline Aequipecten tehuelchus (d'Orbigny 1842) & $\mathbf{X}$ & $\mathbf{X}$ & & & & $\mathbf{X}$ \\
\hline \multicolumn{7}{|l|}{ Familia Ostreidae Rafinesque,1815 } \\
\hline Ostrea & $\mathbf{X}$ & & $\mathbf{X}$ & $\mathbf{X}$ & & \\
\hline Ostreola equestris (Say, 1834) & & $\mathbf{X}$ & & & & \\
\hline Crassostrea rhizophorae (Guilding, 1828) & & & & & & $\mathbf{X}$ \\
\hline \multicolumn{7}{|l|}{ Familia Carditidae Fleming, 1828} \\
\hline Carditamera plata (Inhering, 1907) & & $\mathbf{X}$ & & $\mathbf{X}$ & & \\
\hline \multicolumn{7}{|l|}{ Familia Cardiidae Lamarck, 1809} \\
\hline Trachycardium muricatum (Linné, 1758) & $\mathbf{X}$ & $\mathbf{X}$ & & & & \\
\hline \multicolumn{7}{|l|}{ Familia Mactridae Lamarck,1809 } \\
\hline Mactra isabelleana d'Orbigny, 1846 & $\mathbf{X}$ & $\mathbf{X}$ & & $\mathbf{X}$ & & \\
\hline \multicolumn{7}{|l|}{ Mulinia lateralis (Say, 1822) } \\
\hline \multicolumn{7}{|l|}{ Familia Telinidae De Blainville, 1814} \\
\hline Angulus gibber lhering, 1907 & & & & $\mathbf{X}$ & & \\
\hline \multicolumn{7}{|l|}{ Familia Solecurtidae d'Orbigny, 1846} \\
\hline Tagelus (T.) plebeius (Ligthfood,1786) & & & & & $\mathbf{X}$ & \\
\hline \multicolumn{7}{|l|}{ Familia Veneridae Rafinesque,1815 } \\
\hline Pitar (P.) rostratus (Philippi, 1844) & $\mathbf{X}$ & $\mathbf{X}$ & $\mathbf{X}$ & $\mathbf{X}$ & & $\mathbf{X}$ \\
\hline Amiantis purpurata ( Lamarck, 1856) & $\mathbf{X}$ & $\mathbf{X}$ & & $\mathbf{X}$ & & \\
\hline Anomalocardia brasiliana (Gmelin, 1791) & & & & & & $\mathbf{X}$ \\
\hline \multicolumn{7}{|l|}{ Familia Corbulidae Gray, 1823} \\
\hline Corbula (C.) patagonica d'Orbigny, 1846 & & & & $\mathbf{X}$ & & \\
\hline \multicolumn{7}{|l|}{ Familia Erodonidae Winckworth, 1932} \\
\hline Erodona mactroides Bosc, 1801 & & $\mathbf{X}$ & & & & \\
\hline
\end{tabular}

T.10.2: Distribución de los bivalvos en el Pleistoceno en distintas áreas del sector norte y sur Provincia de Buenos Aires citado por (Aguirre y Fucks, 2004; Aguirre y Farinati, 1999). 


\begin{tabular}{|c|c|c|c|c|c|c|}
\hline GASTERÓPODOS & $\begin{array}{l}\text { Cañada de } \\
\text { Arregui }\end{array}$ & $\begin{array}{l}\text { Punta } \\
\text { Indio }\end{array}$ & $\begin{array}{c}\text { B. } \\
\text { Samborombón }\end{array}$ & $\begin{array}{l}\text { Faro de } \\
\text { Querandí }\end{array}$ & $\begin{array}{l}\text { Quenquén } \\
\text { Salado }\end{array}$ & $\begin{array}{c}\text { B. } \\
\text { Blanca }\end{array}$ \\
\hline \multicolumn{7}{|l|}{ Familia Fissurellidae Fleming,1822 } \\
\hline Diodora (D.) patagonica (d'Orbigny, 1841) & & $\mathbf{X}$ & & & & \\
\hline \multicolumn{7}{|l|}{ Familia Calliostomatidae Thiele, 1924} \\
\hline Tegula (A.) patagonica (d'Orbigny, 1835) & & $\mathbf{X}$ & & & & $\mathbf{X}$ \\
\hline \multicolumn{7}{|l|}{ Familia Calyptraeidae Lamarck,1809 } \\
\hline Bostrycapulus odites (Collin, 2005) & & & & $\mathbf{X}$ & & $\mathbf{X}$ \\
\hline $\begin{array}{l}\text { Crepidula argentina Simone, Pastorino \& } \\
\text { Penchaszadeh, } 2000\end{array}$ & $\mathbf{X}$ & & & $\mathbf{X}$ & & \\
\hline \multicolumn{7}{|l|}{ Familia Naticidae Forbes, 1828} \\
\hline Notocochlis isabelleana (d'Orbigny, 1840) & & $\mathbf{X}$ & & & & $\mathbf{X}$ \\
\hline \multicolumn{7}{|l|}{ Familia Hydrobiidae } \\
\hline Heleobia australis ( d'Orbigny, 1835) & & & $\mathbf{X}$ & & $\mathbf{X}$ & $\mathbf{X}$ \\
\hline \multicolumn{7}{|l|}{ Familia Muricidae Rafinesque, 1815} \\
\hline Urosalpinx rushi Pilsbry, 1897 & $\mathbf{X}$ & $\mathbf{X}$ & $\mathbf{X}$ & & & \\
\hline \multicolumn{7}{|l|}{ Familia Volutidae Rafinesque, 1815} \\
\hline Zidona dufresnei ( Donovan, 1823) & & $\mathbf{X}$ & & & & \\
\hline Adelomelon (P.) brasiliana (Lamarck, 1811) & $\mathbf{X}$ & $\mathbf{X}$ & & & & \\
\hline Adelomelon ancilla (Lightfoot, 1789) & & & & $\mathbf{X}$ & & \\
\hline \multicolumn{7}{|l|}{ Familia Olividae Latreille,1825 } \\
\hline Olivella (O.) tehuelcha ( Dúclos, 1835) & & & & $\mathbf{X}$ & & $\boldsymbol{X}$ \\
\hline Olivancillaria urceus ( Röding, 1798) & & & & & $\mathbf{X}$ & \\
\hline Olivancillaria carcellesi Klappenbach, 1965 & $\mathbf{X}$ & & & & & \\
\hline \multicolumn{7}{|l|}{ Familia Buccinidae Refinesque, 1815} \\
\hline Pareutheria plumbea (Philippi, 1844) & & & & $\mathbf{X}$ & & \\
\hline \multicolumn{7}{|l|}{ Familia Nassariidae Iredale,1916 } \\
\hline Buccinanops cochlidium (Dilwyn, 1817) & $\mathbf{X}$ & & & & & \\
\hline Buccinanops globulosus (Kiener, 1834) & $\mathbf{X}$ & $\mathbf{X}$ & & & & $\mathbf{X}$ \\
\hline \multicolumn{7}{|l|}{ Familia Thaididae Röding, 1798} \\
\hline Thais haemastoma (Linné, 1767) & $\mathbf{X}$ & $\mathbf{X}$ & & & & \\
\hline \multicolumn{7}{|l|}{ Familia Conidae Rafinesque, 1815} \\
\hline Conus Inheringi Frenguelli, 1946 & $\mathbf{X}$ & $\mathbf{X}$ & & & & \\
\hline
\end{tabular}

10.3: Distribución de gasterópodos en el Pleistoceno en distintas áreas del sector norte y sur Provincia de Buenos Aires citado por (Aguirre y

Fucks, 2004; Aguirre y Farinati, 1999). 
Para el Interglacial MIS 5e del norte patagónico, se encuentran representados en el sur de la Provincia de Buenos Aires entre un 50 - $44 \%$ de especies de aguas cálidasde bivalvos, a diferencia del norte de la Provincia de Río Negro donde esta proporcionalidad sólo se detecta en un $27 \%$ de la totalidad. Para el área de estudio se reconocieron moluscos de estirpe cálida, y entre las especies más destacadas en este interglacial, en el sur bonaerense, se encuentra el bivalvo Crassostrea rhizophorae. Es una especie de estirpe cálida, que vive actualmente en el Caribe, Venezuela (Surinam), y Brasil hasta Uruguay, sin registros en la costa argentina actual. Sin embargo, como fósil, hay registros de esta especie en el noreste de la Provincia de Buenos Aires, en el Interglacial MIS 5e ya que Tonni y Fidalgo (1978) mencionan la presencia de Ostrea parasitica (=Crassostrea rhizophorae) entre la fauna marina encontrada. También Chaar y Farinati (1988) encontraron esta especie en abundancia en los depósitos pleistocenos de Bahía Blanca.

Otra especie de estirpe cálida hallada en el norte patagónico es el bivalvo Anomalocardia brasiliana, que se registró en la región norte del río Negro (Sitio E21), y esta mención merece atención ya que representa uno de los hallazgos más australes de la especie en las costas argentinas. Esta especie se distribuye en la actualidad desde las Antillas Francesas $\left(18^{\circ} \mathrm{N}\right)$ hasta las costas de Brasil $\left(33^{\circ} \mathrm{S}\right)$, siendo una especie infaunal superficial y capaz de soportar grandes rangos de salinidad (Monti et al. 1991; Ríos, 1994; Arruda et al., 2009; Oliveira et al., 2011). Como fósil ha sido hallada en Uruguay, tanto en el Interglacial MIS 5e (Formación Nueva Palmira; Martínez et al., 2001) como en el Holoceno (MIS1) (Formación Villa Soriano; Martínez et al., 2006). En Argentina, esta especie se menciona para depósitos marinos dentro del Pampiano de Lomas de Zamora (3446’S, noreste de la Provincia de Buenos Aires) (Valentin, 1987) como así también para la localidad de Magdalena, Punta Piedras y para el sector sur de la Provincia de Entre Ríos (Aguirre y Fucks, 2004). En los depósitos pleistocenos de Bahía Blanca, sur de la Provincia de Buenos Aires, se destacó la presencia de esta especie en abundancia con Crassostrea rhizophorae (Chaar y Farinati, 1988). Una de las especies más abundantes en el Pleistoceno de la región norte de Rio Negro (región norte del golfo San Matías) es el gasterópodo Tegula atra, que 
se encuentra bien preservado en los depósitos de los interglaciales MIS 7 y MIS 5e, no existiendo en el sur de la Provincia de Buenos Aires.

En relación al gasterópodo Tegula atra, merece una discusión en particular ya que probablemente sea un paleoindicador de temperaturas, aunque existe actualmente controversia en cuanto a las interpretaciones sobre su uso como indicador ambiental. En cuanto a su morfología, las características más acentuadas de Tegula atra es poseer una concha de forma trocoide o piramidal gruesa, formada por cinco vueltas, donde la última es ancha y aplanada, y cuyo color externo varía en tonos oscuros de pardo violáceo a negro e interiormente es nacarado (Guzmán et al., 1998). Respecto a su hábitat y distribución geográfica, esta especie vive en la actualidad en ambientes intermareales y submareales asociados a sustratos rocosos y sobre macroalgas (Veliz y Vásquez, 2000; Palacios y Aldea, 2011) y se distribuye, por el Pacífico, desde Pacasmayo ( $7^{\circ} 24^{\prime} \mathrm{S}$, Perú) hasta el Estrecho de

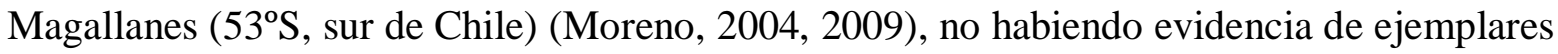
vivos en las costas del Atlántico sur, ni tampoco registros paleontológicos durante el Holoceno (Gordillo 1988; Pastorino 2000, Aguirre et al. 2006). Sin embargo, en el Pleistoceno de la costa atlántica, esta especie se encuentra en abundancia en el Interglacial MIS 7 persistiendo en menor proporción hasta el Interglacial MIS 5e en la región norte de Rio Negroel N de Río Negro. Hacia el sur, siguiendo por la costa atlántica, Tegula atra hace su aparición en los depósitos pleistocenos de Chubut (Pastorino 1991, 1994, 2000; Aguirre 2003, Aguirre et al. 2005), aunque no aparece ni en los depósitos pleistocenos ni holocenos de la costa atlántica de Tierra del Fuego (Gordillo y Isla, 2011). Respecto al género Tegula este aparece en el registro fósil en California (EEUU) aproximadamente en el Mioceno Medio y la especie Tegula atra ya se menciona en la costa Pacífica del Hemisferio Sur para el Plioceno (Hellberg, 1998). En Perú hay varios registros pleistocenos: se ha mencionado en los depósitos del Pleistoceno Tardío en la Región de San Juan-Lomas (costa norte de Perú) y la Región de Chala (costa sur de Perú) (Ortlieb y Díaz, 1991) y durante el Holoceno en la provincia del Santa $\left(9^{\circ} \mathrm{S}\right.$, extremo noroccidental del departamento de Ancash), siendo en la actualidad una especie viviente típica de Perú (Díaz y Ortlieb, 1993). En las costas chilenas, hay numerosos registros de la presencia de Tegula atra en el Pleistoceno, como por ejemplo, los depósitos del Pleistoceno Tardío en Caleta Coloso, al norte y sur del área de 
Antofagasta (233' S, norte de Chile) (Ortlieb et al., 1994), habiendo también registros arqueológicos de Tegula atra en el Pleistoceno Tardío y Holoceno Medio en el sitio de la Quebrada de Lazareto (sur de Chile) (Jackson et al., 2005), en el Holoceno Medio en la región IV de Chile, Los Vilos (Méndez y Jackson, 2004) y hacia el extremo sur de Chile, en depósitos marinos holocenos del Estrecho de Magallanes (Cárdenas y Gordillo, 2009). En base a su rango bioestratigráfico, con mayor antigüedad sobre la costa pacífica, su presencia en el Atlántico podría vincularse a una antigua conexión Cenozoica entre el Atlántico y el Pacífico; y su existencia en los depósitos pleistocenos del norte patagónico argentino probablemente se deba a que las temperaturas en el área donde esta especie hace su aparición (MIS 7 y MIS 5e) hayan sido más propicias para el desarrollo larval. Respecto a esto último, observaciones realizadas en poblaciones vivientes en la costa de Valdivia (Región de Los Ríos, en Chile) han demostrado que los asentamientos de Tegula atra son mayores cuando la temperatura superficial del mar se encuentra sobre los $14^{\circ} \mathrm{C}$ (Moreno, 2004). Este autor también señala que, probablemente, las larvas planctónicas se desarrollan y crecen más rápido en mar abierto y luego son arrastradas por frentes de baja presión y regresadas a las costas en los lugares de asentamiento intermareal. Según este autor las larvas de esta especie reclutan en mayor cantidad cuando el frente de aguas cálidas colisiona con la zona costera, siendo éste un microclima próspero para su desarrollo. Por otro lado, Aguirre et al. (2011) caracterizan a Tegula atra como un gasterópodo de aguas frías y atribuyen su desaparición en el Atlántico a cambios oceanográficos relacionados con la influencia de la Corriente del Brasil, o con la menor intensidad de la Corriente de Malvinas después del Último Máximo Glacial. Sin embargo, no se ha dado aún una explicación convincente sobre cómo los cambios oceanográficos acontecidos a fines del Pleistoceno podrían haber afectado la etapa larvaria (asentamiento) y/o la etapa adulta de esta especie, teniendo en cuenta que esta especie vive principalmente sobre macroalgas de las cuales se alimenta. En base a estudios interdisciplinarios que contemplen variables ecológicas, el acervo genético y limitantes ecofisiológicos de la especie viviente y el registro paleontológico del género Tegula en Sudamérica, se podría arribar a una conclusión convincente sobre la relación de Tegula atra y su aparición en el Interglacial MIS 7 y en el Interglacial MIS 5e en el Océano Atlántico en la Patagonia Argentina. 


\subsection{Interglacial MIS 1}

La fauna marina del Interglacial MIS 1 del norte patagónico (sur de la Provincia de Buenos Aires y norte de Río Negro), registró un total de 58 especies (31 bivalvos y 27 gasterópodos) a diferencia del área noreste de la Provincia de Buenos Aires en que previamente (Aguirre, 1990) se registró un total de 62 especies ( 25 bivalvos y 37 gasterópodos). En relación a la composición faunística de moluscos, en el área noreste bonaerense son más abundantes los gasterópodos que los bivalvos tanto en número de especies como de individuos. A modo comparativo, entre las regiones estudiadas, se menciona que: la región A (región del delta del río Colorado) registró un total de 51 especies (29 bivalvos y 22 gasterópodos), y la región B (región de bahía Anegada) un total de 49 especies (25 bivalvos y 24 gasterópodos); habiendo encontrado en ambas regiones más especies de bivalvos que gasterópodos. Mientras que en la región C (región de isla Jabalí - Villa 7 de Marzo) se registró un total de 34 especies (17 bivalvos y 17 gasterópodos), a diferencia de la región norte de Rio Negro (región norte del golfo San Matías) donde se registró un total de 42 especies (20 bivalvos y 22 gasterópodos), siendo en esta última levemente mayor el número de gasterópodos respecto a los bivalvos.

Los depósitos marinos del sur de la Provincia de Buenos Aires (A, B y C), pertenecientes al Interglacial MIS 1 se componen por dos tipos de depósitos: planicies de marea y cordones litorales. Los depósitos marinos que corresponden a planicies de marea y entre la fauna marina figuran principalmente Tagelus plebeius (bivalvo) y Heleobia australis (gasterópodo). Estas especies son de salinidad variable existiendo asociaciones faunísticas oligohalinas - mesohalinas - polihalinas (salinidades entre 3 y $30 \mathrm{gr} / \mathrm{l}$ ), típicas de ambientes de menor energía, conteniendo en su mayoría bajos índices de diversidad. En los cordones litorales, en su mayoría, los índices de diversidad son más altos que los representados en las planicies de mareas. Entre la fauna marina figuran: Pitar rostratus, Amiantis purpurata, Ostreola equestris (bivalvos) y Buccinanops cochlidium y Heleobia australis (gasterópodos), característicos de ambientes de alta energía. En comparación con la fauna marina estudiada en el área noreste bonaerense desde el N de la localidad de La Plata (34 ${ }^{\circ} 55^{\prime}$ 
S) hasta Mar de Cobos ( $\left.37^{\circ} 45^{\prime} \mathrm{S}\right)$ figuran entre las más abundantes: Mactra isabelleana, Pitar rostratus, Tagelus plebeius, Corbula patagonica (bivalvos) y Heleobia australis (gasterópodos) representando antiguos ambientes de mezcla (Aguirre, 1993). En los cordones litorales pertenecientes al Miembro Cerro de la Gloria de la Formación Las Escobas, representados entre el sector Berisso - General Lavalle, la fauna se caracteriza por la dominancia de Mactra isabelleana, bivalvo polihalino-eurihalino, y especies marinas estenohialinas, mayoritariamente de sustratos arenosos con índices de alta diversidad (Aguirre, 1990). En las facies marinas de la Formación Mar Chiquita la fauna se caracteriza por la dominancia de Heleobia australis y por la abundancia de otros microgasterópodos intertidales o supralitorales y baja diversidad faunística. La fauna del Miembro Canal 18 de la Formación Canal Las Escobas y las facies estuáricas de la Formación Mar Chiquita presentan muy baja diversidad y se caracterizan por constituir ambientes de baja energía de fondos arcillosos o limosos representados por especies estuariales encontrados en posición de vida (Aguirre, 1990, 1993; Fucks et al., 2010) (T.10.4 y 10.5).

De acuerdo a los análisis efectuados en este trabajo, los depósitos marinos y la fauna marina representada, en las áreas noreste de la Provincia de Buenos Aires y el área sur bonaerense (A, B y C) se asemejan entre sí por los dos tipos de depósitos representados en el Interglacial MIS 1. Las planicies de mareas se representan en las tres regiones pertenecientes al sur de la Provincia de Buenos Aires y su existencia se relaciona con el desarrollo del río Colorado y la bahía Anegada, afectando también el N de la región C. Siendo las especies más comunes el gasterópodo Heleobia australis y los bivalvos Tagelus plebeius (articulados y en posición de vida) y Corbula patagonica, siendo semejante a la fauna marina encontrada en el noreste bonaerense del Miembro Canal 18 de la Formación Canal Las Escobas y las facies estuáricas de la Formación Mar Chiquita. En cuanto a la biodiversidad, se menciona que la fauna marina del noreste bonaerense resultó distinta en abundancia y en composición con respecto al área sur. Entre ellas se destaca la presencia de Noetia bisulcata, bivalvo marino infaunal de estirpe cálida, de sustratos arenosos que se encuentra en abundancia en los cordones litorales de Punta Indio y bahía Samborombón y Mactra isabelleana, bivalvo polihalino-eurihalino infaunal de sustrato arenoso, representado en los cordones litorales del área noreste de Provincia de Buenos Aires. Ambas especies resultaron más abundantes en el 
Interglacial MIS 1. Además, este último bivalvo aparece sólo de manera ocasional en los cordones litorales del sur de la Provincia de Buenos Aires. Entre las especies menor representadas en los cordones litorales del noreste bonaerense figuran: Petricola lapicida, Erodona mactroides (bivalvos) y Fuegotrophon pallidus (gasterópodos) no mencionados con anterioridad para el norte patagónico. Otras diferencias entre la fauna marina holocena de la región noreste bonaerense con respecto al norte patagónico es la existencia de especies de estirpe cálida como Anomalocardia brasiliana, Urosalpinx rushi y Thais haemastoma, entre otras especies desplazadas en la actualidad hacia latitudes más altas, y que están ausentes en el norte patagónico durante el Interglacial MIS 1; siendo el bivalvo Crassostrea rhizophorae el único bivalvo de estirpe cálida presente en ambas áreas, registrado en el sur bonaerense solo en la región B (región de bahía Anegada).

\subsubsection{Mesodesma mactroides en la Provincia de Río Negro}

En la región norte de Rio Negro, en el área norte de Río Negro, el Interglacial MIS 1 está representado por cordones litorales. Entre la fauna marina se destaca la presencia del bivalvo Mesodesma mactroides, viviendo en playas arenosas expuestas al oleaje, y distribuido actualmente desde Río de Janeiro ( $23^{\circ} \mathrm{S}$, Brasil) hasta isla Jabalí (40오 , Provincia de Buenos Aires, Argentina) (ej. Ríos 1994; Fiori y Morsan, 2004; Fiori y Defeo, 2006) y asociado a temperaturas templadas desde la zona intermareal hasta profundidades someras del infralitoral (Bastida et al., 1991; Rosenberg, 2009). Las evidencias a nivel malacofaunístico mencionan el límite sur de la especie en isla Jabalí (sur de la Provincia de Buenos Aires, Argentina) (Fiori y Morsan, 2004; Charó et al., 2013), aunque otros autores registran actualmente la especie hasta la desembocadura del Río Negro (Bastida et al., 1991) o hasta la Provincia de Río Negro (41ºS) (ej. Thompson y Sánchez de Bock, 2007). Su aparición en uno de los cordones holocenos (Sitio F27) cerca del puerto de San Antonio Este (4047'S), indica que la especie habría llegado a esas latitudes durante el Holoceno. Estudios previos, en poblaciones actuales demostraron que la densidad de la población de Mesodesma mactroides decrece exponencialmente desde temperaturas medias hacia temperaturas altas. Otro factor que aparentemente influye en la densidad de la población de esta especie sería el 
tipo de playa. Las playas constituidas de arena fina - mediana, con suaves pendientes, fuerte oleaje y gran producción primaria son el hábitat ideal para que Mesodesma mactroides se encuentre en grandes densidades (ej. Defeo y Scarabino, 1990; Fiori y Defeo, 2006). Posiblemente, en el Sitio F27, el tipo de playa haya sido el mejor condicionante, ofreciendo un hábitat propicio para esta especie. Estudios arqueomalacofaunísticos recientes también indican que este bivalvo se encuentra ausente en los concheros holocenos del área norte del golfo San Matías, aunque resultó abundante en el sur de la Provincia de Buenos Aires (Zudimendi, 2007).

\subsection{2. Óptimo Climático}

El Óptimo Climático o Hypsitermal (Holoceno Medio), es un evento registrado tanto en el HN como en el HS, responsable de la ingresión máxima del Holoceno y caracterizado por una temperatura oceánica superficial (SST) ligeramente superior a la actual (ej. Lutaenko, 1993; Hjort et al., 1995). Este evento ha sido reconocido en la fauna marina de moluscos (bivalvos y gasterópodos), principalmente en el área noreste de la Provincia de Buenos Aires (Aguirre, 1993, 2002; Aguirre y Farinati, 1999) y fue asociado a un aumento en la riqueza y abundancia en las especies. En comparación con este trabajo, la fauna de moluscos marinos del norte patagónico en el Interglacial MIS 1, no se caracteriza por el aumento de la riqueza ni la abundancia de las distintas especies. Por otro lado, en coincidencia con otra investigación realizada a lo largo de Patagonia central (Provincia de Chubut y norte de la Provincia de Santa Cruz) (Pastorino 2000), tampoco se registran cambios en las asociaciones faunísticos asociados al evento del Holoceno Medio. Sin embargo, Aguirre et al. (2007) hacen referencia a una mayor abundancia de especies templadas - cálidas en coincidencia con el Óptimo Climático en el área de bahía Vera - Camarones (44.2 ${ }^{\circ} \mathrm{S}$ $\left.45^{\circ} \mathrm{S}\right)$, costa sur patagónico. 


\begin{tabular}{|c|c|c|c|c|c|}
\hline Bivalvos & $\begin{array}{l}\text { Cañada } \\
\text { de } \\
\text { Arregui }\end{array}$ & $\begin{array}{l}\text { Punta } \\
\text { Indio }\end{array}$ & $\begin{array}{c}\text { Bahía } \\
\text { Samborombón }\end{array}$ & $\begin{array}{c}\text { M. } \\
\text { Chiquita }\end{array}$ & $\begin{array}{l}\text { Bahía } \\
\text { Blanca }\end{array}$ \\
\hline \multicolumn{6}{|l|}{ Familia Nuculidae Gray,1824 } \\
\hline Nucula (N.) nucleus ( Linné, 1758) & & $\mathbf{X}$ & $\mathbf{X}$ & $\mathbf{X}$ & $\mathbf{X}$ \\
\hline Ennucula grayi (d’Orbigny, 1846) & & & $\mathbf{X}$ & $\mathbf{X}$ & $\mathbf{X}$ \\
\hline \multicolumn{6}{|l|}{ Familia Nuculanidae H. y A. Adams, 1858} \\
\hline Nuculana (C.) whitensis Farinati, 1978 & & & & & $\mathbf{X}$ \\
\hline Adrana electa (A. Adams, 1856) & & & & & $\mathbf{X}$ \\
\hline \multicolumn{6}{|l|}{ Familia Noetiidae Steward, 1930} \\
\hline Noetia bisulcata (Lamarck, 1819) & & $\mathbf{X}$ & $\mathbf{X}$ & & \\
\hline \multicolumn{6}{|l|}{ Familia Glycymerididae Newton, 1922} \\
\hline Glycymeris (G.) longior ( Sowerby,1832) & & & & $\mathbf{X}$ & $\mathbf{X}$ \\
\hline \multicolumn{6}{|l|}{ Familia Mytilidae Rafinesque,1815 } \\
\hline Mytilus (M.) edulis Linné, 1758 & & $\mathbf{X}$ & $\mathbf{X}$ & $\mathbf{X}$ & $\mathbf{X}$ \\
\hline Brachidontes (B) rodriguezii ( d'Orbigny, 1846) & & $\mathbf{X}$ & $\mathbf{X}$ & $\mathbf{X}$ & $\mathbf{X}$ \\
\hline Musculus viator (d'Orbigny, 1846) & & & & & $\mathbf{X}$ \\
\hline \multicolumn{6}{|l|}{ Familia Plicatulidae Watson, 1930} \\
\hline Plicatula gibbosa Lamarck, 1801 & & & & & $\mathbf{X}$ \\
\hline \multicolumn{6}{|l|}{ Familia Pectinidae Rafinesque, 1815} \\
\hline Aequipecten tehuelchus (d'Orbigny 1842) & & & & & $\mathbf{X}$ \\
\hline \multicolumn{6}{|l|}{ Familia Diplodontidae Dall, 1895} \\
\hline Diplodonta (D.) patagonica ( d'Orbigny, 1842) & & & & $\mathbf{X}$ & $\mathbf{X}$ \\
\hline Diplodonta vilardeboana (d'Orbigny, 1846) & & $\mathbf{X}$ & & & $\mathbf{X}$ \\
\hline Phlyctiderma semiaspera (Philippi, 1836) & & & & & $\mathbf{X}$ \\
\hline \multicolumn{6}{|l|}{ Familia Ostreidae Rafinesque,1815 } \\
\hline Crassostrea rhizophorae (Guilding, 1828) & & $\mathbf{X}$ & & & \\
\hline Ostreola equestris (Say, 1834) & & & & & $\mathbf{X}$ \\
\hline \multicolumn{6}{|l|}{ Familia Carditidae Fleming, 1828} \\
\hline Carditamera plata (Inhering, 1907) & & & $\mathbf{X}$ & $\mathbf{X}$ & $\mathbf{X}$ \\
\hline \multicolumn{6}{|l|}{ Familia Cardiidae Lamarck, 1809} \\
\hline \multicolumn{6}{|l|}{ Trachycardium muricatum (Linné, 1758) } \\
\hline \multicolumn{6}{|l|}{ Familia Mactridae Lamarck,1809 } \\
\hline Mactra isabelleana d'Orbigny, 1846 & & $\mathbf{X}$ & $\mathbf{X}$ & $\mathbf{X}$ & $\mathbf{X}$ \\
\hline Mulinia lateralis (Say, 1822) & & & & & $\mathbf{X}$ \\
\hline Raeta (R.) plicatella (Lamarck,1818) & & & $\mathbf{X}$ & $\mathbf{X}$ & $\mathbf{X}$ \\
\hline
\end{tabular}




\begin{tabular}{|c|c|c|c|c|c|}
\hline Bivalvos & $\begin{array}{l}\text { Cañada } \\
\text { de } \\
\text { Arregui }\end{array}$ & $\begin{array}{l}\text { Punta } \\
\text { Indio }\end{array}$ & $\begin{array}{c}\text { Bahía } \\
\text { Samborombón }\end{array}$ & $\begin{array}{c}\text { M. } \\
\text { Chiquita }\end{array}$ & $\begin{array}{l}\text { Bahía } \\
\text { Blanca }\end{array}$ \\
\hline Darina solenoides ( King and Broderip,1832) & & & & & $\mathbf{X}$ \\
\hline \multicolumn{6}{|l|}{ Familia Telinidae De Blainville, 1814} \\
\hline Tellina petitiana d'Orbigny, 1846 & & & & & $\mathbf{X}$ \\
\hline Angulus gibber Ihering, 1907 & & & & & $\mathbf{X}$ \\
\hline \multicolumn{6}{|l|}{ Familia Semelidae Stoliczka, 1870} \\
\hline Semele proficua (Pulteney, 1799) & & & & & $\mathbf{X}$ \\
\hline \multicolumn{6}{|l|}{ Familia Solenidae Lamarck, 1809} \\
\hline Solen tehuelchus (Hanley, 1842) & & & & & $\mathbf{X}$ \\
\hline \multicolumn{6}{|l|}{ Familia Telinidae De Blainville, 1814} \\
\hline Macoma (P.) uruguayensis (Smith, 1885) & & & $\mathbf{X}$ & $\mathbf{X}$ & $\mathbf{X}$ \\
\hline Strigilla carnaria (Linné, 1758) & & & & & $\mathbf{X}$ \\
\hline \multicolumn{6}{|l|}{ Familia Semelidae Stoliczka,1870 } \\
\hline Abra (A.) aequalis (Say,1822) & & & $\mathbf{X}$ & $\mathbf{X}$ & $\mathbf{X}$ \\
\hline \multicolumn{6}{|l|}{ Familia Solecurtidae d'Orbigny,1846 } \\
\hline Tagelus (T.) plebeius (Ligthfood,1786) & & $\mathbf{X}$ & $\mathbf{X}$ & $\mathbf{X}$ & $\mathbf{X}$ \\
\hline \multicolumn{6}{|l|}{ Familia Donacidae Fleming, 1828} \\
\hline Donax hanleyanus Philippi, 1845 & & & & & $\mathbf{X}$ \\
\hline \multicolumn{6}{|l|}{ Familia Veneridae Rafinesque, 1815} \\
\hline Tivela isabelleana ( d'Orbigny, 1846) & & & & & $\mathbf{X}$ \\
\hline Anomalocardia brasiliana (Gmelin, 1791) & & $\mathbf{X}$ & $\mathbf{X}$ & & $\mathbf{X}$ \\
\hline Pitar (P.) rostratus (Philippi, 1844) & & $\mathbf{X}$ & $\mathbf{X}$ & $\mathbf{X}$ & $\mathbf{X}$ \\
\hline Amiantis purpurata ( Lamarck, 1856) & & & & & $\mathbf{X}$ \\
\hline \multicolumn{6}{|l|}{ Familia Petricolidae Deshayes, 1839} \\
\hline Petricola (P.) lapicida (Chemnitz, 1788) & & $\mathbf{X}$ & $\mathbf{X}$ & & \\
\hline Petricola pholadiformis Lamarck, 1818 & & $\mathbf{X}$ & $\mathbf{X}$ & & \\
\hline \multicolumn{6}{|l|}{ Familia Myidae Lamarck, 1809} \\
\hline Sphenia hatcheri Pilsbry, 1899 & & & & & $\mathbf{X}$ \\
\hline \multicolumn{6}{|l|}{ Familia Corbulidae Gray, 1823} \\
\hline Corbula (C.) patagonica d'Orbigny, 1846 & & $\mathbf{X}$ & $\mathbf{X}$ & $\mathbf{X}$ & $\mathbf{X}$ \\
\hline & & & & $\mathbf{X}$ & $\mathbf{X}$ \\
\hline \multicolumn{6}{|l|}{ Familia Erodonidae Winckworth, 1932} \\
\hline Erodona mactroides Bosc, 1801 & & & & & $\mathbf{X}$ \\
\hline
\end{tabular}




\begin{tabular}{|l|l|l|l|l|l|}
\hline Bivalvos & $\begin{array}{c}\text { Cañada } \\
\text { de } \\
\text { Arregui }\end{array}$ & $\begin{array}{c}\text { Punta } \\
\text { Indio }\end{array}$ & $\begin{array}{c}\text { Bahía } \\
\text { Samborombón }\end{array}$ & $\begin{array}{c}\text { M. } \\
\text { Chiquita }\end{array}$ & $\begin{array}{c}\text { Bahía } \\
\text { Blanca }\end{array}$ \\
\hline Familia Pholadidae Lamarck,1809 & & & & & \\
\hline Cyrtopleura (S.) Ianceolata (d'Orbigny, 1846) & & $\mathbf{X}$ & $\mathbf{X}$ & $\mathbf{X}$ & $\mathbf{X}$ \\
\hline Barnea lamellosa (d'Orbigny, 1846) & & & & & $\mathbf{X}$ \\
\hline Nettastomella darwini (Sowerby, 1849) & & & & & $\mathbf{X}$ \\
\hline Familia Lyonsiidae Rafinesque, 1815 & & & & $\mathbf{X}$ & $\mathbf{X}$ \\
\hline Lyonsia (L.)alvarezii d'Orbigny,1846 & & $\mathbf{X}$ & $\mathbf{X}$ & $\mathbf{X}$ & \\
\hline Entodesma (E.) patagonicum (d'Orbigny, 1846) & & & & & \\
\hline Familia Periplomatidae Dall, 1895 & & & & & $\mathbf{X}$ \\
\hline Periploma ovatum d'Orbigny, 1846 & & & & & $\mathbf{X}$ \\
\hline Familia Thraciidae Stoliczka, 1870 & & & & & $\mathbf{X}$ \\
\hline Thracia similis Couthouy, 1839 & & & \\
\hline Bushia rushi (Pilsbry, 1897) & & & \\
\hline
\end{tabular}

T.10.4: Distribución de bivalvos en el holoceno en distintas áreas del sector norte y sur Provincia de Buenos Aires citado por (Aguirre y Fucks, 2004; Aguirre y Farinati, 1999). 


\begin{tabular}{|c|c|c|c|c|c|}
\hline GASTERÓPODOS & $\begin{array}{l}\text { Cañada } \\
\text { de } \\
\text { Arregui }\end{array}$ & $\begin{array}{l}\text { Punta } \\
\text { Indio }\end{array}$ & $\begin{array}{c}\text { Bahía } \\
\text { Samboro } \\
\text { mbón }\end{array}$ & $\begin{array}{c}\text { M. } \\
\text { Chiquita }\end{array}$ & $\begin{array}{l}\text { Bahía } \\
\text { Blance }\end{array}$ \\
\hline \multicolumn{6}{|l|}{ Familia Fissurellidae Fleming, 1822} \\
\hline Diodora (D.) patagonica (d'Orbigny, 1841) & $\mathbf{X}$ & & $\mathbf{X}$ & $\mathbf{X}$ & $\mathbf{X}$ \\
\hline Lucapinella henseli (Martens, 1900) & & & & & $\mathbf{X}$ \\
\hline \multicolumn{6}{|l|}{ Familia Calliostomatidae Thiele, 1924} \\
\hline \multicolumn{6}{|l|}{ Calliostoma carcellesi Clench y Aguacho, 1940 ) } \\
\hline Calliostoma coppingeri (Smith, 1880) & $\mathbf{X}$ & & & & $\mathbf{X}$ \\
\hline Calliostoma nordenskioldi Strebel, 1908 & & & & & $\mathbf{X}$ \\
\hline \multicolumn{6}{|l|}{ Tegula (A.) patagonica (d'Orbigny, 1835) } \\
\hline \multicolumn{6}{|l|}{ Familia Calyptraeidae Lamarck,1809 } \\
\hline Bostrycapulus odites (Collin, 2005) & & $\mathbf{X}$ & $\mathbf{X}$ & $\mathbf{X}$ & $\mathbf{X}$ \\
\hline Crepidula argentina Simone, Pastorino \& Penchaszadeh, 2000 & $\mathbf{X}$ & $\mathbf{X}$ & $\bar{x}$ & $\bar{x}$ & \\
\hline Crepidula dilatata Lamarck, 1822 & & $\mathbf{X}$ & $\mathbf{X}$ & & \\
\hline \multicolumn{6}{|l|}{ Familia Naticidae Forbes, 1828} \\
\hline Notocochlis isabelleana (d'Orbigny, 1840) & & $\mathbf{X}$ & & & $\mathbf{X}$ \\
\hline Falsilunatia patagonica (Philippi, 1845) & & & & & $\mathbf{X}$ \\
\hline \multicolumn{6}{|l|}{ Familia Hydrobiidae } \\
\hline Heleobia australis ( d’Orbigny, 1835) & & $\mathbf{X}$ & $\mathbf{X}$ & $\mathbf{X}$ & $\mathbf{X}$ \\
\hline \multicolumn{6}{|l|}{ Familia Epitoniidae S. S.Berry, 1910} \\
\hline Epitonium (E.) georgettinum (d'Orbigny,1840) & & $\mathbf{X}$ & $\mathbf{X}$ & $\mathbf{X}$ & $\mathbf{X}$ \\
\hline Epitenium tenuistriatum (d'Orbigny, 1840 ) & & & & & $\mathbf{X}$ \\
\hline \multicolumn{6}{|l|}{ Familia Muricidae Rafinesque, 1815} \\
\hline Fuegotrophon pallidus (Broderip, 1833) & & $\mathbf{X}$ & $\mathbf{X}$ & & \\
\hline Urosalpinx cala (Pilsbry, 1897) & & & $\mathbf{X}$ & & \\
\hline Urosalpinx rushi Pilsbry, 1897 & & & $\mathbf{X}$ & & \\
\hline \multicolumn{6}{|l|}{ Familia Thaididae Röding, 1798} \\
\hline Morula necocheana (Pilsbry, 1900) & & & & & $\mathbf{X}$ \\
\hline \multicolumn{6}{|l|}{ Familia Volutidae Rafinesque, 1815} \\
\hline Zidona dufresnei ( Donovan, 1823) & & & $\mathbf{X}$ & & \\
\hline Adelomelon (P.) brasiliana (Lamarck, 1811) & $\mathbf{X}$ & & $\mathrm{X}$ & & $\mathbf{X}$ \\
\hline
\end{tabular}




\begin{tabular}{|c|c|c|c|c|c|}
\hline GASTERÓPODOS & $\begin{array}{c}\text { Cañada } \\
\text { de } \\
\text { Arregui }\end{array}$ & $\begin{array}{l}\text { Punta } \\
\text { Indio }\end{array}$ & $\begin{array}{c}\text { Bahía } \\
\text { Samboro } \\
\text { mbón }\end{array}$ & $\begin{array}{c}\text { M. } \\
\text { Chiquita }\end{array}$ & $\begin{array}{c}\text { Bahía } \\
\text { Blanca }\end{array}$ \\
\hline Adelomelon beckii (Broderip,1838) & & & & & $\mathbf{X}$ \\
\hline Adelomelon ancilla (Lightfood, 1786) & & & & & $\mathbf{X}$ \\
\hline \multicolumn{6}{|l|}{ Familia Marginellidae Fleming,1828 } \\
\hline Marginela martini Petit, 1853 & & & & & $\mathbf{X}$ \\
\hline \multicolumn{6}{|l|}{ Familia Terebridae H. y A. Adams, 1854} \\
\hline Terebra gemmulata Kiener, 1835 & & & & & $\mathbf{X}$ \\
\hline \multicolumn{6}{|l|}{ Familia Olividae Latreille,1825 } \\
\hline Olivella (O.) tehuelcha ( Dúclos, 1835) & & & $\mathbf{X}$ & $\mathbf{X}$ & $\mathbf{X}$ \\
\hline Olivancillaria urceus ( Röding, 1798) & $\mathbf{X}$ & & $\mathbf{X}$ & & $\mathbf{X}$ \\
\hline Olivancillaria carcellesi Klappenbach, 1965 & $\mathbf{X}$ & & $\mathbf{X}$ & & \\
\hline Olivancillaria uretai Klappenbach, 1965 & & & & & $\mathbf{X}$ \\
\hline \multicolumn{6}{|l|}{ Familia Nassariidae Iredale, 1916} \\
\hline Buccinanops monilifer ( Kiener, 1834) & & & & $\mathbf{X}$ & \\
\hline Buccinanops cochlidium (Dilwyn, 1817) & $\mathbf{X}$ & & & $\mathbf{X}$ & \\
\hline Buccinanops globulosus (Kiener, 1834) & $\mathbf{X}$ & & & $\mathbf{X}$ & \\
\hline \multicolumn{6}{|l|}{ Familia Pyramidellidae Gray, 1840} \\
\hline Turbonilla uruguayensis Pilsbry, 1897 & & & $\mathbf{X}$ & $\mathbf{X}$ & $\mathbf{X}$ \\
\hline \multicolumn{6}{|l|}{ Familia Siphonariidae Gray, 1840} \\
\hline Siphonaria lessoni (Blainville, 1824) & & & & $\mathbf{X}$ & $\mathbf{X}$ \\
\hline
\end{tabular}

T.10.5: Distribución de gasterópodos en el Holoceno en distintas áreas del sector norte y sur provincia de Buenos Aires citado por (Aguirre y Fucks, 2004; Aguirre y Farinti, 1999) 


\subsection{Fauna marina del $\mathbf{S}$ de provincia de Buenos Aires vs $\mathbf{N}$ de río Negro}

La fauna de bivalvos y gasterópodos marinos encontrados en los diferentes interglaciales analizados (MIS 7, MIS 5e, MIS 1) en la región norte del golfo San Matías difiere en composición y abundancia de especies en comparación con las regiones analizadas al $\mathrm{S}$ de la Provincia de Buenos Aires. Entre estas diferencias se destaca que, en la región norte de Rio Negro (norte del golfo San Matías) durante los interglaciales MIS 7 y MIS 5e se encuentra presente el gasterópodo Tegula atra. En el Interglacial MIS 1 se destaca la presencia de los bivalvos: Aulacomya atra, Retrotapes exalbidus, Ameghinomya antiqua y los gasterópodos Nacella magallanica y Fissurella radiosa radiosa, típicos de aguas templado-frías y aguas frías de la Provincia Magallánica, no representados en el área sur bonaerense (región A, B y C). Entre la fauna actual, la presencia de los bivalvos Ameghinomya antiqua, Retrotapes exalbidus y Aulacomya atra, y gasterópodos como Crepidula dilatata, en las playas del norte del golfo de San Matías, difieren marcadamente con los bivalvos más comunes encontradas en las playas del sur de la Provincia de Buenos Aires como Cyrtopleura lanceolata, Barnea lamellosa, Solen tehuelchus y Mesodesma mactroides. A pesar de estas diferencias, tanto el área norte (regiones $\mathrm{A}, \mathrm{B}$ y $\mathrm{C}$, pertenecientes al sur de la provincia de Buenos Aires) y el área sur (región D, del norte del golfo San Matías) tienen en común 34 especies (44\%) de la fauna marina total. Entre estas especies figuran: Amiantis purpurata, Glycymeris longior y Brachidontes rodriguezii (bivalvos); y Tegula patagonica, Bostrycapulus odites, Buccinanops cochlidium y Buccinanops globulosus (gasterópodos). Todas estas especies se encuentran en los diferentes interglaciales a lo largo de las cuatro regiones estudiadas en este trabajo.

Finalmente, y en virtud de las diferencias y semejanzas, la región del N del golfo San Matías, es considerada desde el punto de vista malacológico como un ecotono, es decir una zona de transición entre las regiones biogeográficas Argentina y Magallánica. 


\subsection{Principales características geomorfológicas y cambios faunísticos en el período comprendido entre el MIS 9 y la actualidad para el área estudiada}

En el área de estudio se identificaron cuatro regiones (A, B, C y D) según sus características geomorfológicas. Dentro de la región estudiada se encuentran presentes los interglaciales $\geq$ MIS 9, MIS 7, MIS 5e y MIS 1, representados geomorfológicamente por paleoacantilados, plataformas costeras, paleoplayas, cordones litorales y planicies de marea, todos con fauna de moluscos asociados.

En las tres primeras regiones (regiones A, B y C), que en conjunto constituyen la costa sur de la Provincia de Buenos Aires, se describe la presencia de los interglaciales $\geq$ MIS 9, MIS 5e y MIS 1, a diferencia de lo que acontece en la región Norte del golfo San Matías (Región D) en donde se detectó la presencia de los interglaciales MIS 7, MIS 5e y MIS 1 y un cuarto interglacial, situado a cota de $60 \mathrm{~m}$, y que probablemente corresponda a un Interglacial $\geq$ MIS 9 .

Durante el desarrollo del Interglacial $\geq$ MIS 9, todos los sitios analizados corresponden a paleoplayas y cordones litorales, ambientes de alta energía donde la mayoría de la fauna marina representada es eurihalina (salinidad > de 30 - $35 \mathrm{gr} / \mathrm{l}$ ) y de sustrato arenoso.

Los bivalvos y los gasterópodos constituyen herramientas paleoclimáticas ("proxies" paleoclimáticos), siendo los primeros mejores indicadores a los fines de estimar indirectamente paleotemperaturas del agua de mar. En consonancia con ello es posible concluir que para el Interglacial $\geq$ MIS 9 existe una mayor cantidad de especies de aguas cálidasrespecto a los demás interglaciales detectados en el área sur de la Provincia de Buenos Aires.

En el Interglacial MIS 5e, y para toda el área de estudio, los sitios analizados corresponden, mayoritariamente, a cordones litorales; es decir, ambientes de alta energía, donde la mayoría de las asociaciones faunísticas son eurihalinas, mayormente de sustrato arenoso y rocoso subordinado.

En consonancia con las asociaciones faunísticas detectadas, en el Interglacial MIS 5e existe un $44 \%$ a un $50 \%$ de especies de aguas cálidasen el sur de la Provincia de Buenos Aires, a diferencia del norte de la Provincia del Río Negro donde esta proporcionalidad sólo se detecta en un $27 \%$ de la totalidad de los bivalvos. 
En el Interglacial MIS 7 todos los sitios analizados corresponden a paleoplayas, representados actualmente por plataformas costeras; es decir ambientes de alta energía, donde la mayoría de las asociaciones faunísticas son eurihalinas de sustrato arenoso y rocoso subordinado. Respecto a los indicadores paleoclimáticos de temperatura del agua de mar, las asociaciones faunísticas determinan la presencia de un $20 \%$ de especies bivalvos cálidos en este interglacial.

El Interglacial MIS 1 se detectó en toda el área de estudio, constituyendo en el sur de la Provincia de Buenos Aires dos tipos de depósitos: cordones litorales, ambientes de alta energía, y planicies de marea, ambientes de baja energía. En los primeros las asociaciones faunísticas en su mayoría son eurihalinas, y de sustratos arenosos; en cambio, en las segundas, los rangos de salinidad varían ampliamente existiendo asociaciones faunísticas oligohalinas - mesohalinas - polihalinas (salinidades entre 3 y $30 \mathrm{gr} / \mathrm{l}$ ), de sustratos arenosos finos. Esto último estaría en consonancia con los primeros atisbos de la conformación de los rasgos geomorfológicos actuales de ambientes de baja energía (extensas planicies de mareas, canales de marea y cursos fluviales no funcionales), dando como resultado la formación de islas que se visualizan en toda el área sur de la Provincia de Buenos Aires. En el norte de Río Negro, el Interglacial MIS 1 se encuentra constituido por cordones litorales siendo las asociaciones faunísticas representadas en su mayoría eurihalinas, de sustrato arenoso y rocoso subordinado.

En consonancia con las asociaciones faunísticas detectadas, en el Interglacial MIS 1 existe un $45 \%$ a un $50 \%$ de especies de aguas cálidas en el sur de la Provincia de Buenos Aires, a diferencia del norte de la Provincia del Río Negro donde esta proporcionalidad sólo se detecta en un $18 \%$ de la totalidad de los bivalvos.

En la actualidad, el sur de la Provincia de Buenos Aires, y a excepción de lo que acontece en el sector norte de bahía Anegada coexisten playas arenosas con playas areno-fangosas y las asociaciones faunísticas responden a parámetros marinos de alta energía, eurihalinas de sustrato arenoso y con parches de sustrato rocoso subordinado fundamentalmente en la región de isla Jabalí a Villa 7 de Marzo. En cambio, las playas actuales de la región norte del golfo San Matías (norte de la Provincia de Río Negro), son más extensas y muchas veces superan en dimensión los centenares de metros. Existen desde el punto de vista 
granulométrico 2 tipos de playas: por un lado, un sector intermareal bajo de arena finamediana con sectores distales altos, gravosos y de composición organógena; y por otro lado, un sector intermareal bajo y distal alto, de arena fina-mediana. Ambos se asocian a ambientes de alta energía donde las asociaciones faunísticas son en su mayoría eurihalinas, de sustrato arenoso con menor proporción de fauna de parches de sustrato rocoso.

Existen dos excepciones a lo descripto en el punto anterior. La playa actual de la localidad de Villa 7 de Marzo presenta un rasgo particular respecto a las demás. Se trata de un tipo de playa, de sustrato arenoso fino, donde abundan dos especies de bivalvos, Plicatula gibbosa y Ostrea puelchana, y el gasterópodo Crepidula lo que podrían atribuirse a la influencia del río Negro. Lo mismo ocurre en el sector sur del mismo río, en la playa del balneario El Cóndor, que presenta un ambiente similar y la misma fauna recién descripta.

Las asociaciones faunísticas actuales determinan la presencia de un 33 a $50 \%$ de especies de aguas cálidas en el sur de la Provincia de Buenos Aires y un $31 \%$ en el norte de la Provincia de Río Negro durante la actualidad.

Para el sur de la Provincia de Buenos Aires se concluye que en el Interglacial $\geq$ MIS 9 tuvo lugar, en comparación a los demás interglaciales detectados en el área, una mayor frecuencia de especies de aguas cálidas en las asociaciones faunísticas de bivalvos (50 67\%) a pesar de no haberse encontrado ningún bivalvo o gasterópodo de estirpe cálida que constituya en sí mismo un paleoindicador. En el Interglacial MIS 5e se registra a su vez una proporcionalidad menor de asociaciones faunísticas de especies de aguas cálidas respecto al interglacial anterior ( $44 \%$ a $50 \%$ ) destacándose la presencia del bivalvo de estirpe cálida (Crassostrea rhizophorae), excelente paleoindicador. En el Interglacial MIS 1 se registran asociaciones faunísticas que ameritan una proporcionalidad similar de especies de aguas cálidas (45\% a $50 \%$ ) respecto al interglacial MIS 5e, destacándose también la presencia del bivalvo (Crassostrea rhizophorae).

Finalmente, en las playas actuales se registra un tenor variable entre el 33 al $50 \%$ de bivalvos de aguas cálidas.

De lo expuesto, y para el norte de la Provincia de Río Negro, se concluye que en el Interglacial MIS 7, las asociaciones faunísticas determinan una proporcionalidad de bivalvos de aguas cálidas $(20 \%)$, sin por ello dejar de hacer notar la presencia en este 
interglacial del gasterópodo Tegula atra, probablemente un paleoindicador de aguas cálidas. En el Interglacial MIS 5e se registra a su vez una proporcionalidad levemente mayor de asociaciones faunísticas de especies de aguas cálidas (27\%) respecto al interglacial anterior, destacándose la presencia de Anomalocardia brasiliana y de Tegula atra: el primero, excelente paleoindicador, y, muy probablemente también el segundo. En el Interglacial MIS 1 se registran asociaciones faunísticas que ameritan una proporcionalidad menor de especies de aguas cálidas (18\%) respecto al Interglacial MIS 5e, destacándose la presencia del bivalvo Mesodesma mactroides. Respecto a la presencia de Aulacomya atra, Retrotapes exalbidus, Ameghinomya antiqua (bivalvos) y Fisurella radiosa radiosa y Crepidula dilatata (gasterópodos) encontradas en las playas de Río Negro, y siendo que las mismas no han sido descriptas en la fauna marina actual del sur de la Provincia de Buenos Aires, se vincula a la afluencia de aguas frías a templadas procedentes del sur argentino. Ello significaría que la región de Patagonia Norte representa una zona de ecotono biogeográfico a partir del Interglacial MIS 1 y hasta la actualidad.

Respecto a la salinidad, se concluye que en el norte patagónico las faunas marinas asociadas en todos los interglaciales detectados no presentan una variación manifiesta ya que las especies son mayormente eurihalinas. Una excepción, sin embargo, es lo que acontece para el Interglacial MIS 1 en el sur de la Provincia de Buenos Aires donde se registran asociaciones que contienen componentes de una menor salinidad (oligo, meso y polihalinos), cuestión que también se verifica en las playas actuales con la presencia del bivalvo Tagelus plebeius y el gasterópodo Heleobia australis.

La presencia del bivalvo Crassostrea rhizophorae en el sur de la Provincia de Buenos Aires, como así también del bivalvo Anomalocardia brasiliana y muy posiblemente del gasterópodo Tegula atra, en el norte de Río Negro, podrían evidenciar que los interglaciales MIS 7, MIS 5e y MIS 1 fueron períodos ligeramente más cálidos que el actual. Sin embargo, las asociaciones faunísticas determinadas para los interglaciales analizados no sufrieron cambios detectables en cuanto a la composición faunística en su conjunto $\mathrm{y}$, salvo los corrimientos latitudinales de las 3 especies mencionadas anteriormente, y la presencia de asociaciones faunísticas de aguas frías a templadas a partir del Interglacial MIS 1 a la actualidad en el norte de Río Negro (ecotono), la composición 
faunística permaneció similar registrándose sólo cambios en la abundancia poblacional de las especies presentes.

Respecto a las causas de los cambios acontecidos en el área de estudiodentro del lapso considerado, si bien no se discute en esta tesis, obedecen en parte a cambios climáticos globales vinculados a la alternancia de períodos glaciales e interglaciales, que habrían dado lugar a importantes a cambios en el nivel del mar afectando la distribución de determinadas especies, y en parte a factores regiones/locales como cambios circulatorios y a la existencia de heterogeneidad de habitats donde se desarrollan diferentes subambientes que habrían condicionado el desarrollo de distintas asociaciones faunísticas locales, entre otras causas. 


\section{CONCLUSIONES}

En base todo lo anterior se concluye que:

Para el período geológico considerado, existen variaciones entre las paleocomunidades de moluscos del sur de Buenos Aires y norte de Río Negro.

La biodiversidad de gasterópodos y bivalvos de los Interglaciales ( $\geq$ MIS 9 , MIS 7 y MIS 5e) correspondientes al período Pleistoceno varían entre sí en abundancia y no en composición faunística con respecto a la fauna de moluscos encontrada en el Interglacial MIS 1.

La biodiversidad de gasterópodos y bivalvos del Interglacial MIS 1 varían con respecto a la fauna de moluscos encontrados en la actualidad en el área de estudio.

Existen desplazamientos geográficos de algunas especies relacionados a cambios climáticos ocurridos durante el Cuaternario.

Durante el Óptimo Climático, el aumento de las temperaturas superficiales oceánicas en su mayoría no se reflejan en las paleocomunidades de moluscos del Interglacial MIS 1 en el área de estudio.

Las causas de estos cambios se vincularían a factores globales, regionales y locales, difíciles de discriminar. 


\section{REFERENCIAS}

Aguirre, M.L., 1990. Holocene Macrobenthic Molluscan Associations from North-eastern Buenos Aires Province, Argentina. Quaternary of South America \& Antarctic Peninsula, 7: 161-195.

Aguirre, M. L., 1993a. Carcaterización faunística del Cuaternario marino en el Noreste Bonaerense. Revista de la Asociación Geológica Argentina, 47(1): 31-54.

Aguirre, M. L., 1993b. Palaeobiogeography of the Holocene molluscan fauna from Northeastern Buenos Aires Province, Argentina: its relation to coastal evolution and sea level changes. Palaeogeography, Palaeoclimatology, Palaeoecology, 102:1-26.

Aguirre, M. L., 1993c. Type Specimens of Quaternary Marine Gastropods from Argentina. Ameghiniana, 30 (1): 23-38.

Aguirre, M. L., 1994. Type Specimens of Quaternary Marine Bivalves from Argentina. Ameghiniana, 31 (4): 347-374.

Aguirre, M. L., 2002. Óptimo climático en el Holoceno marino de la Argentina: evidencias Malacológicas. Actas XV Congreso Geológico Argentino, Calafate. Tomo I, 548-553.

Aguirre, M. L., 2003. Late Pleistocene and Holocene palaeoenviroments in Golfo San Jorge, Patagonia: molluscan evidence. Marine Geology, 194: 3-30.

Aguirre, M.L. y Farinati, E. A., 1997. Paleobiogeografía de las faunas de Moluscos Marinos del Neoógeno y Cuaternario del Atlántico Sudoccidental. Revista Sociedad Geológicas de España, 12 (1): 93-112.

Aguirre, M. L. y Farinati, E. A., 1999. Paleobiogeografía de las faunas de moluscos marinos del Neógeno y Cuaternario del Atlántico Sudoccidental. Revista Sociedad Geológica de España, 12 (1): 93-112. 
Aguirre, M. L. y Farinati, E. A., 2000. Moluscos del Cuaternario Marino de la Argentina. Boletín de la Academia Nacional de Ciencias, 64: 235-333.

Aguirre, M. L. y Fucks, E. E., 2004. Moluscos y paleoambientes del Cuaternario marino en el sur de Entre Ríos y litoral bonaerense. Temas de Biodiversidad del litoral fluvial argentino. Miscelánea, 12: 55-70.

Aguirre, M. L. y Urrutia, M. I., 2002. Morphological variability of Littoridina australis (d’Orbigny, 1835) (Hydrobiidae) in the Bonaerensian Marine Holocene (Argentina). Palaeogeography, Palaeoclimatology, Palaeoecology, 183: 1-23.

Aguirre, M. L. y Whatley, R. C., 1995. Late Quaternary Marginal Marine Deposits from NorthEastern Buenos Aires Province, Argentina: A Review. Quaternary Science Reviews, 14: 223-254.

Aguirre, M. L., Leng, M. Spiro, B., 1998. Palaeoenvironments in Golfo San Jorge, Patagonia: molluscan evidence. Marine Geology, 194: 3-30.

Aguirre, M. L., Negro Sirch, Y., Richiano, S., 2005. Late Quaternary molluscan assemblages from the coastal area of Bahía Bustamante (Patagonia, Argentina): Paleoecology and paleoenviroments. Journal of South Earth Sciences, 20: 13 -32.

Aguirre, M. L., Richiano, S., Negro Sirch, Y., 2006. Palaeoenvironments and palaeoclimates of the Quaternary molluscan faunas from the coastal area of Bahía Vera-Camarones (Chubut, Patagonia). Palaeogeography, Palaeoclimatology, Palaeoecology, 229: $251-286$.

Aguirre, M. L., Richiano, S., Negro Sirch, Y., 2007. Moluscos de terrazas marinas cuaternarias del área de Camarones, Patagonia. Bolletín de la Societat d’Història Natural de las Balears, 14: 81-120.

Aguirre, M. L., Donato, M., Richiano, S., Farinati, E. A., 2011. Pleistocene and Holocene interglacial molluscan assemblages from Patagonian and Bonaerensian littoral (Argentina, SW Atlantic): Palaeobiodiversity and palaeobiogeography. Palaeogeography, Palaeoclimatology, Palaeoecology, 308: 277-292. 
Alberó, M. C., Angioloni, F. Balbuena, J.M.L., Codignotto, J. O., Linares, E., Weiler, N. E., 1980. Primeras edades Carbono-14 de afloramientos de conchillas de la República Argentina. Asociación Geológica Argentina, Revista XXXV (3): 363-374.

Alcalde, R., 2011. Programa integral de calidad de aguas del río Colorado: Calidad del medio acuático. Comité Interjurisdiccional del río Colorado. Secretaria de Energía de la Nación, 341 p.

Alley, R.D., 2000. The Younger Dryas cold interval as viewed from central Greenland.Quaternary Science Reviews, 19: 213-226.

Ambrosini, G. L., 1984. Geomorfología de la isla del Jabalí, Departamento de Patagones, provincia de Buenos Aires. Noveno Congreso Geológico Argentino, Actas III: 497-512, San Carlos de Bariloche.

Ameguino, F., 1889. Contribución al conocimiento de los mamíferos fósiles de la República Argentina. Actas de la Academia Nacional de Córdoba, 6: 1-1027.

Ameghino, F., 1898. Sinopsis geológico - paleontológica de la Argentina. II Censo de la República Argentina, Tomo I: $112-255$.

Ameguino, F., 1908. Las formaciones sedimentarias de la región litorak de Mar del Plata y Chapadmalán. Anales del Museo Nacional de Buenos Aires, 10, 3ª Sección: 343-428.

Angulo, E., Fidalgo, F., Peral Gomez, M. A., Schnack, E. J., 1978. Las ingresiones marinas cuaternarias en la bahía de San Antonio y sus vecindades, provincia de Río Negro. VII Congreso Geológico Argentino, Actas I: 271-283.

Angulo, R., Fidalgo, F., Gómez Peral, M.A., Schnack, E.J., 1981. Geología y geomorfología del bajo de San Antonio y alrededores, provincia de Río Negro. Centro de Investigaciones científicas, Secretaria de planeamiento. Estudios y documentos, 8 . 
Angulo, R. J. y Lessa, G. C., 1997. The Brazilian sea-level curves: a critical review with emphasis on the curves from the Paranaguá and Cananéia regions. Marine Geology, 140: 141-166.

Angulo, R. J., Giannini, P. C. F., Suguio, K., Pessenda, L. C. R., 1999. Relative sea-level changes in the last 5.500 years in southern Brazil (Laguna-Imbituba region, Santa Catarina State) based on vermetid ${ }^{14} \mathrm{C}$ ages. Marine Geology, 159: 323-339.

Arruda, C. C. B., Beasley, C. R., Vallinoto, M., Marques - Silva, N. S., Tagliaro, C. H., 2009. Significant genetic differentiation among populations of Anomalocardia brasiliana (Gmelin, 1791): a bivalve with planktonic larval dispersion. Genetic Mololecular Biology, 32: 423-430.

Auer, V., 1959. The Pleistocene of Fuego-Patagonia. Parte III. Shoreline Displacements. Ann. Acad. Sci. Fennicae, III, A 60: 1-237.

Auer, V., 1970. The Pleistocene of Fuego-Patagonia. Parte V. Ann. Acad. Sci. . Fennicae, A 100: 1193.

Averbuj, A., 2009. Biología reproductiva, crecimiento y dieta del caracol ciego Buccinanops cochlidium (Gastropoda: Nassaridae) en el golfo San José, Argentina. Tesis doctoral, UBA.

Bala, L. O., 1989. Biología y ecología del mejillón (Mytilus edulis platensis) en el golfo San José, provincia de Chubut. Tesis Doctoral, Facultad de Ciencias Naturales y Museo, UNLP, 250p.

Balech, E. y Ehrich, M.D., 2008. Esquema biogeográfico del mar argentino. Revista de investigación de desarrollo pesquero $\mathrm{N}^{\mathrm{o}}$ : 19: 45-75.

Barré, N., Provost, C., Sacareno, M., 2006. Spatial and temporal scales of the Brazil-Malvinas Currents influence documented by simultaneous MODIS Aqua $1.1 \mathrm{~km}$ resolution SST and color images. Advances in Space Research, 37: 770-786.

Barreto, A. M. F., Becerra, F. H. R., Suguio, K., Batumi S. H., Yee, M., Paiva R. P., Munita, C. S., 2002.Late Pleistocene marine terrace deposits in northeastern Brazil: sea - nevel change and tectonic implications. Palaeogeography, Palaeoclimatology, Palaeoecology, 179: 57 - 69. 
Bastida, R., Roux, A., Martinez, D., 1992. Benthic communities of the Argentine Continental Shelf. Oceanológica, 15 (6): 687:698.

Bastida, R., Roux, A., Bremec, C., Gerpe, M., Sorensen, M., 1991. Estado actual de la comunidad de la almeja amarilla (Mesodesma mactroides, Deshayes, 1854) en la provincia de Buenos Aires, Frente Marítimo, 9: 83-92.

Bastida, R., Zamponi, M., Bremec, C., Roux, A., Genzano, G., Elías, R., 2007. Las comunidades bentónicas. El mar argentino y sus recursos pesqueros, 5: 91 - 125 .

Bayer, M., Gordillo, S., Fucks, E., 2010. Análisis Tafonómico en Amiantis purpurata (Lamarck), Bivalvia: una clase para descifrar los paleoambientes del cuaternario en el golfo San Matías, Río Negro, Argentina. X Congreso Latinoamericano de Paleontología, 1: 111.

Bayer, S. y Gordillo, S., 2013. A new Pleistocene species of Glycymeris (Bivalvia, Glycymerididae) from northern patagonia, Argentina. Ameghiniana, 50 (2): 265-268.

Beu, A., 1974. Molluscan evidence of Warm Sea Temperaturesin New Zeland during Kapitean (Late Miocene) and Wapipian (Middle Pliocene) time. N. Z. Journal of Geographic and Geologic, 17 (2): 465-479.

Bezerra, F. H. R., Barreto, A. M. F., Suguio, K., 2003. Holocene sea-level history in the Rio do Grande do Norte State coast, Brazil. Marine Geology, 186: 73-89.

Bigatti, G., 2005. Anatomia, ecologia y reproduccion del caracol rojo Odontocymbiola magellanica (Gastropoda: Volutidae) en golfos norpatagonicos. Tesis Doctoral, UBA.

Blunier, T., Schwander, J., Stauffer, B., Stocker, T., Dällenbach, A. Indermühle, A., Tschumi, J., 1997. Timing of the Antarctic Cold Reversal and the atmospheric $\mathrm{CO}_{2}$ increase with respect to the Younger Dryas event. Geophysical Research Letters, 24: 2683-2686. 
Boltovskoy, D., 2007. Atlas de Sensibilidad Ambiental de la costa y el Mar Argentino. atlas.ambiente.gov.ar.

Bond, G. C., Lotti, R., 1995. Icebergs Discharges into the North Atlantic on Millennial Time Scales During the Last Glaciation. Science, 267 (5200): 1005-1010.

Boretto, G., Aguirre, M., Lomovosky, B. , Zanchetta, G., Fucks, E., Consoloni, I., Arregui, M, Charó, M., 2009. Protothaca antiqua (King) (Bivalvia, Veneroida) en el Cuaternario Marino del área Bahía Bustamante - Bahía Solano (Patagonia central, Argentina): herramienta paleoambiental. Reunión Anual de comunicaciones de la asociación paleontológica argentina. Acta:, CABA.

Boretto, G., Gordillo, S., Cioccale, M., Colombo, F., Fucks, E., 2013. Multi-proxy evidence of Late Quaternary environmental changes in the coastal area of Puerto Lobos (Northern Patagonia, Argentina). Quaternary International. doi: http://dx.doi.org/10.1016/j.quaint.2013.02.017.

Bouchet, P. y Rocroi, J.P., 2005. Classification and Nomenclator of Gastropod families. Malacologia, 47 (1-2): 1-139.

Bradley, R. S., 1999. Paleoclimatology: Reconstructing cliamtes of the Quaternary. Second Editions, 614p.

Braun, H., Christ, M., Rahmstorf, S, Ganopolski, A., Mangini, A., Kubatzki, C, Roth, K., Kromer, B., 2005. Possible solar origin of the 1.470 -year glacial climate cycle demonstrated in a coupled model. Nature, 438: 208-211.

Bremec, C., 1986a. Asociaciones de macrobentos infralitoral de Monte Hermoso (3900`S61ำ 17 , República Argentina). Spheniscus, 2: 1-18.

Bremec, C., 1986b. Inventario y ecología del macrobentos marinos de un sector de la provincia de Buenos Aires. Facultad de Ciencias Naturales y Museo, Universidad Nacional de la Plata, 209 p.

Bremec, C., 1988. Macrobentos del área de Bahía Blanca, con especial referencia a la malacofauna infralitoral. Comunicaciones Asociación Malacológica Uruguay, 7 (52-53): 39 p. 
Bremec, C., Brey., T., Lasta, M., Valero, J., Lucifora, L., 2000. Zygochlamys patagonica beds on the Argentinian shelf. Part I: Energy flor through the scallop bed community. Archive of Fishery and Marine Research, 48 (3): 295-303.

Broecker, W. S., 2002. Massive iceberg discharges as triggers for global climate changes. Nature, 372 (6505): 421-424.

Bujalesky, G. G. y Isla, F. I., 2006. Depósitos cuaternarios de la costa atlántica fueguina, entre los Cabos Peñas y Ewan. Revista de la Asociación Geológica Argentina, 61(1): 81-92.

Camacho, H., 1966. Paleontografía Bonaerense. III. Invertebrados. En: A. V. Borrello (ed.), Comisión de Investigaciones Científicas, 3: 159 p.

Camacho, H., 1967. Las transgresiones del Cretácico Superior y Terciario de la Argentina. Revista de la Asociación Geológica Argentina, 22 (4): 253-279.

Camacho, H., 2008. Los invertebrados fósiles. (2 volúmenes). Vázquez Manzini Eds., 950 p.

Cantolla, Antón Uriarte, 2003. Historia del clima de la Tierra. Gobierno Vasco, 305 p.

Cappannini, D. y Lores, R., 1966. Los suelos del valle inferior del río Colorado. INTA. Colección suelos, $\mathrm{N}^{\circ} 1$. Buenos Aires.

Cardenas, J. y Gordillo, S., 2009. Paleoenvironmental interpretation of late Quaternary molluscan assemblages from southern South America: A taphonomic comparison between the Strait of Magellan and the Beagle Channel. Andean Geology, 36 (1): 81-93.

Carcelles, A., 1944. Catálogo de los moluscos marinos de Puerto Quenquén. Revista del Museo de la Plata, Sección Zoología, 3: 233-309.

Carcelles, A. 1950. Catálogo de moluscos marinos de la Patagonia. Anales del Museo Nahuel Huapí, 3:155-250. 
Carcelles, A. y Williamsom, S., 1951. Catálogos de los moluscos marinos de la Provincia Magallánica. Revista del Museo Argentino de Ciencias Naturales Bernardino Rivadavia. Ciencias Zoológicas 2, 5: 225-383.

Cárdenas, J. y Gordillo, S., 2009. Late Quaternary molluscan assemblages from Tierra del Fuego (southern South America): a taphonomic analysis. Andean Geology, 36 (1): 81-93.

Caruso, Jr. F., Sugui, K. Nakamuras, T., 2000. The Quaternary Geological History of the Santa Catarina Southeastern Region (Brazil). Anais Academia Brasileira de Ciências., 72 (2), 257 - 270.

Castaños, C., Pascual, M., Camacho, A.P., 2009.Reproductive Biology of the Nonnative Oyster, Crassostrea gigas(Thunberg, 1793), as a Key Factor for Its Successful Spread Along the Rocky Shores of Northern Patagonia, Argentina. Journal of Shellfish Research, 28(4):837-847. doi: http://dx.doi.org/10.2983/035.028.0413.

Castellanos, Z., 1967. Catálogo de los Moluscos Marinos Bonaerenses. Anales de la Comisión de Investigaciones Científicas, 8, 365 p.

Castellanos, Z., 1982. Los Pyramidellidae de la Republica Argentina (Moll. Entomotaeniata). Comunicaciones del Museo Argentino de Ciencias Naturales "Bernardino Rivadavia". Hidrobiología, 2(7): 61-85.

Castellanos, Z., 1990. Catálogo descriptivo de la malacofauna marina magallánica 5Mesogastrópoda. Comisión de Investigaciones Científicas de la Provincia de Buenos Aires, 36 p.

Castellanos, Z., 1992. Catálogo descriptivo de la malacofauna marina magallánica 7Neogastrópoda. Comisión de Investigaciones Científicas de la Provincia de Buenos Aires, 27 p.

Cavallotto, J. L., 1995. Evolución de la topografía del sustrato del Holoceno del "Río de la Plata". 4 Jornada Geológica y Geofísica Bonaerenses. Acta: 223-230, Junín. 
Cavallotto, J. L., 2002. Evolución holocena de la llanura costera del margen sur del Río de la Plata. Revista de la Asociación Geológica Argentina, 57(4): 376-388.

Chaar, E. y Farinati, E., 1988. Evidencias paleontológicas y sedimentológicas de un nivel marino pleistocenico en Bahía Blanca, provincia de Buenos Aires, Argentina. Segunda Jornadas Geológicas Bonaerenses, Acta 1: 47 - 54. Bahía Blanca, Argentina.

Chaar, E., Farinati, E., Aliotta, S., Tassone, A., 1992. Pleistoceno marino al sur de la ciudad de Bahía Blanca. 3ras Jornadas Geológicas Bonaerense, Acta, 59-62, La Plata.

Chappell, J., 2002. Sea level changes torced ice breakouts in the Last Glacial Cycle: new results from coral terraces. Quaternary Science Review, 21 (10): 1229-1240.

Charó, M., Fucks, E., Gordillo, S., 2012. Moluscos marinos del Holoceno Tardío de Península Verde, sur de la provincia de Buenos Aires, Argentina. VIII Jornadas Nacionales de las Ciencias del mar y XVI Coloquio de Oceanografía. Comodoro Rivadavia, Chubut, Argentina.

Charó, M. P., Gordillo, S., Fucks, E. E., 2013. Paleoecology significance of Late Quaternary molluscan faunas of the Bahía San Blas area, Argentina. Quaternary Internacional, 301: 135-149.

Ciocco, N. F., 1998. Observaciones sobre la ecología del molusco bivalvo Chlamys tehuelchues (d’Orb.) en el Golfo San José (Chubut, Argentina). I. Análisis biocenótico. Geotrópica, 34(91): 322.

Ciocco, N.F., 2000. Almeja panopea, un nuevo recurso pesquero para el Mar Argentino. Infopesca Inter., 6: 36-39.

Cionchi, J., 1987. Depósitos marinos cuaternarios de bahía Bustamente, provincia del Chubut. Revista de la Asociación Geológica Argentina, 42 (1-2): 61-72.

Clavijo, C., Scarabino, F., Rojas, A., Martínez, S., 2005. Lista sistemática de moluscos marinos y estuarios del Cuaternario de Uruguay: Comunicaciones de la Sociedad Malacológica del Uruguay, 9: $385-411$. 
Cléroux, C. C., Cortijo, E., A., P., Labeyrie, L., Bassinot, F., Caillon, N., Duplessy, J.C., 2008. $\mathrm{Mg} / \mathrm{Ca}$ and $\mathrm{Sr} / \mathrm{Ca}$ ratios in planktonic foraminifera: Proxies for upper water column temperature reconstruction. Paleoceanography 23, PA3214. doi: 10.1029/2007PA001505.

Codignotto, J. O. y Weiler, N. E., 1980. Evolución morfodinámica del sector costero comprendido entre Punta Laberinto e Isla Olga, Provincia de Buenos Aires. En: Simposio sobre problemas Geológicos del litoral Atlántico Bonaerense. CIC. Acta: 35-45, Mar del Plata.

Codignotto, J. O. y Aguirre, M. L., 1993. Coastal evolution in sea level and molluscan fauna in northeastern Argentina during the Late Quaternary. Marine Geology, 110: 163-175.

Codignotto, J. O., Marcomini, S. C., Santillana, S. N., 1988. Terrazas marinas entre Puerto Deseado y Bahía Bustamante, Santa Cruz, Chubut. Revista de la Asociación Geológica Argentina, 43: 43 50.

Cohen, A. L., Parkington, J. E., Brundrit, G. B., Van der Merwe, N. J., 1992. A Holocene marine climate record in mollusc shells from the Southwest African coast. Quaternary Research, 38 (3): 379-385.

Collin, R., 2005. Development, phylogeny and taxonomy of Bostrycapulus (Caenogastropoda: Calyptraeidae), an ancient cryptic radiation. Zoological Journal of the Linnean Society, 144: 75101.

Cortelezzi, C., De Salvo, O., De Francesco, F., 1963. Estudio de las gravas Tehuelches de la región comprendida entre el Río Colorado y el Río Negro, desde la costa de la Provincia de Buenos Aires hasta Choele-Choele. Acta Geológica Lilloana, 6: 65-86.

Cortelezzi, C., De Francesco, F., De Salvo, O., 1966. Estudio de las gravas Tehuelches de la región comprendida entre el Río Colorado y el Río Negro, desde la costa atlántica hasta la cordillera. III Jornadas Geológicas Argentinas.Actas 3: 123-145. 
Cortez-Lucero, G., Arreola-Lizárraga, J. A., Chávez-Villalba, J., Aragón-Noriega, E. A., 2011. Edad, crecimiento y mortalidad de la almeja sifón, Panopea globosa (Bivalvia: Hiatellidae) en la región central del Golfo de California, México. Revista de Biología Marina y Oceanografía, 46(3): 453-462.

Cremonte, F. y Figueras, A, 2004. Parasites as possible cause of mass mortalities of the presently critically endangered clam Mesodesma mactroides on the Southwest Atlantic coast. Bulletin of European Association of Fish Pathologist, 24 (3): 166-171.

Cuadrado, D. G. y Gomez, E. A., 2010. Geomorfología y dinámica del Canal San Blas, provincia de Buenos Aires (Argentina). Latin American Journal of Sedimentology and Basin Análisis, 17(1): 316.

Cuerda, J., Vicens, D., Gracia, F., 1991. Malacofauna y estratigrafía del Pleistoceno Superior marino de San Real (Santa Margalida, Mallorca). Bolletín de la Societat d' Història Natural de las Balears, 34: 99 - 108.

Cumplido, M., 2009. Ciclo de vida y desarrollo embrionario del caracol Trophon geversianus en el intermareal de Punta Cuevas, Golfo Nuevo". Tesis de Licenciatura, UNPSJB.

Darwin, C., 1846. Geological Observations on South American. Smith Elder and Co., Londres, 279 p.

De Diego - Forbis, T., Douglas, R., Gorsline, D., Nava - Sanchez, E., Mack, L., Banner, J., 2004. Late Pleistocene (Last Interglacial) terrace deposists, Bahía Coyote, Baja California Sur, Mexico. Quaternary Intenacional, 120: 29-40.

Del Río, J. L. y Colado, U. R., 1999. Ambientes sedimentarios actuales de la Caleta de los Loros, provincia de Río Negro, República Argentina. Thalassas, 15: 35-44.

Del Blanco, M., Marchionni, D., Romero, S., Cábana, C., 2005. Depósitos evaporíticos de la provincia de Buenos Aires. Geología y Recursos Minerales de la Provincia de Buenos Aires. XVI Congreso Geológico Argentino, Volumen XXVII: 417-444, La Plata. 
deMenocal, P., Ortiz, J., Guilderson, T., Sarnthein,M., 2000. Coherent high and low latitude climate variability during the Holocene warm period'.Science, 288: 2.198-2.202

Defeo, 0, y Scarabino V, 1990. Ecological singificance of a possible deposit-feeding strategy in Mesodesma mactroides (Deshayes, 1854) (Mollusca: Pelecypoda). Atlantica 12: 55-65.

Desprat, S., Sanchez Groñi, M. F., Turon, J-L.,Duprat, J., Malaizé, B., Peypouquet, J-P., 2006. Climatic variability of marine isotope stage 7: direct land-sea-ice correlation from a multiproxy analysis of a north-western Iberian margin deep-sea core. Quaternary Science Reviews, 25 (9-10): 1010-1026.

Domínguez, J. M. L., Bitterncourt, A.C.S.P., Leão, Z. M. Z. N., Azaevedo, A. E. G., 1990. Geologia do Quaternário costeiro do estado do Pernambuco. Revista Brasileira de Geociências, 20 (1-4): 208215.

D’Orbigny A., 1834-1847. Voyage dans l’Amérique Méridionale. Mollusques, 5 (3), 758 p. atlas (Tome 9) Paris.

D’Orbigny A., 1842-1844. Voyage dans l’Amérique Méridionale. Paléontologie, 3 (4), 152 p. Paris $\&$ Strassbourg.

De Francesco, C. G. y Zárate, M. A., 1999. Análisis tafonómico de Littoridina Souleyet, 1852 (Gastropoda: Hydrobiidae) en perfiles holocenos del río Quenquén Grande (provincia de Buenos Aires): significado paleobiológico y paleoambiental. Ameghiniana, 36(3): 297-310.

De Francesco, C. G. y Hassan, G. S., 2009. The significance of molluscs as paleoecological indicators of freshwater systems in central-western Argentina. Palaeogeography, Palaeoclimatology, Palaeoecology 274: 105-113.

Díaz, A. y Ortlieb, L., 1993. El fenómeno del Niño y los moluscos de la costa peruana. Bulletin de Institut Francais d'Estudes Andines, 22 (1): 159-177. 
Dumas, B., Guérémy, P., Raffy, J., 2005. Evidence for sea level oscillating by the "characteristic thickness" of marine deposits from raised terraces of Southern Calabria (Italy). Quaternary Science Reviews, 24 (18-19): 2120-2136.

Dutton, A., Antonioli, F., Bard, E., 2009. A new chronology of sea level highstands for the penultimate interglacial. Nature Geoscience, 17: 66-68.

Efremov, J.A., 1940. Taphonomy: new branch of paleontologye.PanAmerican Geologist, 74: 81-93.

Elías, R., Bremec, C., Giberto, D., Gravina, M., Schejter, L., 2001. Estudio faunístico de las comunidades bentónicas infaunales de plataforma somera del Atlántico S. O. Y de Bahía Blanca. En: COLACMAR, IX Congreso Latinoamericano de Ciencias del mar, San Andres, Colombia.

Emiliani, C., 1955. Pleistocene temperatures. Journal of Geology, 63: 538-578.

Escofet, A., Orensanz, J. M., Olivier, S., Scarabino, V., 1978. Benthic studies of the Gulf of San Matías (Río Negro, Argentina): methodology, experiencies and results of the ecological studies in a large geographic area in Latin America. An. Inst. Cienc. Mar. Limnol. Universidad Nacional Autónoma de México., 5 (1): 59 - 81.

Etcheverría, M. Folguera, A., Dal Molín, C., 2006. Hojas geológicas 4163 - II/IV y I/II Viedman y General Conesa. Provincias de Río Negro y Buenos Aires. SEGEMAR, Boletín N³66, 67 p.

Farinati, E. A., 1978. Microfauna de moluscos Querandinenses (Holoceno), Ingeniero White, Provincia de Buenos Aires. Revista de la Asociación Geológica Argentina, 33 (3): 211-232.

Farinati, E. A., 1985. Paleontología de los sedimentos marinos holocenos de los alrededores de Bahía Blanca, Provincia de Buenos Aires. Ameghiniana, 21 (2-4):211- 222.

Farinati, E., 1993. Pyramidellidos (Mollusca, Gastropoda) en sedimentos holocenos de Bahía Blanca, Argentina. Ameghiniana, 30(3): 297-310. 
Farinati, E. A., 1994. Micromoluscos (Gastropoda y Bivalvia) del Holoceno del área de Bahía Blanca, Argentina. Ameghiniana, 31 (4):303- 316.

Farinati, E. A. y Camacho, H. H., 1980. Contribución al conocimiento de la malacofauna del Cuaternario marino de los alrededores de Bahía Blanca, Provincia de Buenos Aires, República Argentina. Actas $2^{\circ}$ Congreso Argentino de paleontología y Bieoestratigrafía y $1^{\circ}$ Congreso Latinoamericano de Paleontología, Tomo III: 257-265, Buenos Aires.

Farinati, E., Aliotta, S., Ginsberg, S., 1992. Mass mortality of a Holocene Tagelus plebeius (Mollusca, Bivalvia) population in the Bahía Blanca, Estuary, Argentina. Marine Geology, 106: 301-308.

Farinati, E. y Aliotta, S., 1995. Análisis tafonómico de conchillas en cordones holocenos, Bahía Blanca, Argentina. 4ta Jornadas Geológicas y Geofísicas Bonaerenses, Actas 1: 89-97, Junín.

Farinati, E. y Zavala, C., 1995. Análisis tafonómico de moluscos y análisis de facies en la Serie Holocena del Río Quequen Salado, Provincia de Buenos Aires, Argentina. VI Congreso Argentino de Paleontología y Bioestratigrafía, Actas: 117-122, Trelew.

Farinati, A., Spagnuolo, J., Aliotta, S., 2006. Bioerosión en micromoluscos holocenos del estuario de Bahía Blanca, Argentina. Ameghiniana, 43 (1): 45-54.

Favier Dubois, C. M., Borella F., Manzi L., Cardillo M., Lanzelotti S., Scartascini F. L., Borges Vaz, E., 2006. Aproximación regional al registro arqueológico de la costa rionegrina. Arqueología de la Costa Patagónica. Perspectivas para la conservación, e Universidad Nacional de la Patagonia Austral y Secretaría de Cultura de la Provincia de Chubut.dictado por I. Cruz y S. Caracotche: 50$68 \mathrm{p}$.

Fernández Alfaya, J. E., 2007. Estructura poblacional y reproducción de la almeja amarilla Mesodesma mactroides en las playas de Santa Teresita. Cambios en 35 años. Tesis de grado, UBA. 
Feruglio, E., 1933. Nuevos datos sobre terrazas marinas de la Patagonia. Boletín Informaciones Petrolíferas, 10: 87-111.

Feruglio, E., 1950. Descripción Geológica de la Patagonia. Tomo III. Dirección General de Yacimientos Petrolíferos Fiscales. Buenos Aires. 432 p.

Fidalgo, F., Colado, U. C., De Francesco, F. O., 1973. Sobre ingresiones marinas cuaternarias en los partidos Castelli, Chascomús y Magdalena (Provincia de Buenos Aires). $5^{\circ}$ Congreso Geológico Argentino, Actas 4: 225-240, Carlos Paz.

Fidalgo, F., Figini, A. J., Gómez, G. J., Carbonari, J. E., Huarte, R. H., 1980. Algunas dataciones absolutas en sedimentos marinos de la Bahía San Antonio. Simposio Problemas Geológicos del Litoral Atlántico Bonaerense, CIC: 243-251.

Fiori, S. y Morsan, E., 2004. Age and individual growth of Mesodesma mactroides (bivalvia) in the southernmost range of its distribution. ICES Journal of Marine Science, 61 (8): 1253 - 1259. ISSN: 1054-3139.

Fiori, S. y Defeo, O., 2006. Biogeographic Patterns in Life-History Traits of the Yellow Clam, Mesodesma mactroides, in Sandy Beaches of South America. Journal of Coastal Research, 22 (4): $872-880$.

Franchi, M., 1977. Descripción geológica de las Hojas 39m y 40m, Viedma y 39n, isla San Blas, Provincias de Buenos Aires y Río Negro. Servicio Geológico Nacional. Informe Inédito. Buenos Aires.

Frenguelli, J., 1928. Observaciones geológicas en la región costanera sur de la Provincia de Buenos Aires.Anales de la Facultad de Ciencias de la Educación, 2: 1-145.

Frenguelli, J., 1945. El Piso Platense. Revista del Museo de la Plata (Nueva Serie), 2 (17): 283-311. 
Frenguelli, J., 1950. Rasgos generales de la morfología y geología de la provincia de Buenos Aires. Publicación del Laboratorio de Ensayo de Materiales e Investigaciones Tecnológicas (Lemit), Serie 2 (33): 1-72.

Frenguelli, J., 1957.Neozoico. En Sociedad Argentina de Estudios Geográficos (GAEA) (eds.). Geografía de la República Argentina, Sociedad Argentina de Estudios Geográficos, GAEA, 2(3): 1218, Buenos Aires.

Forcelli, D. O., 2000. Moluscos magallánicos: guía de moluscos de Patagonia y sur de Chile. Vásquez Mazzini Editores: 200 p.

Fucks, E. E., Aguirre, M., Deschamps, C., 2005. Late Quaternary Continental And Marine Sediments At Northeastern Bonaerensian Area (Argentina): Fossil Content And Palaeoenvironmental Interpretation. Journal of South American Earth Sciences, Vol. 20, Issues 1-2: 57-64.

Fucks, E. E., Aguirre, M. L., Schnack, E. Erra, G., Ramos, N., 2006. Rasgos litológicos y Fosilíferos de la Formación Pascua (Pleistoceno Tardío) en su Localidad Tipo, Provincia de Buenos Aires. $3^{\circ}$ Congreso de Geomorfología y Geología del Cuaternario, Actas 2: 727-736.

Fucks, E. E., Schnack, E., Aguire, M., 2008. Reconsideración estratigráfica de las Secuencias Marinas Holocenas del Sector Continental de la Bahía Samborombón, Provincia de Buenos Aires. 17º Congreso Geológico Argentino, Actas 3: 1210-1211, Jujuy.

Fucks, E. E., Aguirre, M., Richiano, S., Boretto, G., Zanchetta, G., Consoloni, I., Isola, I., Pappalardo, M., Ribolini, A., 2009.Depósitos Litorales en el Sector Continental del Norte del Golfo San Jorge. IV Congreso Argentino de Cuaternario y Geomorfología, XII Congresso da Associação Brasileira de Estudos do Quaternário y II Reunión sobre el Cuaternario de América del Sur, 1:114.

Fucks E. E. y Schnack, E., 2011. Evolución geomorfológica en el sector norte del golfo San Matías. XVIII Congreso Geológico Argentino, Actas: 273-274. 
Fucks, E. E., Schnack, E. J. y Aguirre, M.L., 2010. Nuevo ordenamiento estratigráfico de las secuencias marinas del sector continental de la Bahía Samborombón, provincia de Buenos Aires. Revista de la Asociación Argentina, 67 (1): 27-39.

Fucks, E. E., Charó, M., Pisano, F., 2012a. Aspectos estratigráficos y geomorfológicos del sector oriental patagónico bonaerense. Revista de la Sociedad Geológica de España, 25 (1-2): 29-44.

Fucks, E. E., Schnack, E. J., Charó, M. P., 2012b.Aspectos geológicos y geomorfológicos del sector N del Golfo San Matías, Río Negro, Argentina. Revista de la Sociedad Geológica de España, 25 (12): $95-105$.

Funder, S. y Weidick, A., 1991. Holocene boreal mollusk in Greenland: palaeoceaonographic implications. Palaeogeography, Palaeoclimatology, Palaeoecology, 85 (1-2): 123-135.

Gelos, E. M., Spagnuolo, J. O., Schillizzi, R. A., 1988. Las unidades morfológicas de la costa norte del golfo San Matías y su evolución. Asociación Geológica Argentina, XLIII (3): 315-326.

Gelos, E., Spagnuolo, L., Schillizzi, R., 1993. Las unidades morfológicas de la costa oeste del golfo San Matías y su evolución. Revista de la Asociación Geológica Argentina, 47 (3): 315-326.

Golfieri, G. A., Ferrero, L., Zarate, M., 1998. Tafonomía y paleoecología de Tagelus plebeius (Lightfoot, 1786) (Mollusca, Bivalvia) en sedimentos holocenos del Río Quequen, provincia de Buenos Aires, Argentina. Ameghiniana, 33 (3): 255-264.

Gómez, G., Huarte, R., Figini, A., Carbonari, J., Zubiaga, A., Fidalgo, F., 1985. Análisis y comparaciones de dataciones radiocarbonáticas de conchas de la Formación Las Escobas, en la localidad de bahía Samborombón, Provincia de Buenos Aires, Argentina. $2^{\text {da }}$ Jornadas Geológicas Bonaerenses (Bahía Blanca): 221-281.

Gónzalez Uriarte, M, 1984. Características geomorfológicas de la porción continental que rodea la Bahía Blanca, Provincia de Buenos Aires. Noveno Congresoi Geológico Argentino. Actas III: 556576, San Carlos de Bariloche. 
González Díaz, E. F. y Malagnino, E. C., 1984. Geomorfología. IX Congreso Geológico Argentino, Relatorio, I (9): 215-266, Buenos Aires.

González, M. A. y Weiler, N. E., 1983. Ciclicidad de niveles marinos holocénicos en Bahía Blanca y en el delta del río Colorado. Simposio "Oscilaciones del nivel del mar durante el Último Hemiciclo Deglacial en la Argentina". Revista de la asociación Geológica Argentina, Actas: 69-90, Mar del Plata.

González, M. A., Weiler, N. E., Guida, N. C., 1986. Late Pleistocene transgressive deposists from $33^{\circ}$ to $44^{\circ} \mathrm{S}$, Argentine Republic. Journal of Coastal Research. Special Issues, No 1 : 39-48.

González, M. A. y Guida, N. G., 1990. Earth magnetic reversals in Late Pleistocene litoral deposits of the Argentine Republic ( $33^{\circ}$ to $40^{\circ} \mathrm{S}$ ). Blake Event probable Lake Mungo. Journal of Coastal Research, 6 (1): 357-366.

González, M. A. y Ravizza, G., 1987. Sedimentos estuáricos del Pleistoceno Tardío y Holoceno en la isla Martín Garcia, Río de la Plata. Revista de la Asociación Geológica Argentina, 42 (3-4): 231243, Buenos Aires.

Gordillo, S., 1992. Tafonomía y Paleoecología de moluscos bivalvos de edad holocena del Canal Beagle (Tierra del Fuego). Tesis doctoral. Universidad Nacional de Córdoba, 286p.

Gordillo, S., 1993. Las terrazas marinas holocenas de la región del Beagle (Tierra del Fuego) y su fauna asociada. $12^{\circ}$ Congreso Geológico Argentino, Actas 6: 34-39. Mendoza.

Gordillo, S., 1998. Distribución Biogeográfica de los moluscos Holocenos del litoral ArgentinoUruguayo. Ameghiniana, 35 (2): 163-180.

Gordillo, S., 1999. Holocene molluscan assemblages in the Magellan region. Scientia Marina, 63 (Supl. 1): 15-22. 
Gordillo, S., 2009. Quaternary marine mollusks in Tierra del Fuego: Insights from integrated taphonomic and paleoecologic analysis of shell assemblages in raised deposits. Anales Instituto Patagonia, 37 (2): 5-16.

Gordillo, S., Isla, F., 2011. Faunistic changes between the Middle/Late Pleistocene and the Holocene on the Atlantic coast of Tierra del Fuego: molluscan evidence. Quaternary International, 233: 101-112.

Gordillo, S., Bayer, M. S., Martinelli, J., 2010. Moluscos Recientes del Canal Beagle, Tierra del Fuego: un análisis cualitativo y cuantitativo de los ensambles de valvas fósiles y actuales. Anales del instituto de la Patagonia, 38(2): 95-106.

Gordillo, S., Bujalesky, G., Pirazzoli, P. A, Rabassa, J. O., Saliege, J. F., 1992. Holocene raised beaches along the northern coast od the Beagle Channel, Tierra del Fuego, Argentina.Palaeogeogarphy, Palaeoclimatology, Palaeoecology, 99: 41-54.

Gordillo, S., Coronato, A. M. J., Rabassa, J.O., 2005. Quaternary molluscan faunas from the Island of Tierra del Fuego after the Last Glacial Maximun. Scientia Marina, 69 (2): 337-348.

Gordillo, S., Rabassa, J., Coronato, A., 2008. Paleoecology and paleobiogeographic patterns of midHolocene mollusks from the Beagle Channel (southern Tierra del Fuego, Argentina). Revista Geológica de Chile, 35 (2): 321-333.

Goso Aguilar, C., 2006. Aspectos sedimentológicos y estratigráficos de los depósitos cuaternarios de la costa platense del Departamento de Canelones (Uruguay. Latin American Journal of sedimentology and Basin Analysis, 13 (1): 77-89.

Guilderson, T. P., 2000. Late Pleistocene sea level variations derived from the Argentine Shelf. Geochemestry, Geophysics. Geosystems. An Electronic Journal of the Earth Sciences, 1. ISSN: $1525-2027$.

Guerrero, R. A. y Piola, A. R., 1997. Masas de aguas en la plataforma continental. El mar argentino y sus recursos pesqueros, 1: 107-118. 
Guida, N. G. y M. A. González, 1984. Evidencias paleoestuáricas en el sudeste de Entre Ríos, República Argentina su vinculación con niveles marinos relativamente elevados del Pleistoceno Superior y Holoceno". IX Congreso Geológico Argerntino, Actas III: 577-594. Buenos Aires.

Gutiérrez Elorza, M., 2001. Geomorfología climática. Ediciones Omega, 627p.

Gutiérrez Elorza, M., Desir, G., Gutiérrez-Santolalla, F., Martín, C., 2005. Origin and evolution of playas and blowouts in the semiarid zone of Tierra de Pinares (Suero Basin, Spain). Geomorphology, 72: 177-192.

Gutiérrez, J. L. y Valero, J. L., 2001. La almeja navaja y su participación en mecanismos ecológicos de comunidades intermareales mediante la producción de valvas. En: Iribarne O. (Ed.). Reserva de Biósfera Mar Chiquita: Características físicas, biológicas y ecológicas. Editorial Martín, 121-128.

Guzmán, N., Saá, S. y Ortlieb, L., 1998.Catálogo descriptivo de los moluscos litorales (Gastropoda y Pelecypoda) de la zona de Antofagasta, $23^{\circ} \mathrm{S}$ (Chile). Estudios Oceanológicos, 17: 17-86.

Guzmán, N., Díaz, A., Ortlieb, L., Clarke, M., 2001. TAMAs, ocurrencia episódica de moluscos tropicales en el Norte de Chile y el evento del Niño. En J. Tarazona, W. E., Arntz y E. Castillo de Marruenda. El Niño en América Latina. Impactos Biológicos y Sociales: 385-393.

Groeber, P., 1947. Resumen preliminar de las observaciones realizadas en el viaje a la región sur de bahía Blanca. Notas del Museo de la Plata. Tomo XIV, Geología, No57. La Plata.

Groeber, P., 1949. Glacial Tardío y Posglacial en Patagonia. Revista del Museo Municipal de Ciencias Naturales y Tradicional de Mar del Plata, Volumen 1, Mar del Plata.

Grün, R., Stringer C., McDermott, F., Nathan, R., Porat N., Robertson, S., Taylor, L., Mortimer, G., Eggins, S., McCulloch, M., 2005. U-series and ESR analyses of bones and teeth relating to the human burials from Skhul. Journal of Human Evolution, 49: 316 - 334. 
Hammer, Øyving y Harper, D. A. T., 2006. Paleontological Data Analysis. Blackwell Publishing, 345 p.

Hearty, P. J., 2002. Revision of the late Pleistocene stratigraphy of Bermuda. Sedimentary Geology, 53: $1-21$.

Hearty, P. J., Hollin, J. T., Neumann, A. C., O'Leary, M. J., McCulloc, M., 2007. Global sea - level flutuaction during the last Interglaciation (MIS5e). Quaternary Science Reviews, 26: 2090 -2112.

Hellberg, M. E., 1998. Sympatric sea shells along the sea's shore: The geography of speciation in the marine gastropod Tegula. Evolution, 52: 1311-1324.

Herrman, M., Alfada, E. F., Lepore, M. L., Penchaszadeh, P. E., Arntz, W. E., 2010. Population structure, growth and production of the yellow clam Mesodesma mactroides (Bivalvia: Mesodesmatidae) from a high-energy, temperate beach in northern Argentina. Helgoland Marine Research. DOI 10.1007/s10152-010-0222-3.

Hidalgo, C. E., Flores, J. A., Sierro, F. J., Grimalt, J. O., 2005. Reconstrucción de las temperaturas superficiales marinas del margen ibérico sudoriental durante el último período glacial mediante el empleo de cocolitofóridos. Geogaceta, 38: 195-198.

Hillaire-Marcel, C., Carro, C., Causse, O., Goy, J.L., Zazo, C., 1986. Th/U dating of Strombus bubonius-bearing marine terraces in southeastern Spain. Geology, 14: 613-329.

Hjort, C., Mangerud, J., Adrielsson, L., Bondevik S., Landvik, J., Salvigsen, O., 1995. Radiocarbon dated common mussels Mytilus edulis from eastern Svalbard and the Holocene marine climatic optimum. Polar Research, 14 (2): 239-243.

Hodell, D. A., Charles, C. D., Ninnemann, U. S., 2000. Comparison of interglacial stages in the South Atlantic sector of the southern for the past $450 \mathrm{kyr}$ : implifications for Marine Isotopes Stages (MIS) 11. Global and Planetary Changes, 24: 7-26. 
Ihering, H. I. von, 1907. Les Mollusques fossils du Tertiaire et du Cretacé de 1'Argentine. Anales del Museo Nacional de Buenos Aires, serie 2, tomo 8.

Iribarne, O., Bortolus, A., Botto, F., 1997. Between-habitat differences in burrow characteristic and trophic modes in the southwestern Atlantic burrowing crab Chasmagnathus granulate. Marine Ecology Progress Series, 155: 137-145.

Iribarne, O., Valero, J. Martinez, M. Lucifora, L., Bachmann, S., 1998. Shorebird predation may explain the origin of Holocene beds of scout razor in life position. Marine Ecology Progress Series, 167: 301-306.

Isla, F. I., 1989. Holocene sea-level fluctuation in the Southern Hemisphere. Quaternary Sciences Review, 8: 359-368.

Isla, F., 1998. Holocene coastal evolution in Buenos Aires province, Argentina.Quaternary of South America and Antartic Peninsula, 4: 137-157.

Isla, F. y Bértola G., 2003. Morfodinámica de las playas meso y micromareales entre Bahía Blanca y Río Negro. Revista de la AAS, 9 (1):12-34.

Isla, F.I. y Espinosa, M.A., 1998. Modelo sedimentario de colmatación de pequeños estuarios dominados por limo, provincia de Buenos Aires. $7^{\circ}$ Reunión Argentina de Sedimentología, Actas: 24-36, Salta.

Isla, F.I., Bértola, G.R., Schnack, E.J., 2001. Morfodinámica de playas meso y macromareales de Buenos Aires, Río Negro y Chubut. AAS Revista, 8:51-60.

Isla, F. I. y Bujalesky, G., 2008. Coastal Geology and morphology of Patagonia and Fueguian Archipielago. In: Rabassa, J. R. (ed) The Late Cenozoic of Patagonia and Tierra del Fuego., Elsevier Sciences Publication of Chile, 10: 227-240.

Isla, F., Rutter, N., Schnack, E., Zárate, M., 2000. La trasgresión Belgranense en Buenos Aires. Una revisión a cien años de su definición. Cuaternario y Ciencias Ambientales, 1: 3-14. 
Jackson, D. S., Méndez, M. C., López, M. P., Jackson, D. S., Sequel, R. Q., 2005. Evaluación de un asentamiento arqueológico en el semiárido de Chile: procesos de formación, fauna extinta y componentes culturales. Intersecciones en Antropología, 6: 139-151.

Jones, K. B., Hodgins, G. W. L., Andrés, C. F. T, Etayo-Cadavid, M. F., 2010. Modeling molluscan marine reservoir ages in a variable - upwelling environment, Palaios, 25: 126-131.

Kaaschieter, J. P. H., 1965. Geología de la cuenca del Colorado. II Jornada Geológica Argentina, Acta, III: 251-269, Buenos Aires.

Kauffman, E. G. y Scout, R. W., 1976. Basic concepts of community, ecology and paleoecology. En: R. W. Scott y R. R. West (eds.) Structure and classification of paleocommunities, Dowden Hutchinson y Ross. Inc. Pensylvania, 1-28 p.

Kidwell, S., Fürsich, F. y Aigner, T., 1986.Conceptual framework for the analysis and classification of fossil concentrations. Palaios, 1: 228-238.

Kidwell, S.M., 2001. Preservation of species abundance in marine death assemblages Science, vol. 294: 1091-1094.

Kidwell, S. M., 2002. Time-averaged molluscan death assemblages: Palimpsests of richness, snapshots of abundance. Geology 30: 803-806.

Kidwell, S. M., 2008. Ecological fidelity of open marine molluscan death assemblages: effects of post-mortem transportation, shelf health, and taphonomic inertia. Lethaia 41:199-217.

Kidwell, S. M., 2013. Time-averaging and fidelity of modern death assemblages: building a taphonomic foundation for conservation palaeobiology. Palaeontology, 56: 487-522.

Kidwell, S. M. y Tomasovych, A., 2013. Implications of Time - Averaged death assemblages for ecology and Conservation biology. Ann. Rev. Ecol.Evol. Syst., 44: 539-563. 
Kim, K. H., Tanaka, T., Nakamura, T., Nagao, K., Youn, J. S., Kim, K. R., Yun, M. Y.,1999. Palaeoclimatic and chronostratigraphic interpretations from strontium, carbon and oxygen isotopic ratios in molluscan fossils of Quaternary Seoguipo and Shinyangri. Palaeogeography, Palaeoclimatology, Palaeoecology, 154 (3): 219-235.

Kindt, R. y Coe, R., 2005. Tree diversity analysis. A manual and software for common statistical method for ecological and biodiversity studies. Nairobi: World Agroforestry Centre (ICRAF), 196 p.

Kitamura, A., Omole, H., Oda, M., 2000. Molluscan response to early Pleistocene rapid warning in the Sea of Japan. Geology, 28:723-726.

Klein, E., 2004. Estructura de las comunidades: una guía de análisis de datos utilizando R. 1-19.

Kokot, R. R., Codignotto, J. O., Elissondo, M., 2004. Vulnerabilidad al ascenso del nivel del mar en la costa de la provincia de Río Negro Revista de la Asociación Geológica Argentina, 59 (3): 477 487.

Lario, J., Zazo, C., Goy, J. L., Somoza, L., Hoyos, M., Silva, P.G., Hernandez - Molina, F. J., 1993. Los episodios marinos cuaternarios de la costa de Malaga (España). Revista Sociedad Geológica de España, 6: 42-46.

Lasta, M. y Bremec, C., 1998. Zygochlamys patagonica in the Argentine Sea: a new scallop fishery. Journal Shellfish Research, 17: 103-111.

Lasta, L. M., Ciocco, C. F., Bremen, C. S., Roux, A. M., 1998. El mar Argentino y sus recursos pesqueros, 2, 115- 142 .

Legendre, P. y Legendre, L., 2012. Numerical Ecology. 3nd English Edition. Elsevier. Paginas?

Lutaenko, K. A., 1993. Climatic optimum during the Holocene and the distribution of warm - water mollusks in the Sea of Japan. Palaeogeography, Palaeoclimatology, Palaeoecology, 102: 273 - 281. 
Massch, K., Sandweiss, D., Houk, S., 2001. Molluskan evidence for Mid - to - Late Holocene evolution of El Niño conditions in coastal Peru. Actas V REQUI/ICPLI, Lisboa Portugal, 353p.

Martin, L. y Suguio, K., 1978. Excursion rout along the coastline between the town of Cananéia (State of São Paulo) and Guaratiba outlet (state of Rio de Janeiro). International Symposium Coastal Evolution, São Paulo,. Spec. Publ. São Paulo, IG, USP, SBG, 2: 98p.

Martin, L. y Suguio, K., 1989. Excursion Route along the Brazilian Coast Between Santos (SP) and Campos (RJ) (North of State of Río de Janeiro). International Symposium Global Changes in South America During the Quaternary. Spec. Publ. 2, ABEQUA- INQUA, São Paulo, 296-331.

Martin, L., Suguio, K., Flexor, J. M., 1979. Le Quaternaire marin du littoral brésilien entre Cananéia (SP) et Barra de Guaratiba (RJ). Proc. Int. Symp. Coastal Evolution in the Quaternary, IGCP, São Paulo: 296-331.

Martín, L., Dominguez, J. M. L., Bittencout, C. S. P. A., 2003. Fluctuating Holocene Sea levels in Eastern and Southeastern Brazil: Evidence from Multiple Fossil and Geometric Indicators. Journal of Coastal Research 19 (1): 101-124.

Martínez, S., Verde, M., Ubilla, M., Perea, D., Guérèquiz, R., Piñeiro, G., 1997. Asociaciones de moluscos fósiles del Cuaternario marino del Uruguay: Geocronología, tafonomía y paleoecología. In "Boletim de Resumos XV Congreso Brasileiro de Paleontología”, 45p.

Martínez, S. y del Río, C. J., 2002a. Late Miocene molluscs from the southwestern Atlantic Ocean (Argentina and Uruguay): a palaeobiogeographic análisis. Palaeogeography, Palaeoclimatology, Palaeoecology, 188: 167-187.

Martínez, S. y del Río, C. J., 2002b. Las provincias malacológicas miocenas y recientes del Atlántico Sudoccidental. Anales de Biología, 24: 121-130.

Martínez, S. y del Río, C. J., 2005. Las ingresiones marinas del Neógeno en el sur de Entre Ríos (Argentina) y Litoral Oeste de Uruguay y su contenido malacológico. Tema de la Biodiversidad del Litoral fluvial argentino II, Miscelánea, 14: 13-26. 
Martínez, H., Náñez, C., Lizuain, A., Dal Molin, C., Turel, A., 2001. Hoja Geológica 4166-II, San Antonio Oeste. Provincia de Río Negro. Instituto de Geología y Recursos Minerales, Servicio Geológico Minero Argentino. Boletín 254: 32 p. Buenos Aires, Argentina.

Martínez, S., Ubilla, M., Verde, M., Perea, D., Rojas, A., Guéréquiz, R., Piñeiro G., 2001. Paleoecology and Geochronology of Uruguayan Coastal Marine Plesitocene Deposits. Quaternary Research, 55: 246 - 254.

Martínez, S., Rojas, A., Ubilla, M., Verde, M. Perea, D., Piñeiro, G., 2006. Molluscan assemblages from the marine Holocene of Uruguay: composition, geocronology, and paleoenvironmen signals. Ameghiniana, 43 (2): 385-397.

Mc Culloch, M. T. y Esat, T., 2000. The coral record of last interglacial sea levels and sea surface temperatura. Chemical Geology, 169: 107 - 129.

Méndez, M. C. A. y Jackson, S. D. G., 2004. Ocupaciones humanas del Holoceno tardío en Los Vilos (IV Región: Chile): origen y características conductuales de la población local de cazadores recolectores del litoral. Revista de Antropología Chilena, 36: 279-293.

Melo, A. G. C., Varela, E. S., Beasley, C. R., Schneider, H., Sampaio, I., Gafney, P. M., Reece, K. S., Tagliaro, C. H., 2010. Molecular identification, phylogeny and geographic distribution of Brasilian mangrove oysters (Crassostrea): Genetics and Molecular Biology, 33 (3): 564 - 572.

Monti, D., Frenkiel, L., Moueza, M., 1991. Demography and grown of Anomalocardia brasiliana (Gmelin) (Bivalvia: Veneridae) in a mangrove, in Guadeloupe (French best Indies). Journal of Molluscan Studies, 57: 249-257.

Moreno, C.A., 2004. Efectos de El Niño en el reclutamiento de Concholepas concholepas y Tegula atra (Mollusca, Gastropoda) en la costa de Valdivia, Sur de Chile. En Avaria y otros Eds. El NiñoLa Niña 1997-2000 Sus efectos en Chile. Comité Oceanográfico Nacional (CONA), 179 - 190, Valparaiso. 
Morris, P.J. y G. Rosenberg, 2005. Search interface and documentation for Malacolog, an online database of Western Atlantic marine Mollusks. [WWW database (version 4.1.1)] URL http://www.malacolog.org.

Morsán, E. M., 1997. Extracción intermareal de almeja púrpura (Amiantis purpurata) en la costa norte del golfo San Matías. Informes Técnicos del Plan de Manejo Integrado de la Zona Costera Patagónica (Puerto Madryn, Argentina) Nº33.

Morsan, E. M. y Orensanz, J. M., 2004. Age structure and growth in an unusual population of purple clams, Amiantis purpuratus (Lamarck, 1818) (Bivalvia; Veneridae), from Argentine Patagonia. Journal of Shellfish Research, 23 (1): 73 80. ISSN: 07308000.

Murray-Wallace, C. V. and Belperio, A. P., 1991. The last interglacial shoreline in Australia-A review. Quaternary Science Reviews, 10: 441-461.

Murray-Wallace, C. V., Beu, A. G., Kendric, G. W., Brown, L. J., Belperio, A. P., Sherwood, J. E., 2000. Palaeoclimatic implication of the occurrence of the arcoid bivalve Anadara trapezia (Deshayes) in the Quaternary of Australasia. Quaternary Science Review, 19: 559-590.

Muhs, D. R., Miller, G. H., Whelan, J. F., Kennedy, G. L., 1992. Aminostratigraphy and oxygen isotope stratigraphy of marine-terrace deposits, Palos Verdes Hills and San Pedro areas, Los Angeles County, California. In: Fletcher III, C.H., Wehmiller, J.F. (Eds.), Quaternary Coasts of the United States: Marine and Lacustrine Systems. SEPM (Society for Sedimentary Geology) Special Publication, 48: 363-376.

Muhs, D. R., Simmons, K. R., Kennedy, G. L., Rockwell, T. R., 2002. The last interglacial period on the Pacific coast of North America. Geological Society of America Bulletin, 114 (5): 569 - 592.

Muhs, D. R., Simmons, K. R., Schumann, R. R., Groves, L. T., Mitrovica, X. T., Laurel, D., 2012. Sea-level history during the Last Interglacial complex on San Nicolas Island, California: 
implications for glacial isostatic adjustment processes, paleozoogeography and tectonics. Quaternary Science Reviews, 37:1-25.

Nakada, M. y Lambeck, K., 1989. Late Pleistocene and Holocene sea-level change in the Australian region and mantle rheology. Geophysical Journal, 96: 497-517.

Naranjo García, E., 2003. Moluscos continentales de México: Terrestres. Revista de Biología Tropical, 51 (3): 483-493.

Neumann, A.C. y Hearty, P. J., 1996. Rapid sea-level changes at the close of the last interglacial (substage 5e) recorder in Bahamian island. Geology, 24: 775 - 778.

Nicolas, R., Kostadinoff, J., Schillizi, R., 1986. Correlación entre geoformas superficiales y observaciones geofísicas en la bahía Anegada, Buenos Aires. Revista de la Asociación Geológica Argentina, 41(3-4): 245-255.

Obelic, B., Álvarez, A., Argullós, J., Piana, E. L., 1998. Determination of water palaeotemperature in the Beagle Channel (Argentina) during the last $6000 \mathrm{yr}$ through stable isotope composition of Mytilis edulis shells. Quaternary of South America and Antartic Peninsula, 11: 47-71.

Oksanen, J., 2011. Multivariate Analysis of Ecological Communities in R: vegan tutorial (en línea), actualización: 30 de Octubre 2011, http://cran.r-project.org/, http://vegan.r-forge.r- project.org/, última consulta: 18 de mayo del 2013.

Okolodkov, Y. B., 2010. Biogeografía marina. Universidad Autónoma de Campeche. 122 p.

Oliveira, I., Amorim, A., Lavander, H., Peixoto, S., Gálvez, A. O., 2011.Spatial and temporal distribution of the shellfish Anomalocardia brasiliana (Gmelin, 1791) on Mangue Seco beach, Pernambuco, Brazil. International Journal of Acuatic Science, 2: 68 - 79.

Ortlieb, L., 1987. Neotectonic and Quaternary sea level variations in the gulf of California region. Bulletin of the Inqua Neotectonic Commission, 10: 28-31. 
Ortlieb, L., 1991. Quaternary shorelines along the northeastern Gulf of California: Geocronological data and neotectonic implications. Geological Society of America Special Paper, 254.

Ortlieb, L. y Díaz, A., 1991. Distribuciones de moluscos litorales del Perú en el Pleistoceno Superior: primeras interpretaciones paleoceanográficas y paleoclimáticas. IIIa Reunión anual Proyecto PICG, 281: 39-56.

Ortlieb, L., Guzmán, N., Candia, M., 1994. Moluscos litorales del Pleistoceno superior en el área de Antofagasta, Chile: Primeras determinaciones e indicaciones paleoceanográficas. Estudios Oceanológicos, 13: 57-63.

Ortlieb, L., Guzmán, N., Marquardt, C., Vargas, G., 1997. El Cuaternario marino de norte de Chile: revisiones cronológicas e identificación posible de depósitos de 400 ka. VIII Congreso Geológico Chileno, Acta 1: 371-375.

Palacios, M. y Aldea, C., 2011. Aspectos morfométricos de Tegula atra (Lesson, 1830) (Gastropoda: Trochidae) y sus variaciones latitudinales en el sur de Chile. VIII Congreso Latinoamericano de Malacología, Acta: 230p.

Parham, P.R., Riggs, S.R., Culver, S.J., Mallinson, D.J., Wehmiller, J.F., 2007.Quaternary depositional patterns and sea-level fluctuations, northeastern North Carolina. Quaternary Research, 67: 83-99.

Parmesan, C., 2006. Ecological and Evolutionary Responses to Recent Climate Change. Annual Review of Ecology, Evolution and Systematic, 37: 637-674.

Pastorino, G., 1991. Lista preliminar de moluscos Cuaternarios de algunos yacimientos de Río Negro y Chubut, Argentina. Comunicaciones de la Sociedad Malacológica del Uruguay, 9: 129137.

Pastorino, G., 1993. The taxonomic status of Buccinanops d Orbigny, 1841. The Veliger, 36(2):160-165. ISSN: 0042-3211. 
Pastorino, G., 1994. Los moluscos gastrópodos de las Terrazas Marinas de Río Negro y Chubut. Tesis Doctoral, Facultad de Ciencias Exactas y Museo, UNLP. 205 p.

Pastorino, G., 1999. A new species of gastropod of the genus Trophon Montfort, 1810 (Mollusca: Gastropoda: Muricidae) from subantarctic waters. The Veliger, 42(2):169-174. ISSN: 0042-3211

Pastorino, G., 2000. Asociaciones de moluscos de las terrazas marinas Cuaternarias de Río Negro y Chubut, Argentina. Ameghiniana, 37: 131 - 156.

Pastorino, G., 2002. Systematics and phylogeny of the genus Trophon Montfort, 1810 (Gastropoda: Muricidae) from Patagonia and Antarctica: morphological patterns. Bollettino Malacologico, 4:127134. ISSN: 0394-7149.

Pastorino, G., 2005. Recent Naticidae (Mollusca: Gastropoda) from the Patagonian coast. The Veliger, 47(4):225-258. ISSN: 0042-3211.

Pastorino, G., 2009. The genus Olivella Swainson, 1831(Gastropoda: Olividae) in Argentine waters. The Nautilus, 123(3):189-201. ISSN: 0028-1344.

Pastorino, G. y Ivanov, V., 1996. Marcas de predación en bivalvos del Cuaternario marino de la costa de la provincia de Buenos Aires, Argentina. IBERUS, 14(1):93-101. ISSN: 0212-3010.

Pastorino, G., Darrigran, S.M., Lunaschi, L., 1993. Limnoperna fortunei (Dunker, 1957) (Mytilidae) nuevo bivalvo invasor en aguas del Río de la Plata. Geotrópica, 39: 101.

Pedoja, K, Weishen, J., Kerhaw, S., Tang, C., 2008. Coastal Quaternary morphologies in the northern coast of the South China Sea, China, and their implications for current tectonic models: A review and prelimitary study. Marine Geology, 255: 193-117.

Pedoja, K., Regard, V., Husson, L., Martinod, J., Guillaume, B., Fucks, E., Iglesias, M., Weill, P., 2011.Uplift of Quaternary shorelines in eastern Patagonia: Darwin revisited. Geomorphology, $127: 121-142$. 
Penchaszadeh, P., 1973. Ecología de las comunidades del mejillón (Brachidontes rodriguezii d’Orb.) en el medio litoral rocoso de Mar del Plata: el proceso de recolonización. Phycis A, 32 (84): 51-64.

Penchaszadeh, P., Pastorino, G., Cledón, M., 2002. Crepidula dilatata Lamarck, 1822 truly living in the South Western Atlantic. The Veliger, 45(2):172-174. ISSN: 0042-3211.

Penchaszadeh, P., Pablo, E., Boltovkoy, D., Borges, M., Cataldo, D., Damborenea, C., Darrigan, G., Obenat, S., Pastorino, G., Schwindt, E., Spivak, E., Silvestre, F., 2007a. Invasores. Invertebrados exóticos en el Río de la Plata y región marina aledaña. Eudeba. Buenos Aires, 377 p.

Penchaszadeh, P., Pastorino, G., Brögger, M., 2007b. Moluscos gasterópodos y bivalvos. En: Boltovskoy D (ed). Atlas de sensibilidad ambiental de la costa y el Mar Argentino. [en línea] $<$ http://atlas.ambiente.gov.ar/>.

Peréz, D. E., del Río, C. J., Nielsen, S. V., 2013. Sistemática y filogenia del género Ameghinomya Ihering, 1907 (Bivalvia: Chioninae) del Cenozoico de Argentina y Chile. Ameghiniana, 50(3): 1-2.

Pimenta, A.D., dos Santos, F.N., R.S. Absalão, 2011. Taxonomic revision of the genus Eulimella (Gastropoda, Pyramidellidae) from Brazil, with description of three new species: Zootaxa, 3063: 22-38.

Piola, A. R. and Matano, R. P., 2001. Brazil and Falklands (Malvinas). Currents. Ocean Currents: A Derivate of Encyclopedia of Ocean Sciences, $2^{\text {nd }}$ Edition. 612p.

Piola, A. R. y Rivas, A. L. 1997. Corrientes en la plataforma continental. El mar argentino y sus recursos pesqueros 1: 119-132.

Piola, A. R. y Scasso, L. M. L. 1988. Circulación en el Golfo San Matías. Geoactas 15: 33-51.

Pla, L., 2006. Biodiversidad: Inferencias basada en el Índice de Shannon y la riqueza. INCI, 31(6): 583-590. 
Poppe, G. T. y Taggaro, S., 2006. New Mitridae and Costellaridae from the Philippines and the East China Sea. Visaya. Conchology, Inc., Ocasional Publications. Philippines. Conchbooks, 1 (6): 7688.

Porter, S. C, Stuiver, M. y Heusser, C. J., 1984. Holocene sea-level changes along the Strait of Magellan and Beagle Channel, Southernmost South America. Quaternary Research, 22: 59-67.

Quezada, J., González, G., Dunai, T., Jensen, A. y Juez-Larré, J., 2007.Alzamiento litoral Pleistoceno del norte de Chile: edades $21 \mathrm{Ne}$ de la terraza costera más alta del área de Caldera-Bahía Inglesa. Revista geológica de Chile, 34 (1): 81-96.

Rabassa, J.A., Coronato, A., Gordillo, S., Candel, M., Martínez, M., 2009. Paleoambientes litorales durante la transgresión marina Holocena en Bahía Lapatais, Canal de Beagle, Parque Nacional Tierra del Fuego, Argentina. Revista de la Asociación Geológica Argentina, 65: 648-659.

Ragainia, L., Bianuccia, G., Cantalamessab, G., Valleric, G., Landinia, W., 2002. Paleoecology and paleobiogeography of fossil mollusks from Isla Isabela (Galápagos, Ecuador). Journal of South American Earth Sciences, 15: 381-389.

Raymo, M.E., Lisiecki, L.E., Nisancioglu, 2006. Plio-Pleistocene ice volume, Antarctic Climate, and the global dO18 record. Science, 313: 492-495.

Richards, H.G. y Craig, J.R., 1963. Pleistocene Mollusks from the Continental Shelf off Argentina. Proceedings Academy of natural Sciences of Philadelphia, 115 (6): 127-147.

Ríos, E.C., 1994. Seashells of Brazil: 2nd edition, Fundação Universidade do Rio Grande, Rio Grande, 492 p.

Robinson, L.F., Henderson, G.M., Slowey, N.C., 2002. U-Th dating of marine isotope stages 7 in Bahamas slope sediments. Earth and Planetary Science Letters, 196: 175-187. 
Rohling, E.J. y De Rijk. S., 1999. The Holocene Climate Optimum and Last Glacial Maximum in the Mediterranean: the marine oxygen isotope record. Marine Geology, 153: 57-75.

Rohling, E. J., Grant, K., Hemleben, C. H., Siddall, M., Hoogakker, B. A. A., Bolshow, Kucera, M., 2008. High rates of sea-level rise during the last interglacial period. Nature Geoscience, 1: 38 - 42.

Rojas, A. y Urteaga, D., 2011. Late Pleistocene and Holocene chitons (Mollusca, Polyplacophora) from Uruguay. Palaeobiogeography and palaeoenvironmental reconstruction in mid latitudes of the southwestern Atlantic. Geobios, 44: 377-386.

Rostami, K., Peltier, W., Mangini, A., 2000.Quaternary marine terraces, sea -level changes and uplift history of Patagonia, Argentina: compararisons with predictions of the ICE -4G (VM2) model of the global process of glacial isostatic adjustment. Quaternary Science Reviews, 19:1495-1525.

Roux, A., Bastida, R., Bremec, C., 1993. Comunidades bentónicas de la Plataforma Continental Argentina. Campañas Transacción BIP Oca Balda 1987/88/89. Bol. Inst. Ocean. Univ. S. Paulo, 41(1-2): 81-94.

Roy, K., Jablonsky, D., Valentine, J. W., Rosenberg, G., 1998. Marine latitudinal diversity gradients: test of causal hypothesis. Proceedings of the National Academy of Sciences of the United States of America, 95: 699-3702.

Rutherford S. y D'Hondt S., 2000. Early onset and tropical forcing of 100,000-year Pleistocene glacial cycles. Nature, 408: 72-75.

Rutter, N., Schnack, E., Del Río, J., Fasano J., Isla, F., Rudtke U., 1989. Correlation and dating of Quaternary littoral zones along the patagonian coast, Argentina. Quaternary Science Reviews, 8:213-234.

Rutter, N., Radtke, U., Schnack, E., 1990. Comparison of ESR and amino acid data in correlating and dating quaternary shorelines along the Patagonian coast, Argentina. Journal of Coastal Research, 6 (2): 391-411. 
Salvador Figueras, M., 2003. Análisis de correspondencia. (en línea) 5campus.com. Estadística <http://www.5campus/leccion/correspondencias> [última consulta: 17 de octubre del 2012].

Salvigsen, O., Elgersma, A., Landvik, J.Y., 1991. Radiocarbon dated raised beaches in northwestern Wedel Jarlsberg Land, Spitsbergen, Svalbard. Wyprawy Geograficzne na Spitsbergen, Lublin, Poland: 9-16.

Shannon, C. E. y Weaver, W., 1949. The mathematical theory of communication. University of Illinois. Press. Urbana, IL, EEUU, 144 p.

Scarabino, 1977. Moluscos del Golfo San Matías (provincia de Río Negro, República Argentina). Inventario y claves para su identificación. Comunicación de la Sociedad Malacológica del Uruguay, 4 (31-32): 177-197.

Schelmann, G., 1998. Coastal development in Southern South America (Patagonia and Chile) since the younger Middle Pleistocene - sea -level changes and neotectonics. In: Kelletat, D. (Ed.), German Geographical Coastal Research: The Last Decade: Tübingen, Institute for Scientific Cooperation Tübingen. IGU Sonderband, 289 - 304.

Schellmann, G. y Radtke, U., 2000. ESR dating stratigraphically well-constrained marine terraces along the Patagonian Atlantic coast (Argentina). Quaternary International, 68-71: 261-273.

Schellmann, G. y Radtke, U., 2003. Coastal terraces and Holocene sea-level changes along the Patagonian Atlantic coast. Journal of Coastal Research, 19(4): 983-996.

Schnack, E. J., Fasano, J. L., Isla, F. I., 1980. Los ambientes ingresivos del Holoceno en la región de Mar Chiquita, Provincia de Buenos Aires. Simposio sobre Problemas Geológicas del Litoral Atlántico Bonaerense, Comisión de Investigaciones Científicas de la Provincia de Buenos Aires, Acta: 229 - 242, Mar del Plata.

Schnack, E. J., Fasano, J. L., Isla, F. I., 1982. The evolution of the Mar Chiquita Lagoon, province of Buenos Aires, Argentina. In: Colquhoun D J (ed). Holocene sea level fluctuations: magnitudes and causes. IGCP 61, Univ. S. Carolina, Columbia, SC: 269-282. 
Schnack, E. J., Isla, F. I., De Francesco, F. O., Fucks, E. E., 2005. Estratigrafía del Cuaternario Marino Tardío en la Provincia de Buenos Aires. Geología y Recursos Minerales de la Provincia de Buenos Aires. Relatorio del XVI Congreso Geológico Argentino. Capítulo X: 159-182, La Plata.

Schwarcz, H. P. y Grün, R., 1992. Electro spiin resonance (ESR) dating of the origin of modern man. Philosophical Transactions: Biological Sciences. In The Origin of Modern Humans and the Impact of Chronometric Dating, 337: 145-148.

Shackleton, N. J. y Kennet, J.P., 1975a. Paleotemperatures history of the Cenozoic and the initiation of Antarctic galciation: Oxigen and carbon isotopic analysis in DSDP 277, 279 and 281. In Rep. DSDP 29, 743.

Shackleton, N. J. y Kennet, J.P., 1975b. Late Cenozoic oxygen and carbon isotopic changes, DSDP Site 284: Implication for glacial history of Northern Hemisphere and Antarctica. In. Rep. DSDP $299,801$.

Shackleton, N. J., 1987. Oxigen isotopes, ice volumen and sea level: Quaternary Science Review, 6: $183-190$.

Shackleton, N. J., Berger, A., Peltier, W. R., 1990. An alternative astronomical calibration of the lower Pleistocene timescale based on ODP Site 677. Earth and Environmental Science Transactions of the Royal Society of Edinburgh, 81 (4): 251-261.

Shackleton, N. J., Le, J., Mix, A., Hall, M. A., 1992. Carbon isotope records from pacific surface waters and atmospheric carbon dioxide. Quaternary Science Review, 11 (4): 387-400.

Shackleton, N. J., Sánchez-Goñi, M. F., Pailler, D., Lancelot, Y., 2003. Marine Isotope Substage 5e and the Eemian Interglacial. Global and Planetary Change, 36:151-155.

Shindell, D. T., Schmidt, G. A., Mann, M. E., Rind, D., Waple, A., 2001. Solar Forcing of Regional Climate Change during the Maunder Minimum. Science, 294: 2149-2152. 
Siddall, M., Chappell, J., Potter, E. K., 2006. Eustatic Sea level during Past Interglacial. In Sirocko, F. Litt, T. Claussen, M. Sanchez-Goni, M. F. (Eds). The Climate of Past Interglacials, Elsevier, Amsterdam.

Siddall, M, Rohling, E. J., Thompson, W. G., Waelbroeck, C., 2008. MIS 3 sea -level fluctuactions: data synthesis and new outlook. Review of Geophysic, 46, RG4003, doi: 10.1029/2007/RG000226.

Siddall, M, Hönisch, B., Waelbroeck, C., Huybers, P., 2010. Changes in deep Pacific temperature during the mid-Pleistocene transition and Quaternary. Quaternary Science Reviews, 29: 170-181.

Signorelli, J. H., 2010. Taxonomía de las especies pertenecientes a la Familia Mactridae Lamarck, 1809 (Bivalvia: Heterodonta) presentes en la provincias malacológicas Argentina y Magallánicas. Tesis Doctoral, UBA.

Simone, L. R., Pastorino, G., Penchaszadeh, P. E., 2000. Crepidula argentina (Gastropoda: Calyptraeidae) a new species from the littoral of Argentina. The Nautilus, 114(4):127-141. ISSN: 0028-1344.

Spalletti, L.A. y Isla F. I., 2003. Características y evolución del delta del río Colorado (“Colúleuvú), provincia de Buenos Aires, República Argentina. Asociación Argentina de Sedimentología, 10: 2337.

Stirling, C. H., Esat, T. M., Lambeck, K., Mc Culloch, M. T., Blake, S. G., Lee, D. C., Halliday, A. N., 2001. Orbital Forcing of the Marine Isotope Stage 9 Interglacial. Science 291, (5502): 290-293. doi: 10.1126 /Science.291.5502.290.

Stuiver, M., Reimer, P. J., Braziunas, T. F., 1998. Datación por carbono-14 de alta precisión para muestras terrestres y marinas. Radiocarbon, 40: 1127-1151.

Suguio, K., Tatumi, S. H., Kowata, E. A., Munita, C. S., Paivas, R. P., 2003. Upper Pleistocene deposits of the Comprida Island (São Paulo State) dated by thermoluminescence method. Anais Brasileira de Ciências, 75 (1): 91-96. 
Teso, V. y Pastorino, G., 2011. A revision of the genus Olivancillaria (Mollusca: Olividae) from the Southwestern Atlantic. Zootaxa, 2889: 1-34.

Thompson, G. y Sanchez de Bock, M. F., 2007. Mortandad masiva de Mesodesma mactroides (Bivalvia: Mactracea) en el partido de la costa, Buenos Aires, Argentina, en septiembre 2004. Atlântica, 29(2): 115-119.

Tonni, E. P. y Fidalgo, F., 1978. Consideraciones sobre los cambios climáticos durante el Pleistoceno Tardío - Reciente en la provincia de Buenos Aires. Aspectos ecológicos y zoogeográficos relacionados. Revista de Asociación Paleontológica Argentina, Tomo XV, No 1-2: $235-253$.

Tonini, M., Palma, E. D., Rivas, A. L., 2007. Simulación numérica de la circulación y frentes térmicos en los Golfos norpatagónicos. Mecánica Computacional, 26: 3757 - 3768.

Trebino, L., 1987. Geomorfología y evolución de la costa en los alrededores del pueblo de San Blas, Provincia de Buenos Aires. Revista de la Asociación Geológica Argentina, 42 (1-2): 9-22.

Tuccimei, P., Ginés, J., Detitala, M. C., Ginés, A., Gràcia, F., Fornós, J. J., Taddeucci, A., 2006. High precision U-series data from phreatic overgrowths on speleothems. Zeitschriftfür. Geomorphology, 50 (1): 1-21.

Valentin, J. 1987. Noticia sobre un yacimiento de conchillas en el cementerio de Lomas de Zamora. Anales del Museo Nacional de Buenos Aires 5: 227-231.

Valentine, J. W., 1955. Upwelling and thermally anomalous Pacific coast Pleistocene molluscan faunas. Americal Journal Sciences, 253: 462-474.

Valentine, J. W., 1958. Late Pleistocene megafauna of Cayucos, California ans its zoogeographic significance. Journay of Paleontology, 32 (4): 687-696. 
Varela, E.S., Beasley, C.R., Schneider, H., Sampaio, I., Marques-Silva, N.S., Tagliaro C.H., 2007.Molecular phylogeny of mangrove oysters (Crassostrea) from Brazil: J Molluscan Studies, 73: 229-234.

Veliz, D. y Vásquez, J. A., 2000. La Familia Trochidae (Mollusca: Gastropoda) en el norte de Chile: consideraciones ecológicas y taxonómicas. Revista Chilena de Historia Natural, 73: 757-769.

Vilela, C. R. y Riggi, J. C., 1956. Rasgos geológicos y petrográficos de la Sierra del Lihuel Calel y área circundante, Provincia de la Pampa. Asociación Geológica Argentina, Revista XI (4): 217-272.

Violante, A. R. y Parker, G, 1992. Estratigrafía y rasgos evolutivos del Pleistoceno medio a superior Holoceno en la llanura costera de la región de Faro Querandí (Provincia de Buenos Aires). Revista de la Asociación Geológica Argentina, 47 (2): 215-227.

Violante, A. R. y Parker, G, 2000. El Holoceno en las regiones marinas y costeras del nordeste de la provincia de Buenos Aires. Revista de la Asociación Geológica Argentina, 55 (4): 337-351.

Voelker, A. H. L., 2002. Global distributionof centenal-scale records for marine isotope stage (MIS) 3: a database. Quaternary Science Reviews, 21: 1185-1212.

Wahnish, E., 1939. Noticia preliminar sobre la revisión de la fauna marina del Postpampeano. Con una nota sobre el Querandino en General Lavalle y revisión de la especie "Labiosa (R.) canaliculata" Say. Physis, 14 (46): 473-479.

Walker, M., Johnsen, S., Rasmussen, S. O., Popp, T., Steffensen, J.P., Gibbard, P., Hoek, W., Lowe, J., Andrews, J., Björck, S., Cwynar, L.C., Hughen, K., Kershaw, P., Kromer, B., Litt, T., Lowe, D.J., Nakagawa, T.,Newnham, R., Schwander, J., 2009. Formal definition and dating of the GSSP (Global Stratotype Section and Point) for the base of the Holocene using the Greenland NGRIP ice core, and selected auxiliary records. Journal of Quaternary Science, 24(1): 3-17.

Weiler, N. E., 1984. Rasgos geomorfológicos evolutivos del sector costero comprendido entre bahía Verde e isla Gaviota, provincia de Buenos Aires. Asociación Geológica Argentina, Revista XXXVIII (3-4): 392-404. 
Weiler, N. E., 1988, Depósitos litorales del Pleistoceno tardío y Holoceno en Bahía Anegada, Provincia de Buenos Aires: Segunda Reunión Argentino de Sedimentología, Buenos Aires, Actas, 245-249.

Weiler, N. E., 1993. Niveles marinos del Pleistoceno tardío y Holoceno en Bahía Anegada, Provincia de Buenos Aires. Geocronología y correlaciones. Revista de la Asociación Geológica Argentina, 48 (3-4): 207-216.

Weiler, N. E., 2000. Evolución de los depósitos litorales en Bahía Anegada, Provincia de Buenos Aires, durante el Cuaternario tardío. Tesis Doctoral, Facultad de Ciencias Exactas y Naturales, Universidad de Buenos Aires, $184 \mathrm{p}$.

Wichmann, R., 1918. Estudios geológicos e hidrológicos en la región comprendida entre la Boca de Río Negro, San Antonio y Choele Choele. Anales del Ministerio de Agricultura de la Nación, Sec. Geología y Mineralogía y Minería, tomo XIII, N³. Argentina.

Witte, L. 1916. Estudios Geológicos de la Región de San Blas (Partido de Patagones). Revista del Museo de La Plata 24: 7-99.

Yuan, L.X., Sun, L. G., Wei, G., Long, N., Xie, Z., Yuhong, W., 2011. 9.400 yr B. P.: the mortality of mollusk shell (Mya truncata) at high Artic is associated with a sudden cooling event. Environmental Earth Sciences, 63: 1385-1393.

Zanchetta, G., Consoloni, I., Isola, I., Pappalardo, M., Ribolini, A., Aguirre, M., Fucks, E., Baneschi, I., Bini, M., Ragaini, L., Terrasi, F., Boretto, G, 2012. New insigthts in the Holocene marine transgression in the Bahía Camarones (Chubut, Argentina). Italian Journal of Geosciences Bollettino della Societá Geológica I'Italia, 131 (1): 19-31.

Zazo, C., 1999. Interglacial sea levels. Quaternary International, 55: 101-113. 
Zazo, C. y Goy, J. L., 1989. Sea level changes in the Iberian Peninsula during Last 200.000 years. Late Quaternary Sea - Level correlation and applications (D. B. Scott, P. A. Pirazolli and A. Honing, eds), NATO ASI Series C, 256, Blackwell Publication, 27-39.

Zazo, C., Goy, J.L., Dabrio, C.J., Bardají, T., Hillaire-Marcel, C., Ghaleb, B., González-Delgado, J.A., Soler, V., 2003a. Pleistocene raised marine terraces of the Spanish Mediterranean and Atlantic coasts: records of coastal uplift, sea-level highstands and climate changes. Marine Geology, 194:103-133.

Zazo, C., Goy, J. L., Hillaire-Marcel, C., González Delgado, J. A., Soler, V., Ghaleb, B., Dabrio, C. J., 2003b. Registros de los cambios del nivel del mar durante el Cuaternario en las Islas Canarias Occidentales (Tenerife y La Palma). Estudios geológicos, 59: 133-144.

Zazo, C., Goy, J. L., Hillaire-Marcel, C., Dabrio, C. J., Gonzalez Delgado, J. A., Cabero, A., Bardají, T., Ghaleb, B., Soler, V., 2010. Sea level changes during the last and present interglacial in Sal Island (Cape Verde archipiélago). Global and Planetary Changes .doi:10.1016/j.gloplacha.2010.01.006.

Zudimendi, M.A., 2007. Discusión sobre la malacofaunas presentes en sitios arqueológicos de la patagonia continental argentina. In: Actas VI Jornadas de Arqueología e Historia de las regiones Pampeana y Patagonia. Mar del Plata, ISBN: 978-987-544-241-2. 